Portland State University

PDXScholar

Spring 6-2-2016

\title{
The Terroir of Pinot Noir Wine in the Willamette Valley, Oregon : A Broad Analysis of Vineyard Soils, Grape Juice and Wine Chemistry
}

Kathryn Nora Barnard

Portland State University

Follow this and additional works at: https://pdxscholar.library.pdx.edu/open_access_etds

Part of the Environmental Sciences Commons, Geology Commons, Soil Science Commons, and the Viticulture and Oenology Commons

Let us know how access to this document benefits you.

\section{Recommended Citation}

Barnard, Kathryn Nora, "The Terroir of Pinot Noir Wine in the Willamette Valley, Oregon : A Broad Analysis of Vineyard Soils, Grape Juice and Wine Chemistry" (2016). Dissertations and Theses. Paper 2941. https://doi.org/10.15760/etd.2936

This Dissertation is brought to you for free and open access. It has been accepted for inclusion in Dissertations and Theses by an authorized administrator of PDXScholar. Please contact us if we can make this document more accessible: pdxscholar@pdx.edu. 
The Terroir of Pinot Noir Wine in the Willamette Valley, Oregon - A Broad Analysis of Vineyard Soils, Grape Juice and Wine Chemistry

by

Kathryn Nora Barnard

A dissertation submitted in partial fulfillment of the requirements for the degree of

Doctor of Philosophy

in

Environmental Sciences and Resources: Geology

Dissertation Committee:

Scott F. Burns, Chair

Robert B. Perkins

Andrew Fountain

Martin LaFrenz

Teresa Bulman

Portland State University

2016 
C 2016 Kathryn Nora Barnard 


\begin{abstract}
Terroir is determined by a combination of factors in the vineyard including the grape varietal, geology and soil, soil hydrology, physiography, and climate. Although most studies have examined regional differences in wine flavors and associated provenance of wine based on chemistry, few have examined the chemistry of the soil and the ability to trace that chemistry to grape juice and, finally, to the wine. This dissertation examines what soil physical and chemical differences specific to this region might influence grape juice chemistry and wine chemistry.

Wine-grapes in the Willamette Valley, Oregon, are grown on three major soil parent materials: volcanic, marine sediments, and loess/volcanic. Winemakers have observed differences in the flavor of Pinot Noir wine made from grapes grown on these different parent materials. This dissertation examines differences in the soil properties and elemental chemistry of the soil parent materials at various vineyards to document their effect on wine chemistry as a step towards understanding differences in flavor. All aspects of the terroir are controlled by carefully selecting vineyards with similar exposure and elevation, the same grape varietal and wine making techniques, and only the soils vary. The hypothesis is that the chemistry of the grape juice and wine reflect the soil in which the grapes were grown and that the three parent materials have soils that can be distinguished by their physical and chemical characteristics.
\end{abstract}


Soil pits were excavated in 20 vineyards, soil properties were described in the field, and soil samples were later analyzed in the laboratory particle size, organic matter, color, $\mathrm{pH}$, cation exchange capacity (ammonium acetate method), clay mineralogy (x-ray diffraction), and elemental chemistry (ICP-MS/AES). X-ray fluorescence was used to examine the pisolites. ICP-MS/AES was used for elemental analysis of grape juice and wines produced from these vineyards. Principal component analysis was used to compare soil physical and chemical characteristics, grape juice and wine chemistry.

The physical characteristics of soils from all the three parent materials indicate: they are old ( $>50,000$ years) based on their high clay content, low cation exchange capacity, red colors, and high $\mathrm{Fe}$ and $\mathrm{Al}$ content. These features indicate enough time has passed to reduce organic matter and other cations at depth, leave behind insoluble Fe and $\mathrm{Al}$, and develop pedogenic clays. In my study region, volcanic and marine sediment soils are more developed with slightly lower acidity than the loess/volcanic soils. A new finding for this region is the presence of pisolites ( $\mathrm{Fe} / \mathrm{Mg}$ concretions) in the volcanic and the loess/volcanic soils, but absent in the marine sediment soils. Winemakers hypothesized that pisolites were present only in loess soils and influenced wine flavor in some way.

Volcanic soils have the highest $\mathrm{P}, \mathrm{S}, \mathrm{Fe}, \mathrm{Co}, \mathrm{Mn}$, and $\mathrm{V}$ concentrations and the lowest $\mathrm{As}$ and $\mathrm{Sr}$ values. Marine sediment soils have higher $\mathrm{Cl}$ and $\mathrm{Sr}$ and lower $\mathrm{P}, \mathrm{Co}$, $\mathrm{Mn}, \mathrm{Ba}$, and $\mathrm{V}$ concentrations than volcanic soils. Loess soils have the highest values of 
$\mathrm{K}$ and $\mathrm{Mg}$ and are similar to volcanic soils with higher $\mathrm{P}$ and $\mathrm{V}$ values and similar to marine sediment soils with higher $\mathrm{Sr}$ values. The main elements found to be significant in determining one parent material from another are $\mathrm{V}$ and $\mathrm{Mn}$ (volcanic soils), $\mathrm{Mg}$ and $\mathrm{K}$ (loess soils), and $\mathrm{Sr}$ (marine sediment or loess soils). Sr is slightly higher in grape juice and wine from vines grown on marine sediment parent material compared to volcanic and loess parent material, whereas $\mathrm{Mn}$ is higher in the juice and wine from grapes grown in volcanic parent material. $\mathrm{P}, \mathrm{S}, \mathrm{Fe}, \mathrm{Co}, \mathrm{V}, \mathrm{Cl}, \mathrm{Ba}, \mathrm{Mg}$, and $\mathrm{K}$ did not maintain their relative concentration levels from soil to grape juice to wine. The principal component analysis shows that soil and wine chemistry differs between parent material, but is inconclusive for grape juice chemistry. 


\title{
Dedication
}

\section{To Seth D. Boss}

1983-2010

\begin{abstract}
Knowing that you and I will always have a bond as strong as the bows we climbed, as constant as the flowing creeks we crossed, as deep as the waters we navigated, and as eternal as the darkness in which we both desperately grasped for the light, I surrender this effort to your memory. Your death, as much as your life, gave me the courage to discover my brokenness and begin the arduous journey of healing and growth. Without you I would have surely fallen and your spirit would not have been there to help me up. This work is dedicated to you, Seth, my best friend and partner in crime in this life and the next.
\end{abstract}

RIP 


\section{Acknowledgements}

I would like to give my deepest gratitude to my advisor Dr. Scott F. Burns. His support, enthusiasm, and undying optimism are the backbone of my success. I would like to thank my committee for comment and criticism that encouraged my reflection throughout this process: Dr. Robert B. Perkins, Dr. Andrew Fountain, Dr. Martin LaFrenz, and Dr. Teresa Bulman. Thanks to other professors and classmates who helped me with my dissertation. I thank my mother for encouraging and supporting me throughout this long and difficult process. There is nothing more motivating than knowing someone is proud of you.

I thank the wineries and vineyards in the Willamette Valley for allowing access and having patience for results they are eager to utilize: Elk Cove Vineyards, Willakenzie Estate Winery, Chehalem, Lange Estate Winery and Vineyards, Rex Hill, and Ken Wright Cellars. Many thanks to APEX Laboratories, Dr. Reed Glasmann of Willamette Geological Services, Oregon State University, and Washington State University for their lab analyses. I am grateful for the support of the Erath Family Foundation for funding much of the outside lab work, and to the NSF Cascades to Coast GK-12 Program for financial support and connecting me to many in the Portland community with whom I can share my knowledge and grow. I also want to thank Cooper Mountain Vineyards, Gilles de Domingo, Barbara Gross, and Dr. Robert Gross for their support, knowledge, and a love for organic and biodynamic farming. 


\section{Table of Contents}

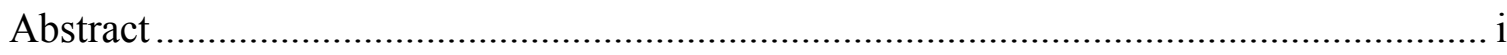

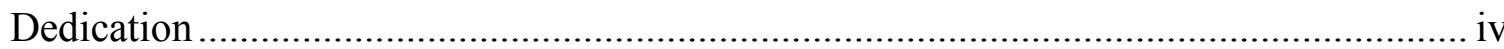

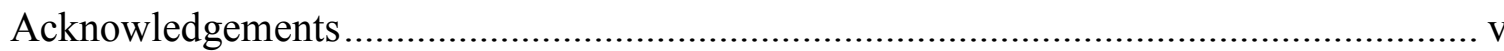

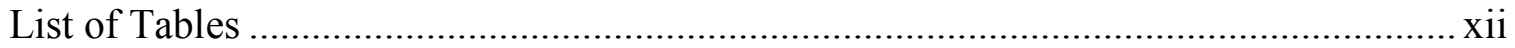

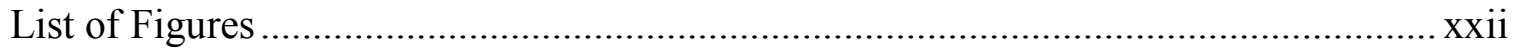

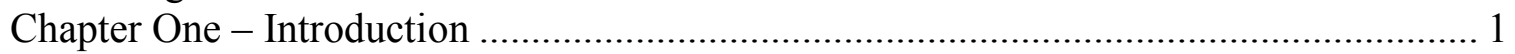

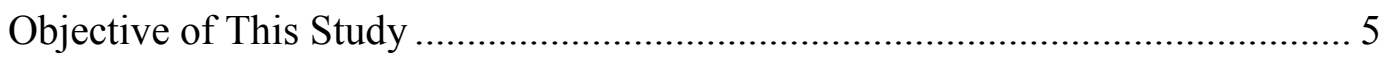

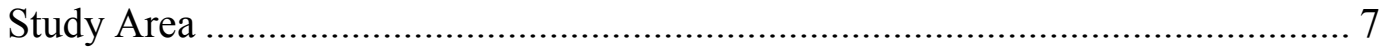

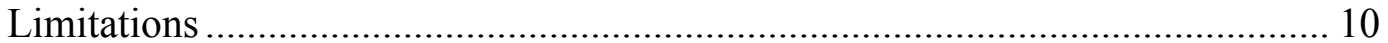

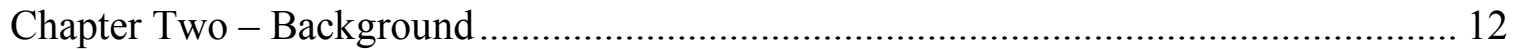

Implications of Research............................................................................... 12

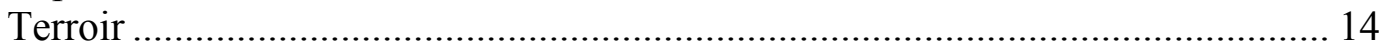

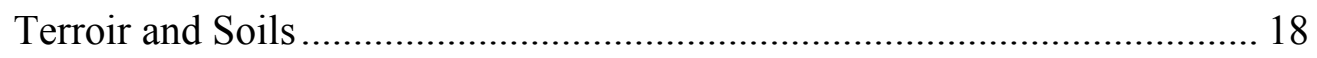

Willamette Valley Geology ...................................................................... 20

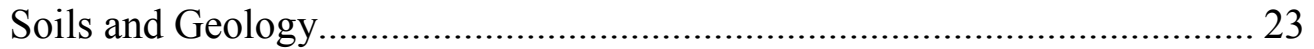

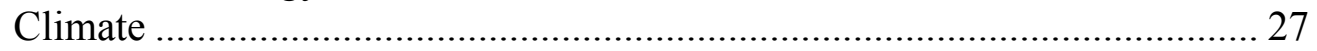

Oregon's American Viticulture Areas............................................................ 29

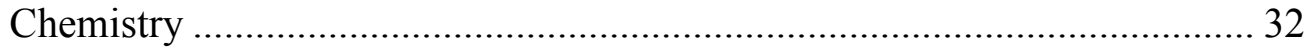

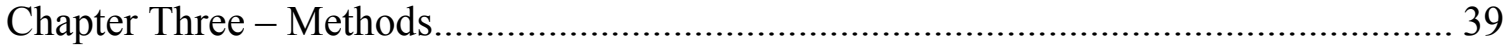

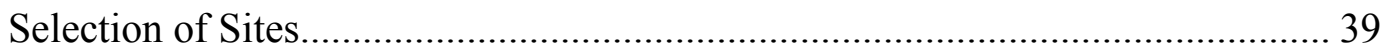

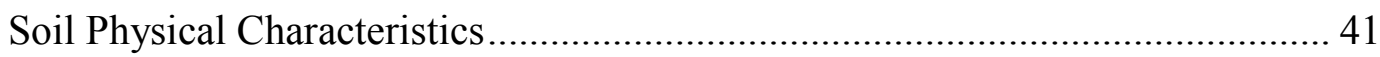

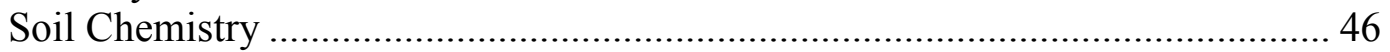

Grape Juice and Wine Chemistry ……………………....................................... 49

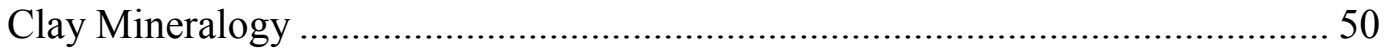

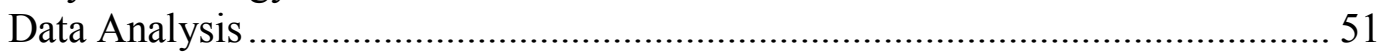

Chapter Four - Elk Cove Vineyards Results ..................................................................... 52

Volcanic Parent Material - Clay Court Vineyard, Block E................................... 52

Physical Characteristics........................................................................... 52

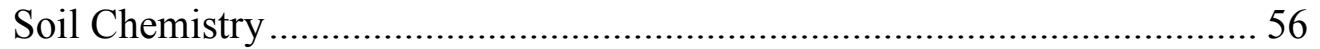

Grape Juice Chemistry ................................................................................. 58

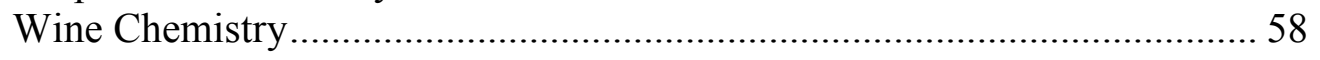

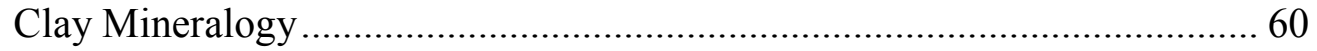

Marine Sediment Parent Material - Roosevelt Estate Vineyard ............................ 61

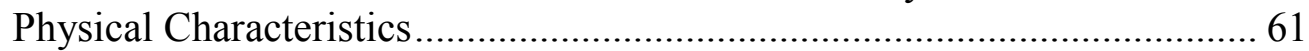

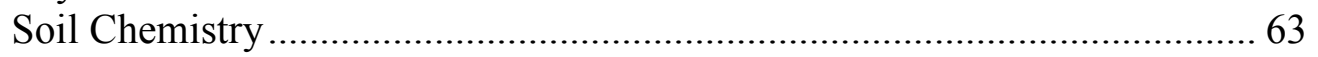

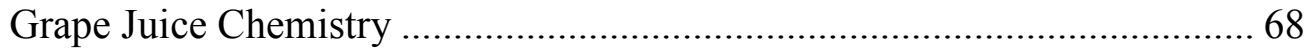

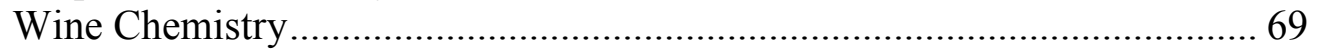


Clay Mineralogy ............................................................................ 70

Loess and Volcanic Parent Material - Five Mountain Vineyard......................... 71

Physical Characteristics ....................................................................... 71

Soil Chemistry …............................................................................... 75

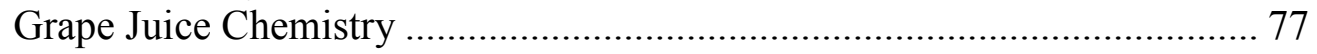

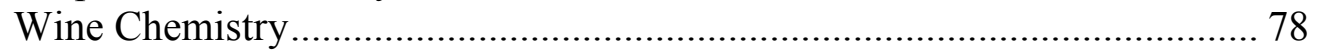

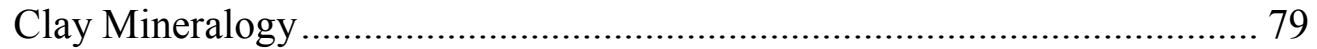

Chapter Five - Willakenzie Estate Winery Results ................................................... 81

Volcanic Parent Material - The Jory Hills Vineyard, Block 50c ...................... 81

Physical Characteristics .................................................................... 81

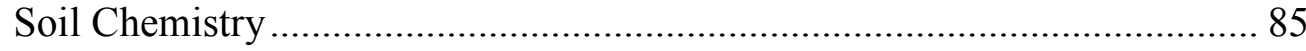

Grape Juice Chemistry ........................................................................ 86

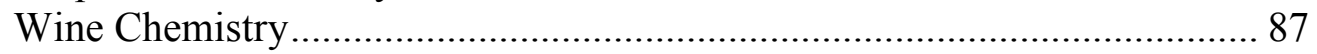

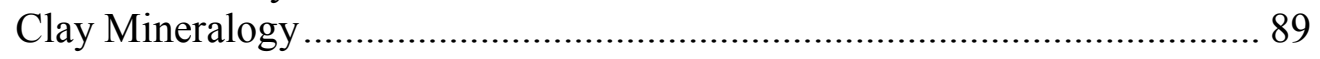

Marine Sediment Parent Material - Aliette Vineyard, Block 2b ........................ 89

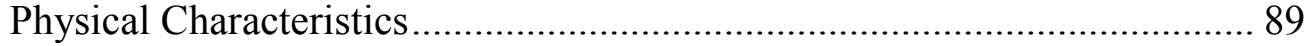

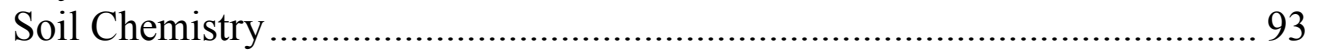

Grape Juice Chemistry ....................................................................... 95

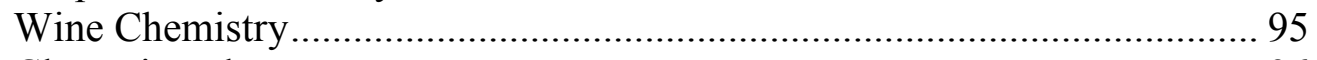

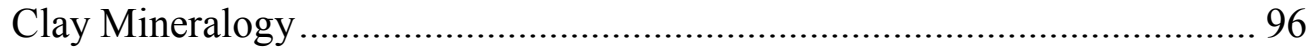

Missoula Flood Sediment over Shale Parent Material - Terres Basses Vineyard 97

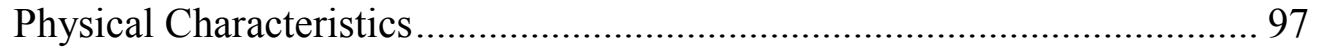

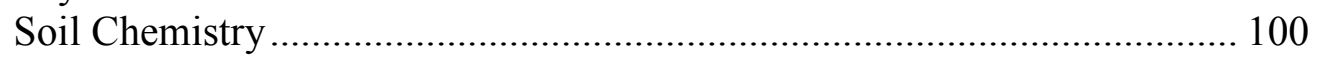

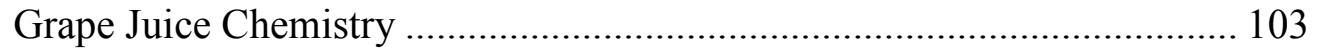

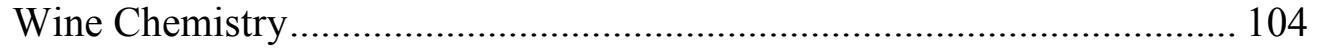

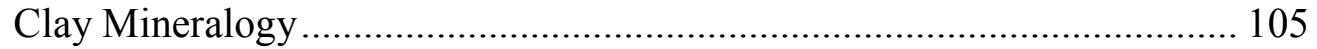

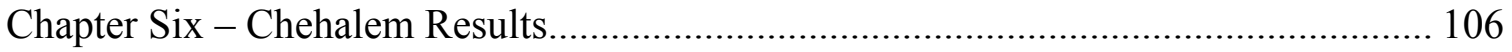

Volcanic Parent Material - Stoller Vineyard ............................................. 106

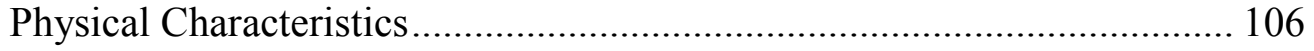

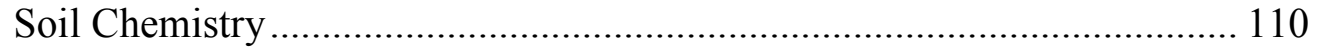

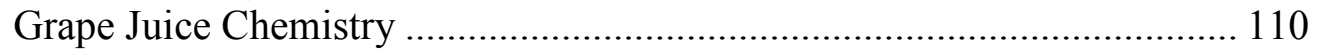

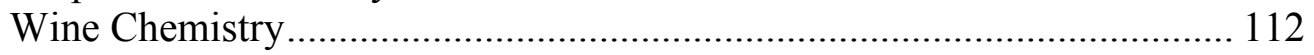

Clay Mineralogy ............................................................................. 114

Marine Sediment Parent Material - Ridgecrest Vineyard ............................. 115

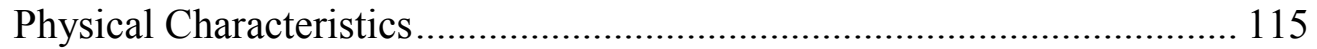

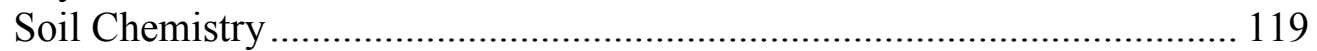

Grape Juice Chemistry ........................................................................ 119

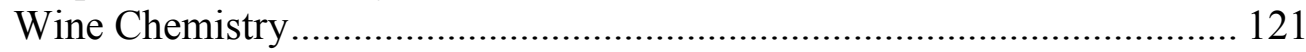

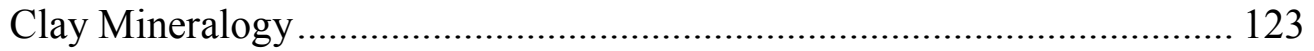

Loess and Volcanic Parent Material - Corral Creek Vineyard.......................... 124 


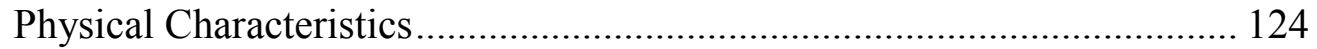

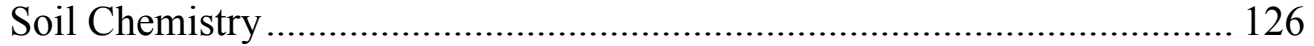

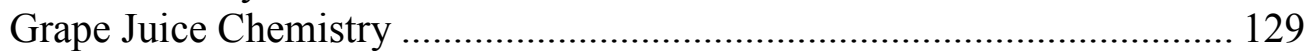

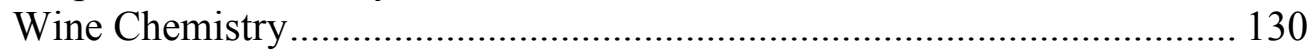

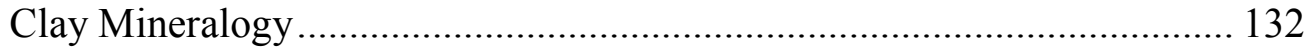

Chapter Seven - Lange Estate Winery and Vineyards Results ...................................... 133

Volcanic Parent Material - Estate Vineyard, Mia Block North ........................... 133

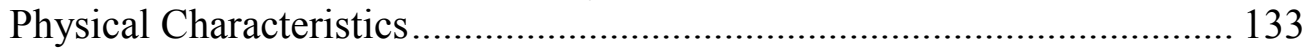

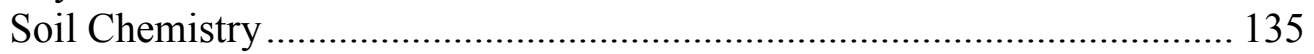

Grape Juice Chemistry .......................................................................... 137

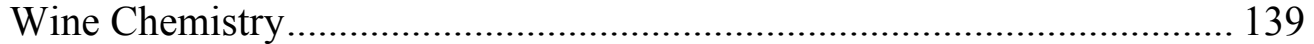

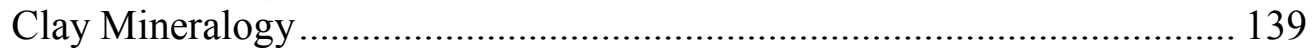

Marine Sediment Parent Material - Yamhill Vineyard ....................................... 140

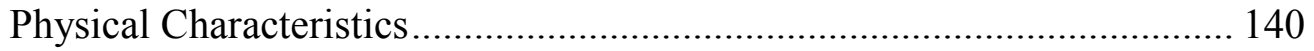

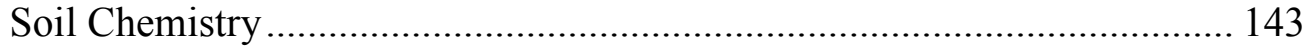

Grape Juice Chemistry ........................................................................ 146

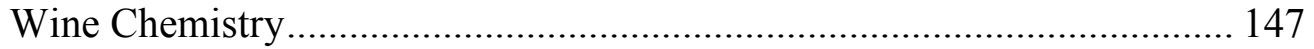

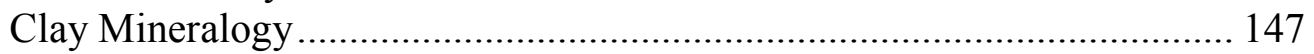

Marine Sediment Parent Material - Freedom Hill Vineyard............................... 148

Physical Characteristics...................................................................... 148

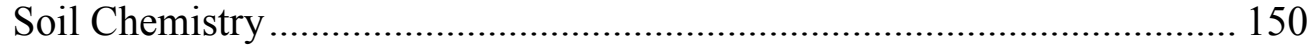

Grape Juice Chemistry ......................................................................... 154

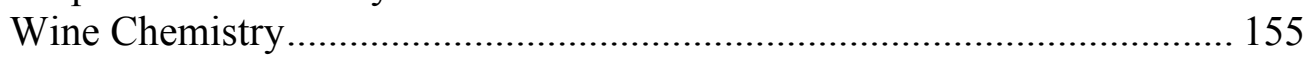

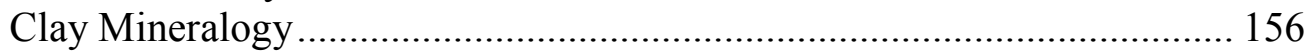

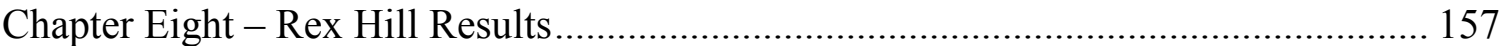

Volcanic Parent Material - Sims Vineyard, Block 2 …….................................. 157

Physical Characteristics..................................................................... 157

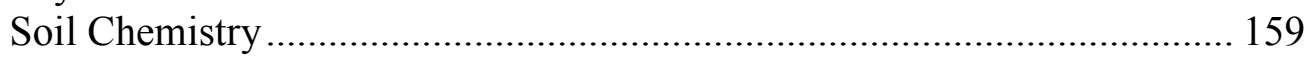

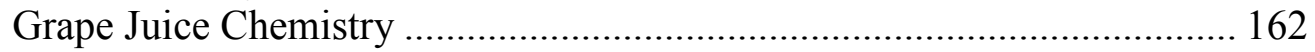

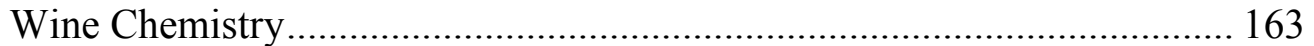

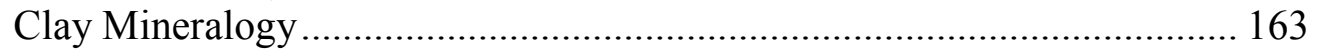

Loess and Volcanic Parent Material - Estate Vineyard, Block 12 ..................... 164

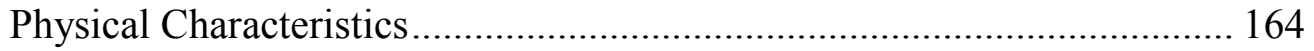

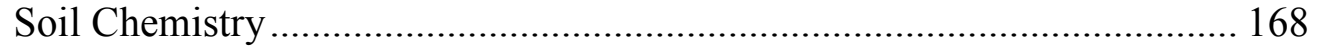

Grape Juice Chemistry ....................................................................... 169

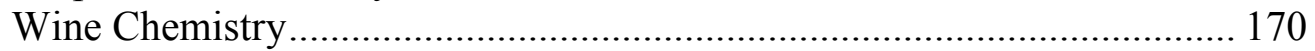

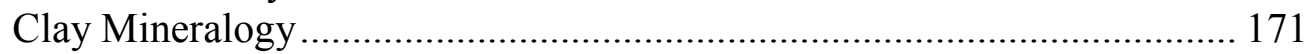

Volcanic Landslide Parent Material - Jacob-Hart Vineyard, Block 1................. 172

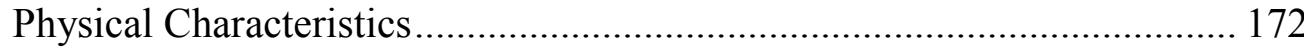

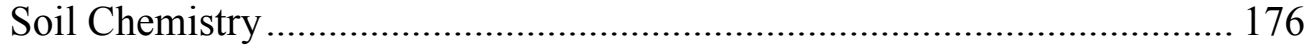


Grape Juice Chemistry ............................................................................ 177

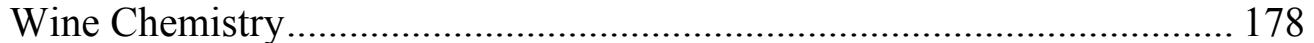

Clay Mineralogy ............................................................................ 179

Volcanic Landslide Parent Material - Jacob-Hart Vineyard, Block 5............... 180

Physical Characteristics..................................................................... 180

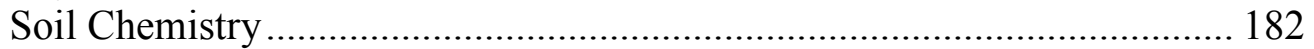

Grape Juice Chemistry ............................................................................ 185

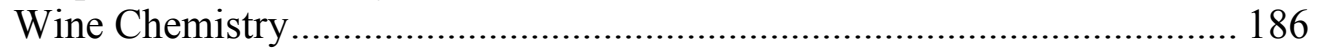

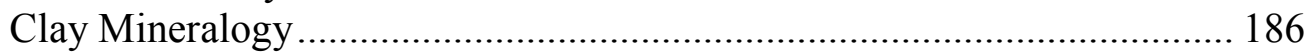

Chapter Nine - Ken Wright Cellars Results ................................................................ 188

Volcanic Parent Material - Nysa Vineyard, Midblock........................................ 188

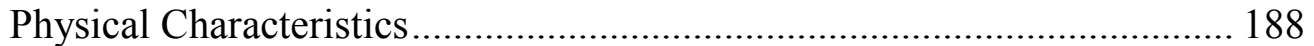

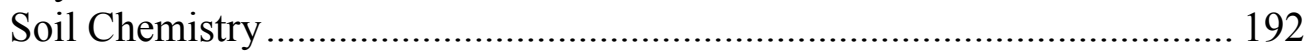

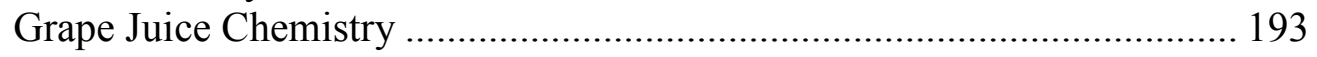

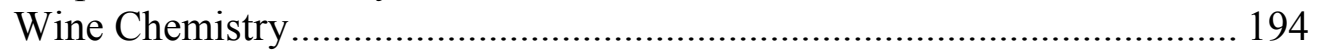

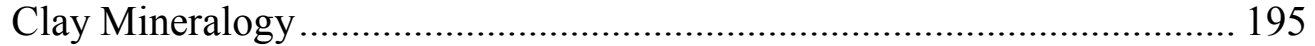

Marine Sediment Parent Material - Abbott Claim Vineyard ………………....... 196

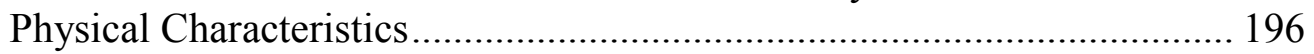

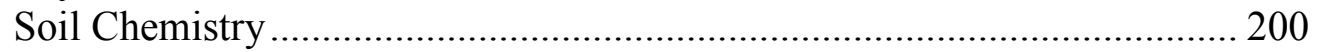

Grape Juice Chemistry .......................................................................... 200

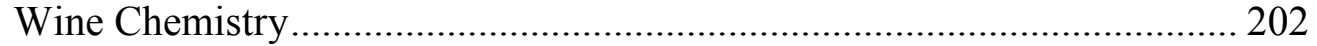

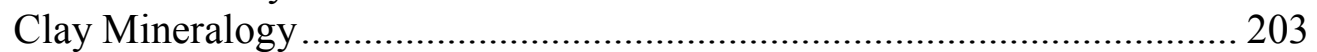

Marine Sediment Parent Material - Freedom Hill Vineyard.............................. 203

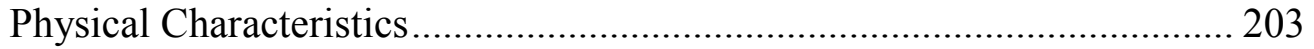

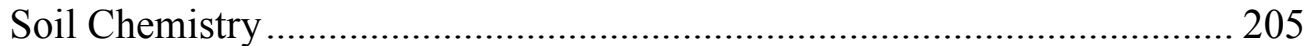

Grape Juice Chemistry ........................................................................... 208

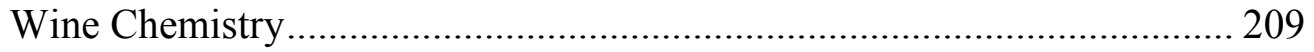

Clay Mineralogy …………………...................................................... 210

Volcanic Parent Material - Meredith Mitchell Vineyard, Martha Block ........... 211

Physical Characteristics......................................................................... 211

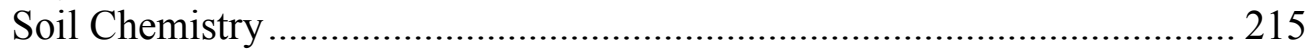

Grape Juice Chemistry ......................................................................... 217

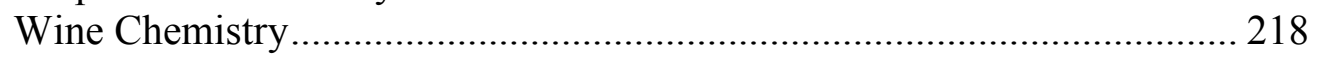

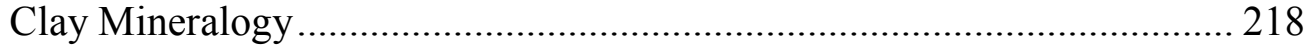

Chapter Ten - Data Analysis ............................................................................. 220

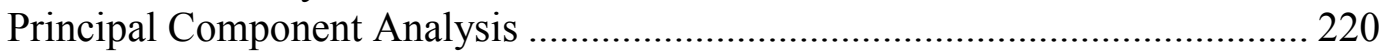

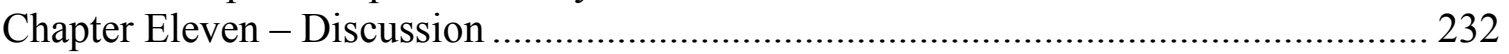

Soil Physical Characteristics................................................................... 232

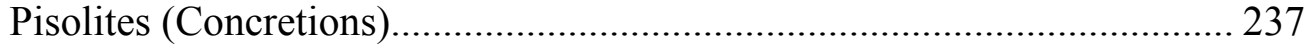

Buntley-Westin Soil Development Index................................................... 241 


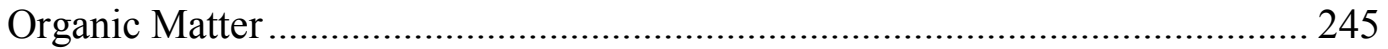

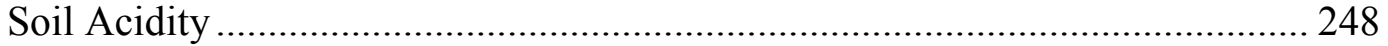

Cation Exchange Capacity ......................................................................... 250

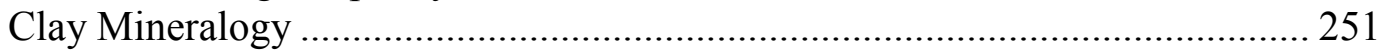

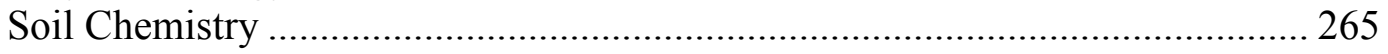

Grape Juice Chemistry ................................................................................... 268

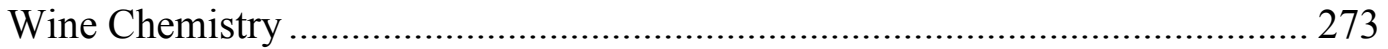

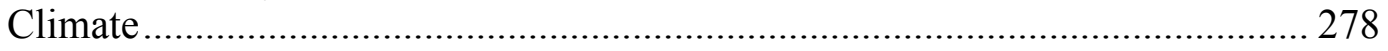

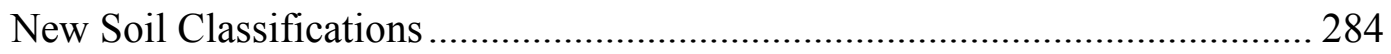

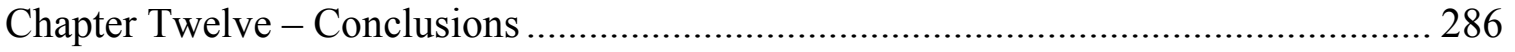

Chapter Thirteen - Future Work........................................................................ 294

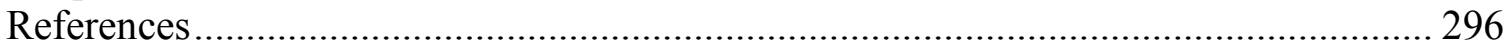

Appendix A Vineyard Soil Descriptions ....................................................................... 311

Elk Cove Vineyards, Clay Court Vineyard Block E.............................................. 311

Elk Cove Vineyards, Roosevelt Estate Vineyard ................................................. 313

Elk Cove Vineyards, Five Mountain Vineyard.................................................... 315

Willakenzie Estate Winery, The Jory Hills Vineyard Block 50c ....................... 317

Willakenzie Estate Winery, Aliette Vineyard Block 2b ..................................... 319

Willakenzie Estate Winery, Terres Basses Vineyard ........................................... 321

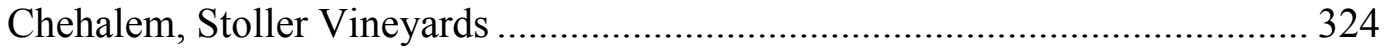

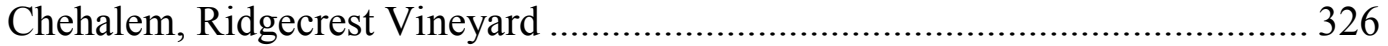

Chehalem, Corral Creek Vineyards Mid North Block.......................................... 328

Lange Estate Winery and Vineyards, Estate Vineyard Mia Block North............ 330

Lange Estate Winery and Vineyards, Yamhill Vineyard.................................... 332

Lange Estate Winery and Vineyards, Freedom Hill Vineyard ............................ 334

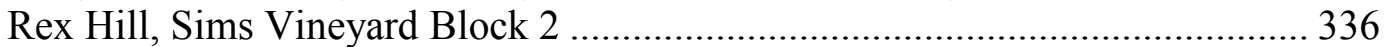

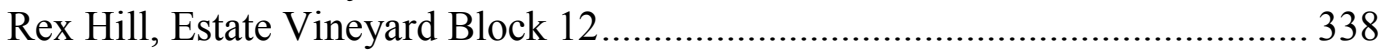

Rex Hill, Jacob-Hart Vineyard Block 1 ............................................................ 340

Rex Hill, Jacob-Hart Vineyard Block 5 ........................................................ 342

Ken Wright Cellars, Nysa Vineyard Midblock.................................................. 344

Ken Wright Cellars, Abbott Claim Vineyard ………………............................ 346

Ken Wright Cellars, Freedom Hill Vineyard .......................................................... 349

Ken Wright Cellars, Meredith Mitchell Vineyard Martha Block .......................... 351

Appendix B Clay Mineralogy ........................................................................................ 353

Elk Cove Vineyards, Clay Court Vineyard Block E............................................. 353

Elk Cove Vineyards, Roosevelt Estate Vineyard ............................................ 354

Elk Cove Vineyards, Five Mountain Vineyard...................................................... 356

Willakenzie Estate Winery, The Jory Hills Vineyard Block 50c ........................ 357

Willakenzie Estate Winery, Aliette Vineyard Block 2b ..................................... 357

Willakenzie Estate Winery, Terres Basses Vineyard ........................................ 360 


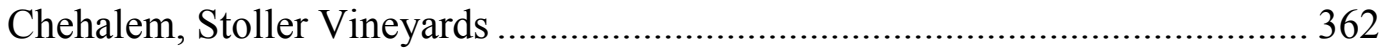

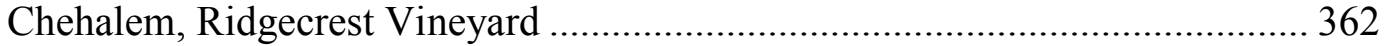

Chehalem, Corral Creek Vineyards Mid North Block......................................... 365

Lange Estate Winery and Vineyards, Estate Vineyard Mia Block North........... 365

Lange Estate Winery and Vineyards, Yamhill Vineyard..................................... 368

Lange Estate Winery and Vineyards, Freedom Hill Vineyard ........................... 368

Rex Hill, Sims Vineyard Block 2 ………………....................................... 368

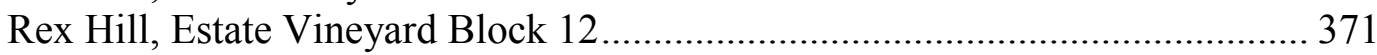

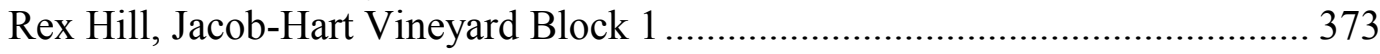

Rex Hill, Jacob-Hart Vineyard Block 5 ........................................................... 373

Ken Wright Cellars, Nysa Vineyard Midblock.................................................... 376

Ken Wright Cellars, Abbott Claim Vineyard …………................................... 376

Ken Wright Cellars, Freedom Hill Vineyard ......................................................... 378

Ken Wright Cellars, Meredith Mitchell Vineyard Martha Block ........................ 380

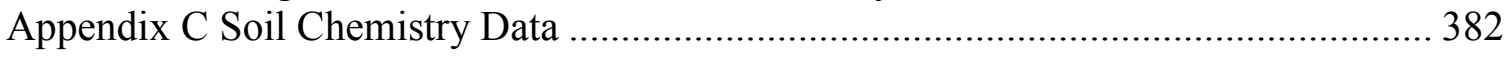

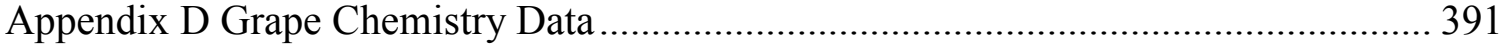

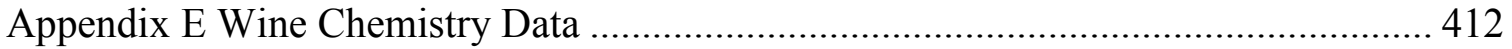

Appendix F Quality Assurance/Quality Control........................................................... 456

Appendix G Cation Exchange Capacity Data.................................................................. 463

Appendix H NSF Cascades to Coast GK-12 Fellowship Requirement ........................... 465

Created Curriculum - Radon Gas from the Missoula Floods.............................. 465

Created Curriculum - Introduction to Soil Texture.......................................... 468

Appendix I Farming Practices and Certification ....................................................... 473

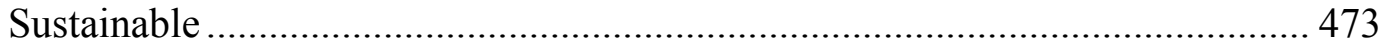

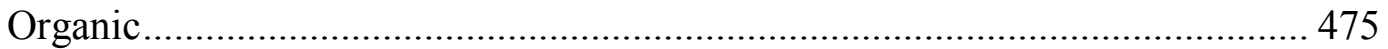

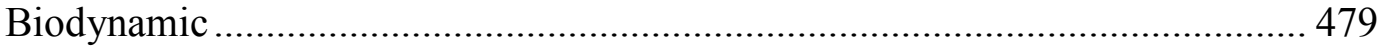

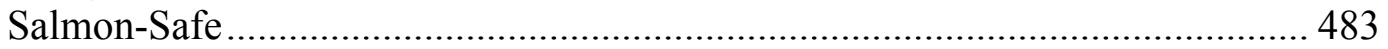

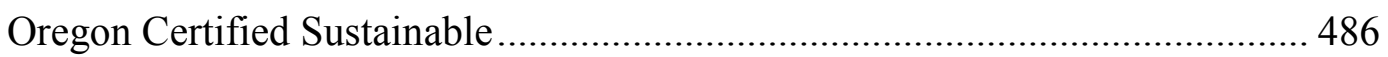

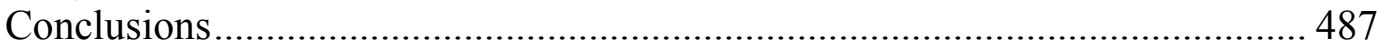

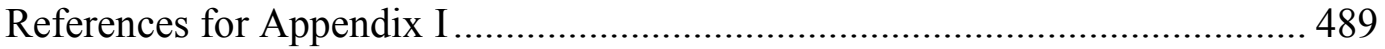




\section{List of Tables}

Table 1. Statistics on wine production in 2014 from the Department of the Treasury, Alcohol and Tobacco Tax and Trade Bureau (TTB) by volume in gallons, compiled by the author (ttb.gov, 2015).......................................................................................... 3

Table 2. Vineyard sites organized by parent material with main soil series in parentheses.

Table 3. Publications that address terroir using sensory characteristics of wines from

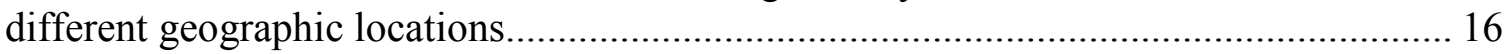

Table 4. Major geologic units in the northern Willamette Valley................................... 22

Table 5. Distribution of soils in the vineyards in the northern Willamette Valley (StarrPeace, 2005, and Burns, 2012).................................................................................. 26

Table 6. Sample ID and parent material information for the vineyards sampled in 2011.42

Table 7. Sample ID and parent material information for the vineyards sampled in 2012.43

Table 8 . Winery and vineyard name for each sample location with the year the vines were planted, clone, and rootstock used (ND - No Data). ....................................................... 45

Table 9. Elk Cove Vineyards, Clay Court Vineyard Block E field and lab data.............. 54

Table 10. Macronutrient, micronutrient, and trace element concentrations (all values in $\mathrm{mg} / \mathrm{kg}$ ) for the Elk Cove Vineyard, Clay Court Vineyard, Block E soil pit (ND - Non-

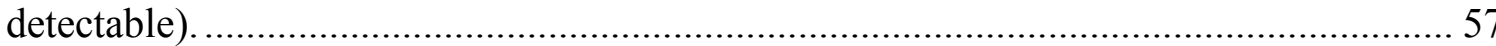

Table 11. Elemental concentrations measured by ICP-MS in the grape juice from clusters collected from vines immediately adjacent to the soil pit location at Elk Cove Vineyards, Clay Court Vineyard, Block E (ND - Non-detectable)..................................................... 58

Table 12. Elemental concentrations measured by ICP-MS in the 2011 Elk Cove Vineyards, Clay Court Vineyard and a $350 \mathrm{ml}$ sample of unblended wine from the same

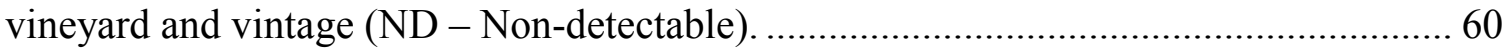

Table 13. Elk Cove Vineyards, Roosevelt Estate Vineyard field and lab data................. 64 
Table 14. Macronutrient and micronutrient concentrations (all values in $\mathrm{mg} / \mathrm{kg}$ ) for the

Elk Cove Vineyards, Roosevelt Estate soil pit (ND - Non-detectable).

Table 15. Trace element concentrations and other elements tested (all values in $\mathrm{mg} / \mathrm{kg}$ ) for the Elk Cove Vineyards, Roosevelt Estate soil pit (ND - Non-detectable)................ 68

Table 16. Elemental concentrations measured by ICP-MS in the grape juice from clusters collected from vines immediately adjacent to the soil pit location at Elk Cove Vineyards, Roosevelt Vineyard (ND - Non-detectable).

Table 17. Elemental concentrations measured by ICP-MS in the 2011 Elk Cove Vineyards, Roosevelt Vineyard wine and a $350 \mathrm{ml}$ sample of unblended wine from the same vineyard and vintage (ND - Non-detectable) ................................................. 70

Table 18. Elk Cove Vineyards, Five Mountain Vineyard field and lab data................... 73

Table 19. Macronutrient, micronutrient and trace element concentrations (all values in $\mathrm{mg} / \mathrm{kg}$ ) for the Elk Cove Vineyards, Five Mountain Vineyard soil pit (ND - Nondetectable).

Table 20. Elemental concentrations measured by ICP-MS in the grape juice from clusters collected from vines immediately adjacent to the soil pit location at Elk Cove Vineyards, Five Mountain Vineyard (ND - Non-detectable). 78

Table 21. Elemental concentrations measured by ICP-MS in the 2011 Elk Cove Vineyards, Five Mountain Vineyard wine (two bottles purchased and analyzed), and a $350 \mathrm{ml}$ sample of unblended wine from the same vineyard and vintage (ND - Nondetectable, *denotes mean of samples from two different bottles) ............................... 79

Table 22. Willakenzie Estate Winery, The Jory Hills Vineyard Block 50c field and lab data.

Table 23. Macronutrient, micronutrient and trace element concentrations (all values in $\mathrm{mg} / \mathrm{kg}$ ) for the Willakenzie Estate Winery, The Jory Hills Vineyard, Block 50c soil pit

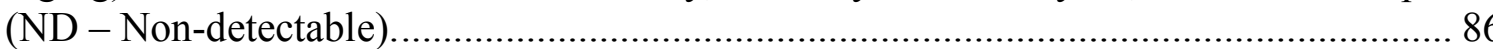

Table 24. Elemental concentrations measured by ICP-MS in the grape juice from clusters collected from vines immediately adjacent to the soil pit location at Willakenzie Estate Winery, The Jory Hills Vineyard, Block 50c (ND - Non-detectable). 
Table 25. Elemental concentrations measured by ICP-MS of a $750 \mathrm{ml}$ unblended wine sample from the 2011 Willakenzie Estate Winery, The Jory Hills Vineyard (ND - Non-

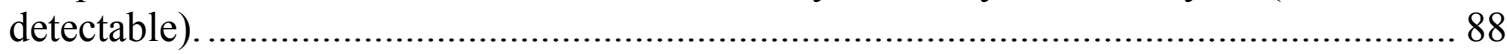

Table 26. Willakenzie Estate Winery, Aliette Vineyard Block 2b field and lab data. ..... 91

Table 27. Macronutrient, micronutrient and trace element concentrations (all values in $\mathrm{mg} / \mathrm{kg}$ ) for the Willakenzie Estate Winery, Aliette Vineyard, Block $2 \mathrm{~b}$ soil pit (ND Non-detectable).

Table 28. Elemental concentrations measured by ICP-MS in the grape juice from clusters collected from vines immediately adjacent to the soil pit location at Willakenzie Estate Winery, Aliette Vineyard, Block 2b (ND - Non-detectable).

Table 29. Elemental concentrations measured by ICP-MS of a $750 \mathrm{ml}$ unblended wine sample from the 2011 Willakenzie Estate Winery, Aliette Vineyard (ND - Nondetectable)....

Table 30. Willakenzie Estate Winery, Terres Basses Vineyard field and lab data..... 99

Table 31. Macronutrient concentrations (all values in $\mathrm{mg} / \mathrm{kg}$ ) for the Willakenzie Estate Winery, Terres Basses Vineyard soil pit (ND - Non-detectable). 102

Table 32. Elemental concentrations measured by ICP-MS in the grape juice from clusters collected from vines immediately adjacent to the soil pit location at Willakenzie Estate Winery, Terres Basses Vineyard (ND - Non-detectable).

Table 33. Elemental concentrations measured twice by ICP-MS of the same $750 \mathrm{ml}$ unblended wine sample from the 2011 Willakenzie Estate Winery, Terres Basses Vineyard (ND - Non-detectable, * denotes mean of two samples from the same bottle).

Table 34. Chehalem, Stoller Vineyards field and lab data.

Table 35. Macronutrient concentrations (all values in $\mathrm{mg} / \mathrm{kg}$ ) for the Chehalem, Stoller Vineyard soil pit (ND - Non-detectable).

Table 36. Elemental concentrations measured by ICP-MS in the grape juice from clusters collected from vines immediately adjacent to the soil pit location at Chehalem, Stoller Vineyard (ND - Non-detectable). 
Table 37. Elemental concentrations measured by ICP-MS of a $750 \mathrm{ml}$ unblended wine sample from the 2011 vintage of Chehalem, Stoller Vineyard (ND - Non-detectable, * denotes mean of three samples from the same bottle).

Table 38. Elemental concentrations measured by ICP-MS of multiple vintages of Chehalem, Stoller Vineyard wine (ND - Non-detectable) . ......................................... 114

Table 39. Chehalem, Ridgecrest Vineyard field and lab data................................... 117

Table 40. Macronutrient, micronutrient and trace element concentrations (all values in $\mathrm{mg} / \mathrm{kg}$ ) for the Chehalem, Ridgecrest Vineyard soil pit (ND - Non-detectable). .......... 120

Table 41. Elemental concentrations measured by ICP-MS in the grape juice from clusters collected from vines immediately adjacent to the soil pit location at Chehalem, Ridgecrest Vineyard (ND - Non-detectable).

Table 42. Elemental concentrations measured by ICP-MS of three samples of the same $750 \mathrm{ml}$ unblended wine sample from the 2011 vintage of Chehalem, Ridgecrest Vineyard (ND - Non-detectable, * denotes mean of three samples from the same bottle)........... 122

Table 43. Elemental concentrations measured by ICP-MS of multiple vintages of Chehalem, Ridgecrest Vineyard wine (ND - Non-detectable, * denotes mean of two samples from the same bottle).

Table 44. Chehalem, Corral Creek Vineyards Mid North Block field and lab data....... 126

Table 45. Macronutrient concentrations (all values in $\mathrm{mg} / \mathrm{kg}$ ) for the Chehalem, Corral Creek Vineyard soil pit (ND - Non-detectable). ................................................... 128

Table 46. Elemental concentrations measured by ICP-MS in the grape juice from clusters collected from vines immediately adjacent to the soil pit location at Chehalem, Corral Creek Vineyard (ND - Non-detectable).

Table 47. Elemental concentrations measured by ICP-MS of three samples of the same $750 \mathrm{ml}$ unblended wine from the 2011 vintage of Chehalem, Corral Creek Vineyard wine (ND - Non-detectable, * denotes mean of two samples from the same bottle)............. 130

Table 48. Elemental concentrations measured by ICP-MS of multiple vintages of Chehalem, Corral Creek Vineyard wine (ND - Non-detectable, * denotes mean of two samples from the same bottle). 
Table 49. Lange Estate Winery and Vineyards, Estate Vineyard Mia Block North field and lab data.

Table 50. Macronutrient, micronutrient and trace element concentrations (all values in $\mathrm{mg} / \mathrm{kg}$ ) for the Lange Estate Winery and Vineyards, Estate Vineyard, Mia Block North soil pit (ND - Non-detectable).

Table 51. Elemental concentrations measured by ICP-MS in the grape juice from clusters collected from vines immediately adjacent to the soil pit location at Lange Estate, Estate Vineyard Mia Block North (ND - Non-detectable). 139

Table 52. Elemental concentrations measured twice by ICP-MS of the same $750 \mathrm{ml}$ unblended wine sample from the 2012 Lange Estate Winery, Mia Block North Vineyard (ND - Non-detectable, * denotes mean of two samples from the same bottle)............. 140

Table 53. Lange Estate Winery and Vineyards, Yamhill Vineyard field and lab data... 142

Table 54. Macronutrient, micronutrient and trace element concentrations (all values in $\mathrm{mg} / \mathrm{kg}$ ) for the Lange Estate Winery and Vineyards, Yamhill Vineyard soil pit (ND Non-detectable).

Table 55. Elemental concentrations measured by ICP-MS in the grape juice from clusters collected from vines immediately adjacent to the soil pit location at Lange Estate, Yamhill Vineyard (ND - Non-detectable).

Table 56. Elemental concentrations measured by ICP-MS of a $750 \mathrm{ml}$ unblended wine sample from the 2012 Lange Estate Winery, Yamhill Vineyard (ND - Non-detectable).

Table 57. Lange Estate Winery and Vineyards, Freedom Hill Vineyard field and lab data.

Table 58. Macronutrient, micronutrient and trace element concentrations (all values in $\mathrm{mg} / \mathrm{kg}$ ) for the Lange Estate Winery and Vineyards, Freedom Hill Vineyard soil pit (ND

- Non-detectable).

Table 59. Elemental concentrations measured by ICP-MS in the grape juice from clusters collected from vines immediately adjacent to the soil pit location at Lange Estate, Freedom Hill Vineyard (ND - Non-detectable). 
Table 60. Elemental concentrations measured by ICP-MS of a $750 \mathrm{ml}$ unblended wine sample from the 2012 Lange Estate Winery, Freedom Hill Vineyard (ND - Nondetectable).

Table 61. Rex Hill, Sims Vineyard Block 2 field and lab data

Table 62. Macronutrient, micronutrient and trace element concentrations (all values in $\mathrm{mg} / \mathrm{kg}$ ) for the Rex Hill, Sims Vineyard, Block 2 soil pit (ND - Non-detectable). ....... 161

Table 63 Elemental concentrations measured by ICP-MS in the grape juice from clusters collected from vines immediately adjacent to the soil pit location at Rex Hill, Sims Vineyard, Block 2 (ND - Non-detectable). 162

Table 64. Elemental concentrations measured twice by ICP-MS of the same $750 \mathrm{ml}$ unblended wine sample from the 2012 Rex Hill, Sims Vineyard (ND - Non-detectable, * denotes mean of two samples from the same bottle). 164

Table 65. Rex Hill, Estate Vineyard Block 12 field and lab data. 166

Table 66. Macronutrient, micronutrient and trace elements concentrations (all values in $\mathrm{mg} / \mathrm{kg}$ ) for the Rex Hill, Estate Vineyard, Block 12 soil pit (ND - Non-detectable)..... 168

Table 67. Elemental concentrations measured by ICP-MS in the grape juice from clusters collected from vines immediately adjacent to the soil pit location at Rex Hill, Estate Vineyard, Block 12 (ND - Non-detectable). 170

Table 68. Elemental concentrations measured by ICP-MS of a $750 \mathrm{ml}$ unblended wine sample from the 2012 Rex Hill, Estate Vineyard, Block 12 (ND - Non-detectable)..... 171

Table 69. Rex Hill, Jacob-Hart Vineyard Block 1 field and lab data. 174

Table 70. Macronutrient, micronutrient and trace element concentrations (all values in $\mathrm{mg} / \mathrm{kg}$ ) for the Rex Hill, Jacob-Hart Vineyard, Block 1 soil pit (ND - Non-detectable).

Table 71. Elemental concentrations measured by ICP-MS in the grape juice from clusters collected from vines immediately adjacent to the soil pit location at Rex Hill, Jacob-Hart Vineyard, Block 1 (ND - Non-detectable). 178 
Table 72. Elemental concentrations measured by ICP-MS of a $750 \mathrm{ml}$ unblended wine sample from the 2012 Rex Hill, Jacob-Hart Vineyard, Block 1 (ND - Non-detectable).

Table 73. Rex Hill, Jacob-Hart Vineyard Block 5 field and lab data.

Table 74. Macronutrient, micronutrient and trace element concentrations (all values in $\mathrm{mg} / \mathrm{kg}$ ) for the Rex Hill, Jacob-Hart Vineyard, Block 5 soil pit (ND - Non-detectable).

Table 75. Elemental concentrations measured by ICP-MS in the grape juice from clusters collected from vines immediately adjacent to the soil pit location at Rex Hill, Jacob-Hart Vineyard, Block 5 (ND - Non-detectable).

Table 76. Elemental concentrations measured twice by ICP-MS of the same $750 \mathrm{ml}$ unblended wine sample from the 2012 Rex Hill, Jacob-Hart Vineyard, Block 5 (ND Non-detectable, $*$ denotes mean of two samples from the same bottle)

Table 77. Ken Wright Cellars, Nysa Vineyard Midblock field and lab data.

Table 78. Macronutrient, micronutrient and trace element concentrations (all values in $\mathrm{mg} / \mathrm{kg}$ ) for the Ken Wright Cellars, Nysa Vineyard, and Midblock soil pit (ND - Nondetectable).

Table 79. Elemental concentrations measured by ICP-MS in the grape juice from clusters collected from vines immediately adjacent to the soil pit location at Ken Wright Cellars, Nysa Vineyard, Midblock (ND - Non-detectable).

Table 80. Elemental concentrations measured by ICP-MS of a $750 \mathrm{ml}$ unblended wine sample from the 2012 Ken Wright, Nysa Vineyard (ND - Non-detectable).................. 195

Table 81. Ken Wright Cellars, Abbott Claim Vineyard field and lab data..................... 198

Table 82. Macronutrient, micronutrient and trace element concentrations (all values in $\mathrm{mg} / \mathrm{kg}$ ) for the Ken Wright Cellars, Abbott Claim Vineyard soil pit (ND - Nondetectable). 201

Table 83. Elemental concentrations measured by ICP-MS in the grape juice from clusters collected from vines immediately adjacent to the soil pit location at Ken Wright Cellars, Abbott Claim Vineyard (ND - Non-detectable). 202 
Table 84. Elemental concentrations measured by ICP-MS of a $750 \mathrm{ml}$ unblended wine sample from the 2012 Ken Wright, Abbott Claim Vineyard (ND - Non-detectable).... 203

Table 85. Ken Wright Cellars, Freedom Hill Vineyard field and lab data. 206

Table 86. Macronutrient, micronutrient and trace element concentrations (all values in $\mathrm{mg} / \mathrm{kg}$ ) for the Ken Wright Cellars, Freedom Hill Vineyard soil pit (ND - Nondetectable).

Table 87. Elemental concentrations measured by ICP-MS in the grape juice from clusters collected from vines immediately adjacent to the soil pit location at Ken Wright Cellars, Freedom Hill Vineyard (ND - Non-detectable). 209

Table 88. Elemental concentrations measured by ICP-MS of a $750 \mathrm{ml}$ unblended wine sample from the 2012 Ken Wright, Freedom Hill Vineyard (ND - Non-detectable)... 210

Table 89. Ken Wright Cellars, Meredith Mitchell Vineyard Martha Block field and lab data.

Table 90. Macronutrient, micronutrient and trace element concentrations (all values in $\mathrm{mg} / \mathrm{kg}$ ) for the Ken Wright Cellars, Meredith Mitchell Vineyard, Martha Block soil pit (ND - Non-detectable).

Table 91. Elemental concentrations measured by ICP-MS in the grape juice from clusters collected from vines immediately adjacent to the soil pit location at Ken Wright Cellars, Meredith Mitchell Vineyard, Martha Block (ND - Non-detectable). 217

Table 92. Elemental concentrations measured by ICP-MS of a $750 \mathrm{ml}$ unblended wine sample from the 2012 Ken Wright, Meredith Mitchell Vineyard, Martha Block (ND Non-detectable).

Table 93. Comparison of physical characteristics of vineyard soils in the Willamette Valley.

Table 94. Major elements measured in pisolites from soils formed on two different parent materials in the Willamette Valley using XRF. LEM - Lange Estate Mia vineyard on volcanic parent material. ECFM - Elk Cove Five Mountain vineyard on windblown and volcanic parent material. 240 
Table 95. Soil development rating based on Buntley-Westin Color Index. Value is the maximum for each soil pit compared to all horizons sampled within that pit separated by parent material.

Table 96. Percent organic matter for the A horizon of each soil pit in this study separated by parent material. Organic matter determined using loss on ignition separated by parent material. 246

Table 97. Minimum soil $\mathrm{pH}$ for each vineyard site according to parent material. ......... 248

Table 98. Maximum CEC (meq/100g) for each soil pit by parent material. ................. 250

Table 99. Clay mineralogy by parent material..................................................... 253

Table 100. Common clay minerals, chemical formulas, and notes concerning their

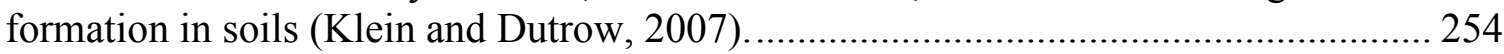

Table 101. Clay mineral interpretation from x-ray diffraction. Key: - none present, o trace amounts, + minor amounts, ++ moderate amounts, +++ abundant amounts, bold grayscale $=$ interlayers

Table 102. Maximum macronutrient values for vineyard soils separated by parent material (* Indicates value after removing outlier value of $4670 \mathrm{ppm}$ from the Lange Estate Yamhill Vineyard).

Table 103. Maximum micronutrient values for vineyard soils separated by parent material (* Indicates value after removing Na outlier value of 3330 ppm from Ken Wright Freedom Hill Vineyard). 267

Table 104. Maximum trace element values for vineyard soils separated by parent material (* Indicates value after removing $\mathrm{Pb}$ outlier value of $669 \mathrm{ppm} \mathrm{Ba}$ from Chehalem Coral Creek Vineyard and 47.1 ppm Pb from Rex Hill Estate Vineyard)....... 268

Table 105. Elemental concentration (ppm) for grape juice obtained from vines adjacent to soil pits in this study. 270

Table 106. Mean and standard deviation values (with maximum in parentheses) for elemental concentrations in grape juice separated by parent material. 
Table 107. Macronutrient concentration ( $\mathrm{ppm}$ ) for wines obtained from vines adjacent to soil pits in this study (mean calculated from multiple runs of the same bottle of wine).

ND - Non-detected.

Table 108. Micronutrient concentration ( $\mathrm{ppm}$ ) for wines obtained from vines adjacent to soil pits in this study (mean calculated from multiple runs of the same bottle of wine). ND - Non-detected.

Table 109. Trace element concentration ( $\mathrm{ppm}$ ) for wines obtained from vines adjacent to soil pits in this study (mean calculated from multiple runs of the same bottle of wine). ND - Non-detected.

Table 110. Mean and standard deviation values (with maximum in parentheses) for elemental concentrations in wines separated by parent material disregarding vintage. . 276

Table 111. Elevations of soil pit locations for each vineyard, sorted by parent material (rounded to the nearest foot)......

Table 112. Mean and standard deviation values (with maximum in parentheses) for elemental concentrations in wines from the northern Willamette Valley separated vintage disregarding parent material. 


\section{List of Figures}

Figure 1. Oregon's 17 (Elkton AVA, the 17 ${ }^{\text {th }}$, not shown) wine regions or American Viticulture Areas (AVA), many of which are located within a larger AVA and are termed Sub-AVAs (http://essentialnorthwestwines.com/oregon-wine/).

Figure 2. Geologic map of the Willamette Valley sub-AVAs (black outline) (Jones et al., 2010) in the Willamette Valley AVA based on geologic map compilation data (Madin, 2009).

Figure 3. Preliminary geologic map produced by the USGS showing how the new SubAVAs of the northern Willamette Valley are outlined based on bedrock geology types. Ty - Tertiary Yamhill Formation, Tdb - Tertiary Diabase intrusions, Tes - Tertiary Spencer Formation, Tk - Tertiary Keasey Formation, Tpe - Tertiary Pittsburg Bluff Formation, Tsd - Tertiary Scappoose Formation, CRB - Columbia River Basalt (Wells, 2006).

Figure 4. A general soil series map highlighting the Willakenzie, Jory, Woodburn and Laurelwood soils from the NRCS soil data (Soil Survey Staff, 2010b) with the sub-AVAs in the Willamette Valley AVA outlined (Jones et al., 2010).

Figure 5. The Willamette Valley American Viticultural Area (AVA) outline and the northern Willamette Valley Sub-AVAs (Jones et al., 2010).

Figure 6. Soil pit locations in the northern Willamette Valley, Oregon provided by six different wineries with AVA boundaries shown (Jones et al., 2010).

Figure 7. Soil map of Elk Cove Vineyards, Clay Court Vineyard Block E. Pit location marked. 45C - Jory silty clay loam, 8 to 15 percent slopes. 45B - Jory silty clay loam, 2 to 8 percent slopes. 45D - Jory silty clay loam, 15 to 30 percent slopes (NRCS, 2014)..... 53

Figure 8. Sample soil pit at Elk Cove Vineyards, Clay Court Vineyard Block E. A - View of sample location, facing south. B - Picture of the face of the soil pit with horizon depths and boundaries marked. C - Soil retrieved using a hand auger with horizon depths and boundaries marked.

Figure 9. Soil map of Elk Cove Vineyards, Roosevelt Estate Vineyard. Pit location marked. 2771E - Goodin-Melbourne complex, 2 to 30 percent slopes. $2763 \mathrm{~F}-$ Willakenzie-Sitton complex, 30 to 75 percent slopes, 2769C - Melbourne-Witham 
complex, hummocky, 2 to 25 percent slopes (NRCS, 2015). Previously mapped as WeC

- Willakenzie silty clay loam, 2 to 12 slopes (NRCS, 2014). ........................................... 62

Figure 10. Sample soil pit at Elk Cove Vineyards, Roosevelt Estate Vineyard. A - View of sample location, facing south. B - Picture of the face of the soil pit with horizon depths and boundaries marked. C - Soil retrieved using a hand auger with horizon depths and boundaries marked.

Figure 11. Soil map of Elk Cove Vineyards, Five Mountain Vineyard. Pit location marked. 28C - Laurelwood silt loam, 7 to 12 percent slopes. 28B - Laurelwood silt loam, 3 to 7 percent slopes. 28E - Laurelwood silt loam, 20 to 30 percent slopes (NRCS, 2014).

Figure 12. Sample soil pit at Elk Cove Vineyards, Five Mountain Vineyard. A - View of sample location, facing west. B - Picture of the face of the soil pit with horizon depths and boundaries marked. C - Soil retrieved using a hand auger with horizon depths and boundaries marked.

Figure 13. Soil map of Willakenzie Estate Winery, The Jory Hills Vineyard Block 50c. Pit location marked. 2711D - Jory silty clay loam, 12 to 20 percent slopes. 2711E - Jory silty clay loam, 20 to 30 percent slopes. $2780 \mathrm{C}$ - Jory-Gelderman silty clay loams, 2 to 12 percent slopes (NRCS, 2015).

Figure 14. Sample soil pit at Willakenzie Estate Winery, The Jory Hills Vineyard Block $50 \mathrm{c}$. A - View of sample location, facing southwest. B - Picture of the face of the soil pit with horizon depths and boundaries marked.

Figure 15. Soil map of Willakenzie Estate Winery, Aliette Vineyard Block 2b. Pit location marked. 2770C - Melbourne-Goodin silt loams, 2 to 12 percent slopes. 2770D Melbourne-Goodin silt loams, 12 to 20 percent slopes. 2770E - Melbourne-Goodin silt loams, 20 to 30 percent slopes. $2770 \mathrm{~F}$ - Melbourne-Goodin silt loams, 30 to 60 percent slopes. $2763 \mathrm{~F}$ - Willakenzie-Sitton complex, 30 to 75 percent slopes (NRCS, 2015). Previously mapped as $\mathrm{WeC}$ - Willakenzie silty clay loam, 2 to 12 percent slopes (NRCS, 2014).

Figure 16. Sample soil pit at Willakenzie Estate Winery, Aliette Vineyard Block 2b. A View of sample location, facing south. B - Picture of the face of the soil pit with horizon depths and boundaries marked. C - Soil retrieved using a hand auger with horizon depths and boundaries marked. 
Figure 17. Soil map of Willakenzie Estate Winery, Terres Basses Vineyard. Pit location marked. 2798D - Witham silty clay loam, hummocky, 2 to 25 percent slopes with 2769C - Melbourne-Witham complex and 2825C - Hazelair-Witham complex surrounding (NRCS, 2015). Previously mapped as HcD - Hazelair silty clay loam, 7 to 20 percent slopes (NRCS, 2014).

Figure 18. Sample soil pit at Willakenzie Estate Winery, Terres Basses Vineyard. A View of sample location, facing southwest. B - Picture of the face of the soil pit with horizon depths and boundaries marked. C - Soil retrieved using a hand auger with horizon depths and boundaries marked.

Figure 19. Soil map of Chehalem, Stoller Vineyards. Pit location marked. 2711D - Jory silty clay loam, 12 to 20 percent slopes. $2711 \mathrm{E}$ - Jory silty clay loam, 20 to 30 percent slopes. 2780C - Jory-Gelderman silty clay loams, 2 to 12 percent slopes (NRCS, 2015). Previously mapped as JrC - Jory clay loam, 7 to 12 percent slopes (NRCS, 2014). ..... 107

Figure 20. Sample soil pit at Chehalem, Stoller Vineyards. A - View of sample location, facing north. B - Picture of the face of the soil pit with horizon depths and boundaries marked.

Figure 21. Soil map of Chehalem, Ridgecrest Vineyard. Pit location marked. 2779C Wellsdale loam, 2 to 12 percent slopes. 2779D - Wellsdale loam, 12 to 20 percent slopes. $2779 \mathrm{E}$ - Wellsdale loam, 20 to 30 percent slopes. 2770F - Melbourne-Goodin silt loams, 30 to 60 percent slopes (NRCS, 2015). Previously mapped as WeC - Willakenzie silty clay loam, 2 to 12 percent slopes (NRCS, 2014).

Figure 22. Sample soil pit at Chehalem, Ridgecrest Vineyard. A - View of sample location, facing east. B - Picture of the face of the soil pit with horizon depths and boundaries marked. C - Soil retrieved using a hand auger with horizon depths and boundaries marked.

Figure 23. Soil map of Chehalem, Corral Creek Vineyard Mid North Block. Pit location marked. 2712D - Laurelwood silt loam 12 to 20 percent slopes. 2712 E - Laurelwood silt loam, 20 to 30 percent slopes. $2712 \mathrm{~F}$ - Laurelwood silt loam, 30 to 60 percent slopes. 2712C - Laurelwood silt loam, 2 to 12 percent slopes. 2310C - Woodburn silt loam, 2 to 12 percent slopes. 2301A - Amity silt loam, 0 to 3 percent slopes (NRCS, 2015).

Previously mapped as LuD - Laurelwood silt loam (NRCS, 2014). 125

Figure 24. Sample soil pit at Chehalem, Corral Creek Vineyard Mid North Block. A View of sample location, facing north. B - Picture of the face of the soil pit with horizon depths and boundaries marked. 
Figure 25. Soil map of Lange Estate Winery and Vineyards, Estate Vineyard Mia North Block. Pit location marked. 2780C - Jory-Gelderman silty clay loams, 2 to 12 percent slopes. $2711 \mathrm{D}$ - Jory silty clay loam, 12 to 20 percent slopes. $2711 \mathrm{~F}$ - Jory silty clay loam, 30 to 60 percent slopes (NRCS, 2015). Previously mapped as JrC - Jory clay loam, 7 to 12 percent slopes (NRCS, 2014). 134

Figure 26. Sample soil pit at Lange Estate Winery and Vineyards, Estate Vineyard Mia Block North. A - View of sample location, facing north. B - Picture of the face of the soil pit with horizon depths and boundaries marked. C - Soil retrieved using a hand auger with horizon depths and boundaries marked.

Figure 27. Soil map of Lange Estate Winery and Vineyards, Yamhill Vineyard. Pit location marked. 2760C - Wellsdale-Willakenzie-Dupee complex, 2 to 12 percent slopes. 2762D - Willakenzie-Wellsdale complex, 12 to 20 percent slopes. 2762E - WillakenzieWellsdale complex, 20 to 30 percent slopes. 2761E - Wellsdale-Willakenzie complex, 20 to 30 percent slopes (NRCS, 2015). Previously mapped as WeC - Willakenzie silty clay loam, 2 to 12 percent slopes (NRCS, 2014).

Figure 28. Sample soil pit at Lange Estate Winery and Vineyards, Yamhill Vineyard. A View of sample location, facing northwest. B - Picture of the face of the soil pit with horizon depths and boundaries marked. C - Soil retrieved using a hand auger with horizon depths and boundaries marked.

Figure 29. Soil map of Lange Estate Winery and Vineyards, Freedom Hill Vineyard. Pit location marked. $8 \mathrm{C}-$ Bellpine silty clay loam, 3 to 12 percent slopes. $36 \mathrm{C}$ - Jory silty clay loam, 2 to 12 percent slopes. 36D - Jory silty clay loam, 12 to 20 percent slopes (NRCS, 2015). Two sites were analyzed at the Freedom Hill Vineyard; one for Lange and one for Ken Wright.

Figure 30. Sample soil pit at Lange Estate Winery and Vineyards, Freedom Hill Vineyard. A - View of sample location, facing south. B - Picture of the face of the soil pit with horizon depths and boundaries marked. C - Soil retrieved using a hand auger with horizon depths and boundaries marked.

Figure 31. Soil map for Rex Hill, Sims Vineyard Block 2. Pit location marked. 2711D Jory silty clay loam, 12 to 20 percent slopes. $2711 \mathrm{E}$ - Jory silty clay loam, 20 to 30 percent slopes (NRCS, 2015). Previously JrD - Jory clay loam, 12 to 20 percent slopes (NRCS, 2014).

Figure 32. Sample soil pit at Rex Hill, Sims Vineyard Block 2. A - View of sample location, facing north. B - Picture of the face of the soil pit with horizon depths and 
boundaries marked. C - Soil retrieved using a hand auger with horizon depths and boundaries marked.

Figure 33. Soil map of Rex Hill, Estate Vineyard Block 12. Pit location marked. 2712C Laurelwood silt loam, 2 to 12 percent slopes. 2712D - Laurelwood silt loam, 12 to 20 percent slopes. 2712E - Laurelwood silt loam, 20 to 30 percent slopes (NRCS, 2015). Previously mapped as YhD - Yamhill silt loam, moderately shallow, 7 to 20 percent slopes and LuC - Laurelwood silt loam, 3 to 12 percent slopes (NRCS, 2014).

Figure 34. Sample soil pit at Rex Hill, Estate Vineyard Block 12. A - View of sample location, facing north. B - Picture of the face of the soil pit with horizon depths and boundaries marked. C - Soil retrieved using a hand auger with horizon depths and boundaries marked.

Figure 35. Soil map of Rex Hill, Jacob-Hart Vineyard Block 1. Pit location marked. $2702 \mathrm{C}$ - Dixonville silty clay loam, 3 to 12 percent slopes. 2702D - Dixonville silty clay loam, 12 to 20 percent slopes. $2304 \mathrm{C}$ - Carlton silt loam, 2 to 12 percent slopes. 2793C Witzel-Dixonville complex, 2 to 12 percent slopes (NRCS, 2015). Previously mapped as $\mathrm{SuD}$ - Steiwer silty clay loam, basalt substratum, 5 to 20 percent slopes (NRCS, 2014).

Figure 36. Sample soil pit at Rex Hill, Jacob-Hart Vineyard Block 1. A - View of sample location, facing south. B - Picture of the face of the soil pit with horizon depths and boundaries marked. C - Soil retrieved using a hand auger with horizon depths and boundaries marked.

Figure 37. Soil map of Rex Hill, Jacob-Hart Vineyard Block 5. Pit location marked. 2702C - Dixonville silty clay loam, 3 to 12 percent slopes. 2702D - Dixonville silty clay loam, 12 to 20 percent slopes. $2304 \mathrm{C}$ - Carlton silt loam, 2 to 12 percent slopes. $2793 \mathrm{C}-$ Witzel-Dixonville complex, 2 to 12 percent slopes (NRCS, 2015). Previously mapped as SuD - Steiwer silty clay loam, basalt substratum, 5 to 20 percent slopes (NRCS, 2014).

Figure 38. Sample soil pit at Rex Hill, Jacob-Hart Vineyard Block 5. A - View of sample location, facing south. B - Picture of the face of the soil pit with horizon depths and boundaries marked. C - Soil retrieved using a hand auger with horizon depths and boundaries marked.

Figure 39. Soil map for Ken Wright Cellars, Nysa Vineyard Midblock. Pit location marked. $2711 \mathrm{D}$ - Jory silty clay loam, 12 to 20 percent slopes. $2711 \mathrm{E}$ - Jory silty clay loam, 20 to 30 percent slopes. 2780C Jory-Gelderman silty clay loams, 2 to 12 percent 
slopes (NRCS, 2015). Previously mapped as JrD - Jory clay loam, 12 to 20 percent slopes (NRCS, 2014).

Figure 40. Sample soil pit at Ken Wright Cellars, Nysa Vineyard Midblock. A - View of sample location, facing north. B - Picture of the face of the soil pit with horizon depths and boundaries marked. C - Soil retrieved using a hand auger with horizon depths and boundaries marked.

Figure 41. Soil map for Ken Wright Cellars, Abbott Claim Vineyard. Pit location marked. 2760C - Wellsdale-Willakenzie-Dupee complex, 2 to 12 percent slopes. 2760D Wellsdale-Willakenzie-Dupee complex, 2 to 12 percent slopes. 2762D - WillakenzieWellsdale complex, 12 to 20 percent slopes (NRCS, 2015). Previously mapped as $\mathrm{WeC}-$ Willakenzie silty clay loam, 2 to 12 percent slopes (NRCS, 2014).

Figure 42. Sample soil pit at Ken Wright Cellars, Abbott Claim Vineyard. A - View of sample location, facing north. B - Picture of the face of the soil pit with horizon depths and boundaries marked. C - Soil retrieved using a hand auger with horizon depths and boundaries marked.

Figure 43. Soil map of Ken Wright Cellars, Freedom Hill Vineyard. Pit location marked. $36 \mathrm{D}$ - Jory silty clay loam, 12 to 20 percent slopes. $8 \mathrm{C}$ - Bellpine silty clay loam, 3 to 12 percent slopes. 36C - Jory silty clay loam, 2 to 12 percent slopes (NRCS, 2014). Two sites were analyzed at the Freedom Hill Vineyard; one for Lange and one for Ken Wright.

Figure 44. Sample soil pit at Ken Wright Cellars, Freedom Hill Vineyard. A - View of sample location, facing south. B - Picture of the face of the soil pit with horizon depths and boundaries marked.

Figure 45. Soil map for Ken Wright Cellars, Meredith Mitchell Vineyard Martha Block. Pit location marked. 2793C - Witzel-Dixonville complex, 2 to 12 percent slopes. 2792D - Witzel-Dixonville complex, 12 to 20 percent slopes. 2795E - Gellatly-Dixonville complex, 20 to 30 percent slopes. $2791 \mathrm{~F}$ - Gellatly silty clay loam, 30 to 60 percent slopes (NRCS, 2015). Previously mapped as YhD - Yamhill silt loam, moderately shallow, 7 to 20 percent slopes (NRCS, 2014).

Figure 46. Sample soil pit at Ken Wright Cellars, Meredith Mitchell Vineyard Martha Block. A - View of sample location, facing south. B - Picture of the face of the soil pit with horizon depths and boundaries marked. C - Soil retrieved using a hand auger with horizon depths and boundaries marked. 
Figure 47. Principal component analysis of physical characteristics of vineyard soils in this study including \% Clay, Mean $\mathrm{pH}$, Mean OM, Depth to Cr, and CEC in comparison to vineyard soil parent materials $(\mathrm{Red}=$ volcanic, Blue $=$ marine sediment, Orange $=$ loess/volcanic, Purple $=$ Other)

Figure 48. PCA biplot of soil macronutrients, CEC, and percent clay. Red labels volcanic parent material. Blue labels - marine sediment parent material. Orange labels loess/volcanic parent material. Purple labels - other parent material.

Figure 49. PCA plot of macronutrients, micronutrients and trace elements. Triangles volcanic parent material. Squares - marine sediment parent material. Circles loess/volcanic parent material. Diamonds - other parent material (Meredith Mitchell vineyard outlier data removed).

Figure 50. PCA biplot of the soil micronutrients grouping soil parent materials by color. Red labels - volcanic parent material. Blue labels - marine sediment parent material. Orange labels - loess/volcanic parent material. Purple labels - other parent material... 225

Figure 51. PCA biplot of the soil trace elements grouping soil parent materials by color. Red labels - volcanic parent material. Blue labels - marine sediment parent material. Orange labels - loess/volcanic parent material. Purple labels - other parent material... 226

Figure 52. PCA biplot of grape chemistry by vineyard. Red labels - volcanic parent material. Blue labels - marine sediment parent material. Orange labels - loess/volcanic parent material. Purple labels - other parent material.

Figure 53. PCA biplot of mean wine chemistry by vineyard. Red labels - volcanic parent material. Blue labels - marine sediment parent material. Orange labels - loess/volcanic parent material. Purple labels - other parent material. 229

Figure 54. Pisolites from the Lange Estate, Mia Block (A - LEM) and Elk Cove, Five Mountain Vineyards (B - ECFM).

Figure 55. Trace elements of pisolites from soils formed on two different parent materials in the Willamette Valley using ICP-MS. LEM - Lange Estate Mia vineyard on volcanic parent material. ECFM - Elk Cove Five Mountain vineyard on windblown and volcanic parent material. 241

Figure 56. Map of the maximum Buntley \& Westin color from a B horizon in each soil pit for vineyards in this study that were located in the northern Willamette Valley AVAs. 
Figure 57. Map showing the mean organic matter determined using loss on ignition on each horizon in each soil pit for vineyards in this study that were located in the northern Willamette Valley AVAs.

Figure 58. Cation Exchange Capacity (CEC) in meq/100 g soil for each vineyard sorted by parent material in a box and whisker plot.

Figure 59. Pathways for the formation of soil clay minerals (adapted from Wilson, 1999

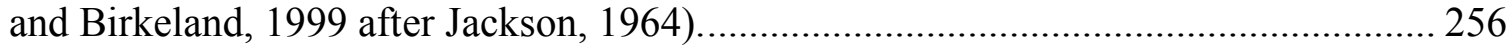

Figure 60. High and low average monthly temperatures as well as cumulative rainfall for the two vintages (2011 and 2012) included in this study (NOAA, 2013)................... 279 


\section{Chapter One - Introduction}

Terroir is a French term referring to the environmental conditions in which grapes are grown and the unique taste of wine created by these conditions. In reference to wine, terroir is the way the soil, geology, climate and grape type create unique flavors due to location (Robert, 2008). Research in terroir spreads across many disciplines. A geologist's perspective of terroir is one of physical characteristics of a site that are measureable. The question of how soil influences wine flavor has pointed the role of soil chemistry. Certain elemental concentrations in the soil prove to be a reliable fingerprinting technique for discerning wine of one region from another (Almeida and Vasconcelos, 2003; Coetzee et al., 2005; Di Paola-Narajo et al., 2011; Fabani et al., 2010;

Gozálvez et al., 2009; Greenough et al., 2005; Kment et al., 2005 and Taylor et al., 2006). In this study, chemistry of soil samples, grape juice, and wine all coming from a single location are analyzed in order to determine if there is a chemical fingerprint tying the wine from the Willamette Valley to the different soils used to grow grapes. This study also focuses on the physical soil properties of the different soils used to grow grapes in this region as well as the chemical properties.

Burns (2012) states that there are seven different factors that affect the end flavor of wine and that these factors can be measured and used to help explain the terroir of an area. The factors include the type of grape (varietal), the bedrock geology and resulting soils, the climate, the soil hydrology, and the physiography of the site (slope, aspect, and 
elevation). In his publication, Burns (2012) stresses that terroir (the combination of the soil, geology, climate, and topography on the flavor of wine) is a combination of measurable variables that contribute to wine flavor. In the Willamette Valley there are specific regions that are known for producing wine of different flavors. Therefore, specific questions have developed in regards to how the geology affects the physical properties of vineyard soils. Pisolites (concretions) are present in vineyard soils in the Willamette Valley, but what affect do they have on soil characteristics and chemistry? What macronutrients, micronutrients, and trace elements are present in vineyard soils in the Willamette Valley, and is there a correlation between soil chemistry, soil physical properties, and geology? Do grapevines incorporate the elements found in vineyard soils into the grape juice in the same ratio as found in the soils, and can chemistry be used to create a fingerprint for wines produced on different soils in the Willamette Valley?

These questions are addressed in this dissertation. Using "transparent" grapes, which are thin-skinned and more easily influenced by variations in terroir that could affect flavor than other grape varietals, the soil physical and chemical properties are presented here to commence research into this topic. The three transparent grapes varietals that are most useful in terroir studies, because you can taste the flavor variation attributed to vineyard location, are Pinot Noir, Riesling, and Chardonnay (Burns, 2012). In this study the focus is on Pinot Noir wine because it makes up $88 \%$ of winegrapes 
grown in the Willamette Valley (USDA, 2012). Over 12,560 acres of Pinot Noir are planted in Oregon with a value over 53.8 million dollars in 2011 (USDA, 2012).

Oregon ranks third in the United States in number of wineries after California and Washington, and fifth in volume of wine produced after California, New York, Washington, and Pennsylvania (Table 1) (ttb.gov, 2015). Its modern wine industry has been active since 1961, when pioneers planted the first vinifera grapes. There are now over 676 (winesnw.com, 2015) wineries in Oregon, many of them located within one of the 17 wine regions known as American Viticultural Areas (AVA) the largest of these AVAs is the Willamette Valley, the focus of this dissertation (Hodgen, 2011). The northern portion of the Willamette Valley AVA includes six smaller sub-AVAs: The Chehalem Mountains, Ribbon Ridge, Yamhill-Carlton, Dundee Hills, McMinnville, and Eola-Amity Hills AVAs that were delineated based on geology, soils, and a distinct difference in wine flavors produced from them (i.e. terroir) (Figure 1).

Table 1. Statistics on wine production in 2014 from the Department of the Treasury, Alcohol and Tobacco Tax and Trade Bureau (TTB) by volume in gallons, compiled by the author (ttb.gov, 2015)

\begin{tabular}{cccccc}
\hline $\begin{array}{c}\text { Bulk Wine } \\
\text { Gallons by State }\end{array}$ & Still Wine & Effervescent Wines & Other & Total Production & Percent \\
\hline \hline CALIFORNIA & $709,647,220$ & $26,647,879$ & $24,895,572$ & $761,190,671$ & $85.09 \%$ \\
NEW YORK & $34,616,418$ & $2,212,257$ & 499,666 & $37,328,341$ & $4.17 \%$ \\
WASHINGTON & $34,011,480$ & 483,473 & 12,775 & $34,507,728$ & $3.86 \%$ \\
PENNSYLVANIA & $15,479,868$ & 7,629 & 1,183 & $15,488,680$ & $1.73 \%$ \\
OREGON & $11,698,997$ & 67,798 & 11,315 & $11,778,110$ & $1.32 \%$ \\
All Other States & $29,759,971$ & 514,659 & 601,536 & $30,876,166$ & $3.48 \%$ \\
\hline
\end{tabular}




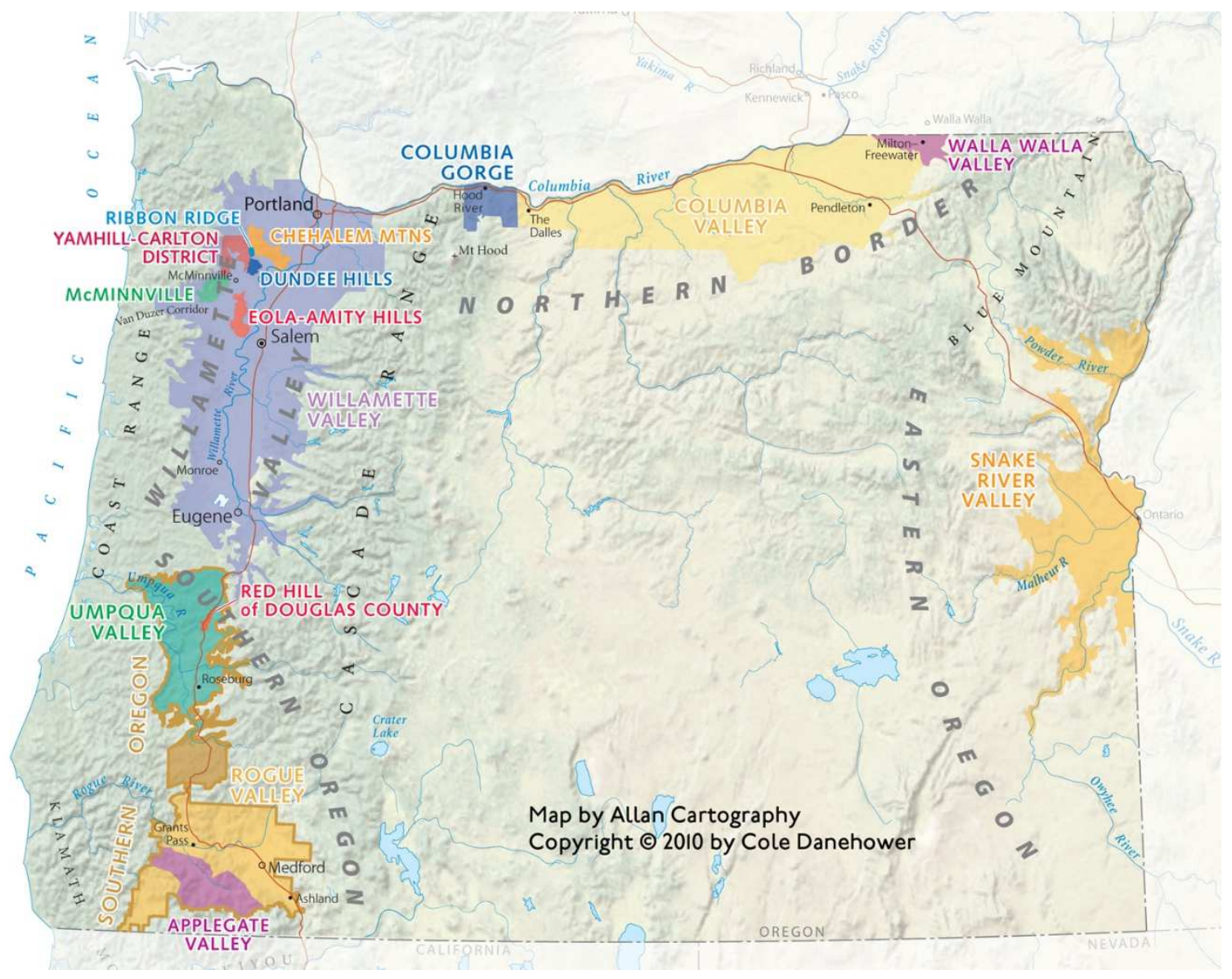

Figure 1. Oregon's 17 (Elkton AVA, the $17^{\text {th }}$, not shown) wine regions or American Viticulture Areas (AVA), many of which are located within a larger AVA and are termed Sub-AVAs (http://essentialnorthwestwines.com/oregon-wine/).

The three major soil series groups that are used for growing Pinot Noir winegrapes in the Willamette Valley of Oregon are the Jory (Oregon's State Soil), the Willakenzie, and the Laurelwood soil series (Burns, 2012). These soils develop on different bedrock and parent material and vary slightly in their age and horizon development (Moore, 2002). Parent material for the soil includes material added over time like Quaternary eolian or windblown silt (loess). The Laurelwood soil series has 
loess overlying volcanic bedrock parent material while the Jory soil series has volcanic parent material and the Willakenzie soil series has marine sediment parent material. The winemakers in the Willamette Valley have noticed variation in the flavor of their Pinot Noir wine produced from vines on each of these soil groups. This observation led us to find out what it is that separates and defines these soil groups, and these differences form the basis of this study.

\section{Objective of This Study}

My hypothesis is that the physical and chemical differences in the soil can be tested and compared to the grape juice and wine chemistry to determine the contribution of soil to the terroir of this region. Using Pinot Noir, which is a thin-skinned and "transparent" grape whose flavor is easily affected by the location where it is grown, a natural laboratory exists in the Willamette Valley, one where if wine-making techniques are kept constant when comparing soil, grape juice, and wine from each winery then the main variation between the wines is the soil type the grapes are grown on (Burns, 2012). In order to find out what makes these soils different from one another, I started by sampling and analyzing the soil characteristics, soil chemistry, soil mineralogy, and then the grape and wine chemistry.

First, the differences in physical characteristics based on field descriptions of the soils were analyzed. This was followed by laboratory analysis of the physical characteristics, elemental concentrations, and the clay mineralogy of the soils. The 
differences expected between soil parent materials are more horizon development (i.e. red colors) in the volcanic and marine sediment soils than the loess/volcanic soils. It is also expected that the volcanic and marine sediment soils will have higher clay percentage and a clay mineral assemblage of minerals that take more time to develop than the loess/volcanic soils. Pisolites are expected in the loess/volcanic soils and not in the others. The chemistry of the different soils based on parent material should reflect the available trace elements in the bedrock as well as differences based on depletion of macronutrients and micronutrients over time. Therefore, the volcanic and marine sediment soil should have different chemical fingerprints. The elemental concentrations in grape juice from the vines next to each soil pit, and the elemental concentrations of the finished wine from the vineyard block that contained the soil pit should reflect the soil chemistry. No other studies have attempted to track the elemental composition of the wine to the soil through the grape juice. This study was designed to fill this gap and take a closer look at what elements the vine is taking up from the soil that can be traced to the finished wine.

In general, wine-makers determined that the tannin, fruit flavors, and mouthfeel were so different between soil types that a cause for these differences was desired. Experimental constants include the macro-climate, grape varietal (Pinot Noir) and winemaking techniques (same winemaker for the three different soil types) (Burns, 2012). The macro-climate is controlled because all sample sites are located just south of 
Salem to Portland, referred to as the northern Willamette Valley, and all sites are located on southeast to southwest facing slopes. Winemakers taking part in this study have agreed to process the fruit from the different soil types as consistently as possible and wine samples were taken before blending with other blocks. Therefore, the winemaking

processes for each winery are constant, though winemaking techniques may vary between winemakers cooperating in this study. Further research into this variable, winemaking effects on flavor, is needed in the Willamette Valley.

\section{Study Area}

Different types of bedrock and parent material have created three different groups of soils that affect the flavor of wine in the Willamette Valley (Moore, 2005). Therefore, the vineyards selected for this study are located throughout the Willamette Valley on various types of geologic bedrock and parent material. The geomorphic surfaces above approximately 90 meters (300 feet) elevation, or the valley sides, are the result of the uplift of volcanic rock or marine sediments. The lower elevations are mostly Missoula Flood sediments or alluvial terraces. In some instances, loess was accumulated to the slopes of volcanic rock, creating a unique soil that has both volcanic rock and weathered loess as parent material. The weathered loess, in this case, dominates the soil properties.

This study used current vineyard locations on three different types of parent material: volcanic, marine sediment, and loess on volcanic bedrock. Soil pit locations 
were determined by the participating wineries, with the understanding that the purpose of this study is to compare soils and wine from soils that form on these three types of parent material. The current viticulture boundaries in the Willamette Valley partially follow these geologic boundaries (Figure 2). The Dundee Hills AVA is mostly volcanic parent material, and the majority of soils used for winegrapes there are Jory or closely related soil series. The Yamhill-Carlton District AVA is mostly marine sediment parent material, and the majority of soils used for winegrapes there are Willakenzie or closely related soil series. The Chehalem Mountains AVA is mostly loess on volcanic parent material, and the majority of soils used for winegrapes there are Laurelwood or closely related soil series. This study describes and compares the soils formed on these three parent materials.

The wineries that participated in this study were chosen based on their interest in the flavor differences they saw in wines produced from these different soils. These vineyards are separated into the three main soil series and parent material (Table 2). I could also separate the vineyards in the study by AVA (Dundee Hills, Yamhill-Carlton, and Chehalem Mountains) that are generally associated with the three different geologies and soil series. This study included vineyards in other Sub-AVAs (Ribbon Ridge and McMinnville) as well as two vineyards located in the general Willamette Valley AVA. 


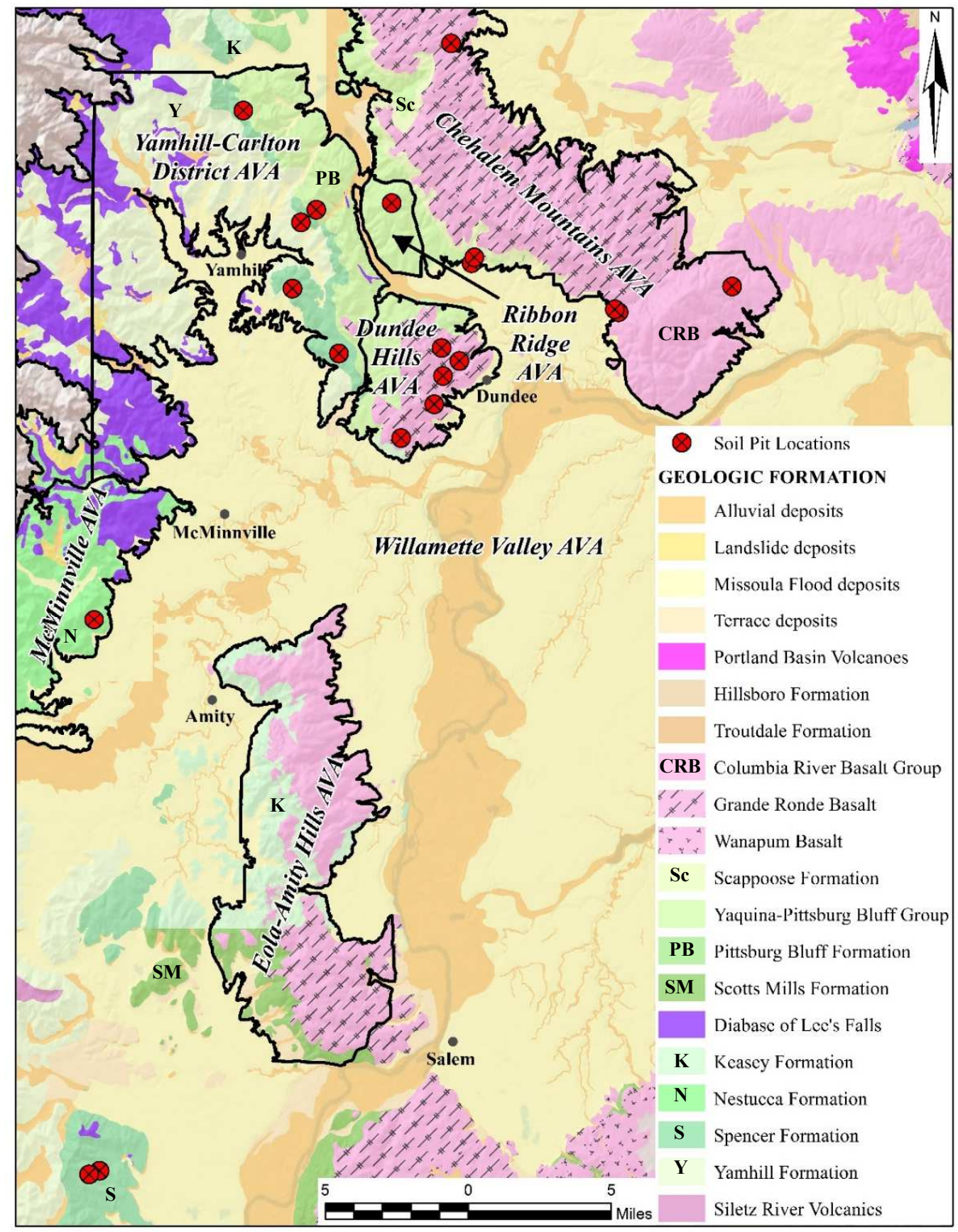

Figure 2. Geologic map of the Willamette Valley sub-AVAs (black outline) (Jones et al., 2010) in the Willamette Valley AVA based on geologic map compilation data (Madin, 2009). 
Table 2. Vineyard sites organized by parent material with main soil series in parentheses.

\begin{tabular}{|c|c|c|c|c|}
\hline \multirow{2}{*}{$\begin{array}{l}\text { Participating } \\
\text { Winery }\end{array}$} & \multicolumn{4}{|c|}{$\begin{array}{c}\text { Parent Material (Soil Series) } \\
\text { Vineyard Name }\end{array}$} \\
\hline & $\begin{array}{l}\text { Volcanic } \\
\text { (Jory) }\end{array}$ & $\begin{array}{l}\text { Marine Sediment } \\
\text { (Willakenzie) }\end{array}$ & $\begin{array}{l}\text { Loess/volcanic } \\
\text { (Laurelwood) }\end{array}$ & $\begin{array}{l}\text { Other Parent } \\
\text { Material }\end{array}$ \\
\hline Elk Cove & Clay Court & Roosevelt & Five Mountain & - \\
\hline Willakenzie & $\begin{array}{l}\text { The Jory } \\
\text { Hills }\end{array}$ & Aliette & - & Terres Basses \\
\hline Chehalem & Stoller & Ridgecrest & Corral Creek & - \\
\hline Lange & Estate & Yamhill \& Freedom Hill & - & - \\
\hline Rex Hill & Sims & - & Estate & Jacob-Hart \\
\hline Ken Wright & Nysa & $\begin{array}{l}\text { Abbott Claim \& Freedom } \\
\text { Hill }\end{array}$ & - & Meredith Mitchell \\
\hline
\end{tabular}

\section{Limitations}

The terroir of the Willamette Valley is also influenced by its climate, within each AVA and within each vineyard, and the winemaking and grape-growing techniques that are employed while growing the grapes and making the wine. The many variables that were documented during this research include the variation in the macroclimate between sampling years (2011 and 2012) as well as the different clones of Pinot Noir, rootstock that may or may not have been employed, trellis type and row direction, as well as farming techniques including cover crop usage, pruning, spraying, differences in soil biota, and organic or biodynamic practices. Wine-making techniques are held constant by each winery to determine differences in wine chemistry between the soils that they employ. Comparing wine chemistry between wineries does not control for various wine- 
making techniques. The inability to control all these variables make evident that further study is needed. At this time, these variables were documented, but an attempt to understand their direct influence on wine flavor are research questions for another project and were not undertaken in this dissertation as I am trying to decipher the differences in the physical and chemical properties of the soils. 


\section{Chapter Two - Background}

\section{Implications of Research}

Sequin (1986) hypothesized that terroir has an effect on the end flavor of wine. It is not substantiated, though, what exactly about the terroir influences the flavor of the wine. It is thought that in the northern Willamette Valley, the physical and chemical soil properties may control the variation in wine flavor (Burns, 2012). Therefore, a thorough study of the chemistry of distinct soils in comparison to the juice and wine produced from those soils may shed some light on the subject. A connection between macronutrient, micronutrient and trace elements in the soil, grape juice and wine is established here as well as the impacts of soil chemistry on wine chemistry in this region. More research based on this study may discover the impacts that soil has on wine flavor. Sensory tests were carried out after this study on the wines from the vineyards from which I collected soils. If there is a correlation between soil chemistry and the wine, sensory analysis may also show connection between the soil and the flavor of the wine.

In 1999, Simon J. Haynes wrote the first in the eleven paper series "Geology and Wine" published in Geoscience Canada which was later compiled, in addition to a few new papers, in 2006 and published by the Geological Society of Canada. Haynes (2006a) defines the factors that affect terroir into five groups. These groups are meteorological, physiographic, petrologic, geologic and viticultural factors. In short, climate, topography, soils, geology, and vineyard techniques affect the quality and taste of wine. These factors 
form complex interrelationships that are included in concept of terroir. In the New World, it is very common to address one or two of these factors at a time, with the geology, and topography usually ignored (Haynes, 2006a). Haynes (2006b) focused his research in the Niagara Peninsula in Ontario, Canada and proposed that designated appellations (similar to AVA in the U.S. and previously designated by climate only) should be subdivided based on significant differences in geology, landform physiography, soils types, and groundwater flow. Washington, Oregon, and California are very prolific in wine production, and studies in these states have stressed the importance of many factors that influence the distinct terroir that are found there.

Terroir-based studies have been performed on geology and wine in the Umpqua Valley of Oregon (Jones et al., 2006), the Okanagan and Similkameen Valleys of British Columbia (Bowen et al., 2006), the Red Mountain Appellation (Busacca \& Meinert, 2003; Meinert \& Busacca, 2006a), the Walla Walla Valley Appellation in Washington (Busacca \& Meinert, 2003; Meinert \& Busacca, 2006b), and in the Coastal Region of South Africa (Bargmann, 2006). These studies have attempted to find correlations, trends, and connections between wine and the physical aspects of the land on which it was produced. All aforementioned studies refer to the areas where grapes of a certain quality are grown as terroir. In these papers, it is understood that geologic bedrock is the parent material for the soil, controlling composition and texture, and ultimately controls the topography of a region through weathering (Haynes, 2006b). 
According to Haynes (2006a) the terroir that contributes to quality wine from a specific area includes factors of physical geology, petrology, and hydrogeology. To be more specific, these factors are elevation, types of landform, azimuth to the sun, slope aspect, and gradient, mineralogy, texture, porosity, and geochemistry, surface water and groundwater flow rate, direction and chemistry. It seems only appropriate that geoscientists be involved with viticulture and that the delineation of AVAs be based on geology, soils, and even soil chemistry (Barnard, 2009). Since the AVAs in the Willamette Valley are already separated by geology and soils, this study will fill the gap where soil chemistry is involved and provide further insight into how terroir affects the flavor of wine.

\section{Terroir}

The interest in the connection between geology and wine was sparked in the 1990's by the book Terroir: The Role of Geology, Climate, and Culture in the Making of French Wines (Wilson, 1998). In this book, Wilson explains the historic and cultural aspects of French winemaking and how quality wines have a connection with certain soils and the bedrock geology that lies underneath. According to the French dictionary, Le Petit Robert, the word "terroir" has many definitions, all of which can be molded together to help one understand the relationship between terroir and wine (Robert et al., 2008). The word terroir is rooted in the word territory, which refers to land that is used for diverse activities by the rural community. This territory possesses certain 
homogeneous physical properties (soil, geology, drainage, etc.) which are suitable for certain agricultural products. Specifically, the nature of the soil is thought to be communicated through the character of certain products, most notably with wine. Wine, according to its terroir, will have a particular taste that is associated with the soil, geology, topography, and climate where the vineyard is located. Because of this, terroir refers to a certain region, province, or countryside that has a cultural tradition of producing wine (or other agricultural products like cheese or meat) that has certain characteristics that reflect the place of origin (Barnard, 2009). It is the "taste of the place".

Although this concept seems subjective, many studies have used wine flavors and chemical composition to explain differences between terroirs. This dissertation attempts to fill in the gap between the soil and the finished wine. The actual uptake of elements from the soil to the vine is not well understood and testing the grapes before they undergo fermentation is a crucial part in the connection between the soil and the flavor of the wine. There are many papers that address terroir and taste or chemistry (Table 3). These publications use various methodologies to analyze chemical compounds in wines and in the vineyard soils in order to compare the wine with its terroir. Other studies use organized sensory tests to compare the flavor of wines to their terroir. This list is not exhaustive, as there are many new publications from the last ten years of research in this area of geology, soils, climate, and wine. Researchers have also performed elemental 
Table 3. Publications that address terroir using sensory characteristics of wines from different geographic locations.

\begin{tabular}{|c|c|}
\hline Author & Paper Title \\
\hline Arrhenius et al., 1996 & $\begin{array}{c}\text { Chemical markers for aroma of Vitis vinifera var. chardonnay regional } \\
\text { wines }\end{array}$ \\
\hline Fischer et al., 1999 & $\begin{array}{l}\text { The impact of geographic origin, vintage and wine estate on sensory } \\
\text { properties of Vitis vinifera } \mathrm{cv} \text {. Riesling wines }\end{array}$ \\
\hline Douglas et al., 2001 & $\begin{array}{c}\text { Canadian terroir: characterization of Riesling wines from the Niagara } \\
\text { Peninsula }\end{array}$ \\
\hline Sabon et al., 2002 & $\begin{array}{c}\text { Determination of volatile compounds in Grenache wines in relation with } \\
\text { different terroirs in the Rhone Valley }\end{array}$ \\
\hline Kontkanen et al., 2005 & $\begin{array}{c}\text { Canadian terroir: sensory characterization of Bordeaux-style red wine } \\
\text { varieties in the Niagara Peninsula }\end{array}$ \\
\hline Schlosser et al., 2005 & $\begin{array}{l}\text { Canadian terroir: sensory characterization of chardonnay in the Niagara } \\
\text { Peninsula }\end{array}$ \\
\hline Eggers et al., 2006 & $\begin{array}{c}\text { Classification of British Columbia's Okanagan chardonnay wines by } \\
\text { origin using volatile components }\end{array}$ \\
\hline Andrés-De Prado et al., 2007 & $\begin{array}{l}\text { Effect of soil type on wines produced from Vitis vinifera } \mathrm{L} . \mathrm{CV} \text {. } \\
\text { Grenache in commercial vineyards }\end{array}$ \\
\hline West et al., 2007 & Geography and vintage predicted by a novel GIS model of wine $\delta 180$ \\
\hline Vilanova et al., 2007 & Effect of terroir on the volatiles of Vitis vinifera $\mathrm{cv}$. Albariño \\
\hline Vilanova et al., 2009 & $\begin{array}{l}\text { Volatile composition of wines from cvs. Blanco Lexítimo, Agudelo and } \\
\text { Serradelo (Vitis vinifera) grown in Betazos (NW Spain) }\end{array}$ \\
\hline Tomasino et al., $2012 \mathrm{~b}$ & $\begin{array}{l}\text { Regional differentiation of New Zealand Pinot Noir wine by } \\
\text { professionals using canonical variate analysis }\end{array}$ \\
\hline
\end{tabular}

analysis on wine from different vineyards in order to establish a way of fingerprinting wines to establish their location of origin (Almeida and Vasconcelos, 2003; Arvanitoyannis et al., 1999; Baxter et al., 1996; Coetzee et al., 2005; Di Paola-Narajo et al., 2011; Eggers et al, 2006; Fabani et al., 2010; Galgano et al., 2008; Greenough et al., 2005; Latorre et al., 1994; Saurina, 2010; Taylor et al., 2006; and Theil et al., 2004). 
Most of these studies were able to make use of trace element analysis to discriminate and separate wines by region.

Greenough et al. (2005) concluded that climate had a great effect on trace element solubility and uptake by the vines. The increase in photosynthesis, by increasing temperature, would therefore increase water uptake by the vines and increase the trace element concentration in the grapes. The clay mineralogy and amount of clay in the soil might also have an impact on the concentration of trace elements available for the vine to take up. Greenough et al. (2005) also discovered a higher concentration of some metals in red wines compared to white wines. This time the red wine stays with the skins during fermentation, increases the concentration of $\mathrm{Rb}, \mathrm{Cs}, \mathrm{Sr}, \mathrm{Ba}$, and $\mathrm{Mo}$ in solution, therefore red wines have higher concentrations of these elements over white wines (Greenough et al., 2005). This is because the red wines are made by allowing for the grape juice to remain in contact with the skins, seeds, and other parts of the crushed grape and these elements can be released into solution during this time. White wines are only in contact with the skins for a short amount of time, limiting the contact with parts of the plants that may have more of these elements and minimizing their content in the juice. In order to control this variation based on wine type in this study, the wine used from every vineyard was Pinot Noir. The issue remains that each clone, rootstock, microclimate, and winemaking techniques may still impact the amount of trace elements taken up by the vine and incorporated into the wine. 
Taylor et al. (2006) tested the correlation between trace elements in soils and wines, finding the concentration of elements in wines clustered based on location within the Okanagan Valley. This is an indication that vineyard soils, geology, and climate have an effect on the concentration of trace elements that end up in the wine produced from that vineyard. The correlation between the actual wine chemistry and soil chemistry was not strong, suggesting that wine making techniques change the trace elements in the final product and their concentrations because of precipitation, co-precipitation, filtering, and contamination from equipment. For example, the barrels, pipes, and tanks that are used may contribute trace elements to the wine that are not actually found in the soils. The winemaking equipment used for all samples in this study was not controlled, but the winemaking equipment used for all wines from each winery were, so comparison between wines from different soils can be completed.

\section{Terroir and Soils}

Terroir in France, according to Seguin (1986), can be described and delineated based on soil alone. His quick method of characterizing separate terroir uses the physical, chemical, and physicochemical analysis of the soil and subsoil. His studies concluded that the only soil parameter that is generally associated with quality wine is calcium carbonate $\left(\mathrm{CaCO}_{3}\right)$, which affects $\mathrm{pH}$ and nutrient uptake (Seguin, 1986). According to most university viticulture research and extensions in the United States, nitrogen-rich land usually produces unsatisfactory grapes because too many nutrients can increase the 
vines' sensitivity to rot and the fruit from deep, fertile soils and large, leafy vines is not as complex as from vines that are stressed nutritionally (Dami et al., 2005). High quality wines are produced from soils that are stony, with very little clay, or from soils that are clayey and have very few pebbles (Dami et al., 2005). The variety in types of soils that are found to produce high quality wines suggests that something else in the soil, besides gravel and clay, influences wine quality. Because of the human influences on soil, which include fertilization, irrigation, and mechanical manipulations (i.e. plowing and ripping), the usable soils can vary greatly. It is well understood that the best soils, are well-drained, well-aerated, and contain no restrictive layers, like a caliché, hardpan, or fragipan (Dami et al., 2005).

The best soil is characterized by having a high degree of macroporosity (Seguin, 1986) causing rainfall to percolate quickly and allow for air in the soil for the roots of the vines. The vines require some clay in the soil mixed with organic matter, sand, and silt so that the roots can easily penetrate it (Seguin, 1986). The best soils are meters deep, with no restrictive layers, allowing for the roots to penetrate and reach the available water and nutrients (Dami et al., 2005). The soil texture (sand, silt, clay ratio) and structure (visual description of the packing of soil particles in situ) is important and ultimately controls internal drainage. More sand in the soil results in quicker drainage and the need for deeper soil thickness. The regions with quality soils in France have soil structure, porosity, and permeability that allow for root development and regulation of water supply 
to the vine. These physical properties of the soil will ultimately limit the effects of climatic destruction from either heavy rainfall or drought by allowing for the vines to neither be suffocated by too much water nor dry out from the lack (Seguin, 1986).

\section{Willamette Valley Geology}

The geology of the Willamette Valley is the main influence on the soil development. The bedrock, subsequent weathering, and geomorphic processes determine the topography of an area. Chemical nutrients are liberated from the bedrock as it is weathered into soil, making them available for the grape vine. Physical characteristics of the soil like depth, particle size, and drainage greatly affect the quality of the grapes (Andrés-de Prado et al., 2007; Berry, 1990; Burns, 2012; Busacca and Meinert, 2003; Haynes, 2006a; Haynes 2006b; Joyce, 2004; Moore, 2005; White, 2009; and Wilson, 1998).

The geology of Western Oregon consists of bedrock that ranges in age from about 52 million years ago to present. The western Cascades make up the eastern edge of the Willamette valley and are composed of lava flows, tuff, and alluvial sediments of the now buried volcanic arc. The Coast Range flanks the Willamette Valley to the west. These marine sediments were deposited over millions of years during the Paleogene and Neogene periods are now uplifted and form the Coast Range due to continued subduction off the coast of Oregon and the down-warping of the Willamette Valley. The Coast 
Range also includes volcanic and intrusive rocks of the Siletz volcanics from uplifted seafloor rock (Madin, 2009).

About 17 to 15 million years ago, the Columbia River Basalts were deposited as lava flowed from hot spot vents in eastern Washington and Oregon toward the ocean. These basalt flows covered much of the state and are exposed in the Willamette Valley. The ancient rivers in the last 15 million years ago deposited sands and gravels in the Willamette Valley, and these sediments are now referred to as the Troutdale Formation. The Cascade Range is only a few million years old and young volcanoes, referred to as the Boring Lavas, penetrate the Troutdale Formation in the valley forming many of the uplands in the urbanized area around Portland (Moore, 2002; Madin, 2009). This is not commonly where vineyards are located but is included in the description of the Willamette Valley geology in order to provide context and explain map units.

From 15,000 to 18,000 years ago, the Willamette Valley was affected by cataclysmic floods referred to as the Missoula Floods (Allen et al., 2009; Atwater, 1984; Bretz, 1969; DOGAMI, 2015; Moore, 2002; and Peterson et al., 2011). These deposited many rhythmites, graded beds of sand and silt, that represent each flooding event, in the valley bottom up to around 91.5 meters (300 feet) above sea level (Moore, 2002). These events are named the Missoula Floods after the glacial Lake Missoula that breached its ice dam and scoured eastern Washington's Channeled Scablands and flowed down the Columbia River Gorge (Allen et al., 2009; Atwater, 1984; Bretz, 1969; and Peterson et 
al., 2011). It has also been shown that there were many floods that occurred before the Missoula Floods referred to as the ancient cataclysmic floods (2.6 million to 18,000 years ago) that may have deposited sediment in the Willamette Valley (Medley, 2012).

The major geologic events important to this study are the deposition and subsequent uplift of marine sediments in the Coast Range, the volcanic rocks of the Columbia River Basalt flows, and the Missoula Floods and other ancient flood deposits. Following the flood deposits, loess from the valley bottoms was deposited on the hillsides through eolian transport, which adds parent material to soils that were already developing on the volcanic rocks there. For this study, the geological units that exist in the Willamette Valley are separated into four groups as parent material for the soils. These are volcanic rock, marine sediments, loess and volcanic rock, and Missoula Flood sediments (Table 4).

Table 4. Major geologic units in the northern Willamette Valley.

\begin{tabular}{|c|c|c|}
\hline $\begin{array}{l}\text { Parent Material } \\
\text { or Bedrock }\end{array}$ & Geologic Units & Includes \\
\hline Volcanic & Columbia River Basalt Group (CRB) & $\begin{array}{c}\text { Grand Ronde Basalt and } \\
\text { Wanapum Basalt }\end{array}$ \\
\hline Marine Sediments & $\begin{array}{l}\text { Yaquina-Pittsburg Bluff Fm., Keasey Fm., } \\
\text { Spencer Fm., Yamhill Fm., Scotts Mills Fm., } \\
\text { Nestucca Fm. }\end{array}$ & $\begin{array}{c}\text { Sandstone, siltstone, and } \\
\text { mudstone }\end{array}$ \\
\hline Loess & No Unit (Overlies Volcanic CRB) & Quaternary eolian silt \\
\hline Flood Sediments & Missoula Flood Deposits & Silt, sands, and gravels \\
\hline
\end{tabular}


The current Sub-AVAs in the Willamette Valley AVA were delineated based on broad geologic differences (Figure 3). In general, the Chehalem Mountains and Dundee Hills AVAs are delineated by the Columbia River Basalt (CRB) bedrock and the soils that formed on this parent material. The addition of loess to various parts of these two AVAs further separates the soils that form in this area. The loess dominates as the parent material in the Chehalem Mountains, hence a different Sub-AVA. The Yamhill-Carlton AVA is outlined around the Coast Range marine sedimentary bedrock, and the soils that develop on this parent material are physically and chemically different from soils that develop on the Columbia River Basalts.

\section{Soils and Geology}

Wilson (1998) noticed that the Alsace and Haut-Beaujolais regions of France were mostly underlain by acidic and sandy soils on granite type bedrock. Most of the other regions were on carbonate bedrock that creates alkaline soils with good soil structure and have active calcium carbonate that favors moisture retention (Wilson, 1998). He claims that grapevine roots can obtain great depths to avoid drought, and that the most popular soils had no caliché, or hardpan, and a granular structure with approximately $25 \%$ sand. Higher clay content and abundant rock fragments or pebbles were also commonly found within the $A O C$ boundaries compared to directly outside them. The sloping bedrock, created by the uplift and deformation from mountain building, helps drainage, and the fractures in the bedrock contribute to an increase in 

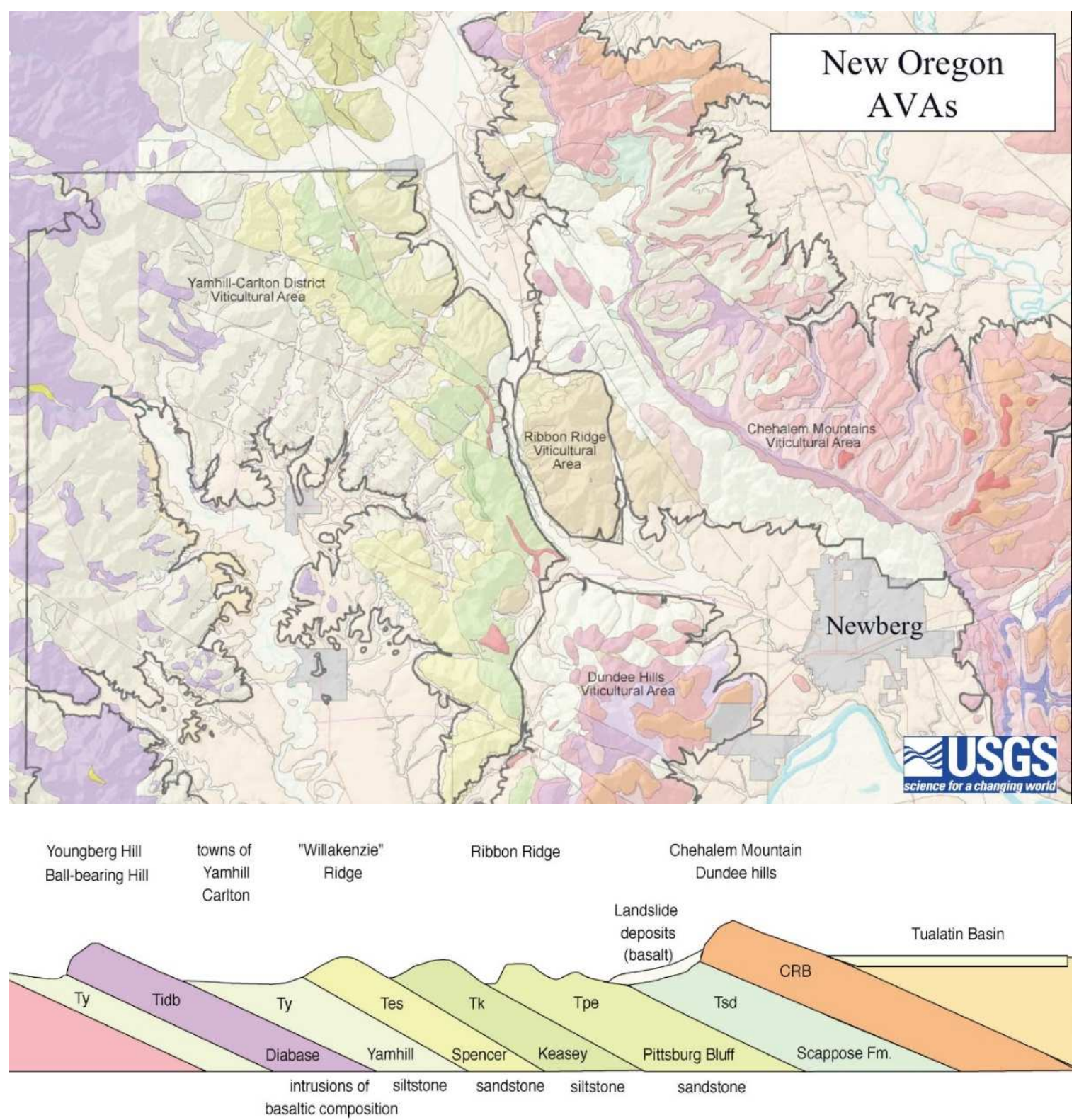

Figure 3. Preliminary geologic map produced by the USGS showing how the new Sub-AVAs of the northern Willamette Valley are outlined based on bedrock geology types. Ty - Tertiary Yamhill Formation, Tdb - Tertiary Diabase intrusions, Tes - Tertiary Spencer Formation, Tk - Tertiary Keasey Formation, Tpe - Tertiary Pittsburg Bluff Formation, Tsd - Tertiary Scappoose Formation, CRB - Columbia River Basalt (Wells, 2006). 
water storage. Therefore, the vigor of the grape vines is closely related, through porosity and permeability, to bedrock geology and soil type. Wilson (1998) emphasizes the importance of soils to the complexity of regional terroir studies.

In a previous study, GIS revealed 23 soils were being used for wine-grape growing purposes (Table 5) in the northern Willamette Valley (Starr-Peace, 2005). The most common was the Jory soil series, which forms on volcanic parent material and is an Ultisol, which is defined as "a highly weathered leached red or reddish-yellow acid soil with a clay-rich B horizon (subsoil), occurring in warm, humid climates" (Soil Survey Staff, 1999). The second most common was the Willakenzie soil series, which forms on marine sediments and is an Alfisol, which is defined as "a soil of an order comprising leached basic or slightly acid soils with a clay-enriched B horizon (subsoil)" (Soil Survey Staff, 1999). The third most common is the Laurelwood soil series, which forms on loess and volcanic parent material and is also an Alfisol. The other soils have Missoula Floods parent material (only 10\%) or are similar to the first three based on parent material (StarrPeace, 2005 and Burns, 2012).

In the Willamette Valley the Columbia River Basalt, volcanic rocks, underlie the Jory soil series (called the Nekia soil series where it is thin). The uplifted marine sedimentary rocks of the Oregon Coast Range underlie the Willakenzie soil series and its 
Table 5. Distribution of soils in the vineyards in the northern Willamette Valley (Starr-Peace, 2005, and Burns, 2012)

\begin{tabular}{|c|c|c|c|}
\hline Soil series & Parent Material & Order & Acres \\
\hline Jory & Basalt & Ultisol & 1,504 \\
\hline Willakenzie & Marine sediments & Alfisol & 1,245 \\
\hline Laurelwood & Basalt [\& Old loess] & Alfisol & 825 \\
\hline Yamhill & Basalt & Mollisol & 333 \\
\hline Woodburn & Missoula Floods & Alfisol & 298 \\
\hline Nekia & Basalt & Ultisol & 195 \\
\hline Cornelius & Old loess & Alfisol & 141 \\
\hline Saum & Basalt & Inceptisol & 126 \\
\hline Bellpine & Marine sediments & Ultisol & 118 \\
\hline Willamette & Missoula Floods & Mollisol & 110 \\
\hline Dupee & Marine sediments & Alfisol & 58 \\
\hline Peavine & Marine sediments & Ultisol & 50 \\
\hline Helvetia & Mixed & Mollisol & 45 \\
\hline Cascade & Young loess & Inceptisol & 31 \\
\hline Wellsdale & Marine sediments & Alfisol & 31 \\
\hline Steiwer & Marine sediments & Mollisol & 28 \\
\hline Carlton & Missoula Floods & Mollisol & 25 \\
\hline Amity & Missoula Floods & Mollisol & 24 \\
\hline Melbourne & Marine sediments & Alfisol & 18 \\
\hline Aloha & Missoula Floods & Inceptisol & 15 \\
\hline Hazelair & Missoula Floods & Mollisol & 12 \\
\hline Chehalem & Mixed & Mollisol & 10 \\
\hline Dayton & Missoula Floods & Alfisol & 6 \\
\hline
\end{tabular}

cousins (Goodin, Wellsdale, Melbourne, Dupee, and Bellpine). The areas that consist of underlying Columbia River Basalt but also have loess deposits underlie the Laurelwood soil series (Figure 4). At elevations below approximately 90 meters (300 feet), the Missoula Flood sediments underlie the Woodburn Soil Series and its soil series cousins 
(Amity, Aloha, Concord, Dayton, and Willamette). In general, the soil order is determined by many factors including color, clay percent, depth, base saturation, and $\mathrm{pH}$, and these orders can develop on any sort of parent material based on climate, time, biota, and other variables.

\section{Climate}

The climate has an effect on wine at many levels. Firstly, regional climate determines which varietals can grow at a given site. In a cool-climate region with a xeric moisture regime (dry in the late growing season), like the northern Willamette Valley (Jones et al., 2012), the best varietals include Pinot Noir, Pinot Gris, Pinot Blanc,

Chardonnay, Riesling, Gewürztraminer and Müller Thurgau. Warm-climate regions (Jones et al., 2012) like the Walla Walla area in Washington or the AVAs in southern Oregon can grow grapes that require more growing degree days (GDD). These varietals include Merlot, Cabernet Sauvignon, Zinfandel, Cabernet Franc, Sauvignon Blanc, Tempranillo, and others (Jones et al., 2012). GDD are calculated by taking the average temperature for each day and then subtracting the base of $50^{\circ} \mathrm{F}$ or $10^{\circ} \mathrm{C}$ (Equation 1). Cumulative GDD are calculated by adding any GDD for that season above zero. Grapes will ripen when a certain number of GDD are reached, depending on the varietal. This is the reason that Pinot Noir is the preferred varietal for the Willamette Valley; it matures in areas with lower GDD's. 


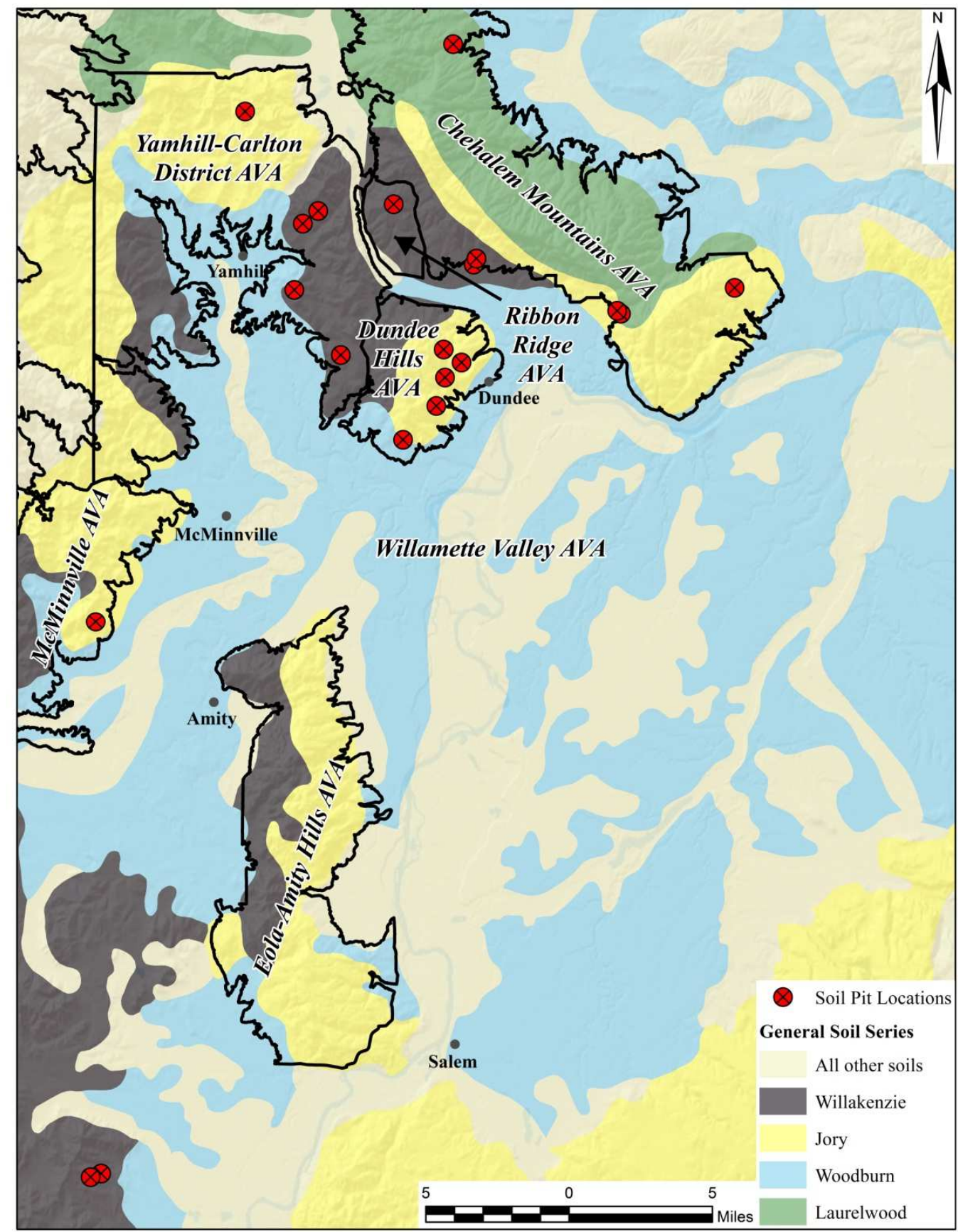

Figure 4. A general soil series map highlighting the Willakenzie, Jory, Woodburn and Laurelwood soils from the NRCS soil data (Soil Survey Staff, 2010b) with the sub-AVAs in the Willamette Valley AVA outlined (Jones et al., 2010). 
Equation 1. Growing degree days (GDD) where $T_{\max }=$ daily maximum temperature, $T_{\min }=$ daily minimum temperature, and $\mathrm{T}_{0}=50^{\circ} \mathrm{F}$ or $10^{\circ} \mathrm{C}$.

$$
G D D=\left(\frac{T_{\max }+T_{\min }}{2}\right)-T_{0}
$$

In addition to the climate variability that occurs because of latitude, topography has a major role in the microclimate in a vineyard. At this scale, a hill's slope can have variable growing degree days because of the tendency for cool air to sink to the lower elevations and slow the ripening process (Wilson, 1998). The microclimates in a vineyard are based on the variable sun exposure that is controlled by the aspect and slope, the primary wind direction, and its relation to vine row orientation, and elevation differences.

\section{Oregon's American Viticulture Areas}

An AVA is an area designated by the US Department of Treasury - Alcohol and Tobacco Tax and Trade Bureau (ATTTB) that has a history of wine making and applied for the label (TTB, 2007). The geographic "pedigree" of a wine is labeled with its origin, and the wine must meet certain federal and state requirements. An AVA is one type of appellation, and a vintage labeled with the AVA origin must have used $85 \%$ of the grapes from inside the AVA boundary (see US Code of Federal Regulations 27 CFR). According to Pomeral (1989) the geological and pedological nature of an area determines the delineation of an appellation and the terroir for that specific wine. The close relationship that exists between the bedrock geology, soil texture and structure, stoniness, depth and chemical composition (Barham, 2002). From this, the description of current 
AVAs, the justification of their boundaries, and creation of new AVAs should be based, at least partly, on the geology, soil, and topography of the vineyards in that region (Barham, 2002; Haynes, 2006b; and Barnard, 2009).

An AVA can range in size and in the concentration of vineyards within their boundaries. AVAs may cover up to 3 states, and if the AVA is to be on the vintage, $100 \%$ of the grapes must be grown in the labeled states. A bottle can be labeled from a state appellation, different than a designated AVA, if at least $75 \%$ of the grapes are grown within the state (TTB, 2007). An AVA does not guarantee the quality of any wine like the French AOC does but guarantees from where a substantial portion of the grapes originated. The boundaries of an AVA usually follow rivers, township and county lines, mountain ranges and valleys, or even power lines and roads. Most AVA boundaries in the United States were not drawn with consideration of soil and geology, and many are now being separated into sub-appellations because, when taken into account, these physical parameters are connected to the growing requirements of certain grape varieties (Haynes, 2006b).

Oregon is split up into 17 AVAs (Figure 1), some of which include areas in Idaho or Washington like the Snake River Valley, Walla Walla, Columbia Valley, and the Columbia Gorge AVAs. The Southern Oregon AVA is split into five separate AVAs called the Umpqua Valley, which includes Red Hills Douglas County and Elkton AVAs, 
and the Applegate Valley AVA which is in the middle of the Rogue Valley AVA. The Willamette Valley AVA includes six smaller sub-AVAs (Figure 5). Of these six, the Chehalem Mountains AVA is the most northern and closest to the city of Portland. The other sub-AVAs, from the north to south, are the Ribbon Ridge, Yamhill-Carlton, Dundee Hills, McMinnville, and Eola-Amity Hills (Moore, 2002). These AVAs were all delineated based on the geology and soils that influence the variation in wine that is produced in each location (Burns, 2012; Moore, 2002).

The Chehalem Mountains AVA consists mostly of upraised Miocene age Grand Ronde Basalt of the Columbia River Basalt Group bedrock overlain by a layer of weathered loess (Figure 2). Most of the loess is "older loess" deposited on the north east side of Chehalem Mountain that was blown up from the Tualatin Valley floor after ancient floods, older than the Missoula Floods, and the soils are more weathered than Missoula Flood loess (Burns, 2012). The southern part of the Chehalem Mountain AVA is mapped as having Jory or Willakenzie soils.

One sample is in the Chehalem Mountain AVA, Elk Cove's Clay Court Vineyard, which is clearly a Jory soil and two sample sites on the southwest side of the Chehalem Mountains that are located on the ancient landslide complex and potentially overlying Coast Range marine sediments and incorporating volcanic rocks of the Columbia River basalt group. The Ribbon Ridge and Yamhill-Carlton AVAs consist of marine 
sedimentary rocks from the Oligocene age Yaquina-Pittsburg Bluff Group and Eocene age Spencer Formation and Yamhill Formations. The Dundee AVA consists of the Grand Ronde Basalt without the layer of loess. The Eola-Amity Hills are mostly Grand Ronde Basalt with marine sedimentary rocks of the Keasey or Pittsburg Bluff Formations on the western side. The McMinnville AVA is mostly marine sedimentary rocks of the Nestucca or Yamhill Formations with pockets of basalt and diabase of Lee's Falls (Madin, 2009).

\section{Chemistry}

The chemistry of vineyard soils is important to know for the health and growth of the plant, but also because some believe the flavors in wine are somehow connected to the amount of certain elements in the soil. These elements can be separated into a few groups. Macronutrients derived from air and water include carbon $(\mathrm{C})$, hydrogen $(\mathrm{H})$, and oxygen (O). Primary macronutrients to sustain plant life include phosphorus (P), potassium (K) and nitrogen $(\mathrm{N})$ and secondary macronutrients include sulfur (S), calcium (Ca), magnesium (Mg), chloride (Cl), and silicon (Si) (White, 2003; White, 2009; and Burns, 2012). Also needed to sustain plant life, but in lesser quantities, are micronutrients which include iron (Fe), molybdenum (Mo), boron (B), copper $(\mathrm{Cu})$, manganese (Mn), sodium $(\mathrm{Na})$, zinc $(\mathrm{Zn})$, and aluminum $(\mathrm{Al})$. There are other elements found in soils that are not considered nutrients and I will refer to them as trace elements throughout this study. These trace elements include arsenic (As), barium $(\mathrm{Ba})$, beryllium $(\mathrm{Be})$, cadmium 


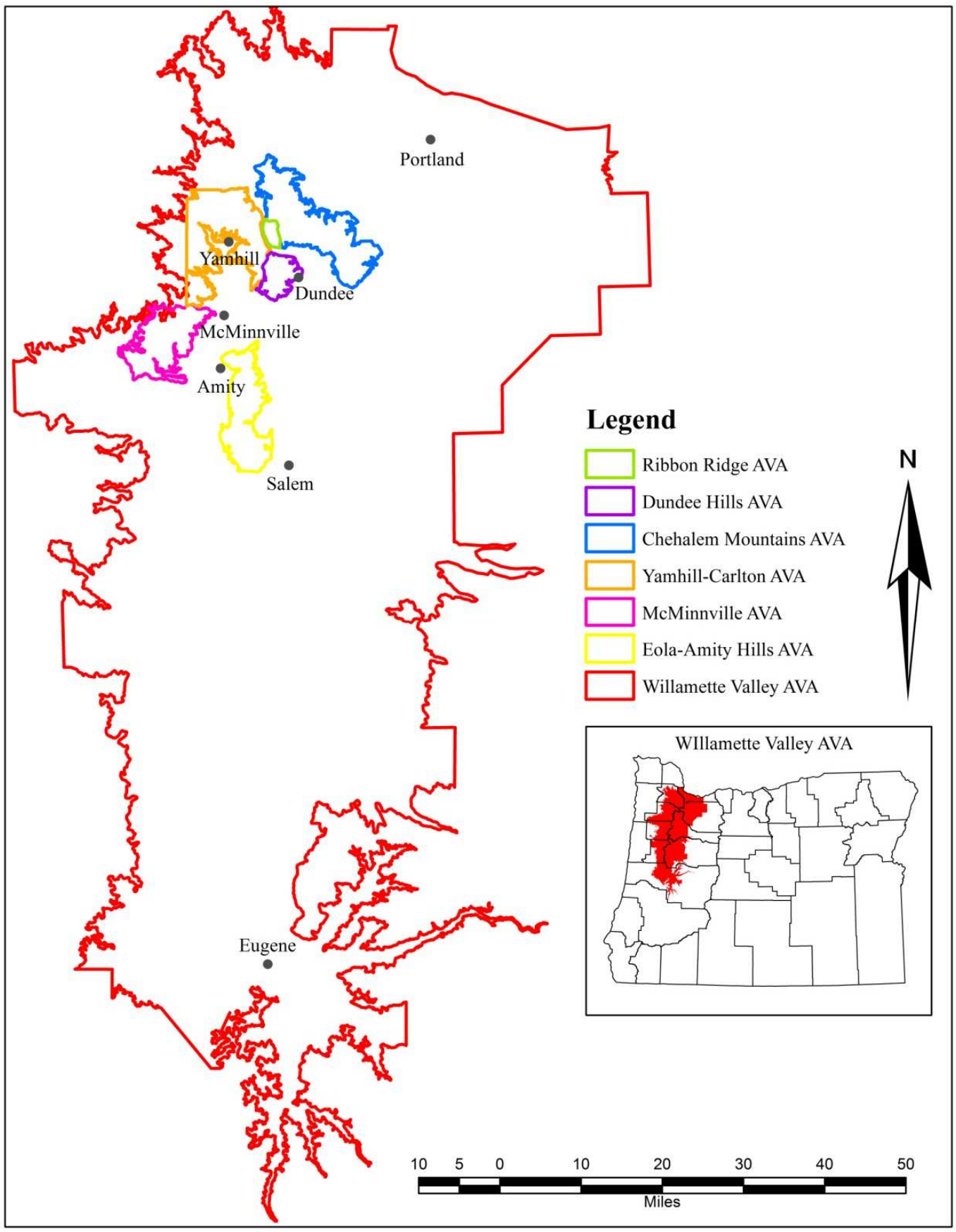

Figure 5. The Willamette Valley American Viticultural Area (AVA) outline and the northern Willamette Valley Sub-AVAs (Jones et al., 2010). 
$(\mathrm{Cd})$, chromium $(\mathrm{Cr})$, cobalt $(\mathrm{Co})$, lead $(\mathrm{Pb})$, mercury $(\mathrm{Hg})$, nickel $(\mathrm{Ni})$, selenium $(\mathrm{Se})$, strontium (Sr), and vanadium (V) (White, 2003; White, 2009; and Burns, 2012).

Studies that successfully determined a correlation between trace elements found in wine and region of origin used an ICP-MS, or similar equipment, to determine trace element concentrations and a "fingerprint" for each wine region was established. It has been shown that inorganic chemical patterns in wine are a reflection of the local geochemical composition of the soil and are a highly influenced by the bioavailability of these compounds (Greenough et al., 1997). Wine authenticity can be identified using organic constituents, metal composition or by stable isotopes (Almeida et al., 2002; Álvarez et al., 2007; Arvanitoyannis et al., 1999; Augagneur and Medina, 1996; Castiñeira-Gómez et al., 2004; Coetzee et al., 2005; Eschnauer et al., 1989; Frías et al., 2003; Louw et al., 2009; and Pohl, 2007).

In some cases, $\mathrm{Li}$ and $\mathrm{Rb}$ or $\mathrm{Mg}$ has been shown as a useful tool to discriminate wines from different Spanish regions (Galgano et al., 2008 and Gonzalvez et al., 2009). Mg was also shown to be a statistically significant element when connecting the vineyard soil to the wine produced from it in both Czech (Kment et al., 2005) and Argentinean wines (Fabani et al., 2009 and Fabani et al., 2010). Kment et al. (2005) analyzed wine samples in the Czech Republic with ICP-MS after microwave digestion to determine Ag, $\mathrm{Al}, \mathrm{As}, \mathrm{Ba}, \mathrm{Be}, \mathrm{Cd}, \mathrm{Co} \mathrm{Cr}, \mathrm{Cs}, \mathrm{Cu}, \mathrm{Li}, \mathrm{Ni}, \mathrm{Pb}, \mathrm{Rb}, \mathrm{Sr}, \mathrm{Sb}, \mathrm{Tl}, \mathrm{U}, \mathrm{V}$ and $\mathrm{Zn}$. From this 
research, many correlations were determined between elements based on the plants ability to take them up or because of their existence coming from the same source. The most statistically significant correlation between soil chemistry and wine chemistry was found for Mg suggesting that it is the most reliable element that can be traced from the soil to wine chemistry (Kment et al., 2005).

In the study conducted by Di Paola-Naranjo et al. (2011), the analysis of elements was carried out using ICP-MS for all elements except $\mathrm{Na}$, which was measured using flame atomic absorption spectrometry (FAAS). The results of this analysis found a significant correlation between the wine and soil $\mathrm{Ba}, \mathrm{K}, \mathrm{La}, \mathrm{B}, \mathrm{V}, \mathrm{Cd}$, and $\mathrm{Ca}$ from the regions tested in Argentina. The overall soil-plant interaction is so complex that the relationship between the elemental composition of the soil and the wine is hard enough to distinguish without the complicating factors of wine making and processing (Taylor et al., 2003). In the study performed on Okanagan and Niagara regions, $\mathrm{Sr}$ and $\mathrm{Rb}$ seem to be the most useful elements when distinguishing wine produced in the two regions because the soil Sr concentrations also differed. This result has been seen in many other studies including those by Baxter et al. (1996), Szentmihalyi et al. (2000), and others suggesting that multielement analyses using ICP-MS are useful in determining wine fingerprints and provenance. 
The amount of these elements in the wine is greatly determined by the solubility of the element in the soil (Perk, 2006). Other factors that might impact the amount of these elements in wine include agricultural practices, climate changes (drought), and winemaking techniques as well as the type of grape since plant uptake might vary between varietals. In a study of multiple elements in soil, grapes, juice along the many stages of fermentation, and the final wine, Almeida and Vasconcelos (2003) used ICPMS and AAS to find elemental concentrations. Conclusions showed that $\mathrm{Cd}, \mathrm{Cr}, \mathrm{Cu}, \mathrm{Fe}$, $\mathrm{Ni}, \mathrm{Pb}, \mathrm{V}$, and $\mathrm{Zn}$ were all added to the grape juice during the winemaking process. Most concentrations of other elements were similar or even lower in the final product than in the grape juice prepared in the factory. This is attributed to precipitation or coprecipitation in sediments of some elements and organic complexing agents like polyphenols and tannins for others (Almeida and Vasconcelos; 2003). This suggests that the presence of these elements may cause the precipitation of some polyphenols and tannins, and therefore affects the end flavor of the wine. This study also determined, from collecting soil samples every two months and analyzing them that the elemental concentrations did not vary seasonally, and therefore any month could be used when comparing soil and wine concentrations. Although there are lower concentrations of the elements in the final product than in the soil, a significant correlation between all elements except Al, Fe, and Ca was found (Almeida and Vasconcelos, 2003). 


\section{Grape Juice Chemistry}

The chemistry of grape juice should mimic the chemistry of the soil on which the grapes were grown since some elements in the soil are taken up by the grapevine and incorporated in the grapes themselves. With enough water in the soil, the vines will be able to take up macro and micronutrients and incorporate them into various parts of the plant. Elements such as $\mathrm{B}, \mathrm{Cu}, \mathrm{Fe}, \mathrm{Mn}, \mathrm{Mo}, \mathrm{Ni}$, and $\mathrm{Zn}$ are all involved in many metabolic and cellular functions including protein stabilization and enzyme activation and should be present in the berry clusters (Yang., 2010). Fe will be present in the highest levels in the berry skin, pulp, and seeds and $\mathrm{Sr}, \mathrm{Mn}, \mathrm{Zn}, \mathrm{B}$, and $\mathrm{Cu}$ will also be present but at much lower concentrations (Yang, 2010). Therefore, the more of these elements are present in the soils on which these vines are grown, the more there will be in the grapes produced on those vines depending on how long the grape juice is in contact with the seeds, skins, pulp, and stems.

\section{Wine Chemistry}

Similar to the juice chemistry, the wine chemistry should mimic the soil chemistry with the exception of contamination from wine making techniques. Pinot Noir, as a red wine, should have concentrations of trace elements that are similar to the juice and soil chemistry since the wine is in contact with the skins, seeds, and pulp for a time and therefore is able to release the trace elements that are incorporated in those tissues (Yang, 2010). This mimicry will enable us to use the trace elements to create regional 
fingerprints for the Willamette Valley wine chemistry (Taylor et al., 2003, Coetzee et al., 2005, Galgano et al., 2008). The input of various yeasts, wine treatments, and use of different types of oak will either diminish or increase some of these trace elements in amounts that are unknown at this time. 


\section{Chapter Three - Methods}

\section{Selection of Sites}

Six wineries were chosen with the three soil groups to keep the factors affecting the wines constant as much as possible. Two wineries had all three soil groups (Elk Cove Vineyards and Chehalem), three had volcanic and marine soil groups (Willakenzie Estate, Lange Estate Winery and Vineyards, and Ken Wright Cellars) and Rex Hill had volcanic and loess/volcanic soil groups (Table 2). In order to compare physical and chemical differences in soils, the samples were collected by hand during the summers of 2011 and 2012 from twenty different vineyard sites (Figure 6). I am able to compare grape juice and wine chemistry made by the same winemaker but from grapes grown on the different soils. Winemakers allowed for me to collect grape samples directly from the vineyards within a week of their scheduled harvesting. Wine samples were collected by the winemakers before blending with other parts of the vineyard or before blending with other vineyards in order to associate the wine chemistry with the grape and soil chemistry.

According to prior research, Burns (2012) found that the three most used soil series in the northern Willamette Valley are the Jory, Willakenzie, and Laurelwood soils (Table 5). During the summers of 2011 and 2012, twenty soils were sampled belonging to 


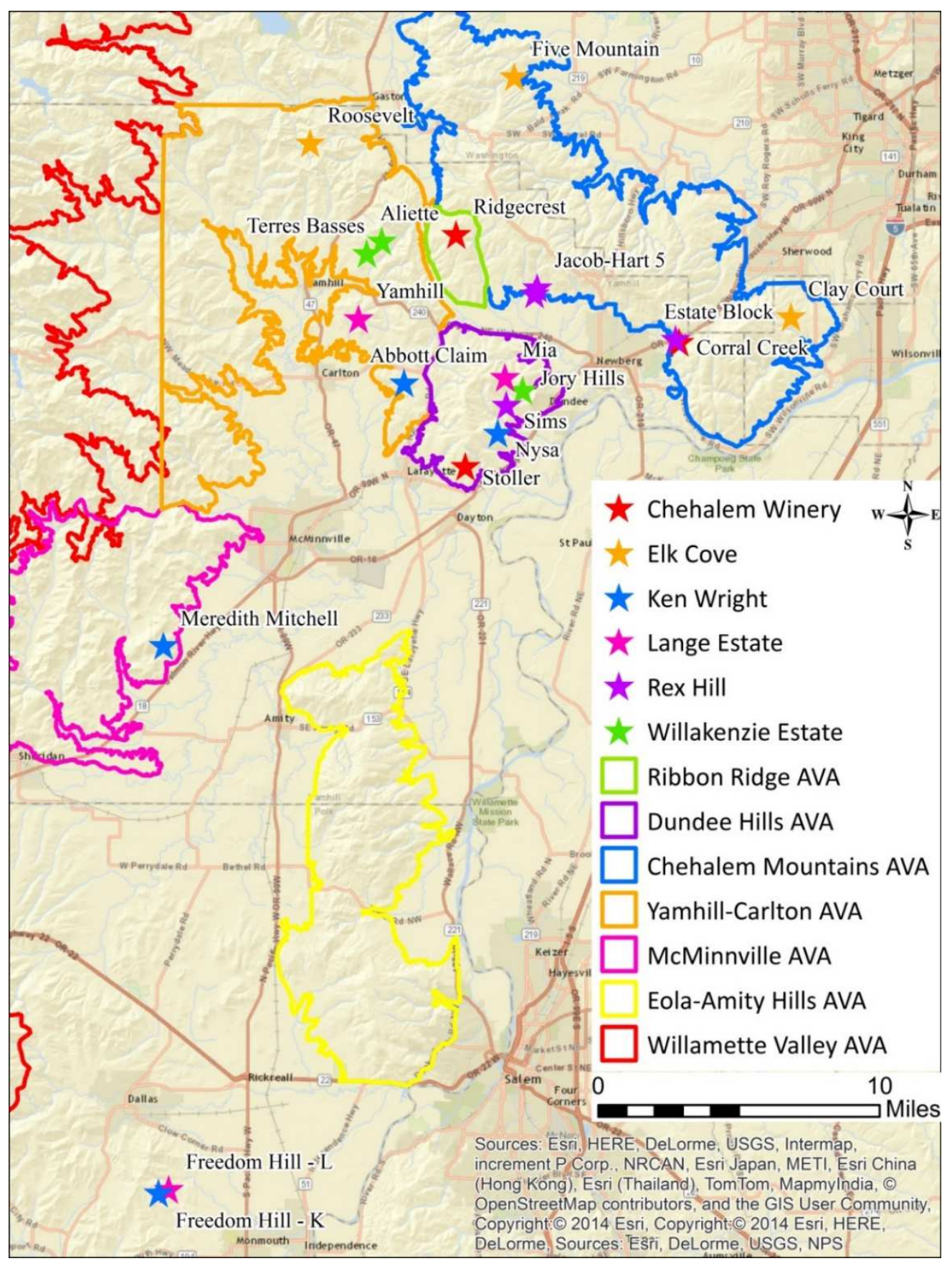

Figure 6. Soil pit locations in the northern Willamette Valley, Oregon provided by six different wineries with AVA boundaries shown (Jones et al., 2010). 
these six different wineries (Table 6 and Table 7). It was determined that, out of the 20 soils sampled, six do not belong to the Willakenzie, Jory, or Laurelwood series and three of those six are close "cousins." The Bellpine Series is a close "cousin" to the Willakenzie and the Nekia series is a close "cousin" to the Jory (Moore, 2002; Burns, 2012). Two soil pits were later designated as Witham series (Terres Basses) and Dixonville series (Jacob-Hart Block 1). One soil pit (Meredith Mitchell) was located in the McMinnville AVA and is mapped as Yamhill Series while Jacob-Hart Block 5 is mapped as Yamhill but is not likely to belong to that group and is more likely to be a part of the Steiwer series. This information belies the need to not only use current soil maps when looking for a vineyard soil, but also the need for site specific soil sampling since they maps are inaccurate at this scales in this instance.

\section{Soil Physical Characteristics}

Soil pits were dug using a pick axe and shovels until the pit was about one cubic meter in size. A soil auger was then used until refusal or the end of the auger (another meter depth) in order to collect deep samples and complete the soil profile. At each soil pit a full description of horizons was done in the field according to the procedures outlined in Birkeland (1999). This description includes depth of the horizon, dry soil color using the Munsell Soil Color Chart, structure, hardness/friability, stickiness and plasticity, soil texture, horizon boundary, pores and clay films, and any other notable observations like roots, concretions, and signs of krotovina (animal burrows) or other 
Table 6. Sample ID and parent material information for the vineyards sampled in 2011.

\begin{tabular}{|c|c|c|c|c|c|c|c|}
\hline $\begin{array}{c}\text { Sample } \\
\text { ID } \\
\end{array}$ & Winery & Vineyard & Parent Material & Bedrock Mapped & NRCS Mapped Soil Series & AVA & $\begin{array}{c}\text { Elevation } \\
\text { (feet) }\end{array}$ \\
\hline ECCC & $\begin{array}{l}\text { Elk Cove } \\
\text { Vineyards }\end{array}$ & Clay Court & Volcanic & $\begin{array}{c}\text { Columbia River } \\
\text { Basalt }\end{array}$ & Jory & $\begin{array}{l}\text { Chehalem } \\
\text { Mountains }\end{array}$ & 610 \\
\hline ECRV & $\begin{array}{l}\text { Elk Cove } \\
\text { Vineyards }\end{array}$ & Roosevelt & $\begin{array}{c}\text { Marine } \\
\text { Sediments }\end{array}$ & $\begin{array}{l}\text { Spencer } \\
\text { Formation }\end{array}$ & $\begin{array}{l}\text { Goodin-Melbourne complex } \\
\text { (Willakenzie) }\end{array}$ & $\begin{array}{c}\text { Yamhill-Carlton } \\
\text { District }\end{array}$ & 620 \\
\hline ECFM & $\begin{array}{l}\text { Elk Cove } \\
\text { Vineyards }\end{array}$ & $\begin{array}{l}\text { Five } \\
\text { Mountain }\end{array}$ & Loess/volcanic & $\begin{array}{c}\text { Columbia River } \\
\text { Basalt }\end{array}$ & Laurelwood & $\begin{array}{l}\text { Chehalem } \\
\text { Mountains }\end{array}$ & 360 \\
\hline WEJH & $\begin{array}{l}\text { Willakenzie } \\
\text { Estate }\end{array}$ & $\begin{array}{l}\text { The Jory } \\
\text { Hills }\end{array}$ & Volcanic & $\begin{array}{c}\text { Columbia River } \\
\text { Basalt }\end{array}$ & Jory & Dundee & 490 \\
\hline WEA & $\begin{array}{l}\text { Willakenzie } \\
\text { Estate }\end{array}$ & Aliette & $\begin{array}{c}\text { Marine } \\
\text { Sediments }\end{array}$ & $\begin{array}{l}\text { Spencer } \\
\text { Formation }\end{array}$ & $\begin{array}{l}\text { Melbourne-Goodin complex } \\
\text { (Willakenzie) }\end{array}$ & $\begin{array}{l}\text { Yamhill-Carlton } \\
\text { District }\end{array}$ & 600 \\
\hline WETB & $\begin{array}{l}\text { Willakenzie } \\
\text { Estate }\end{array}$ & $\begin{array}{l}\text { Terres } \\
\text { Basses }\end{array}$ & $\begin{array}{l}\text { Missoula Flood } \\
\text { Sediments }\end{array}$ & $\begin{array}{c}\text { Yamhill } \\
\text { Formation }\end{array}$ & Witham & $\begin{array}{c}\text { Yamhill-Carlton } \\
\text { District }\end{array}$ & 290 \\
\hline CWS & Chehalem & Stoller & Volcanic & $\begin{array}{c}\text { Columbia River } \\
\text { Basalt }\end{array}$ & Jory & Dundee & 480 \\
\hline CWR & Chehalem & Ridgecrest & $\begin{array}{c}\text { Marine } \\
\text { Sediments }\end{array}$ & $\begin{array}{l}\text { Pittsburg Bluff } \\
\text { Formation }\end{array}$ & Wellsdale (Willakenzie) & Ribbon Ridge & 640 \\
\hline CWCC & Chehalem & $\begin{array}{l}\text { Corral } \\
\text { Creek }\end{array}$ & Loess/volcanic & $\begin{array}{c}\text { Columbia River } \\
\text { Basalt }\end{array}$ & Laurelwood & $\begin{array}{l}\text { Chehalem } \\
\text { Mountains }\end{array}$ & 370 \\
\hline
\end{tabular}


Table 7. Sample ID and parent material information for the vineyards sampled in 2012.

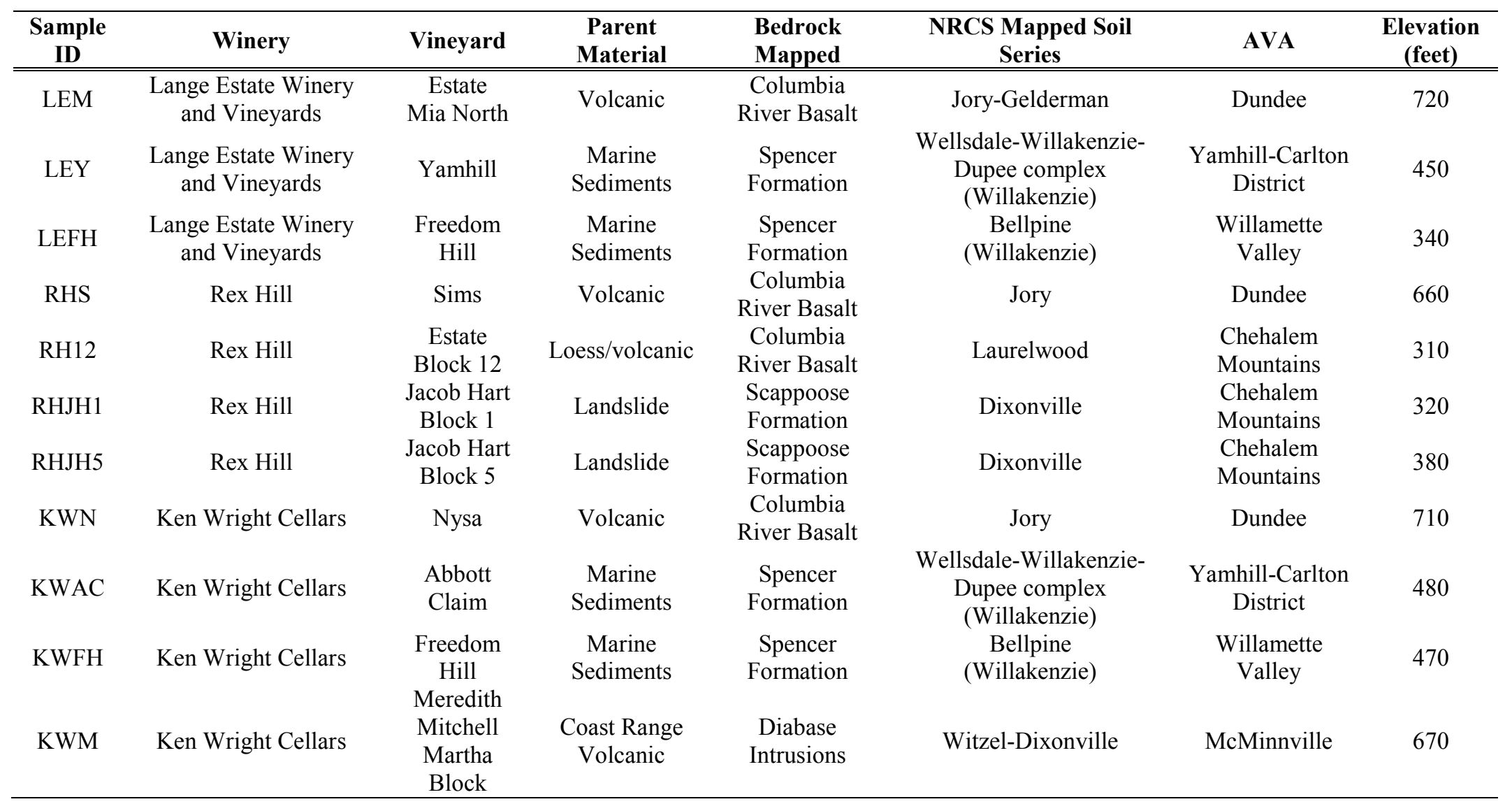


bioturbation. Field descriptions were carried out by me and my advisor, Dr. Burns, with various field assistants. The field documents were organized so that no part of the soil description was overlooked. Each horizon was sampled with $1 / 2$ liter of soil in Ziploc ${ }^{\circledR}$ Brand bags to be taken back to the lab for further analysis. Pits were filled and sod replaced in order to limit visibility of the hole and effect on vine roots. Vines immediately adjacent to the pit were flagged in order to find them to collect grape berry clusters at harvest for elemental analysis. Photos were taken of each site of the vineyard and the soil pit as well as the GPS location and elevation. Vineyard managers and winery owners/winemakers were also asked the clone, rootstock, and age of vines (Table 8).

I used Buntley-Westin (Buntley and Westin, 1965) color index to determine the level of soil profile development and relative age of the soils. This index utilizes the rubification (color) of the dry soil to determine the level of soil profile development that has occurred. The air dried lab samples are given colors using the Munsell Soil Color Charts, and this information is used to determine the relative age of the soils. The index is based on the idea that the soils get redder with age, and the higher the index number, the older the soil is (Birkeland, 1999). A Buntley-Westin value larger than 10 indicates the soil is at least 5000 years old and values larger than 15 indicate soils greater than 10,000 years old (Miller and Birkeland, 1974). Grain size analysis determined the percentage of 
gravel, sand, silt, and clay that contributes to the soil as a whole using the pipette method (Gee and Bauder, 1986).

Table 8. Winery and vineyard name for each sample location with the year the vines were planted, clone, and rootstock used (ND - No Data).

\begin{tabular}{cccc}
\hline Sample ID & Year & Clone & Rootstock \\
\hline \hline ECCC & 2001 & Dijon 777 & RG \\
ECRV & 1994 & Pommard & Own-rooted \\
ECFM & 1993 & Dijon $777 / 115 /$ Pommard & $101-14$ \\
WEJH & 2002 & Dijon 115 & $101-14$ \\
WEA & 1992 & Pommard & 5 C \\
WETB & 1997 & Dijon 113/115 & 3309 \\
CWS & 1995 & Pommard & 3309 C \\
CWR & 1985 & Pommard & Own-rooted \\
CWCC & 1985 & Pommard & Own-rooted \\
LEM & 2004 & Dijon 777 & 3309 \\
LEY & 1986 & Pommard & Own-rooted \\
LEFH & 2002 & Dijon 777 & $44-53$ \\
RHS & 2000 & Pommard & 3309 \\
RH12 & 1982 & Dijon 777 & 108 Chardonnay \\
RHJH1 & 1989 & Wädenswil & Own-rooted \\
RHJH5 & 2001 & Pommard & Own-rooted \\
KWN & 1990 & Pommard & Own-rooted \\
KWAC & 2001 & Dijon 777 & $101-14$ \\
KWFH & 2002 & Wädenswil & 4453 \\
KWM & 1988 & Pommard & Own-rooted \\
\hline
\end{tabular}




\section{Soil Chemistry}

Soil $\mathrm{pH}$ was assessed in the lab using the Hanna Instruments bench top $211 \mathrm{pH}$ meter. A 1:1 (soil:deionized water) sample of soil was prepared by taking 20 gram sample from each horizon and mixing with $20 \mathrm{ml}$ of de-ionized water in order to fully submerge the probe (Soil Survey Staff, 1975). Three samples from each horizon were taken and the mean calculated. Organic matter was determined by loss on ignition using the methods adapted from Lim and Jackson (1982) and the Method of Soil Analysis used in the Soil Testing Laboratory at Oregon State University (Horneck et al., 1989).

I analyzed the macronutrients $(\mathrm{P}, \mathrm{K}, \mathrm{Ca}, \mathrm{Mg}, \mathrm{S}$, and $\mathrm{Cl})$, micronutrients $(\mathrm{Fe}, \mathrm{Mn}$, $\mathrm{Mo}, \mathrm{Cu}, \mathrm{Zn}, \mathrm{Na}$, and $\mathrm{Al}$ ) and other trace elements (As, Ba, Be, Cd, Cr, Co, $\mathrm{Pb}, \mathrm{Hg}, \mathrm{Ni}$, Se, Sr, and V) (Perk, 2006; White, 2009; and Burns, 2012) in soil samples, grape juice, and wine produced from these vineyard soils in the northern Willamette Valley. C, H, O, and $\mathrm{N}$ were not analyzed because these elements vary greatly based on time of day or year of sampling and vineyard management practices. Because of lab limitations, B was not measured even though it is an important micronutrient. $\mathrm{Al}$ and $\mathrm{Na}$ are micronutrients and $\mathrm{Co}$ and $\mathrm{Ni}$ are trace elements that were added to this analysis even though not considered by White (2009) to be significant to wines. The physiography (elevation, slope, aspect) at each site was documented during sample collection and the age of the vine, rootstock used, vineyard management techniques, and other information was 
gathered from the vineyard managers and owners. The amalgamation of these data provides a base for further study into the terroir of the Willamette Valley, Oregon.

Soil bulk chemistry was completed by Apex Laboratories (Tigard, Oregon) using three different methods after completing microwave digestion following method 3051 A (EPA, 2007a). Soils were digested and acid-preserved prior to analysis (EPA, 1998; EPA, 2007a; EPA, 2007b: and EPA, 2007c). Chloride (Cl) content of the soils was measured using Ion Chromatography method 9056A (EPA, 2007c). In order to measure elemental concentrations of many orders of magnitude, both ICP-MS and inductively coupled atomic emission spectrometry (ICP-AES) were used. Al, $\mathrm{As}, \mathrm{Ba}, \mathrm{Be}, \mathrm{Cd}, \mathrm{Ca}, \mathrm{Cr}, \mathrm{Co}, \mathrm{Cu}$, $\mathrm{Fe}, \mathrm{Pb}, \mathrm{Mg}, \mathrm{Mn}, \mathrm{Hg}, \mathrm{Mo}, \mathrm{Ni}, \mathrm{K}, \mathrm{Se}, \mathrm{V}$ and $\mathrm{Zn}$ were measured using ICP-MS method 6020A (EPA, 1998). ICP-AES was used to determine trace elements including Al, Ca, $\mathrm{Fe}, \mathrm{Mg}, \mathrm{P}, \mathrm{K}, \mathrm{Na}$, Sr, and $\mathrm{S}$ using method 6010C (EPA, 2007b). This method also requires acid digestion prior to analysis. The lab utilized both ICP-MS and ICP-AES for some elements including $\mathrm{Al}, \mathrm{Ca}, \mathrm{Fe}, \mathrm{Mg}$, and $\mathrm{K}$, because some samples had higher concentrations than the ICP-MS allowed. This method is not a total digestion technique for most samples, but it is a strong acid digestion that will dissolve almost all elements that could become "environmentally available" (EPA, 2007a). The digestion of soil samples utilized nitric acid $\left(\mathrm{HNO}_{3}\right)$ and hydrogen peroxide $\left(\mathrm{H}_{2} \mathrm{O}_{2}\right)$. Trace elements analyzed using 6010C were digested with an addition of hydrochloric acid $(\mathrm{HCl})(\mathrm{EPA}$, 2007a). 
Most elements were measured using method 6020A after digestion, with a determination of sub- $\mu \mathrm{g} / \mathrm{L}(\mathrm{ppb})$ in digests (EPA, 1998). Trace elements were measured using method 6010C after digestion (EPA, 2007b). Chloride was measured using method 9056A (EPA, 2007c). Dilutions were performed and appropriate factors were applied to sample values. The accuracy of the results returned by Apex Laboratories is summarized in Appendix C. The methods used for QAQC at Apex Laboratories include calibration every morning and control samples are run every ten samples. Blanks should return a $\mathrm{ND}$, or non-detect, to ensure no cross-contamination in the analytical methodology. Then known amounts are analyzed to check for analytical accuracy.

All blanks for the ion chromatography resulted in ND. The accuracy of the ion chromatography shows a recovery percent (\%REC) between $91 \%$ and $101 \%$ for spikes of $\mathrm{Cl}$ between $39.3 \mathrm{mg} / \mathrm{kg}$ and $40.0 \mathrm{mg} / \mathrm{kg}$ with a \%REC limit between 90 and $110 \%$ and a relative percent difference (RPD) between $0.2 \%$ and $4 \%$ with a RPD limit of $15 \%$ for multiple batches. Similar results were reported for the ICP-MS where all blanks resulted in ND and spikes were done for each element. For example, the Ca spike was 5000 $\mathrm{mg} / \mathrm{kg}$ and the result was $4890 \mathrm{mg} / \mathrm{kg}$, a $98 \%$ REC with REC limits between $80 \%$ and $120 \%$. The RPD value for Cr was 0.08, well within the laboratory's QAQC RPD limit of $40 \%$. The spike recovery and/or RPD was outside acceptance limits only 12 times and spike recovery and/or RPD was outside control limits due to high concentration of analyte present in the sample 31 times during QAQC. The original batch QC sample was 
reanalyzed in most cases. A matrix interference was suspected twice for CWS V and Se and a serial dilution fail or matrix interference may have occurred once in the WETB Al analyses. For more details, refer to Appendix C.

\section{Grape Juice and Wine Chemistry}

Grape juice and wine samples were analyzed for the same bulk elemental composition as the soils by Apex Laboratories LLC in Tigard, Oregon using ICP-MS (EPA method 6020A) and ICP-AES (EPA method 6010C). Whole berry clusters from vines immediately adjacent to the soil pits were collected at harvest in the fall of 2011 and 2012. The grapes were frozen until all were collected and then approximately $150 \mathrm{ml}$ of whole berries were delivered to APEX Laboratories for analysis. Whole berries were crushed, and the juice was acid digested prior to analysis using EPA method 3051a (EPA, 2007a). Wine was analyzed using the same methods as the juice. Both the grape juice and wine were analyzed by APEX Laboratories in the same manner as the soil samples using ICP-MS and ICP-AES as well as ion chromatography for the Cl. Quality control data is located in Appendix C.

Samples of wine from the soil pit block were collected from the wineries before the wine from that block could be blended with others. Vineyards are usually broken up into smaller blocks by varietal, clone, or to provide space for tractors to navigate through the vineyard. These blocks usually consist of a small amount of rows that can be 
harvested and grouped together. Extra vintages from Chehalem and others from the same vineyards were also analyzed to look for trends in wine chemistry relating to vintage. There were 21 wine samples in total from the six different wineries. Approximately 150 $\mathrm{ml}$ of each wine was collected from the wine bottle when opened for sensory analysis. The wine samples were taken immediately to Apex Laboratories at the end of the day. Some wines were sampled and analyzed multiple times for the same elements, therefore the mean concentration and standard deviation using both sets of results for these sites is reported in the results section.

\section{Clay Mineralogy}

After pipette analysis was completed and the exact texture of the soil can be obtained from percentages of sand, silt and clay, $50 \mathrm{ml}$ of sample was drawn from the graduated cylinder from the upper $30 \mathrm{~cm}$ of the column and placed in a cup to settle and allow some of the water to evaporate. This sample contains only the clay fraction and was analyzed using the x-ray diffraction (XRD) by Dr. Reed Glasmann at the Willamette Geological Service (Philomath, Oregon). Clays were Mg-saturated by rinsing several times with $0.5 \mathrm{~N} \mathrm{MgCl}_{2}$, then rinsed with distilled water. Clays were then $\mathrm{K}$-saturated by washing several times with $1.0 \mathrm{M} \mathrm{KCl}$, then rinsed with $50 \%$ methanol solution. The $\mathrm{Mg}$ saturated slides were analyzed after air drying, then solvated with ethylene glycol and rescanned. The K-saturated slides were analyzed after air drying then rescanned after 6 hours in an 110C oven. The scan conditions were shortened to try to limit re-hydration 
during analysis, but some minor re-expansion of smectitic clays was found in the patterns (Appendix B).

\section{Data Analysis}

These data were then analyzed using XLSTAT for Microsoft Excel 365. Principal Component Analysis (PCA) was used to find correlations between soil physical characteristics and soil chemistry, grape juice chemistry, and wine chemistry. All vineyard sites were included. Soil physical and chemical characteristics included in the analysis were clay percent, silt percent, and sand percent from grain size analysis, Buntley \& Westin soil color index, depth to Bt horizon, depth to bedrock, organic matter, $\mathrm{pH}, \mathrm{CEC}$, and elemental analysis of the 25 elements using ICP-MS, ICP-AES, and ion chromatography (Al, As, Ba, Be, Cd, Ca, Cl, Cr, Co, Cu, Fe, Pb, Mg, Mn, Hg, Mo, Ni, P, $\mathrm{K}$, Se, Na, Sr, S, V, and Zn). Grape juice chemistry included 9 elements detected in the grape juice (K, Na, Sr, P, Mg, Mn, Ca, Cu, and Zn). Wine chemistry included 15 elements detected in the wine ( $\mathrm{Ba}, \mathrm{Ca}, \mathrm{Co}, \mathrm{Cu}, \mathrm{Fe}, \mathrm{Pb}, \mathrm{Mg}, \mathrm{Mn}, \mathrm{Ni}, \mathrm{P}, \mathrm{K}, \mathrm{Na}, \mathrm{Sr}, \mathrm{S}$, and Zn). Pearson type PCA was used for all data. 


\section{Chapter Four - Elk Cove Vineyards Results}

\section{Volcanic Parent Material - Clay Court Vineyard, Block E Physical Characteristics}

The Clay Court Vineyard (ECCC), owned and operated by Elk Cove Vineyards, is located in Sherwood, Oregon. This vineyard is on basaltic rocks of the Columbia River Basalt group on a hillcrest of a south facing slope of 0 to 1 degrees with vine rows running north and south (Lat. 45.325479 N, Long. -122.834909 W). The soil pit location is at 611 feet (186 meters) elevation between rows 60 and 61 . The soil is mapped as the Jory soil series (Figure 7) and is located in the Chehalem Mountains AVA. According to the vineyard manager, the spacing between rows was planted with permanent cover four years prior to sampling (2007). The vines are Pinot Noir Dijon 777 clone planted in 2001 and are trellised as bilateral cordon in vertical shoot position. The vines are grafted onto RG rootstock (Table 8$)$.

The Jory soil is characterized as a Xeric Palehumult. The soil pit is $150+\mathrm{cm}$ deep, and I did not reach the parent material or refusal at that depth (Table 9). The basalt parent material is small chips and gravel (10\%) in the Bt2 horizon from 115 to $150 \mathrm{~cm}$ depth. Percent sand decreases with depth from 10\% to 5\% from Ap to Bt3 horizon at $150 \mathrm{~cm}$. Dry colors for the Ap horizon are dark yellowish brown (10 YR 4/4), the Bt1 and Bt2 are both brown (7.5 YR 4/4), and the Bt3 is dark reddish brown (5 YR 3/4) (Figure 8). 


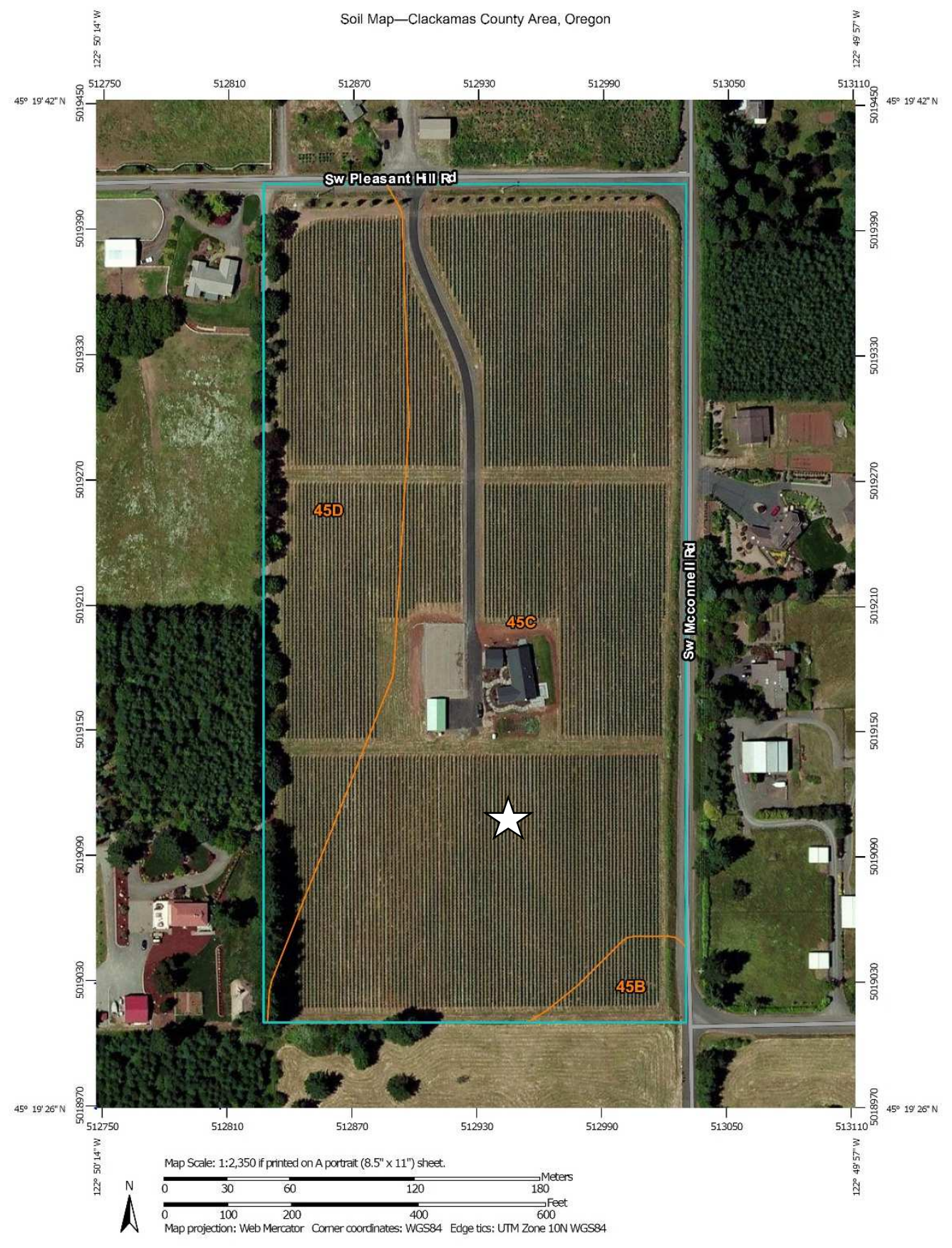

Figure 7. Soil map of Elk Cove Vineyards, Clay Court Vineyard Block E. Pit location marked. 45C Jory silty clay loam, 8 to 15 percent slopes. 45B - Jory silty clay loam, 2 to 8 percent slopes. 45D Jory silty clay loam, 15 to 30 percent slopes (NRCS, 2014). 
Structures throughout the soil profile are medium subangular blocky with some granular texture in the Ap horizon. The Ap horizon is slightly sticky and slightly plastic, but the Bt1 is very sticky and very plastic due to a jump in clay percent from $22 \%$ in the Ap to $46 \%, 50 \%$, and $57 \%$ in the Bt $1, \mathrm{Bt} 2$, and Bt3, respectively. Texture of the Ap horizon is silt loam, the Bt1 and Bt2 are silty clay, and Bt3 is clay. Clay films located on ped faces, increase in number from Bt1 to Bt3 (common and dominant). Pisolites are found abundantly throughout the profile. The $\mathrm{pH}$ decreases from 6.4 in the Ap horizon to 5.0 with depth. Organic matter $(\mathrm{OM})$ ranges from $9-12 \%$ for this profile. The CEC is highest in the Ap horizon and decreases with depth (Table 9).

Table 9. Elk Cove Vineyards, Clay Court Vineyard Block E field and lab data.

\begin{tabular}{|c|c|c|c|c|c|c|}
\hline \multirow{3}{*}{$\begin{array}{l}\text { Depth } \\
\text { (cm) }\end{array}$} & \multirow{3}{*}{ Horizon } & \multicolumn{3}{|c|}{ Total } & \multirow[b]{2}{*}{$\begin{array}{l}\text { Coarse } \\
\text { Fragment } \\
(>2 \mathrm{~mm})\end{array}$} & \multirow[b]{2}{*}{$\begin{array}{c}\text { Texture } \\
\text { Lab }\end{array}$} \\
\hline & & $\begin{array}{l}\text { Sand } \\
(2-0.05 \\
\text { mm) }\end{array}$ & $\begin{array}{c}\text { Silt } \\
(0.05-0.002 \\
\text { mm) }\end{array}$ & $\begin{array}{c}\text { Clay } \\
(<0.002 \\
\text { mm) }\end{array}$ & & \\
\hline & & \multicolumn{4}{|c|}{ 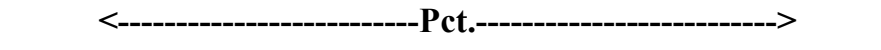 } & \\
\hline $0-15$ & Ap & 10.1 & 66.6 & 22.3 & 0.0 & $\mathrm{SiL}$ \\
\hline $15-90$ & Bt1 & 5.3 & 45.2 & 46.1 & 0.0 & $\mathrm{SiC}$ \\
\hline $90-115$ & $\mathrm{Bt} 2$ & 8.4 & 40.3 & 49.7 & 0.0 & $\mathrm{SiC}$ \\
\hline $115-150+$ & Bt3 & 4.7 & 37.7 & 57.2 & 0.0 & $\mathrm{C}$ \\
\hline $\begin{array}{l}\text { Depth } \\
\text { (cm) }\end{array}$ & Horizon & Dry Color & Structure & $\begin{array}{c}\text { Organic } \\
\text { Matter } \\
\text { LOI (Pct.) }\end{array}$ & $\begin{array}{c}\text { pH } \\
\left(1: 1 \mathrm{H}_{2} \mathrm{O}\right)\end{array}$ & $\begin{array}{c}\text { CEC } \\
(\mathrm{meq} / \mathbf{1 0 0 g})\end{array}$ \\
\hline $0-15$ & Ap & 10YR 4/4 & $2, \mathrm{~m}, \mathrm{gr}$ to $\mathrm{sbk}$ & 10 & 6.4 & 31.2 \\
\hline $15-90$ & Bt1 & 7.5YR 4/4 & $2, \mathrm{~m}, \mathrm{sbk}$ & 9.0 & 5.6 & 16.1 \\
\hline $90-115$ & $\mathrm{Bt} 2$ & 7.5YR 4/4 & $1, \mathrm{~m}, \mathrm{sbk}$ & 11 & 5.3 & 16.8 \\
\hline $115-150+$ & Bt3 & $5 Y R 3 / 4$ & $2, \mathrm{~m}, \mathrm{sbk}$ & 12 & 5.0 & 14.4 \\
\hline
\end{tabular}



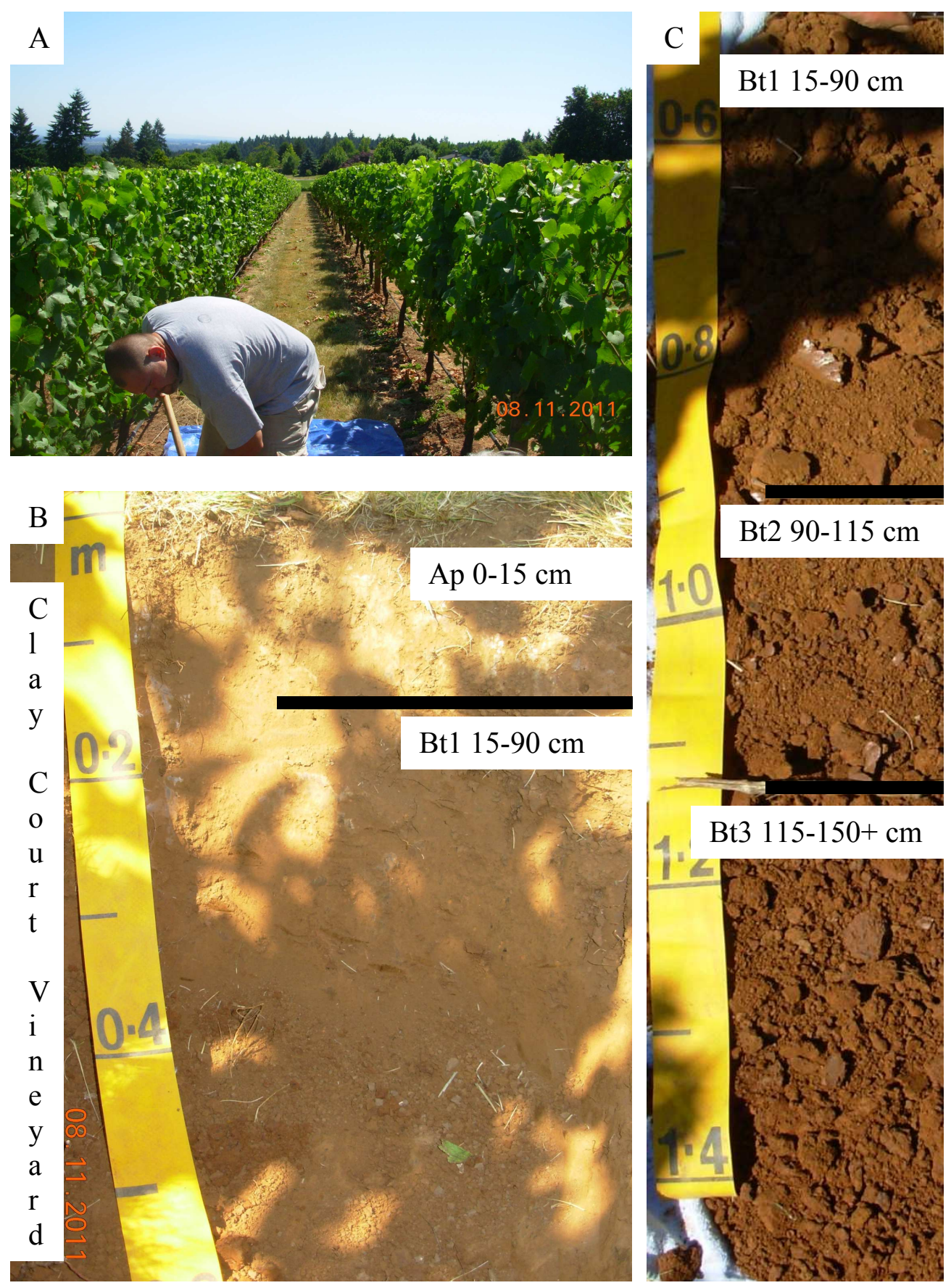

Figure 8. Sample soil pit at Elk Cove Vineyards, Clay Court Vineyard Block E. A - View of sample location, facing south. B - Picture of the face of the soil pit with horizon depths and boundaries marked. C - Soil retrieved using a hand auger with horizon depths and boundaries marked. 


\section{Soil Chemistry}

The Clay Court Vineyard soil pit was separated into four horizons. Maximum concentrations are shown in bold in the following tables of macronutrients, micronutrients, trace, and other elements (Table 10). The macronutrient concentration of $\mathrm{K}, \mathrm{Ca}, \mathrm{Mg}$, and $\mathrm{S}$ all decrease with depth. The concentrations of $\mathrm{Mg}, \mathrm{Ca}$, and $\mathrm{K}$ are highest in the Ap horizon. $\mathrm{P}$ concentrations are highest in the in the Bt3 horizon and variable in the rest of the profile with the lowest concentration is in the Btl horizon. S only registered at detectable levels in the top two horizons, the Ap and Bt1 horizons.

The micronutrient concentrations measured in the soil horizons from the Clay Court Vineyard vary greatly with the maximum in the A horizon and variability with depth or the maximum in the Bt3 horizon after increasing with depth. Fe concentrations increase with depth. Al decreased with depth with a slight bulge in the Bt2 horizon. Co concentrations are highest in the Bt1 horizon and then decrease with depth whereas $\mathrm{Cu}$ values are variable with the maximum in the Bt3 horizon. Mn also decreases then has a bulge in the Bt3 horizon. Mo was only measured above detection limits in the Bt3 horizon. Na decreases with depth and a bulge in the Bt2 horizon. Ni decreases with depth and $\mathrm{Zn}$ is highest in the Ap horizon. Trace element concentrations for the Clay Court Vineyard range in magnitude with some values increasing with depth and some decreasing. As, $\mathrm{Ba}, \mathrm{Cd}$, and $\mathrm{Se}$ all decrease with depth with a bulge in the $\mathrm{Bt} 2$ or Bt3 horizon. Be has no trend and the maximum concentration is in the Bt1 horizon. $\mathrm{Cr}$ and $\mathrm{V}$ 
both increase with depth. Se was only detected in the Ap horizon. Pb concentrations are highest in the Bt1 horizon and decrease with depth.

Table 10. Macronutrient, micronutrient, and trace element concentrations (all values in $\mathrm{mg} / \mathrm{kg}$ ) for the Elk Cove Vineyard, Clay Court Vineyard, Block E soil pit (ND - Non-detectable).

\begin{tabular}{|c|c|c|c|c|c|c|c|c|c|c|}
\hline \multicolumn{2}{|c|}{ Horizon (cm) } & $\mathbf{P}$ & \multicolumn{2}{|c|}{$\mathbf{K}$} & $\mathbf{C a}$ & \multicolumn{2}{|c|}{ Mg } & $\mathbf{S}$ & \multicolumn{2}{|r|}{ Cl } \\
\hline \multicolumn{2}{|l|}{ Ap (0-15) } & 1220 & \multicolumn{2}{|c|}{591} & 2420 & \multicolumn{2}{|c|}{1910} & 191 & \multicolumn{2}{|r|}{ ND } \\
\hline \multicolumn{2}{|c|}{ Bt1 (15-90) } & 954 & \multicolumn{2}{|c|}{408} & 1060 & \multicolumn{2}{|c|}{1140} & 155 & \multicolumn{2}{|r|}{ ND } \\
\hline \multicolumn{2}{|c|}{ Bt2 (90-115) } & 1240 & \multicolumn{2}{|c|}{245} & 606 & \multicolumn{2}{|c|}{594} & ND & \multicolumn{2}{|r|}{ ND } \\
\hline \multicolumn{2}{|c|}{ Bt3 (115-150+) } & 1740 & \multicolumn{2}{|c|}{221} & 446 & \multicolumn{2}{|c|}{427} & ND & \multicolumn{2}{|r|}{ ND } \\
\hline \multicolumn{2}{|l|}{ Mean } & 1290 & \multicolumn{2}{|c|}{366} & 1130 & \multicolumn{2}{|c|}{1020} & 173 & \multicolumn{2}{|r|}{$N D$} \\
\hline \multicolumn{2}{|l|}{$S D$} & 328 & \multicolumn{2}{|c|}{171} & 897 & \multicolumn{2}{|c|}{668} & 25.5 & \multicolumn{2}{|r|}{$N D$} \\
\hline \multicolumn{2}{|l|}{ Maximum } & 1740 & 59 & & 2420 & & 10 & 191 & & $N D$ \\
\hline Horizon (c & & $\mathbf{F e}$ & Al & Co & $\mathbf{C u}$ & Mn & Мo & $\mathbf{N a}$ & $\mathbf{N i}$ & Zn \\
\hline Ap $(0-15$ & & 35500 & 18200 & 18.1 & 15.3 & 1730 & ND & 206 & 8.36 & 46.5 \\
\hline Bt1 $(15-9$ & & 37700 & 16900 & 27.9 & 14.9 & 1060 & ND & 185 & 6.17 & 25.1 \\
\hline Bt2 (90-11 & & 45100 & 17500 & 23.1 & 16.8 & 1040 & ND & 210 & 4.33 & 22.8 \\
\hline Bt3 (115-15 & & 61800 & 16500 & 18.9 & 18.2 & 1260 & 0.692 & 178 & 3.29 & 26.8 \\
\hline Mean & & 45000 & 17300 & 22.0 & 16.3 & 1270 & 0.692 & 195 & 5.54 & 30.3 \\
\hline$S D$ & & 11900 & 741 & 4.50 & 1.51 & 321 & 0 & 15.6 & 2.23 & 10.9 \\
\hline Maximun & & 61800 & 18200 & 27.9 & 18.2 & 1730 & 0.692 & 210 & 8.36 & 46.5 \\
\hline $\begin{array}{c}\text { Horizon } \\
(\mathrm{cm})\end{array}$ & As & $\mathbf{B a}$ & $\mathrm{Be}$ & Cd & $\mathrm{Cr}$ & $\mathrm{Hg}$ & $\mathbf{P b}$ & Se & $\mathrm{Sr}$ & $\mathbf{V}$ \\
\hline $\begin{array}{c}\mathrm{Ap} \\
(0-15)\end{array}$ & 2.78 & 190 & 0.778 & 0.267 & 24.3 & ND & 10.7 & 0.733 & 13.2 & 114 \\
\hline $\begin{array}{c}\text { Bt1 } \\
(15-90)\end{array}$ & 1.66 & 69.4 & 0.828 & 0.197 & 26.8 & ND & 10.9 & ND & 12.3 & 118 \\
\hline $\begin{array}{c}\text { Bt2 } \\
(90-115)\end{array}$ & 1.87 & 74.3 & 0.778 & 0.178 & 21.3 & 0.0448 & 9.94 & ND & 8.76 & 136 \\
\hline $\begin{array}{c}\text { Bt3 } \\
(115-150+) \\
\end{array}$ & 2.08 & 77.8 & 0.817 & 0.260 & 30.0 & 0.0393 & 9.40 & ND & 7.38 & 178 \\
\hline Mean & 2.10 & 103 & 0.800 & 0.226 & 25.6 & 0.0421 & 10.2 & 0.733 & 10.4 & 137 \\
\hline$S D$ & 0.486 & 58.2 & 0.0261 & 0.0447 & 3.70 & 0.00389 & 0.693 & 0 & 2.78 & 29.3 \\
\hline Maximum & 2.78 & 190 & 0.828 & 0.267 & 30.0 & 0.0448 & 10.9 & 0.733 & 13.2 & 178 \\
\hline
\end{tabular}




\section{Grape Juice Chemistry}

It is interesting to note that the grape juice samples were void of many elements as seen in Table 11. All 24 elements (same as the soils) were analyzed for in the grape juice from grapes collected adjacent to the soil pits. $\mathrm{K}, \mathrm{Na}, \mathrm{Sr}$ are the only elements found in all 20 grape juice samples and $P$ is detected in 15 of the 20 sites. The majority of these elements were found to be non-detectable using this method, therefore only the elements found in any sample are shown in Table 11 . The concentrations of $\mathrm{K}$ and $\mathrm{Na}$ in the Clay Court grape juice are $530 \mathrm{mg} / \mathrm{kg}$ and $161 \mathrm{mg} / \mathrm{kg}$, respectively. Sr concentration, one of only three elements found in all grape juice samples, is measured as $0.973 \mathrm{mg} / \mathrm{kg}$, which is the $6^{\text {th }}$ highest concentration of $\mathrm{Sr}$ for the 20 vineyard samples (Table 105). Mean $\mathrm{Sr}$ concentration for all grape juice samples from the 20 different sites is $0.805 \pm 0.261$ $\mathrm{mg} / \mathrm{kg}$.

Table 11. Elemental concentrations measured by ICP-MS in the grape juice from clusters collected from vines immediately adjacent to the soil pit location at Elk Cove Vineyards, Clay Court Vineyard, Block E (ND - Non-detectable).

\begin{tabular}{cccccccccc}
\hline Element & Sr & P & K & Na & Mg & Mn & Ca & Cu & Zn \\
\hline \hline Grape Juice $(\mathrm{mg} / \mathrm{kg})$ & 0.973 & ND & 530 & 161 & ND & ND & ND & ND & ND \\
\hline
\end{tabular}

\section{Wine Chemistry}

Elk Cove Vineyards supplied a $350 \mathrm{ml}$ sample of unblended wine from the 2011 vintage of Clay Court Vineyard wine. This sample was meant to be analyzed for elemental concentrations along with the 2011 vintage of a purchased bottle of Clay Court wine assuming the bottle of wine was a blend of more blocks within the vineyard than the 
sample collected. Results of this analysis show reduction and contamination of certain elements that must have taken place during the winemaking process (Table 12). Also, in comparison to the grape juice analysis, many more elements are detectable, suggesting that there is an addition of elements during the winemaking, either from the extended contact with skins, seeds, and stems, or from the winemaking equipment or process.

The 14 elements that were measured at detectable levels in either the sample or the bottle of wine include $\mathrm{Ba}, \mathrm{Ca}, \mathrm{Co}, \mathrm{Cu}, \mathrm{Fe}, \mathrm{Pb}, \mathrm{Mg}, \mathrm{Mn}, \mathrm{P}, \mathrm{K}, \mathrm{Na}, \mathrm{Sr}, \mathrm{S}$, and $\mathrm{Zn}$. Macronutrient concentrations are highest for $\mathrm{K}$ at $458 \mathrm{mg} / \mathrm{kg}$ in the bottle and $413 \mathrm{mg} / \mathrm{kg}$ in the sample. $\mathrm{P}$ is higher in the bottle at $99.3 \mathrm{mg} / \mathrm{kg}$ than the sample at $46.7 \mathrm{mg} / \mathrm{kg} . \mathrm{Mg}$ and $\mathrm{Ca}$ are the opposite with higher concentrations in the sample than in the bottle. $\mathrm{S}$ concentrations are similar at $52.7 \mathrm{mg} / \mathrm{kg}$ in the bottle and $50.4 \mathrm{mg} / \mathrm{kg}$ in the sample. The amount of $\mathrm{Na}$ in the wine is an order of magnitude less than that found in the grape juice, and $\mathrm{Sr}$ concentrations are consistent for all three.

Eight micronutrients and trace elements were measured in the wine sample and/or bottle. Ba concentrations are higher in the bottle $(0.592 \mathrm{mg} / \mathrm{kg})$ than the sample $(0.292$ $\mathrm{mg} / \mathrm{kg}$ ). Similarly, $\mathrm{Zn}$ increases from $0.096 \mathrm{mg} / \mathrm{kg}$ in the sample to $0.204 \mathrm{mg} / \mathrm{kg}$ in the bottle. Some elements only found in the bottle of finished wine and not in the wine sample include Co $(0.0262 \mathrm{mg} / \mathrm{kg}), \mathrm{Cu}(0.12 \mathrm{mg} / \mathrm{kg})$, and $\mathrm{Pb}(0.0598 \mathrm{mg} / \mathrm{kg})$. $\mathrm{Mn}$ is 1.38 
$\mathrm{mg} / \mathrm{kg}$ in the sample and $1.19 \mathrm{mg} / \mathrm{kg}$ in the bottle while Fe concentrations are almost identical at $1.06 \mathrm{mg} / \mathrm{kg}$ in the sample and $1.05 \mathrm{mg} / \mathrm{kg}$ in the bottle.

Table 12. Elemental concentrations measured by ICP-MS in the 2011 Elk Cove Vineyards, Clay Court Vineyard and a $350 \mathrm{ml}$ sample of unblended wine from the same vineyard and vintage (ND Non-detectable).

\begin{tabular}{|c|c|c|c|c|c|}
\hline Element & $\begin{array}{l}2011 \text { Wine } \\
\text { Sample } \\
\text { (mg/kg) }\end{array}$ & $\begin{array}{c}2011 \text { Bottle } \\
(\mathrm{mg} / \mathrm{kg})\end{array}$ & Element & $\begin{array}{l}2011 \text { Wine } \\
\text { Sample } \\
\text { (mg/kg) }\end{array}$ & $\begin{array}{c}2011 \text { Bottle } \\
\text { (mg/kg) }\end{array}$ \\
\hline $\mathrm{Al}$ & ND & ND & $\mathrm{Mn}$ & 1.38 & 1.19 \\
\hline As & ND & ND & $\mathrm{Hg}$ & ND & ND \\
\hline $\mathrm{Ba}$ & 0.292 & 0.592 & Mo & ND & ND \\
\hline $\mathrm{Be}$ & ND & ND & $\mathrm{Ni}$ & ND & ND \\
\hline $\mathrm{Cd}$ & ND & ND & $\mathrm{P}$ & 46.7 & 99.3 \\
\hline $\mathrm{Ca}$ & 37.5 & 28.8 & K & 413 & 458 \\
\hline $\mathrm{Cr}$ & ND & ND & $\mathrm{Se}$ & ND & ND \\
\hline $\mathrm{Co}$ & ND & 0.0262 & $\mathrm{Na}$ & 2.72 & 4.92 \\
\hline $\mathrm{Cu}$ & ND & 0.12 & $\mathrm{Sr}$ & 0.99 & 0.973 \\
\hline $\mathrm{Fe}$ & 1.06 & 1.05 & S & 50.4 & 52.7 \\
\hline $\mathrm{Pb}$ & ND & 0.0598 & $\mathrm{~V}$ & ND & ND \\
\hline $\mathrm{Mg}$ & 53.4 & 39 & $\mathrm{Zn}$ & 0.096 & 0.204 \\
\hline
\end{tabular}

\section{Clay Mineralogy}

The clay mineralogy of the Clay Court Vineyard soil pit was determined from a sample of clay taken from the $\mathrm{Bt} 2$ horizon. The results show the sample contains moderate amounts of disordered kaolinite with minor amounts of halloysite, abundant illite and chlorite along with moderate amounts of hydroxy interlayered smectite. The smectite resisted expansion due to the development of chlorite and interlayered sheets of Fe and Al. Cristobalite is found in minor amounts and moderate amounts of goethite are 
in this sample. The amount of illite in this sample suggests a contribution of loess over time since the parent material is volcanic. The kaolinite, cristobalite, and goethite suggest an older soil.

\section{Marine Sediment Parent Material - Roosevelt Estate Vineyard Physical Characteristics}

Elk Cove Vineyards produce wine from their estate vineyards in Gaston, Oregon. These vineyards are located on rolling hills of the Coast Range marine sedimentary rocks (Figure 2). Roosevelt Estate Vineyard is located directly south of the tasting room (Lat. 45.414466 N, Long. -123.185770 W) and winery at the summit of a west to southwest facing slope ranging from $0-1$ degrees with vine rows running northeast to south west. The soil pit location is at 623 feet (190 meters) elevation between rows 8 and 9 , and the soils are mapped as the Willakenzie soil series in the past and now is mapped as the Goodin - Melbourne complex (a subset of the previously mapped Willakenzie soil series) (Figure 9). According to the vineyard manager, the area in between rows in this vineyard was planted with cover crop two years prior to sampling (2009) and has been farmed organically since 2004 (Appendix D). The vines are Pinot Noir Pommard clone planted in 1993 and are trellised as unilateral cordon in vertical shoot position. The vines are ownrooted (Table 8). 


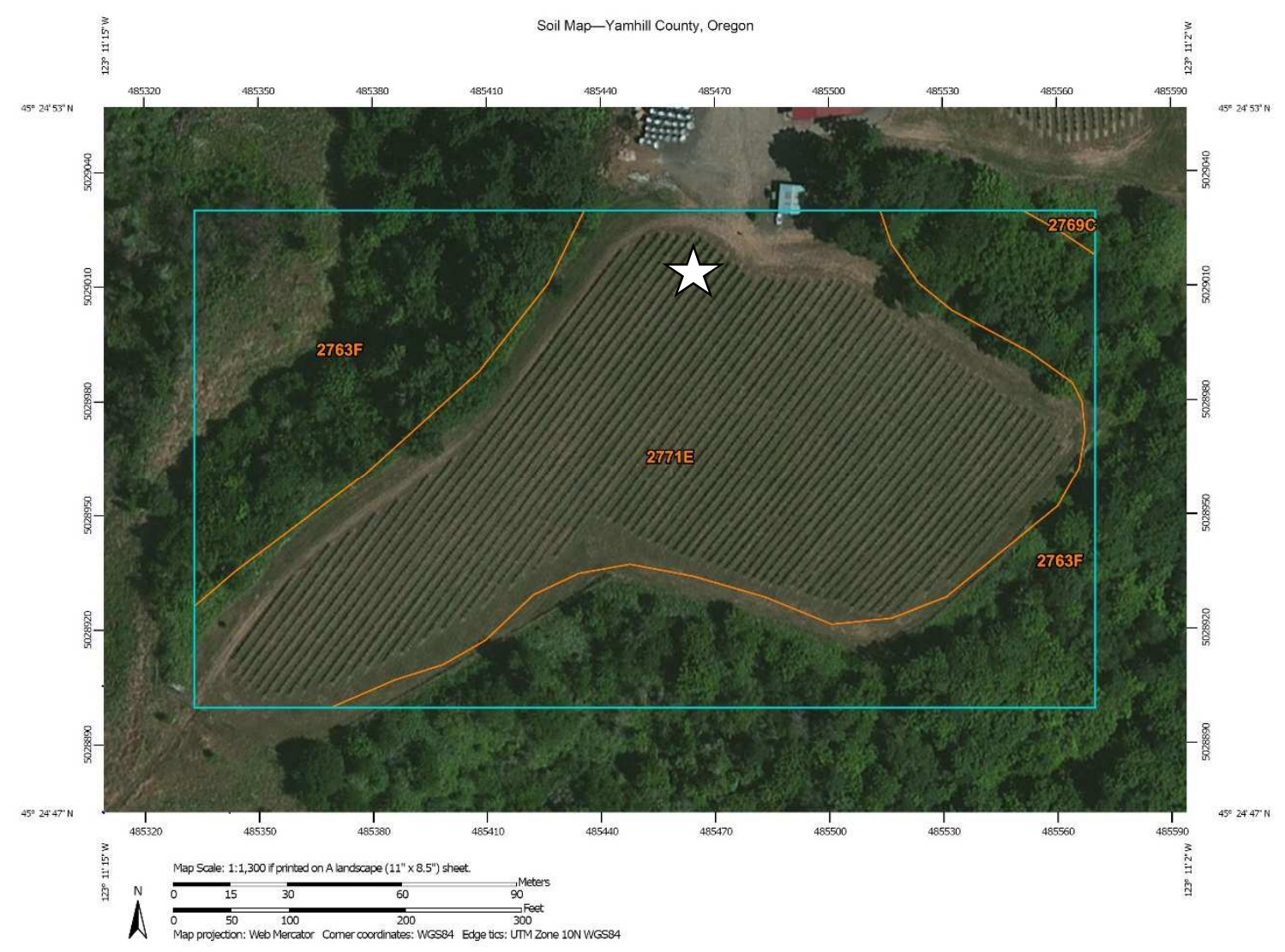

Figure 9. Soil map of Elk Cove Vineyards, Roosevelt Estate Vineyard. Pit location marked. 2771E Goodin-Melbourne complex, 2 to 30 percent slopes. $2763 \mathrm{~F}$ - Willakenzie-Sitton complex, 30 to 75 percent slopes, 2769C - Melbourne-Witham complex, hummocky, 2 to 25 percent slopes (NRCS, 2015). Previously mapped as WeC - Willakenzie silty clay loam, 2 to 12 slopes (NRCS, 2014).

The Goodin - Melbourne soil is characterized as an Ultic Haploxeralf - Ultic Palexeralf. The soil pit was $161 \mathrm{~cm}$ deep with friable sandstone parent material at the bottom. The bedrock and parent material belong to the Pittsburg Bluff Sandstone (Figure 2). The sandstone parent material strongly influences the soil at $110 \mathrm{~cm}$ depth, recognizable in a texture change, determined in the lab, from silty clay in Bt3 to silty clay loam in the $\mathrm{Bt} 4, \mathrm{C} 1, \mathrm{C} 2$, and $\mathrm{Cr}$ horizons (Figure 10). Percent sand increases from $2 \%$ to 
$20 \%$ from $\mathrm{Bt} 4$ to $\mathrm{C} 1$ at $110 \mathrm{~cm}$. The $\mathrm{pH}$ decreases with depth from 5.4 to 4.7 . CEC decreases from the surface horizon and then increases with depth and OM ranges from $6.7 \%$ to $15 \%$.

Dry colors also change from brown (7.5 YR 4/4) to yellow (10 YR 7/6) and yellowish brown (10 YR 5/6) from Bt3 to $\mathrm{C} 1$. Structures throughout the soil profile are medium subangular blocky. The Ap horizon is nonsticky and non-plastic, but the Bt horizons are all very sticky and very plastic. Clay films increase in number from Bt1 to Bt3 and are located on ped faces and in the interstitial pores. Clay percent increases with depth from $\mathrm{Ap}(18 \%)$ to $\mathrm{Bt} 2(60 \%)$ and $\mathrm{Bt} 3(55 \%)$, then decreases as more sand is introduced with depth. The C horizons contain $28 \%$ to $37 \%$ clay. Krotovina exist in Ap horizon, and large roots from the vines are visible at depth. The presence of muscovite mica and quartz sand coincides with the sandstone parent material and bedrock being marine sediments. There are no pisolites in this soil.

\section{Soil Chemistry}

The Roosevelt Vineyard soil pit is separated into nine horizons, including three Chorizons that are of friable sandstone parent material. The macronutrients $(\mathrm{Ca}, \mathrm{Mg}, \mathrm{K}, \mathrm{P}$, and S) for this soil pit exhibit some trends with depth (Table 14). In general, all macronutrients decrease with depth. $\mathrm{P}$ and $\mathrm{K}$ have maximum concentrations in the Ap horizon and decrease with depth. P has a slight bulge in the Bt3 horizon and again in the 
Table 13. Elk Cove Vineyards, Roosevelt Estate Vineyard field and lab data.

\begin{tabular}{|c|c|c|c|c|c|c|}
\hline \multirow{3}{*}{$\begin{array}{c}\text { Depth } \\
\text { (cm) }\end{array}$} & \multirow{3}{*}{ Horizon } & \multicolumn{3}{|c|}{ Total } & \multirow[b]{2}{*}{$\begin{array}{c}\text { Coarse } \\
\text { Fragment } \\
(>2 \mathrm{~mm})\end{array}$} & \multirow[b]{2}{*}{$\begin{array}{c}\text { Texture } \\
\text { Lab }\end{array}$} \\
\hline & & $\begin{array}{c}\text { Sand } \\
(2-0.05 \\
\text { mm) }\end{array}$ & $\begin{array}{c}\text { Silt } \\
(\mathbf{0 . 0 5 - 0 . 0 0 2} \\
\text { mm) }\end{array}$ & $\begin{array}{c}\text { Clay } \\
(<0.002 \text { mm) }\end{array}$ & & \\
\hline & & \multicolumn{4}{|c|}{ <- } & \\
\hline $0-15$ & Ap & 7.6 & 76.3 & 18.2 & 0.0 & $\mathrm{SiL}$ \\
\hline $15-25$ & $\mathrm{AB}$ & 6.0 & 69.8 & 24.8 & 0.0 & $\mathrm{SiL}$ \\
\hline $25-36$ & $\mathrm{Bt1}$ & 4.8 & 64.6 & 31.4 & 0.0 & $\mathrm{SiCL}$ \\
\hline $36-64$ & Bt2 & 2.6 & 39.5 & 60.3 & 0.0 & $\mathrm{C}$ \\
\hline $64-84$ & $\mathrm{Bt} 3$ & 1.2 & 38.4 & 55.0 & 0.0 & $\mathrm{SiC}$ \\
\hline $84-110$ & $\mathrm{Bt} 4$ & 1.6 & 55.8 & 37.4 & 0.0 & $\mathrm{SiCL}$ \\
\hline $110-144$ & $\mathrm{C} 1$ & 19.7 & 40.4 & 31.0 & 0.2 & $\mathrm{SiCL}$ \\
\hline 144-161 & $\mathrm{C} 2$ & 11.8 & 41.7 & 37.0 & 0.1 & $\mathrm{SiCL}$ \\
\hline $161+$ & $\mathrm{Cr}$ & 4.7 & 61.2 & 28.4 & 0.8 & $\mathrm{SiCL}$ \\
\hline $\begin{array}{c}\text { Depth } \\
\text { (cm) }\end{array}$ & Horizon & Dry Color & Structure & $\begin{array}{c}\text { Organic } \\
\text { Matter } \\
\text { LOI (Pct.) } \\
\end{array}$ & $\begin{array}{c}\text { pH } \\
\left(1: 1 \mathrm{H}_{2} \mathrm{O}\right)\end{array}$ & $\begin{array}{c}\text { CEC } \\
(\mathrm{meq} / \mathbf{1 0 0 g})\end{array}$ \\
\hline $0-15$ & Ap & 10 YR $5 / 3$ & $2, \mathrm{~m}, \mathrm{sbk}$ & 9.3 & 5.4 & 18.5 \\
\hline $15-25$ & $\mathrm{AB}$ & 7.5 YR $5 / 3$ & $2, \mathrm{~m}, \mathrm{sbk}$ & 6.9 & 5.5 & 15.4 \\
\hline $25-36$ & $\mathrm{Bt1}$ & 10YR 5/4 & $2, \mathrm{~m}, \mathrm{sbk}$ & 6.7 & 5.4 & 16.9 \\
\hline $36-64$ & $\mathrm{Bt} 2$ & 7.5YR 4/4 & $2, \mathrm{~m}, \mathrm{sbk}$ & 12 & 5.4 & 20.7 \\
\hline $64-84$ & $\mathrm{Bt} 3$ & $7.5 \mathrm{YR} 4 / 4$ & $2, \mathrm{~m}, \mathrm{sbk}$ & 15 & 5.1 & \\
\hline $84-110$ & $\mathrm{Bt} 4$ & $\begin{array}{l}\text { 10YR 7/6 } \\
2.5 Y 8 / 4\end{array}$ & $2, \mathrm{~m}, \mathrm{sbk}$ & 13 & 4.9 & \\
\hline $110-144$ & $\mathrm{C} 1$ & $\begin{array}{l}\text { 10YR 7/8 } \\
10 Y R ~ 8 / 4\end{array}$ & $\mathrm{~m}, \mathrm{f}, \mathrm{sbk}$ & 14 & 4.9 & \\
\hline 144-161 & $\mathrm{C} 2$ & 10 YR 5/6 & $\mathrm{m} / \mathrm{sg}$ & 15 & 4.9 & \\
\hline $161+$ & $\mathrm{Cr}$ & $\begin{array}{l}2.5 \mathrm{Y} 8 / 3 \\
10 \mathrm{YR} 6 / 6\end{array}$ & $\mathrm{~m} / \mathrm{sg}$ & 13 & 4.7 & \\
\hline
\end{tabular}



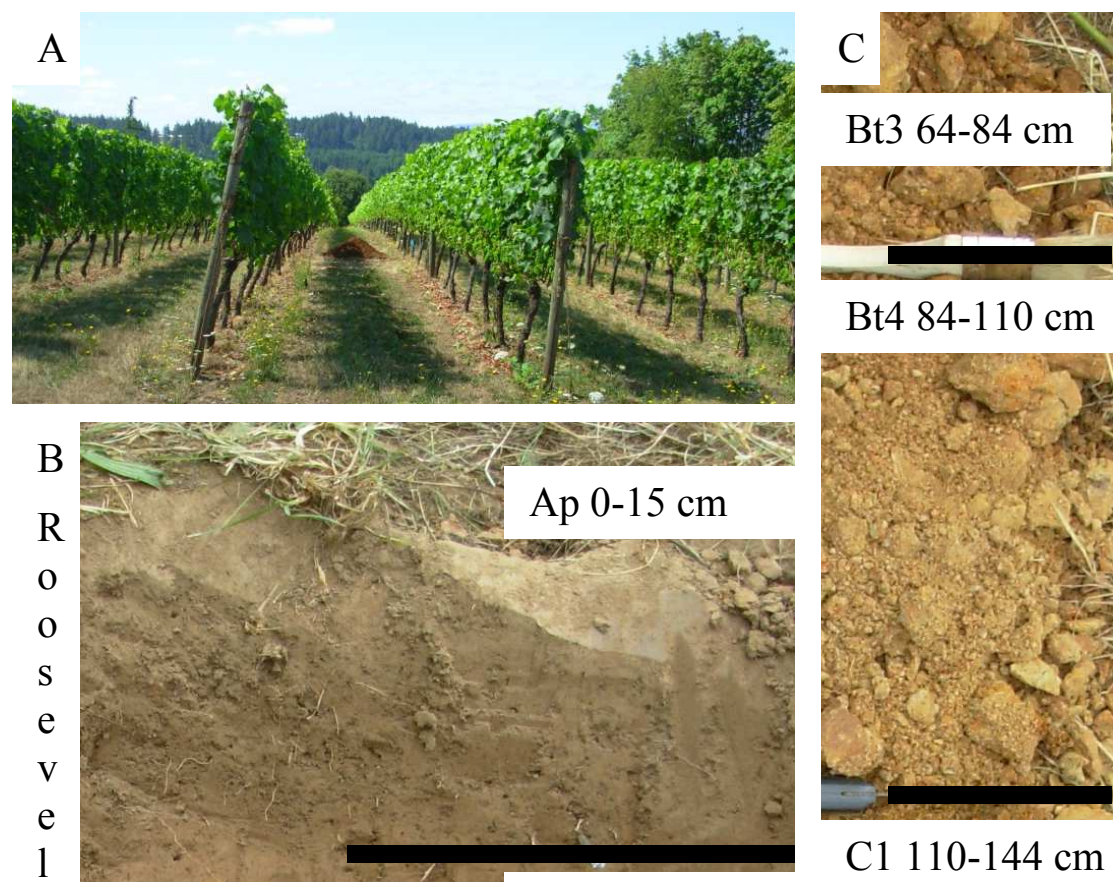

C1 $110-144 \mathrm{~cm}$
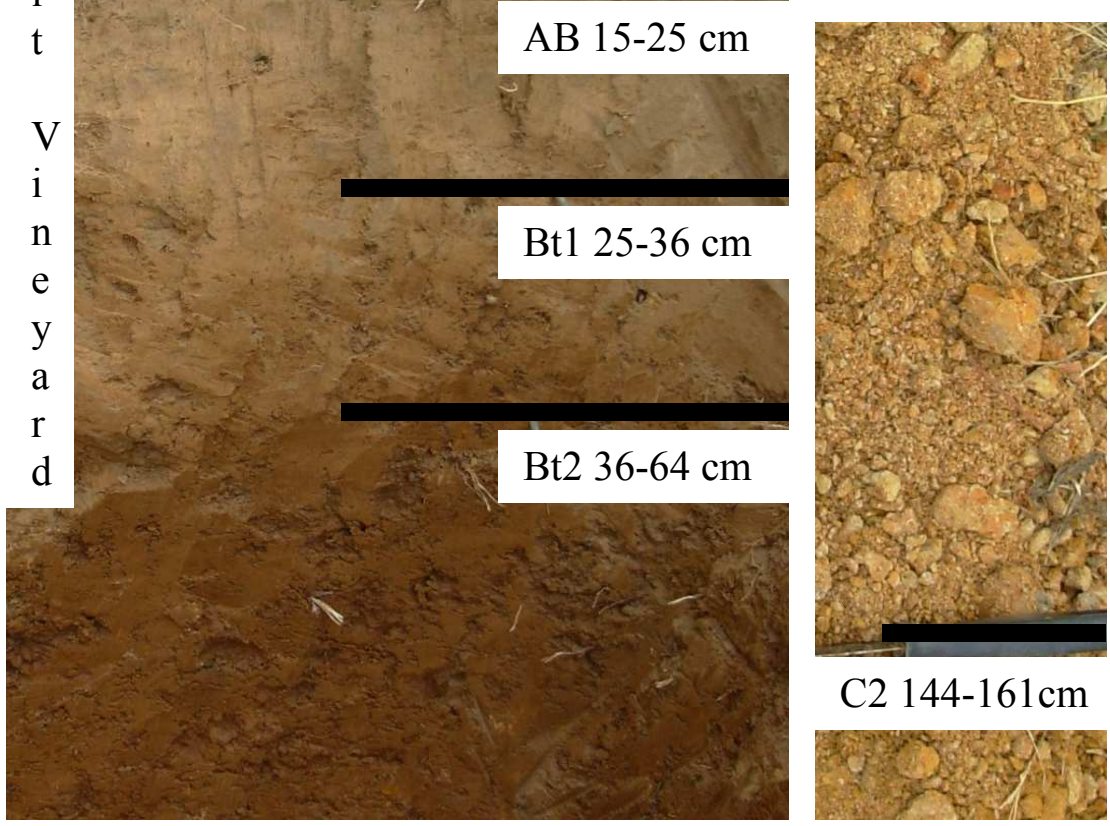

Figure 10. Sample soil pit at Elk Cove Vineyards, Roosevelt Estate Vineyard. A - View of sample location, facing south. B - Picture of the face of the soil pit with horizon depths and boundaries marked. C - Soil retrieved using a hand auger with horizon depths and boundaries marked. 
$\mathrm{C} 1$ horizon. The $\mathrm{Ca}$ concentration in the soil decreases with depth with a bulge in the $\mathrm{Bt} 2$ horizon to a maximum concentration of $\mathrm{Ca}$ for the profile. $\mathrm{Mg}$ is variable with depth but generally decreases with bulges in the $\mathrm{Bt} 1$ and $\mathrm{Bt} 3$ horizons. $\mathrm{S}$ only registered at detectable levels in the $\mathrm{Ap}$ and $\mathrm{AB}$ horizons. This is most likely to be the result of added S, not naturally derived. The majority of the profile had non-detectable concentrations of $\mathrm{Cl}$ with the exception of the Ap horizon and the parent material at depth.

Micronutrient concentrations in the Roosevelt Vineyard soil pit were also analyzed for each horizon to show the trends with depth. Fe concentrations increase with depth to the $\mathrm{Bt} 3$ horizon. After a notable decrease in the $\mathrm{Bt} 4$ horizon, the $\mathrm{Fe}$ concentrations again increase, reaching a maximum in the $\mathrm{C} 2$ horizon. $\mathrm{Al}$ concentrations increase to the Bt3 horizon and then decrease with depth. Co decreases with depth with a bulge in the $\mathrm{AB}$ horizon. $\mathrm{Cu}$ increases with depth with a bulge in the $\mathrm{AB}$ horizon. Mo concentrations are not detectable at this site. Mn concentrations were the highest in the Ap horizon and decrease with depth with slightly bulges in both $\mathrm{Bt} 3$ and $\mathrm{C} 2$ horizons. Na and Ni decrease with depth with a bulge in the in the Bt1 horizon. $\mathrm{Zn}$ has little trend, but generally decreases with depth with bulges in the Bt1, Bt3 and $\mathrm{C} 2$ horizons.

Some of the trace and other elements increase with depth and some decrease with depth in the Roosevelt Vineyard soil pit (Table 15). As has three bulges in the Bt1, Bt3, and the maximum concentration in the $\mathrm{C} 1$ horizon. Ba decreases with depth. Be increases 
Table 14. Macronutrient and micronutrient concentrations (all values in $\mathrm{mg} / \mathrm{kg}$ ) for the Elk Cove Vineyards, Roosevelt Estate soil pit (ND - Non-detectable).

\begin{tabular}{|c|c|c|c|c|c|c|c|c|c|}
\hline Horizon (cm) & $\mathbf{P}$ & & $\mathbf{K}$ & Ca & & Mg & $\mathbf{S}$ & & Cl \\
\hline Ap (0-15) & 637 & & 841 & 1720 & & 1600 & 158 & & 29.8 \\
\hline $\mathrm{AB}(15-25)$ & 565 & & 766 & 1370 & & 1690 & 101 & & ND \\
\hline Bt1 (25-36) & 478 & & 730 & 1470 & & 1950 & ND & & ND \\
\hline Bt2 (36-64) & 329 & & 447 & 1760 & & 1790 & ND & & ND \\
\hline Bt3 (64-84) & 389 & & 458 & 1700 & & 1840 & ND & & ND \\
\hline Bt4 (84-110) & 241 & & 267 & 1030 & & 1340 & ND & & ND \\
\hline C1 (110-144) & 319 & & 299 & 587 & & 1190 & ND & & 11.7 \\
\hline C2 (144-161) & 289 & & 291 & 445 & & 1180 & ND & & ND \\
\hline $\mathrm{Cr}(161+)$ & 249 & & 280 & 456 & & 1100 & ND & & 17.3 \\
\hline Mean & 388 & & 487 & 1170 & & 1520 & 130 & & 19.6 \\
\hline$S D$ & 142 & & 232 & 554 & & 322 & 40.3 & & 9.27 \\
\hline Maximum & 637 & & 841 & 1760 & & 1950 & 158 & & 29.8 \\
\hline Horizon (cm) & $\mathbf{F e}$ & Al & Co & $\mathrm{Cu}$ & Mn & Mo & $\mathbf{N a}$ & $\mathbf{N i}$ & $\mathbf{Z n}$ \\
\hline Ap $(0-15)$ & 18800 & 9840 & 11.8 & 8.29 & 971 & ND & 213 & 5.33 & 33.3 \\
\hline $\mathrm{AB}(15-25)$ & 19800 & 10800 & 13.2 & 7.76 & 903 & ND & 209 & 5.95 & 30.7 \\
\hline Bt1 (25-36) & 22100 & 13400 & 12.7 & 9.79 & 550 & ND & 223 & 6.45 & 30.9 \\
\hline Bt2 (36-64) & 28100 & 18200 & 3.05 & 14.7 & 95.5 & ND & 199 & 4.11 & 19.8 \\
\hline Bt3 (64-84) & 31700 & 20500 & 3.54 & 14.9 & 107 & ND & 204 & 4.72 & 21.6 \\
\hline Bt4 (84-110) & 15900 & 19400 & 1.47 & 14.1 & 8.18 & ND & 194 & 1.72 & 13.5 \\
\hline C1 (110-144) & 31000 & 17900 & 1.35 & 18.2 & 11.5 & ND & 178 & 1.76 & 11.5 \\
\hline C2 (144-161) & 43600 & 17300 & 1.46 & 22.2 & 24.3 & ND & 165 & 1.81 & 14.0 \\
\hline $\mathrm{Cr}(161+)$ & 21700 & 19400 & 1.46 & 18.3 & 16.6 & ND & 168 & 1.43 & 11.4 \\
\hline Mean & 25900 & 16300 & 5.56 & 14.2 & 299 & $N D$ & 195 & 3.70 & 20.7 \\
\hline$S D$ & 8640 & 3940 & 5.32 & 4.92 & 400 & $N D$ & 20.4 & 2.03 & 8.89 \\
\hline Maximum & 43600 & 20500 & 13.2 & 22.2 & 971 & $N D$ & 223 & 6.45 & 33.3 \\
\hline
\end{tabular}

to the Bt2 horizon then decreases with depth. Cd concentrations are highest in the Ap horizon then decrease. $\mathrm{Cr}$ increases to the $\mathrm{Bt} 3$ horizon and then decreases. $\mathrm{Hg}$ is measured in the $\mathrm{Bt} 2$ through $\mathrm{C} 1$ horizons at very low quantities. $\mathrm{Pb}$ decreases with depth 
with a bulge in the Bt3 horizon and parent material. Se was only detected in the Bt3, Bt4, and $\mathrm{C} 1$ horizons and the highest concentration in the $\mathrm{C} 1$ horizon. There is a bulge in $\mathrm{Sr}$ concentration in the $\mathrm{Bt} 2, \mathrm{Bt} 3$, and $\mathrm{Bt} 4$ horizons, the Ap horizon and parent material have similar values. $\mathrm{V}$ also has a bulge in the Bt3 horizon at then decreases to the $\mathrm{Cr}$ horizon.

Table 15. Trace element concentrations and other elements tested (all values in $\mathrm{mg} / \mathrm{kg}$ ) for the Elk Cove Vineyards, Roosevelt Estate soil pit (ND - Non-detectable).

\begin{tabular}{ccccccccccc}
\hline Horizon (cm) & As & Ba & Be & Cd & Cr & Hg & Pb & Se & Sr & V \\
\hline \hline Ap (0-15) & 3.87 & 205 & 0.510 & 0.174 & 14.2 & ND & 8.68 & ND & 17.2 & 42.1 \\
AB (15-25) & 3.48 & 187 & 0.572 & ND & 14.8 & ND & 7.85 & ND & 14.5 & 45.2 \\
Bt1 (25-36) & 4.31 & 147 & 0.621 & ND & 16.7 & ND & 7.78 & ND & 15.7 & 50.8 \\
Bt2 (36-64) & 3.04 & 86.6 & 0.661 & 0.107 & 20.0 & 0.0417 & 7.70 & ND & 22.9 & 56.3 \\
Bt3 (64-84) & 4.97 & 87.2 & 0.631 & 0.120 & 21.6 & 0.0408 & 7.96 & 0.521 & 23.0 & 60.0 \\
Bt4 (84-110) & 4.65 & 43.6 & 0.654 & 0.121 & 15.0 & 0.0511 & 5.92 & 0.543 & 22.3 & 30.6 \\
C1 (110-144) & 6.17 & 39.5 & 0.546 & 0.117 & 17.7 & 0.0506 & 6.86 & 0.673 & 17.7 & 38.3 \\
C2 (144-161) & 4.44 & 32.3 & 0.468 & ND & 17.6 & ND & 7.04 & ND & 15.1 & 30.4 \\
Cr (161+) & 4.68 & 37.1 & 0.448 & 0.109 & 13.1 & ND & 6.64 & ND & 16.6 & 26.7 \\
\hline \hline Mean & $\mathbf{4 . 4 0}$ & $\mathbf{9 6 . 1}$ & $\mathbf{0 . 5 6 8}$ & $\mathbf{0 . 1 2 5}$ & $\mathbf{1 6 . 7}$ & $\mathbf{0 . 0 4 6 1}$ & 7.38 & $\mathbf{0 . 5 7 9}$ & $\mathbf{1 8 . 3}$ & $\mathbf{4 2 . 3}$ \\
SD & $\mathbf{0 . 9 0 7}$ & $\mathbf{6 7 . 4}$ & $\mathbf{0 . 0 7 9 9}$ & $\mathbf{0 . 0 2 4 8}$ & $\mathbf{2 . 7 9}$ & $\mathbf{0 . 0 0 5 5 6}$ & $\mathbf{0 . 8 3 5}$ & $\mathbf{0 . 0 8 2 1}$ & $\mathbf{3 . 4 5}$ & $\mathbf{1 1 . 9}$ \\
Maximum & $\mathbf{6 . 1 7}$ & $\mathbf{2 0 5}$ & $\mathbf{0 . 6 6 1}$ & $\mathbf{0 . 1 7 4}$ & $\mathbf{2 1 . 6}$ & $\mathbf{0 . 0 5 1 1}$ & $\mathbf{8 . 6 8}$ & $\mathbf{0 . 6 7 3}$ & $\mathbf{2 3 . 0}$ & $\mathbf{6 0 . 0}$ \\
\hline
\end{tabular}

\section{Grape Juice Chemistry}

Grape juice from clusters of grapes collected from vines adjacent to the soil pit were analyzed for the same 24 elements as the soils. The majority of these elements are non-detectable using this method, therefore only the elements found in any sample are shown in Table 16. The highest elemental concentration measured in the Roosevelt Vineyard grape juice is $\mathrm{K}$ at $1240 \mathrm{mg} / \mathrm{kg}$. $\mathrm{P}$ is also detected at $361 \mathrm{mg} / \mathrm{kg}$ and $\mathrm{Na}$ is 144 
$\mathrm{mg} / \mathrm{kg}$. Sr, one of only three elements to be detected in all 20 grape juice samples, has a concentration of $0.852 \mathrm{mg} / \mathrm{kg}$ in this sample. It is the $7^{\text {th }}$ highest concentration where the mean concentration for all grape juice samples is $0.805 \pm 0.261 \mathrm{mg} / \mathrm{kg}$ (Table 105).

Table 16. Elemental concentrations measured by ICP-MS in the grape juice from clusters collected from vines immediately adjacent to the soil pit location at Elk Cove Vineyards, Roosevelt Vineyard (ND - Non-detectable).

\begin{tabular}{cccccccccc}
\hline Element & Sr & $\mathbf{P}$ & $\mathbf{K}$ & Na & Mg & Mn & Ca & Cu & Zn \\
\hline \hline Grape Juice (mg/kg) & 0.852 & 361 & 1240 & 144 & ND & ND & ND & ND & ND \\
\hline
\end{tabular}

\section{Wine Chemistry}

Elk Cove Vineyards provided a $350 \mathrm{ml}$ sample of the wine produced from each vineyard in 2011. The unblended wine was stored until sensory analysis could take place during the winter of 2014. At that time, a bottle of Elk Cove Roosevelt Vineyard Pinot Noir 2011 was purchased in order to complete the sensory analysis. Therefore, samples were taken of both the unblended wine and the finished bottle for chemical analysis (Table 17). As noted in the previous chapter on the Clay Court results, the concentrations of certain elements are similar between the sample and the finished bottle, while others have increased or decreased as a reflection of contamination or precipitation and removal during winemaking.

The 14 elements that are detected in the Roosevelt Vineyard wine include $\mathrm{Ba}, \mathrm{Ca}$, $\mathrm{Co}, \mathrm{Cu}, \mathrm{Fe}, \mathrm{Pb}, \mathrm{Mg}, \mathrm{Mn}, \mathrm{P}, \mathrm{K}, \mathrm{Na}, \mathrm{Sr}, \mathrm{S}$, and $\mathrm{Zn}$. Ba concentration increased from the sample to the wine from the bottle. Ca concentrations were consistent between the sample 
and the bottle. Co was detected in the finished wine and was below detection limits in the sample. $\mathrm{Cu}$ concentration increased from the sample to the finished bottle. Other elements that increased in concentration from the sample to the finished wine include $\mathrm{Pb}$, $\mathrm{Sr}, \mathrm{P}, \mathrm{Na}$, and $\mathrm{Zn}$. S concentrations were similar from sample to bottle and $\mathrm{Mg}, \mathrm{Mn}$, and $\mathrm{K}$ all decreased from sample to finished wine.

Table 17. Elemental concentrations measured by ICP-MS in the 2011 Elk Cove Vineyards, Roosevelt Vineyard wine and a $350 \mathrm{ml}$ sample of unblended wine from the same vineyard and vintage (ND Non-detectable).

\begin{tabular}{cccccc}
\hline Element & $\begin{array}{c}\mathbf{2 0 1 1 ~ W i n e} \\
\text { Sample } \\
(\mathbf{m g} / \mathbf{k g})\end{array}$ & $\begin{array}{c}\mathbf{2 0 1 1} \text { Bottle } \\
(\mathbf{m g} / \mathbf{k g})\end{array}$ & Element & $\begin{array}{c}\text { 2011 Wine } \\
\text { Sample } \\
(\mathbf{m g} / \mathbf{k g})\end{array}$ & $\begin{array}{c}\mathbf{2 0 1 1} \text { Bottle } \\
(\mathbf{m g} / \mathbf{k g})\end{array}$ \\
\hline \hline $\mathrm{Al}$ & $\mathrm{ND}$ & $\mathrm{ND}$ & $\mathrm{Mn}$ & 1.09 & 0.996 \\
$\mathrm{As}$ & $\mathrm{ND}$ & $\mathrm{ND}$ & $\mathrm{Hg}$ & $\mathrm{ND}$ & $\mathrm{ND}$ \\
$\mathrm{Ba}$ & 0.268 & 0.754 & $\mathrm{Mo}$ & $\mathrm{ND}$ & $\mathrm{ND}$ \\
$\mathrm{Be}$ & $\mathrm{ND}$ & $\mathrm{ND}$ & $\mathrm{Ni}$ & $\mathrm{ND}$ & $\mathrm{ND}$ \\
$\mathrm{Cd}$ & $\mathrm{ND}$ & $\mathrm{ND}$ & $\mathrm{P}$ & 443 & 560 \\
$\mathrm{Ca}$ & 46.1 & 53.8 & $\mathrm{~K}$ & 829 & 752 \\
$\mathrm{Cr}$ & $\mathrm{ND}$ & $\mathrm{ND}$ & $\mathrm{Se}$ & $\mathrm{ND}$ & $\mathrm{ND}$ \\
$\mathrm{Co}$ & $\mathrm{ND}$ & 0.0255 & $\mathrm{Sr}$ & 0.915 & 1.07 \\
$\mathrm{Cu}$ & 0.046 & 0.12 & $\mathrm{Na}$ & 2.59 & 4.10 \\
$\mathrm{Fe}$ & 0.738 & 0.684 & $\mathrm{~S}$ & 76.8 & 74.6 \\
$\mathrm{~Pb}$ & $\mathrm{ND}$ & 0.061 & $\mathrm{~V}$ & $\mathrm{ND}$ & $\mathrm{ND}$ \\
$\mathrm{Mg}$ & 85.7 & 58.9 & $\mathrm{Zn}$ & 0.0785 & 0.126 \\
\hline
\end{tabular}

\section{Clay Mineralogy}

The clays mineral assemblage for Elk Cove Vineyards, Roosevelt Estate soil were analyzed from the Bt2 horizon. This horizon was chosen because it had the highest clay percentage based on my lab analysis. The results based on x-ray diffraction (Appendix B) 
included minor fully expansive smectite clay and a trace amount of mica. The clays also include moderate chlorite intergrade, minor amounts of disordered kaolinite and possibly a minor amount of dehydrated halloysite. Vermiculite was not present in this sample and minor amounts of illite were present. Quartz is the main silica phase with only trace amounts of cristobalite. Weak development of hydroxy interlayered clays and no vermiculite/chlorite intergrade were present. Minor goethite was present suggesting an older soil with the illite portion being a result of weathering of mica in the parent material and not from an eolian loess component.

\section{Loess and Volcanic Parent Material - Five Mountain Vineyard Physical Characteristics}

Five Mountain Vineyard is owned and operated by Elk Cove Vineyards and located in Cornelius, Oregon. These vineyards are located on basaltic rocks of the Columbia River Basalt group with ancient weathered loess on top of the basalt. The soil pit location was at 362 feet (110 meters) elevation between rows 27 and 28, and the soil is mapped as Laurelwood soil series (Figure 11). Five Mountain Vineyard is located on midslope of a slightly south facing slope with vine rows running north and south (Lat. 45.448694 N, Long. $-123.036566 \mathrm{~W})$. According to the vineyard manager, this vineyard was cultivated with permanent grass cover in 2010 and utilizes sustainable farming practices (Appendix D). The vines are Pinot Noir Dijon 115 clone planted in 1996 and 
are trellised as bilateral cordon in vertical shoot position with 5 foot by 9 foot (1.5 meters by 2.75 meters) spacing. The vines are grafted onto 101-14 rootstock (Table 8 ).

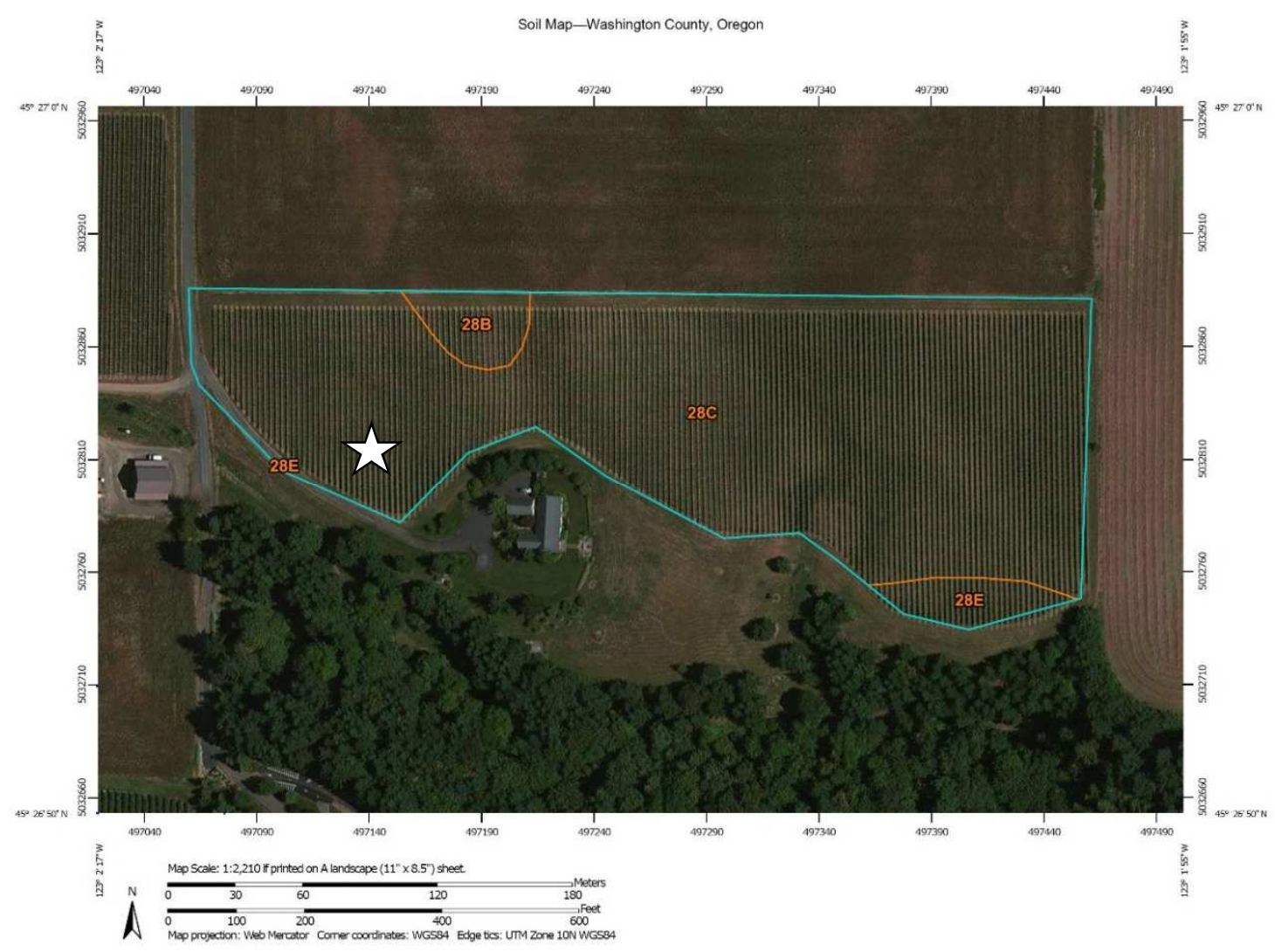

Figure 11. Soil map of Elk Cove Vineyards, Five Mountain Vineyard. Pit location marked. 28C Laurelwood silt loam, 7 to 12 percent slopes. 28B - Laurelwood silt loam, 3 to 7 percent slopes. 28E Laurelwood silt loam, 20 to 30 percent slopes (NRCS, 2014).

The Laurelwood soil is characterized as an Ultic Haploxeralf. The soil pit was $171+\mathrm{cm}$ deep, and I did not reach the parent material or refusal at that depth. The bedrock is part of the Columbia River Basalt group with an addition of loess (Figure 2). The CEC decreases with depth and OM ranges from 5.1\% to 9.2\% (Table 18). The $\mathrm{pH}$ of 
this soil profile decreases with depth from 5.7 to 5.5 with a bulge in the Bt1 horizon to 6.0. The silt content of this soil pit ranges from $47 \%$ (Bt3) to $63 \%$ (Ap) depending on the horizon. Percent sand decreases with depth from $23 \%$ to $7 \%$ from Ap to Bt3 at $114 \mathrm{~cm}$.

Table 18. Elk Cove Vineyards, Five Mountain Vineyard field and lab data.

\begin{tabular}{|c|c|c|c|c|c|c|}
\hline \multirow{3}{*}{$\begin{array}{l}\text { Depth } \\
\text { (cm) }\end{array}$} & \multirow{3}{*}{ Horizon } & \multicolumn{3}{|c|}{ Total } & \multirow[b]{2}{*}{$\begin{array}{c}\text { Coarse } \\
\text { Fragment } \\
(>2 \mathrm{~mm})\end{array}$} & \multirow[b]{2}{*}{$\begin{array}{c}\text { Texture } \\
\text { Lab }\end{array}$} \\
\hline & & $\begin{array}{c}\text { Sand } \\
(2-0.05 \\
\text { mm) }\end{array}$ & $\begin{array}{c}\text { Silt } \\
(0.05-0.002 \\
\text { mm })\end{array}$ & $\begin{array}{c}\text { Clay } \\
(<0.002 \mathrm{~mm})\end{array}$ & & \\
\hline & & \multicolumn{4}{|c|}{ <--------------------------Pct.-----------------------> } & \\
\hline $0-30$ & Ap & 23.0 & 63.2 & 12.1 & 2.9 & $\mathrm{SiL}$ \\
\hline $30-61$ & Bt1 & 4.7 & 58.5 & 32.8 & 0.0 & $\mathrm{SiCL}$ \\
\hline $61-114$ & Bt2 & 3.8 & 61.8 & 31.7 & 0.0 & $\mathrm{SiCL}$ \\
\hline $114-171+$ & $\mathrm{Bt} 3$ & 7.0 & 46.8 & 38.9 & 0.7 & $\mathrm{C}$ \\
\hline $\begin{array}{l}\text { Depth } \\
\text { (cm) }\end{array}$ & Horizon & Dry Color & Structure & $\begin{array}{c}\text { Organic } \\
\text { Matter } \\
\text { LOI (Pct.) }\end{array}$ & $\begin{array}{c}\text { pH } \\
\left(1: 1 \mathrm{H}_{2} \mathrm{O}\right)\end{array}$ & $\begin{array}{c}\text { CEC } \\
(\mathrm{meq} / 100 \mathrm{~g})\end{array}$ \\
\hline $0-30$ & Ap & 10 YR $5 / 4$ & $1, \mathrm{f}, \mathrm{sbk}$ & 7.9 & 5.7 & 18.6 \\
\hline $30-61$ & Bt1 & 10YR 5/4 & $2, \mathrm{~m}, \mathrm{sbk}$ & 5.1 & 6.0 & 14.2 \\
\hline $61-114$ & $\mathrm{Bt} 2$ & 10YR 5/4 & $2, \mathrm{~m}, \mathrm{sbk}$ & 5.5 & 5.8 & 14.9 \\
\hline $114-171+$ & $\mathrm{Bt} 3$ & 10YR 4/4 & $2, \mathrm{~m}, \mathrm{sbk}$ & 9.2 & 5.5 & 13.8 \\
\hline
\end{tabular}

Dry colors for the Ap, Bt1 and Bt2 horizons are yellowish brown (10 YR 5/4), and Bt3 is dark yellowish brown (10 YR 4/4). Structure throughout the soil profile is medium subangular blocky (Figure 12). The Ap horizon is slightly sticky and slightly plastic, but the Bt1 is very sticky and very plastic due to a jump in clay percent from $12 \%$ in the Ap to 33\%, 32\%, and 39\% in Bt1, Bt2, and Bt3, respectively. Clay films, located 


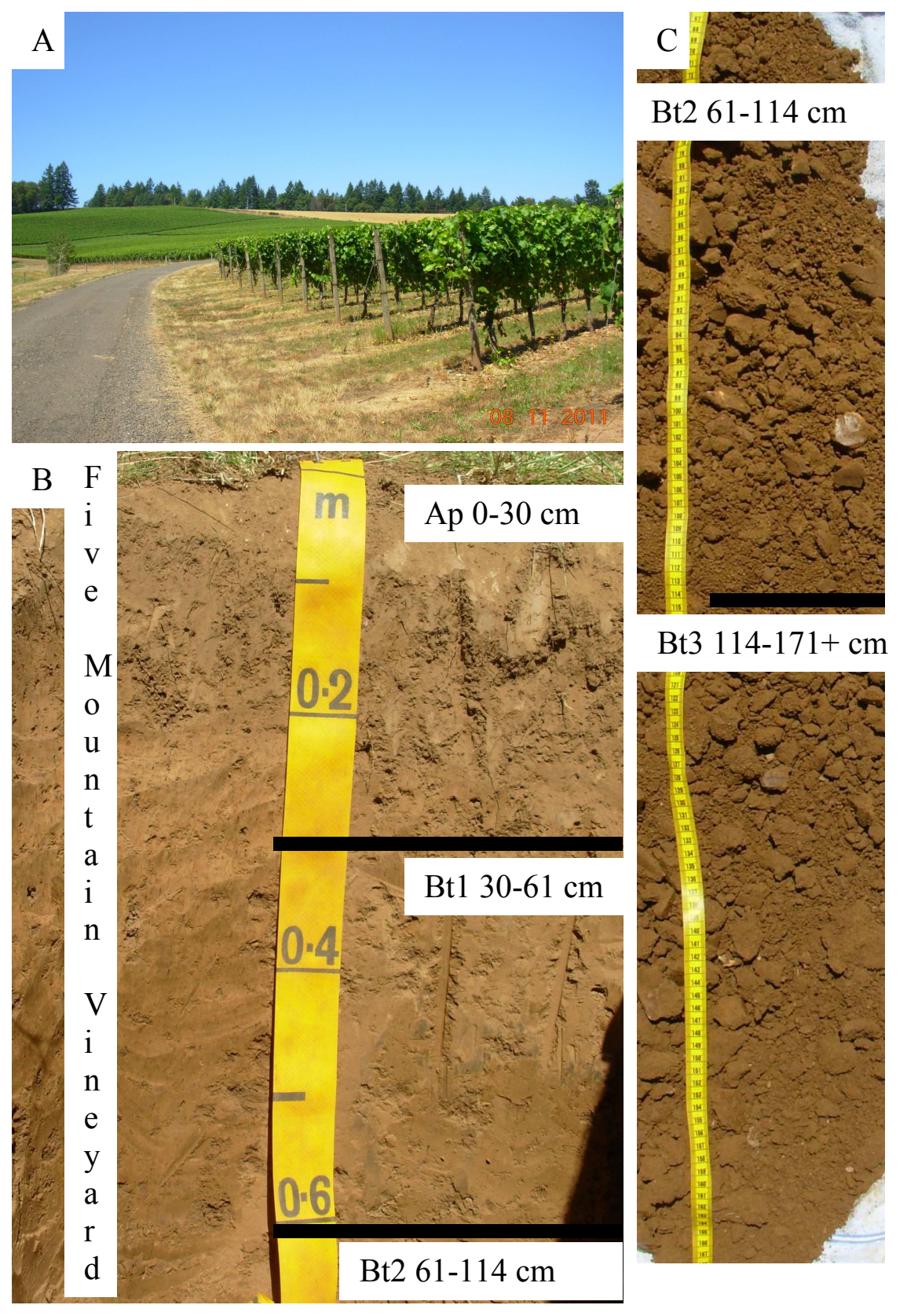

Figure 12. Sample soil pit at Elk Cove Vineyards, Five Mountain Vineyard. A - View of sample location, facing west. B - Picture of the face of the soil pit with horizon depths and boundaries marked. C - Soil retrieved using a hand auger with horizon depths and boundaries marked. 
on ped faces, are the most common and dominant in the Bt1 horizon while the $\mathrm{Bt} 2$ and Bt3 horizons only have few faint clay films on the ped faces. Pisolites are found abundantly throughout the profile and can be seen in the Ap horizon.

\section{Soil Chemistry}

Four horizons were designated in the Five Mountain Vineyard soil pit. The maximum concentration of $\mathrm{P}$ and $\mathrm{S}$ are in the Ap horizon while concentrations of the other macronutrients increased with depth, then decreased in the deepest horizon (Table 19). P decreases with depth, the maximum concentration in the Ap horizon and a bulge in the $\mathrm{Bt} 3$ horizon. $\mathrm{K}$ concentration bulges in the $\mathrm{Bt} 1$ horizon. $\mathrm{Ca}$ and $\mathrm{Mg}$ both increase with depth and the maximum concentration is in the Bt2 horizon. $\mathrm{S}$ was only detected in the Ap horizon at the surface.

The micronutrient concentrations were measured in the four soil horizons from the Five Vineyard. Fe concentrations are highest in the deepest horizon, Bt3, and Al increased with depth from the Ap horizon the Bt2 horizon. A non-detectable concentration in the $\mathrm{Bt} 3$ horizon for $\mathrm{Al}$ was not expected and may be due to instrument error since it is unlikely that there was such a significant decrease in $\mathrm{Al}$ from the $\mathrm{Bt} 2$ to Bt3 horizon to cause it to be unmeasurable. Mo is non-detectable. Co concentrations increase with depth from the $\mathrm{Bt} 3$ horizon. $\mathrm{Cu}$ values increase from the surface horizons to the Bt2 horizon. Mn decreases with depth. Na decreases with depth and a bulge in the Bt3 
horizon and the maximum concentration in the Ap horizon. Ni concentrations slightly bulge with depth from the Ap horizon to the $\mathrm{Bt} 2$ horizon. $\mathrm{Zn}$ is highest in the Ap horizon and decreases with depth.

Table 19. Macronutrient, micronutrient and trace element concentrations (all values in $\mathrm{mg} / \mathrm{kg}$ ) for the Elk Cove Vineyards, Five Mountain Vineyard soil pit (ND - Non-detectable).

\begin{tabular}{|c|c|c|c|c|c|c|c|c|c|c|}
\hline Horizon (cm) & $\mathbf{P}$ & & $\mathbf{K}$ & $\mathbf{C a}$ & & Mg & $\mathrm{S}$ & & & Cl \\
\hline Ap $(0-30)$ & 1550 & & 998 & 1420 & & 2000 & 17 & & & ND \\
\hline Bt1 (30-61) & 669 & & 1430 & 1480 & & 3210 & NI & & & ND \\
\hline Bt2 (61-114) & 508 & & 1420 & 1560 & & 3380 & NI & & & ND \\
\hline Bt3 (114-171+) & 572 & & 396 & 988 & & 927 & NI & & & ND \\
\hline Mean & 825 & & 1060 & 1360 & & 2380 & 17 & & & ND \\
\hline$S D$ & 488 & & 487 & 256 & & 1150 & 0 & & & $N D$ \\
\hline Maximum & 1550 & & 1430 & 1560 & & 3380 & 17 & & & $N D$ \\
\hline Horizon (cm) & $\mathbf{F e}$ & Al & Co & $\mathrm{Cu}$ & Mn & Mo & $\mathbf{N a}$ & & $\mathrm{Ni}$ & Zn \\
\hline Ap (0-30) & 19400 & 14300 & 11.1 & 12.5 & 1330 & ND & 220 & & 12 & 56.9 \\
\hline Bt1 (30-61) & 27000 & 20900 & 14.8 & 12.5 & 476 & ND & 187 & & 0.2 & 43.5 \\
\hline Bt2 (61-114) & 31200 & 20900 & 14.4 & 15.3 & 491 & ND & 154 & & 0.5 & 42.6 \\
\hline Bt3 $(114-171+)$ & 35400 & ND & 20.1 & 13.6 & 515 & ND & 188 & & 37 & 28.3 \\
\hline Mean & 28300 & 18700 & 15.1 & 13.5 & 703 & $N D$ & 187 & & 80 & 42.8 \\
\hline$S D$ & 6820 & 3810 & 3.72 & 1.32 & 418 & $N D$ & 26.9 & & 36 & 11.7 \\
\hline Maximum & 35400 & 20900 & 20.1 & 15.3 & 1330 & $N D$ & 220 & & 0.5 & 56.9 \\
\hline Horizon (cm) & As & $\mathbf{B a}$ & Be & Cd & $\mathrm{Cr}$ & Hg & $\mathbf{P b}$ & Se & $\mathrm{Sr}$ & $\mathbf{V}$ \\
\hline Ap $(0-30)$ & 2.49 & 244 & 0.540 & 0.244 & 14.9 & 0.0426 & 8.85 & ND & 10.7 & 54.1 \\
\hline Bt1 (30-61) & 3.51 & 107 & 0.683 & 0.163 & 20.5 & ND & 8.44 & ND & 19.2 & 84.6 \\
\hline Bt2 (61-114) & 3.31 & 106 & 0.754 & 0.218 & 24.1 & ND & 9.15 & ND & 20.1 & 95.3 \\
\hline Bt3 $(114-171+)$ & 0.86 & 75.4 & 0.827 & 0.229 & 24.1 & ND & 8.68 & ND & 15.3 & 127 \\
\hline Mean & 2.54 & 133 & 0.701 & 0.214 & 20.9 & 0.0426 & 8.78 & $N D$ & 16.3 & 90.3 \\
\hline$S D$ & 1.21 & 75.4 & 0.122 & 0.0353 & 4.35 & 0 & 0.299 & $N D$ & 4.29 & 30.1 \\
\hline Maximum & 3.51 & 244 & 0.827 & 0.244 & 24.1 & 0.0426 & 9.15 & $N D$ & 20.1 & 127 \\
\hline
\end{tabular}


The trace and other elements were also measured in the Five Mountain Vineyard soil pit. Hg was only detectable in the Ap horizon and Se was below detection limits throughout the profile. The maximum concentration of As in the profile is in the Bt1 horizon. Ba decreases with depth. Be concentrations increase with depth. $\mathrm{Cd}$ concentrations are highest in the Ap horizon and the concentration decreases in the Bt1 horizon but increases. $\mathrm{Cr}$ increases with depth. $\mathrm{Pb}$ concentrations are consistent from the surface horizons to depth. There is a bulge in Sr concentration in the Bt1 and Bt2 horizons. V bulges in the Bt3 horizon.

\section{Grape Juice Chemistry}

Grape juice was obtained by crushing a sample of the grapes collected from vines immediately adjacent to the soil pit at the time of harvest. All 24 of the elements were analyzed, but the elements measured in the grape juice from Five Mountain Vineyard were scarce. They include Sr, P, K, Na, and Mn. Only the elements found in any of the 20 grape juice samples are shown in Table 20. The highest elemental concentration measured in the Five Mountain grape juice is $\mathrm{K}$ at $1340 \mathrm{mg} / \mathrm{kg}$. $\mathrm{P}$ is also detected at 232 $\mathrm{mg} / \mathrm{kg}$ and $\mathrm{Na}$ is $145 \mathrm{mg} / \mathrm{kg}$. Mn is also measured at $2.14 \mathrm{mg} / \mathrm{kg}$, one of the four vineyards (The Jory Hills, Stoller, and Sims Vineyards) where Mn is measured in the grape juice. Sr, one of only three elements detected in all 20 grape juice samples, has a concentration of $1.02 \mathrm{mg} / \mathrm{kg}$ in this sample. It is the $5^{\text {th }}$ highest concentration where the mean concentration for all grape juice samples is $0.805 \pm 0.261 \mathrm{mg} / \mathrm{kg}$ (Table 105). 
Table 20. Elemental concentrations measured by ICP-MS in the grape juice from clusters collected from vines immediately adjacent to the soil pit location at Elk Cove Vineyards, Five Mountain Vineyard (ND - Non-detectable).

\begin{tabular}{cccccccccc}
\hline Element & Sr & $\mathbf{P}$ & $\mathbf{K}$ & Na & Mg & Mn & Ca & Cu & Zn \\
\hline $\begin{array}{c}\text { Grape Juice } \\
(\mathrm{mg} / \mathrm{kg})\end{array}$ & 1.02 & 232 & 1340 & 145 & ND & 2.04 & ND & ND & ND \\
\hline
\end{tabular}

\section{Wine Chemistry}

Two bottles of the Five Mountain Vineyard wine were used during the sensory analysis, therefore each bottle of wine was sampled and sent to the lab for analysis along with the wine sample from $350 \mathrm{ml}$ bottle given to me before blending occurred. There is only a slight difference between the values for elements found in the sample and in the finished bottles of wine, but the bottles of wine were most similar. The 14 elements that are detected in the Five Mountain wine include $\mathrm{Ba}, \mathrm{Ca}, \mathrm{Cu}, \mathrm{Fe}, \mathrm{Mg}, \mathrm{Mn}, \mathrm{P}, \mathrm{K}, \mathrm{Na}, \mathrm{Sr}, \mathrm{S}$, and $\mathrm{Zn}$. The mean and standard deviation calculations for the elemental concentrations of these two bottles and one sample reveal that only $\mathrm{P}$ increased significantly from the sample to the finished wine from $180 \mathrm{mg} / \mathrm{kg}$ to $280 \mathrm{mg} / \mathrm{kg}$ and $282 \mathrm{mg} / \mathrm{kg}$.

Almost all other elements increased slightly from sample to bottle with the exception of the concentration of $\mathrm{Ba}$, which decreased from $0.576 \mathrm{mg} / \mathrm{kg}$ in the sample to 0.414 and $0.404 \mathrm{mg} / \mathrm{kg}$ in the bottle and zine which decreased from $0.222 \mathrm{mg} / \mathrm{kg}$ in the sample to $0.172 \mathrm{mg} / \mathrm{kg}$ in the bottles. Ca increased from $31.1 \mathrm{mg} / \mathrm{kg}$ to $49.4 \mathrm{mg} / \mathrm{kg}$, Fe increased from $0.63 \mathrm{mg} / \mathrm{kg}$ to $0.858 \mathrm{mg} / \mathrm{kg}$, and $\mathrm{Mg}$ increased from $58.6 \mathrm{mg} / \mathrm{kg}$ to 66.6 $\mathrm{mg} / \mathrm{kg}$. Na concentration in the sample was below detection limits, while it registered at 
$4.34 \mathrm{mg} / \mathrm{kg}$ in one bottle. $\mathrm{Sr}$ concentrations were fairly constant from sample to bottle, ranging only from $0.774 \mathrm{mg} / \mathrm{kg}$ in one bottle to $0.8 \mathrm{mg} / \mathrm{kg}$ in the other and the sample was $0.779 \mathrm{mg} / \mathrm{kg}$. S increased slightly from $55.1 \mathrm{mg} / \mathrm{kg}$ to $68.1 \mathrm{mg} / \mathrm{kg}$ in one bottle.

Table 21. Elemental concentrations measured by ICP-MS in the 2011 Elk Cove Vineyards, Five Mountain Vineyard wine (two bottles purchased and analyzed), and a $350 \mathrm{ml}$ sample of unblended wine from the same vineyard and vintage (ND - Non-detectable, *denotes mean of samples from two different bottles).

\begin{tabular}{cccccc}
\hline Element & $\begin{array}{c}\mathbf{2 0 1 1} \text { Wine } \\
\text { Sample } \\
(\mathbf{m g} / \mathbf{k g})\end{array}$ & $\begin{array}{c}\mathbf{2 0 1 1 ~ B o t t l e *} \\
(\mathbf{m g} / \mathbf{k g})\end{array}$ & Element & $\begin{array}{c}\text { 2011 Wine } \\
\text { Sample } \\
(\mathbf{m g} / \mathbf{k g})\end{array}$ & $\begin{array}{c}\mathbf{2 0 1 1} \mathbf{~ B o t t l e *} \\
(\mathbf{m g} / \mathbf{k g})\end{array}$ \\
\hline \hline $\mathrm{Al}$ & $\mathrm{ND}$ & $\mathrm{ND}$ & $\mathrm{Mn}$ & 1.03 & 0.964 \\
$\mathrm{As}$ & $\mathrm{ND}$ & $\mathrm{ND}$ & $\mathrm{Hg}$ & $\mathrm{ND}$ & $\mathrm{ND}$ \\
$\mathrm{Ba}$ & 0.576 & 0.409 & $\mathrm{Mo}$ & $\mathrm{ND}$ & $\mathrm{ND}$ \\
$\mathrm{Be}$ & $\mathrm{ND}$ & $\mathrm{ND}$ & $\mathrm{Ni}$ & $\mathrm{ND}$ & $\mathrm{ND}$ \\
$\mathrm{Cd}$ & $\mathrm{ND}$ & $\mathrm{ND}$ & $\mathrm{P}$ & 180 & 281 \\
$\mathrm{Ca}$ & 31.1 & 48.0 & $\mathrm{~K}$ & 828 & 811 \\
$\mathrm{Cr}$ & $\mathrm{ND}$ & $\mathrm{ND}$ & $\mathrm{Se}$ & $\mathrm{ND}$ & $\mathrm{ND}$ \\
$\mathrm{Co}$ & $\mathrm{ND}$ & $\mathrm{ND}$ & $\mathrm{Na}$ & $\mathrm{ND}$ & 4.12 \\
$\mathrm{Cu}$ & 0.0805 & 0.0975 & $\mathrm{Sr}$ & 0.779 & 0.787 \\
$\mathrm{Fe}$ & 0.63 & 0.844 & $\mathrm{~S}$ & 55.1 & 65.6 \\
$\mathrm{~Pb}$ & $\mathrm{ND}$ & $\mathrm{ND}$ & $\mathrm{V}$ & $\mathrm{ND}$ & $\mathrm{ND}$ \\
$\mathrm{Mg}$ & 58.6 & 63.0 & $\mathrm{Zn}$ & 0.222 & 0.172 \\
\hline
\end{tabular}

\section{Clay Mineralogy}

The Elk Cove, Five Mountain (loess/volcanic parent material) clays were very similar to the Clay Court (volcanic parent material) sample. The clay mineralogy was determined from the Bt3 horizon for this site. These two sites are both located in the Chehalem Mountain AVA at opposite ends, with Five Mountain in the northwest and Clay Court to the east. The original thought during the site selection was that Clay Court 
did not have an eolian loess component. The Five Mountain sample includes minor disordered kaolinite with dehydrated halloysite, moderate illite, and hydroxy interlayered smectite. The smectite was resistant to collapse because of $\mathrm{Fe}$ and $\mathrm{Al}$ as well as chlorite interlayers. This suggests moderate weathering or a mix of soil age based on constant input of loess as with the Clay Court sample. The quartz phase also included minor cristobalite, and the Fe phase was a mix of goethite and traces of hematite. 


\section{Chapter Five - Willakenzie Estate Winery Results}

\section{Volcanic Parent Material - The Jory Hills Vineyard, Block 50c Physical Characteristics}

The Jory Hills Vineyard is owned and operated by Willakenzie Estate Winery and located in Dundee, Oregon. This vineyard is planted on volcanic basalt bedrock, part of the Columbia River Basalt Group (Figure 2), and the soils are mapped as the Jory soil series but is more similar to a Nekia soil series because of the shallow bedrock. The Jory Hills Vineyard soil pit is located on the midslope of an east facing slope with vine rows running east and west (Lat. 45.287902 N, Long. -123.030467 W). The soil pit location was at 493 feet (150 meters) elevation between rows 69 and 70 (Figure 13). The vines are Pinot Noir Dijon 115 clone planted in 2002 and are trellised as bilateral cordon in vertical shoot position. The vines here were grafted onto 101-14 rootstock (Table 8).

The Jory soil is characterized as a Xeric Palehumult, and the Nekia soil is a Xeric Haplohumult. The soil pit was $43+\mathrm{cm}$ deep with refusal caused by greater than $75 \%$ rock fragments. The bedrock and parent material is the Columbia River Basalt Group (Figure 2). The silt content of this soil pit remains fairly constant with depth ranging from $46 \%$ (Ap) to 38\% (Bt2). Dry color for the Ap and Bt1 horizons are brown (7.5 YR 4/4), Bt2 and $\mathrm{Bt} 3$ are yellowish red (5 YR 4/6). 


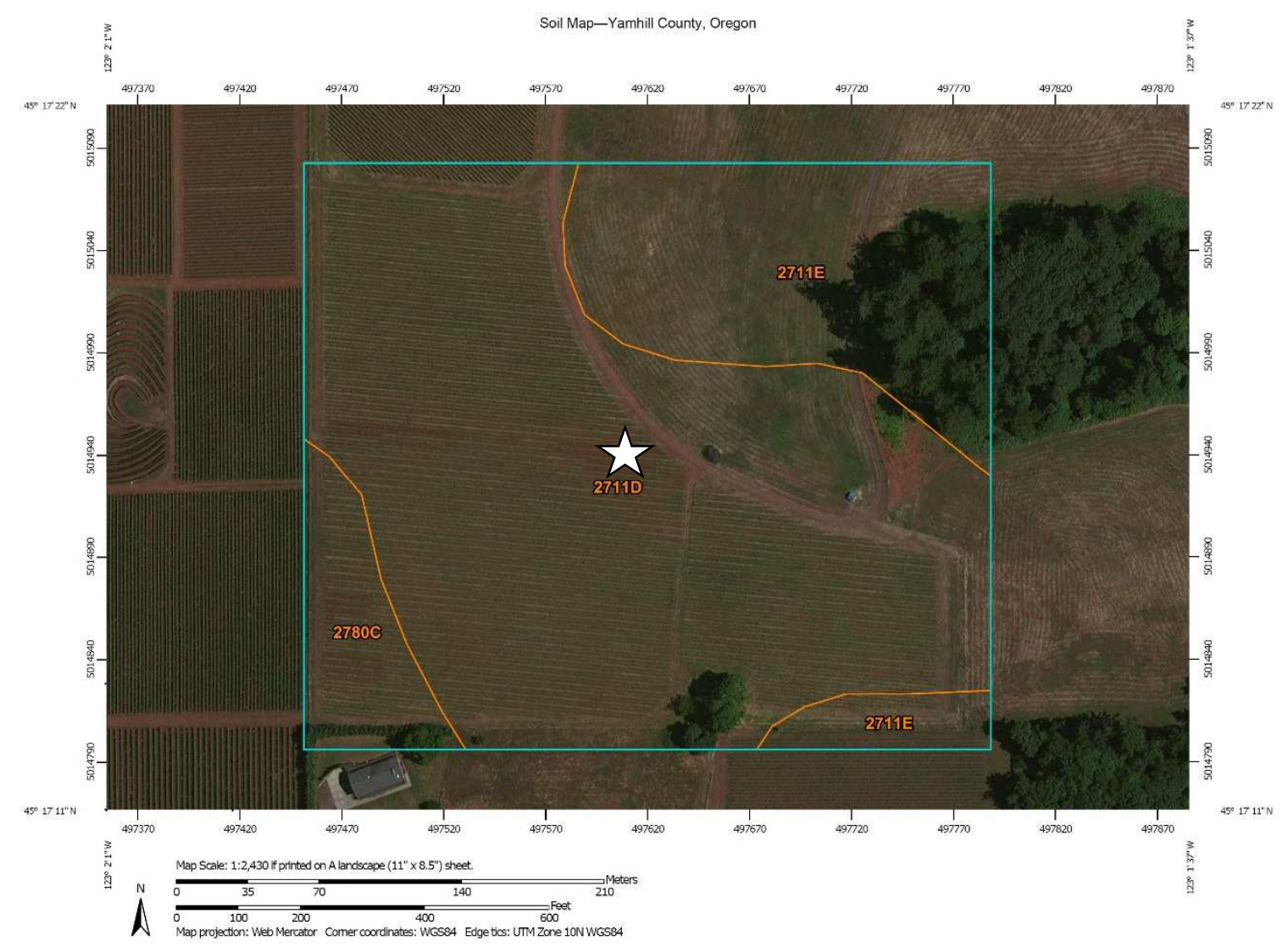

Figure 13. Soil map of Willakenzie Estate Winery, The Jory Hills Vineyard Block 50c. Pit location marked. 2711D - Jory silty clay loam, 12 to 20 percent slopes. $2711 \mathrm{E}$ - Jory silty clay loam, 20 to 30 percent slopes. $2780 \mathrm{C}$ - Jory-Gelderman silty clay loams, 2 to 12 percent slopes (NRCS, 2015).

Textures are silty clay loam and silty clay at depth. Structures for the soil profile are weak, very fine to medium subangular blocky (Figure 14). The Ap horizon is sticky and plastic, and the Bt1 and Bt2 horizons are very sticky and very plastic. Clay percent increases with depth from $34 \%$ in the Ap to $46 \%$ in Bt2. Clay films located on ped faces are common and distinct in the $\mathrm{Bt} 1$ and $\mathrm{Bt} 2$ horizons. Pisolites are common throughout the soil profile, and most abundant in the Ap horizon. Even though this soil is mapped as the Jory soil series, this soil pit was very shallow to bedrock and technically is classified 
as the Nekia soil series. For this study it has been grouped with the Jory Series since they are the same with the exception of depth to bedrock. I could have dug the pit one row over and found Jory soil. The $\mathrm{pH}$ decreases with depth and the CEC slightly increases in the Bt1 horizon. OM ranges from $9.8 \%$ to $10.7 \%$ (Table 22 ).

Table 22. Willakenzie Estate Winery, The Jory Hills Vineyard Block 50c field and lab data.

\begin{tabular}{|c|c|c|c|c|c|c|}
\hline \multirow{3}{*}{$\begin{array}{l}\text { Depth } \\
\text { (cm) }\end{array}$} & \multirow{3}{*}{ Horizon } & \multicolumn{3}{|c|}{ Total } & \multirow[b]{2}{*}{$\begin{array}{c}\text { Coarse } \\
\text { Fragment } \\
(>2 \mathrm{~mm})\end{array}$} & \multirow{3}{*}{$\begin{array}{c}\text { Texture } \\
\text { Lab }\end{array}$} \\
\hline & & $\begin{array}{c}\text { Sand } \\
(2-0.05 \\
\mathrm{mm})\end{array}$ & $\begin{array}{c}\text { Silt } \\
(0.05-0.002 \\
\text { mm) }\end{array}$ & $\begin{array}{c}\text { Clay } \\
(<0.002 \text { mm) }\end{array}$ & & \\
\hline & & \multicolumn{4}{|c|}{ 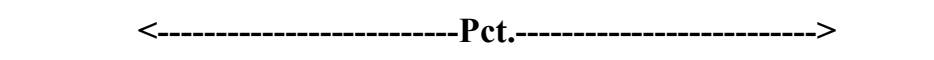 } & \\
\hline $0-18$ & Ap & 17.4 & 46.0 & 34.1 & 0.9 & $\mathrm{SiCL}$ \\
\hline $18-33$ & Bt1 & 16.4 & 44.5 & 37.4 & 0.8 & $\mathrm{SiCL}$ \\
\hline $33-43$ & Bt2 & 7.8 & 37.9 & 46.5 & 0.6 & $\mathrm{SiC}$ \\
\hline $43+$ & $\mathrm{Cr}$ & 11.1 & 41.4 & 40.6 & 28.2 & $\mathrm{SiC}$ \\
\hline $\begin{array}{l}\text { Depth } \\
\text { (cm) }\end{array}$ & Horizon & Dry Color & Structure & $\begin{array}{c}\text { Organic } \\
\text { Matter } \\
\text { LOI (Pct.) }\end{array}$ & $\begin{array}{c}\text { pH } \\
\left(1: 1 \mathbf{H}_{2} \mathrm{O}\right)\end{array}$ & $\begin{array}{c}\text { CEC } \\
(\mathrm{meq} / 100 \mathrm{~g})\end{array}$ \\
\hline $0-18$ & Ap & $7.5 Y R 4 / 4$ & $1, \mathrm{f}, \mathrm{sbk}$ & 10.7 & 5.6 & 14.4 \\
\hline $18-33$ & Bt1 & $7.5 \mathrm{YR} 4 / 4$ & $1, \mathrm{~m}, \mathrm{sbk}$ & 9.8 & 5.5 & 15.4 \\
\hline $33-43$ & $\mathrm{Bt} 2$ & $5 \mathrm{YR} 4 / 6$ & $1, \mathrm{vf}, \mathrm{sbk}$ & 10.4 & 5.2 & 14.6 \\
\hline $43+$ & $\mathrm{Cr}$ & $5 Y R 4 / 6$ & & & & \\
\hline
\end{tabular}



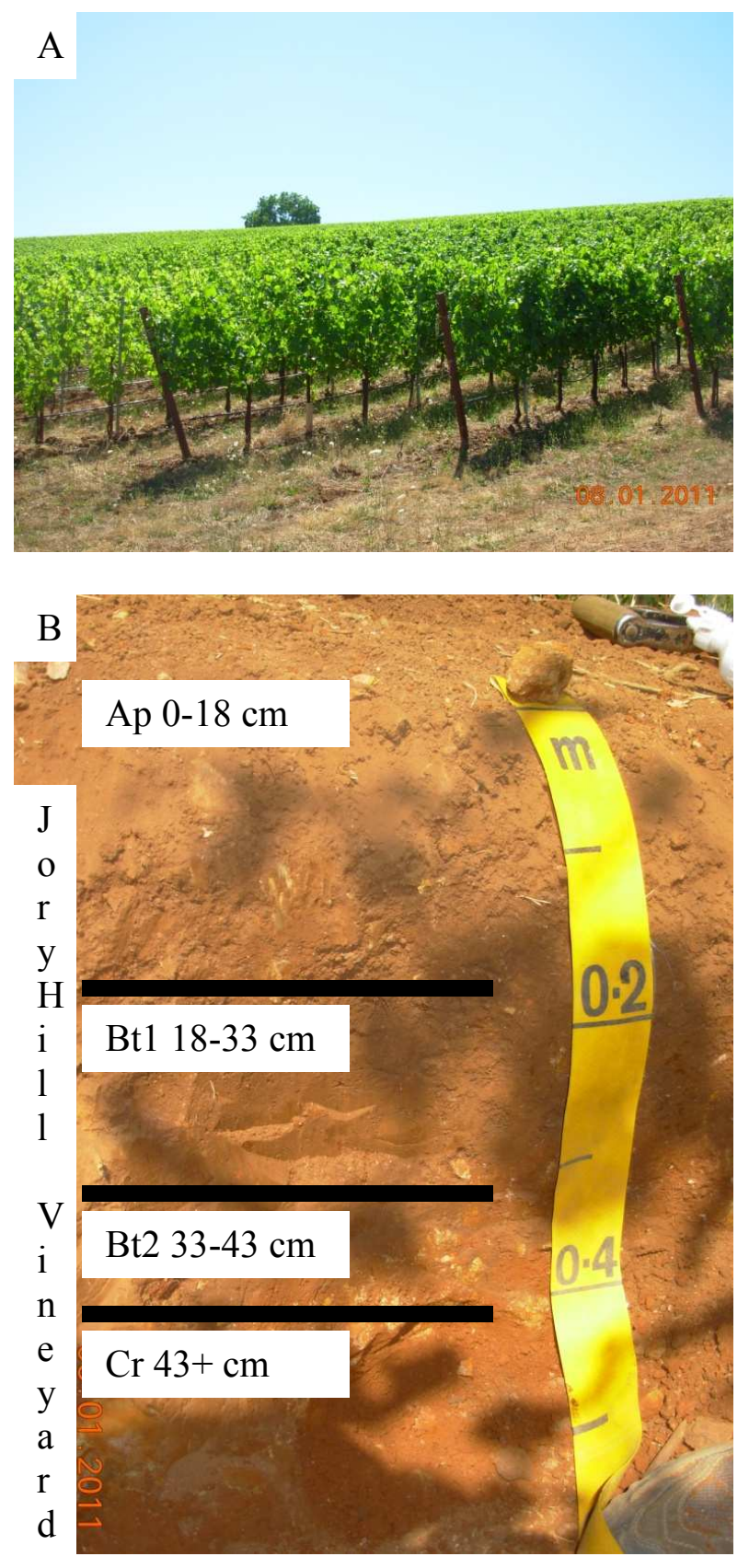

Figure 14. Sample soil pit at Willakenzie Estate Winery, The Jory Hills Vineyard Block 50c. A View of sample location, facing southwest. B - Picture of the face of the soil pit with horizon depths and boundaries marked. 


\section{Soil Chemistry}

The Jory Hills Vineyard soil pit was separated into four horizons and the macronutrient (P, K, C, Mg, and S) concentrations are reported below (Table 10). This soil pit is one of the shallowest in this study at only $43 \mathrm{~cm}$. The maximum concentrations of $\mathrm{K}, \mathrm{Ca}$, and $\mathrm{Mg}$ are in the Ap horizon. $\mathrm{K}, \mathrm{Ca}$, and $\mathrm{Mg}$ decrease with depth. There is little trend in $\mathrm{P}$ concentrations. The maximum concentration of $\mathrm{P}$ is in the $\mathrm{Bt} 1$ horizon, and there is little trend in this profile for this element. $\mathrm{Cl}$ is only detected in the two lower horizons, the $\mathrm{Bt} 2$ and $\mathrm{Cr}$ horizons.

The micronutrient concentrations measured in the soil horizons from the Jory Hills Vineyard mostly reach a maximum concentration in the Bt1 horizon. Fe and Al bulge in the $\mathrm{Bt} 2$ horizon, decreasing with depth. $\mathrm{Co}, \mathrm{Cu}, \mathrm{Mn}, \mathrm{Ni}$ and $\mathrm{Zn}$ have a bulge in the Bt1 horizon. Na increases with depth. Mo is below detections limits. Trace element concentrations, with maximum concentrations are shown in bold, for The Jory Hills Vineyard are reported. $\mathrm{Ba}, \mathrm{Be}, \mathrm{Cr}, \mathrm{Sr}$, ad $\mathrm{V}$ have variable concentrations throughout the profile with the maximum concentration in the $\mathrm{Cr}$ horizon. $\mathrm{Hg}$ and $\mathrm{Se}$ are below detection limits. As and $\mathrm{Pb}$ both are highest in the Ap and Bt1 horizons and decrease with depth. Cd decreases with depth with the maximum concentration in the Ap horizon. 
Table 23. Macronutrient, micronutrient and trace element concentrations (all values in $\mathrm{mg} / \mathrm{kg}$ ) for the Willakenzie Estate Winery, The Jory Hills Vineyard, Block 50c soil pit (ND - Non-detectable).

\begin{tabular}{|c|c|c|c|c|c|c|c|c|c|c|}
\hline Horizon (cm) & \multicolumn{2}{|l|}{$\mathbf{P}$} & $\mathbf{K}$ & \multicolumn{2}{|l|}{$\mathbf{C a}$} & Mg & \multicolumn{3}{|c|}{$\mathbf{S}$} & $\mathbf{C l}$ \\
\hline Ap $(0-18)$ & \multicolumn{2}{|l|}{1530} & 685 & \multicolumn{2}{|l|}{1110} & 951 & \multicolumn{3}{|c|}{182} & ND \\
\hline Bt1 (18-33) & \multicolumn{2}{|l|}{1580} & 510 & \multicolumn{2}{|l|}{994} & 922 & \multicolumn{3}{|c|}{196} & ND \\
\hline Bt2 (33-43) & \multicolumn{2}{|l|}{1140} & 111 & \multicolumn{2}{|l|}{375} & 188 & \multicolumn{3}{|c|}{194} & 10.0 \\
\hline $\mathrm{Cr}(43+)$ & \multicolumn{2}{|l|}{1560} & 60.3 & \multicolumn{2}{|l|}{302} & 79.5 & \multicolumn{3}{|c|}{274} & 17.6 \\
\hline Mean & \multicolumn{2}{|l|}{1450} & 342 & \multicolumn{2}{|l|}{695} & 535 & \multicolumn{3}{|c|}{212} & 13.8 \\
\hline$S D$ & \multicolumn{2}{|l|}{209} & 305 & \multicolumn{2}{|l|}{416} & 466 & \multicolumn{3}{|c|}{42.1} & 5.37 \\
\hline Maximum & \multicolumn{2}{|l|}{1580} & 685 & \multicolumn{2}{|l|}{1110} & 951 & \multicolumn{3}{|c|}{274} & 17.6 \\
\hline Horizon (cm) & $\mathbf{F e}$ & Al & Co & $\mathbf{C u}$ & Mn & Mo & $\mathbf{N a}$ & & i & $\mathbf{Z n}$ \\
\hline Ap (0-18) & 55800 & 17900 & 23.0 & 18.0 & 2060 & ND & 160 & & 61 & 47.1 \\
\hline Bt1 (18-33) & 55300 & 18000 & 28.4 & 19.8 & 2580 & ND & 171 & & 76 & 47.9 \\
\hline Bt2 (33-43) & 60000 & 19100 & 12.8 & 19.5 & 524 & ND & 175 & & 31 & 24.9 \\
\hline $\mathrm{Cr}(43+)$ & 48100 & 10900 & 22.8 & 13.1 & 380 & ND & 206 & & 73 & 22.4 \\
\hline Mean & 54800 & 16500 & 21.8 & 17.6 & 1390 & $N D$ & 178 & & 23 & 35.6 \\
\hline$S D$ & 4940 & 3760 & 6.51 & 3.10 & 1100 & $N D$ & 19.7 & & 37 & 13.8 \\
\hline Maximum & 60000 & 19100 & 28.4 & 19.8 & 2580 & $N D$ & 206 & & 76 & 47.9 \\
\hline Horizon (cm) & As & $\mathbf{B a}$ & $\mathrm{Be}$ & Cd & $\mathrm{Cr}$ & Hg & $\mathbf{P b}$ & Se & $\mathrm{Sr}$ & $\mathbf{V}$ \\
\hline Ap $(0-18)$ & 1.59 & 202 & 0.781 & 0.346 & 24.1 & ND & 11.4 & ND & 14.7 & 153 \\
\hline Bt1 (18-33) & 1.62 & 195 & 0.808 & 0.308 & 23.3 & ND & 11.4 & ND & 13.4 & 150 \\
\hline Bt2 (33-43) & 0.566 & 168 & 0.734 & 0.252 & 29.0 & ND & 7.31 & ND & 5.87 & 127 \\
\hline $\mathrm{Cr}(43+)$ & ND & 430 & 0.910 & 0.219 & 31.8 & ND & 8.57 & ND & 15.4 & 195 \\
\hline Mean & 1.26 & 249 & 0.808 & 0.281 & 27.1 & $N D$ & 9.67 & $N D$ & 12.3 & 156 \\
\hline$S D$ & 0.600 & 122 & 0.0744 & 0.0567 & 4.05 & $N D$ & 2.06 & $N D$ & 4.39 & 28.3 \\
\hline Maximum & 1.62 & 430 & 0.910 & 0.346 & 31.8 & $N D$ & 11.4 & $N D$ & 15.4 & 195 \\
\hline
\end{tabular}

\section{Grape Juice Chemistry}

The grape juice samples have concentrations of many elements that are below detection limits in this study, as seen in Table 24. All 24 elements were analyzed for in the grape juice from grapes collected adjacent to the soil pits. These elements include Al, 
As, Ba, Be, Cd, Ca, Cr, Co, Cu, Fe, Pb, Mg, Mn, Hg, Mo, Ni, P, K, Se, Na, Sr, S, V, and Zn. $\mathrm{K}, \mathrm{Na}$, and $\mathrm{Sr}$ are the only elements found in all 20 grape juice samples and $\mathrm{P}$ is detected in 15 of the 20 sites. The concentrations of $\mathrm{K}$ and $\mathrm{Na}$ in The Jory Hills grape juice are $1150 \mathrm{mg} / \mathrm{kg}$ and $141 \mathrm{mg} / \mathrm{kg}$, respectively. Sr concentration, one of only three elements found in all grape juice samples, is measured as $0.506 \mathrm{mg} / \mathrm{kg}$, which is the $18^{\text {th }}$ highest concentration of $\mathrm{Sr}$ for the 20 vineyard samples (Table 105). Mean $\mathrm{Sr}$ concentration for all grape juice samples from the 20 different sites is $0.805 \pm 0.261$ $\mathrm{mg} / \mathrm{kg}$. P concentration is $275 \mathrm{mg} / \mathrm{kg}$ and $\mathrm{Mn}$ is measured as $2.14 \mathrm{mg} / \mathrm{kg}$ for this sample. $\mathrm{Mn}$ is measured only in grape juice from The Jory Hills, Five Mountain, Stoller, and Sims Vineyards.

Table 24. Elemental concentrations measured by ICP-MS in the grape juice from clusters collected from vines immediately adjacent to the soil pit location at Willakenzie Estate Winery, The Jory Hills Vineyard, Block 50c (ND - Non-detectable).

\begin{tabular}{cccccccccc}
\hline Element & Sr & $\mathbf{P}$ & $\mathbf{K}$ & $\mathbf{N a}$ & $\mathbf{M g}$ & $\mathbf{M n}$ & $\mathbf{C a}$ & $\mathbf{C u}$ & $\mathbf{Z n}$ \\
\hline \hline $\begin{array}{c}\text { Grape Juice } \\
(\mathrm{mg} / \mathrm{kg})\end{array}$ & 0.506 & 275 & 1150 & 141 & ND & 2.14 & ND & ND & ND \\
\hline
\end{tabular}

\section{Wine Chemistry}

Willakenzie Estate Winery provided a $750 \mathrm{ml}$ sample of the wine produced from each vineyard in 2011. The unblended wine was stored until sensory analysis could take place during the winter of 2014. As noted in the previous results chapter of Elk Cove Vineyards, the concentrations of many of the 24 elements tested in the wine (same as the elements tested in the soil samples) were below detection limits. The 14 elements that 
were detected in The Jory Hills wine sample include $\mathrm{Ba}, \mathrm{Ca}, \mathrm{Co}, \mathrm{Cu}, \mathrm{Fe}, \mathrm{Pb}, \mathrm{Mg}, \mathrm{Mn}, \mathrm{P}$, $\mathrm{K}, \mathrm{Na}, \mathrm{Sr}, \mathrm{S}$, and Zn (Table 25).

Table 25. Elemental concentrations measured by ICP-MS of a $750 \mathrm{ml}$ unblended wine sample from the 2011 Willakenzie Estate Winery, The Jory Hills Vineyard (ND - Non-detectable).

\begin{tabular}{cccc}
\hline Element & 2011 Wine Sample (mg/kg) & Element & 2011 Wine Sample (mg/kg) \\
\hline \hline $\mathrm{Al}$ & $\mathrm{ND}$ & $\mathrm{Mn}$ & 1.3 \\
$\mathrm{As}$ & $\mathrm{ND}$ & $\mathrm{Hg}$ & $\mathrm{ND}$ \\
$\mathrm{Ba}$ & 0.464 & $\mathrm{Mo}$ & $\mathrm{ND}$ \\
$\mathrm{Be}$ & $\mathrm{ND}$ & $\mathrm{Ni}$ & $\mathrm{ND}$ \\
$\mathrm{Cd}$ & $\mathrm{ND}$ & $\mathrm{P}$ & 187 \\
$\mathrm{Ca}$ & 51.6 & $\mathrm{~K}$ & 818 \\
$\mathrm{Cr}$ & $\mathrm{ND}$ & $\mathrm{Se}$ & $\mathrm{ND}$ \\
$\mathrm{Co}$ & $\mathrm{Na}$ & 4.5 \\
$\mathrm{Cu}$ & 0.031 & $\mathrm{Sr}$ & 0.954 \\
$\mathrm{Fe}$ & 0.0272 & $\mathrm{~S}$ & 72.7 \\
$\mathrm{~Pb}$ & 0.645 & $\mathrm{~V}$ & $\mathrm{ND}$ \\
$\mathrm{Mg}$ & 0.0615 & $\mathrm{Zn}$ & 0.164 \\
\hline
\end{tabular}

The highest concentrations include K $(818 \mathrm{mg} / \mathrm{kg}), \mathrm{P}(187 \mathrm{mg} / \mathrm{kg}), \mathrm{S}(72.7$

$\mathrm{mg} / \mathrm{kg}), \mathrm{Ca}(51.6 \mathrm{mg} / \mathrm{kg})$, and $\mathrm{Mg}(40.6 \mathrm{mg} / \mathrm{kg})$. Na concentration is $4.5 \mathrm{mg} / \mathrm{kg}$ for this wine sample and $\mathrm{Mn}$ is $1.3 \mathrm{mg} / \mathrm{kg}$. Concentrations in descending order for the rest of the elements tested are $\mathrm{Sr}(0.954 \mathrm{mg} / \mathrm{kg}), \mathrm{Fe}(0.645 \mathrm{mg} / \mathrm{kg}), \mathrm{Ba}(0.464 \mathrm{mg} / \mathrm{kg})$, and Zn $(0.164$ $\mathrm{mg} / \mathrm{kg})$. Trace amounts of $\mathrm{Pb}(0.0615 \mathrm{mg} / \mathrm{kg}), \mathrm{Co}(0.0272 \mathrm{mg} / \mathrm{kg})$, and $\mathrm{Cu}(0.031 \mathrm{mg} / \mathrm{kg})$ were also measured in The Jory Hills wine sample. 


\section{Clay Mineralogy}

The Jory Hills clay mineral assemblage from the Bt2 horizon is similar to the Elk Cove, Five Mountain (loess/volcanic parent material) and Chehalem, Stoller Vineyards (volcanic parent material). Moderate kaolinite and minor dehydrated halloysite are the main clays present. There is minor illite in this sample and minor chlorite intergrade clays are present but are non-expansive. Vermiculite is not present. There are minor amounts of cristobalite, and abundant goethite as the main Fe phase with minor gibbsite.

\section{Marine Sediment Parent Material - Aliette Vineyard, Block 2b Physical Characteristics}

Aliette Vineyard is owned and operated by Willakenzie Estate Winery and also located in Yamhill, Oregon. This vineyard is planted on sandstone bedrock associated with the marine sedimentary rocks of the Coast Range. This sandstone is most likely the Spencer Formation (Figure 2), and the soil is Melbourne - Goodin soil series (previously mapped as Willakenzie soil series). Aliette Vineyard is located on the upland of a south facing slope with vine rows running north and south (Lat. $45.364343 \mathrm{~N}$, Long. 123.133329 W). The soil pit location was at 604 feet (185 meters) elevation between rows 35 and 36 (Figure 15). According to the vineyard manager, this vineyard has permanent fescue cover between rows. The vines are Pinot Noir Pommard clone planted in 1992 and are trellised as bilateral cordon in vertical shoot position. The vines here were grafted onto $5 \mathrm{C}$ rootstock (Table 8 ). 


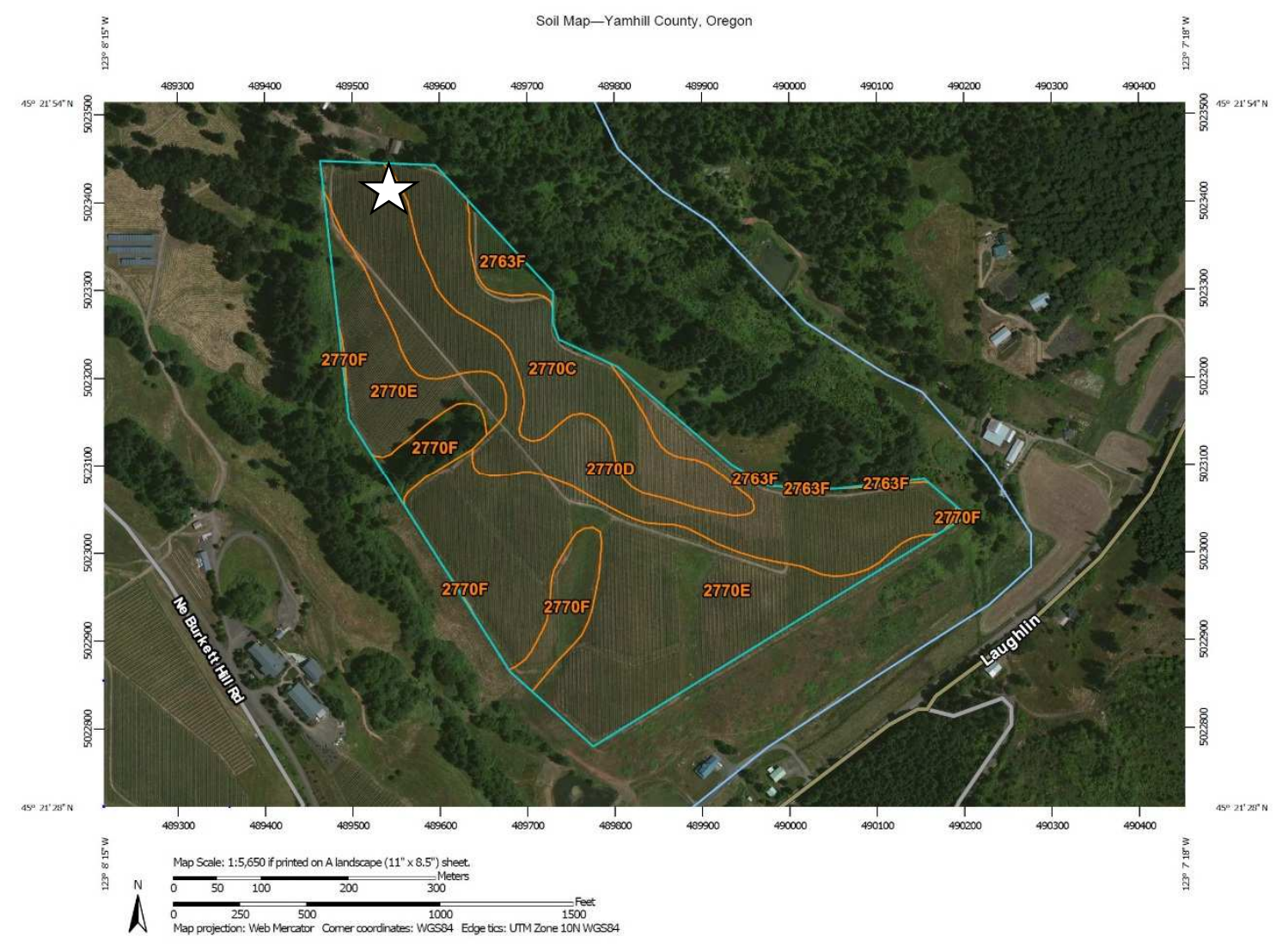

Figure 15. Soil map of Willakenzie Estate Winery, Aliette Vineyard Block 2b. Pit location marked. 2770C - Melbourne-Goodin silt loams, 2 to 12 percent slopes. 2770D - Melbourne-Goodin silt loams, 12 to 20 percent slopes. $2770 \mathrm{E}$ - Melbourne-Goodin silt loams, 20 to 30 percent slopes. 2770F Melbourne-Goodin silt loams, 30 to 60 percent slopes. 2763F - Willakenzie-Sitton complex, 30 to 75 percent slopes (NRCS, 2015). Previously mapped as WeC - Willakenzie silty clay loam, 2 to 12 percent slopes (NRCS, 2014).

The Melbourne - Goodin soil is characterized as an Ultic Palexeralf - Ultic Haploxeralf. The soil pit was $150+\mathrm{cm}$ deep without refusal. The silt content of this soil pit decreases with depth from $42 \%$ (Ap) to $23 \%(\mathrm{Bt} 3)$. The $\mathrm{pH}$ is consistent at 5.8. CEC decreases with depth with a bulge in the Bt1 horizon. OM ranges from 5.9\% to $9.4 \%$ (Table 26). Textures are loam, clay loam, and clay at depth. Structures for the soil profile 
are moderate medium subangular blocky. The Ap horizon is slightly sticky and slightly plastic, and all Bt horizons are very sticky and very plastic. Clay percent increases with depth from $18 \%$ in the Ap to $47 \%$ in Bt3. Clay films located on ped faces are few to common and faint to distinct in the $\mathrm{AB}, \mathrm{Bt} 1, \mathrm{Bt} 2$, and $\mathrm{Bt} 3$ horizons. The presence of

Table 26. Willakenzie Estate Winery, Aliette Vineyard Block 2b field and lab data.

\begin{tabular}{|c|c|c|c|c|c|c|}
\hline \multirow{3}{*}{$\begin{array}{l}\text { Depth } \\
\text { (cm) }\end{array}$} & \multirow{3}{*}{ Horizon } & \multicolumn{3}{|c|}{ Total } & \multirow[b]{2}{*}{$\begin{array}{c}\text { Coarse } \\
\text { Fragment } \\
(>2 \mathrm{~mm})\end{array}$} & \multirow{3}{*}{$\begin{array}{c}\text { Texture } \\
\text { Lab }\end{array}$} \\
\hline & & $\begin{array}{l}\text { Sand } \\
(2-0.05 \\
\text { mm) }\end{array}$ & $\begin{array}{c}\text { Silt } \\
(0.05-0.002 \\
\text { mm })\end{array}$ & $\begin{array}{c}\text { Clay } \\
(<0.002 \mathrm{~mm})\end{array}$ & & \\
\hline & & \multicolumn{4}{|c|}{ 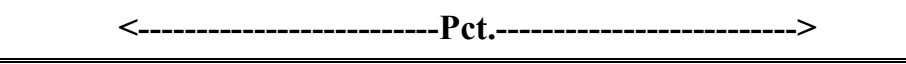 } & \\
\hline $0-26$ & A & 38.8 & 42.0 & 18.0 & 0.0 & $\mathrm{~L}$ \\
\hline $26-35$ & $\mathrm{AB}$ & 40.0 & 38.7 & 21.6 & 0.0 & $\mathrm{~L}$ \\
\hline $35-100$ & Bt1 & 28.7 & 32.7 & 38.4 & 0.0 & $\mathrm{CL}$ \\
\hline $100-150$ & Bt2 & 29.4 & 24.4 & 43.4 & 0.2 & $\mathrm{C}$ \\
\hline $150+$ & Bt3 & 28.5 & 22.6 & 47.1 & 0.0 & $\mathrm{C}$ \\
\hline $\begin{array}{l}\text { Depth } \\
\text { (cm) }\end{array}$ & Horizon & Dry Color & Structure & $\begin{array}{c}\text { Organic } \\
\text { Matter } \\
\text { LOI (Pct.) } \\
\end{array}$ & $\begin{array}{c}\mathrm{pH} \\
\left(1: 1 \mathrm{H}_{2} \mathrm{O}\right) \\
\end{array}$ & $\begin{array}{c}\text { CEC } \\
(\mathbf{m e q} / 100 \mathrm{~g})\end{array}$ \\
\hline $0-26$ & A & 10YR 5/4 & $2, \mathrm{~m}, \mathrm{sbk}$ & 8.0 & 5.9 & 15.9 \\
\hline $26-35$ & $\mathrm{AB}$ & $10 \mathrm{YR} 5 / 4$ & $2, \mathrm{~m}, \mathrm{sbk}$ & 5.9 & 5.8 & 12.9 \\
\hline $35-100$ & Bt1 & 10YR 4/6 & $2, \mathrm{~m}, \mathrm{sbk}$ & 7.3 & 5.8 & 17.5 \\
\hline $100-150$ & Bt2 & 7.5YR 4/6 & $2, \mathrm{~m}, \mathrm{sbk}$ & 7.4 & 5.8 & 14.9 \\
\hline $150+$ & Bt3 & $5 \mathrm{YR} 4 / 6$ & $2, \mathrm{~m}, \mathrm{sbk}$ & 9.4 & 5.8 & \\
\hline
\end{tabular}

muscovite mica and quartz sand in the lower horizons originates from the sandstone and siltstone bedrock here. There are no pisolites in this profile. Dry colors for the $\mathrm{A} / \mathrm{E}$ and $\mathrm{AB}$ is yellowish brown (10 YR 5/4), Bt1 is dark yellowish brown (10 YR 4/6) and Bt2 and Bt3 were both strong brown (7.5 YR 4/6 and 5 YR 4/6) (Figure 16). 

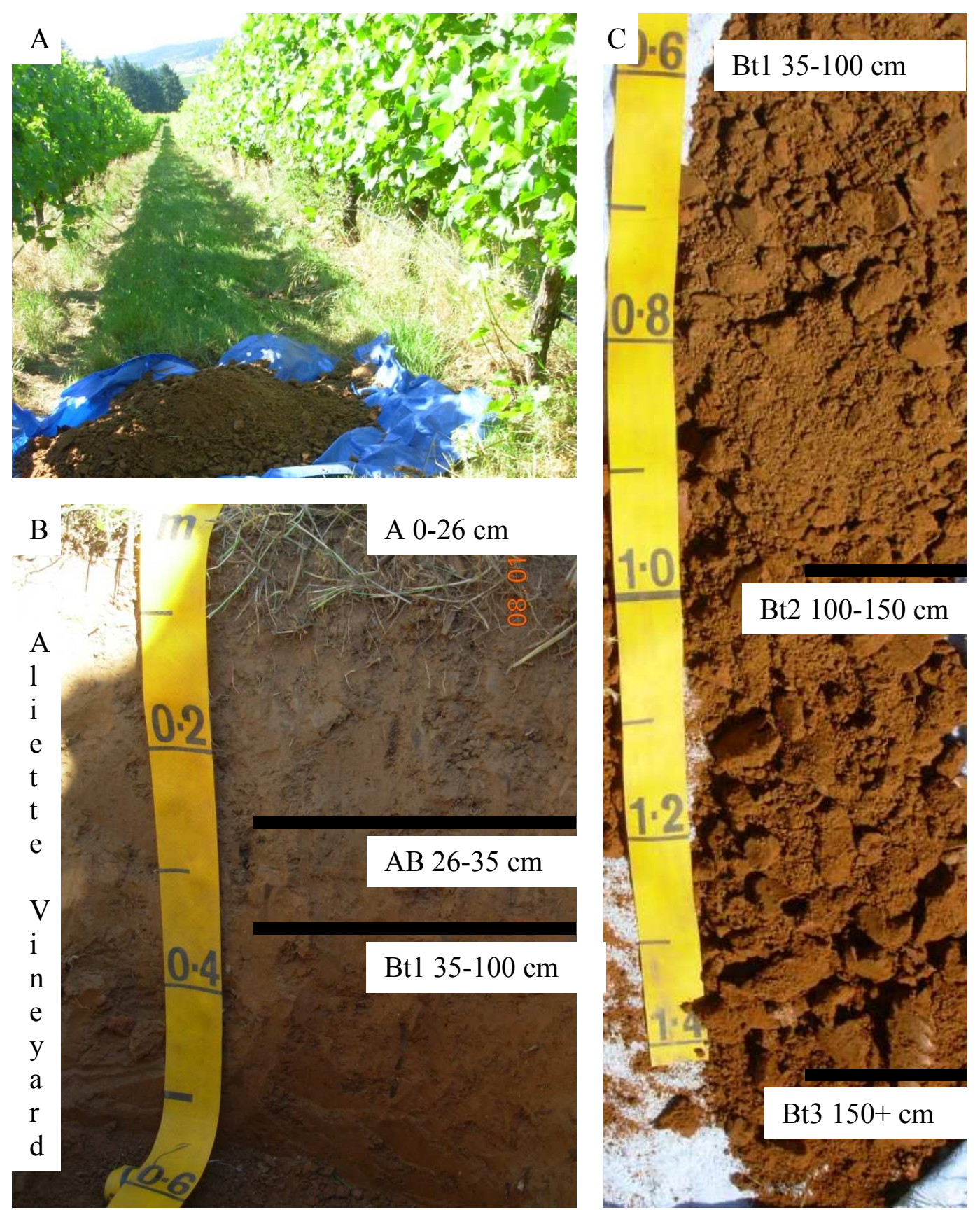

Figure 16. Sample soil pit at Willakenzie Estate Winery, Aliette Vineyard Block 2b. A - View of sample location, facing south. $B$ - Picture of the face of the soil pit with horizon depths and boundaries marked. $\mathrm{C}$ - Soil retrieved using a hand auger with horizon depths and boundaries marked. 


\section{Soil Chemistry}

The Aliette Vineyard soil pit was separated into five horizons and each was analyzed for the macronutrient concentrations (Table 27). The maximum concentrations of $\mathrm{P}, \mathrm{Ca}$, and $\mathrm{S}$ are in the Ap horizon. $\mathrm{P}$ decreases with depth with a slight bulge in the $\mathrm{Bt} 2$ horizon. $\mathrm{K}$ concentration is highest in the $\mathrm{AB}$ horizon and then decreases with depth. $\mathrm{Ca}$ decreases with depth and has a slight bulge in the Btl horizon. $\mathrm{Mg}$ increases from the surface to the Bt1 horizon then decreases before reaching a maximum in the Bt3 horizon. $\mathrm{S}$ is highest in the $\mathrm{A} / \mathrm{E}$ horizon then decreases with depth and until it is not detected in the Bt2 horizon.

The micronutrient concentrations measured in the five soil horizons from the Aliette Vineyard are highest in the Ap horizon or in the Bt1 horizon. Fe concentration increases with the maximum in the Bt 3 horizon. Al increases with depth similarly to Fe. Co concentration is highest in the $\mathrm{Bt} 1$ horizon. $\mathrm{Cu}$ values are variable with the highest in the A/E horizon. Mn constantly decreases with depth. Na and Zn decrease with depth with a bulge in the $\mathrm{Bt} 2$ horizon. $\mathrm{Ni}$ is highest in the Bt1 horizon. Mo is non-detectable in the profile. Trace element concentrations for the five horizons of the Aliette Vineyard are reported. $\mathrm{As}, \mathrm{Pb}$, and $\mathrm{V}$ concentrations are highest in the $\mathrm{Bt} 1$ horizon. $\mathrm{Ba}, \mathrm{Cd}$, and $\mathrm{Sr}$ all have maximum concentrations in the $\mathrm{A} / \mathrm{E}$ horizon, decrease with depth, and then have a bulge at the bottom of the profile. Be and $\mathrm{Cr}$ increase with depth. $\mathrm{Hg}$ and Se were not detected in the profile. 
Table 27. Macronutrient, micronutrient and trace element concentrations (all values in $\mathrm{mg} / \mathrm{kg}$ ) for the Willakenzie Estate Winery, Aliette Vineyard, Block 2b soil pit (ND - Non-detectable).

\begin{tabular}{|c|c|c|c|c|c|c|c|c|c|c|}
\hline Horizon (cm) & $\mathbf{P}$ & \multicolumn{2}{|r|}{$\mathbf{K}$} & \multicolumn{2}{|l|}{$\mathrm{Ca}$} & Mg & \multicolumn{3}{|c|}{$\mathbf{S}$} & Cl \\
\hline $\mathrm{A} / \mathrm{E}(0-26)$ & \multicolumn{2}{|l|}{594} & 1020 & \multicolumn{2}{|l|}{2240} & 1020 & \multicolumn{3}{|c|}{245} & ND \\
\hline $\mathrm{AB}(26-35)$ & \multicolumn{2}{|l|}{497} & 1030 & \multicolumn{2}{|l|}{1290} & 1220 & \multicolumn{3}{|c|}{128} & ND \\
\hline Bt1 (35-100) & \multicolumn{2}{|l|}{413} & 667 & \multicolumn{2}{|l|}{1340} & 1250 & \multicolumn{3}{|c|}{99.8} & ND \\
\hline Bt2 (100-150) & \multicolumn{2}{|l|}{445} & 542 & \multicolumn{2}{|l|}{1190} & 960 & \multicolumn{3}{|c|}{ ND } & ND \\
\hline Bt3 (150+) & \multicolumn{2}{|l|}{477} & 586 & \multicolumn{2}{|l|}{1160} & 1390 & \multicolumn{3}{|c|}{ ND } & ND \\
\hline Mean & \multicolumn{2}{|l|}{485} & 769 & \multicolumn{2}{|l|}{1440} & 1170 & \multicolumn{3}{|c|}{158} & $N D$ \\
\hline$S D$ & \multicolumn{2}{|l|}{68.7} & 238 & 451 & & 176 & & 0 & & $N D$ \\
\hline Maximum & 594 & & 1030 & 2240 & & 1390 & & 5 & & $N D$ \\
\hline Horizon (cm) & $\mathrm{Fe}$ & Al & Co & $\mathrm{Cu}$ & Mn & Mo & $\mathbf{N a}$ & & i & $\mathbf{Z n}$ \\
\hline $\mathrm{A} / \mathrm{E}(0-26)$ & 17500 & 6600 & 9.63 & 17.0 & 751 & ND & 188 & & 42 & 33.8 \\
\hline $\mathrm{AB}(26-35)$ & 20300 & 8340 & 9.74 & 10.1 & 717 & ND & 148 & & 4 & 31 \\
\hline Bt1 (35-100) & 29500 & 14400 & 12.0 & 16.9 & 337 & ND & 145 & & 0 & 29.8 \\
\hline Bt2 (100-150) & 27600 & 11700 & 3.54 & 12.3 & 116 & ND & 161 & & 79 & 22.7 \\
\hline Bt3 $(150+)$ & 32000 & 14400 & 2.59 & 12.2 & 69.6 & ND & 155 & & 3 & 26.7 \\
\hline Mean & 25400 & 11100 & 7.50 & 13.7 & 398 & $N D$ & 159 & & 95 & 28.8 \\
\hline$S D$ & 6200 & 3540 & 4.17 & 3.09 & 323 & $N D$ & 17.2 & & 61 & 4.26 \\
\hline Maximum & 32000 & 14400 & 12.0 & 17.0 & 751 & $N D$ & 188 & & 0 & 33.8 \\
\hline Horizon $(\mathrm{cm})$ & As & $\mathbf{B a}$ & $\mathbf{B e}$ & Cd & $\mathrm{Cr}$ & $\mathbf{H g}$ & $\mathbf{P b}$ & Se & $\mathrm{Sr}$ & $\mathbf{V}$ \\
\hline $\mathrm{A} / \mathrm{E}(0-26)$ & 3.46 & 125 & 0.389 & 0.233 & 12.6 & ND & 6.30 & ND & 18.4 & 34.0 \\
\hline AB (26-35) & 3.62 & 124 & 0.471 & ND & 14.5 & ND & 6.44 & ND & 9.81 & 39.1 \\
\hline Bt1 (35-100) & 4.92 & 65.4 & 0.589 & 0.116 & 17.7 & ND & 8.89 & ND & 13.1 & 59.4 \\
\hline Bt2 (100-150) & 2.86 & 74.3 & 0.682 & 0.119 & 17.2 & ND & 6.65 & ND & 14.2 & 50.9 \\
\hline $\mathrm{Bt3}(150+)$ & 3.67 & 92.5 & 0.711 & 0.138 & 19.4 & ND & 6.84 & ND & 17.4 & 55.0 \\
\hline Mean & 3.71 & 96.2 & 0.568 & 0.152 & 16.3 & $N D$ & 7.02 & $N D$ & 14.6 & 47.7 \\
\hline$S D$ & 0.751 & 27.6 & 0.137 & 0.0552 & 2.71 & $N D$ & 1.06 & $N D$ & 3.45 & 10.7 \\
\hline Maximum & 4.92 & 125 & 0.711 & 0.233 & 19.4 & $N D$ & 8.89 & $N D$ & 18.4 & 59.4 \\
\hline
\end{tabular}




\section{Grape Juice Chemistry}

The grape juice samples have concentrations of many elements that are below detection limits in this study (Table 28). All 24 elements, the same as were tested in the soil samples, were analyzed for in the grape juice from grapes collected adjacent to the soil pits. The concentrations of $\mathrm{K}$ and $\mathrm{Na}$ in Aliette Vineyard grape juice are $1680 \mathrm{mg} / \mathrm{kg}$ and $158 \mathrm{mg} / \mathrm{kg}$, respectively. Sr concentration, one of only three elements found in all grape juice samples, is measured as $0.716 \mathrm{mg} / \mathrm{kg}$, which is the $11^{\text {th }}$ highest concentration of Sr for the 20 vineyard samples (Table 105). Mean Sr concentration for all grape juice samples from the 20 different sites is $0.805 \pm 0.261 \mathrm{mg} / \mathrm{kg}$. P concentration is $267 \mathrm{mg} / \mathrm{kg}$ for these grapes.

Table 28. Elemental concentrations measured by ICP-MS in the grape juice from clusters collected from vines immediately adjacent to the soil pit location at Willakenzie Estate Winery, Aliette Vineyard, Block 2b (ND - Non-detectable).

\begin{tabular}{cccccccccc}
\hline Element & Sr & $\mathbf{P}$ & $\mathbf{K}$ & $\mathbf{N a}$ & $\mathbf{M g}$ & $\mathbf{M n}$ & $\mathbf{C a}$ & $\mathbf{C u}$ & $\mathbf{Z n}$ \\
\hline \hline $\begin{array}{c}\text { Grape Juice } \\
(\mathrm{mg} / \mathrm{kg})\end{array}$ & 0.716 & 267 & 1680 & 158 & ND & ND & ND & ND & ND \\
\hline
\end{tabular}

\section{Wine Chemistry}

Willakenzie Estate Winery provided a $750 \mathrm{ml}$ sample of the wine produced from the Aliette Vineyard in 2011. Many of the 24 elements tested in the wine (same as the elements tested in the soil samples) were below detection limits. The 14 elements that were detected in Aliette Vineyard wine sample include $\mathrm{Ba}, \mathrm{Ca}, \mathrm{Co}, \mathrm{Cu}, \mathrm{Fe}, \mathrm{Pb}, \mathrm{Mg}, \mathrm{Mn}$, P, K, Na, Sr, S, and Zn (Table 29). The highest concentrations in descending order 
include K (835 mg/kg), P (222 mg/kg), S (71.3 mg/kg), Ca (55.8 mg/kg), and Mg (47.9 $\mathrm{mg} / \mathrm{kg}$ ). Na concentration is $4.45 \mathrm{mg} / \mathrm{kg}$ for this wine sample and $\mathrm{Mn}$ is $0.995 \mathrm{mg} / \mathrm{kg}$. Concentrations for the rest of the elements, also in descending order, are $\mathrm{Sr}(1.21 \mathrm{mg} / \mathrm{kg})$, $\mathrm{Fe}(0.768 \mathrm{mg} / \mathrm{kg}), \mathrm{Ba}(0.439 \mathrm{mg} / \mathrm{kg})$, and $\mathrm{Zn}(0.333 \mathrm{mg} / \mathrm{kg})$. Trace amounts of $\mathrm{Pb}(0.061$ $\mathrm{mg} / \mathrm{kg}), \mathrm{Co}(0.0258 \mathrm{mg} / \mathrm{kg}$, and $\mathrm{Cu}(0.102 \mathrm{mg} / \mathrm{kg})$ were also measured in the Aliette Vineyard wine sample.

Table 29. Elemental concentrations measured by ICP-MS of a $750 \mathrm{ml}$ unblended wine sample from the 2011 Willakenzie Estate Winery, Aliette Vineyard (ND - Non-detectable).

\begin{tabular}{cccc}
\hline Element & 2011 Wine Sample (mg/kg) & Element & 2011 Wine Sample (mg/kg) \\
\hline \hline $\mathrm{Al}$ & $\mathrm{ND}$ & $\mathrm{Mn}$ & 0.995 \\
$\mathrm{As}$ & $\mathrm{ND}$ & $\mathrm{Hg}$ & $\mathrm{ND}$ \\
$\mathrm{Ba}$ & 0.439 & $\mathrm{Mo}$ & $\mathrm{ND}$ \\
$\mathrm{Be}$ & $\mathrm{ND}$ & $\mathrm{Ni}$ & $\mathrm{ND}$ \\
$\mathrm{Cd}$ & $\mathrm{ND}$ & $\mathrm{P}$ & 222 \\
$\mathrm{Ca}$ & 55.8 & $\mathrm{~K}$ & 835 \\
$\mathrm{Cr}$ & $\mathrm{ND}$ & $\mathrm{Se}$ & $\mathrm{ND}$ \\
$\mathrm{Co}$ & 0.0258 & $\mathrm{Na}$ & 4.45 \\
$\mathrm{Cu}$ & 0.102 & $\mathrm{Sr}$ & 1.21 \\
$\mathrm{Fe}$ & 0.768 & $\mathrm{~S}$ & 71.3 \\
$\mathrm{~Pb}$ & 0.061 & $\mathrm{~V}$ & $\mathrm{ND}$ \\
$\mathrm{Mg}$ & 47.9 & $\mathrm{Zn}$ & 0.333 \\
\hline
\end{tabular}

\section{Clay Mineralogy}

The Aliette Vineyard clay mineralogy were determined using the Bt3 horizon. This site is the least illitic of the samples from Elk Cove Vineyards, Chehalem, and Willakenzie Estate with most of the clays present being kaolinite and vermiculite with a 
well-developed chlorite intergrade. There is no dehydrated halloysite present. Trace amounts of mica and illite are present, moderate amounts of chlorite, vermiculite, and kaolinite. Cristobalite is also present in this profile and minor amounts of goethite and gibbsite.

\section{Missoula Flood Sediment over Shale Parent Material - Terres Basses Vineyard Physical Characteristics}

Terres Basses Vineyard, owned and operated by Willakenzie Estate Winery, is located in Yamhill, Oregon. This vineyard is located on presumably shale, associated with the marine sedimentary rocks of the Coast Range (Figure 2). I located a thin layer of Missoula Flood sediments overlying the shale bedrock at this site. This shale layer may be part of the Yamhill or Spencer Formation. Terres Basses Vineyard is located on foot slope of a slightly west-northwest facing slope with vine rows running north and south (Lat. 45.357946 N, Long. -123.144353 W). The soil pit location was at 293 feet (90 meters) elevation between rows 91 and 92 , and the soil is mapped as the Witham (previously Hazelair) soil series (Figure 17). According to the vineyard manager, this vineyard was cultivated, needs some irrigation, and is usually the first to ripen in the fall. 


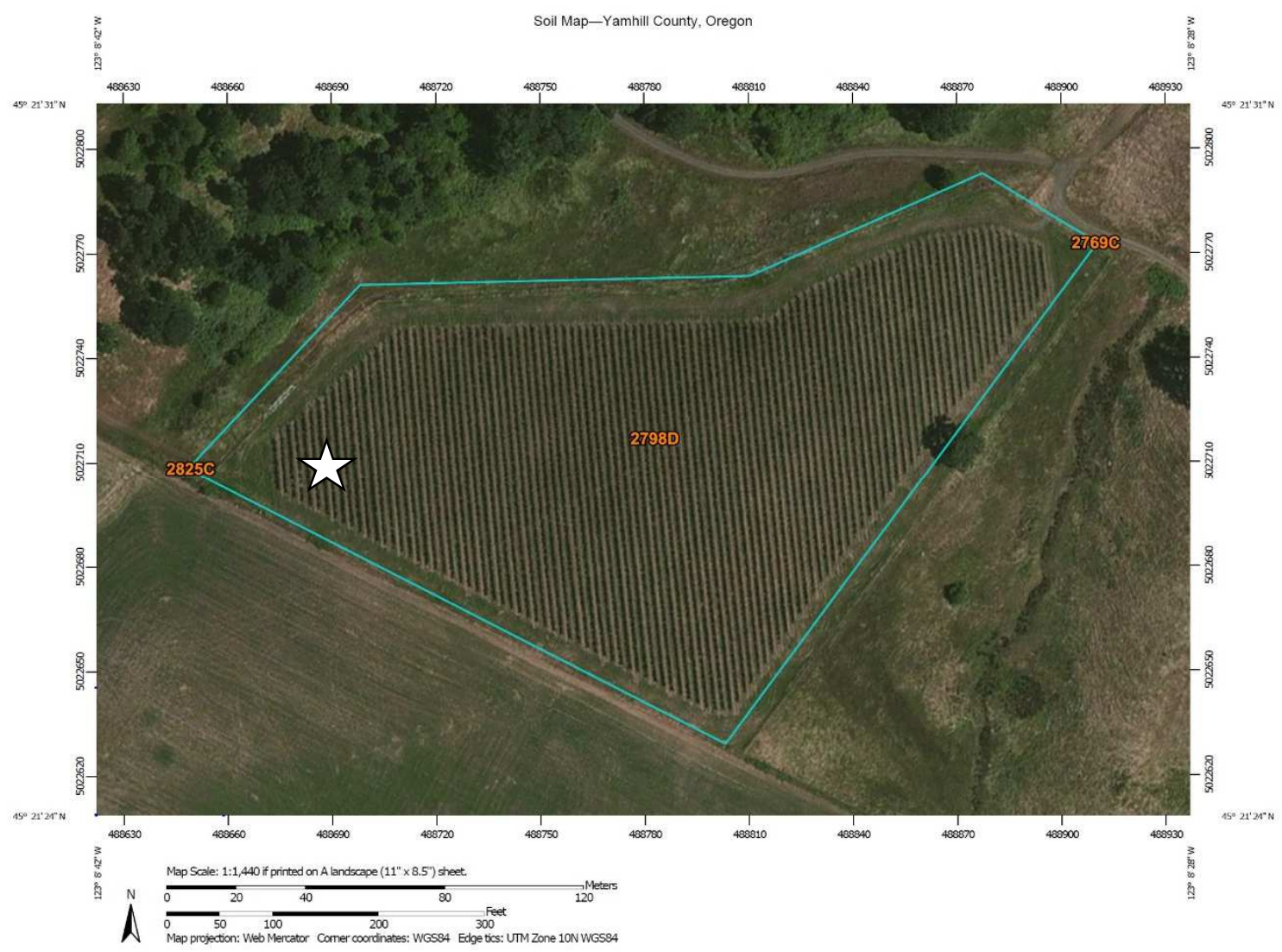

Figure 17. Soil map of Willakenzie Estate Winery, Terres Basses Vineyard. Pit location marked. 2798D - Witham silty clay loam, hummocky, 2 to 25 percent slopes with 2769C - Melbourne-Witham complex and 2825C - Hazelair-Witham complex surrounding (NRCS, 2015). Previously mapped as HcD - Hazelair silty clay loam, 7 to 20 percent slopes (NRCS, 2014).

The vines are Pinot Noir Dijon 113 and 115 clones planted in 1997 and are trellised as single cordon in vertical shoot position with 10 to 12 buds per vine preserved at pruning. The vines are grafted onto 3309 rootstocks (Table 8).

The Witham soil is characterized as a Vertic Haploxeroll, the only Mollisol in this study. The soil pit was $118+\mathrm{cm}$ deep reaching parent material at $102 \mathrm{~cm}$ depth without 
refusal. The bedrock is part of the Coast Range marine sedimentary rocks (Figure 2). The silt content of this soil pit decreases with depth from $47 \%$ (Ap) to $23 \%(\mathrm{Bg} 2)$. The $\mathrm{pH}$ ranges from 5.3 to 5.9 with no trend while CEC seems to increase with depth and OM ranges from $6.9 \%$ to $10.8 \%$ (Table 30 ). Textures for this profile are silty clay loam, silty clay and clay. The soil profile structures are mostly fine to medium subangular blocky.

Table 30. Willakenzie Estate Winery, Terres Basses Vineyard field and lab data.

\begin{tabular}{|c|c|c|c|c|c|c|}
\hline \multirow{3}{*}{$\begin{array}{l}\text { Depth } \\
\text { (cm) }\end{array}$} & \multirow{3}{*}{ Horizon } & \multicolumn{3}{|c|}{ Total } & \multirow[b]{2}{*}{$\begin{array}{c}\text { Coarse } \\
\text { Fragment } \\
(>2 \mathrm{~mm})\end{array}$} & \multirow[b]{2}{*}{$\begin{array}{l}\text { Texture } \\
\text { Lab }\end{array}$} \\
\hline & & $\begin{array}{c}\text { Sand } \\
(2-0.05 \\
\text { mm) }\end{array}$ & $\begin{array}{c}\text { Silt } \\
(0.05-0.002 \\
\text { mm) }\end{array}$ & $\begin{array}{c}\text { Clay } \\
(<0.002 \mathrm{~mm})\end{array}$ & & \\
\hline & & \multicolumn{4}{|c|}{ 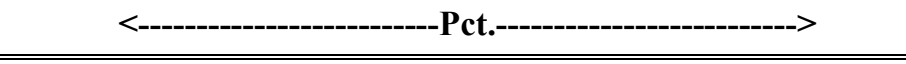 } & \\
\hline $0-25$ & A & 15.4 & 46.7 & 31.0 & 0.0 & $\mathrm{SiCL}$ \\
\hline $25-36$ & $\mathrm{AB}$ & 15.2 & 43.2 & 36.2 & 0.0 & $\mathrm{SiCL}$ \\
\hline $36-65$ & $\mathrm{Bg} 1$ & 14.0 & 31.6 & 41.8 & 0.1 & $\mathrm{SiC}$ \\
\hline $65-86$ & $\mathrm{Bg} 2$ & 21.6 & 23.3 & 47.9 & 1.2 & $\mathrm{C}$ \\
\hline $86-102$ & $\mathrm{Cg}$ & & & & & \\
\hline $102-118+$ & $\mathrm{R}$ & & & & & \\
\hline $\begin{array}{c}\text { Depth } \\
\text { (cm) }\end{array}$ & Horizon & Dry Color & Structure & $\begin{array}{c}\text { Organic } \\
\text { Matter } \\
\text { LOI (Pct.) } \\
\end{array}$ & $\begin{array}{c}\text { pH } \\
\left(1: 1 \mathrm{H}_{2} \mathrm{O}\right)\end{array}$ & $\begin{array}{c}\text { CEC } \\
(\mathrm{meq} / \mathbf{1 0 0 g})\end{array}$ \\
\hline $0-25$ & A & 10 YR $5 / 3$ & $1, \mathrm{~m}, \mathrm{~g}$ to $\mathrm{sbk}$ & 9.0 & 5.4 & 25.3 \\
\hline $25-36$ & $\mathrm{AB}$ & 10 YR $5 / 3$ & $1, \mathrm{~m}, \mathrm{sbk}$ & 6.9 & 5.9 & 23.1 \\
\hline $36-65$ & $\mathrm{Bg} 1$ & $\begin{array}{c}\text { 10YR 5/3 } \\
5 Y R 4 / 6\end{array}$ & $2, \mathrm{~m}, \mathrm{sbk}$ & 7.9 & 5.3 & 38.1 \\
\hline $65-86$ & $\mathrm{Bg} 2$ & $\begin{array}{c}\text { 10YR 5/3 } \\
5 \text { YR 5/6 }\end{array}$ & $2, \mathrm{~m}, \mathrm{sbk}$ & 10.8 & 5.4 & 34.6 \\
\hline $86-102$ & $\mathrm{Cg}$ & & $1, \mathrm{f}, \mathrm{sbk}$ & 10.8 & 5.7 & \\
\hline $102-118+$ & $\mathrm{R}$ & & & 9.0 & 5.4 & \\
\hline
\end{tabular}


The Ap horizon is very sticky and very plastic, and this trend persists through the profile. Clay percent increases with depth from $31 \%$ in the Ap to $48 \%$ in Bg2. Clay films located on ped faces, and interstitial pores are common and distinct in the $\mathrm{Bg} 1$ and $\mathrm{Bg} 2$ horizons. These horizons also portray mottling (redoximorphic features) within 20 inches of the surface suggesting somewhat poorly drained soil. The presence of quartz sand in the lower horizons coincides with the shale bedrock being associated with the sandstone and siltstones of the Coast Range marine sedimentary rocks. There are no pisolites in this profile. Dry colors for the Ap, $\mathrm{AB}$ and $\mathrm{Bg} 1$ and $\mathrm{Bg} 2$ horizons are brown (10 YR 5/3) with yellowish red (5 YR 4/6) secondary colors (Figure 18).

\section{Soil Chemistry}

The Terres Basses Vineyard soil pit was separated into six horizons, and samples of each horizon were sent for elemental analysis (Table 31). The maximum concentrations of $\mathrm{P}, \mathrm{K}$, and $\mathrm{S}$ are in the Ap horizon and the maximum concentrations of $\mathrm{Ca}$ and $\mathrm{Mg}$ were measured at depth in the parent material or R horizon. $\mathrm{P}, \mathrm{K}$, and $\mathrm{S}$ decrease with depth and bulge in the $\mathrm{Cg}$ horizon. $\mathrm{Ca}$ and $\mathrm{Mg}$ increase with depth with the highest concentration in the $\mathrm{R}$ horizon. 

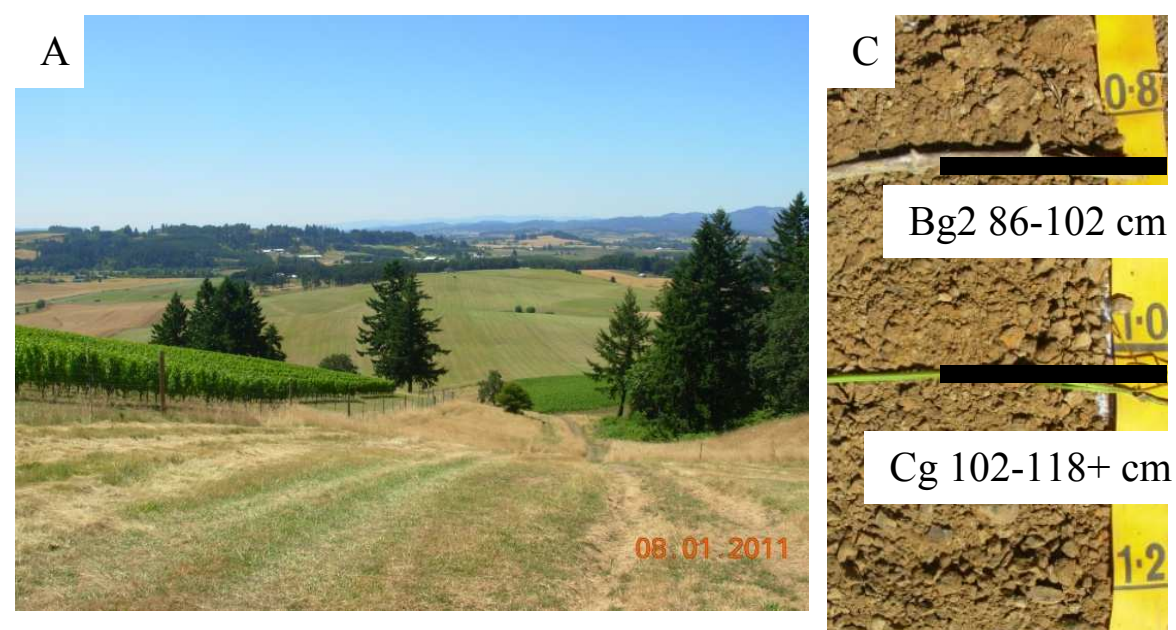

$\mathrm{Bg} 286-102 \mathrm{~cm}$

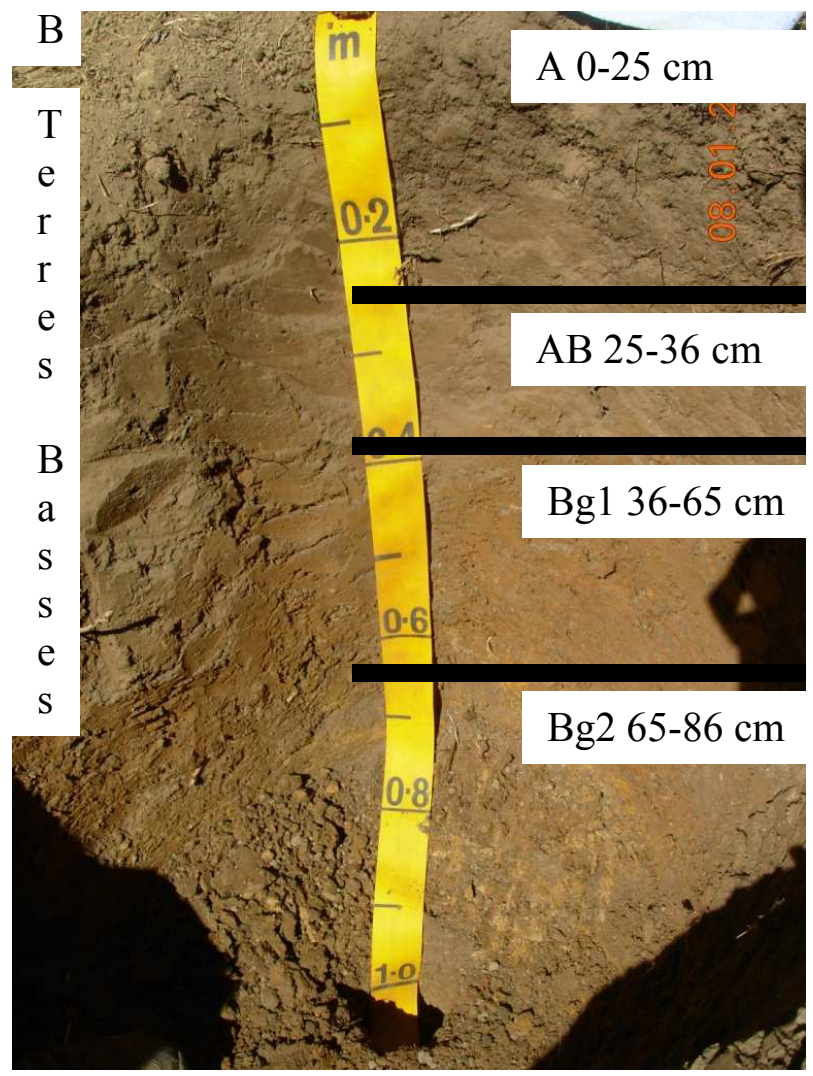

Figure 18. Sample soil pit at Willakenzie Estate Winery, Terres Basses Vineyard. A - View of sample location, facing southwest. B - Picture of the face of the soil pit with horizon depths and boundaries marked. C - Soil retrieved using a hand auger with horizon depths and boundaries marked. 
Table 31. Macronutrient concentrations (all values in $\mathrm{mg} / \mathrm{kg}$ ) for the Willakenzie Estate Winery, Terres Basses Vineyard soil pit (ND - Non-detectable).

\begin{tabular}{|c|c|c|c|c|c|c|c|c|c|c|}
\hline Horizon $(\mathrm{cm})$ & $\mathbf{P}$ & & $\mathbf{K}$ & \multicolumn{2}{|c|}{$\mathrm{Ca}$} & \multicolumn{2}{|c|}{ Mg } & $\mathbf{S}$ & \multicolumn{2}{|r|}{ Cl } \\
\hline$A(0-25)$ & 758 & & 970 & \multicolumn{2}{|c|}{3410} & \multicolumn{2}{|c|}{1400} & 270 & \multicolumn{2}{|r|}{ ND } \\
\hline $\mathrm{AB}(25-36)$ & 674 & & 894 & \multicolumn{2}{|c|}{2860} & \multicolumn{2}{|c|}{1600} & 174 & \multicolumn{2}{|r|}{ ND } \\
\hline Bg1 (36-65) & 318 & & 676 & \multicolumn{2}{|c|}{3990} & \multicolumn{2}{|c|}{2370} & ND & \multicolumn{2}{|r|}{ ND } \\
\hline $\mathrm{Bg} 2(65-86)$ & 295 & & 647 & \multicolumn{2}{|c|}{4260} & \multicolumn{2}{|c|}{2380} & ND & \multicolumn{2}{|r|}{ ND } \\
\hline Cg (86-102) & 645 & & 673 & \multicolumn{2}{|c|}{5620} & \multicolumn{2}{|c|}{3310} & 105 & \multicolumn{2}{|r|}{ ND } \\
\hline $\mathrm{R}(118+)$ & 534 & & 688 & \multicolumn{2}{|c|}{6050} & \multicolumn{2}{|c|}{3330} & ND & \multicolumn{2}{|r|}{ ND } \\
\hline Mean & 537 & & 758 & \multicolumn{2}{|c|}{4370} & \multicolumn{2}{|c|}{2400} & 183 & \multicolumn{2}{|r|}{$N D$} \\
\hline$S D$ & 193 & & 138 & \multicolumn{2}{|c|}{1240} & \multicolumn{2}{|c|}{817} & 82.9 & \multicolumn{2}{|r|}{$N D$} \\
\hline Maximum & 758 & & 970 & \multicolumn{2}{|c|}{6050} & \multicolumn{2}{|c|}{3330} & 270 & & $N D$ \\
\hline Horizon (cm) & $\mathrm{Fe}$ & Al & Co & $\mathrm{Cu}$ & & Mn & Mo & $\mathbf{N a}$ & $\mathbf{N i}$ & Zn \\
\hline A $(0-25)$ & 24500 & 7400 & 20.5 & 34. & & 849 & ND & 172 & 10.2 & 42.6 \\
\hline $\mathrm{AB}(25-36)$ & 27100 & 8810 & 24.4 & 36. & & 821 & ND & 185 & 11.0 & 40.4 \\
\hline Bg1 (36-65) & 26300 & 14100 & 5.24 & 32. & & 151 & ND & 108 & 7.57 & 29.9 \\
\hline $\mathrm{Bg} 2(65-86)$ & 23400 & 15400 & 6.82 & 38. & & 280 & ND & 127 & 9.34 & 33.5 \\
\hline Cg (86-102) & 28600 & 18400 & 11.1 & 64. & & 200 & ND & 216 & 16.3 & 58.7 \\
\hline $\mathrm{R}(118+)$ & 23000 & 18100 & 9.53 & 50. & & 194 & ND & 289 & 15.9 & 56.9 \\
\hline Mean & 25500 & 13700 & 12.9 & 42. & & 416 & $N D$ & 183 & 11.7 & 43.7 \\
\hline$S D$ & 2210 & 4650 & 7.75 & 12. & & 327 & $N D$ & 65.1 & 3.58 & 11.9 \\
\hline Maximum & 28600 & 18400 & 24.4 & 64. & & 849 & $N D$ & 289 & 16.3 & 58.7 \\
\hline Horizon $(\mathrm{cm})$ & As & $\mathbf{B a}$ & Be & Cd & $\mathrm{Cr}$ & Hg & $\mathbf{P b}$ & Se & $\mathrm{Sr}$ & $\mathbf{V}$ \\
\hline A $(0-25)$ & 8.97 & 157 & 0.654 & 0.120 & 11.1 & ND & 9.00 & ND & 36.3 & 54.3 \\
\hline $\mathrm{AB}(25-36)$ & 8.93 & 153 & 0.691 & ND & 12.7 & ND & 8.89 & 0.638 & 35.5 & 58.5 \\
\hline Bg1 (36-65) & 6.07 & 117 & 0.438 & ND & 12.8 & ND & 7.28 & 0.531 & 47.0 & 49.1 \\
\hline Bg2 (65-86) & 4.40 & 156 & 0.600 & ND & 10.7 & ND & 6.03 & ND & 49.1 & 45.1 \\
\hline $\mathrm{Cg}(86-102)$ & 4.29 & 250 & 0.748 & 0.128 & 12.6 & ND & 5.14 & 0.512 & 75.2 & 35.4 \\
\hline $\mathrm{R}(118+)$ & 3.83 & 226 & 0.570 & 0.132 & 12.1 & ND & 5.27 & ND & 81.5 & 30.3 \\
\hline Mean & 6.08 & 177 & 0.617 & 0.1 & 12.0 & $N D$ & 6.94 & 0.560 & 54.1 & 45.5 \\
\hline$S D$ & 2.35 & 50.5 & 0.108 & 0.006 & 0.894 & $N D$ & 1.73 & 0.068 & 19.7 & 10.9 \\
\hline Maximum & 8.97 & 250 & 0.748 & 0.132 & 12.8 & $N D$ & 9.00 & 0.638 & 81.5 & 58.5 \\
\hline
\end{tabular}


The trends in the micronutrient concentrations measured in the six soil horizons from the Terres Basses Vineyard are highly variable. $\mathrm{Fe}, \mathrm{Ni}, \mathrm{Zn}$ and $\mathrm{Cu}$ are variable with the maximum concentration in the $\mathrm{Cg}$ horizon. $\mathrm{Al}$ increases with depth and is highest in the $\mathrm{Cg}$ horizon as well. $\mathrm{Na}$, is variable with a maximum in the $\mathrm{R}$ horizon. $\mathrm{Mn}$ is highest in the A horizon and variable with depth, decreasing mostly. Co bulges in the AB horizon and is variable with depth. Mo is non-detectable. Trace element concentrations for the six horizons of the Terres Basses Vineyard were also analyzed. As and $\mathrm{Pb}$ both decrease with depth and the maximum is in the A horizon. Sr and $\mathrm{Cd}$ increase with depth and the maximum is in the $\mathrm{R}$ horizon. $\mathrm{Ba}$ and $\mathrm{Be}$ are variable with depth and the maximum is in the $\mathrm{Cg}$ horizon. Se and $\mathrm{V}$ bulge in the $\mathrm{AB}$ horizon and $\mathrm{Cr}$ bulges in the $\mathrm{Bg} 1$ horizon. $\mathrm{Hg}$ is non-detectable.

\section{Grape Juice Chemistry}

The grape juice samples have concentrations of many elements that are below detection limits in this study (Table 32). All 24 elements, the same as were tested in the soil samples, were analyzed for in the grape juice from grapes collected adjacent to the soil pits. The concentrations of $\mathrm{K}$ and $\mathrm{Na}$ in the Terres Basses Vineyard grape juice are $1940 \mathrm{mg} / \mathrm{kg}$ and $159 \mathrm{mg} / \mathrm{kg}$, respectively. This is the highest reported level of $\mathrm{K}$ in all 20 grape samples (Table 105). Sr concentration, one of only three elements found in all grape juice samples, is measured as $0.739 \mathrm{mg} / \mathrm{kg}$, which is the $10^{\text {th }}$ highest concentration of $\mathrm{Sr}$ for the 20 vineyard samples. Mean $\mathrm{Sr}$ concentration for all grape juice samples from 
the 20 different sites is $0.805 \pm 0.261 \mathrm{mg} / \mathrm{kg}$. P concentration is $324 \mathrm{mg} / \mathrm{kg}$ for these grapes.

Table 32. Elemental concentrations measured by ICP-MS in the grape juice from clusters collected from vines immediately adjacent to the soil pit location at Willakenzie Estate Winery, Terres Basses Vineyard (ND - Non-detectable).

\begin{tabular}{cccccccccc}
\hline Element & Sr & $\mathbf{P}$ & $\mathbf{K}$ & $\mathbf{N a}$ & $\mathbf{M g}$ & $\mathbf{M n}$ & $\mathbf{C a}$ & $\mathbf{C u}$ & $\mathbf{Z n}$ \\
\hline \hline $\begin{array}{c}\text { Grape Juice } \\
(\mathrm{mg} / \mathrm{kg})\end{array}$ & 0.739 & 324 & 1940 & 159 & ND & ND & ND & ND & ND \\
\hline
\end{tabular}

\section{Wine Chemistry}

The Terres Basses Vineyard sample was also collected and used in the sensory analysis. Two samples of the same bottle were sent to measure the concentrations of the same 24 elements tested in the soil samples. Again, many elemental concentrations were below detection limits. The 15 elements that were detected in the Terres Basses wine sample include $\mathrm{Ba}, \mathrm{Ca}, \mathrm{Co}, \mathrm{Cu}, \mathrm{Fe}, \mathrm{Pb}, \mathrm{Mg}, \mathrm{Mn}, \mathrm{Ni}, \mathrm{P}, \mathrm{K}, \mathrm{Na}, \mathrm{Sr}, \mathrm{S}$, and $\mathrm{Zn}$ (Table 33). The concentration of $\mathrm{K}$ in the wine is $908 \mathrm{mg} / \mathrm{kg}, \mathrm{P}$ is $207 \mathrm{mg} / \mathrm{kg}, \mathrm{S}$ is $90.7 \mathrm{mg} / \mathrm{kg}, \mathrm{Ca}$ is $50.5 \mathrm{mg} / \mathrm{kg}$, and $\mathrm{Mg}$ is $52.7 \mathrm{mg} / \mathrm{kg}$. Na concentration is $4.04 \mathrm{mg} / \mathrm{kg}$ for this location and $\mathrm{Mn}$ is $2.56 \mathrm{mg} / \mathrm{kg}$. Concentrations in descending order for the rest of the elements tested are $\operatorname{Sr}(1.15 \mathrm{mg} / \mathrm{kg}), \mathrm{Fe}(1.07 \mathrm{mg} / \mathrm{kg}), \mathrm{Ba}(0.419 \mathrm{mg} / \mathrm{kg})$, and $\mathrm{Zn}(0.208 \mathrm{mg} / \mathrm{kg})$. Trace amounts of $\mathrm{Cu}(0.127 \mathrm{mg} / \mathrm{kg}), \mathrm{Pb}(0.0890 \mathrm{mg} / \mathrm{kg}), \mathrm{Co}(0.0315 \mathrm{mg} / \mathrm{kg})$, and $\mathrm{Ni}(0.026$ $\mathrm{mg} / \mathrm{kg}$ ) were also measured in the Terres Basses wine. 
Table 33. Elemental concentrations measured twice by ICP-MS of the same $750 \mathrm{ml}$ unblended wine sample from the 2011 Willakenzie Estate Winery, Terres Basses Vineyard (ND - Non-detectable, * denotes mean of two samples from the same bottle).

\begin{tabular}{cccc}
\hline Element & 2011 Wine Sample* $(\mathbf{m g} / \mathbf{k g})$ & Element & 2011 Wine Sample* $\mathbf{( m g} / \mathbf{k g})$ \\
\hline $\mathrm{Al}$ & $\mathrm{ND}$ & $\mathrm{Mn}$ & 2.56 \\
$\mathrm{As}$ & $\mathrm{ND}$ & $\mathrm{Hg}$ & $\mathrm{ND}$ \\
$\mathrm{Ba}$ & 0.419 & $\mathrm{Mo}$ & $\mathrm{ND}$ \\
$\mathrm{Be}$ & $\mathrm{ND}$ & $\mathrm{Ni}$ & 0.026 \\
$\mathrm{Cd}$ & $\mathrm{ND}$ & $\mathrm{P}$ & 207 \\
$\mathrm{Ca}$ & 50.5 & $\mathrm{~K}$ & 908 \\
$\mathrm{Cr}$ & $\mathrm{ND}$ & $\mathrm{Se}$ & $\mathrm{ND}$ \\
$\mathrm{Co}$ & $\mathrm{Na}$ & 4.04 \\
$\mathrm{Cu}$ & 0.0315 & $\mathrm{Sr}$ & 1.15 \\
$\mathrm{Fe}$ & 0.127 & $\mathrm{~S}$ & 90.7 \\
$\mathrm{~Pb}$ & 1.07 & $\mathrm{~V}$ & $\mathrm{ND}$ \\
$\mathrm{Mg}$ & 0.0890 & $\mathrm{Zn}$ & 0.208 \\
\hline
\end{tabular}

\section{Clay Mineralogy}

My Terres Basses location is located on Missoula Flood deposits and is highly smectitic. Clay mineralogy was determined from the Bg1 horizon. Only traces of mica exist and no interlayer chlorite layers are present. Trace amounts of kaolinite and minor vermiculite as well as Fe oxides suggest a wetter site. The Bg soil horizons in the profile corroborate this, suggesting that this site is poorly drained, leaving most $\mathrm{Fe}$ in the reduced phase instead of oxidized. Only minor amounts of quartz are found in the sample and no cristobalite. 


\section{Chapter Six - Chehalem Results}

\section{Volcanic Parent Material - Stoller Vineyard Physical Characteristics}

Stoller Vineyard is owned by Bill Stoller of Stoller Family Estate and located in Dayton, Oregon. This vineyard is planted on volcanic basalt bedrock, part of the Columbia River Basalt Group. The Stoller Vineyard soil pit is located on the midslope of a southeast facing slope with vine rows running north and south (Lat. 45.248827 N, Long. - 123.072347 W). The soil pit location was at 475 feet (145 meters) elevation between rows 67 and 68 and is mapped as the Jory soil series (Figure 19). The vines are Pinot Noir Pommard clone planted in 1995 and are trellised as bilateral cordon in vertical shoot position.

The Jory soil is characterized as a Xeric Palehumult. The soil pit was $135 \mathrm{~cm}$ deep with refusal at the Columbia River Basalt bedrock and parent material (Figure 2). The silt content of this soil pit remains fairly constant with depth ranging from 58\% (Bt3) to 64\% (Bt1). Dry color for all horizons is dark yellowish brown (10 YR 4/4) (Figure 20).

Textures are silt loam throughout the profile. Structures for the soil profile are strong fine subangular blocky in the Ap horizon grading to weak fine subangular blocky in Bt2. The Bt 3 horizon has less than 10 percent coarse fragments and structure is weak, fine loose single grain to subangular blocky. The Ap horizon is slightly sticky and slightly plastic, 


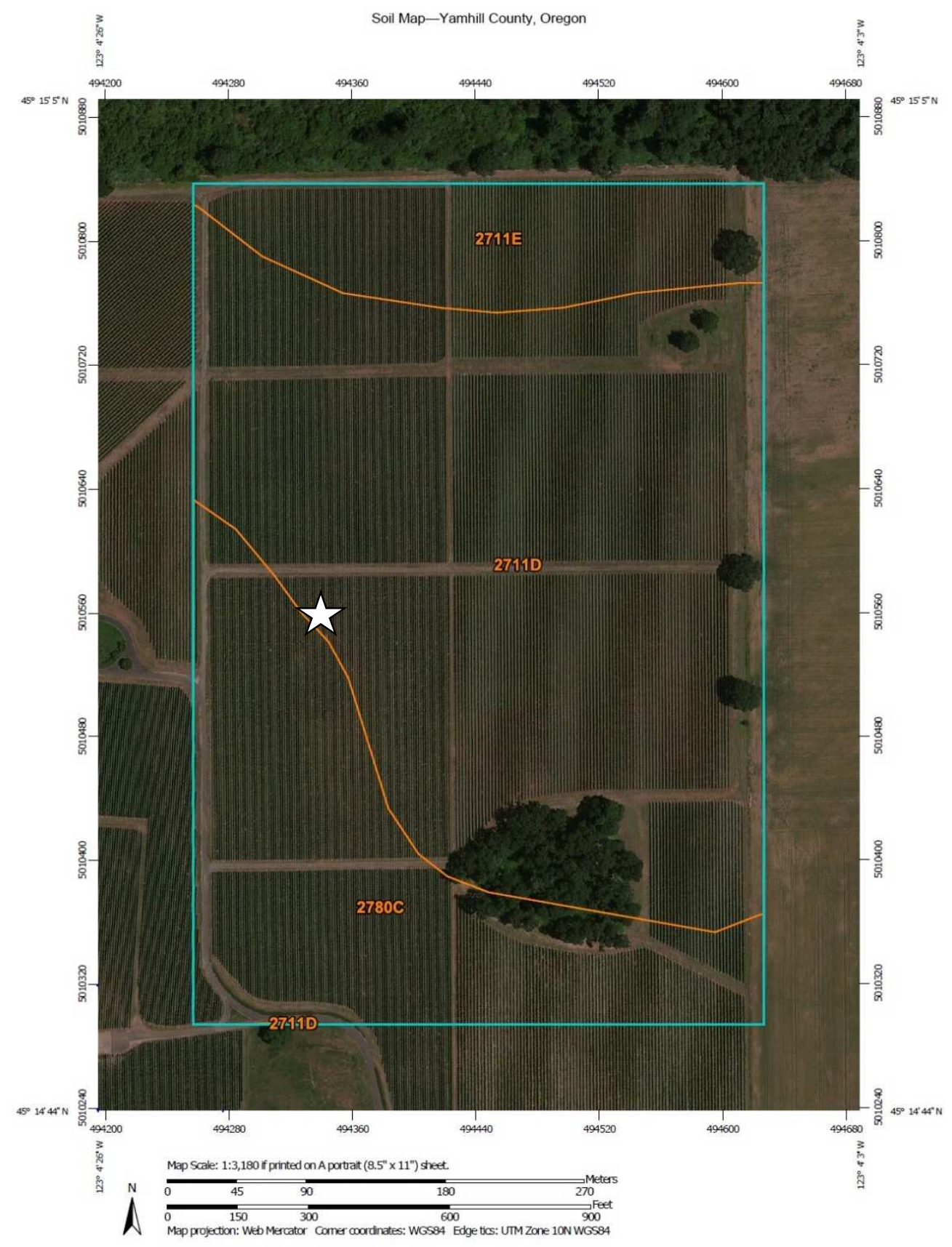

Figure 19. Soil map of Chehalem, Stoller Vineyards. Pit location marked. 2711D - Jory silty clay loam, 12 to 20 percent slopes. $2711 \mathrm{E}$ - Jory silty clay loam, 20 to 30 percent slopes. $2780 \mathrm{C}$ - JoryGelderman silty clay loams, 2 to 12 percent slopes (NRCS, 2015). Previously mapped as JrC - Jory clay loam, 7 to 12 percent slopes (NRCS, 2014). 
the $\mathrm{Bt} 1$ and $\mathrm{Bt} 2$ horizons are very sticky and very plastic, and the Bt3 horizon is slightly sticky and slightly plastic. Clay percent increases with depth from $18 \%$ in the Ap to $24 \%$ in Bt1 and 27\% in Bt3. Clay films located on ped faces are few and faint in the Bt1 and Bt2 horizons. Pisolites are few and fine but throughout the soil profile. The CEC and OM both decrease with depth with $\mathrm{OM}$ ranging from $9.8 \%$ to $13.8 \%$. The $\mathrm{pH}$ decreases with depth from 5.6 to 5.4 (Table 34).

Table 34. Chehalem, Stoller Vineyards field and lab data.

\begin{tabular}{|c|c|c|c|c|c|c|}
\hline \multirow{3}{*}{$\begin{array}{l}\text { Depth } \\
\text { (cm) }\end{array}$} & \multirow{3}{*}{ Horizon } & \multicolumn{3}{|c|}{ Total } & \multirow[b]{2}{*}{$\begin{array}{c}\text { Coarse } \\
\text { Fragment } \\
(>2 \mathrm{~mm})\end{array}$} & \multirow{3}{*}{$\begin{array}{c}\text { Texture } \\
\text { Lab }\end{array}$} \\
\hline & & $\begin{array}{c}\text { Sand } \\
(2-0.05 \\
\text { mm) }\end{array}$ & $\begin{array}{c}\text { Silt } \\
(0.05-0.002 \\
\text { mm) }\end{array}$ & $\underset{(<0.002 \mathrm{~mm})}{\text { Clay }}$ & & \\
\hline & & \multicolumn{4}{|c|}{ 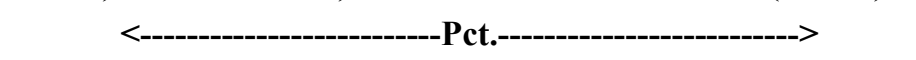 } & \\
\hline $0-10$ & Ap & 15.0 & 62.4 & 17.7 & 0.0 & $\mathrm{SiL}$ \\
\hline $10-60$ & Bt1 & 11.8 & 64.4 & 24.0 & 0.0 & $\mathrm{SiL}$ \\
\hline $60-100$ & $\mathrm{Bt} 2$ & 12.2 & 61.6 & 25.6 & 0.0 & $\mathrm{SiL}$ \\
\hline $100-135$ & $\mathrm{Bt} 3$ & 13.9 & 57.9 & 27.0 & 0.0 & $\mathrm{SiL}$ \\
\hline $\begin{array}{c}\text { Depth } \\
\text { (cm) }\end{array}$ & Horizon & Dry Color & Structure & $\begin{array}{c}\text { Organic } \\
\text { Matter } \\
\text { LOI (Pct.) }\end{array}$ & $\begin{array}{c}\mathrm{pH} \\
\left(1: 1 \mathrm{H}_{2} \mathrm{O}\right)\end{array}$ & $\underset{(\mathrm{meq} / \mathbf{1 0 0 g})}{\text { CEC }}$ \\
\hline $0-10$ & Ap & 10YR $4 / 4$ & $3, \mathrm{f}, \mathrm{sbk}$ & 13.8 & 5.6 & 23.5 \\
\hline $10-60$ & $\mathrm{Bt} 1$ & 10YR 4/4 & $2, \mathrm{f}, \mathrm{sbk}$ & 10.4 & 5.4 & 18.7 \\
\hline $60-100$ & $\mathrm{Bt} 2$ & $10 Y R 4 / 4$ & $1, \mathrm{f}, \mathrm{sbk}$ & 9.9 & 5.4 & 17.0 \\
\hline $100-135$ & Bt3 & $10 \mathrm{YR} 4 / 4$ & sg to $1, f, s b k$ & 9.8 & 5.5 & 16.5 \\
\hline
\end{tabular}



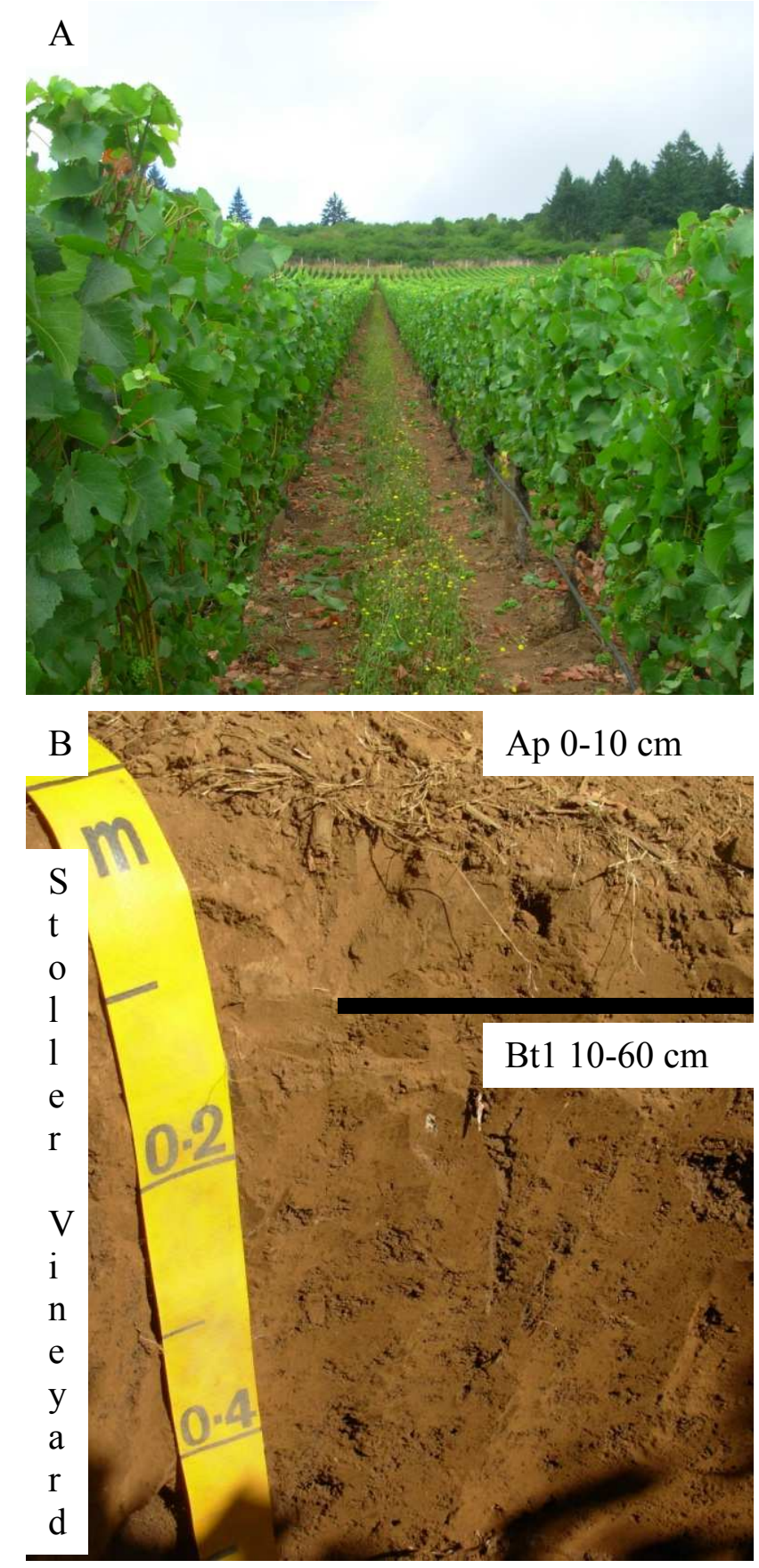

Figure 20. Sample soil pit at Chehalem, Stoller Vineyards. A - View of sample location, facing north. B - Picture of the face of the soil pit with horizon depths and boundaries marked. 


\section{Soil Chemistry}

The Stoller Vineyard soil pit was separated into four horizons, and samples of each horizon were sent for analysis (Table 35). The maximum concentrations of $\mathrm{P}, \mathrm{K}, \mathrm{Ca}$, and $\mathrm{S}$ are in the Ap horizon, and the maximum concentrations of $\mathrm{Mg}$ is at depth in the Bt3 horizon. $\mathrm{P}, \mathrm{K}, \mathrm{Ca}$, and $\mathrm{S}$ decrease with depth. $\mathrm{Mg}$ constantly increases with depth. $\mathrm{Cl}$ is only detected in the Ap horizon. The micronutrient concentrations measured in the four soil horizons from the Stoller Vineyard are all highest in the Ap horizon, within the top $10 \mathrm{~cm} . \mathrm{Fe}, \mathrm{Al}, \mathrm{Co}, \mathrm{Cu}, \mathrm{Mn}, \mathrm{Ni}$, and $\mathrm{Zn}$ have the highest concentration in the Ap horizon, decrease with depths and have small bulges exhibited in the Bt2 horizon. Mo is only detected in the Ap horizon. Na has the highest value in the Ap horizon and the lowest in the Bt1 and then increases with depth below that horizon. Trace element concentrations were also measured for the four horizons of the Stoller Vineyard. Highest values are in the Ap horizon for all elements except $\mathrm{Be}, \mathrm{Hg}$, and $\mathrm{Sr}$. As, $\mathrm{Cd}, \mathrm{Cr}, \mathrm{Pb}$, and $\mathrm{V}$ are highest in the Ap horizon and decrease with depth with bulges in the Bt2 horizon. Be is highest in the $\mathrm{Bt} 2$ horizon and $\mathrm{Sr}$ is highest in the $\mathrm{Bt} 3$ horizon.

\section{Grape Juice Chemistry}

All 24 elements, the same as were tested in the soil samples, were analyzed for the grape juice from grapes collected adjacent to the soil pits. The grape juice samples have concentrations of many elements that are below detection limits in this study (Table 36). $\mathrm{K}, \mathrm{Na}$, and $\mathrm{Sr}$ are the only elements found in all 20 grape juice samples, and $\mathrm{P}$ is 
Table 35. Macronutrient concentrations (all values in $\mathrm{mg} / \mathrm{kg}$ ) for the Chehalem, Stoller Vineyard soil pit (ND - Non-detectable).

\begin{tabular}{|c|c|c|c|c|c|c|c|c|c|c|}
\hline Horizon (cm) & \multicolumn{2}{|l|}{$\mathbf{P}$} & $\mathbf{K}$ & \multicolumn{2}{|l|}{$\mathbf{C a}$} & \multicolumn{2}{|l|}{ Mg } & \multicolumn{2}{|l|}{$\mathbf{S}$} & $\mathrm{Cl}$ \\
\hline Ap $(0-10)$ & \multicolumn{2}{|l|}{2380} & 1800 & \multicolumn{2}{|l|}{2570} & \multicolumn{2}{|l|}{1300} & \multicolumn{2}{|l|}{309} & 17.7 \\
\hline Bt1 (10-60) & \multicolumn{2}{|l|}{1150} & 1090 & \multicolumn{2}{|l|}{1400} & \multicolumn{2}{|l|}{1390} & \multicolumn{2}{|l|}{148} & ND \\
\hline Bt2 (60-100) & \multicolumn{2}{|l|}{1060} & 1030 & \multicolumn{2}{|l|}{1250} & \multicolumn{2}{|l|}{1620} & \multicolumn{2}{|l|}{122} & ND \\
\hline Bt3 (100-135) & \multicolumn{2}{|l|}{922} & 745 & \multicolumn{2}{|l|}{1260} & \multicolumn{2}{|l|}{1850} & \multicolumn{2}{|l|}{125} & ND \\
\hline Mean & \multicolumn{2}{|l|}{1380} & 1170 & \multicolumn{2}{|l|}{1620} & \multicolumn{2}{|l|}{1540} & \multicolumn{2}{|l|}{176} & 17.7 \\
\hline$S D$ & \multicolumn{2}{|l|}{675} & 449 & \multicolumn{2}{|l|}{637} & \multicolumn{2}{|l|}{247} & \multicolumn{2}{|l|}{89.4} & 0 \\
\hline Maximum & \multicolumn{2}{|l|}{2380} & 1800 & \multicolumn{2}{|l|}{2570} & \multicolumn{2}{|l|}{1850} & \multicolumn{2}{|l|}{309} & 17.7 \\
\hline Horizon (cm) & $\mathrm{Fe}$ & Al & Co & $\mathbf{C u}$ & Mn & & & $\mathbf{N a}$ & $\mathbf{N i}$ & $\mathbf{Z n}$ \\
\hline Ap (0-10) & 60500 & 19500 & 60.3 & 33.4 & 3190 & 0.6 & & 201 & 7.25 & 111 \\
\hline Bt1 (10-60) & 50300 & 18300 & 35.6 & 15.6 & 1810 & & & 174 & 6.12 & 78.4 \\
\hline Bt2 (60-100) & 55600 & 19500 & 42.7 & 16.2 & 2050 & & & 184 & 6.79 & 82.8 \\
\hline Bt3 (100-135) & 43400 & 18100 & 29.4 & 13.7 & 1470 & & & 199 & 5.99 & 74.7 \\
\hline Mean & 32500 & 18900 & 42.0 & 19.7 & 2130 & & & 190 & 6.54 & 86.7 \\
\hline$S D$ & 7330 & 755 & 13.4 & 9.18 & 746 & & & 12.8 & 0.590 & 16.5 \\
\hline Maximum & 60500 & 19500 & 60.3 & 33.4 & 3190 & & & 201 & 7.25 & 111 \\
\hline Horizon (cm) & As & Ba & Be & Cd & $\mathrm{Cr}$ & $\mathbf{H g}$ & $\mathbf{P b}$ & Se & $\mathrm{Sr}$ & $\mathbf{V}$ \\
\hline Ap (0-10) & 2.40 & 310 & 1.49 & 0.558 & 18.3 & ND & 15.3 & 0.569 & 14.9 & 219 \\
\hline Bt1 (10-60) & 1.63 & 204 & 1.45 & 0.370 & 16.6 & ND & 10.7 & ND & 10.8 & 185 \\
\hline Bt2 (60-100) & 1.69 & 208 & 1.52 & 0.391 & 17.3 & ND & 11.7 & ND & 14.5 & 191 \\
\hline Bt3 (100-135) & 1.29 & 217 & 1.31 & 0.355 & 15.5 & ND & 10.6 & ND & 16.8 & 159 \\
\hline Mean & 1.75 & 235 & 1.44 & 0.419 & 16.9 & $N D$ & 12.1 & 0.569 & 14.3 & 189 \\
\hline$S D$ & 0.466 & 50.5 & 0.0929 & 0.0942 & 1.18 & $N D$ & 2.21 & 0 & 2.51 & 24.6 \\
\hline Maximum & 2.40 & 310 & 1.52 & 0.558 & 18.3 & $N D$ & 15.3 & 0.569 & 16.8 & 219 \\
\hline
\end{tabular}

detected in 15 of the 20 sites. The concentrations of $\mathrm{K}$ and $\mathrm{Na}$ in the Stoller Vineyard grape juice are $1400 \mathrm{mg} / \mathrm{kg}$ and $153 \mathrm{mg} / \mathrm{kg}$, respectively. Sr concentration, one of only three elements found in all grape juice samples, is measured as $0.633 \mathrm{mg} / \mathrm{kg}$, which is the $17^{\text {th }}$ highest concentration of $\mathrm{Sr}$ for the 20 vineyard samples (Table 105). Mean $\mathrm{Sr}$ 
concentration for all grape juice samples from the 20 different sites is $0.805 \pm 0.261$ $\mathrm{mg} / \mathrm{kg}$. P concentration is $213 \mathrm{mg} / \mathrm{kg}$ and $\mathrm{Mn}$ is $4.56 \mathrm{mg} / \mathrm{kg}$ for these grapes. This is the highest concentration of Mn, which is only found in four vineyards including Stoller, Five Mountain, The Jory Hills, and Sims Vineyards.

Table 36. Elemental concentrations measured by ICP-MS in the grape juice from clusters collected from vines immediately adjacent to the soil pit location at Chehalem, Stoller Vineyard (ND - Nondetectable).

\begin{tabular}{cccccccccc}
\hline Element & Sr & P & K & Na & Mg & Mn & Ca & Cu & Zn \\
\hline \hline Grape Juice $(\mathrm{mg} / \mathrm{kg})$ & 0.633 & 213 & 1400 & 153 & ND & 4.56 & ND & ND & ND \\
\hline
\end{tabular}

\section{Wine Chemistry}

Chehalem provided a $750 \mathrm{ml}$ sample of the wine produced from the Stoller Vineyard in 2011. Many of the 24 elements tested in the wine (same as the elements tested in the soil samples) were below detection limits. The 14 elements that were detected in Stoller Vineyard wine sample include $\mathrm{Ba}, \mathrm{Ca}, \mathrm{Co}, \mathrm{Cu}, \mathrm{Fe}, \mathrm{Pb}, \mathrm{Mg}, \mathrm{Mn}, \mathrm{P}, \mathrm{K}$, $\mathrm{Na}$, Sr, S, and $\mathrm{Zn}$ (Table 37). $\mathrm{K}$ and $\mathrm{P}$ concentrations are the highest at $785 \mathrm{mg} / \mathrm{kg}$ and $233 \mathrm{mg} / \mathrm{kg}$, respectively. $\mathrm{S}$ is $75.1 \mathrm{mg} / \mathrm{kg}, \mathrm{Ca}$ is $52.3 \mathrm{mg} / \mathrm{kg}, \mathrm{Mg}$ is $50.1 \mathrm{mg} / \mathrm{kg}$, and $\mathrm{Na}$ is $17.5 \mathrm{mg} / \mathrm{kg}$ for this wine. In much lower amounts, $\mathrm{Mn}$ is reported at $1.70 \mathrm{mg} / \mathrm{kg}$ and $\mathrm{Fe}$ at $1.64 \mathrm{mg} / \mathrm{kg}$. In descending order, Sr concentration is $0.698 \mathrm{mg} / \mathrm{kg}, \mathrm{Zn}$ is $0.436 \mathrm{mg} / \mathrm{kg}$, and $\mathrm{Ba}$ is $0.408 \mathrm{mg} / \mathrm{kg}$. Trace amounts of $\mathrm{Pb}(0.0815 \mathrm{mg} / \mathrm{kg}), \mathrm{Cu}(0.0704 \mathrm{mg} / \mathrm{kg})$, and $\mathrm{Co}$ $(0.0282 \mathrm{mg} / \mathrm{kg})$ are also detected in the Stoller Vineyard wine sample. 
Table 37. Elemental concentrations measured by ICP-MS of a $750 \mathrm{ml}$ unblended wine sample from the 2011 vintage of Chehalem, Stoller Vineyard (ND - Non-detectable, * denotes mean of three samples from the same bottle).

\begin{tabular}{cccc}
\hline Element & 2011 Wine Sample* $(\mathbf{m g} / \mathbf{k g})$ & Element & 2011 Wine Sample* $\mathbf{m g} / \mathbf{k g})$ \\
\hline \hline $\mathrm{Al}$ & $\mathrm{ND}$ & $\mathrm{Mn}$ & 1.70 \\
$\mathrm{As}$ & $\mathrm{ND}$ & $\mathrm{Hg}$ & $\mathrm{ND}$ \\
$\mathrm{Ba}$ & 0.408 & $\mathrm{Mo}$ & $\mathrm{ND}$ \\
$\mathrm{Be}$ & $\mathrm{ND}$ & $\mathrm{Ni}$ & $\mathrm{ND}$ \\
$\mathrm{Cd}$ & $\mathrm{ND}$ & $\mathrm{P}$ & 233 \\
$\mathrm{Ca}$ & 52.3 & $\mathrm{~K}$ & 785 \\
$\mathrm{Cr}$ & $\mathrm{ND}$ & $\mathrm{Se}$ & $\mathrm{ND}$ \\
$\mathrm{Co}$ & $\mathrm{Na}$ & 17.5 \\
$\mathrm{Cu}$ & 0.0282 & $\mathrm{Sr}$ & 0.698 \\
$\mathrm{Fe}$ & 0.0704 & $\mathrm{~S}$ & 75.1 \\
$\mathrm{~Pb}$ & 1.64 & $\mathrm{~V}$ & $\mathrm{ND}$ \\
$\mathrm{Mg}$ & 0.0815 & $\mathrm{Zn}$ & 0.436 \\
\hline
\end{tabular}

Chehalem also contributed multiple vintages of each vineyard to this study in order to look further into the possible influence of climate on the uptake of elements from the soil. The 2007, 2008, and 2009 vintages of the Stoller Vineyard site are shown in (Table 38). In brief comparison, the 2007 vintage has higher concentrations of $\mathrm{Ba}, \mathrm{Cu}$, $\mathrm{Mn}$, and $\mathrm{Na}$. The 2008 vintage has the highest concentration of Fe, S, and Co but the lowest concentration of $\mathrm{Mg}$ and $\mathrm{Ca}$. The bottle of the 2009 vintage has the highest concentration of $\mathrm{Ca}$ and $\mathrm{K}$, but the lowest concentration of $\mathrm{Ba}, \mathrm{Cu}, \mathrm{Fe}, \mathrm{Mn}, \mathrm{Na}$, and $\mathrm{Sr}$. Further analysis needs to be completed in order to determine if these differences are significant. Direct comparison of vineyard climate to the uptake of elements should be done in the future. 
Table 38. Elemental concentrations measured by ICP-MS of multiple vintages of Chehalem, Stoller Vineyard wine (ND - Non-detectable).

\begin{tabular}{|c|c|c|c|}
\hline Element & 2007 Bottle (mg/kg) & 2008 Bottle (mg/kg) & 2009 Bottle $(\mathrm{mg} / \mathrm{kg})$ \\
\hline $\mathrm{Al}$ & ND & ND & ND \\
\hline As & ND & ND & ND \\
\hline $\mathrm{Ba}$ & 0.557 & 0.393 & 0.358 \\
\hline $\mathrm{Be}$ & ND & ND & ND \\
\hline $\mathrm{Cd}$ & ND & ND & ND \\
\hline $\mathrm{Ca}$ & 49 & 32.5 & 51.6 \\
\hline $\mathrm{Cr}$ & ND & ND & ND \\
\hline Co & ND & 0.0358 & ND \\
\hline $\mathrm{Cu}$ & 0.298 & 0.213 & 0.14 \\
\hline $\mathrm{Fe}$ & 2.68 & 2.82 & 1.7 \\
\hline $\mathrm{Pb}$ & ND & 0.0812 & 0.0475 \\
\hline $\mathrm{Mg}$ & 71.5 & 46.8 & 60.8 \\
\hline $\mathrm{Mn}$ & 2.12 & 1.95 & 1.91 \\
\hline $\mathrm{Hg}$ & ND & ND & ND \\
\hline Mo & ND & ND & ND \\
\hline $\mathrm{Ni}$ & ND & ND & ND \\
\hline $\mathrm{P}$ & 327 & 289 & 319 \\
\hline K & 774 & 710 & 860 \\
\hline $\mathrm{Se}$ & ND & ND & ND \\
\hline $\mathrm{Na}$ & 3.93 & 3.87 & 3.32 \\
\hline $\mathrm{Sr}$ & 0.858 & 0.812 & 0.732 \\
\hline $\mathrm{S}$ & 68.4 & 88.1 & 77.4 \\
\hline V & ND & ND & ND \\
\hline $\mathrm{Zn}$ & 0.702 & 0.55 & 0.356 \\
\hline
\end{tabular}

\section{Clay Mineralogy}

The Stoller Vineyard soil contains a similar clay mineral assemblage as Elk Cove

Five Mountain (loess/volcanic parent material) and Willakenzie Estate Jory Hills

Vineyards (volcanic parent material). The clay mineralogy was determined from the Bt3 
horizon. There is moderate cristobalite and goethite as the main Fe phase at this site. Clays include moderate illite, kaolinite, and halloysite. Minor hydroxy interlayered smectite, which may contain chlorite, is also present. The clays also included some mica, suggesting a loess addition.

\section{Marine Sediment Parent Material - Ridgecrest Vineyard Physical Characteristics}

The site at Ridgecrest Vineyard is owned by Chehalem and located in Newberg, Oregon. This vineyard is planted on sandstone of the Coast Range marine sediments (Figure 2). The Ridgecrest Vineyard soil pit is located on the midslope of an east facing slope with vine rows running north and south (Lat. 45.367757 N, Long. -123.079108 W). The soil pit location was at 638 feet (195 meters) elevation between rows 23 and 24 and is mapped as Wellsdale (previously Willakenzie) soil series (Figure 21). The vines are Pinot Noir Pommard clone planted in 1985 and are trellised as bilateral cordon in vertical shoot position. The vines are grafted onto Chardonnay Dijon clone rootstock (Table 8).

The Wellsdale soil is characterized as an Aquultic Haploxeralf. The soil pit was $220+\mathrm{cm}$ deep without refusal and $20 \mathrm{~cm}$ of $\mathrm{C}$ horizon was collected using an auger. The $\mathrm{C} 1$ and $\mathrm{C} 2$ horizons were sandstone of the Coast Range marine sediments (Figure 2). Sand percent increased from $23 \%$ in the Ap horizon to $47 \%$ in the C2 horizon (Table 39). 


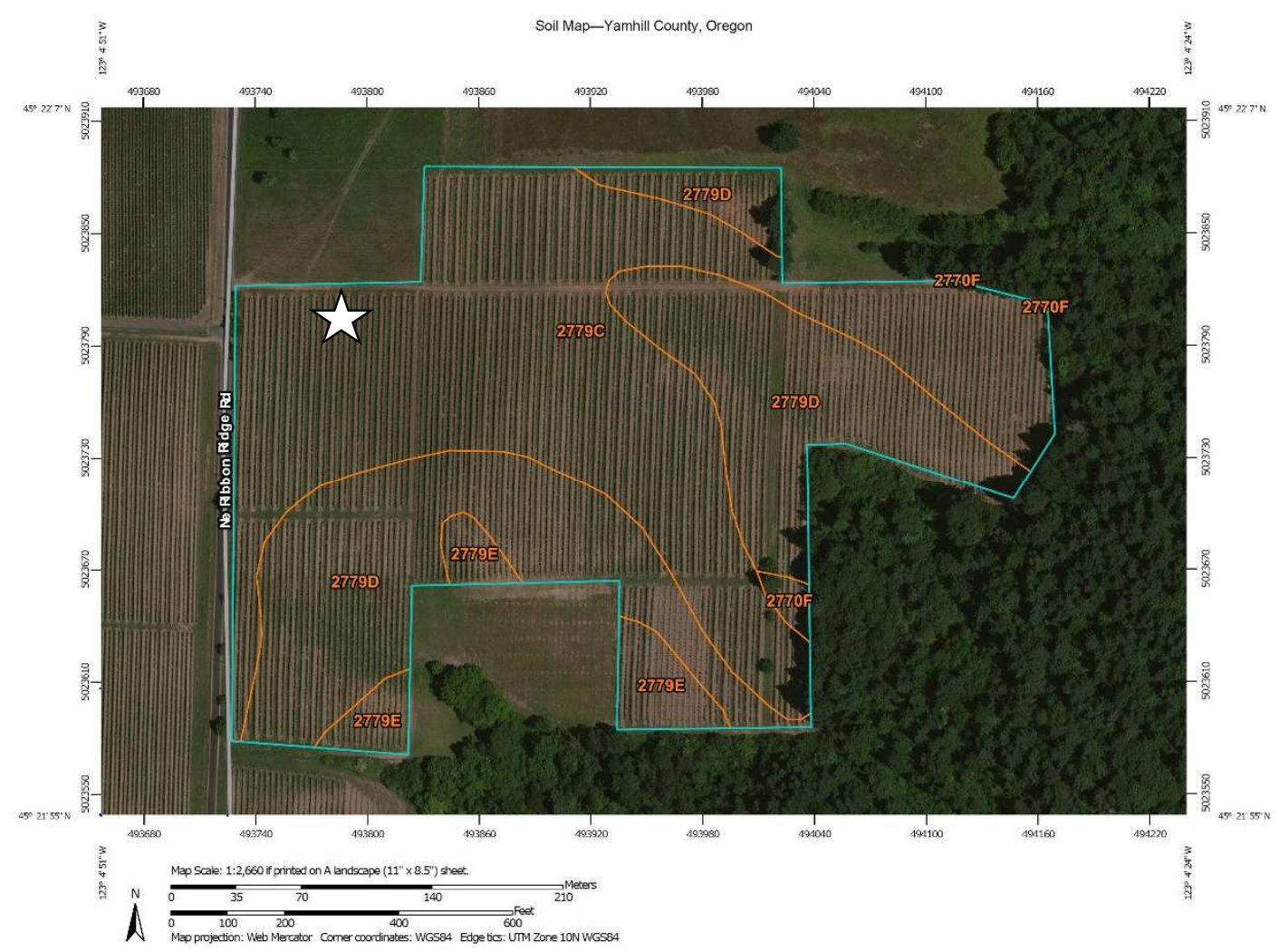

Figure 21. Soil map of Chehalem, Ridgecrest Vineyard. Pit location marked. 2779C - Wellsdale loam, 2 to 12 percent slopes. 2779D - Wellsdale loam, 12 to 20 percent slopes. 2779E - Wellsdale loam, 20 to 30 percent slopes. 2770F - Melbourne-Goodin silt loams, 30 to 60 percent slopes (NRCS, 2015). Previously mapped as WeC - Willakenzie silty clay loam, 2 to 12 percent slopes (NRCS, 2014).

The $\mathrm{pH}$ decreases with depth from 5.5 in the Ap horizon to 5.0. CEC decreases from the Ap horizon but bulges in the $\mathrm{Bt} 2$ horizon and $\mathrm{OM}$ ranges from 3.9\% to $16.1 \%$. Dry color for the upper horizons (Ap, Bt1 and Bt2) is yellowish brown and dark yellowish brown (10 YR 5/4 and 10 YR 4/4). The C horizons portrayed two colors of sand/silt, one strong brown (7.5 YR 5/6) and light yellowish brown (2.5 Y 7/4) (Figure 22). Textures are silt loam in the Ap horizon, Bt2 is clay loam, and the C horizons are loam. Structures for the upper horizons of the soil profile are weak to moderate, fine subangular blocky, and the $\mathrm{C}$ 
horizons are single grain. The $\mathrm{Bt} 2, \mathrm{C} 1$ and $\mathrm{C} 2$ horizons have $10 \%$ coarse fragments of sandstone bedrock. The Ap horizon is nonsticky and non-plastic, the Bt1 and Bt2 horizons are sticky and plastic. Clay percent increases with depth from $14 \%$ in the Ap to $29 \%$ in $\mathrm{Bt} 2$ but then decreases to $14 \%$ in the $\mathrm{C} 2$ horizon. Common, faint clay films are located on ped faces in the Bt1 horizon. The soil contains muscovite mica and quartz sand. There are no pisolites in this profile.

Table 39. Chehalem, Ridgecrest Vineyard field and lab data.

\begin{tabular}{|c|c|c|c|c|c|c|}
\hline \multirow{3}{*}{$\begin{array}{l}\text { Depth } \\
\text { (cm) }\end{array}$} & \multirow{3}{*}{ Horizon } & \multicolumn{3}{|c|}{ Total } & \multirow[b]{2}{*}{$\begin{array}{c}\text { Coarse } \\
\text { Fragment } \\
(>2 \mathrm{~mm})\end{array}$} & \multirow{3}{*}{$\begin{array}{c}\text { Texture } \\
\text { Lab }\end{array}$} \\
\hline & & $\begin{array}{l}\text { Sand } \\
(2-0.05 \\
\text { mm) }\end{array}$ & $\begin{array}{c}\text { Silt } \\
(0.05-0.002 \\
\text { mm) }\end{array}$ & $\underset{(<0.002 \text { mm) }}{\text { Clay }}$ & & \\
\hline & & \multicolumn{4}{|c|}{ <----------------------------Pct.--------------------------> } & \\
\hline $0-25$ & Ap & 23.2 & 59.6 & 13.7 & 0.0 & $\mathrm{SiL}$ \\
\hline $25-65$ & Bt1 & 20.9 & 56.3 & 21.4 & 0.0 & $\mathrm{SiL}$ \\
\hline $65-115$ & Bt2 & 25.8 & 42.6 & 29.0 & 0.0 & $\mathrm{CL}$ \\
\hline $115-200$ & $\mathrm{C} 1$ & 43.0 & 35.7 & 10.4 & 0.1 & $\mathrm{~L}$ \\
\hline $200-220+$ & $\mathrm{C} 2$ & 46.6 & 31.3 & 13.5 & 0.1 & $\mathrm{~L}$ \\
\hline $\begin{array}{l}\text { Depth } \\
\text { (cm) }\end{array}$ & Horizon & Dry Color & Structure & $\begin{array}{c}\text { Organic } \\
\text { Matter } \\
\text { LOI (Pct.) }\end{array}$ & $\begin{array}{c}\text { pH } \\
\left(1: 1 \mathrm{H}_{2} \mathrm{O}\right)\end{array}$ & $\begin{array}{c}\text { CEC } \\
(\mathrm{meq} / \mathbf{1 0 0 g})\end{array}$ \\
\hline $0-25$ & Ap & 10 YR $5 / 4$ & $1, \mathrm{f}, \mathrm{gr}$ & 3.9 & 5.5 & 14.8 \\
\hline $25-65$ & Bt1 & $10 \mathrm{YR} 4 / 4$ & $2, \mathrm{f}, \mathrm{sbk}$ & 6.0 & 5.6 & 11.2 \\
\hline $65-115$ & Bt2 & 10YR 5/4 & $2, \mathrm{f}, \mathrm{sbk}$ & 8.6 & 5.3 & 19.1 \\
\hline $115-200$ & $\mathrm{C} 1$ & $\begin{array}{c}7.5 \text { YR 5/6 } \\
2.5 Y 7 / 4\end{array}$ & $\mathrm{sg}$ & 16.1 & 5.1 & \\
\hline $200-220+$ & $\mathrm{C} 2$ & $\begin{array}{c}7.5 \text { YR 5/8 } \\
2.5 Y 6 / 4\end{array}$ & $\mathrm{sg}$ & 15.5 & 5.0 & \\
\hline
\end{tabular}




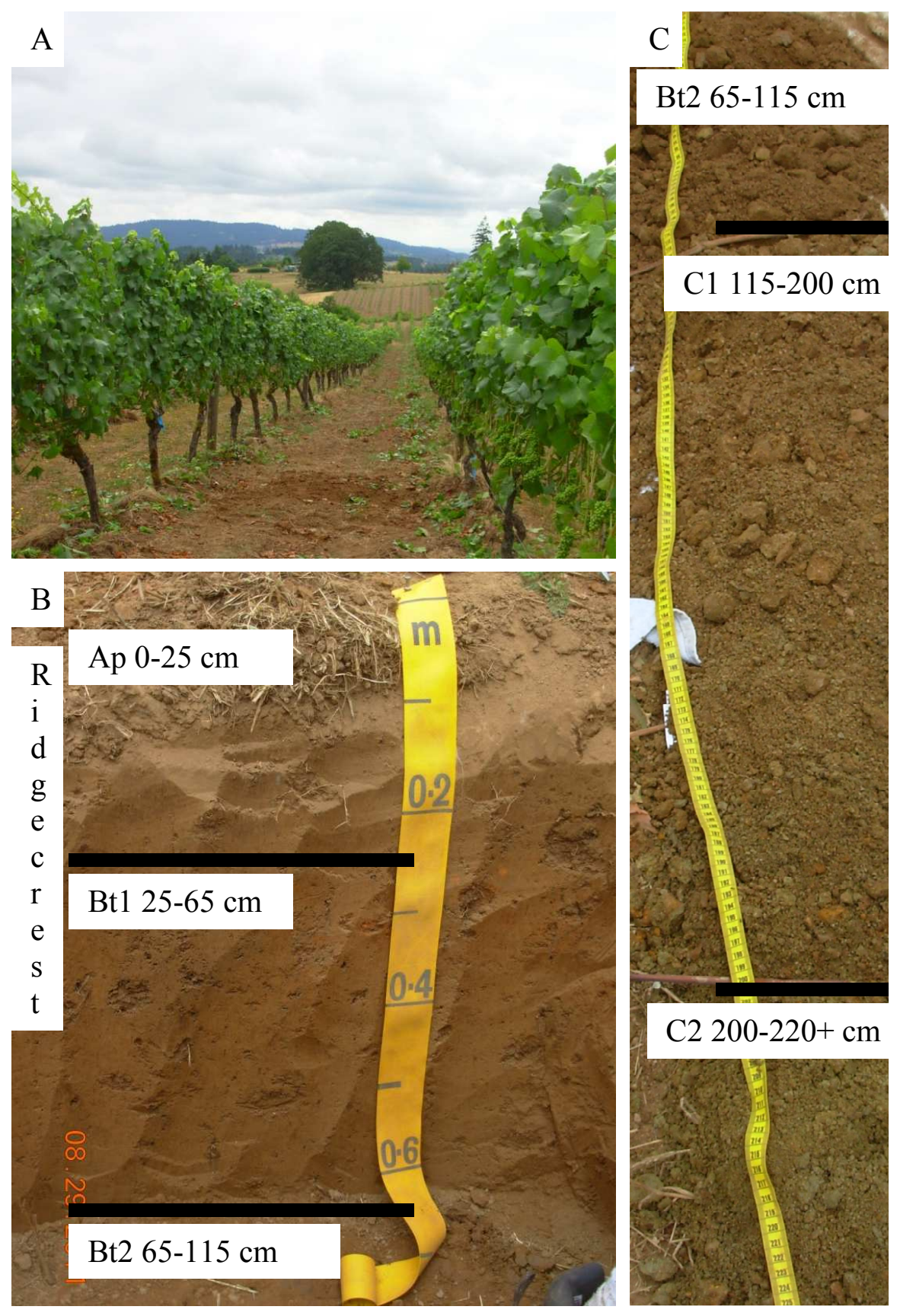

Figure 22. Sample soil pit at Chehalem, Ridgecrest Vineyard. A - View of sample location, facing east. B - Picture of the face of the soil pit with horizon depths and boundaries marked. C - Soil retrieved using a hand auger with horizon depths and boundaries marked. 


\section{Soil Chemistry}

The Ridgecrest Vineyard soil pit was separated into six horizons, and samples of each horizon were sent for analysis (Table 40). This is one of the deepest soil pits reaching the $\mathrm{R}$ horizon at depths greater than $220 \mathrm{~cm}$. $\mathrm{P}$ and $\mathrm{K}$ decrease with depth. $\mathrm{Ca}$ and $\mathrm{Mg}$ increase with depth. S is only detected in the Ap horizon. The micronutrient concentrations measured in the six soil horizons from the Ridgecrest Vineyard have varying trends. $\mathrm{Co}, \mathrm{Fe}$, and $\mathrm{Al}$ increase with depth to the $\mathrm{C} 1$ horizon, then decrease. $\mathrm{Cu}$ and $\mathrm{Mn}$ are highest at the top of the profile and decrease with depth. $\mathrm{Na}, \mathrm{Ni}$ and $\mathrm{Zn}$ are variable with the highest concentrations at the bottom of the profile. Trace element concentrations vary for the six horizons of the Ridgecrest Vineyard (Table 40). As and Se are highest in the Ap horizon at the top of the profile and decrease with depth with a bulge in the $\mathrm{R}$ horizon for $\mathrm{As} . \mathrm{Ba}, \mathrm{Be}, \mathrm{Cd}, \mathrm{Cr}, \mathrm{Pb}$, and $\mathrm{V}$ are all highest in the $\mathrm{R}$ horizon as well. Disregarding the $\mathrm{R}$ horizon, $\mathrm{Ba}$ and $\mathrm{Cd}$ decrease with depth with a bulge in the $\mathrm{C} 1$ horizon. $\mathrm{Be}, \mathrm{Sr}$, and $\mathrm{V}$ increases with depth. $\mathrm{Cr}$ and $\mathrm{Pb}$ decrease with depth.

\section{Grape Juice Chemistry}

As previously stated, 24 elements (same as the soil samples) were analyzed in the grape juice from grapes collected adjacent to the soil pits. The grape juice samples have concentrations of many elements that are below detection limits in this study and only 
Table 40. Macronutrient, micronutrient and trace element concentrations (all values in $\mathrm{mg} / \mathrm{kg}$ ) for the Chehalem, Ridgecrest Vineyard soil pit (ND - Non-detectable).

\begin{tabular}{|c|c|c|c|c|c|c|c|c|c|c|}
\hline Horizon (cm) & $\mathbf{P}$ & & $\mathbf{K}$ & $\mathbf{C a}$ & & Mg & & $\mathbf{S}$ & & $\mathbf{C l}$ \\
\hline Ap (0-25) & 713 & & 902 & 1290 & & 1590 & & 174 & & ND \\
\hline Bt1 (25-65) & 528 & & 711 & 965 & & 1690 & & ND & & ND \\
\hline Bt2 (65-115) & 378 & & 525 & 1350 & & 1720 & & ND & & ND \\
\hline C1 (115-200) & 260 & & 182 & 2960 & & 2840 & & ND & & ND \\
\hline C2 (200-220) & 324 & & 115 & 3050 & & 2510 & & ND & & ND \\
\hline $\mathrm{R}(220+)$ & 1040 & & 307 & 1060 & & 930 & & ND & & ND \\
\hline Mean & 541 & & 457 & 1780 & & 1880 & & 174 & & $N D$ \\
\hline$S D$ & 294 & & 311 & 961 & & 688 & & 0 & & $N D$ \\
\hline Maximum & 1040 & & 902 & 3050 & & 2840 & & 174 & & $N D$ \\
\hline Horizon (cm) & $\mathbf{F e}$ & Al & Co & $\mathrm{Cu}$ & Mn & $\mathbf{M}$ & & $\mathbf{N a}$ & $\mathbf{N i}$ & Zn \\
\hline Ap (0-25) & 27000 & 13700 & 17.7 & 19.2 & 1470 & NI & & 196 & 6.21 & 44.3 \\
\hline Bt1 (25-65) & 28600 & 14700 & 18.6 & 12.7 & 1160 & NI & & 172 & 6.57 & 41.8 \\
\hline Bt2 (65-115) & 29900 & 14500 & 20.7 & 10.9 & 698 & NI & & 183 & 4.31 & 36.4 \\
\hline C1 (115-200) & 49000 & 36000 & 24.6 & 11.9 & 522 & NI & & 219 & 6.56 & 82.7 \\
\hline C2 (200-220) & 44800 & 34400 & 18.4 & 13.3 & 302 & NI & & 215 & 5.72 & 78.6 \\
\hline $\mathrm{R}(220+)$ & 34100 & 22600 & 14.3 & 17.4 & 240 & NI & & 267 & 15.9 & 85.8 \\
\hline Mean & 35600 & 22700 & 19.1 & 14.2 & 732 & $N I$ & & 209 & 7.55 & 61.6 \\
\hline$S D$ & 9190 & 10300 & 3.42 & 3.30 & 490 & $N L$ & & 33.8 & 4.18 & 23.0 \\
\hline Махіmum & 49000 & 36000 & 24.6 & 19.2 & 1470 & $N L$ & & 267 & 15.9 & 85.8 \\
\hline Horizon (cm) & As & $\mathbf{B a}$ & $\mathrm{Be}$ & Cd & $\mathrm{Cr}$ & Hg & $\mathbf{P b}$ & Se & $\mathrm{Sr}$ & $\mathbf{V}$ \\
\hline Ap $(0-25)$ & 2.34 & 170 & 0.708 & 0.219 & 16.2 & ND & 9.58 & 0.594 & 14.1 & 74.3 \\
\hline Bt1 (25-65) & 2.22 & 128 & 0.699 & 0.180 & 16.1 & ND & 8.50 & 0.572 & 11.4 & 80.1 \\
\hline Bt2 (65-115) & 1.31 & 97.9 & 0.719 & 0.177 & 13.7 & ND & 8.68 & ND & 16.8 & 86.8 \\
\hline C1 (115-200) & 0.389 & 267 & 0.758 & 0.277 & 7.32 & ND & 5.47 & ND & 43.1 & 97.6 \\
\hline C2 (200-220) & 0.43 & 250 & 0.796 & 0.258 & 6.18 & ND & 6.61 & ND & 46.2 & 107 \\
\hline $\mathrm{R}(220+)$ & 1.34 & 328 & 1.220 & 0.916 & 23.8 & ND & 16.2 & 0.568 & 11.1 & 127 \\
\hline Mean & 1.34 & 207 & 0.817 & 0.338 & 13.9 & $N D$ & 9.17 & 0.578 & 23.8 & 95.5 \\
\hline$S D$ & 0.838 & 89.0 & 0.201 & 0.286 & 6.50 & $N D$ & 3.76 & 0.014 & 16.3 & 19.4 \\
\hline Maximum & 2.34 & 328 & 1.220 & 0.916 & 23.8 & $N D$ & 16.2 & 0.594 & 46.2 & 127 \\
\hline
\end{tabular}


elements found in any grape sample are show in Table 41 . The concentrations of $\mathrm{K}$ and $\mathrm{Na}$ in the Ridgecrest Vineyard grape juice are $851 \mathrm{mg} / \mathrm{kg}$ and $155 \mathrm{mg} / \mathrm{kg}$, respectively. This is one of the lowest concentrations of $\mathrm{K}$ in all 20 of the grape samples. $\mathrm{Sr}$ concentrations are measured as $1.1 \mathrm{mg} / \mathrm{kg}$, which is the $4^{\text {th }}$ highest concentration of $\mathrm{Sr}$ for the 20 vineyard samples (Table 105). Mean Sr concentration for all grape juice samples from the 20 different sites is $0.805 \pm 0.261 \mathrm{mg} / \mathrm{kg}$. P and Mn concentrations are both below detection limits for these grapes.

Table 41. Elemental concentrations measured by ICP-MS in the grape juice from clusters collected from vines immediately adjacent to the soil pit location at Chehalem, Ridgecrest Vineyard (ND Non-detectable).

\begin{tabular}{cccccccccc}
\hline Element & Sr & P & K & Na & Mg & Mn & Ca & Cu & Zn \\
\hline \hline Grape Juice $(\mathrm{mg} / \mathrm{kg})$ & 1.1 & ND & 851 & 155 & ND & ND & ND & ND & ND \\
\hline
\end{tabular}

\section{Wine Chemistry}

Chehalem provided a $750 \mathrm{ml}$ sample of the wine produced from the Ridgecrest Vineyard in 2011. Many of the 24 elements tested in the wine (same as the elements tested in the soil samples) were below detection limits. The 14 elements that were detected in Ridgecrest Vineyard wine sample include $\mathrm{Ba}, \mathrm{Ca}, \mathrm{Co}, \mathrm{Cu}, \mathrm{Fe}, \mathrm{Pb}, \mathrm{Mg}, \mathrm{Mn}, \mathrm{P}$, $\mathrm{K}, \mathrm{Na}, \mathrm{Sr}, \mathrm{S}$, and $\mathrm{Zn}$ (Table 42). K and P concentrations are the highest at $673 \mathrm{mg} / \mathrm{kg}$ and $364 \mathrm{mg} / \mathrm{kg}$, respectively. $\mathrm{S}$ is $86.0 \mathrm{mg} / \mathrm{kg}$, Ca is $61.6 \mathrm{mg} / \mathrm{kg}, \mathrm{Mg}$ is $61.5 \mathrm{mg} / \mathrm{kg}$, and $\mathrm{Na}$ is $9.94 \mathrm{mg} / \mathrm{kg}$ for this wine. In much lower amounts, Fe concentration is $2.14 \mathrm{mg} / \mathrm{kg}$ and $\mathrm{Mn}$ is reported at $1.31 \mathrm{mg} / \mathrm{kg}$. The concentration of $\mathrm{Sr}$ is $1.19 \mathrm{mg} / \mathrm{kg}, \mathrm{Zn}$ is $1.09 \mathrm{mg} / \mathrm{kg}$, 
$\mathrm{Ba}$ is $0.288 \mathrm{mg} / \mathrm{kg}$, and $\mathrm{Cu}$ is $0.162 \mathrm{mg} / \mathrm{kg}$. Trace amounts of $\mathrm{Pb}(0.0622 \mathrm{mg} / \mathrm{kg})$ and $\mathrm{Co}$ $(0.030 \mathrm{mg} / \mathrm{kg})$ are also detected in the Stoller Vineyard wine sample.

Table 42. Elemental concentrations measured by ICP-MS of three samples of the same $750 \mathrm{ml}$ unblended wine sample from the 2011 vintage of Chehalem, Ridgecrest Vineyard (ND - Nondetectable, * denotes mean of three samples from the same bottle).

\begin{tabular}{cccc}
\hline Element & 2011 Wine Sample* $(\mathbf{m g} / \mathbf{k g})$ & Element & 2011 Wine Sample* $\mathbf{m g} / \mathbf{k g})$ \\
\hline \hline $\mathrm{Al}$ & $\mathrm{ND}$ & $\mathrm{Mn}$ & 1.31 \\
$\mathrm{As}$ & $\mathrm{ND}$ & $\mathrm{Hg}$ & $\mathrm{ND}$ \\
$\mathrm{Ba}$ & 0.288 & $\mathrm{Mo}$ & $\mathrm{ND}$ \\
$\mathrm{Be}$ & $\mathrm{ND}$ & $\mathrm{Ni}$ & $\mathrm{ND}$ \\
$\mathrm{Cd}$ & $\mathrm{ND}$ & $\mathrm{P}$ & 364 \\
$\mathrm{Ca}$ & 61.6 & $\mathrm{~K}$ & 673 \\
$\mathrm{Cr}$ & $\mathrm{ND}$ & $\mathrm{Se}$ & $\mathrm{ND}$ \\
$\mathrm{Co}$ & 0.030 & $\mathrm{Na}$ & 9.94 \\
$\mathrm{Cu}$ & 0.162 & $\mathrm{Sr}$ & 1.19 \\
$\mathrm{Fe}$ & 2.14 & $\mathrm{~S}$ & 86.0 \\
$\mathrm{~Pb}$ & 0.0622 & $\mathrm{~V}$ & $\mathrm{ND}$ \\
$\mathrm{Mg}$ & 61.5 & $\mathrm{Zn}$ & 1.09 \\
\hline
\end{tabular}

Chehalem also contributed multiple vintages of each vineyard to this study in order to look further into the possible influence of climate on the uptake of elements from the soil. The 2007 and 2008 vintages of the Ridgecrest Vineyard site are shown in (Table 43). In brief comparison, the 2007 vintage has higher concentrations of $\mathrm{Ba}, \mathrm{Ca}, \mathrm{Co}, \mathrm{Cu}$, $\mathrm{Fe}, \mathrm{Pb}, \mathrm{P}, \mathrm{Na}, \mathrm{Sr}, \mathrm{S}$, and $\mathrm{Zn}$. The $\mathrm{Ca}, \mathrm{Na}, \mathrm{Sr}, \mathrm{S}, \mathrm{Zn}$ are very similar to the concentrations in the 2008 vintage. The 2008 vintage has the higher concentrations of $\mathrm{Mg}, \mathrm{Mn}$, and $\mathrm{K}$ than the 2007 vintage. Further analysis needs to be completed in order to determine if these differences are significant. 
Table 43. Elemental concentrations measured by ICP-MS of multiple vintages of Chehalem, Ridgecrest Vineyard wine (ND - Non-detectable, * denotes mean of two samples from the same bottle).

\begin{tabular}{cccccc}
\hline Element & $\begin{array}{c}\mathbf{2 0 0 7} \text { Bottle } \\
(\mathbf{m g} / \mathbf{k g})\end{array}$ & $\begin{array}{c}\mathbf{2 0 0 8} \text { Bottle* } \\
(\mathbf{m g} / \mathbf{k g})\end{array}$ & Element & $\begin{array}{c}\mathbf{2 0 0 7} \text { Bottle } \\
(\mathbf{m g} / \mathbf{k g})\end{array}$ & $\begin{array}{c}\mathbf{2 0 0 8} \mathbf{~ B o t t l e *} \\
(\mathbf{m g} / \mathbf{k g})\end{array}$ \\
\hline \hline $\mathrm{Al}$ & $\mathrm{ND}$ & $\mathrm{ND}$ & $\mathrm{Mn}$ & 1.34 & 1.58 \\
$\mathrm{As}$ & $\mathrm{ND}$ & $\mathrm{ND}$ & $\mathrm{Hg}$ & $\mathrm{ND}$ & $\mathrm{ND}$ \\
$\mathrm{Ba}$ & 0.366 & 0.262 & $\mathrm{Mo}$ & $\mathrm{ND}$ & $\mathrm{ND}$ \\
$\mathrm{Be}$ & $\mathrm{ND}$ & $\mathrm{ND}$ & $\mathrm{Ni}$ & $\mathrm{ND}$ & $\mathrm{ND}$ \\
$\mathrm{Cd}$ & $\mathrm{ND}$ & $\mathrm{ND}$ & $\mathrm{P}$ & 326 & 208 \\
$\mathrm{Ca}$ & 40.5 & 39.7 & $\mathrm{~K}$ & 700 & 723 \\
$\mathrm{Cr}$ & $\mathrm{ND}$ & $\mathrm{ND}$ & $\mathrm{Se}$ & $\mathrm{ND}$ & $\mathrm{ND}$ \\
$\mathrm{Co}$ & 0.0345 & $\mathrm{ND}$ & $\mathrm{Na}$ & 8.54 & 8.32 \\
$\mathrm{Cu}$ & 0.553 & 0.377 & $\mathrm{Sr}$ & 1.49 & 1.40 \\
$\mathrm{Fe}$ & 3.84 & 2.77 & $\mathrm{~S}$ & 106 & 99.4 \\
$\mathrm{~Pb}$ & 0.0822 & $\mathrm{ND}$ & $\mathrm{V}$ & $\mathrm{ND}$ & $\mathrm{ND}$ \\
$\mathrm{Mg}$ & 49.5 & 90.0 & $\mathrm{Zn}$ & 0.644 & 0.618 \\
\hline
\end{tabular}

\section{Clay Mineralogy}

The Ridgecrest Vineyard soil includes moderate to abundant illite in the clay fraction of the $\mathrm{Bt} 2$ horizon. This is mostly likely from the weathering of the mica in the parent material, recorded visually during grain size analysis. Minor amounts of hydroxy interlayered smectite and dehydrated halloysite and moderate amounts of highly disordered kaolinite are also present. The minor chloritic intergrade has moderate expansion and little mixed layered chlorite with trace vermiculite. Minor amounts of cristobalite and goethite are present. 


\section{Loess and Volcanic Parent Material - Corral Creek Vineyard Physical Characteristics}

Corral Creek Vineyard is owned by Chehalem and located in Newberg, Oregon. This vineyard is planted on basalt of the Columbia River Basalt Group, (Figure 2), and the soils are part of the Laurelwood soil series (Figure 23). The Corral Creek Vineyard soil pit is located on the midslope of a northwest facing slope with vine rows running slightly northwest and southeast (Lat. 45.312503 N, Long. -122.916342 W). The soil pit location was at 373 feet (114 meters) elevation between rows 2 and 3 . The vines are Pinot Noir Pommard clone planted in 1983 and are trellised as bilateral cordon in vertical shoot position.

The Laurelwood soil is characterized as an Ultic Haploxeralf. The soil pit was $65+\mathrm{cm}$ deep with refusal. The $\mathrm{Cr}$ and $\mathrm{R}$ horizons contained fractured basalt bedrock. The $\mathrm{pH}$ for the pit is around 5.8, and OM ranges from 5.9\% to $6.9 \%$. CEC is very high at 42.2 meq/100 $\mathrm{g}$ in the Ap horizon and abruptly drops to $19.5 \mathrm{meq} / 100 \mathrm{~g}$ in the Bt horizon (Table 44). The silt content of this soil pit decreases with depth as sand and clay percent increase. Silt percent is $68 \%$ in the Ap horizon and decreases to $49 \%$ percent in the $\mathrm{Cr}$ horizon. Dry colors for the entire profile are brown (10 YR 4/3 and 7.5 YR 4/4) (Figure 24). Textures are silt loam in the Ap horizon and silty clay loam with depth. Structures are moderate medium subangular blocky in the Bt horizon. The $\mathrm{Cr}$ horizon contains $50 \%$ coarse fragments of basalt bedrock, and the $\mathrm{R}$ horizon has greater than $75 \%$ rock 


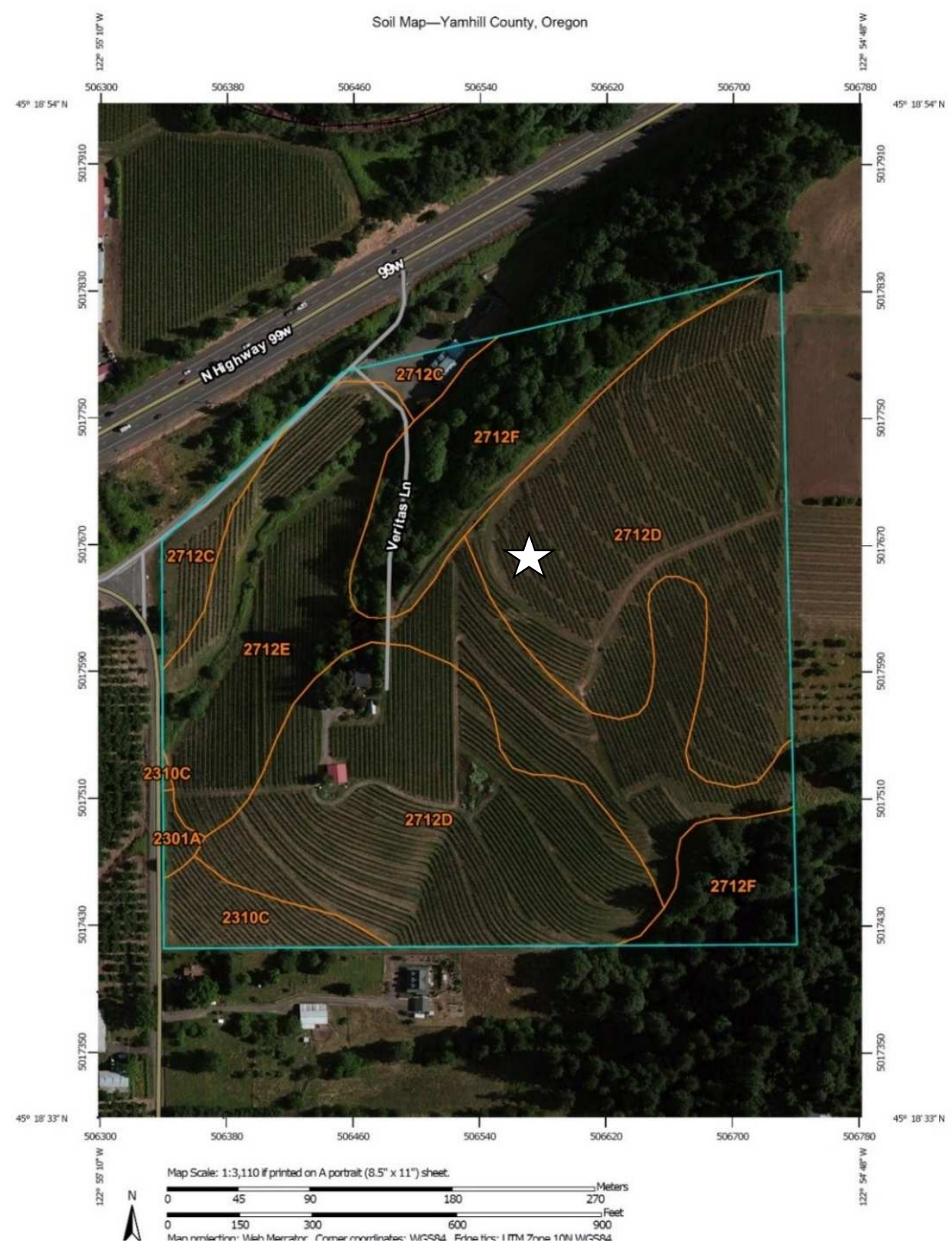

Figure 23. Soil map of Chehalem, Corral Creek Vineyard Mid North Block. Pit location marked. 2712D - Laurelwood silt loam 12 to 20 percent slopes. 2712 E - Laurelwood silt loam, 20 to 30 percent slopes. $2712 \mathrm{~F}$ - Laurelwood silt loam, 30 to 60 percent slopes. 2712C - Laurelwood silt loam, 2 to 12 percent slopes. $2310 \mathrm{C}$ - Woodburn silt loam, 2 to 12 percent slopes. $2301 \mathrm{~A}$ - Amity silt loam, 0 to 3 percent slopes (NRCS, 2015). Previously mapped as LuD - Laurelwood silt loam (NRCS, 2014). 
Table 44. Chehalem, Corral Creek Vineyards Mid North Block field and lab data.

\begin{tabular}{|c|c|c|c|c|c|c|}
\hline \multirow{3}{*}{$\begin{array}{l}\text { Depth } \\
\text { (cm) }\end{array}$} & \multirow{3}{*}{ Horizon } & \multicolumn{3}{|c|}{ Total } & \multirow[b]{2}{*}{$\begin{array}{c}\text { Coarse } \\
\text { Fragment } \\
(>2 \mathrm{~mm})\end{array}$} & \multirow[b]{2}{*}{$\begin{array}{c}\text { Texture } \\
\text { Lab }\end{array}$} \\
\hline & & $\begin{array}{c}\text { Sand } \\
(2-0.05 \\
\mathbf{m m})\end{array}$ & $\begin{array}{c}\text { Silt } \\
(0.05-0.002 \\
\text { mm })\end{array}$ & $\begin{array}{c}\text { Clay } \\
(<0.002 \text { mm })\end{array}$ & & \\
\hline & & \multicolumn{4}{|c|}{ 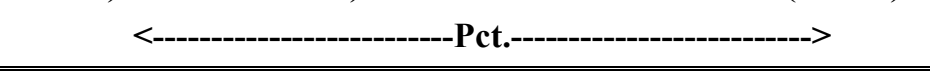 } & \\
\hline $0-35$ & Ap & 6.9 & 67.6 & 18.2 & 0.0 & $\mathrm{SiL}$ \\
\hline $35-55$ & $\mathrm{Bt}$ & 6.9 & 53.4 & 36.7 & 0.0 & $\mathrm{SiCL}$ \\
\hline $55-65$ & $\mathrm{Cr}$ & 14.8 & 49.2 & 34.6 & 5.0 & $\mathrm{SiCL}$ \\
\hline $65+$ & $\mathrm{R}$ & & & & & \\
\hline $\begin{array}{c}\text { Depth } \\
\text { (cm) }\end{array}$ & Horizon & Dry Color & Structure & $\begin{array}{c}\text { Organic } \\
\text { Matter } \\
\text { LOI (Pct.) }\end{array}$ & $\begin{array}{c}\text { pH } \\
\left(1: 1 \mathrm{H}_{2} \mathrm{O}\right)\end{array}$ & $\begin{array}{c}\text { CEC } \\
(\mathbf{m e q} / \mathbf{1 0 0 g})\end{array}$ \\
\hline $0-35$ & Ap & $10 \mathrm{YR} 4 / 3$ & $\mathrm{~m}$ to $1, \mathrm{f}, \mathrm{sbk}$ & 6.7 & 5.7 & 42.2 \\
\hline $35-55$ & $\mathrm{Bt}$ & $7.5 \mathrm{YR} 4 / 4$ & $2, \mathrm{~m}, \mathrm{sbk}$ & 5.9 & 5.9 & 19.5 \\
\hline $55-65$ & $\mathrm{Cr}$ & 7.5 YR $5 / 4$ & & 6.9 & 5.7 & \\
\hline $65+$ & $\mathrm{R}$ & & & & & \\
\hline
\end{tabular}

fragments. Clay percent increases with depth from $18 \%$ in the Ap to $37 \%$ in the $\mathrm{Bt}$ horizon. Very few to common faint to distinct clay films are located on ped faces and interstitial pores of the $\mathrm{Ap}, \mathrm{Bt}$ and $\mathrm{Cr}$ horizons. The soil contains few, fine to medium pisolites in both Ap and Bt horizons.

\section{Soil Chemistry}

The Corral Creek Vineyard soil pit was separated into four horizons, and samples of each horizon were sent for analysis (Table 45). K decreases with depth. S is only detected in the Ap horizon. $\mathrm{P}$ and $\mathrm{Ca}$ concentrations are variable, decreasing from the Ap then increasing to a maximum in the $\mathrm{R}$ horizon. $\mathrm{Mg}$ concentration bulges in the $\mathrm{Bt}$ 

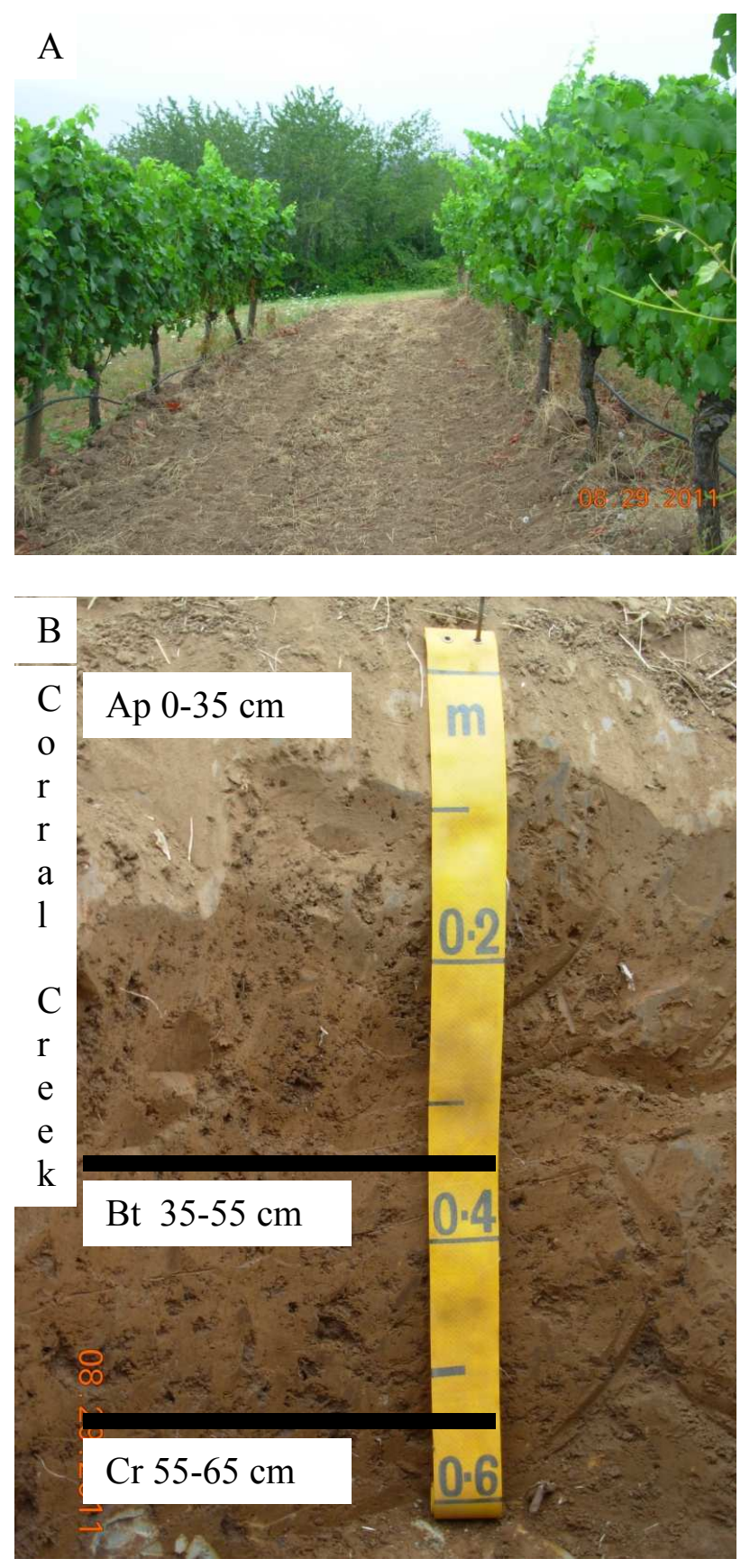

Figure 24. Sample soil pit at Chehalem, Corral Creek Vineyard Mid North Block. A - View of sample location, facing north. B - Picture of the face of the soil pit with horizon depths and boundaries marked. 
Table 45. Macronutrient concentrations (all values in $\mathrm{mg} / \mathrm{kg}$ ) for the Chehalem, Corral Creek Vineyard soil pit (ND - Non-detectable).

\begin{tabular}{|c|c|c|c|c|c|c|c|c|c|c|}
\hline Horizon (cm) & $\mathbf{P}$ & & $\mathbf{K}$ & $\mathbf{C a}$ & & Mg & & $\mathbf{S}$ & & Cl \\
\hline Ap (0-35) & 1280 & & 1560 & 1630 & & 2640 & & 148 & & ND \\
\hline Bt $(35-55)$ & 699 & & 1150 & 1440 & & 2930 & & ND & & ND \\
\hline $\operatorname{Cr}(55-65)$ & 830 & & 1020 & 1570 & & 2730 & & ND & & ND \\
\hline $\mathrm{R}(65+)$ & 1310 & & 393 & 2100 & & 1100 & & ND & & ND \\
\hline Mean & 1030 & & 1030 & 1690 & & 2350 & & 148 & & $N D$ \\
\hline$S D$ & 311 & & 483 & 288 & & 842 & & 0 & & $N D$ \\
\hline Maximum & 1310 & & 1560 & 2100 & & 2930 & & 148 & & 0 \\
\hline Horizon (cm) & $\mathrm{Fe}$ & Al & Co & $\mathbf{C u}$ & Mn & Mc & & $\mathbf{N a}$ & $\mathbf{N i}$ & $\mathbf{Z n}$ \\
\hline Ap (0-35) & 32000 & 19200 & 17.2 & 17.3 & 1210 & ND & & 214 & 9.69 & 66.0 \\
\hline $\mathrm{Bt}(35-55)$ & 31600 & 21600 & 14.8 & 12.9 & 556 & ND & & 217 & 9.5 & 43.0 \\
\hline $\operatorname{Cr}(55-65)$ & 37600 & 25500 & 19.7 & 15.3 & 715 & ND & & 225 & 13.1 & 44.6 \\
\hline $\mathrm{R}(65+)$ & 37300 & 36400 & 12.1 & 28.8 & 176 & ND & & 281 & 35.3 & 63.4 \\
\hline Mean & 34600 & 25700 & 16.0 & 18.6 & 664 & $N L$ & & 234 & 16.9 & 54.3 \\
\hline$S D$ & 3270 & 7600 & 3.25 & 7.05 & 428 & NL & & 31.5 & 12.4 & 12.1 \\
\hline Maximum & 37600 & 36400 & 19.7 & 28.8 & 1210 & 0 & & 281 & 35.3 & 66.0 \\
\hline Horizon (cm) & As & $\mathbf{B a}$ & Be & Cd & $\mathrm{Cr}$ & Hg & $\mathbf{P b}$ & Se & $\mathrm{Sr}$ & $\mathbf{V}$ \\
\hline Ap (0-35) & 3.02 & 222 & 0.645 & 0.222 & 18.2 & ND & 10.7 & ND & 19.2 & 106 \\
\hline $\mathrm{Bt}(35-55)$ & 2.80 & 134 & 0.743 & 0.180 & 19.8 & ND & 9.09 & ND & 19.2 & 98.9 \\
\hline $\operatorname{Cr}(55-65)$ & 2.56 & 240 & 0.979 & 0.372 & 20.6 & ND & 10.2 & ND & 22.5 & 111 \\
\hline $\mathrm{R}(65+)$ & 0.948 & 669 & 1.02 & 0.741 & 19.1 & ND & 12.5 & 0.686 & 34.1 & 87.3 \\
\hline Mean & 2.33 & 316 & 0.847 & 0.379 & 19.4 & $N D$ & 10.6 & 0.686 & 23.8 & 101 \\
\hline$S D$ & 0.942 & 240 & 0.182 & 0.255 & 1.02 & $N D$ & 1.42 & 0 & 7.07 & 10.3 \\
\hline Maximum & 3.02 & 669 & 1.02 & 0.741 & 20.6 & $N D$ & 12.5 & 0.686 & 34.1 & 111 \\
\hline
\end{tabular}

horizon and decreases in the $\mathrm{R}$ horizon. The micronutrient concentrations measured in the four soil horizons from the Corral Creek Vineyard have varying trends. $\mathrm{Al}, \mathrm{Na}, \mathrm{Ni}$, and $\mathrm{Cu}$ increase with depth with the highest in the $\mathrm{R}$ horizon. Fe and Co concentrations bulge in the $\mathrm{Cr}$ horizon. Mn decreases with depth. $\mathrm{Zn}$ decreases from the surface but then 
increases in the R horizon. Trace element concentrations for the four horizons of the Corral Creek Vineyard are reported. Be and Sr increase with depth and the highest concentration is in the $\mathrm{R}$ horizon. $\mathrm{Ba}, \mathrm{Cd}$, and $\mathrm{Pb}$ concentrations vary with depth but are highest also in the $\mathrm{R}$ horizon. Se was only detected in the $\mathrm{R}$ horizon. $\mathrm{Cr}$ and $\mathrm{V}$ increase to a bulge in concentration in the $\mathrm{Cr}$ horizon then decrease. As decreases with depth.

\section{Grape Juice Chemistry}

The 24 elements (same as the soil samples) were analyzed in the grape juice from grapes collected adjacent to the soil pits had concentrations of many elements that are below detection limits in this study, and only elements found in any grape sample are shown in (Table 46). The concentrations of $\mathrm{K}$ and $\mathrm{Na}$ in the Corral Creek Vineyard grape juice are $1530 \mathrm{mg} / \mathrm{kg}$ and $159 \mathrm{mg} / \mathrm{kg}$, respectively. $\mathrm{Sr}$ concentrations are measured as $0.711 \mathrm{mg} / \mathrm{kg}$, which is the $12^{\text {th }}$ highest concentration of $\mathrm{Sr}$, equal to Lange Estate Mia Vineyard, for the 20 vineyard samples (Table 105). Mean Sr concentration for all grape juice samples from the 20 different sites is $0.805 \pm 0.261 \mathrm{mg} / \mathrm{kg}$. P concentration is 303 $\mathrm{mg} / \mathrm{kg}$ for these grapes.

Table 46. Elemental concentrations measured by ICP-MS in the grape juice from clusters collected from vines immediately adjacent to the soil pit location at Chehalem, Corral Creek Vineyard (ND Non-detectable).

\begin{tabular}{cccccccccc}
\hline Element & Sr & P & K & Na & Mg & Mn & Ca & Cu & Zn \\
\hline \hline Grape Juice $(\mathrm{mg} / \mathrm{kg})$ & 0.711 & 303 & 1530 & 159 & ND & ND & ND & ND & ND \\
\hline
\end{tabular}




\section{Wine Chemistry}

Chehalem provided a $750 \mathrm{ml}$ wine sample from the Corral Creek Vineyard in 2011. Many of the 24 elements tested in the wine were below detection limits. The 14 elements that were detected in Corral Creek Vineyard wine sample include $\mathrm{Ba}, \mathrm{Ca}, \mathrm{Co}$, $\mathrm{Cu}, \mathrm{Fe}, \mathrm{Pb}, \mathrm{Mg}, \mathrm{Mn}, \mathrm{P}, \mathrm{K}, \mathrm{Na}, \mathrm{Sr}, \mathrm{S}$, and $\mathrm{Zn}$ (Table 47). K and $\mathrm{P}$ concentrations are the highest at $808 \mathrm{mg} / \mathrm{kg}$ and $467 \mathrm{mg} / \mathrm{kg}$, respectively. $\mathrm{S}$ is $87.7 \mathrm{mg} / \mathrm{kg}, \mathrm{Ca}$ is $57.2 \mathrm{mg} / \mathrm{kg}, \mathrm{Mg}$ is $54.1 \mathrm{mg} / \mathrm{kg}$, and $\mathrm{Na}$ is $8.91 \mathrm{mg} / \mathrm{kg}$ for this wine. In much lower amounts, the concentration of $\mathrm{Fe}$ is $2.13 \mathrm{mg} / \mathrm{kg}$ and $\mathrm{Mn}$ is $0.865 \mathrm{mg} / \mathrm{kg}$. The concentration of $\mathrm{Sr}$ is $0.880 \mathrm{mg} / \mathrm{kg}, \mathrm{Zn}$ is $0.567 \mathrm{mg} / \mathrm{kg}, \mathrm{Ba}$ is $0.298 \mathrm{mg} / \mathrm{kg}$, and $\mathrm{Cu}$ is $0.116 \mathrm{mg} / \mathrm{kg}$. Trace amounts of $\mathrm{Pb}(0.0845 \mathrm{mg} / \mathrm{kg})$ and $\mathrm{Co}(0.0312 \mathrm{mg} / \mathrm{kg})$ are also detected.

Table 47. Elemental concentrations measured by ICP-MS of three samples of the same $750 \mathrm{ml}$ unblended wine from the 2011 vintage of Chehalem, Corral Creek Vineyard wine (ND - Nondetectable, * denotes mean of two samples from the same bottle).

\begin{tabular}{cccc}
\hline Element & 2011 Wine Sample* $(\mathbf{m g} / \mathbf{k g})$ & Element & 2011 Wine Sample* $\mathbf{m g} / \mathbf{k g})$ \\
\hline \hline $\mathrm{Al}$ & $\mathrm{ND}$ & $\mathrm{Mn}$ & 0.865 \\
$\mathrm{As}$ & $\mathrm{ND}$ & $\mathrm{Hg}$ & $\mathrm{ND}$ \\
$\mathrm{Ba}$ & 0.298 & $\mathrm{Mo}$ & $\mathrm{ND}$ \\
$\mathrm{Be}$ & $\mathrm{ND}$ & $\mathrm{Ni}$ & $\mathrm{ND}$ \\
$\mathrm{Cd}$ & $\mathrm{ND}$ & $\mathrm{P}$ & 467 \\
$\mathrm{Ca}$ & 57.2 & $\mathrm{~K}$ & 808 \\
$\mathrm{Cr}$ & $\mathrm{ND}$ & $\mathrm{Se}$ & $\mathrm{ND}$ \\
$\mathrm{Co}$ & $\mathrm{Na}$ & 8.91 \\
$\mathrm{Cu}$ & 0.0312 & $\mathrm{Sr}$ & 0.880 \\
$\mathrm{Fe}$ & 0.116 & $\mathrm{~S}$ & 87.7 \\
$\mathrm{~Pb}$ & 2.13 & $\mathrm{~V}$ & $\mathrm{ND}$ \\
$\mathrm{Mg}$ & 0.0845 & $\mathrm{Zn}$ & 0.567 \\
\hline
\end{tabular}


Chehalem also contributed multiple vintages of each vineyard to this study to look further into the possible influence of climate on the uptake of elements from the soil. The 2008 and 2009 vintages of the Corral Creek Vineyard site are shown in (Table 48). In brief comparison, the 2008 vintage has higher concentrations of $\mathrm{Ba}, \mathrm{Cu}, \mathrm{Fe}, \mathrm{Mg}, \mathrm{Mn}$, and Sr. The Mn and Sr concentrations are very similar to the concentrations in the 2009 vintage. The 2009 vintage has the higher concentrations of $\mathrm{Ca}, \mathrm{P}, \mathrm{K}, \mathrm{Na}, \mathrm{S}$, and $\mathrm{Zn}$ than the 2008 vintage. Further analysis needs to be completed in order to determine if these differences are significant.

Table 48. Elemental concentrations measured by ICP-MS of multiple vintages of Chehalem, Corral Creek Vineyard wine (ND - Non-detectable, * denotes mean of two samples from the same bottle).

\begin{tabular}{cccccc}
\hline Element & $\begin{array}{c}\mathbf{2 0 0 8} \text { Bottle* } \\
(\mathbf{m g} / \mathbf{k g})\end{array}$ & $\begin{array}{c}\mathbf{2 0 0 9} \mathbf{B o t t l e} \\
(\mathbf{m g} / \mathbf{k g})\end{array}$ & Element & $\begin{array}{c}\mathbf{2 0 0 8} \mathbf{~ B o t t l e *} \\
(\mathbf{m g} / \mathbf{k g})\end{array}$ & $\begin{array}{c}\mathbf{2 0 0 9} \mathbf{~ B o t t l e} \\
(\mathbf{m g} / \mathbf{k g})\end{array}$ \\
\hline \hline $\mathrm{Al}$ & $\mathrm{ND}$ & $\mathrm{ND}$ & $\mathrm{Mn}$ & 1.10 & 0.926 \\
$\mathrm{As}$ & $\mathrm{ND}$ & $\mathrm{ND}$ & $\mathrm{Hg}$ & $\mathrm{ND}$ & $\mathrm{ND}$ \\
$\mathrm{Ba}$ & 0.469 & 0.272 & $\mathrm{Mo}$ & $\mathrm{ND}$ & $\mathrm{ND}$ \\
$\mathrm{Be}$ & $\mathrm{ND}$ & $\mathrm{ND}$ & $\mathrm{Ni}$ & $\mathrm{ND}$ & $\mathrm{ND}$ \\
$\mathrm{Cd}$ & $\mathrm{ND}$ & $\mathrm{ND}$ & $\mathrm{P}$ & 246 & 384 \\
$\mathrm{Ca}$ & 39.4 & 49 & $\mathrm{~K}$ & 771 & 828 \\
$\mathrm{Cr}$ & $\mathrm{ND}$ & $\mathrm{ND}$ & $\mathrm{Se}$ & $\mathrm{ND}$ & $\mathrm{ND}$ \\
$\mathrm{Co}$ & $\mathrm{ND}$ & $\mathrm{ND}$ & $\mathrm{Na}$ & 4.87 & 5.32 \\
$\mathrm{Cu}$ & 0.171 & 0.102 & $\mathrm{Sr}$ & 1.08 & 0.992 \\
$\mathrm{Fe}$ & 2.68 & 2.18 & $\mathrm{~S}$ & 75.9 & 84.8 \\
$\mathrm{~Pb}$ & $\mathrm{ND}$ & $\mathrm{ND}$ & $\mathrm{V}$ & $\mathrm{ND}$ & $\mathrm{ND}$ \\
$\mathrm{Mg}$ & 82.6 & 68.2 & $\mathrm{Zn}$ & 0.416 & 0.478 \\
\hline
\end{tabular}




\section{Clay Mineralogy}

The Bt horizon of the Corral Creek Vineyard provides the clay mineralogy for the profile. This site is described as having the most illite clay compared to the other Chehalem, Elk Cove, and Willakenzie samples. Moderate amounts of mica are present as well as minor chlorite and vermiculite interlayers. Moderate kaolinite in the sample is accompanied by trace amounts of smectite and halloysite. Minor cristobalite is also present and gibbsite with just trace amounts of goethite. The variety of clay minerals at this site, suggest a mix of parent material and ages of soil development. 


\section{Chapter Seven - Lange Estate Winery and Vineyards Results}

\section{Volcanic Parent Material - Estate Vineyard, Mia Block North Physical Characteristics}

The Mia Block Vineyard, owned and operated by Lange Estate, is located in Dundee, Oregon. These vineyards are located on basaltic rocks of the Columbia River Basalt group. Mia Block Vineyard is located on the midslope of a south facing slope with vine rows running north and south (Lat. 45.294480 N, Long. -123.043289 W). The soil pit location was at 719 feet (220 meters) elevation between rows 15 and 16, and the soil is mapped as the Jory - Gelderman (previously Jory) soil series (Figure 25). According to the vineyard manager, this vineyard is cultivated every other year. The vines are Pinot Noir Dijon 777 clone planted in 2004 and are trellised as bilateral cordon in vertical shoot position. The vines are grafted onto 3309 rootstocks (Table 8).

The Jory - Gelderman soil is characterized as a Xeric Palehumult - Xeric Haplohumult. The soil pit was $195+\mathrm{cm}$ deep, and I did not reach the parent material or refusal at that depth. Percent silt decreases from $61 \%$ in Ap to $47 \%$ in A/B but then increases again in the Bt1 horizon to $57 \%$ and then decreases again to $42 \%$ in the Bt2 and Bt3 horizons. Dry color of brown (7.5 YR 4/3) is also constant throughout (Figure 26). Structure throughout the soil profile is moderate to strong, medium subangular blocky with some granular texture in the Ap horizon and platy structure in Bt2. The Ap horizon 


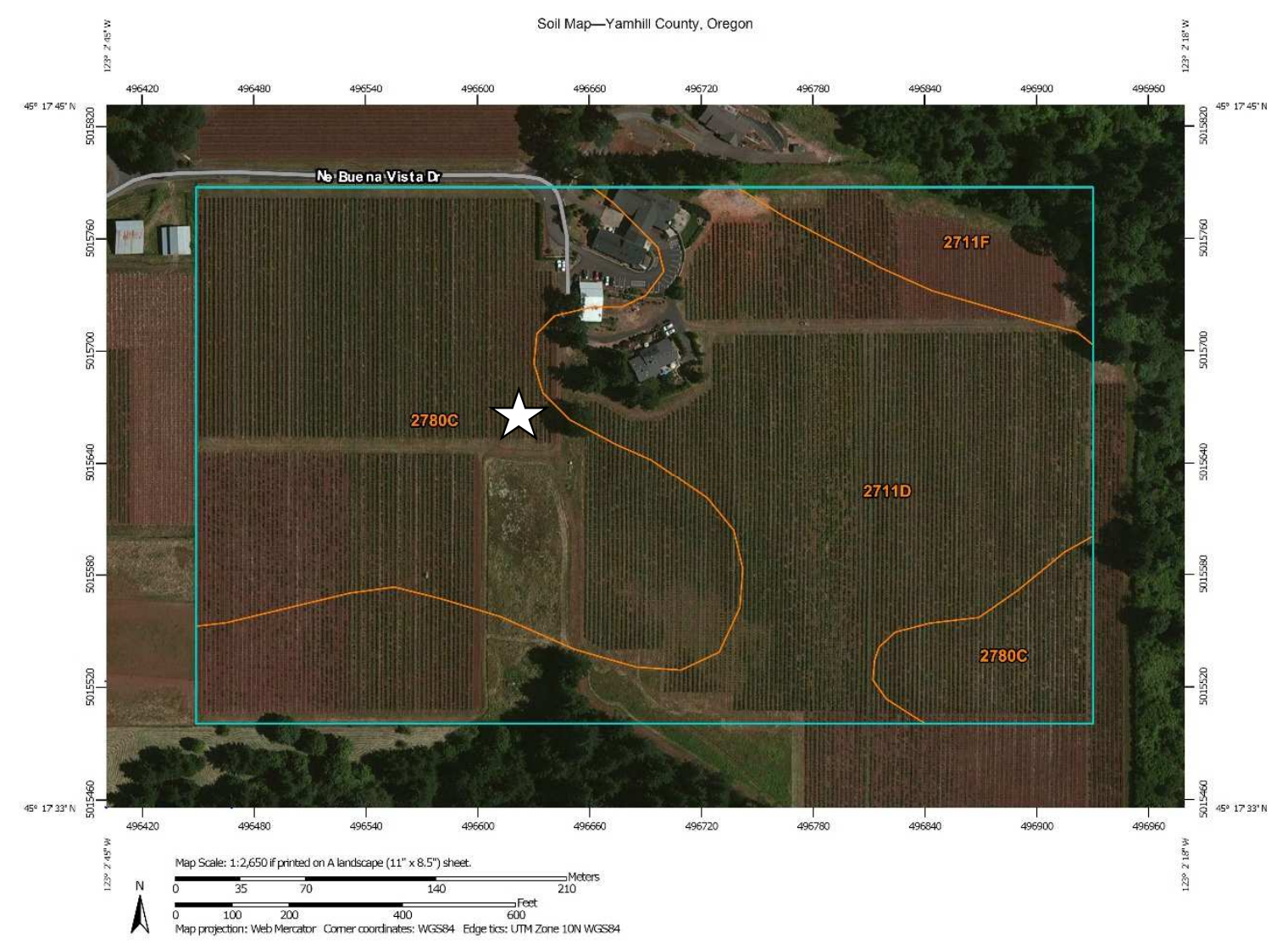

Figure 25. Soil map of Lange Estate Winery and Vineyards, Estate Vineyard Mia North Block. Pit location marked. $2780 \mathrm{C}$ - Jory-Gelderman silty clay loams, 2 to 12 percent slopes. 2711D - Jory silty clay loam, 12 to 20 percent slopes. 2711 F - Jory silty clay loam, 30 to 60 percent slopes (NRCS, 2015). Previously mapped as JrC - Jory clay loam, 7 to 12 percent slopes (NRCS, 2014).

is slightly sticky and slightly plastic, but Bt1 is sticky and plastic, and the Bt2 and Bt3 are very sticky and very plastic due to a jump in clay percent from $19 \%$ in the Ap to $46 \%$ and $43 \%$ in $\mathrm{Bt} 2$ and $\mathrm{Bt} 3$, respectively. Clay films, located on ped faces and interstitial pores, increase in number from $\mathrm{A} / \mathrm{B}$ (very few and faint) to $\mathrm{Bt} 3$ (many and dominant). Pisolites are found abundantly throughout the profile. The $\mathrm{OM}, \mathrm{pH}$ and $\mathrm{CEC}$ decrease with depth 
for this profile. The $\mathrm{pH}$ ranges from 5.3 to $5.8, \mathrm{CEC}$ ranges from 15.6 to 22.6 , and $\mathrm{OM}$ ranges from $7.8 \%$ to $10.7 \%$ (Table 49 ).

Table 49. Lange Estate Winery and Vineyards, Estate Vineyard Mia Block North field and lab data.

\begin{tabular}{|c|c|c|c|c|c|c|}
\hline \multirow{3}{*}{$\begin{array}{l}\text { Depth } \\
\text { (cm) }\end{array}$} & \multirow{3}{*}{ Horizon } & \multicolumn{3}{|c|}{ Total } & \multirow[b]{2}{*}{$\begin{array}{c}\text { Coarse } \\
\text { Fragment } \\
(>2 \mathrm{~mm})\end{array}$} & \multirow[b]{2}{*}{$\begin{array}{c}\text { Texture } \\
\text { Lab }\end{array}$} \\
\hline & & $\begin{array}{c}\text { Sand } \\
(2-0.05 \\
\text { mm) }\end{array}$ & $\begin{array}{c}\text { Silt } \\
(\mathbf{0 . 0 5 - 0 . 0 0 2} \\
\text { mm) }\end{array}$ & $\begin{array}{c}\text { Clay } \\
(<0.002 \\
\text { mm })\end{array}$ & & \\
\hline & & \multicolumn{4}{|c|}{ <---------------------------Pct.--------------------------> } & \\
\hline $0-20$ & Ap & 18.5 & 60.7 & 19.4 & 2.1 & $\mathrm{SiL}$ \\
\hline $20-50$ & $\mathrm{~A} / \mathrm{B}$ & 18.3 & 46.6 & 26.2 & 0.5 & $\mathrm{SiL}$ \\
\hline $50-80$ & Bt1 & 17.7 & 57.4 & 24.1 & 1.0 & $\mathrm{SiL}$ \\
\hline $80-140$ & $\mathrm{Bt} 2$ & 6.9 & 42.2 & 46.2 & 0.0 & $\mathrm{SiC}$ \\
\hline $140-195+$ & $\mathrm{Bt} 3$ & 8.2 & 42.3 & 43.5 & 0.3 & $\mathrm{SiC}$ \\
\hline $\begin{array}{c}\text { Depth } \\
\text { (cm) }\end{array}$ & Horizon & Dry Color & Structure & $\begin{array}{c}\text { Organic } \\
\text { Matter } \\
\text { LOI (Pct.) }\end{array}$ & $\begin{array}{c}\text { pH } \\
\left(1: 1 \mathrm{H}_{2} \mathrm{O}\right)\end{array}$ & $\underset{(\mathrm{meq} / \mathbf{1 0 0 g})}{\mathrm{CEC}}$ \\
\hline $0-20$ & Ap & $7.5 \mathrm{YR} 4 / 3$ & $2, \mathrm{~m}, \mathrm{gr}$ to $\mathrm{sbk}$ & 10.7 & 5.6 & 22.6 \\
\hline $20-50$ & $\mathrm{~A} / \mathrm{B}$ & $7.5 \mathrm{YR} 4 / 3$ & $2, \mathrm{~m}, \mathrm{sbk}$ & 9.8 & 5.8 & 22.4 \\
\hline $50-80$ & $\mathrm{Bt} 1$ & $7.5 Y R \quad 4 / 3$ & $3, \mathrm{~m}, \mathrm{sbk}$ & 8.3 & 5.8 & 18.9 \\
\hline $80-140$ & $\mathrm{Bt} 2$ & 7.5YR 4/4 & $3, \mathrm{~m}, \mathrm{pl}$ to $\mathrm{sbk}$ & 7.8 & 5.5 & 15.6 \\
\hline $140-195+$ & $\mathrm{Bt} 3$ & 7.5YR 4/4 & $3, \mathrm{~m}, \mathrm{sbk}$ & 8.6 & 5.3 & 17.8 \\
\hline
\end{tabular}

\section{Soil Chemistry}

The Lange Estate Vineyard, Mia Block soil pit was separated into five horizons, and samples of each horizon were sent for analysis (Table 50). This is one of the deepest soil pits in the project without reaching the parent material even at $195 \mathrm{~cm}$. P and Ca have bulges in the $\mathrm{A} / \mathrm{B}$ horizon. $\mathrm{K}$ concentration is highest in the Ap horizon and decreases 

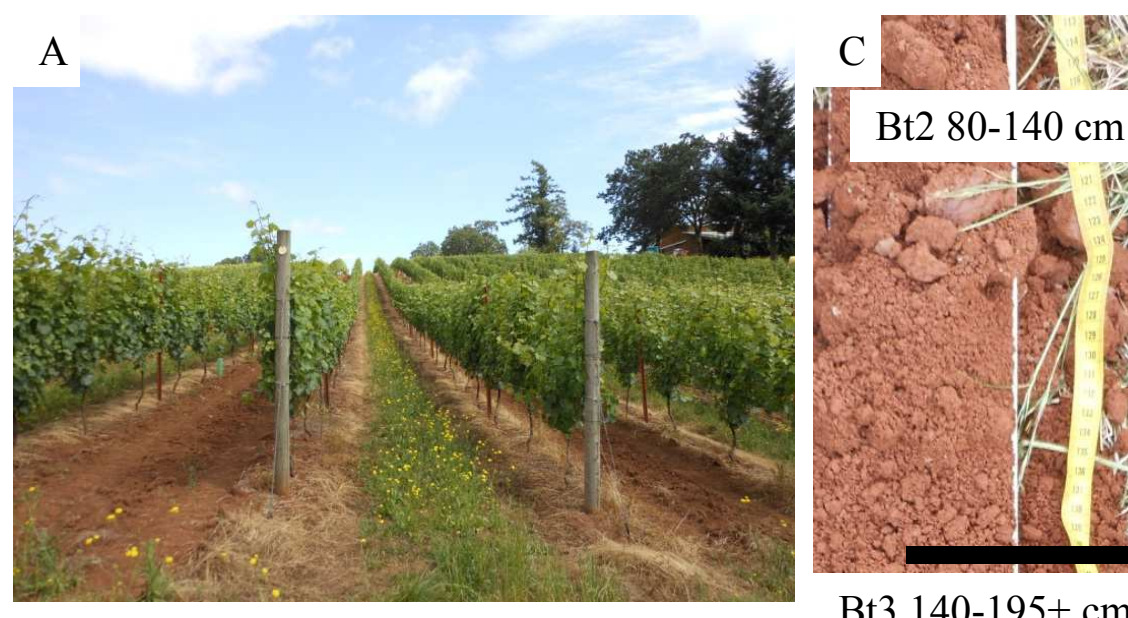

Bt2 80-140 cm

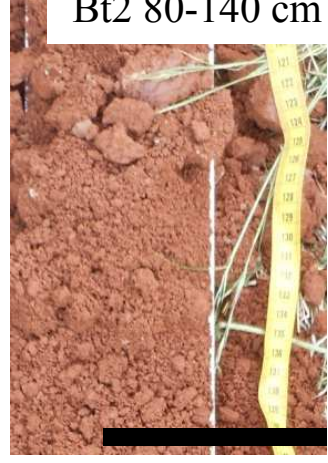

Bt3 140-195+ cm
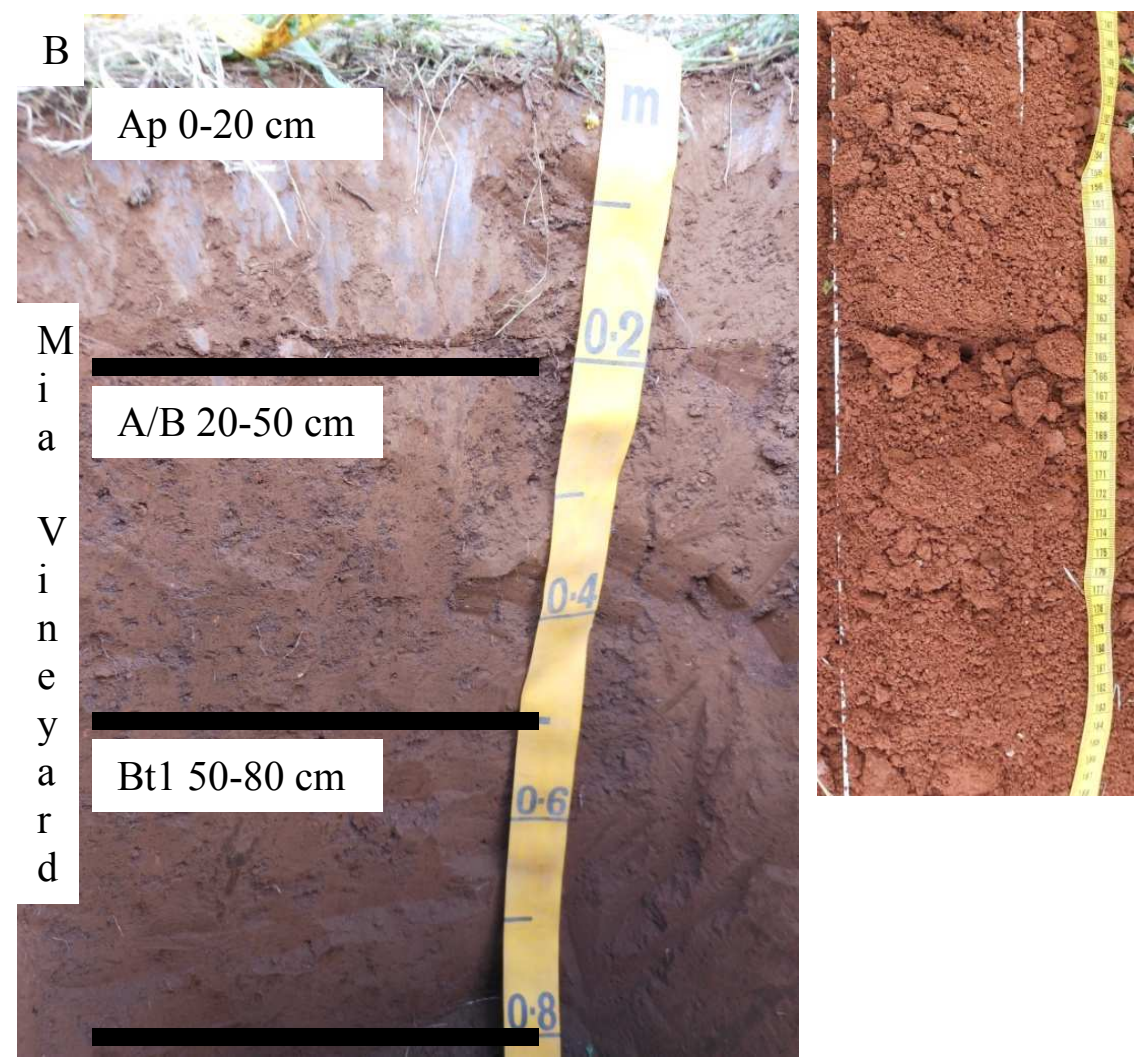

Figure 26. Sample soil pit at Lange Estate Winery and Vineyards, Estate Vineyard Mia Block North. A - View of sample location, facing north. B - Picture of the face of the soil pit with horizon depths and boundaries marked. $\mathrm{C}$ - Soil retrieved using a hand auger with horizon depths and boundaries marked. 
with depth. $\mathrm{Mg}$ reaches a maximum in the $\mathrm{Bt} 1$ and $\mathrm{Bt} 2$ horizons. $\mathrm{S}$ decreases with depth from a maximum concentration in the Ap horizon. The micronutrient concentrations measured in the five soil horizons from the Lange Estate Vineyard, Mia Block also have few trends. Fe concentration is highest in the Ap horizon and then bulges in the Bt1 horizon. $\mathrm{Al}, \mathrm{Co}, \mathrm{Mn}, \mathrm{Ni}$ and $\mathrm{Zn}$ all bulge in the $\mathrm{Bt} 1$ horizon. $\mathrm{Cu}$ is highest in the $\mathrm{A} / \mathrm{B}$ horizon. Na is highest at depth in the Bt3 horizon after variable concentrations through the profile. Trace element concentrations for the five horizons of the Lange Estate Vineyard, Mia Block are also reported. Sr, Se, As and Ba all decrease with depth. V, Be, and $\mathrm{Cr}$ decrease with depth with a bulge in the Bt1 horizon. $\mathrm{Cd}$ and $\mathrm{Pb}$ decrease with depth with a bulge in the $\mathrm{A} / \mathrm{B}$ horizon.

\section{Grape Juice Chemistry}

The grape juice samples have concentrations of many elements that are below detection limits in this study and are not listed in Table 51. All 24 elements, the same as were tested in the soil samples, were analyzed in the grape juice from grapes collected adjacent to the soil pits. $\mathrm{K}, \mathrm{Na}$, and $\mathrm{Sr}$ are the only elements found in all 20 grape juice samples and $\mathrm{P}$ is detected in 15 of the 20 sites. The concentrations of $\mathrm{K}$ and $\mathrm{Na}$ in the Stoller Vineyard grape juice are $1730 \mathrm{mg} / \mathrm{kg}$ and $162 \mathrm{mg} / \mathrm{kg}$, respectively. $\mathrm{Sr}$

concentrations are measured as $0.711 \mathrm{mg} / \mathrm{kg}$, which is the $12^{\text {th }}$ highest concentration, equal to Chehalem Corral Creek Vineyard, of $\mathrm{Sr}$ for the 20 vineyard samples (Table 105). P concentration is $248 \mathrm{mg} / \mathrm{kg}$ for this grape sample. 
Table 50. Macronutrient, micronutrient and trace element concentrations (all values in $\mathrm{mg} / \mathrm{kg}$ ) for the Lange Estate Winery and Vineyards, Estate Vineyard, Mia Block North soil pit (ND - Nondetectable).

\begin{tabular}{|c|c|c|c|c|c|c|c|c|c|c|}
\hline Horizon (cm) & $\mathbf{P}$ & & $\mathbf{K}$ & $\mathbf{C a}$ & & Mg & & $\mathbf{S}$ & & Cl \\
\hline Ap (0-20) & 1680 & & 936 & 1620 & & 1090 & & 270 & & ND \\
\hline $\mathrm{A} / \mathrm{B}(20-50)$ & 1750 & & 891 & 1790 & & 1450 & & 240 & & ND \\
\hline Bt1 (50-80) & 1650 & & 743 & 1030 & & 1590 & & 152 & & ND \\
\hline Bt2 (80-140) & 878 & & 491 & 972 & & 1590 & & ND & & ND \\
\hline Bt3 $(140-195+)$ & 1010 & & 373 & 849 & & 1220 & & ND & & ND \\
\hline Mean & 1390 & & 687 & 1250 & & 1390 & & 221 & & ND \\
\hline$S D$ & 415 & & 247 & 423 & & 225 & & 61.3 & & $N D$ \\
\hline Maximum & 1750 & & 936 & 1790 & & 1590 & & 270 & & $N D$ \\
\hline Horizon $(\mathrm{cm})$ & $\mathbf{F e}$ & Al & Co & $\mathrm{Cu}$ & Mn & Mo & $\mathbf{N}$ & $\mathrm{Ja}$ & $\mathbf{N i}$ & $\mathbf{Z n}$ \\
\hline Ap $(0-20)$ & 45700 & 19000 & 20.0 & 19.3 & 2480 & ND & 17 & 73 & 8.97 & 63.1 \\
\hline $\mathrm{A} / \mathrm{B}(20-50)$ & 39600 & 15200 & 21.1 & 22.3 & 2490 & ND & 13 & 30 & 6.69 & 50.6 \\
\hline Bt1 $(50-80)$ & 44100 & 19300 & 21.1 & 17.0 & 2560 & ND & 18 & 89 & 9.25 & 63.1 \\
\hline Bt2 (80-140) & 42200 & 17300 & 14.0 & 15.9 & 796 & ND & 17 & 77 & 7.34 & 39.5 \\
\hline Bt3 $(140-195+)$ & 43600 & 15900 & 20.4 & 17.5 & 1150 & ND & 19 & 99 & 6.11 & 33.4 \\
\hline Mean & 43000 & 17300 & 19.3 & 18.4 & 1900 & $N D$ & 1 & 74 & 7.67 & 49.9 \\
\hline$S D$ & 2290 & 1820 & 3.01 & 2.50 & 852 & $N D$ & & 6.4 & 1.39 & 13.5 \\
\hline Maximum & 45700 & 19300 & 21.1 & 22.3 & 2560 & $N D$ & & 99 & 9.25 & 63.1 \\
\hline Horizon $(\mathrm{cm})$ & As & $\mathbf{B a}$ & $\mathrm{Be}$ & Cd & $\mathrm{Cr}$ & $\mathrm{Hg}$ & $\mathbf{P b}$ & Se & $\mathrm{Sr}$ & $\mathbf{V}$ \\
\hline Ap $(0-20)$ & 2.75 & 281 & 0.770 & 0.292 & 26.6 & ND & 12.1 & 0.604 & 24.8 & 139 \\
\hline $\mathrm{A} / \mathrm{B}(20-50)$ & 2.12 & 265 & 0.695 & 0.301 & 21.8 & ND & 12.4 & 0.581 & 23.0 & 119 \\
\hline Bt1 (50-80) & 2.25 & 229 & 0.757 & 0.289 & 25.7 & ND & 11.5 & 0.508 & 16.2 & 130 \\
\hline Bt2 (80-140) & 1.49 & 110 & 0.696 & 0.203 & 23.8 & ND & 10.0 & ND & 15.3 & 122 \\
\hline Bt3 (140-195+) & 1.18 & 87.2 & 0.670 & 0.231 & 22.0 & ND & 10.7 & ND & 13.3 & 125 \\
\hline Mean & 1.96 & 194 & 0.718 & 0.263 & 24.0 & $N D$ & 11.3 & 0.564 & 18.5 & 127 \\
\hline$S D$ & 0.625 & 89.9 & 0.0434 & 0.0435 & 2.15 & $N D$ & 0.991 & 0.050 & 5.06 & 7.84 \\
\hline Maximum & 2.75 & 281 & 0.770 & 0.301 & 26.6 & $N D$ & 12.4 & 0.604 & 24.8 & 139 \\
\hline
\end{tabular}


Table 51. Elemental concentrations measured by ICP-MS in the grape juice from clusters collected from vines immediately adjacent to the soil pit location at Lange Estate, Estate Vineyard Mia Block North (ND - Non-detectable).

\begin{tabular}{cccccccccc}
\hline Element & Sr & P & K & Na & Mg & Mn & Ca & Cu & Zn \\
\hline \hline Grape Juice $(\mathrm{mg} / \mathrm{kg})$ & 0.711 & 248 & 1730 & 162 & ND & ND & ND & ND & ND \\
\hline
\end{tabular}

\section{Wine Chemistry}

Lange Estate Winery and Vineyards provided a $750 \mathrm{ml}$ sample of the wine produced from the Estate Vineyard, Mia Block in 2012. Many of the 24 elements tested in the wine (same as the elements tested in the soil samples) were below detection limits. The 14 elements that were detected in Estate Vineyard, Mia Block wine sample include $\mathrm{Ba}, \mathrm{Ca}, \mathrm{Co}, \mathrm{Cu}, \mathrm{Fe}, \mathrm{Pb}, \mathrm{Mg}, \mathrm{Mn}, \mathrm{P}, \mathrm{K}, \mathrm{Na}, \mathrm{Sr}, \mathrm{S}$, and Zn (Table 52). K and P concentrations are the highest at $739 \mathrm{mg} / \mathrm{kg}$ and $168 \mathrm{mg} / \mathrm{kg}$, respectively. $\mathrm{S}$ is $108 \mathrm{mg} / \mathrm{kg}$, $\mathrm{Mg}$ is $73.3 \mathrm{mg} / \mathrm{kg}, \mathrm{Ca}$ is $28.5 \mathrm{mg} / \mathrm{kg}$, and $\mathrm{Na}$ is $10.2 \mathrm{mg} / \mathrm{kg}$ for this wine. In much lower amounts, the concentration of $\mathrm{Mn}$ is $2.30 \mathrm{mg} / \mathrm{kg}$ and $\mathrm{Fe}$ is $1.75 \mathrm{mg} / \mathrm{kg}$. The concentration of $\mathrm{Sr}$ is $1.04 \mathrm{mg} / \mathrm{kg}, \mathrm{Ba}$ is $0.462 \mathrm{mg} / \mathrm{kg}, \mathrm{Zn}$ is $0.274 \mathrm{mg} / \mathrm{kg}$, and $\mathrm{Cu}$ is $0.141 \mathrm{mg} / \mathrm{kg}$. Trace amounts of $\mathrm{Pb}(0.0892 \mathrm{mg} / \mathrm{kg})$ and $\mathrm{Co}(0.0330 \mathrm{mg} / \mathrm{kg})$ are also detected in the Estate Vineyard, Mia Block wine sample.

\section{Clay Mineralogy}

The Mia Block clay mineral assemblage was determined from the Bt3 horizon. It is considered very similar to the Lange Yamhill (marine sediment parent material), Rex Hill Sims (volcanic parent material), and Ken Wright Abbot Claim Vineyards (marine sediment parent material). This soil is dominated by disordered kaolinite with trace 
amounts of halloysite, illite, hydroxy-interlayered smectite-vermiculite and chloriticintergrade clays. Moderate goethite and minor amounts of gibbsite are present. Hydroxy interlayered material is composed of highly pillared clays with lots of hydroxy Al-Fe interlayer material.

Table 52. Elemental concentrations measured twice by ICP-MS of the same $750 \mathrm{ml}$ unblended wine sample from the 2012 Lange Estate Winery, Mia Block North Vineyard (ND - Non-detectable, * denotes mean of two samples from the same bottle).

\begin{tabular}{cccc}
\hline Element & 2012 Wine Sample* $(\mathbf{m g} / \mathbf{k g})$ & Element & 2012 Wine Sample* $\mathbf{m g} / \mathbf{k g})$ \\
\hline \hline $\mathrm{Al}$ & $\mathrm{ND}$ & $\mathrm{Mn}$ & 2.30 \\
$\mathrm{As}$ & $\mathrm{ND}$ & $\mathrm{Hg}$ & $\mathrm{ND}$ \\
$\mathrm{Ba}$ & 0.462 & $\mathrm{Mo}$ & $\mathrm{ND}$ \\
$\mathrm{Be}$ & $\mathrm{ND}$ & $\mathrm{Ni}$ & $\mathrm{ND}$ \\
$\mathrm{Cd}$ & $\mathrm{ND}$ & $\mathrm{P}$ & 168 \\
$\mathrm{Ca}$ & 28.5 & $\mathrm{~K}$ & 739 \\
$\mathrm{Cr}$ & $\mathrm{ND}$ & $\mathrm{Se}$ & $\mathrm{ND}$ \\
$\mathrm{Co}$ & 0.0330 & $\mathrm{Na}$ & 10.2 \\
$\mathrm{Cu}$ & 0.141 & $\mathrm{Sr}$ & 1.04 \\
$\mathrm{Fe}$ & 1.75 & $\mathrm{~S}$ & 108 \\
$\mathrm{~Pb}$ & 0.0892 & $\mathrm{~V}$ & $\mathrm{ND}$ \\
$\mathrm{Mg}$ & 73.3 & $\mathrm{Zn}$ & 0.274 \\
\hline
\end{tabular}

\section{Marine Sediment Parent Material - Yamhill Vineyard}

\section{Physical Characteristics}

Yamhill Vineyard, owned and operated by Ralph Stein, is located in Yamhill, Oregon. These vineyards are located on Coast Range marine sediments. Yamhill Vineyard is located on the summit of a south facing slope with vine rows running north and south (Lat. 45.324441 N, Long. -123.150227 W). The soil pit location was at 453 


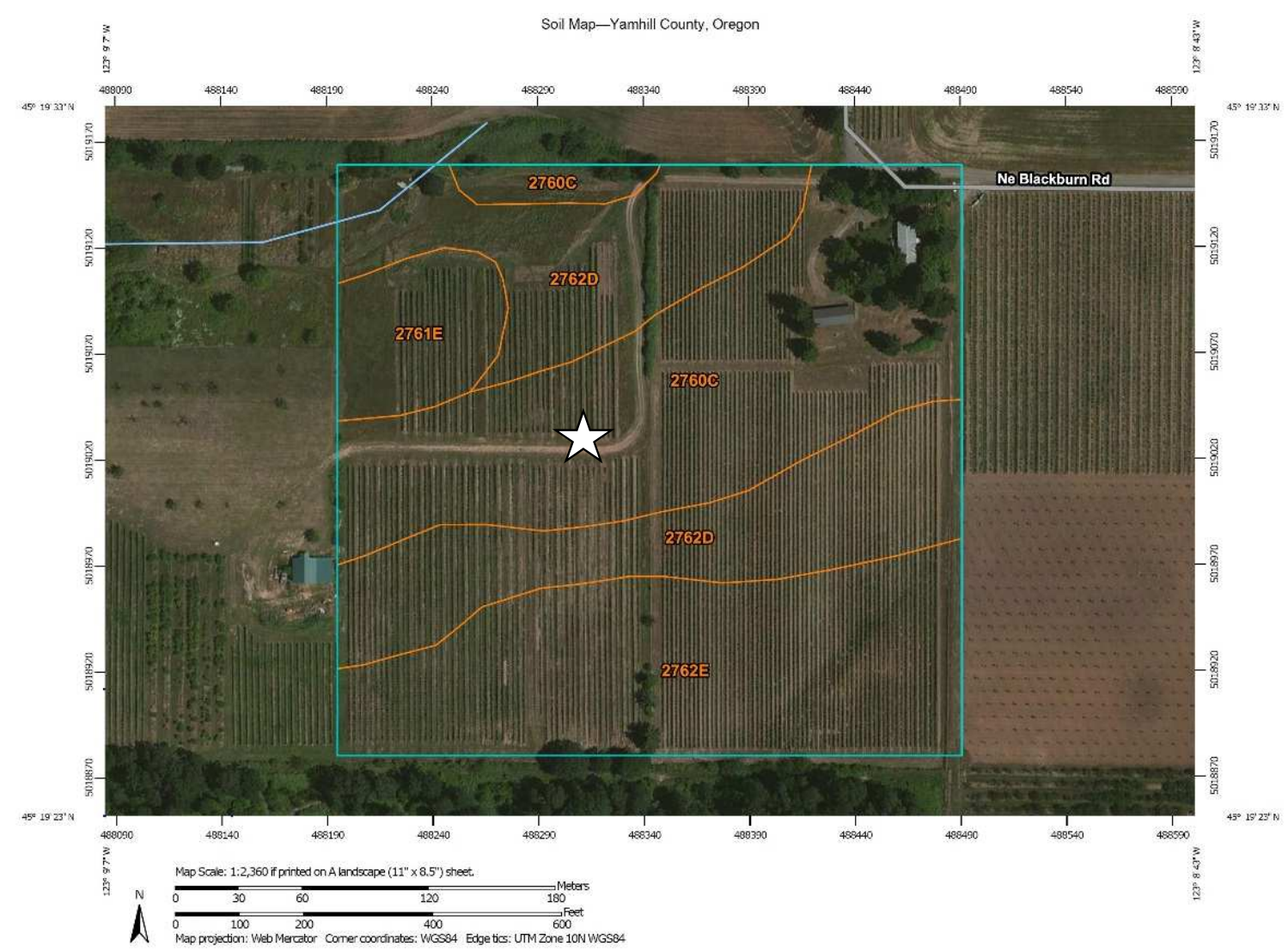

Figure 27. Soil map of Lange Estate Winery and Vineyards, Yamhill Vineyard. Pit location marked. 2760C - Wellsdale-Willakenzie-Dupee complex, 2 to 12 percent slopes. 2762D - WillakenzieWellsdale complex, 12 to 20 percent slopes. 2762E - Willakenzie-Wellsdale complex, 20 to 30 percent slopes. 2761E - Wellsdale-Willakenzie complex, 20 to 30 percent slopes (NRCS, 2015). Previously mapped as WeC - Willakenzie silty clay loam, 2 to 12 percent slopes (NRCS, 2014).

feet (138 meters) elevation between rows 9 and 10, and the soil is mapped as the Wellsdale complex soil series (Figure 27). According to the vineyard owner, this vineyard suffers from phylloxera (Dactylosphaera vitifoliae) and has produced small clusters of grapes since planted. The impact of phylloxera on the roots of the vines, restricting nutrients, may also influence the uptake of trace elements. The vines are Pinot 
Noir Pommard clone planted in 1986 and are trellised as bilateral cordon in vertical shoot position. The vines are most likely own-rooted (Table 8).

Table 53. Lange Estate Winery and Vineyards, Yamhill Vineyard field and lab data.

\begin{tabular}{|c|c|c|c|c|c|c|}
\hline \multirow{3}{*}{$\begin{array}{l}\text { Depth } \\
\text { (cm) }\end{array}$} & \multirow{3}{*}{ Horizon } & \multicolumn{3}{|c|}{ Total } & \multirow[b]{2}{*}{$\begin{array}{c}\text { Coarse } \\
\text { Fragment } \\
(>2 \mathrm{~mm})\end{array}$} & \multirow[b]{2}{*}{$\begin{array}{c}\text { Texture } \\
\text { Lab }\end{array}$} \\
\hline & & $\begin{array}{l}\text { Sand } \\
(2-0.05 \\
\text { mm) }\end{array}$ & $\begin{array}{c}\text { Silt } \\
(0.05-0.002 \\
\text { mm) }\end{array}$ & $\begin{array}{c}\text { Clay } \\
(<0.002 \text { mm) }\end{array}$ & & \\
\hline & & \multicolumn{4}{|c|}{ 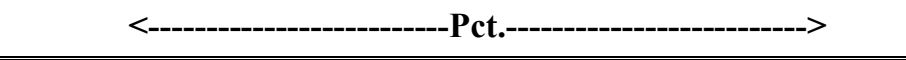 } & \\
\hline $0-26$ & Ap & 39.6 & 43.8 & 18.2 & 0.1 & $\mathrm{~L}$ \\
\hline $26-42$ & Bt1 & 32.6 & 36.3 & 30.7 & 0.0 & $\mathrm{CL}$ \\
\hline $42-75$ & Bt2 & 30.3 & 32.4 & 37.0 & 0.0 & $\mathrm{CL}$ \\
\hline $75-110$ & $\mathrm{Bg}$ & 41.2 & 30.3 & 26.6 & 1.9 & CL \\
\hline $110-160$ & $\mathrm{Cr} 1$ & 58.6 & 27.1 & 13.1 & 0.0 & SL \\
\hline $160-200+$ & $\mathrm{Cr} 2$ & 56.2 & 30.2 & 11.7 & 0.0 & SL \\
\hline $\begin{array}{l}\text { Depth } \\
\text { (cm) }\end{array}$ & Horizon & Dry Color & Structure & $\begin{array}{c}\text { Organic } \\
\text { Matter } \\
\text { LOI (Pct.) }\end{array}$ & $\begin{array}{c}\text { pH } \\
\left(1: 1 \mathrm{H}_{2} \mathrm{O}\right)\end{array}$ & $\begin{array}{c}\text { CEC } \\
(\mathbf{m e q} / \mathbf{1 0 0 g})\end{array}$ \\
\hline $0-26$ & Ap & 10YR 5/4 & $2, \mathrm{f}, \mathrm{gr}$ to $\mathrm{sbk}$ & 5.7 & 5.8 & 14.0 \\
\hline $26-42$ & Bt1 & $10 \mathrm{YR} 6 / 4$ & $2, \mathrm{~m}, \mathrm{sbk}$ & 5.1 & 5.5 & 15.3 \\
\hline \multirow[t]{2}{*}{$42-75$} & Bt2 & 7.5YR 5/6 & $2, \mathrm{~m}, \mathrm{sbk}$ & 6.2 & 5.3 & 17.8 \\
\hline & & 7.5YR 5/4 & & & & \\
\hline \multirow[t]{2}{*}{$75-110$} & $\mathrm{Bg}$ & $5 Y R 6 / 6$ & $1, \mathrm{c} / \mathrm{f}, \mathrm{pl}$ to sbk & 8.7 & 4.9 & 26.1 \\
\hline & & $5 Y R 7 / 3$ & & & & \\
\hline $110-160$ & $\mathrm{Cr} 1$ & $10 \mathrm{YR} 7 / 4$ & $\mathrm{sg}$ to $1, \mathrm{f}, \mathrm{sbk}$ & 8.5 & 5.0 & \\
\hline $160-200+$ & $\mathrm{Cr} 2$ & 10YR $7 / 4$ & sg to $1, f, s b k$ & 8.4 & 5.1 & \\
\hline
\end{tabular}

The Wellsdale complex soil is characterized as an Aquultic Haploxeralf. The soil pit was $200+\mathrm{cm}$ deep, and I did not reach the parent material or refusal at that depth. Percent sand varies from 30\% in the Bt2 horizon to 59\% in $\mathrm{Cr} 1$ and $40 \%$ in Ap. The pH decreases with depth from 5.8 to 4.9.CEC increases with depth and OM ranges from 
$5.1 \%$ to $8.7 \%$ (Table 53). Dry colors for the Ap horizon are yellowish brown (10 YR 5/4). The Bt2 horizon is strong brown (7.5 YR 5/6), and the $\mathrm{Bg}$ horizon is multicolored with brown (7.5 YR 5/4) dominant with reddish yellow (5 YR 6/6) and pink (5 YR 7/3) speckling (Figure 28). Textures include loam, clay loam and sandy loam with depth. Structure is medium subangular blocky with some granular texture in the Ap, Cr1 and $\mathrm{Cr} 2$ horizons. The Bt1 is very sticky and very plastic due to a jump in clay percent from $18 \%$ in the Ap to $31 \%$ in the Bt1 and $37 \%$ percent in the Bt 2 horizon. Clay films located on ped faces are common and dominant in the $\mathrm{Bt} 1$ and $\mathrm{Bt} 2$ horizons. The soil contains muscovite mica and quartz sand, and no pisolites are found in the profile.

\section{Soil Chemistry}

The Yamhill Vineyard soil pit was separated into six horizons, and samples of each horizon were sent for analysis (Table 54). This is one of the deepest soil pits, reaching weathered parent material ( $\mathrm{Cr} 1$ horizon) at $110 \mathrm{~cm}$ but continuing through the friable material to $200 \mathrm{~cm}$. The maximum concentration of most macronutrients is in the $\mathrm{Cr} 2$ horizon. Ca concentration bulges in the $\mathrm{Bg}$ horizon and $\mathrm{Mg}$ bulges in the $\mathrm{Bt} 1$ horizon. $\mathrm{S}$ is only detected in the Ap horizon. $\mathrm{Cl}$ is only detected in the $\mathrm{Cr} 1$ horizon. The micronutrient concentrations measured in the six soil horizons from the Yamhill Vineyard also have few trends. $\mathrm{Na}, \mathrm{Ni}, \mathrm{Zn}$, and $\mathrm{Cu}$ concentrations are highest in the $\mathrm{Cr} 2$ horizon but bulge in the Bt1 horizon. Mn is highest in the Ap horizon with a bulge in the Bt2 horizon. 


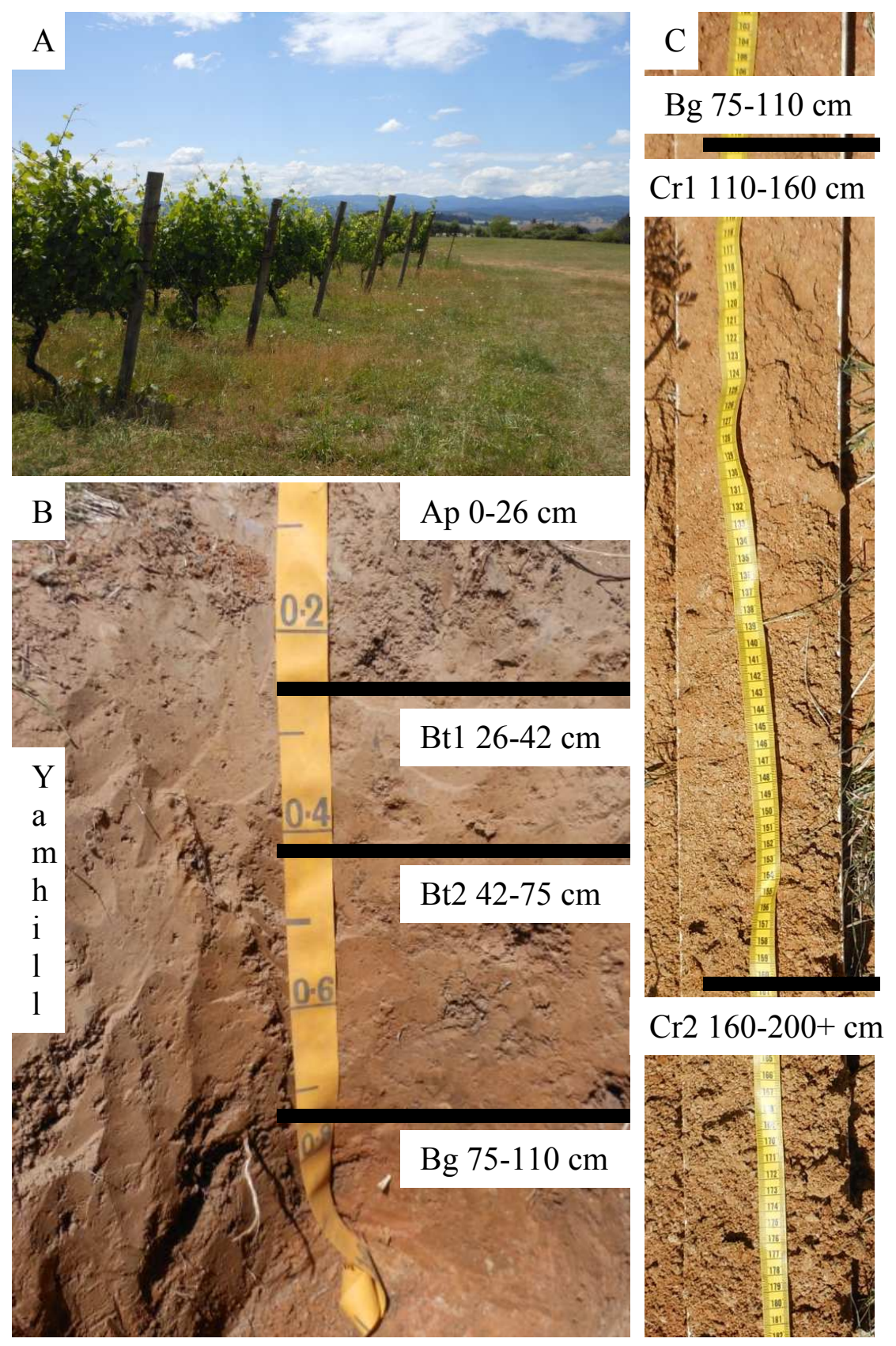

Figure 28. Sample soil pit at Lange Estate Winery and Vineyards, Yamhill Vineyard. A - View of sample location, facing northwest. B - Picture of the face of the soil pit with horizon depths and boundaries marked. $\mathrm{C}$ - Soil retrieved using a hand auger with horizon depths and boundaries marked. 
Table 54. Macronutrient, micronutrient and trace element concentrations (all values in $\mathrm{mg} / \mathrm{kg}$ ) for the Lange Estate Winery and Vineyards, Yamhill Vineyard soil pit (ND - Non-detectable).

\begin{tabular}{|c|c|c|c|c|c|c|c|c|c|c|}
\hline Horizon (cm) & $\mathbf{P}$ & & $\mathbf{K}$ & $\mathbf{C a}$ & & Mg & & $\mathbf{S}$ & & Cl \\
\hline Ap (0-26) & 367 & & 839 & 1120 & & 102 & & 154 & & ND \\
\hline Bt1 (26-42) & 318 & & 1280 & 805 & & 292 & & ND & & ND \\
\hline Bt2 (42-75) & 367 & & 1020 & 1260 & & 145 & & ND & & ND \\
\hline Bg (75-110) & 382 & & 909 & 130 & & 149 & & ND & & ND \\
\hline Cr1 (110-160) & 351 & & 1760 & 836 & & 409 & & ND & & 11.1 \\
\hline Cr2 (160-200+) & 415 & & 1790 & 1500 & & 467 & & ND & & ND \\
\hline Mean & 367 & & 1270 & 1140 & & 261 & & 154 & & 11.1 \\
\hline$S D$ & 32.2 & & 422 & 274 & & 153 & & 0 & & 0 \\
\hline Maximum & 415 & & 1790 & 1500 & & 467 & & 154 & & 11.1 \\
\hline Horizon (cm) & $\mathbf{F e}$ & Al & Co & $\mathrm{Cu}$ & Mn & & & $\mathbf{N a}$ & $\mathbf{N i}$ & $\mathbf{Z n}$ \\
\hline Ap (0-26) & 14500 & 5760 & 8.46 & 10.3 & 549 & & & 178 & 3.83 & 23.5 \\
\hline Bt1 (26-42) & 27200 & 12800 & 4.49 & 12.9 & 126 & & & 204 & 6.33 & 38.0 \\
\hline Bt2 (42-75) & 24700 & 10400 & 8.83 & 11.3 & 326 & & & 184 & 5.31 & 25.7 \\
\hline Bg (75-110) & 27000 & 11000 & 10.2 & 11.6 & 304 & & & 168 & 5.31 & 26.5 \\
\hline Cr1 (110-160) & 27600 & 13200 & 4.54 & 14.7 & 136 & & & 183 & 8.02 & 48.5 \\
\hline Cr2 (160-200+) & 36900 & 12300 & 5.36 & 16.9 & 191 & & & 222 & 11.9 & 53.5 \\
\hline Mean & 26300 & 10900 & 6.98 & 13.0 & 272 & & & 190 & 6.78 & 36.0 \\
\hline$S D$ & 7170 & 2740 & 2.48 & 2.46 & 159 & & & 19.7 & 2.86 & 12.8 \\
\hline Maximum & 36900 & 13200 & 10.2 & 16.9 & 549 & & & 222 & 11.9 & 53.5 \\
\hline Horizon (cm) & As & $\mathbf{B a}$ & Be & Cd & $\mathrm{Cr}$ & $\mathbf{H g}$ & $\mathbf{P b}$ & Se & $\mathrm{Sr}$ & $\mathbf{V}$ \\
\hline Ap $(0-26)$ & 2.07 & 92.5 & 0.342 & 0.101 & 12.5 & ND & 6.92 & ND & 12.3 & 32.1 \\
\hline Bt1 (26-42) & 2.24 & 87.3 & 0.543 & ND & 20.3 & ND & 7.26 & ND & 22.6 & 43.5 \\
\hline Bt2 (42-75) & 2.68 & 93.5 & 0.535 & ND & 19.4 & ND & 6.76 & ND & 15.9 & 51.9 \\
\hline Bg (75-110) & 2.88 & 87 & 0.586 & ND & 19.5 & ND & 7.88 & ND & 17.9 & 55.5 \\
\hline Cr1 (110-160) & 3.41 & 102 & 0.620 & ND & 19.5 & ND & 6.09 & ND & 23.7 & 38.2 \\
\hline $\mathrm{Cr} 2(160-200+)$ & 3.38 & 116 & 0.855 & 0.119 & 21.4 & ND & 6.00 & 0.517 & 36.9 & 37.9 \\
\hline Mean & 2.78 & 96.4 & 0.580 & 0.110 & 18.8 & $N D$ & 6.82 & 0.517 & 21.6 & 43.2 \\
\hline$S D$ & 0.561 & 11.0 & 0.166 & 0.013 & 3.16 & $N D$ & 0.712 & 0 & 8.63 & 8.98 \\
\hline Maximum & 3.41 & 116 & 0.855 & 0.119 & 21.4 & $N D$ & 7.88 & 0.517 & 36.9 & 55.5 \\
\hline
\end{tabular}


Co bulges in the $\mathrm{Bg}$ horizon. $\mathrm{Fe}$ and $\mathrm{Al}$ are highest in the $\mathrm{Cr} 2$ and $\mathrm{Cr} 1$ horizons, respectively, both with small bulges in the Bt1 horizon. Yamhill Vineyard trace element concentrations were also determined for the six horizons. $\mathrm{Ba}, \mathrm{Be}, \mathrm{Cr}$, and $\mathrm{Sr}$ have variable concentrations with the maximum concentration in the $\mathrm{Cr} 2$ horizon. Se was only detected in the $\mathrm{Cr} 2$ horizon. Cd was detected in the Ap horizon and at slightly higher concentrations in the $\mathrm{Cr} 2$ horizon. $\mathrm{Pb}$ concentration is variable with the maximum in the Bg horizon. As increases with depth with the highest in the $\mathrm{Cr} 1$ horizon.

\section{Grape Juice Chemistry}

The same 24 elements that were tested in the soil samples were analyzed in the grape juice from grapes collected adjacent to the soil pits. The grape juice samples have concentrations of many elements that are below detection limits in this study and are not listed in Table 55. The concentrations of $\mathrm{K}$ and $\mathrm{Na}$ in the Yamhill Vineyard grape juice are $1220 \mathrm{mg} / \mathrm{kg}$ and $141 \mathrm{mg} / \mathrm{kg}$, respectively. Sr concentrations are measured as 1.41 $\mathrm{mg} / \mathrm{kg}$, which is the highest concentration of $\mathrm{Sr}$ for the 20 vineyard samples (Table 105). Mean $\mathrm{Sr}$ concentration for all grape juice samples from the 20 different sites is $0.805 \pm$ $0.261 \mathrm{mg} / \mathrm{kg}$. P concentration is $243 \mathrm{mg} / \mathrm{kg}$ for this grape sample. This is the only grape sample with detectable levels of $\mathrm{Mg}(111 \mathrm{mg} / \mathrm{kg})$ and one of two samples, along with Ken Wright Nysa Vineyard, with detectable levels of Ca $(115 \mathrm{mg} / \mathrm{kg})$ in the grapes. 
Table 55. Elemental concentrations measured by ICP-MS in the grape juice from clusters collected from vines immediately adjacent to the soil pit location at Lange Estate, Yamhill Vineyard (ND Non-detectable).

\begin{tabular}{cccccccccc}
\hline Element & Sr & P & K & Na & Mg & Mn & Ca & Cu & Zn \\
\hline \hline Grape Juice $(\mathrm{mg} / \mathrm{kg})$ & 1.41 & 243 & 1220 & 141 & 111 & ND & 115 & ND & ND \\
\hline
\end{tabular}

\section{Wine Chemistry}

Lange Estate Winery and Vineyards provided a $750 \mathrm{ml}$ sample of the wine

produced from the Yamhill Vineyard in 2012. Many of the 24 elements tested in the wine (same as the elements tested in the soil samples) were below detection limits. The 11 elements that were detected in Yamhill Vineyard wine sample include $\mathrm{Ba}, \mathrm{Ca}, \mathrm{Fe}, \mathrm{Mg}$, Mn, $\mathrm{P}, \mathrm{K}, \mathrm{Na}, \mathrm{Sr}, \mathrm{S}$, and $\mathrm{Zn}$ (Table 56). $\mathrm{Co}, \mathrm{Cu}$, and $\mathrm{Pb}$ were not detected in this sample while they are commonly detected in other wine samples in this study. $\mathrm{K}$ and $\mathrm{P}$ concentrations are the highest at $743 \mathrm{mg} / \mathrm{kg}$ and $206 \mathrm{mg} / \mathrm{kg}$, respectively. $\mathrm{S}$ is 74.2 $\mathrm{mg} / \mathrm{kg}, \mathrm{Mg}$ is $94.4 \mathrm{mg} / \mathrm{kg}, \mathrm{Ca}$ is $31.7 \mathrm{mg} / \mathrm{kg}$, and $\mathrm{Na}$ is $4.85 \mathrm{mg} / \mathrm{kg}$ for this wine. In much lower amounts, the concentration of $\mathrm{Mn}$ is $2.36 \mathrm{mg} / \mathrm{kg}$ and $\mathrm{Fe}$ is $1.42 \mathrm{mg} / \mathrm{kg}$. The concentration of $\mathrm{Sr}$ is $1.62 \mathrm{mg} / \mathrm{kg}, \mathrm{Ba}$ is $0.54 \mathrm{mg} / \mathrm{kg}$, and $\mathrm{Zn}$ is $0.334 \mathrm{mg} / \mathrm{kg}$.

\section{Clay Mineralogy}

As stated previously, the Yamhill Vineyard clays are considered very similar to the Lange Estate (volcanic parent material), Rex Hill Sims (volcanic parent material), and Ken Wright Abbot Claim Vineyards (marine sediment parent material). The mineralogy is determined from the $\mathrm{Bt} 2$ horizon of this profile. This soil is dominated by disordered kaolinite, indicating strong weathered material. Trace amounts of mica, illite, chlorite, 
smectite, and halloysite are present. The smectite-vermiculite, chloritic intergrade clays are present in trace amounts as well. Moderate amounts of goethite are present as the main Fe phase.

Table 56. Elemental concentrations measured by ICP-MS of a $750 \mathrm{ml}$ unblended wine sample from the 2012 Lange Estate Winery, Yamhill Vineyard (ND - Non-detectable).

\begin{tabular}{cccc}
\hline Element & 2012 Wine Sample (mg/kg) & Element & 2012 Wine Sample (mg/kg) \\
\hline \hline $\mathrm{Al}$ & $\mathrm{ND}$ & $\mathrm{Mn}$ & 2.36 \\
$\mathrm{As}$ & $\mathrm{ND}$ & $\mathrm{Hg}$ & $\mathrm{ND}$ \\
$\mathrm{Ba}$ & 0.54 & $\mathrm{Mo}$ & $\mathrm{ND}$ \\
$\mathrm{Be}$ & $\mathrm{ND}$ & $\mathrm{Ni}$ & $\mathrm{ND}$ \\
$\mathrm{Cd}$ & $\mathrm{ND}$ & $\mathrm{P}$ & 206 \\
$\mathrm{Ca}$ & 31.7 & $\mathrm{~K}$ & 743 \\
$\mathrm{Cr}$ & $\mathrm{ND}$ & $\mathrm{Se}$ & $\mathrm{ND}$ \\
$\mathrm{Co}$ & $\mathrm{ND}$ & $\mathrm{Na}$ & 4.85 \\
$\mathrm{Cu}$ & $\mathrm{ND}$ & $\mathrm{Sr}$ & 1.62 \\
$\mathrm{Fe}$ & 1.42 & $\mathrm{~S}$ & 74.2 \\
$\mathrm{~Pb}$ & $\mathrm{ND}$ & $\mathrm{V}$ & $\mathrm{ND}$ \\
$\mathrm{Mg}$ & 94.4 & $\mathrm{Zn}$ & 0.334 \\
\hline
\end{tabular}

\section{Marine Sediment Parent Material - Freedom Hill Vineyard}

\section{Physical Characteristics}

The Freedom Hill Vineyard, owned and operated by Dan and Helen Dusschee, is located near Monmouth and Dallas, Oregon. These vineyards are located on marine sedimentary rocks of the Coast Range. Lange's Freedom Hill Vineyard soil is located on the midslope of an east facing slope of 0 to 1 degrees with vine rows running north and south (Lat. 44.877285 N, Long. -123.286436 W). The soil pit location was at 344 feet 
(105 meters) elevation between rows 116 and 117, and the soil is mapped as the Bellpine soil series (Figure 29). The vines are Pinot Noir Dijon 777 clone planted in 2002 and are trellised as bilateral cordon in vertical shoot position. The vines are grafted onto 44-53 rootstock (Table 8).

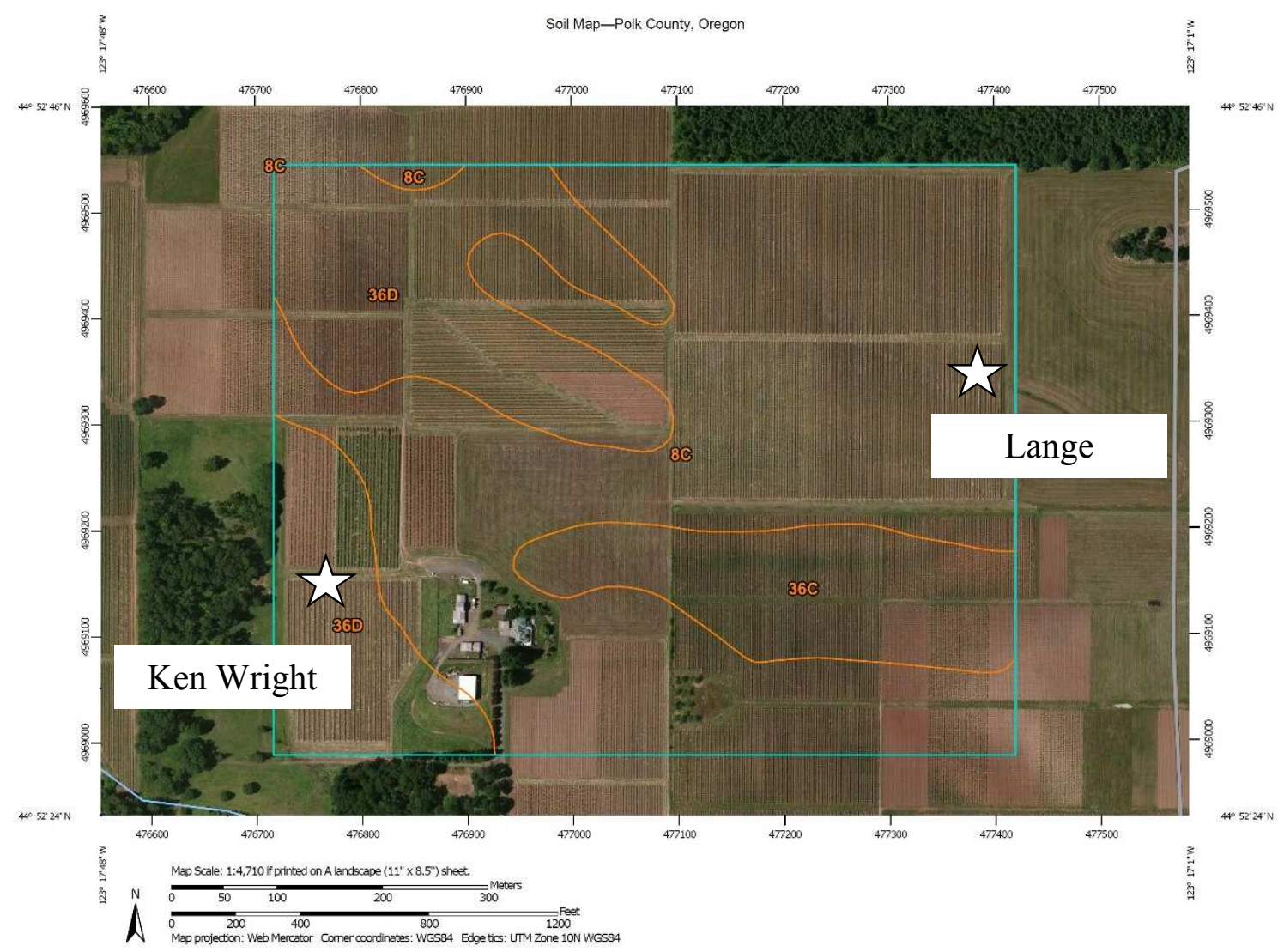

Figure 29. Soil map of Lange Estate Winery and Vineyards, Freedom Hill Vineyard. Pit location marked. 8C - Bellpine silty clay loam, 3 to 12 percent slopes. 36C - Jory silty clay loam, 2 to 12 percent slopes. 36D - Jory silty clay loam, 12 to 20 percent slopes (NRCS, 2015). Two sites were analyzed at the Freedom Hill Vineyard; one for Lange and one for Ken Wright. 
The Bellpine soil is classified as a Xeric Haplohumult. The soil pit was $157+\mathrm{cm}$ deep, and I did reach the sandy parent material but not refusal at that depth. The bedrock is part of the Coast Range marine sediments (Figure 2). Less than $10 \%$ of the Bt horizon consisted of coarse fragments of sandstone parent material. Percent sand decreases with depth from $20 \%$ to $15 \%$ from $\mathrm{Ap}$ to $\mathrm{Bt}$, but then increases to $63 \%$ percent in the $\mathrm{Cr} 2$ horizon. Dry colors for the Ap horizon are brown (10 YR 5/4), the Bt is yellowish brown (10 YR 6/4) and the Cr1 and Cr2 horizons are multi-colored from pale yellow (2.5 Y 8/2) to yellowish red (5 YR 4/6) to dark yellowish brown (10 YR 4/6) (Figure 30).

Structure of the Ap and Bt horizons are subangular blocky, and the $\mathrm{Cr} 1$ and $\mathrm{Cr} 2$ horizons have strong medium platy structure. The Bt1 horizon is sticky and plastic, and the $\mathrm{Cr}$ horizons are nonsticky and nonplastic. Clay percent is highest in the Bt horizon at $29 \%$ but decreases with depth to $12 \%$ in the $\mathrm{Cr} 2$ horizon. Clay films are located on ped faces in the Ap and Bt horizons and are few to common and dominant. The soil contains muscovite mica and quartz sand and no pisolites are found in the profile. The CEC increases with depth from 18.9 meq/100 g. OM ranges from $5.3 \%$ to $8.4 \%$ and $\mathrm{pH}$ decreases from 5.4 to 5.1 with depth (Table 57).

\section{Soil Chemistry}

The Lange Freedom Hill Vineyard soil pit was separated into four horizons, and samples of each horizon were sent for analysis (Table 58). P and S are highest in the Ap 
horizon. $\mathrm{S}$ is detected at the surface and in the $\mathrm{Cr} 2$ horizon. $\mathrm{Ca}$ and $\mathrm{Mg}$ increase to a bulge in the $\mathrm{Cr} 1$ horizon. $\mathrm{K}$ bulges in the $\mathrm{Bt}$ horizon. $\mathrm{P}$ decreases with depth, but increases in the $\mathrm{Cr} 2$ horizon to close to the maximum value for the profile. $\mathrm{Cl}$ is nondetectable throughout the profile.

Table 57. Lange Estate Winery and Vineyards, Freedom Hill Vineyard field and lab data.

\begin{tabular}{|c|c|c|c|c|c|c|}
\hline \multirow{3}{*}{$\begin{array}{l}\text { Depth } \\
\text { (cm) }\end{array}$} & \multirow{3}{*}{ Horizon } & \multicolumn{3}{|c|}{ Total } & \multirow[b]{2}{*}{$\begin{array}{c}\text { Coarse } \\
\text { Fragment } \\
(>2 \mathrm{~mm})\end{array}$} & \multirow{3}{*}{$\begin{array}{c}\text { Texture } \\
\text { Lab }\end{array}$} \\
\hline & & $\begin{array}{c}\text { Sand } \\
(2-0.05 \\
\text { mm) }\end{array}$ & $\begin{array}{c}\text { Silt } \\
(0.05-0.002 \\
\text { mm) }\end{array}$ & $\begin{array}{c}\text { Clay } \\
(<0.002 \text { mm })\end{array}$ & & \\
\hline & & \multicolumn{4}{|c|}{ 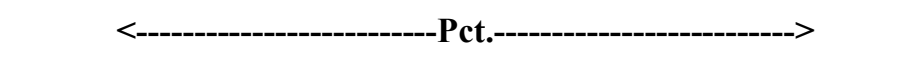 } & \\
\hline $0-34$ & Ap & 20.3 & 56.0 & 22.1 & 0.0 & $\mathrm{SiL}$ \\
\hline $34-63$ & $\mathrm{Bt}$ & 15.5 & 54.1 & 29.1 & 1.6 & $\mathrm{SiCL}$ \\
\hline $63-102$ & $\mathrm{Cr} 1$ & 18.3 & 51.4 & 23.3 & 8.1 & $\mathrm{SiL}$ \\
\hline $102-157+$ & $\mathrm{Cr} 2$ & 62.6 & 23.8 & 12.1 & 3.5 & SL \\
\hline $\begin{array}{l}\text { Depth } \\
\text { (cm) }\end{array}$ & Horizon & Dry Color & Structure & $\begin{array}{c}\text { Organic } \\
\text { Matter } \\
\text { LOI (Pct.) }\end{array}$ & $\begin{array}{c}\text { pH } \\
\left(1: 1 \mathbf{H}_{2} \mathrm{O}\right)\end{array}$ & $\begin{array}{c}\text { CEC } \\
(\mathrm{meq} / 100 \mathrm{~g})\end{array}$ \\
\hline $0-34$ & Ap & 10YR 5/4 & $2, \mathrm{vf}, \mathrm{sbk}$ & 7.6 & 5.4 & 18.9 \\
\hline $34-63$ & $\mathrm{Bt}$ & 10YR 6/4 & $2, \mathrm{~m}, \mathrm{sbk}$ & 8.4 & 5.3 & 20.2 \\
\hline $63-102$ & $\mathrm{Cr} 1$ & $\begin{array}{l}\text { 10YR 6/4 } \\
5 Y R 4 / 6\end{array}$ & $\mathrm{~m}$ to $3, \mathrm{~m}, \mathrm{pl}$ & 6.4 & 5.2 & \\
\hline $102-157+$ & $\mathrm{Cr} 2$ & $\begin{array}{c}10 \mathrm{YR} 4 / 4 \\
10 \mathrm{YR} 4 / 6 \\
2.5 \mathrm{Y} 8 / 2\end{array}$ & $\mathrm{~m}$ to $3, \mathrm{~m}, \mathrm{pl}$ & 5.3 & 5.1 & \\
\hline
\end{tabular}



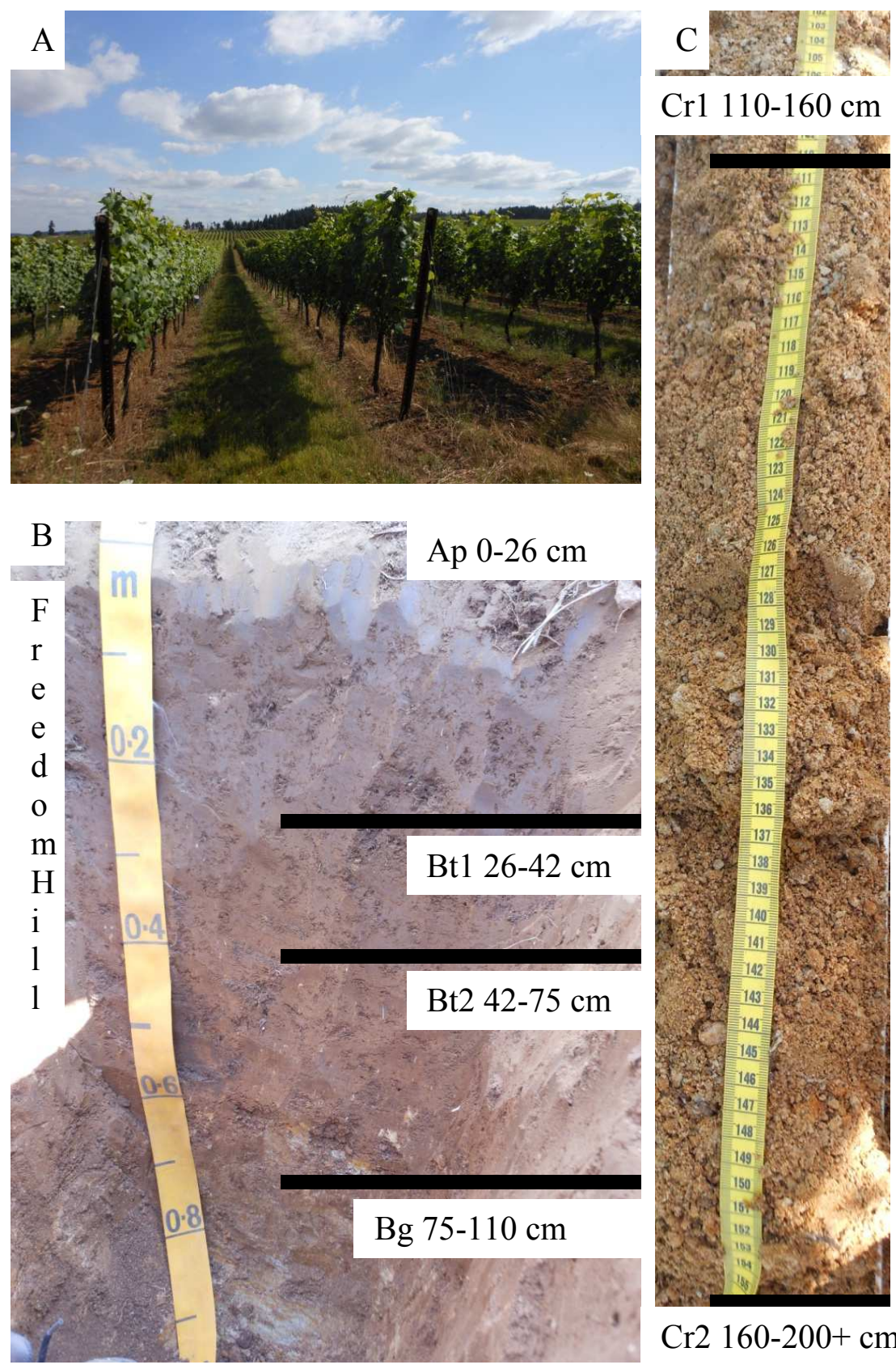

Cr1 110-160 cm

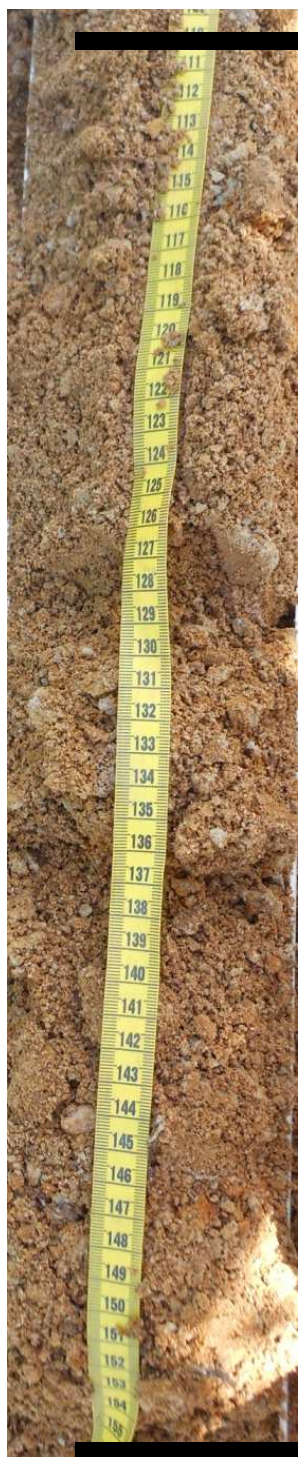

$\mathrm{Cr} 2160-200+\mathrm{cm}$

Figure 30. Sample soil pit at Lange Estate Winery and Vineyards, Freedom Hill Vineyard. A - View of sample location, facing south. B - Picture of the face of the soil pit with horizon depths and boundaries marked. $\mathrm{C}$ - Soil retrieved using a hand auger with horizon depths and boundaries marked. 
Table 58. Macronutrient, micronutrient and trace element concentrations (all values in $\mathrm{mg} / \mathrm{kg}$ ) for the Lange Estate Winery and Vineyards, Freedom Hill Vineyard soil pit (ND - Non-detectable).

\begin{tabular}{|c|c|c|c|c|c|c|c|c|c|c|}
\hline Horizon (cm) & $\mathbf{P}$ & & $\mathbf{K}$ & \multicolumn{2}{|c|}{$\mathbf{C a}$} & Mg & \multicolumn{2}{|c|}{$\mathbf{S}$} & \multicolumn{2}{|r|}{ Cl } \\
\hline Ap (0-34) & 672 & & 683 & 119 & & 1170 & \multicolumn{2}{|c|}{159} & \multicolumn{2}{|r|}{ ND } \\
\hline $\mathrm{Bt}(34-63)$ & 545 & & 828 & 120 & & 1670 & \multicolumn{2}{|c|}{104} & \multicolumn{2}{|c|}{ ND } \\
\hline Cr1 (63-102) & 292 & & 617 & 226 & & 2260 & \multicolumn{2}{|c|}{ ND } & \multicolumn{2}{|c|}{ ND } \\
\hline Cr2 (102-157+) & 651 & & 580 & 122 & & 1860 & \multicolumn{2}{|c|}{130} & \multicolumn{2}{|c|}{ ND } \\
\hline Mean & 540 & & 677 & 147 & & 1740 & \multicolumn{2}{|c|}{131} & \multicolumn{2}{|c|}{$N D$} \\
\hline$S D$ & 174 & & 109 & 528 & & 453 & \multicolumn{2}{|c|}{27.5} & \multicolumn{2}{|c|}{$N D$} \\
\hline Maximum & 672 & & 828 & 226 & & 2260 & \multicolumn{2}{|c|}{159} & \multicolumn{2}{|c|}{$N D$} \\
\hline Horizon (cm) & $\mathbf{F e}$ & Al & Co & $\mathrm{Cu}$ & Mn & Mo & \multicolumn{2}{|c|}{$\mathbf{N a}$} & $\mathbf{N i}$ & $\mathbf{Z n}$ \\
\hline Ap (0-34) & 29600 & 8150 & 11.7 & 13.8 & 584 & ND & \multicolumn{2}{|c|}{189} & 5.77 & 35.8 \\
\hline Bt (34-63) & 38700 & 11300 & 16.0 & 18.0 & 513 & 0.589 & \multicolumn{2}{|c|}{ ND } & 9.67 & 36.7 \\
\hline Cr1 (63-102) & 26000 & 11200 & 3.46 & 19.2 & 96.7 & ND & \multicolumn{2}{|c|}{ ND } & 6.10 & 28.4 \\
\hline Cr2 $(102-157+)$ & 29000 & 7980 & 9.87 & 17.0 & 220 & 0.678 & \multicolumn{2}{|c|}{107} & 4.15 & 22.8 \\
\hline Mean & 30800 & 9660 & 10.3 & 17.0 & 353 & 0.634 & \multicolumn{2}{|c|}{148} & 6.42 & 30.9 \\
\hline$S D$ & 5480 & 1840 & 5.21 & 2.32 & 233 & 0.0629 & \multicolumn{2}{|c|}{58.0} & 2.33 & 6.57 \\
\hline Maximum & 38700 & 11300 & 16.0 & 19.2 & 584 & 0.678 & \multicolumn{2}{|c|}{189} & 9.67 & 36.7 \\
\hline Horizon (cm) & As & Ba & Be & Cd & $\mathrm{Cr}$ & $\mathbf{H g}$ & $\mathbf{P b}$ & Se & $\mathrm{Sr}$ & $\mathbf{V}$ \\
\hline Ap (0-34) & 6.81 & 91.4 & 0.728 & 0.148 & 22.6 & ND & 11.0 & ND & 14.6 & 50.8 \\
\hline Bt (34-63) & 11.2 & 85.5 & 0.888 & 0.120 & 27.3 & ND & 11.9 & ND & 17.8 & 68.8 \\
\hline Cr1 (63-102) & 9.32 & 70.1 & 0.557 & ND & 18.0 & ND & 6.94 & ND & 38.6 & 40.8 \\
\hline Cr2 (102-157+) & 11.8 & 55.5 & 0.719 & ND & 12.3 & 0.0412 & 6.07 & ND & 26.3 & 28.6 \\
\hline Mean & 9.78 & 75.6 & 0.723 & 0.134 & 20.1 & 0.0412 & 8.98 & $N D$ & 24.3 & 47.3 \\
\hline$S D$ & 2.25 & 16.1 & 0.135 & 0.0198 & 6.41 & 0 & 2.90 & $N D$ & 10.7 & 17.0 \\
\hline Maximum & 11.8 & 91.4 & 0.888 & 0.148 & 27.3 & 0.0412 & 11.9 & $N D$ & 38.6 & 68.8 \\
\hline
\end{tabular}

The micronutrient concentrations measured in the four soil horizons from the Freedom Hill Vineyard also have few trends. Fe, Al, Co, Ni and zine bulge in the Bt horizon. Mn decreases with depth, then increases in the $\mathrm{Cr} 2$ horizon. $\mathrm{Cu}$ bulges in the $\mathrm{Cr} 1$ horizon. Mo is detected in the $\mathrm{Bt}$ and $\mathrm{Cr} 2$ horizons, with the highest concentration in the 
$\mathrm{Cr} 2$ horizon. $\mathrm{Na}$ is highest in the Ap horizon. Lange Freedom Hill Vineyard trace element concentrations were also determined for the four horizons. $\mathrm{Cd}$ and $\mathrm{Ba}$ decrease with depth. $\mathrm{Hg}$ was only detected in the $\mathrm{Cr} 2$ horizon. $\mathrm{Be}, \mathrm{V}, \mathrm{Pb}$ and $\mathrm{Cr}$ all bulge in the $\mathrm{Bt}$ horizon. As is variable with the maximum concentration in the $\mathrm{Cr} 2$ horizon. Sr bulges in the $\mathrm{Cr} 1$ horizon. Se is non-detectable in this profile.

\section{Grape Juice Chemistry}

The soil samples were analyzed for the same 24 elements that were tested in the grape juice from grapes collected adjacent to the soil pits. The grape juice samples have concentrations of many elements that are below detection limits in this study and are not listed in Table 59. The concentrations of $\mathrm{K}$ and $\mathrm{Na}$ in the Freedom Hill Vineyard grape juice are $1380 \mathrm{mg} / \mathrm{kg}$ and $150 \mathrm{mg} / \mathrm{kg}$, respectively. Sr concentrations are measured as $0.697 \mathrm{mg} / \mathrm{kg}$, which is the $14^{\text {th }}$ highest concentration of $\mathrm{Sr}$ for the 20 vineyard samples (Table 105). Mean Sr concentration for all grape juice samples from the 20 different sites is $0.805 \pm 0.261 \mathrm{mg} / \mathrm{kg}$. P concentration is $266 \mathrm{mg} / \mathrm{kg}$ for this grape sample. These are the only 4 elements detected in the grape juice from this sample.

Table 59. Elemental concentrations measured by ICP-MS in the grape juice from clusters collected from vines immediately adjacent to the soil pit location at Lange Estate, Freedom Hill Vineyard (ND - Non-detectable).

\begin{tabular}{cccccccccc}
\hline Element & Sr & P & K & Na & Mg & Mn & Ca & Cu & Zn \\
\hline \hline Grape Juice (mg/kg) & 0.697 & 266 & 1380 & 150 & ND & ND & ND & ND & ND \\
\hline
\end{tabular}




\section{Wine Chemistry}

Lange Estate Winery and Vineyards provided a $750 \mathrm{ml}$ sample of the wine produced from the Freedom Hill Vineyard in 2012. The 14 elements that were detected in Freedom Hill Vineyard wine sample include $\mathrm{Ba}, \mathrm{Ca}, \mathrm{Co}, \mathrm{Cu}, \mathrm{Fe}, \mathrm{Pb}, \mathrm{Mg}, \mathrm{Mn}, \mathrm{P}, \mathrm{K}, \mathrm{Na}$, $\mathrm{Sr}, \mathrm{S}$, and $\mathrm{Zn}$ (Table 60). K and P concentrations are the highest at $676 \mathrm{mg} / \mathrm{kg}$ and 199 $\mathrm{mg} / \mathrm{kg}$, respectively. $\mathrm{S}$ is $72.1 \mathrm{mg} / \mathrm{kg}, \mathrm{Mg}$ is $51.6 \mathrm{mg} / \mathrm{kg}, \mathrm{Ca}$ is $27.6 \mathrm{mg} / \mathrm{kg}$, and $\mathrm{Na}$ is 4.3 $\mathrm{mg} / \mathrm{kg}$ for this wine. The concentration of $\mathrm{Mn}$ is $1.25 \mathrm{mg} / \mathrm{kg}$ and $\mathrm{Fe}$ is $0.966 \mathrm{mg} / \mathrm{kg}$. The concentration of $\mathrm{Sr}$ is $1.05 \mathrm{mg} / \mathrm{kg}, \mathrm{Ba}$ is $0.577 \mathrm{mg} / \mathrm{kg}$, and $\mathrm{Zn}$ is $0.118 \mathrm{mg} / \mathrm{kg}$. Trace amounts of $\mathrm{Cu}(0.0865 \mathrm{mg} / \mathrm{kg}), \mathrm{Pb}(0.0782 \mathrm{mg} / \mathrm{kg})$ and $\mathrm{Co}(0.029 \mathrm{mg} / \mathrm{kg})$ are also detected in the Freedom Hill Vineyard wine sample.

Table 60. Elemental concentrations measured by ICP-MS of a $750 \mathrm{ml}$ unblended wine sample from the 2012 Lange Estate Winery, Freedom Hill Vineyard (ND - Non-detectable).

\begin{tabular}{cccc}
\hline Element & 2012 Wine Sample (mg/kg) & Element & 2012 Wine Sample (mg/kg) \\
\hline \hline $\mathrm{Al}$ & $\mathrm{ND}$ & $\mathrm{Mn}$ & 1.25 \\
$\mathrm{As}$ & $\mathrm{ND}$ & $\mathrm{Hg}$ & $\mathrm{ND}$ \\
$\mathrm{Ba}$ & 0.577 & $\mathrm{Mo}$ & $\mathrm{ND}$ \\
$\mathrm{Be}$ & $\mathrm{ND}$ & $\mathrm{Ni}$ & $\mathrm{ND}$ \\
$\mathrm{Cd}$ & $\mathrm{ND}$ & $\mathrm{P}$ & 199 \\
$\mathrm{Ca}$ & 27.6 & $\mathrm{~K}$ & 676 \\
$\mathrm{Cr}$ & $\mathrm{ND}$ & $\mathrm{Se}$ & $\mathrm{ND}$ \\
$\mathrm{Co}$ & 0.029 & $\mathrm{Na}$ & 4.3 \\
$\mathrm{Cu}$ & 0.0865 & $\mathrm{Sr}$ & 1.05 \\
$\mathrm{Fe}$ & 0.966 & $\mathrm{~S}$ & 72.1 \\
$\mathrm{~Pb}$ & 0.0782 & $\mathrm{~V}$ & $\mathrm{ND}$ \\
$\mathrm{Mg}$ & 51.6 & $\mathrm{Zn}$ & 0.118 \\
\hline
\end{tabular}




\section{Clay Mineralogy}

The Lange Freedom Hill and Ken Wright Freedom Hill are essentially the same when looking at the clay minerals. The Lange Freedom Hill clays were determined from the Bt horizon. These two soils are separated by approximately 500 meters of vineyard at this estate. The expansive clay in the sample is moderately interlayered by $\mathrm{Al}$ and $\mathrm{Fe}$ oxides which shows moderate weathering. The soil contains trace amounts of mica and illite. The trace amount of chlorite is weakly developed. Minor hydroxy-interlayered smectite and vermiculite are also present with minor amounts of kaolinite. Cristobalite is also in this sample in minor amounts. The main Fe oxide is goethite and is well ordered and expressed. 


\section{Chapter Eight - Rex Hill Results}

\section{Volcanic Parent Material - Sims Vineyard, Block 2 Physical Characteristics}

Sims Vineyard is located in Dundee, Oregon. This vineyard is located on basaltic rocks of the Columbia River Basalt group. Sims Vineyard soil is located on the midslope of a south facing slope with vine rows running north and south (Lat. 45.280286 N, Long. $-123.042398 \mathrm{~W})$. The soil pit location was at 656 feet (200 meters) elevation between rows 72 and 73, and the soil is mapped as the Jory soil series (Figure 31). According to the vineyard manager, this vineyard was cultivated with permanent fescue blend cover crop and is certified LIVE, Organic and Biodynamic (Appendix D). The vines are Pinot Noir Pommard clone planted in 2000 and are trellised as bilateral cordon in vertical shoot position. The vines are grafted onto 3309 rootstocks (Table 8).

The Jory soil is classified as a Xeric Palehumult. The soil pit was $130+\mathrm{cm}$ deep, and I did reach the parent material but not refusal at that depth. The basalt parent material is found as small chips and gravel (less than 10\%) in the Bt2 and Bt3 horizons at depths greater than $50 \mathrm{~cm}$. Dry colors for the entire profile are brown (10 YR 4/4) and strong brown (10 YR 4/6) (Figure 32). Structures throughout the soil profile are moderate, medium subangular blocky with some fine granular texture in the Ap horizon. The Ap horizon is slightly sticky and slightly plastic, but the Bt horizons are all sticky 


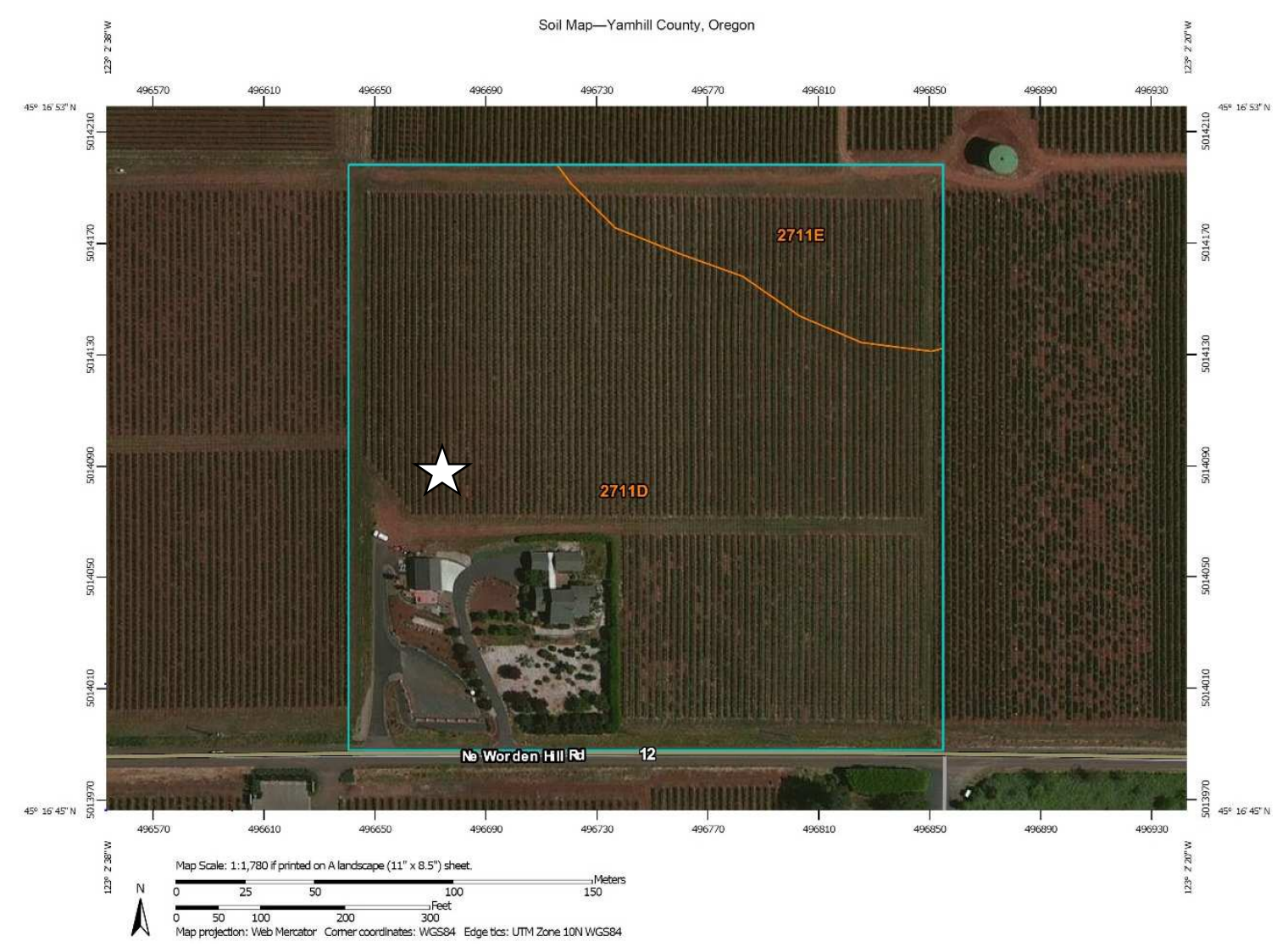

Figure 31. Soil map for Rex Hill, Sims Vineyard Block 2. Pit location marked. 2711D - Jory silty clay loam, 12 to 20 percent slopes. 2711E - Jory silty clay loam, 20 to 30 percent slopes (NRCS, 2015). Previously JrD - Jory clay loam, 12 to 20 percent slopes (NRCS, 2014).

and plastic due to a jump in clay from $28 \%$ in the Ap to $53 \%, 48 \%$, and $48 \%$ in Bt1, Bt2, and Bt3, respectively. Clay films are located on ped faces throughout the profile. They are mostly in the $\mathrm{Bt} 1$ horizon (many prominent) but are also in the $\mathrm{Bt} 2$ and $\mathrm{Bt} 3$ horizons (common dominant to faint). Pisolites are found abundantly throughout the profile. The $\mathrm{pH}$ decreases with depth with a bulge in the Bt1 horizon. CEC also decreases with depth with a similar bulge in the $\mathrm{Bt} 2$ horizon. OM ranges from $10.3 \%$ to $11.9 \%$ (Table 61 ). 
Table 61. Rex Hill, Sims Vineyard Block 2 field and lab data.

\begin{tabular}{|c|c|c|c|c|c|c|}
\hline \multirow{3}{*}{$\begin{array}{l}\text { Depth } \\
\text { (cm) }\end{array}$} & \multirow{3}{*}{ Horizon } & \multicolumn{3}{|c|}{ Total } & \multirow[b]{2}{*}{$\begin{array}{c}\text { Coarse } \\
\text { Fragment } \\
(>2 \mathrm{~mm})\end{array}$} & \multirow[b]{2}{*}{$\begin{array}{l}\text { Texture } \\
\text { Lab }\end{array}$} \\
\hline & & $\begin{array}{l}\text { Sand } \\
(2-0.05 \\
\text { mm) }\end{array}$ & $\begin{array}{c}\text { Silt } \\
(0.05-0.002 \\
\text { mm) }\end{array}$ & $\begin{array}{c}\text { Clay } \\
(<0.002 \mathrm{~mm})\end{array}$ & & \\
\hline & & \multicolumn{4}{|c|}{ 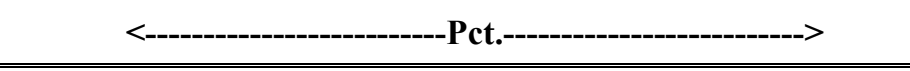 } & \\
\hline $0-12$ & Ap & 22.2 & 47.9 & 28.1 & 0.4 & $\mathrm{CL}$ \\
\hline $12-50$ & Bt1 & 11.8 & 35.5 & 53.4 & 2.3 & $\mathrm{C}$ \\
\hline $50-84$ & $\mathrm{Bt} 2$ & 13.7 & 34.4 & 48.4 & 0.3 & $\mathrm{C}$ \\
\hline $84-130+$ & $\mathrm{Bt} 3$ & 18.8 & 29.9 & 48.5 & 0.0 & $\mathrm{C}$ \\
\hline $\begin{array}{l}\text { Depth } \\
\text { (cm) }\end{array}$ & Horizon & Dry Color & Structure & $\begin{array}{c}\text { Organic } \\
\text { Matter } \\
\text { LOI (Pct.) } \\
\end{array}$ & $\begin{array}{c}\text { pH } \\
\left(1: 1 \mathrm{H}_{2} \mathrm{O}\right)\end{array}$ & $\underset{(\mathrm{meq} / \mathbf{1 0 0 g})}{\mathrm{CEC}}$ \\
\hline $0-12$ & Ap & 7.5YR 4/4 & $2, \mathrm{f}, \mathrm{gr}$ to $\mathrm{sbk}$ & 11.9 & 5.2 & 20.2 \\
\hline $12-50$ & Bt1 & 7.5YR 4/6 & $2, \mathrm{~m}, \mathrm{sbk}$ & 10.3 & 5.4 & 15.0 \\
\hline $50-84$ & $\mathrm{Bt} 2$ & 7.5YR 4/4 & $2, \mathrm{~m}, \mathrm{sbk}$ & 10.9 & 5.6 & 20.0 \\
\hline $84-130+$ & $\mathrm{Bt} 3$ & 7.5 YR 4/4 & $1, \mathrm{~m}, \mathrm{sbk}$ & 10.5 & 5.0 & 16.9 \\
\hline
\end{tabular}

\section{Soil Chemistry}

The Sims Vineyard soil pit was separated into four horizons, and samples of each horizon were sent for analysis (Table 62). The maximum concentrations of $\mathrm{K}, \mathrm{Mg}$, and $\mathrm{S}$ are in the Ap horizon. $\mathrm{K}, \mathrm{Mg}$, and $\mathrm{S}$ decrease with depth. $\mathrm{Ca}$ increases with depth and bulges in the $\mathrm{Bt} 2$ horizon. $\mathrm{P}$ is bimodal with a max in the $\mathrm{Bt} 3$ horizon and the Ap horizon. The micronutrient concentrations measured in the four soil horizons from the Sims Vineyard have few trends but some elements decrease with depth and then increase again in the deepest horizon. $\mathrm{Fe}$ and $\mathrm{Co}$ are highest in the $\mathrm{Bt} 3$ horizon and the second highest in the Ap horizon. $\mathrm{Al}, \mathrm{Cu}, \mathrm{Mn}, \mathrm{Ni}$, and $\mathrm{Zn}$ decrease with depth and then increase again in the $\mathrm{Bt} 3$ horizon. Na is highest in the Bt3 horizon with similar values in the Ap horizon. 

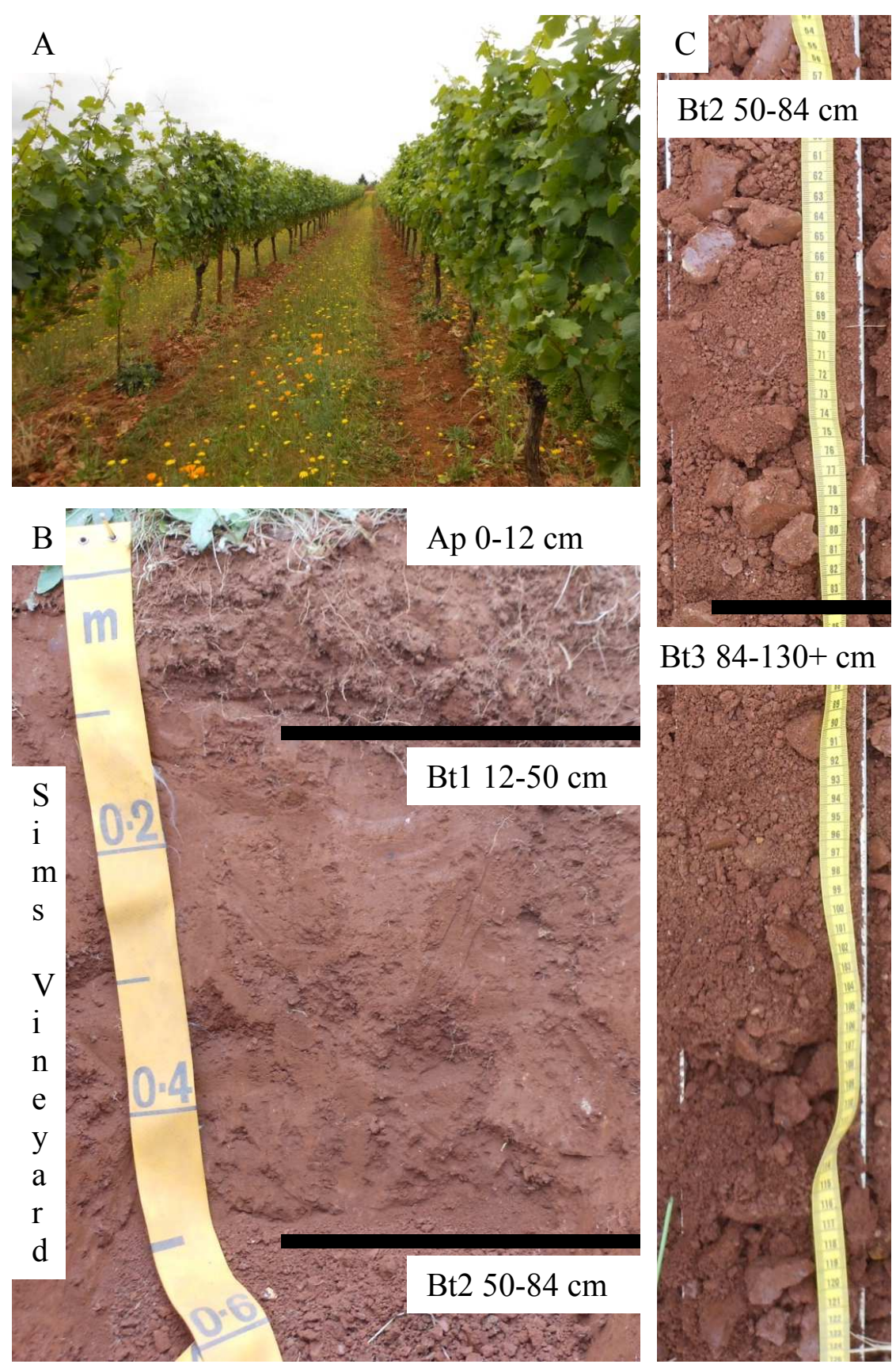

Figure 32. Sample soil pit at Rex Hill, Sims Vineyard Block 2. A - View of sample location, facing north. B - Picture of the face of the soil pit with horizon depths and boundaries marked. C - Soil retrieved using a hand auger with horizon depths and boundaries marked. 
Table 62. Macronutrient, micronutrient and trace element concentrations (all values in $\mathrm{mg} / \mathrm{kg}$ ) for the Rex Hill, Sims Vineyard, Block 2 soil pit (ND - Non-detectable).

\begin{tabular}{|c|c|c|c|c|c|c|c|c|c|c|}
\hline Horizon (cm) & \multicolumn{2}{|c|}{$\mathbf{P}$} & \multicolumn{2}{|c|}{$\mathbf{K}$} & \multicolumn{2}{|c|}{$\mathrm{Ca}$} & \multicolumn{2}{|c|}{ Mg } & \multicolumn{2}{|c|}{$\mathbf{S}$} \\
\hline Ap (0-12) & \multicolumn{2}{|c|}{1530} & \multicolumn{2}{|c|}{515} & \multicolumn{2}{|c|}{585} & \multicolumn{2}{|c|}{907} & \multicolumn{2}{|c|}{213} \\
\hline Bt1 (12-50) & \multicolumn{2}{|c|}{913} & \multicolumn{2}{|c|}{208} & \multicolumn{2}{|c|}{871} & \multicolumn{2}{|c|}{596} & \multicolumn{2}{|c|}{116} \\
\hline Bt2 (50-84) & \multicolumn{2}{|c|}{843} & \multicolumn{2}{|c|}{101} & \multicolumn{2}{|c|}{892} & \multicolumn{2}{|c|}{428} & \multicolumn{2}{|c|}{ ND } \\
\hline $\mathrm{Bt3}(84-130+)$ & \multicolumn{2}{|c|}{1560} & \multicolumn{2}{|c|}{80.7} & \multicolumn{2}{|c|}{661} & \multicolumn{2}{|c|}{431} & \multicolumn{2}{|c|}{ ND } \\
\hline Mean & \multicolumn{2}{|c|}{1212} & \multicolumn{2}{|c|}{226} & \multicolumn{2}{|c|}{752} & \multicolumn{2}{|c|}{591} & \multicolumn{2}{|c|}{165} \\
\hline$S D$ & \multicolumn{2}{|c|}{386} & \multicolumn{2}{|c|}{200} & & & & & & \\
\hline Maximum & & 60 & & 5 & & & & & & \\
\hline Horizon (cm) & $\mathbf{F e}$ & Al & Cl & Co & $\mathbf{C u}$ & Mn & Mo & $\mathbf{N a}$ & $\mathbf{N i}$ & $\mathbf{Z n}$ \\
\hline Ap $(0-12)$ & 62300 & 17800 & ND & 36.4 & 20.6 & 2510 & ND & 178 & 6.49 & 53.9 \\
\hline Bt1 (12-50) & 50400 & 15400 & ND & 34.9 & 14.0 & 1250 & ND & 161 & 4.78 & 34.1 \\
\hline Bt2 (50-84) & 38400 & 11300 & ND & 26.0 & 9.3 & 1090 & ND & 165 & 2.80 & 24.2 \\
\hline Bt3 $(84-130+)$ & 65300 & 16900 & ND & 41.2 & 19.7 & 1890 & ND & 184 & 3.35 & 34.7 \\
\hline Mean & 54100 & 15350 & $N D$ & 34.6 & 15.9 & 1685 & $N D$ & 172 & 4.36 & 36.7 \\
\hline$S D$ & 12286 & 2876 & $N D$ & 6.35 & 5.27 & 650 & $N D$ & 11 & 1.65 & 12.4 \\
\hline Maximum & 65300 & 17800 & $N D$ & 41.2 & 20.6 & 2510 & $N D$ & 184 & 6.49 & 53.9 \\
\hline Horizon (cm) & As & $\mathbf{B a}$ & Be & Cd & $\mathrm{Cr}$ & Hg & $\mathbf{P b}$ & Se & $\mathrm{Sr}$ & $\mathbf{V}$ \\
\hline Ap (0-12) & 1.72 & 127 & 1.05 & 0.475 & 23.1 & ND & 12.0 & 0.759 & 5.95 & 171 \\
\hline Bt1 (12-50) & 0.666 & 168 & 0.772 & 0.296 & 18.3 & ND & 10.1 & ND & 11.1 & 143 \\
\hline Bt2 (50-84) & ND & 72.1 & 0.597 & 0.347 & 12.6 & ND & 6.89 & 0.501 & 10.5 & 101 \\
\hline Bt3 (84-130+) & 0.447 & 55.5 & 0.884 & 0.416 & 13.7 & ND & 8.06 & ND & 7.90 & 125 \\
\hline Mean & 0.944 & 106 & 0.826 & 0.384 & 16.9 & $N D$ & 9.26 & 0.630 & 8.9 & 135 \\
\hline$S D$ & 0.681 & 51.6 & 0.191 & 0.078 & 4.80 & $N D$ & 2.26 & $N D$ & 2.4 & 30 \\
\hline Maximum & 1.72 & 168 & 1.05 & 0.475 & 23.1 & $N D$ & 12.0 & 0.759 & 11.1 & 171 \\
\hline
\end{tabular}

$\mathrm{Cl}$ and Mo were non-detectable in this profile. Sims Vineyard trace element

concentrations were also determined for the four horizons. As and Se are highest in the

Ap horizon and decrease with depth. $\mathrm{Be}, \mathrm{V}, \mathrm{Pb}$, and $\mathrm{Cr}$ decrease with depth and then increase in the $\mathrm{Bt} 3$ horizon. Ba decreases with depth with a bulge in the Bt1 horizon. $\mathrm{Sr}$ 
also bulges in the Bt1 horizon but has little other trend. $\mathrm{Cd}$ is highest in the Ap horizon, decreases to the Bt1 horizon, then increases with depth.

\section{Grape Juice Chemistry}

The same 24 elements that were tested in the soil samples were analyzed in the grape juice from grapes collected adjacent to the soil pits. The grape juice samples have concentrations of many elements that are below detection limits in this study and are not listed in Table 63. K, Na, and $\mathrm{Sr}$ are the only elements found in all 20 grape juice samples and $\mathrm{P}$ is detected in 15 of the 20 sites. The concentrations of $\mathrm{K}$ and $\mathrm{Na}$ in the Sims Vineyard grape juice are $747 \mathrm{mg} / \mathrm{kg}$ (one of the lowest concentrations of K) and 142 $\mathrm{mg} / \mathrm{kg}$, respectively. Sr concentrations are measured as $0.645 \mathrm{mg} / \mathrm{kg}$, which is the $16^{\text {th }}$ highest concentration of $\mathrm{Sr}$ for the 20 vineyard samples (Table 105). Mean $\mathrm{Sr}$ concentration for all grape juice samples from the 20 different sites is $0.805 \pm 0.261$ $\mathrm{mg} / \mathrm{kg}$. P concentration is non-detectable and Mn concentration is $2.02 \mathrm{mg} / \mathrm{kg}$ for this grape sample. Mn is only found in four vineyards, including Stoller (volcanic parent material), Five Mountain (loess/volcanic parent material), The Jory Hills (volcanic parent material), and Sims Vineyards (volcanic parent material).

Table 63 Elemental concentrations measured by ICP-MS in the grape juice from clusters collected from vines immediately adjacent to the soil pit location at Rex Hill, Sims Vineyard, Block 2 (ND Non-detectable).

\begin{tabular}{cccccccccc}
\hline Element & Sr & P & K & Na & Mg & Mn & Ca & Cu & Zn \\
\hline Grape Juice $(\mathrm{mg} / \mathrm{kg})$ & 0.645 & ND & 747 & 142 & ND & 2.02 & ND & ND & ND \\
\hline
\end{tabular}




\section{Wine Chemistry}

Rex Hill provided a $750 \mathrm{ml}$ sample of the wine produced from the Sims Vineyard in 2012. Many of the 24 elements tested in the wine (same as the elements tested in the soil samples) were below detection limits. The 12 elements that were detected in Sims Vineyard wine sample include $\mathrm{Ba}, \mathrm{Ca}, \mathrm{Cu}, \mathrm{Fe}, \mathrm{Mg}, \mathrm{Mn}, \mathrm{P}, \mathrm{K}, \mathrm{Na}, \mathrm{Sr}, \mathrm{S}$, and $\mathrm{Zn}$ (Table 64). $\mathrm{Co}$ and $\mathrm{Pb}$ were not detected in this wine, though they were detected in trace amounts in other wine samples in this study. $\mathrm{K}$ and $\mathrm{P}$ concentrations are the highest at $453 \mathrm{mg} / \mathrm{kg}$ and $186 \mathrm{mg} / \mathrm{kg}$, respectively. $\mathrm{S}$ is $115 \mathrm{mg} / \mathrm{kg}, \mathrm{Mg}$ is $79.9 \mathrm{mg} / \mathrm{kg}, \mathrm{Ca}$ is 35.1 $\mathrm{mg} / \mathrm{kg}$, and $\mathrm{Na}$ is $5.52 \mathrm{mg} / \mathrm{kg}$ for this wine. The concentrations of both $\mathrm{Mn}$ and $\mathrm{Fe}$ are $2.36 \mathrm{mg} / \mathrm{kg}$. The concentration of $\mathrm{Sr}$ is $0.965 \mathrm{mg} / \mathrm{kg}, \mathrm{Ba}$ is $0.369 \mathrm{mg} / \mathrm{kg}$, and $\mathrm{Zn}$ is 0.343 $\mathrm{mg} / \mathrm{kg}$. Trace amounts of $\mathrm{Cu}(0.0473 \mathrm{mg} / \mathrm{kg})$ are detected in the Sims Vineyard wine sample.

\section{Clay Mineralogy}

As stated previously, the Sims Vineyard clay mineral assemblage, determined from the Bt1 horizon, is very similar to the Lange Estate (volcanic parent material), Lange Yamhill (marine sediment parent material), and Ken Wright Abbot Claim (marine sediment parent material) Vineyards. This soil is dominated by moderate amounts of disordered kaolinite with trace amounts of halloysite, chlorite, and smectite. Goethite is moderate, and minor amounts of gibbsite are present. These soils are indicative of deeply weathered material. 
Table 64. Elemental concentrations measured twice by ICP-MS of the same $750 \mathrm{ml}$ unblended wine sample from the 2012 Rex Hill, Sims Vineyard (ND - Non-detectable, * denotes mean of two samples from the same bottle).

\begin{tabular}{cccc}
\hline Element & 2012 Wine Sample* $(\mathbf{m g} / \mathbf{k g})$ & Element & 2012 Wine Sample* $(\mathbf{m g} / \mathbf{k g})$ \\
\hline \hline $\mathrm{Al}$ & $\mathrm{ND}$ & $\mathrm{Mn}$ & 2.36 \\
$\mathrm{As}$ & $\mathrm{ND}$ & $\mathrm{Hg}$ & $\mathrm{ND}$ \\
$\mathrm{Ba}$ & 0.369 & $\mathrm{Mo}$ & $\mathrm{ND}$ \\
$\mathrm{Be}$ & $\mathrm{ND}$ & $\mathrm{Ni}$ & $\mathrm{ND}$ \\
$\mathrm{Cd}$ & $\mathrm{ND}$ & $\mathrm{P}$ & 186 \\
$\mathrm{Ca}$ & 35.1 & $\mathrm{~K}$ & 453 \\
$\mathrm{Cr}$ & $\mathrm{ND}$ & $\mathrm{Se}$ & $\mathrm{ND}$ \\
$\mathrm{Co}$ & $\mathrm{ND}$ & $\mathrm{Na}$ & 5.52 \\
$\mathrm{Cu}$ & $\mathrm{Sr}$ & 0.965 \\
$\mathrm{Fe}$ & 0.0473 & $\mathrm{~S}$ & 115 \\
$\mathrm{~Pb}$ & 2.36 & $\mathrm{~V}$ & $\mathrm{ND}$ \\
$\mathrm{Mg}$ & $\mathrm{ND}$ & $\mathrm{Zn}$ & 0.343 \\
\hline
\end{tabular}

Loess and Volcanic Parent Material - Estate Vineyard, Block 12

Physical Characteristics

The Rex Hill Estate Vineyard Block 12, owned and operated by Rex Hill, is located in Newberg, Oregon. This vineyard is located on basaltic rocks of the Columbia River Basalt group. Block 12 soil pit is located on the midslope of a southeast facing slope with vine rows running north and south (Lat. 45.313974 N, Long. -122.918974 W). The soil pit location was at 611 feet (186 meters) elevation between rows 60 and 61, and the soil is mapped as the Laurelwood soil series (Figure 33). According to the vineyard manager, this vineyard is LIVE certified (Appendix D). The vines are Pinot Noir Dijon 


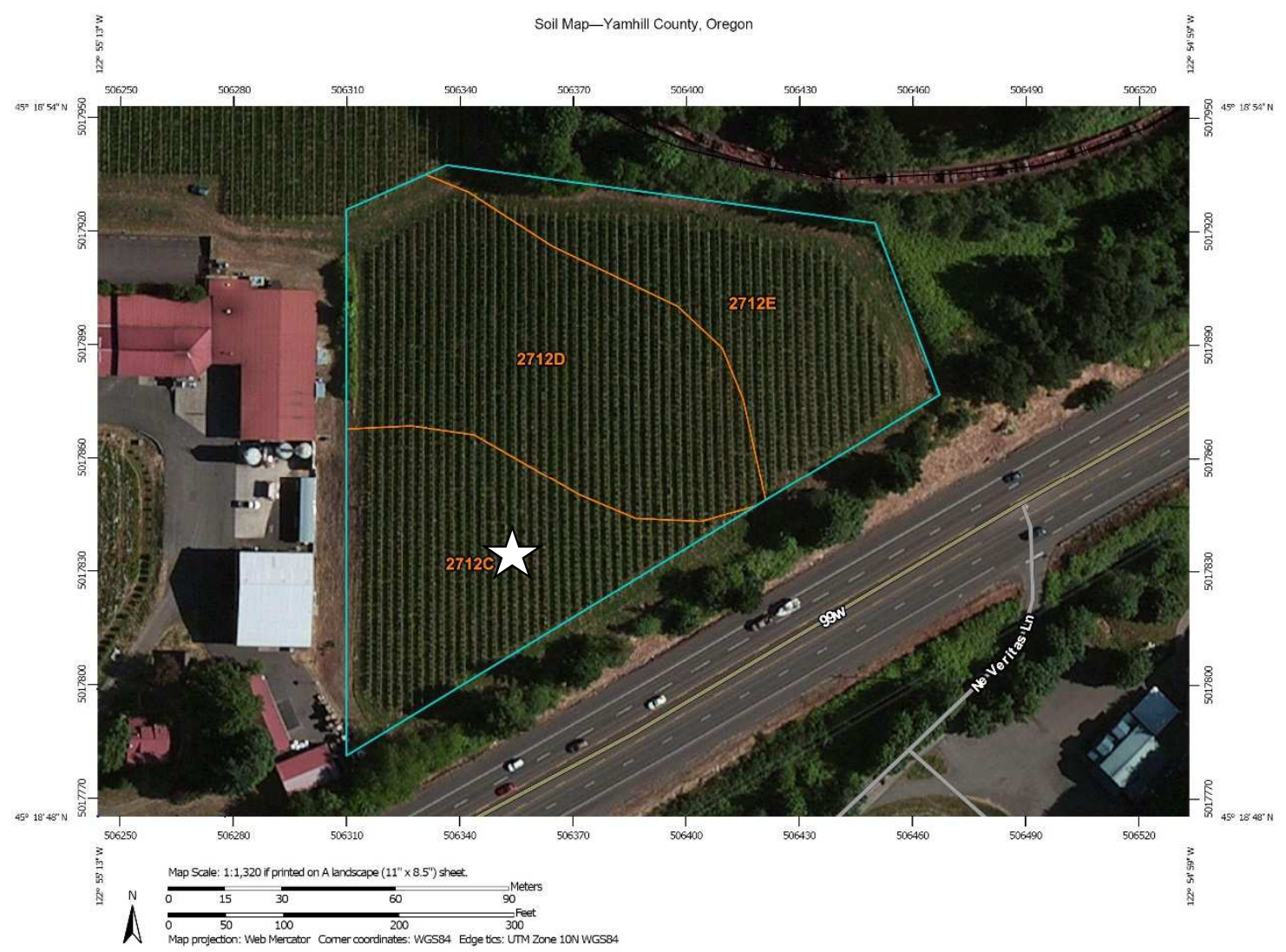

Figure 33. Soil map of Rex Hill, Estate Vineyard Block 12. Pit location marked. 2712C - Laurelwood silt loam, 2 to 12 percent slopes. 2712D - Laurelwood silt loam, 12 to 20 percent slopes. 2712E Laurelwood silt loam, 20 to 30 percent slopes (NRCS, 2015). Previously mapped as YhD - Yamhill silt loam, moderately shallow, 7 to 20 percent slopes and LuC - Laurelwood silt loam, 3 to 12 percent slopes (NRCS, 2014).

777 clone planted in 1982 and are trellised as bilateral cordon in vertical shoot position.

The vines are grafted onto 108 Chardonnay rootstock (Table 8).

The Laurelwood soil is characterized as an Ultic Haploxeralf. The soil pit was 130 $\mathrm{cm}$ deep at refusal. The basalt parent material is found as small chips and gravel $(10 \%)$ in the $\mathrm{Bt} 2$ horizon from 100 to $130 \mathrm{~cm}$ depth. Dry colors for the Ap horizon are brown (10 
YR 5/3), Bt1 and Bt2 are both yellowish brown (10 YR 5/4), and Bt2 also has yellowish red (5 YR 5/8) (Figure 34). Textures are silt loam for the Ap horizon and silty clay loam and silt loam for the Bt horizons. Structures throughout the soil profile are strong medium subangular blocky with some finer texture in the Ap horizon. The Bt1 and Bt2 horizons are very sticky and very plastic due to a jump in clay from $14 \%$ in the Ap to $33 \%$ in the Bt1 horizon. Clay films located on ped faces, increase in number from Ap (few and dominant) to Bt1 (many and prominent). Pisolites are found abundantly throughout the profile. The $\mathrm{pH}$ decreases with depth but $\mathrm{CEC}$ is highest in the $\mathrm{Bt} 2$ horizon. OM ranges from $4.7 \%$ to $8.0 \%$ (Table 65 ).

Table 65. Rex Hill, Estate Vineyard Block 12 field and lab data.

\begin{tabular}{|c|c|c|c|c|c|c|}
\hline \multirow{3}{*}{$\begin{array}{l}\text { Depth } \\
\text { (cm) }\end{array}$} & \multirow{3}{*}{ Horizon } & \multicolumn{3}{|c|}{ Total } & \multirow[b]{2}{*}{$\begin{array}{c}\text { Coarse } \\
\text { Fragment } \\
(>2 \mathrm{~mm})\end{array}$} & \multirow[b]{2}{*}{$\begin{array}{l}\text { Texture } \\
\text { Lab }\end{array}$} \\
\hline & & $\begin{array}{c}\text { Sand } \\
(2-0.05 \\
\text { mm) }\end{array}$ & $\begin{array}{c}\text { Silt } \\
(0.05-0.002 \\
\text { mm) }\end{array}$ & $\begin{array}{c}\text { Clay } \\
(<0.002 \mathrm{~mm})\end{array}$ & & \\
\hline & & \multicolumn{4}{|c|}{ <------------------------------Pct.----------------------------> } & \\
\hline $0-25$ & Ap & 11.0 & 74.0 & 14.4 & 0.1 & $\mathrm{SiL}$ \\
\hline $25-100$ & $\mathrm{Bt} 1$ & 4.5 & 62.3 & 32.6 & 0.0 & $\mathrm{SiCL}$ \\
\hline $100-130$ & $\mathrm{Bt} 2$ & 26.6 & 54.2 & 17.0 & 10.1 & SiL \\
\hline $130+$ & $\mathrm{R}$ & & & & & \\
\hline $\begin{array}{l}\text { Depth } \\
\text { (cm) }\end{array}$ & Horizon & Dry Color & Structure & $\begin{array}{c}\text { Organic } \\
\text { Matter } \\
\text { LOI (Pct.) } \\
\end{array}$ & $\begin{array}{c}\text { pH } \\
\left(1: 1 \mathrm{H}_{2} \mathrm{O}\right)\end{array}$ & $\begin{array}{c}\text { CEC } \\
(\mathrm{meq} / \mathbf{1 0 0 g})\end{array}$ \\
\hline $0-25$ & Ap & $10 \mathrm{YR} 5 / 3$ & $2, \mathrm{f}, \mathrm{sbk}$ & 8.0 & 5.8 & 17.8 \\
\hline $25-100$ & Bt1 & 10YR 5/4 & $3, \mathrm{~m}, \mathrm{sbk}$ & 4.7 & 5.6 & 15.9 \\
\hline $100-130$ & $\mathrm{Bt} 2$ & $\begin{array}{l}\text { 10YR 5/4 } \\
5 Y R 5 / 8\end{array}$ & $3, \mathrm{~m}, \mathrm{sbk}$ & 7.0 & 5.4 & 23.2 \\
\hline $130+$ & $\mathrm{R}$ & & & & & \\
\hline
\end{tabular}




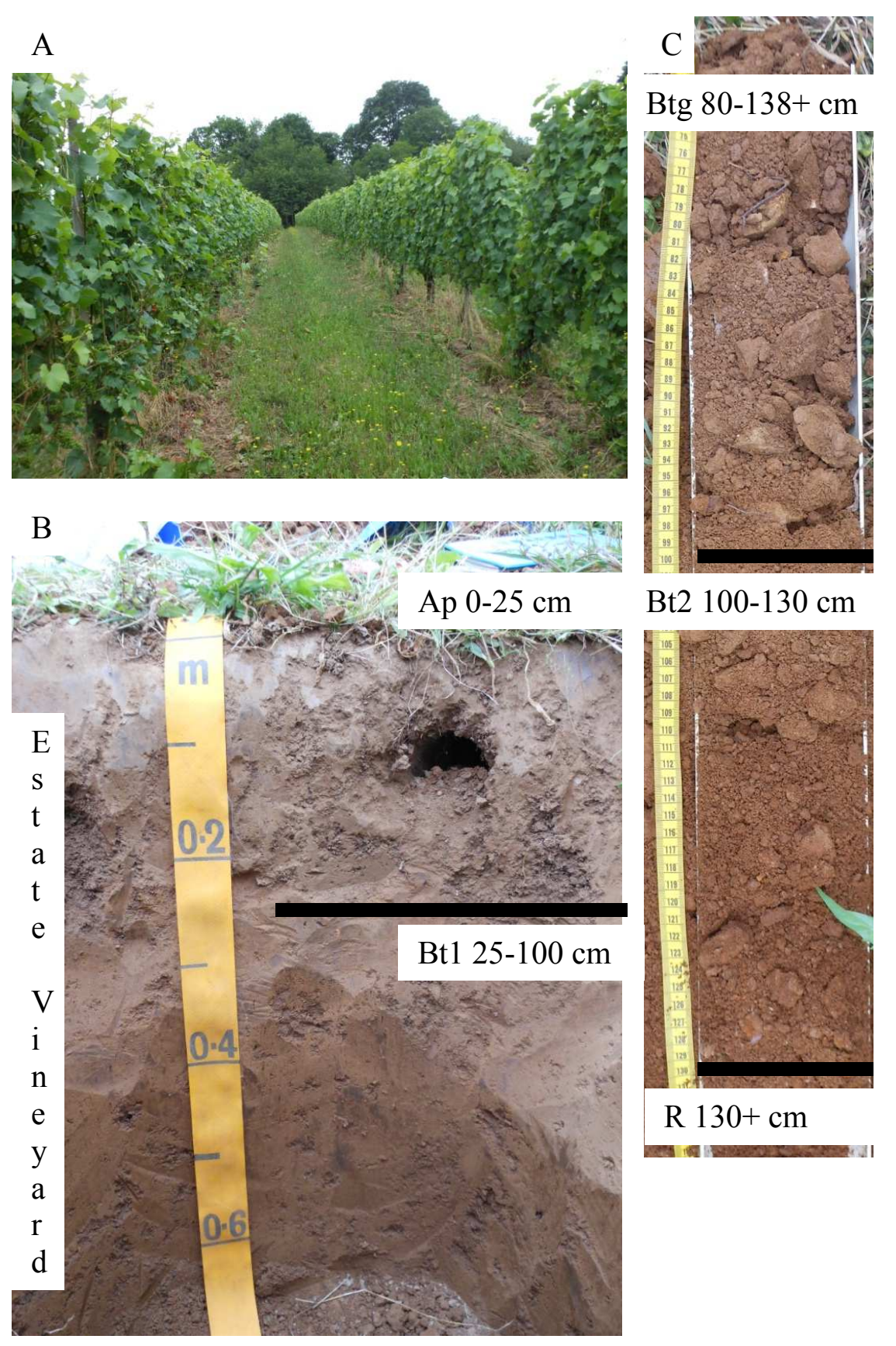

Figure 34. Sample soil pit at Rex Hill, Estate Vineyard Block 12. A - View of sample location, facing north. B - Picture of the face of the soil pit with horizon depths and boundaries marked. C - Soil retrieved using a hand auger with horizon depths and boundaries marked. 


\section{Soil Chemistry}

The Rex Hill Estate Vineyard, Block 12 soil pit was separated into three horizons, and samples of each horizon were sent for analysis (Table 66). The maximum concentrations of $\mathrm{K}$ and $\mathrm{S}$ are in the Ap horizon and they decrease with depth. $\mathrm{K}$ and $\mathrm{Mg}$ both decrease with depth with a bulge in the Bt1 horizon. Ca is highest in the Bt2

Table 66. Macronutrient, micronutrient and trace elements concentrations (all values in $\mathrm{mg} / \mathrm{kg}$ ) for the Rex Hill, Estate Vineyard, Block 12 soil pit (ND - Non-detectable).

\begin{tabular}{|c|c|c|c|c|c|c|c|c|c|c|}
\hline Horizon (cm) & \multicolumn{2}{|l|}{$\mathbf{P}$} & $\mathbf{K}$ & \multicolumn{2}{|c|}{$\mathbf{C a}$} & \multicolumn{2}{|c|}{ Mg } & \multirow{2}{*}{$\frac{\mathbf{S}}{2193}$} & \multicolumn{2}{|r|}{ Cl } \\
\hline Ap $(0-25)$ & \multicolumn{2}{|c|}{1730} & 1450 & \multicolumn{2}{|c|}{1660} & \multicolumn{2}{|c|}{2360} & & \multicolumn{2}{|r|}{ ND } \\
\hline Bt1 (25-100) & \multicolumn{2}{|l|}{774} & 1560 & \multicolumn{2}{|c|}{1300} & \multicolumn{2}{|c|}{3100} & \multicolumn{2}{|l|}{ ND } & ND \\
\hline Bt2 (100-130) & \multicolumn{2}{|l|}{761} & 652 & \multicolumn{2}{|c|}{1680} & \multicolumn{2}{|c|}{2060} & 117 & \multicolumn{2}{|r|}{ ND } \\
\hline Mean & \multicolumn{2}{|c|}{1088} & 1221 & \multicolumn{2}{|c|}{1547} & \multicolumn{2}{|c|}{2507} & 155 & \multicolumn{2}{|r|}{$N D$} \\
\hline$S D$ & \multicolumn{2}{|l|}{556} & 496 & \multicolumn{2}{|c|}{214} & \multicolumn{2}{|c|}{535} & 54 & \multicolumn{2}{|r|}{$N D$} \\
\hline Maximum & \multicolumn{2}{|c|}{1730} & 1560 & & 80 & & & 193 & & $N D$ \\
\hline Horizon (cm) & $\mathbf{F e}$ & Al & Co & $\mathbf{C u}$ & & & Mo & $\mathbf{N a}$ & $\mathbf{N i}$ & Zn \\
\hline Ap (0-25) & 22200 & 12100 & 14.8 & 12.0 & & & ND & 199 & 9.62 & 63.1 \\
\hline Bt1 (25-100) & 25300 & 13500 & 14.9 & 14.2 & & & ND & 184 & 10.2 & 45.5 \\
\hline Bt2 (100-130) & 41000 & 15700 & 22.3 & 16.8 & & & ND & 201 & 8.47 & 42.6 \\
\hline Mean & 29500 & 13767 & 17.3 & 14.3 & & & $N D$ & 195 & 9.43 & 50.4 \\
\hline$S D$ & 10079 & 1815 & 4.30 & 2.40 & & & $N D$ & 9.3 & 0.88 & 11.1 \\
\hline Maximum & 41000 & 15700 & 22.3 & 16.8 & & & $N D$ & 201 & 10.2 & 63.1 \\
\hline Horizon (cm) & As & $\mathbf{B a}$ & $\mathbf{B e}$ & Cd & $\mathrm{Cr}$ & Hg & $\mathbf{P b}$ & Se & $\mathrm{Sr}$ & $\mathbf{V}$ \\
\hline Ap (0-25) & 12.2 & 246 & 0.614 & 0.277 & 15.9 & ND & 47.1 & ND & 20.5 & 63 \\
\hline Bt1 $(25-100)$ & 3.58 & 115 & 0.665 & 0.147 & 19.6 & ND & 10.6 & ND & 17.5 & 76 \\
\hline Bt2 (100-130) & 1.70 & 169 & 0.975 & 0.226 & 20.5 & ND & 8.7 & ND & 28.2 & 130 \\
\hline Mean & 5.83 & 177 & 0.751 & 0.217 & 18.7 & $N D$ & 22.1 & $N D$ & 22.1 & 90 \\
\hline$S D$ & 5.60 & 65.8 & 0.195 & 0.066 & 2.4 & $N D$ & 21.6 & $N D$ & 5.5 & 35 \\
\hline Maximum & 12.2 & 246 & 0.975 & 0.277 & 20.5 & $N D$ & 47.1 & $N D$ & 28.2 & 130 \\
\hline
\end{tabular}


horizon, but has a similarly high concentration in the Ap horizon. Most of the micronutrient concentrations measured in the three soil horizons from the Rex Hill Estate Vineyard, Block 12 increase with depth. $\mathrm{Fe}, \mathrm{Al}, \mathrm{Co}$, and $\mathrm{Cu}$ all increase with depth. $\mathrm{Mn}$ decreases from a maximum concentration in the Ap horizon to the Bt1 horizon, but then increases again. Na has no trend, though the highest concentration is at depth. Ni concentration bulges in the Bt1 horizon. Mo is non-detectable in this profile. There are some trends in trace element concentrations for the three horizons of the Rex Hill Estate Vineyard, Block 12. As and $\mathrm{Pb}$ both decrease in concentration from the Ap horizon. Be, $\mathrm{Cr}$, and $\mathrm{V}$ increase with depth and the highest concentration is in the $\mathrm{Bt} 2$ horizon. Ba and $\mathrm{Cd}$ decrease from a maximum in the Ap horizon, but then increase in the Bt2 horizon. $\mathrm{Sr}$ is highest in the $\mathrm{Bt} 2$ horizon. $\mathrm{Hg}$ and $\mathrm{Se}$ are non-detectable in this profile.

\section{Grape Juice Chemistry}

The same 24 elements that were tested in the soil samples were analyzed in the grape juice from grapes collected adjacent to the soil pits. The grape juice samples have concentrations of many elements that are below detection limits in this study and are not listed in Table 67. The concentrations of $\mathrm{K}$ and $\mathrm{Na}$ in the Rex Hill Estate Vineyard grape juice are $1600 \mathrm{mg} / \mathrm{kg}$ and $139 \mathrm{mg} / \mathrm{kg}$, respectively. Sr concentrations are measured as $0.696 \mathrm{mg} / \mathrm{kg}$, which is the $15^{\text {th }}$ highest concentration of $\mathrm{Sr}$ for the 20 vineyard samples (Table 105). Mean Sr concentration for all grape juice samples from the 20 different sites 
is $0.805 \pm 0.261 \mathrm{mg} / \mathrm{kg}$. P concentration is $361 \mathrm{mg} / \mathrm{kg}$ and Mn concentration is nondetectable for this grape sample.

Table 67. Elemental concentrations measured by ICP-MS in the grape juice from clusters collected from vines immediately adjacent to the soil pit location at Rex Hill, Estate Vineyard, Block 12 (ND Non-detectable).

\begin{tabular}{cccccccccc}
\hline Element & Sr & P & K & Na & Mg & Mn & Ca & Cu & Zn \\
\hline \hline Grape Juice $(\mathrm{mg} / \mathrm{kg})$ & 0.696 & 361 & 1600 & 139 & ND & ND & ND & ND & ND \\
\hline
\end{tabular}

\section{Wine Chemistry}

Rex Hill provided a $750 \mathrm{ml}$ sample of the wine produced from the Estate Vineyard in 2012. Many of the 24 elements tested in the wine (same as the elements tested in the soil samples) were below detection limits. The 12 elements that were detected in the Rex Hill Estate Vineyard wine sample include $\mathrm{Ba}, \mathrm{Ca}, \mathrm{Cu}, \mathrm{Fe}, \mathrm{Mg}, \mathrm{Mn}, \mathrm{P}$, $\mathrm{K}, \mathrm{Na}, \mathrm{Sr}, \mathrm{S}$, and $\mathrm{Zn}$ (Table 68). $\mathrm{Co}$ and $\mathrm{Pb}$ were not detected in this wine, thought they were detected in trace amounts in other wine samples in this study. $\mathrm{K}$ and $\mathrm{P}$ concentrations are the highest at $713 \mathrm{mg} / \mathrm{kg}$ and $447 \mathrm{mg} / \mathrm{kg}$, respectively. $\mathrm{S}$ is $97 \mathrm{mg} / \mathrm{kg}$, $\mathrm{Mg}$ is $80.4 \mathrm{mg} / \mathrm{kg}, \mathrm{Ca}$ is $42.9 \mathrm{mg} / \mathrm{kg}$, and $\mathrm{Na}$ is $7.74 \mathrm{mg} / \mathrm{kg}$ for this wine. The concentration of $\mathrm{Fe}$ is $1.11 \mathrm{mg} / \mathrm{kg}$ and $\mathrm{Mn}$ is $1.06 \mathrm{mg} / \mathrm{kg}$. The concentration of $\mathrm{Sr}$ is 1.18 $\mathrm{mg} / \mathrm{kg}$, Ba is $0.406 \mathrm{mg} / \mathrm{kg}$, and $\mathrm{Zn}$ is $0.394 \mathrm{mg} / \mathrm{kg}$. Trace amounts of $\mathrm{Cu}(0.081 \mathrm{mg} / \mathrm{kg})$ are detected in the Estate Vineyard wine sample. 


\section{Clay Mineralogy}

The Rex Hill Estate Vineyard clay mineralogy is determined from the Bt1 horizon. This soil is abundantly illitic as a result of a huge loess input. It has moderate amounts of mica present that is unweathered. The clay minerals also include moderate amounts of chloritic intergrade, hydroxy interlayered vermiculite, and minor amounts of mixed layer kaolinite with vermiculite or smectite. Trace amounts of halloysite are present as well as cristobalite. Very little goethite has developed, which aligns with this as a younger soil with less development than other sites.

Table 68. Elemental concentrations measured by ICP-MS of a $750 \mathrm{ml}$ unblended wine sample from the 2012 Rex Hill, Estate Vineyard, Block 12 (ND - Non-detectable).

\begin{tabular}{cccc}
\hline Element & 2012 Wine Sample (mg/kg) & Element & 2012 Wine Sample ( $\mathbf{m g} / \mathbf{k g})$ \\
\hline \hline $\mathrm{Al}$ & $\mathrm{ND}$ & $\mathrm{Mn}$ & 1.06 \\
$\mathrm{As}$ & $\mathrm{ND}$ & $\mathrm{Hg}$ & $\mathrm{ND}$ \\
$\mathrm{Ba}$ & 0.406 & $\mathrm{Mo}$ & $\mathrm{ND}$ \\
$\mathrm{Be}$ & $\mathrm{ND}$ & $\mathrm{Ni}$ & $\mathrm{ND}$ \\
$\mathrm{Cd}$ & $\mathrm{ND}$ & $\mathrm{P}$ & 447 \\
$\mathrm{Ca}$ & 42.9 & $\mathrm{~K}$ & 713 \\
$\mathrm{Cr}$ & $\mathrm{ND}$ & $\mathrm{Se}$ & $\mathrm{ND}$ \\
$\mathrm{Co}$ & $\mathrm{ND}$ & $\mathrm{Na}$ & 7.74 \\
$\mathrm{Cu}$ & 0.081 & $\mathrm{Sr}$ & 1.18 \\
$\mathrm{Fe}$ & 1.11 & $\mathrm{~S}$ & 97 \\
$\mathrm{~Pb}$ & $\mathrm{ND}$ & $\mathrm{V}$ & $\mathrm{ND}$ \\
$\mathrm{Mg}$ & 80.4 & $\mathrm{Zn}$ & 0.394 \\
\hline
\end{tabular}




\section{Volcanic Landslide Parent Material - Jacob-Hart Vineyard, Block 1 Physical Characteristics}

The Jacob-Hart Vineyard, owned and operated by Rex Hill, is located in Newberg, Oregon. These vineyards are located on a landslide complex that contains basaltic rocks of the Columbia River Basalt group. Jacob-Hart Block 1 is located at the toe of this ancient landslide and is on a south facing slope with vine rows running north and south (Lat. 45.337304 N, Long. -123.021697 W). The soil pit location was at 315 feet (96 meters) elevation between rows 11 and 12, and the soil is mapped as the Dixonville (previously Steiwer) soil series (Figure 35). According to the vineyard manager, this vineyard is too rocky for tractor tilling, and there is phylloxera (Dactylosphaera vitifoliae) near the oak trees on the edge of the vineyard. The vines are Pinot Noir Wädenswil clone planted in 1989 and are trellised as bilateral cordon in vertical shoot position. The vines are own-rooted (Table 8).

The Dixonville soil is characterized as a Pachic Ultic Argixeroll. The soil pit was $185+\mathrm{cm}$ deep, and the gravel of the parent material was at the surface as well as at depth for this pit. The basalt parent material is found as rock fragments in the Ap and in the $\mathrm{Bt}$ horizon (less than 10\%), but the Cr horizon is $75 \%$ basalt frock fragments. Dry colors are brown (10 YR 5/3) (Figure 36). Texture ranges from silt loam to silty clay loam and clay loam with depth. Structures throughout the soil profile are medium subangular blocky. 


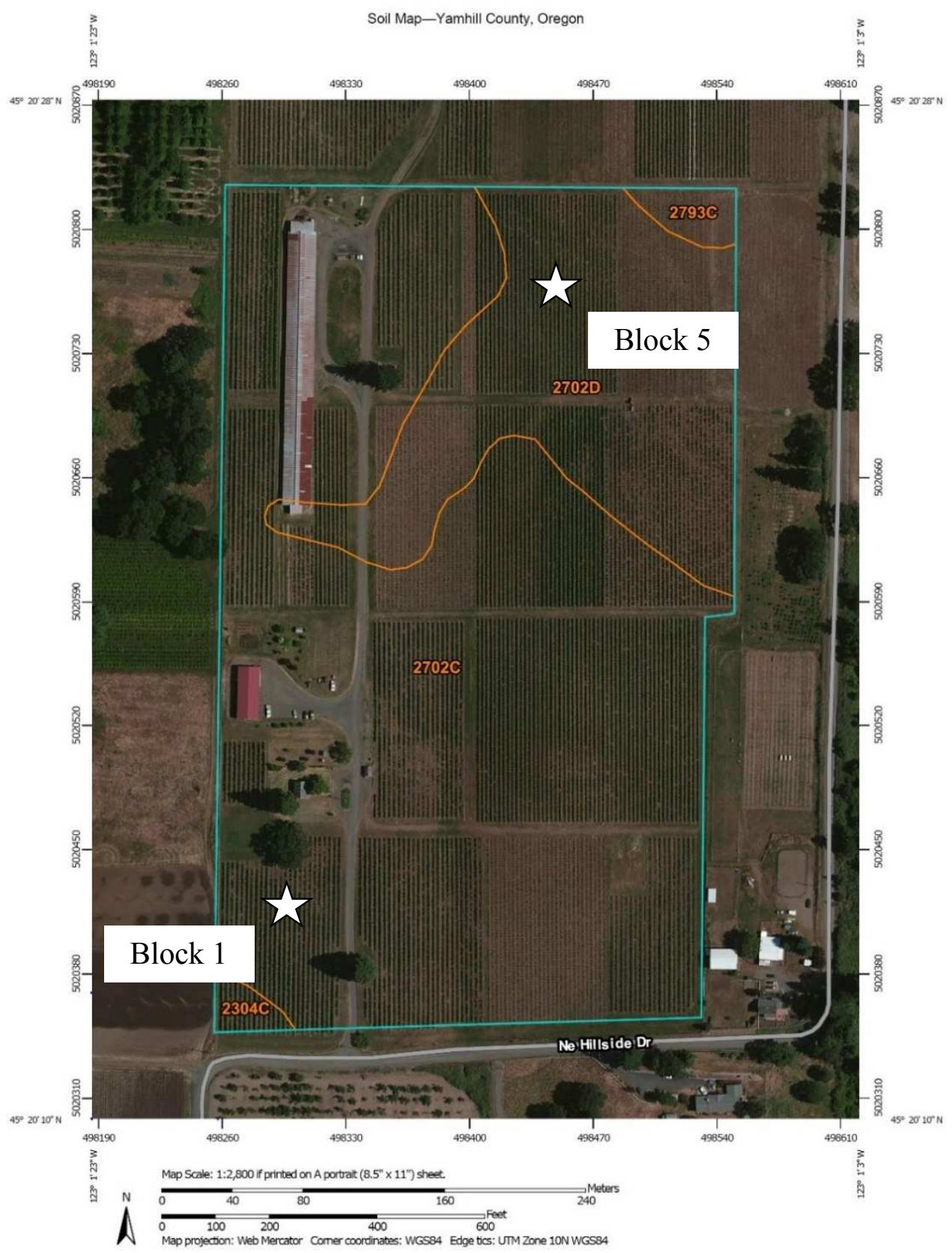

Figure 35. Soil map of Rex Hill, Jacob-Hart Vineyard Block 1. Pit location marked. 2702C Dixonville silty clay loam, 3 to 12 percent slopes. 2702D - Dixonville silty clay loam, 12 to 20 percent slopes. 2304C - Carlton silt loam, 2 to 12 percent slopes. 2793C - Witzel-Dixonville complex, 2 to 12 percent slopes (NRCS, 2015). Previously mapped as SuD - Steiwer silty clay loam, basalt substratum, 5 to 20 percent slopes (NRCS, 2014). 
Clay films located on ped faces increase in number from Ap (common and distinct) to At (many and distinct). Hardly any fine pisolites are found in the profile. The $\mathrm{pH}$ increases with depth to 6.0 and $\mathrm{CEC}$ decreases with a bulge in the Bt horizon. OM also decreases at first, then increases to $11.6 \%$ at depth (Table 69).

Table 69. Rex Hill, Jacob-Hart Vineyard Block 1 field and lab data.

\begin{tabular}{|c|c|c|c|c|c|c|}
\hline \multirow{3}{*}{$\begin{array}{l}\text { Depth } \\
\text { (cm) }\end{array}$} & \multirow{3}{*}{ Horizon } & \multicolumn{3}{|c|}{ Total } & \multirow[b]{2}{*}{$\begin{array}{c}\text { Coarse } \\
\text { Fragment } \\
(>2 \mathrm{~mm})\end{array}$} & \multirow{3}{*}{$\begin{array}{c}\text { Texture } \\
\text { Lab }\end{array}$} \\
\hline & & $\begin{array}{c}\text { Sand } \\
(2-0.05 \\
\mathbf{m m})\end{array}$ & $\begin{array}{c}\text { Silt } \\
(0.05-0.002 \\
\text { mm) }\end{array}$ & $\underset{(<0.002 \mathrm{~mm})}{\text { Clay }}$ & & \\
\hline & & \multicolumn{4}{|c|}{ 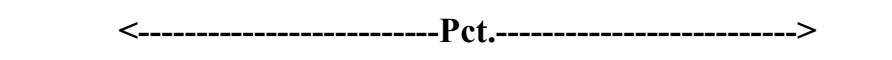 } & \\
\hline $0-30$ & Ap & 13.3 & 65.2 & 19.4 & 1.3 & $\mathrm{SiL}$ \\
\hline $30-78$ & At & 10.7 & 64.0 & 24.6 & 1.4 & $\mathrm{SiL}$ \\
\hline $78-145$ & $\mathrm{Bt}$ & 15.3 & 49.7 & 34.0 & 10.7 & $\mathrm{SiCL}$ \\
\hline $145-185+$ & $\mathrm{Cr}$ & 37.8 & 24.8 & 34.5 & 39.8 & $\mathrm{CL}$ \\
\hline $\begin{array}{l}\text { Depth } \\
\text { (cm) }\end{array}$ & Horizon & Dry Color & Structure & $\begin{array}{c}\text { Organic } \\
\text { Matter } \\
\text { LOI (Pct.) }\end{array}$ & $\begin{array}{c}\text { pH } \\
\left(1: 1 \mathbf{H}_{2} \mathrm{O}\right)\end{array}$ & $\begin{array}{c}\text { CEC } \\
(\mathrm{meq} / \mathbf{1 0 0 g})\end{array}$ \\
\hline $0-30$ & Ap & $10 Y R 5 / 3$ & $2, \mathrm{~m}, \mathrm{sbk}$ & 8.5 & 5.7 & 20.3 \\
\hline $30-78$ & At & $10 \mathrm{YR} 5 / 3$ & $2, \mathrm{~m}, \mathrm{sbk}$ & 6.0 & 5.7 & 16.3 \\
\hline $78-145$ & $\mathrm{Bt}$ & $10 \mathrm{YR} 4 / 3$ & $2, \mathrm{~m}, \mathrm{sbk}$ & 7.7 & 5.7 & 22.3 \\
\hline $145-185+$ & $\mathrm{Cr}$ & $10 Y R 7 / 3$ & & 11.3 & 6.0 & \\
\hline
\end{tabular}



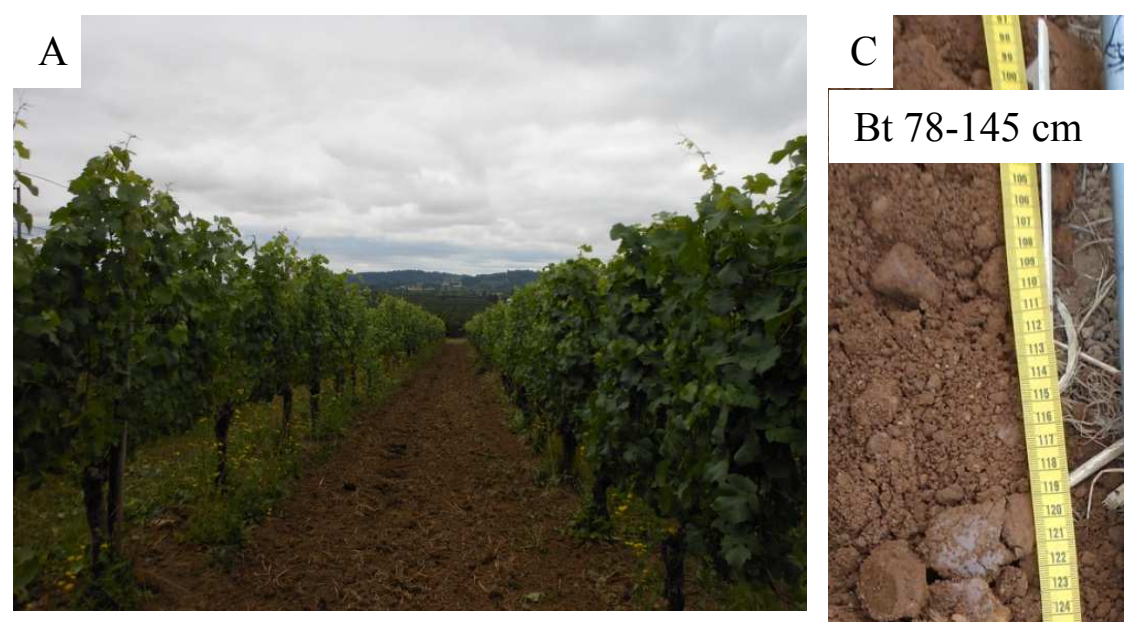

Bt $78-145 \mathrm{~cm}$
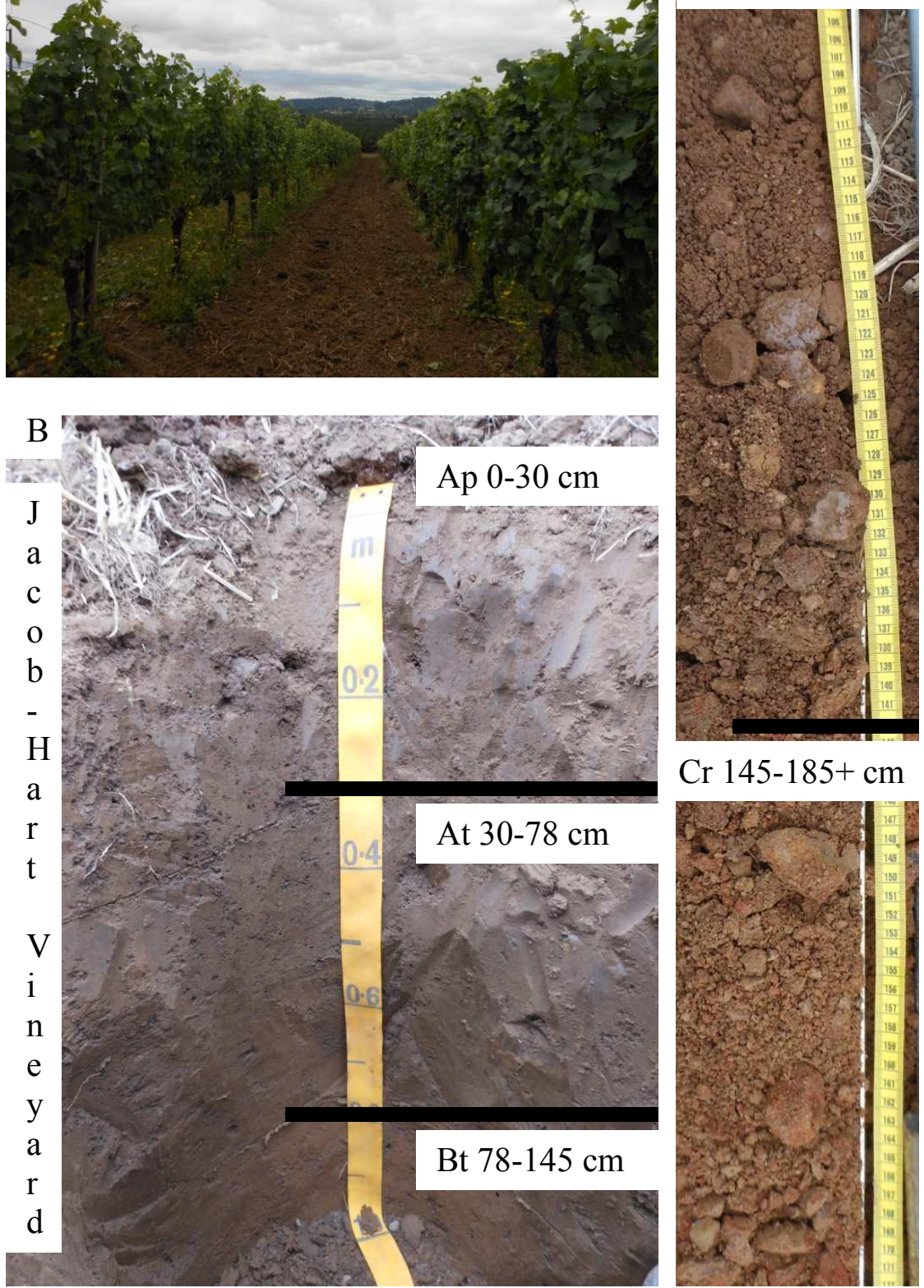

Figure 36. Sample soil pit at Rex Hill, Jacob-Hart Vineyard Block 1. A - View of sample location, facing south. B - Picture of the face of the soil pit with horizon depths and boundaries marked. C Soil retrieved using a hand auger with horizon depths and boundaries marked. 


\section{Soil Chemistry}

The Jacob-Hart Vineyard, Block 1 soil pit was separated into four horizons, and samples of each horizon were sent for analysis (Table 70). The maximum concentrations of $\mathrm{P}, \mathrm{K}$, and $\mathrm{S}$ are in the Ap horizon. $\mathrm{K}$ and $\mathrm{S}$ both decrease with depth. $\mathrm{Mg}$ increases with depth and has a bulge in the Bt horizon. Ca is variable, the maximum concentration in the Cr horizon. $\mathrm{P}$ is highest in the Ap horizon and decreases with depth with a slight bulge in the $\mathrm{Bt}$ horizon. $\mathrm{Cl}$ was only detected in the $\mathrm{Cr}$ horizon. The micronutrient concentrations measured in the four soil horizons from the Jacob-Hart Vineyard, Block 1 mostly decrease from the surface but then increase with depth from the At horizon. Fe and $\mathrm{Al}$ decrease in the At horizon then increase with depth with a maximum in the $\mathrm{Cr}$ horizon. $\mathrm{Co}, \mathrm{Cu}$, and $\mathrm{Zn}$ have maximum concentrations in the Ap horizon and decrease with depth with a bulge in the $\mathrm{Bt}$ or $\mathrm{Cr}$ horizons. Ni also decreases from the surface and the highest concentration in the Bt horizon. Mn decreases with depth. Na increases with depth with the highest concentration in the Cr horizon. Mo was non-detectable in this profile. The trace element concentrations show varying trends for the three horizons of the Jacob-Hart Vineyard, Block 1. As decreases with depth with the maximum concentration in the Ap horizon. $\mathrm{Ba}, \mathrm{Sr}$, and $\mathrm{V}$ increase with depth. $\mathrm{Cd}$ and $\mathrm{Pb}$ are highest in the Ap horizon with little trend. Cd decreases in the At horizon then bulges in the lower horizons. Be and $\mathrm{Cr}$ decrease then bulge in the Bt horizon. $\mathrm{Hg}$ and $\mathrm{Se}$ are nondetectable. 
Table 70. Macronutrient, micronutrient and trace element concentrations (all values in $\mathrm{mg} / \mathrm{kg}$ ) for the Rex Hill, Jacob-Hart Vineyard, Block 1 soil pit (ND - Non-detectable).

\begin{tabular}{|c|c|c|c|c|c|c|c|c|c|c|}
\hline Horizon (cm) & \multicolumn{2}{|l|}{$\mathbf{P}$} & $\mathbf{K}$ & \multicolumn{2}{|c|}{$\mathrm{Ca}$} & \multicolumn{2}{|c|}{ Mg } & $\mathbf{S}$ & \multicolumn{2}{|r|}{$\mathrm{Cl}$} \\
\hline Ap (0-30) & \multicolumn{2}{|c|}{1040} & 1390 & \multicolumn{2}{|c|}{1870} & \multicolumn{2}{|c|}{2090} & 216 & \multicolumn{2}{|r|}{ ND } \\
\hline At (30-78) & 542 & & 989 & \multicolumn{2}{|c|}{1400} & \multicolumn{2}{|c|}{2150} & ND & \multicolumn{2}{|r|}{ ND } \\
\hline Bt (78-145) & \multicolumn{2}{|l|}{569} & 616 & \multicolumn{2}{|c|}{2100} & \multicolumn{2}{|c|}{2600} & 107 & \multicolumn{2}{|r|}{ ND } \\
\hline $\operatorname{Cr}(145-185+)$ & \multicolumn{2}{|c|}{500} & 149 & \multicolumn{2}{|c|}{2650} & \multicolumn{2}{|c|}{1220} & ND & \multicolumn{2}{|r|}{24} \\
\hline Mean & \multicolumn{2}{|c|}{663} & 786 & \multicolumn{2}{|c|}{2005} & \multicolumn{2}{|c|}{2015} & 162 & \multicolumn{2}{|r|}{24} \\
\hline$S D$ & \multicolumn{2}{|c|}{253} & 529 & \multicolumn{2}{|c|}{519} & \multicolumn{2}{|c|}{577} & 77 & & 0 \\
\hline Maximum & 1040 & & 1390 & & 50 & 26 & 00 & 216 & & 24 \\
\hline Horizon (cm) & $\mathbf{F e}$ & Al & Co & $\mathrm{Cu}$ & & & Mo & $\mathbf{N a}$ & $\mathbf{N i}$ & $\mathbf{Z n}$ \\
\hline Ap (0-30) & 33000 & 11300 & 28.0 & 19.3 & & & ND & 190 & 8.01 & 63.2 \\
\hline At $(30-78)$ & 25100 & 9400 & 20.3 & 12.9 & & & ND & 189 & 6.89 & 39.0 \\
\hline $\mathrm{Bt}(78-145)$ & 35000 & 13500 & 18.7 & 18.2 & & & ND & 210 & 8.89 & 53.2 \\
\hline $\mathrm{Cr}(145-185+)$ & 51100 & 19500 & 27.6 & 16.7 & & & ND & 299 & 8.43 & 39.4 \\
\hline Mean & 36050 & 13425 & 23.7 & 16.8 & & & $N D$ & 222 & 8.06 & 48.7 \\
\hline$S D$ & 10906 & 4383 & 4.84 & 2.79 & & & $N D$ & 52 & 0.86 & 11.7 \\
\hline Maximum & 51100 & 19500 & 28.0 & 19.3 & & & $N D$ & 299 & 8.89 & 63.2 \\
\hline Horizon $(\mathbf{c m})$ & As & Ba & Be & Cd & $\mathrm{Cr}$ & $\mathbf{H g}$ & $\mathbf{P b}$ & Se & $\mathbf{S r}$ & $\mathbf{V}$ \\
\hline Ap $(0-30)$ & 6.33 & 196 & 0.757 & 0.259 & 17.1 & ND & 25.9 & ND & 17.9 & 129 \\
\hline At $(30-78)$ & 1.73 & 166 & 0.745 & 0.176 & 15.7 & ND & 10.4 & ND & 17.9 & 92 \\
\hline Bt (78-145) & 1.83 & 219 & 0.942 & 0.251 & 20.2 & ND & 10.3 & ND & 28.0 & 130 \\
\hline $\mathrm{Cr}(145-185+)$ & 0.666 & 630 & 0.809 & 0.256 & 14.6 & ND & 10.7 & ND & 39.4 & 187 \\
\hline Mean & 2.64 & 303 & 0.813 & 0.236 & 16.9 & $N D$ & 14.3 & $N D$ & 25.8 & 134 \\
\hline$S D$ & 2.52 & 219.2 & 0.090 & 0.040 & 2.4 & $N D$ & 7.7 & $N D$ & 10.2 & 39 \\
\hline Maximum & 6.33 & 630 & 0.942 & 0.259 & 20.2 & $N D$ & 25.9 & $N D$ & 39.4 & 187 \\
\hline
\end{tabular}

\section{Grape Juice Chemistry}

Grape juice from clusters of grapes collected from vines adjacent to the soil pit were analyzed for the same 24 elements as the soils. The majority of these elements are non-detectable using this method, therefore only the elements found in any sample are 
shown in Table 71. The highest elemental concentration measured in the Jacob-Hart Vineyard Block 1 grape juice is $\mathrm{K}$ at $1880 \mathrm{mg} / \mathrm{kg}$, which is the $2^{\text {nd }}$ highest $\mathrm{K}$ concentration in all 20 grape juice samples (Table 105). $\mathrm{P}$ is also detected at $397 \mathrm{mg} / \mathrm{kg}$ and $\mathrm{Na}$ is $140 \mathrm{mg} / \mathrm{kg}$. Sr, one of the only elements to be detected in all 20 grape juice samples, has a concentration of $1.12 \mathrm{mg} / \mathrm{kg}$ in this sample. It is the $3^{\text {rd }}$ highest concentration where the mean concentration for all grape juice samples is $0.805 \pm 0.261$ $\mathrm{mg} / \mathrm{kg} . \mathrm{Cu}$ is also detected in the grape juice at $2.41 \mathrm{mg} / \mathrm{kg}$. The Jacob-Hart Vineyard Block 1 and Block 5 are the only vineyards whose grape samples contained $\mathrm{Cu}$.

Table 71. Elemental concentrations measured by ICP-MS in the grape juice from clusters collected from vines immediately adjacent to the soil pit location at Rex Hill, Jacob-Hart Vineyard, Block 1 (ND - Non-detectable).

\begin{tabular}{cccccccccc}
\hline Element & Sr & P & K & Na & Mg & Mn & Ca & Cu & Zn \\
\hline \hline Grape Juice $(\mathrm{mg} / \mathrm{kg})$ & 1.12 & 297 & 1880 & 140 & ND & ND & ND & 2.41 & ND \\
\hline
\end{tabular}

\section{Wine Chemistry}

Rex Hill provided a $750 \mathrm{ml}$ sample of the wine produced from the Jacob-Hart Vineyard, Block 1 in 2012. Many of the 24 elements tested in the wine (same as the elements tested in the soil samples) were below detection limits. The 14 elements that were detected in Jacob-Hart Vineyard, Block 1 wine sample include $\mathrm{Ba}, \mathrm{Ca}, \mathrm{Co}, \mathrm{Cu}, \mathrm{Fe}$, $\mathrm{Pb}, \mathrm{Mg}, \mathrm{Mn}, \mathrm{P}, \mathrm{K}, \mathrm{Na}, \mathrm{Sr}, \mathrm{S}$, and $\mathrm{Zn}$ (Table 72). K and $\mathrm{P}$ concentrations are the highest at $563 \mathrm{mg} / \mathrm{kg}$ and $412 \mathrm{mg} / \mathrm{kg}$, respectively. $\mathrm{S}$ is $119 \mathrm{mg} / \mathrm{kg}, \mathrm{Mg}$ is $59.2 \mathrm{mg} / \mathrm{kg}, \mathrm{Ca}$ is 35.2 $\mathrm{mg} / \mathrm{kg}$, and $\mathrm{Na}$ is $8.42 \mathrm{mg} / \mathrm{kg}$ for this wine. The concentration of Fe is $2.22 \mathrm{mg} / \mathrm{kg}$ and $\mathrm{Mn}$ is $1.07 \mathrm{mg} / \mathrm{kg}$. The concentration of $\mathrm{Sr}$ is $1.12 \mathrm{mg} / \mathrm{kg}, \mathrm{Ba}$ is $0.327 \mathrm{mg} / \mathrm{kg}, \mathrm{Zn}$ is 0.338 
$\mathrm{mg} / \mathrm{kg}$, and $\mathrm{Cu}$ is $0.111 \mathrm{mg} / \mathrm{kg}$. Trace amounts of $\mathrm{Pb}(0.0892 \mathrm{mg} / \mathrm{kg})$ and $\mathrm{Co}(0.0338$ $\mathrm{mg} / \mathrm{kg}$ ) are also detected in the Jacob-Hart Vineyard, Block 1 wine sample.

Table 72. Elemental concentrations measured by ICP-MS of a $750 \mathrm{ml}$ unblended wine sample from the 2012 Rex Hill, Jacob-Hart Vineyard, Block 1 (ND - Non-detectable).

\begin{tabular}{cccc}
\hline Element & 2012 Wine Sample $(\mathrm{mg} / \mathrm{kg})$ & Element & 2012 Wine Sample $(\mathrm{mg} / \mathrm{kg})$ \\
\hline \hline $\mathrm{Al}$ & $\mathrm{ND}$ & $\mathrm{Mn}$ & 1.07 \\
$\mathrm{As}$ & $\mathrm{ND}$ & $\mathrm{Hg}$ & $\mathrm{ND}$ \\
$\mathrm{Ba}$ & 0.327 & $\mathrm{Mo}$ & $\mathrm{ND}$ \\
$\mathrm{Be}$ & $\mathrm{ND}$ & $\mathrm{Ni}$ & $\mathrm{ND}$ \\
$\mathrm{Cd}$ & $\mathrm{ND}$ & $\mathrm{P}$ & 412 \\
$\mathrm{Ca}$ & 35.2 & $\mathrm{~K}$ & 563 \\
$\mathrm{Cr}$ & $\mathrm{ND}$ & $\mathrm{Se}$ & $\mathrm{ND}$ \\
$\mathrm{Co}$ & $\mathrm{Na}$ & 8.42 \\
$\mathrm{Cu}$ & 0.0338 & $\mathrm{Sr}$ & 1.12 \\
$\mathrm{Fe}$ & 0.111 & $\mathrm{~S}$ & 119 \\
$\mathrm{~Pb}$ & 2.22 & $\mathrm{~V}$ & $\mathrm{ND}$ \\
$\mathrm{Mg}$ & 0.0892 & $\mathrm{Zn}$ & 0.338 \\
\hline
\end{tabular}

\section{Clay Mineralogy}

The Jacob-Hart Vineyard Block 1 and Block 5 have similar clay mineralogy, most likely because they are located less than 500 meters apart. The elevation of the site differs by 20 meters with Block 1 at the lower elevation. The clay mineralogy for both sites is determined by the Bt horizon from each soil pit. Moderate amounts of non hydroxyinterlayered smectite dominates the sample. The Block 1 clays have less smectite and slightly more hydroxy interlayering than the Block 5 sample. Both sites have no mica or illite. The clays include trace amounts of disordered kaolinite, vermiculite, and goethite 
as the main Fe phase. No kaolinite/smectite, chlorite/vermiculite, smectite/chlorite interlayers, or chlorite intergrade are present in this sample.

\section{Volcanic Landslide Parent Material - Jacob-Hart Vineyard, Block 5 Physical Characteristics}

The Jacob-Hart Vineyard, owned and operated by Rex Hill, is located in Newberg, Oregon. These vineyards are located on a landslide complex that contains basaltic rocks of the Columbia River Basalt group. Jacob-Hart Block 5 is located at the summit of this ancient landslide and is on a south facing slope with vine rows running north and south (Lat. $45.340408 \mathrm{~N}$, Long. -123.019881 W). The soil pit location was at 377 feet (115 meters) elevation between rows 24 and 25, and the soil is mapped as the Dixonville (previously Yamhill) soil series (Figure 37). According to the vineyard manager, Jacob-Hart is LIVE, Organic, and biodynamically farmed (Appendix D). The vines are Pinot Noir Pommard clone planted in 2001 and are trellised as bilateral cordon in vertical shoot position. The vines are mostly likely also own-rooted like Block 1 (Table 8).

The Dixonville soil is characterized as a Pachic Ultic Argixeroll. The soil pit was $138+\mathrm{cm}$ deep, and I did not reach refusal at that depth. The basalt parent material is found as rock fragments in the Apr (12\%) and in the Bt and Btg horizons (less than 10\%). The OM ranges from $9.0 \%$ to $9.8 \%$ and $\mathrm{pH}$ decreases with depth from 6.1 to 5.7 . 


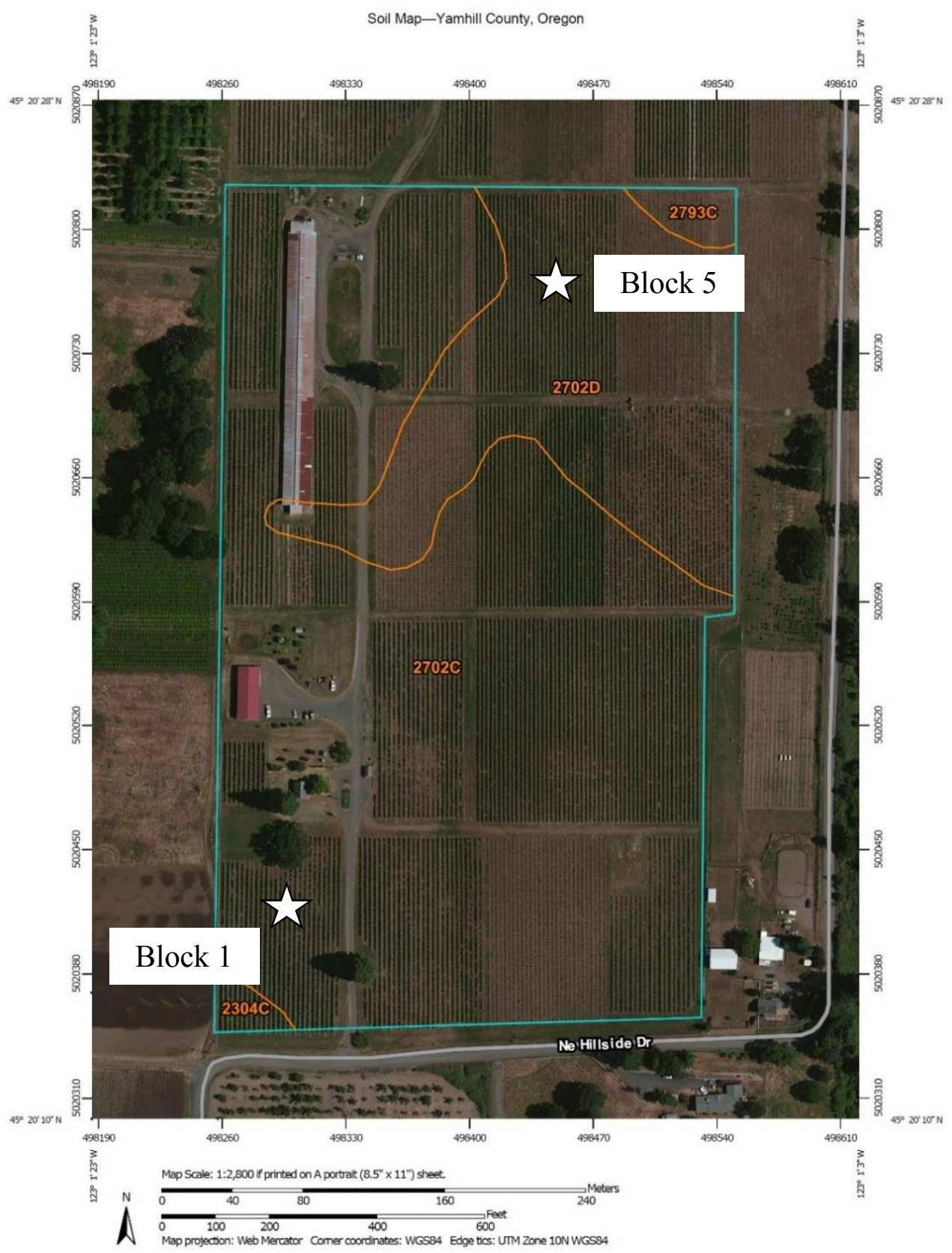

Figure 37. Soil map of Rex Hill, Jacob-Hart Vineyard Block 5. Pit location marked. 2702C Dixonville silty clay loam, 3 to 12 percent slopes. 2702D - Dixonville silty clay loam, 12 to 20 percent slopes. 2304C - Carlton silt loam, 2 to 12 percent slopes. 2793C - Witzel-Dixonville complex, 2 to 12 percent slopes (NRCS, 2015). Previously mapped as SuD - Steiwer silty clay loam, basalt substratum, 5 to 20 percent slopes (NRCS, 2014). 
CEC increases with depth (Table 73). Dry colors for the Apr is brown (10 YR 4/3), Bt is brown (10 YR 4/3) and Btg has two colors dark yellowish brown (10 YR 4/4) and light brownish gray (10 YR 6/2) redoximorphic features (Figure 38). Textures include silt loam, silty clay, and clay in the Btg. Structures are moderate medium subangular blocky. Clay films located on ped faces, increase in number from Apr (common and faint) to Bt (many and distinct). Few fine pisolites are found throughout the profile.

\section{Soil Chemistry}

The Jacob-Hart Vineyard, Block 5 soil pit was separated into three horizons, and samples of each horizon were sent for analysis (Table 74). The maximum concentrations of $\mathrm{P}, \mathrm{K}$, and $\mathrm{S}$ are in the Apr horizon. $\mathrm{P}$ and $\mathrm{K}$ decrease with depth. Ca concentration

Table 73. Rex Hill, Jacob-Hart Vineyard Block 5 field and lab data.

\begin{tabular}{|c|c|c|c|c|c|c|}
\hline \multirow{3}{*}{$\begin{array}{c}\text { Depth } \\
\text { (cm) }\end{array}$} & \multirow{3}{*}{ Horizon } & \multicolumn{3}{|c|}{ Total } & \multirow[b]{2}{*}{$\begin{array}{c}\text { Coarse } \\
\text { Fragment } \\
(>2 \mathrm{~mm})\end{array}$} & \multirow{3}{*}{$\begin{array}{c}\text { Texture } \\
\text { Lab }\end{array}$} \\
\hline & & $\begin{array}{c}\text { Sand } \\
(2-0.05 \\
\text { mm) }\end{array}$ & $\begin{array}{c}\text { Silt } \\
(0.05-0.002 \\
\text { mm) }\end{array}$ & $\begin{array}{c}\text { Clay } \\
(<0.002 \mathrm{~mm})\end{array}$ & & \\
\hline & & \multicolumn{4}{|c|}{ 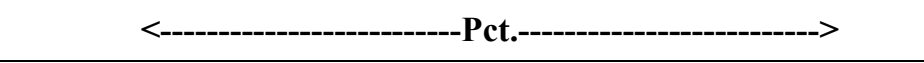 } & \\
\hline $0-60$ & Apr & 14.9 & 54.3 & 25.5 & 1.7 & $\mathrm{SiL}$ \\
\hline $60-80$ & $\mathrm{Bt}$ & 16.6 & 38.8 & 42.9 & 0.0 & $\mathrm{SiC}$ \\
\hline $80-138+$ & Btg & 21.5 & 34.8 & 41.6 & 5.2 & $\mathrm{C}$ \\
\hline $\begin{array}{c}\text { Depth } \\
\text { (cm) }\end{array}$ & Horizon & Dry Color & Structure & $\begin{array}{c}\text { Organic } \\
\text { Matter } \\
\text { LOI (Pct.) } \\
\end{array}$ & $\begin{array}{c}\mathrm{pH} \\
\left(1: 1 \mathrm{H}_{2} \mathrm{O}\right)\end{array}$ & $\begin{array}{c}\text { CEC } \\
\text { (meq/100g) }\end{array}$ \\
\hline $0-60$ & Apr & 10YR 4/3 & $\mathrm{m}$ to $2, \mathrm{~m}, \mathrm{sbk}$ & 9.0 & 6.1 & 28.2 \\
\hline $60-80$ & $\mathrm{Bt}$ & $10 \mathrm{YR} 4 / 3$ & $2, \mathrm{~m}, \mathrm{sbk}$ & 9.8 & 5.9 & 32.9 \\
\hline $80-138+$ & Btg & $\begin{array}{l}\text { 10YR 4/4 } \\
10 Y R \text { 6/2 }\end{array}$ & $2, \mathrm{~m}, \mathrm{sbk}$ & 9.5 & 5.7 & 35.1 \\
\hline
\end{tabular}



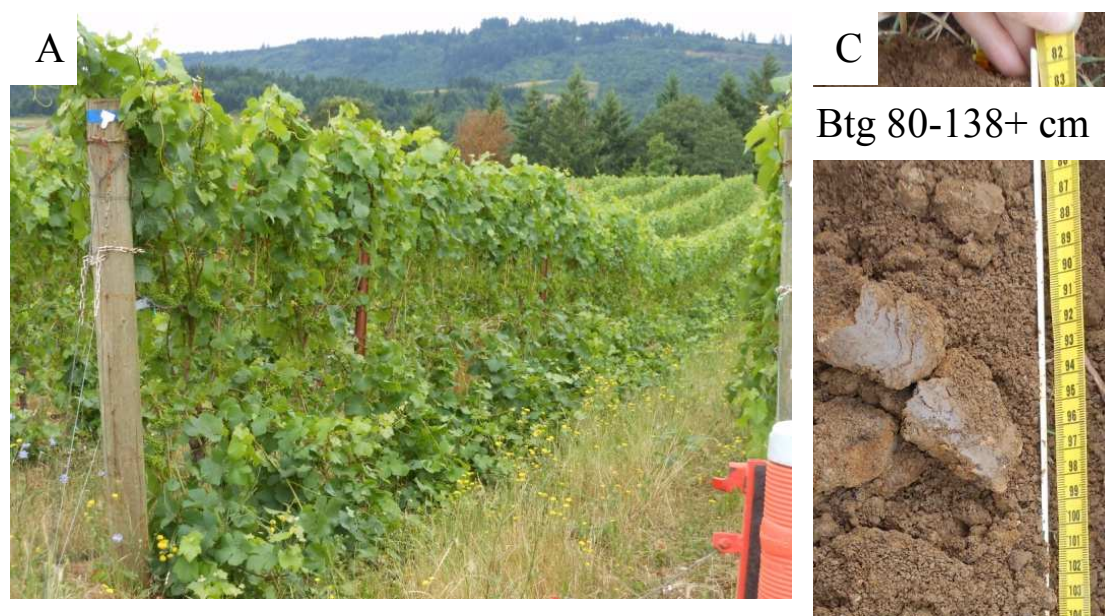

Btg 80-138+ cm
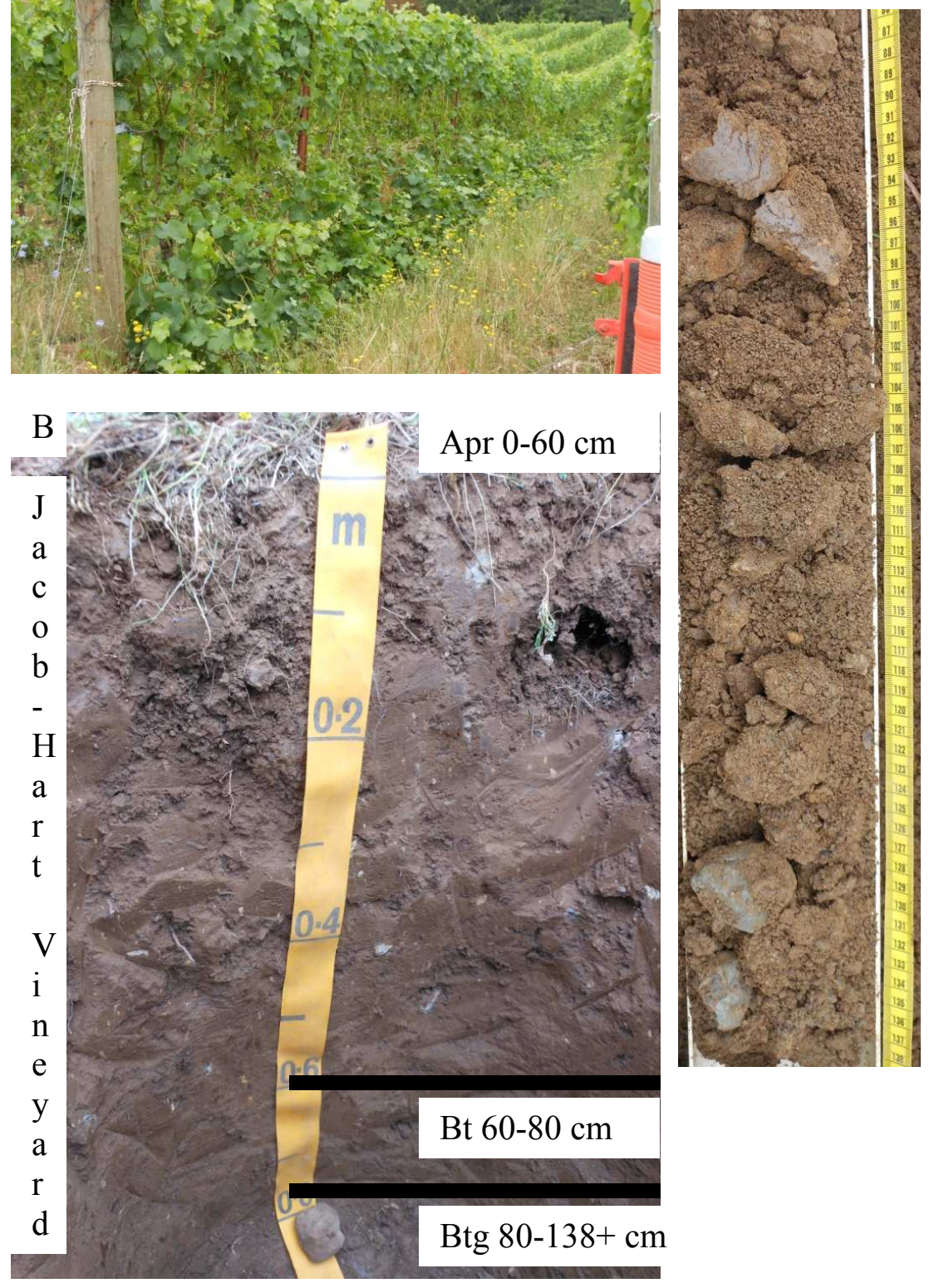

Figure 38. Sample soil pit at Rex Hill, Jacob-Hart Vineyard Block 5. A - View of sample location, facing south. B - Picture of the face of the soil pit with horizon depths and boundaries marked. C Soil retrieved using a hand auger with horizon depths and boundaries marked. 
Table 74. Macronutrient, micronutrient and trace element concentrations (all values in $\mathrm{mg} / \mathrm{kg}$ ) for the Rex Hill, Jacob-Hart Vineyard, Block 5 soil pit (ND - Non-detectable).

\begin{tabular}{|c|c|c|c|c|c|c|c|c|c|c|}
\hline Horizon $(\mathrm{cm})$ & $\mathrm{P}$ & & K & \multicolumn{2}{|c|}{$\mathrm{Ca}$} & \multicolumn{2}{|c|}{$\mathrm{Mg}$} & S & \multicolumn{2}{|r|}{ Cl } \\
\hline Apr (0-60) & 515 & & 718 & \multicolumn{2}{|c|}{3110} & \multicolumn{2}{|c|}{1560} & 152 & \multicolumn{2}{|r|}{ ND } \\
\hline Bt $(60-80)$ & 348 & & 286 & \multicolumn{2}{|c|}{3640} & \multicolumn{2}{|c|}{2020} & ND & \multicolumn{2}{|r|}{ ND } \\
\hline Btg $(80-138+)$ & 314 & & 206 & \multicolumn{2}{|c|}{3580} & \multicolumn{2}{|c|}{2030} & ND & \multicolumn{2}{|r|}{ ND } \\
\hline Mean & 392 & & 403 & \multicolumn{2}{|c|}{3443} & \multicolumn{2}{|c|}{1870} & 152 & \multicolumn{2}{|r|}{$N D$} \\
\hline$S D$ & 108 & & 275 & \multicolumn{2}{|c|}{290} & \multicolumn{2}{|c|}{269} & 0 & \multicolumn{2}{|r|}{$N D$} \\
\hline Maximum & 515 & & 718 & \multicolumn{2}{|c|}{3640} & \multicolumn{2}{|c|}{2030} & 152 & \multicolumn{2}{|r|}{$N D$} \\
\hline Horizon (cm) & $\mathrm{Fe}$ & Al & Co & \multicolumn{2}{|c|}{$\mathbf{C u}$} & \multicolumn{2}{|r|}{ Mo } & $\mathbf{N a}$ & $\mathbf{N i}$ & Zn \\
\hline Apr (0-60) & 40600 & 11500 & 39.4 & \multicolumn{2}{|c|}{14.3} & \multicolumn{2}{|r|}{ ND } & 172 & 4.96 & 64.1 \\
\hline $\mathrm{Bt}(60-80)$ & 42800 & 14900 & 37.1 & \multicolumn{2}{|c|}{14.5} & \multicolumn{2}{|r|}{ ND } & 212 & 5.18 & 59.1 \\
\hline Btg $(80-138+)$ & 46000 & 14500 & 67.4 & \multicolumn{2}{|c|}{15.8} & \multicolumn{2}{|r|}{ ND } & 193 & 8.03 & 62.1 \\
\hline Mean & 43133 & 13633 & 48.0 & \multicolumn{2}{|c|}{14.9} & \multicolumn{2}{|r|}{$N D$} & 192 & 6.06 & 61.8 \\
\hline$S D$ & 2715 & 1858 & 16.9 & \multicolumn{2}{|c|}{0.81} & \multicolumn{2}{|r|}{$N D$} & 20 & 1.71 & 2.5 \\
\hline Maximum & 46000 & 14900 & 67.4 & 15.8 & & 2350 & $N D$ & 212 & 8.03 & 64.1 \\
\hline Horizon (cm) & As & $\mathbf{B a}$ & $\mathrm{Be}$ & Cd & $\mathrm{Cr}$ & $\mathrm{Hg}$ & $\mathbf{P b}$ & Se & $\mathrm{Sr}$ & $\mathbf{V}$ \\
\hline Apr (0-60) & 1.04 & 201 & 1.02 & 0.413 & 13.0 & ND & 9.89 & 0.776 & 29.7 & 187 \\
\hline $\mathrm{Bt}(60-80)$ & 0.826 & 191 & 1.04 & 0.275 & 13.4 & ND & 9.66 & ND & 35.6 & 186 \\
\hline $\operatorname{Btg}(80-138+)$ & 0.945 & 290 & 1.15 & 0.346 & 12.0 & 0.0418 & 9.50 & 0.722 & 36.0 & 185 \\
\hline Mean & 0.937 & 227 & 1.07 & 0.345 & 12.8 & 0.0418 & 9.68 & 0.749 & 33.8 & 186 \\
\hline$S D$ & 0.107 & 54.5 & 0.07 & 0.069 & 0.72 & $N D$ & 0.20 & 0.038 & 3.53 & 1 \\
\hline Maximum & 1.04 & 290 & 1.15 & 0.413 & 13.4 & 0.0418 & 9.89 & 0.776 & 36.0 & 187 \\
\hline
\end{tabular}

bulges in the Bt horizon. $\mathrm{Mg}$ increases with depth and the highest concentration is in the

Btg horizon. S is only detected at the surface. The micronutrient concentrations measured in the three soil horizons from the Jacob-Hart Vineyard, Block 5 mostly increase with depth. $\mathrm{Fe}, \mathrm{Cu}, \mathrm{Ni}$ and $\mathrm{Co}$ increase with depth and the maximum concentration is in the Btg horizon. $\mathrm{Al}$ and $\mathrm{Na}$ both bulge in the Bt horizon. $\mathrm{Zn}$ is highest in the Ap horizon and is variable with depth. Mn is highest in the Btg horizon and variable above. Mo is non- 
detectable. The trace element concentrations for the three horizons of the Jacob-Hart Vineyard, Block 5 have little trend. Be and Sr both increase with depth and the maximum concentration is in the Btg horizon. $\mathrm{Ba}$ is variable with the highest in the Btg horizon. $\mathrm{Hg}$ was only detected in the Btg horizon. $\mathrm{V}$ and $\mathrm{Pb}$ decrease with depth and the highest is in the Apr horizon. As, $\mathrm{Se}$, and $\mathrm{Cd}$ are variable with depth but are also highest in the Apr horizon. Cr decreases with a bulge in the Bt horizon.

\section{Grape Juice Chemistry}

Grape juice from clusters of grapes collected from vines adjacent to the soil pit were analyzed for the same 24 elements as the soils. The majority of these elements are non-detectable using this method, therefore only the elements found in any sample are shown in Table 75. The highest elemental concentration measured in the Jacob-Hart Vineyard Block 5 grape juice is $\mathrm{K}$ at $1500 \mathrm{mg} / \mathrm{kg}$. P is also detected at $272 \mathrm{mg} / \mathrm{kg}$ and $\mathrm{Na}$ is $131 \mathrm{mg} / \mathrm{kg}$. Sr, one of the only elements to be detected in all 20 grape juice samples, has a concentration of $0.447 \mathrm{mg} / \mathrm{kg}$ in this sample. It is the $19^{\text {th }}$ highest concentration (second lowest) where the mean concentration for all grape juice samples is $0.805 \pm$ $0.261 \mathrm{mg} / \mathrm{kg}$ (Table 105). Cu is also detected in the grape juice at $4.19 \mathrm{mg} / \mathrm{kg}$. The JacobHart Vineyard Block 1 and Block 5 are the only vineyards whose grape samples contained $\mathrm{Cu}$. The grape juice from this site also contains $\mathrm{Zn}(2.2 \mathrm{mg} / \mathrm{kg})$, the only juice to have detectable amounts of this element. 
Table 75. Elemental concentrations measured by ICP-MS in the grape juice from clusters collected from vines immediately adjacent to the soil pit location at Rex Hill, Jacob-Hart Vineyard, Block 5 (ND - Non-detectable).

\begin{tabular}{cccccccccc}
\hline Element & Sr & P & K & Na & Mg & Mn & Ca & Cu & Zn \\
\hline Grape Juice $(\mathrm{mg} / \mathrm{kg})$ & 0.447 & 272 & 1500 & 131 & ND & ND & ND & 4.19 & 2.2 \\
\hline
\end{tabular}

\section{Wine Chemistry}

Rex Hill provided a $750 \mathrm{ml}$ sample of the wine produced from the Jacob-Hart Vineyard, Block 1 in 2012. Many of the 24 elements tested in the wine (same as the elements tested in the soil samples) were below detection limits. The 13 elements that were detected in Jacob-Hart Vineyard, Block 5 wine sample include $\mathrm{Ba}, \mathrm{Ca}, \mathrm{Cu}, \mathrm{Fe}, \mathrm{Pb}$, Mg, Mn, P, K, Na, Sr, S, and Zn (Table 76). Co was not detected in this sample even though it is detected in most other wine samples in this study. $\mathrm{K}$ and $\mathrm{P}$ concentrations are the highest at $745 \mathrm{mg} / \mathrm{kg}$ and $368 \mathrm{mg} / \mathrm{kg}$, respectively. $\mathrm{S}$ is $145 \mathrm{mg} / \mathrm{kg}, \mathrm{Mg}$ is $85.4 \mathrm{mg} / \mathrm{kg}$, $\mathrm{Ca}$ is $54.5 \mathrm{mg} / \mathrm{kg}$, and $\mathrm{Na}$ is $7.93 \mathrm{mg} / \mathrm{kg}$ for this wine. The concentration of $\mathrm{Mn}$ is 1.78 $\mathrm{mg} / \mathrm{kg}$ and $\mathrm{Fe}$ is $1.23 \mathrm{mg} / \mathrm{kg}$. The concentration of $\mathrm{Sr}$ is $0.769 \mathrm{mg} / \mathrm{kg}, \mathrm{Zn}$ is $0.453 \mathrm{mg} / \mathrm{kg}$, $\mathrm{Cu}$ is $0.303 \mathrm{mg} / \mathrm{kg}$, and $\mathrm{Ba}$ is $0.177 \mathrm{mg} / \mathrm{kg}$. Trace amounts of $\mathrm{Pb}(0.0678 \mathrm{mg} / \mathrm{kg})$ is also detected in the Jacob-Hart Vineyard, Block 5 wine sample.

\section{Clay Mineralogy}

As stated previously, the Jacob-Hart Vineyard Block 1 and Block 5 are similar and are also located less than 500 meters apart. The elevation of the site differs by 20 meters with Block 5 at the higher elevation. The clay mineralogy for both sites is determined by the Bt horizon from each soil pit. Moderate non hydroxy-interlayered 
smectite dominates the sample. The Block 5 clays have more smectite and less hydroxy interlayering than the Block 1 sample. Both sites have no mica or illite. The clays include lots of disordered kaolinite, vermiculite, and goethite as the main Fe phase. No kaolinite/smectite, chlorite/vermiculite, smectite/chlorite interlayers, or chlorite intergrade are present in this sample.

Table 76. Elemental concentrations measured twice by ICP-MS of the same $750 \mathrm{ml}$ unblended wine sample from the 2012 Rex Hill, Jacob-Hart Vineyard, Block 5 (ND - Non-detectable, * denotes mean of two samples from the same bottle).

\begin{tabular}{cccc}
\hline Element & 2012 Wine Sample* $\mathbf{( m g} / \mathbf{k g})$ & Element & $\mathbf{2 0 1 2}$ Wine Sample* $\mathbf{( m g} / \mathbf{k g})$ \\
\hline \hline $\mathrm{Al}$ & $\mathrm{ND}$ & $\mathrm{Mn}$ & 1.78 \\
$\mathrm{As}$ & $\mathrm{ND}$ & $\mathrm{Hg}$ & $\mathrm{ND}$ \\
$\mathrm{Ba}$ & 0.177 & $\mathrm{Mo}$ & $\mathrm{ND}$ \\
$\mathrm{Be}$ & $\mathrm{ND}$ & $\mathrm{Ni}$ & $\mathrm{ND}$ \\
$\mathrm{Cd}$ & $\mathrm{ND}$ & $\mathrm{P}$ & 368 \\
$\mathrm{Ca}$ & 54.5 & $\mathrm{~K}$ & 745 \\
$\mathrm{Cr}$ & $\mathrm{ND}$ & $\mathrm{Se}$ & $\mathrm{ND}$ \\
$\mathrm{Co}$ & $\mathrm{ND}$ & $\mathrm{Na}$ & 7.93 \\
$\mathrm{Cu}$ & 0.303 & $\mathrm{Sr}$ & 0.769 \\
$\mathrm{Fe}$ & 1.23 & $\mathrm{~S}$ & 145 \\
$\mathrm{~Pb}$ & 0.0678 & $\mathrm{~V}$ & $\mathrm{ND}$ \\
$\mathrm{Mg}$ & 85.4 & $\mathrm{Zn}$ & 0.453 \\
\hline
\end{tabular}




\section{Chapter Nine - Ken Wright Cellars Results}

\section{Volcanic Parent Material - Nysa Vineyard, Midblock \\ Physical Characteristics}

The Nysa Vineyard, owned and operated by Michael Mega, is located in Dayton, Oregon. This vineyard is located on basaltic rocks of the Columbia River Basalt group. Nysa Vineyard is located on the summit of an east facing slope with vine rows running just slightly off north and south (Lat. 45.265995 N, Long. -123.048344 W). The soil pit location was at 712 feet ( 217 meters) elevation between rows 24 and 25, and the soil is mapped as the Jory soil series (Figure 39). According to the vineyard owner, this vineyard is highly stressed because of phylloxera (Dactylosphaera vitifoliae). The vines are Pinot Noir Pommard clone planted in 1990 and are trellised as unilateral cordon very close to the ground in vertical shoot position. The vines are own-rooted (Table 8).

The Jory soil is characterized as a Xeric Palehumult. The soil pit was $150+\mathrm{cm}$ deep, and I did reach the parent material but not refusal at that depth. The bedrock is part of the Columbia River Basalt Group (Figure 2). The basalt parent material is found as small chips and gravel (20\%) in the Bt1 horizon from 35 to $80 \mathrm{~cm}$ depth and then increases to $70 \%$ in the $\mathrm{Bt} 2$ horizon from 80 to $118 \mathrm{~cm}$ and greater than $75 \%$ in the $\mathrm{Cr}$ horizon from 118 to $150+\mathrm{cm}$. Percent silt decreases with depth from $53 \%$ in the Ap 


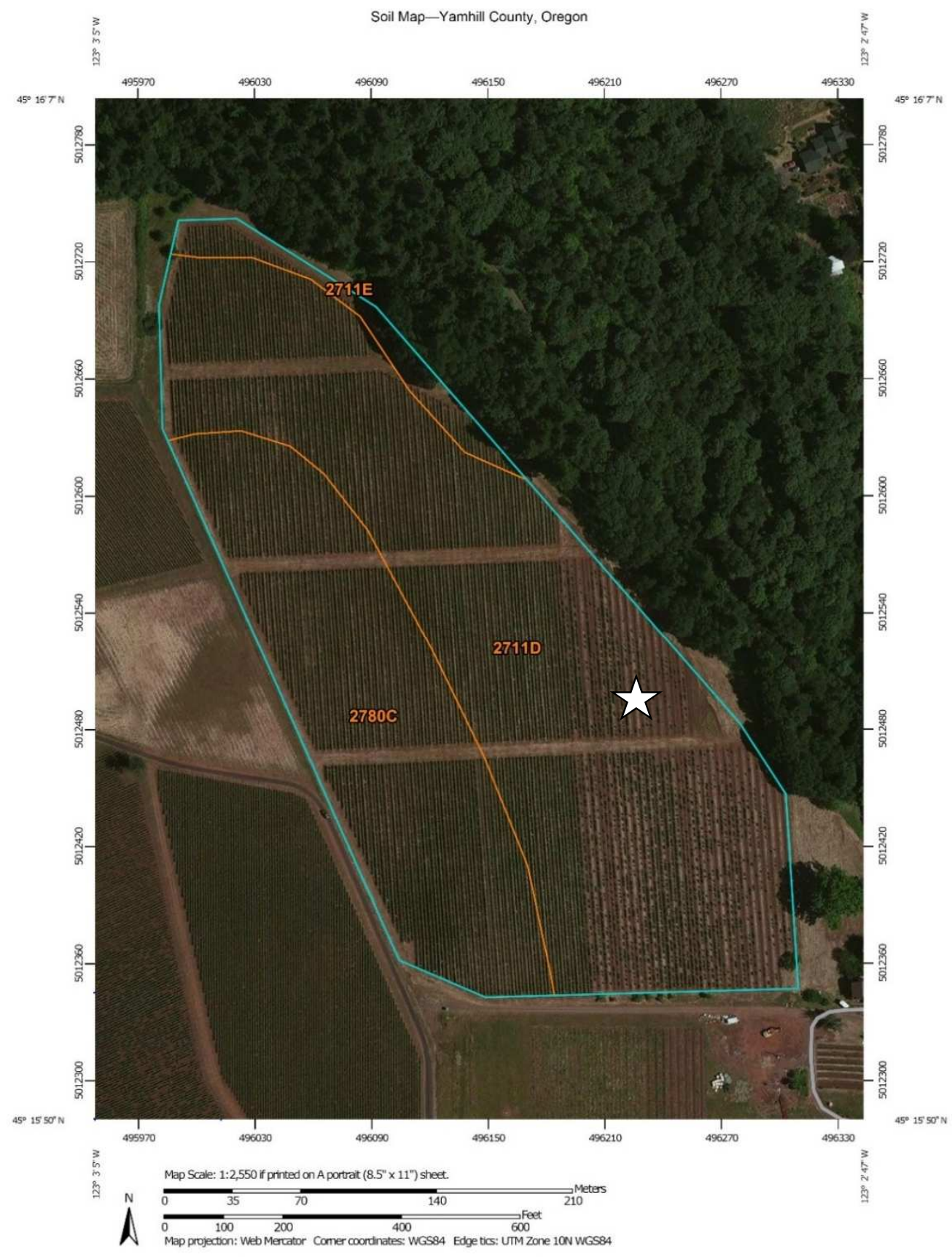

Figure 39. Soil map for Ken Wright Cellars, Nysa Vineyard Midblock. Pit location marked. 2711D Jory silty clay loam, 12 to 20 percent slopes. $2711 \mathrm{E}$ - Jory silty clay loam, 20 to 30 percent slopes. 2780C Jory-Gelderman silty clay loams, 2 to 12 percent slopes (NRCS, 2015). Previously mapped as JrD - Jory clay loam, 12 to 20 percent slopes (NRCS, 2014). 
horizon to $33 \%$ in the $\mathrm{Cr}$ horizon. Dry colors for the Ap, Bt1 and Bt2 horizons brown (7.5 YR 4/3) (Figure 40). Textures are silt loam, silty clay loam, clay loam, and loam with depth. Structures are strong, medium subangular blocky. The Ap horizon is slightly sticky and slightly plastic, but the Bt1 is sticky and plastic due to a jump in clay from $21 \%$ in the Ap to $39 \%$ in the Bt1 horizon. Clay films located on ped faces, decrease in number from the Ap (many and prominent) to the Bt2 (few and dominant). Hardly any fine pisolites are found throughout the profile. The $\mathrm{pH}$ remains consistent at 5.4 or 5.5 throughout the profile. CEC decreases with depth then bulges in the Bt2 horizon. OM ranges from $9.2 \%$ to $12.9 \%$.

Table 77. Ken Wright Cellars, Nysa Vineyard Midblock field and lab data.

\begin{tabular}{|c|c|c|c|c|c|c|}
\hline \multirow{3}{*}{$\begin{array}{l}\text { Depth } \\
\text { (cm) }\end{array}$} & \multirow{3}{*}{ Horizon } & \multicolumn{3}{|c|}{ Total } & \multirow[b]{2}{*}{$\begin{array}{c}\text { Coarse } \\
\text { Fragment } \\
(>2 \mathrm{~mm})\end{array}$} & \multirow{3}{*}{$\begin{array}{c}\text { Texture } \\
\text { Lab }\end{array}$} \\
\hline & & $\begin{array}{c}\text { Sand } \\
(2-0.05 \\
\text { mm) }\end{array}$ & $\begin{array}{c}\text { Silt } \\
(0.05-0.002 \\
\text { mm) }\end{array}$ & $\begin{array}{c}\text { Clay } \\
(<0.002 \mathrm{~mm})\end{array}$ & & \\
\hline & & \multicolumn{4}{|c|}{ 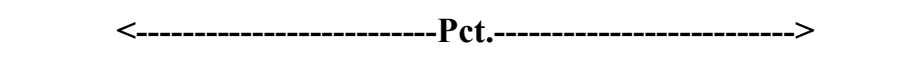 } & \\
\hline $0-35$ & Ap & 24.9 & 52.7 & 20.7 & 1.2 & $\mathrm{SiL}$ \\
\hline $35-80$ & Bt1 & 15.4 & 44.1 & 38.9 & 0.1 & $\mathrm{SiCL}$ \\
\hline $80-118$ & $\mathrm{Bt} 2$ & 26.3 & 35.4 & 35.2 & 23.1 & $\mathrm{CL}$ \\
\hline $118-150+$ & $\mathrm{Cr}$ & 48.6 & 33.5 & 16.2 & 21.7 & $\mathrm{~L}$ \\
\hline $\begin{array}{l}\text { Depth } \\
\text { (cm) }\end{array}$ & Horizon & Dry Color & Structure & $\begin{array}{c}\text { Organic } \\
\text { Matter } \\
\text { LOI (Pct.) } \\
\end{array}$ & $\begin{array}{c}\text { pH } \\
\left(1: 1 \mathrm{H}_{2} \mathrm{O}\right)\end{array}$ & $\underset{(\mathrm{meq} / 100 \mathrm{~g})}{\text { CEC }}$ \\
\hline $0-35$ & Ap & $7.5 Y R 4 / 3$ & $3, \mathrm{~m}, \mathrm{sbk}$ & 10.6 & 5.4 & 20.2 \\
\hline $35-80$ & Bt1 & 7.5YR 4/4 & $3, \mathrm{~m}, \mathrm{sbk}$ & 9.2 & 5.5 & 17.8 \\
\hline $80-118$ & $\mathrm{Bt} 2$ & $7.5 \mathrm{YR} 4 / 4$ & $1, \mathrm{~m}, \mathrm{sbk}$ & 10.0 & 5.5 & 21.7 \\
\hline $118-150+$ & $\mathrm{Cr}$ & $\begin{array}{l}2.5 Y 7 / 4 \\
10 Y R 6 / 6\end{array}$ & sg to $1, f, s b k$ & 12.9 & 5.4 & \\
\hline
\end{tabular}



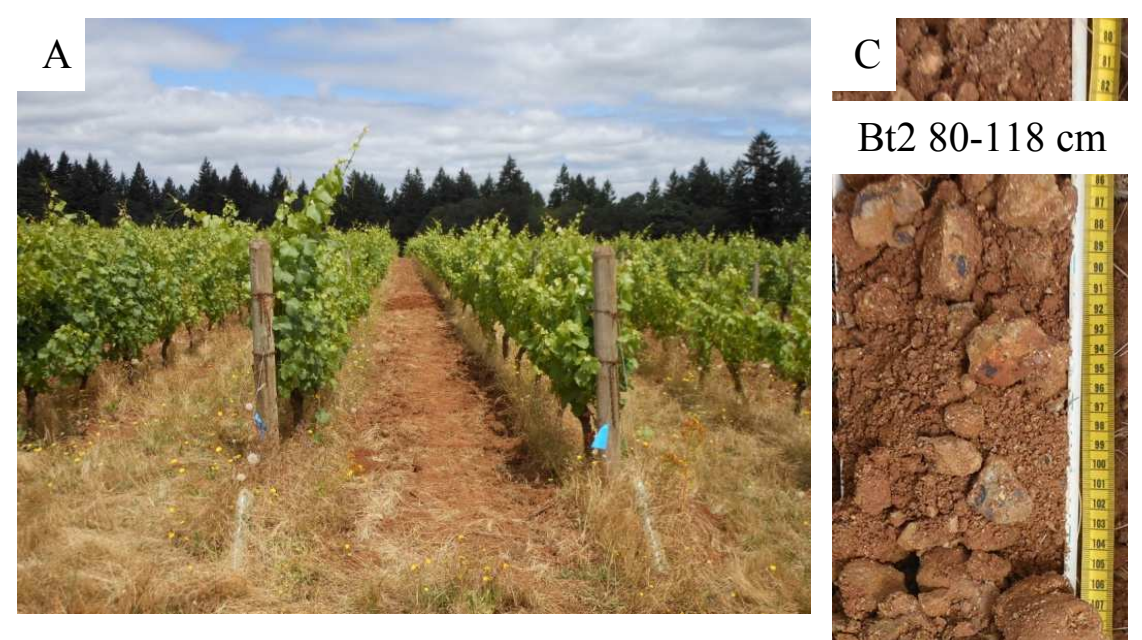

Bt2 80-118 cm
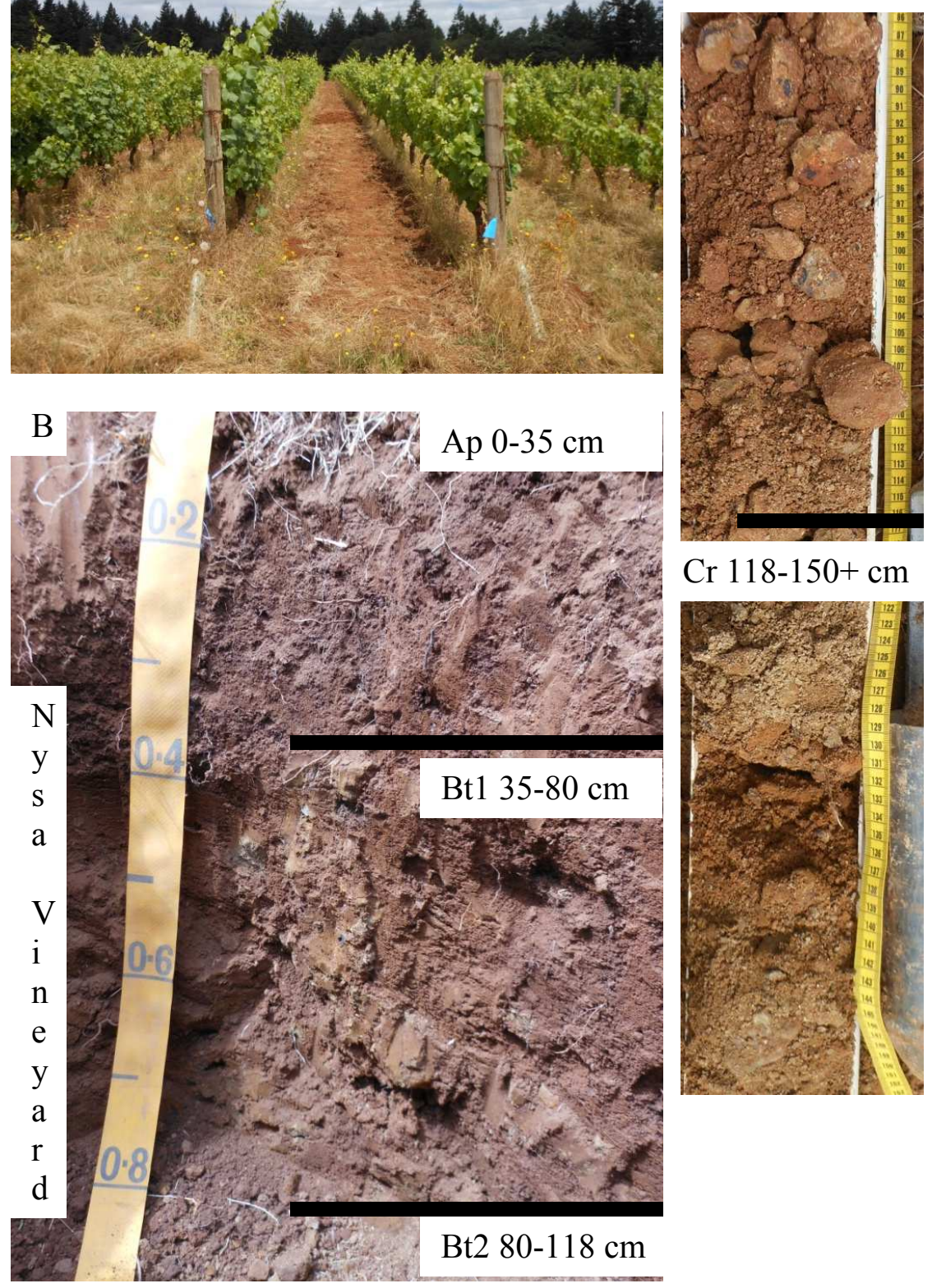

Cr $118-150+\mathrm{cm}$

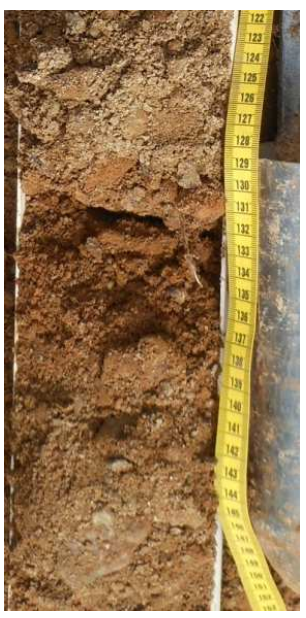

Figure 40. Sample soil pit at Ken Wright Cellars, Nysa Vineyard Midblock. A - View of sample location, facing north. B - Picture of the face of the soil pit with horizon depths and boundaries marked. C - Soil retrieved using a hand auger with horizon depths and boundaries marked. 


\section{Soil Chemistry}

The Nysa Vineyard soil pit was separated into four horizons, and samples of each horizon were sent for analysis (Table 78). The maximum concentration of $\mathrm{P}$ is in the AP horizon and decreases with depth. The P concentration then increases in the Cr horizon. $\mathrm{K}$ decreases with depth with the maximum in the AP horizon. Ca is essentially the same throughout the profile with a maximum in the $\mathrm{Bt} 2$ horizon. $\mathrm{Mg}$ is highest in the $\mathrm{Bt} 1$ horizon and decreases below. S is only detected in the AP and Bt1 horizons.

The micronutrient concentrations measured in the four soil horizons from the Nysa Vineyard mostly decrease with depth. Mn decreases with depth with the maximum concentration in the Ap horizon. $\mathrm{Fe}, \mathrm{Co}, \mathrm{Cu}, \mathrm{Ni}$, and $\mathrm{Zn}$ decrease with depth with a bulge in the $\mathrm{Cr}$ horizon. $\mathrm{Al}$ decreases with depth with the maximum concentration in the $\mathrm{Cr}$ horizon. Na increases with depth. Mo is non-detectable in the profile. The trace element concentrations for the four horizons of the Nysa Vineyard have little variation with depth (Table 78). Ba and $\mathrm{Sr}$ decrease with depth but reach a maximum concentration in the $\mathrm{Cr}$ horizon. As, Cd, and Se are highest in the Ap horizon and decrease without much trend in subsequent horizons. $\mathrm{Cr}$ and $\mathrm{V}$ bulge in in the Bt1 horizon and decrease with depth compared to the surface. $\mathrm{Be}$ is the same throughout the profile. $\mathrm{Pb}$ is highest in the $\mathrm{Ap}$ horizon and decreases with depth. Hg was non-detectable. 
Table 78. Macronutrient, micronutrient and trace element concentrations (all values in $\mathrm{mg} / \mathrm{kg}$ ) for the Ken Wright Cellars, Nysa Vineyard, and Midblock soil pit (ND - Non-detectable).

\begin{tabular}{|c|c|c|c|c|c|c|c|c|c|c|}
\hline Horizon (cm) & \multicolumn{2}{|l|}{$\mathbf{P}$} & $\mathbf{K}$ & \multicolumn{3}{|c|}{$\mathrm{Ca}$} & Mg & $\mathbf{S}$ & \multicolumn{2}{|r|}{ Cl } \\
\hline Ap $(0-35)$ & \multicolumn{2}{|c|}{2200} & 1030 & \multicolumn{2}{|c|}{1150} & \multicolumn{2}{|c|}{1410} & 212 & \multicolumn{2}{|r|}{ ND } \\
\hline Bt1 (35-80) & 1530 & & 744 & \multicolumn{2}{|c|}{1150} & \multicolumn{2}{|c|}{1550} & 107 & \multicolumn{2}{|r|}{ ND } \\
\hline Bt2 (80-118) & \multicolumn{2}{|c|}{1060} & 433 & \multicolumn{2}{|c|}{1160} & \multicolumn{2}{|c|}{1140} & ND & \multicolumn{2}{|r|}{ ND } \\
\hline $\mathrm{Cr}(118-150+)$ & \multicolumn{2}{|c|}{1530} & ND & \multicolumn{2}{|c|}{1120} & \multicolumn{2}{|c|}{757} & ND & \multicolumn{2}{|r|}{ ND } \\
\hline Mean & \multicolumn{2}{|c|}{1580} & 736 & \multicolumn{2}{|c|}{1150} & \multicolumn{2}{|c|}{1210} & 160 & \multicolumn{2}{|r|}{$N D$} \\
\hline$S D$ & \multicolumn{2}{|c|}{469} & 299 & \multicolumn{2}{|c|}{17} & \multicolumn{2}{|c|}{349} & 74.2 & \multicolumn{2}{|r|}{$N D$} \\
\hline Maximum & \multicolumn{2}{|c|}{2200} & 1030 & \multicolumn{2}{|c|}{1160} & & 50 & 212 & & $N D$ \\
\hline Horizon (cm) & $\mathrm{Fe}$ & Al & Co & $\mathbf{C u}$ & & & Mo & $\mathbf{N a}$ & $\mathbf{N i}$ & $\mathbf{Z n}$ \\
\hline Ap (0-35) & 60100 & 23000 & 34.7 & 20.3 & & & ND & 147 & 7.20 & 60.4 \\
\hline Bt1 (35-80) & 47500 & 22600 & 25.5 & 17.1 & & & ND & 175 & 6.51 & 46.8 \\
\hline Bt2 (80-118) & 44300 & 18700 & 19.0 & 11.3 & & & ND & 189 & 4.84 & 32.6 \\
\hline $\mathrm{Cr}(118-150+)$ & 52900 & 23100 & 27.1 & 14.1 & & & ND & 216 & 6.71 & 49.5 \\
\hline Mean & 51200 & 21900 & 26.6 & 15.7 & & & $N D$ & 182 & 6.32 & 47.3 \\
\hline$S D$ & 6910 & 2110 & 6.45 & 3.87 & & & $N D$ & 28.7 & 1.03 & 11.4 \\
\hline Maximum & 60100 & 23100 & 34.7 & 20.3 & & & $N D$ & 216 & 7.20 & 60.4 \\
\hline Horizon (cm) & As & $\mathbf{B a}$ & $\mathrm{Be}$ & Cd & $\mathrm{Cr}$ & Hg & $\mathbf{P b}$ & Se & $\mathrm{Sr}$ & $\mathbf{V}$ \\
\hline Ap (0-35) & 1.61 & 275 & 1.05 & 0.787 & 19.7 & ND & 11.6 & 0.909 & 15.1 & 148 \\
\hline Bt1 (35-80) & 1.01 & 142 & 1.00 & 0.587 & 22.0 & ND & 9.13 & 0.576 & 14.9 & 150 \\
\hline Bt2 (80-118) & ND & 171 & 1.04 & 0.591 & 14.6 & ND & 6.87 & 0.581 & 11.9 & 116 \\
\hline $\mathrm{Cr}(118-150+)$ & ND & 467 & 1.05 & 0.572 & 6.84 & ND & 4.0 & 0.604 & 23.2 & 119 \\
\hline Mean & 1.31 & 264 & 1.04 & 0.634 & 15.8 & $N D$ & 7.90 & 0.668 & 16.3 & 133 \\
\hline$S D$ & 0.424 & 147 & 0.0238 & 0.102 & 6.72 & ND & 3.24 & $N D$ & 4.84 & 18.2 \\
\hline Maximum & 1.61 & 467 & 1.05 & 0.787 & 22.0 & $N D$ & 11.6 & 0.909 & 23.2 & 150 \\
\hline
\end{tabular}

\section{Grape Juice Chemistry}

Grape juice from clusters of grapes collected from vines adjacent to the soil pit were analyzed for the same 24 elements as the soils. The majority of these elements are non-detectable using this method, therefore only the elements found in any sample are 
shown in Table 79. K, Na, and $\mathrm{Sr}$ are the only elements found in all 20 grape juice samples and $\mathrm{P}$ is detected in 15 of the 20 sites. The highest elemental concentration measured in the Nysa Vineyard grape juice is $\mathrm{K}$ at $1500 \mathrm{mg} / \mathrm{kg}$. P is also detected at 272 $\mathrm{mg} / \mathrm{kg}$ and $\mathrm{Na}$ is $131 \mathrm{mg} / \mathrm{kg}$. Sr, one of the only elements to be detected in all 20 grape juice samples, has a concentration of $1.14 \mathrm{mg} / \mathrm{kg}$ in this sample (Table 105). It is the $2^{\text {nd }}$ highest concentration, after Yamhill Vineyard, where the mean concentration for all grape juice samples is $0.805 \pm 0.261 \mathrm{mg} / \mathrm{kg}$. Ca is also detected in this sample at 102 $\mathrm{mg} / \mathrm{kg}$. This is one of only two samples, the other being Yamhill Vineyard, that has detectable levels of $\mathrm{Ca}$ in the grape juice from these vineyards.

Table 79. Elemental concentrations measured by ICP-MS in the grape juice from clusters collected from vines immediately adjacent to the soil pit location at Ken Wright Cellars, Nysa Vineyard, Midblock (ND - Non-detectable).

\begin{tabular}{cccccccccc}
\hline Element & Sr & $\mathbf{P}$ & K & Na & Mg & Mn & Ca & Cu & Zn \\
\hline \hline Grape Juice $(\mathrm{mg} / \mathrm{kg})$ & 1.14 & 257 & 1070 & 138 & ND & ND & 102 & ND & ND \\
\hline
\end{tabular}

\section{Wine Chemistry}

Ken Wright provided a $750 \mathrm{ml}$ sample of the wine produced from the Nysa Vineyard in 2012. Many of the 24 elements tested in the wine (same as the elements tested in the soil samples) were below detection limits. The 14 elements that were detected in the Nysa Vineyard wine sample include $\mathrm{Ba}, \mathrm{Ca}, \mathrm{Co}, \mathrm{Cu}, \mathrm{Fe}, \mathrm{Pb}, \mathrm{Mg}, \mathrm{Mn}, \mathrm{P}$, $\mathrm{K}, \mathrm{Na}, \mathrm{Sr}, \mathrm{S}$, and $\mathrm{Zn}$ (Table 80 ). $\mathrm{K}$ and $\mathrm{P}$ concentrations are the highest at $917 \mathrm{mg} / \mathrm{kg}$ and $542 \mathrm{mg} / \mathrm{kg}$, respectively. $\mathrm{S}$ is $106 \mathrm{mg} / \mathrm{kg}, \mathrm{Mg}$ is $65.7 \mathrm{mg} / \mathrm{kg}, \mathrm{Ca}$ is $37.4 \mathrm{mg} / \mathrm{kg}$, and $\mathrm{Na}$ is $4.5 \mathrm{mg} / \mathrm{kg}$ for this wine. The concentration of $\mathrm{Mn}$ is $1.67 \mathrm{mg} / \mathrm{kg}$ and $\mathrm{Fe}$ is $1.58 \mathrm{mg} / \mathrm{kg}$. 
The concentration of $\mathrm{Sr}$ is $1.09 \mathrm{mg} / \mathrm{kg}, \mathrm{Zn}$ is $0.747 \mathrm{mg} / \mathrm{kg}$, and $\mathrm{Ba}$ is $0.584 \mathrm{mg} / \mathrm{kg}$. Trace amounts of $\mathrm{Cu}(0.0742 \mathrm{mg} / \mathrm{kg}), \mathrm{Pb}(0.0678 \mathrm{mg} / \mathrm{kg})$, and $\mathrm{Co}(0.027 \mathrm{mg} / \mathrm{kg})$ are also detected in the Nysa Vineyard wine sample.

Table 80. Elemental concentrations measured by ICP-MS of a $750 \mathrm{ml}$ unblended wine sample from the 2012 Ken Wright, Nysa Vineyard (ND - Non-detectable).

\begin{tabular}{cccc}
\hline Element & 2012 Wine Sample (mg/kg) & Element & 2012 Wine Sample (mg/kg) \\
\hline \hline $\mathrm{Al}$ & $\mathrm{ND}$ & $\mathrm{Mn}$ & 1.67 \\
$\mathrm{As}$ & $\mathrm{ND}$ & $\mathrm{Hg}$ & $\mathrm{ND}$ \\
$\mathrm{Ba}$ & 0.584 & $\mathrm{Mo}$ & $\mathrm{ND}$ \\
$\mathrm{Be}$ & $\mathrm{ND}$ & $\mathrm{Ni}$ & $\mathrm{ND}$ \\
$\mathrm{Cd}$ & $\mathrm{ND}$ & $\mathrm{P}$ & 542 \\
$\mathrm{Ca}$ & 37.4 & $\mathrm{~K}$ & 917 \\
$\mathrm{Cr}$ & $\mathrm{ND}$ & $\mathrm{Se}$ & $\mathrm{ND}$ \\
$\mathrm{Co}$ & 0.027 & $\mathrm{Na}$ & 4.5 \\
$\mathrm{Cu}$ & 0.0742 & $\mathrm{Sr}$ & 1.09 \\
$\mathrm{Fe}$ & 1.58 & $\mathrm{~S}$ & 106 \\
$\mathrm{~Pb}$ & 0.0678 & $\mathrm{~V}$ & $\mathrm{ND}$ \\
$\mathrm{Mg}$ & 65.7 & $\mathrm{Zn}$ & 0.747 \\
\hline
\end{tabular}

\section{Clay Mineralogy}

The Nysa Vineyard clays indicate more weathering than some of the others samples. This is suggested from the clay mineralogy determined from the Bt1 horizon. The clay minerals are mainly chlorite intergrade and kaolinite with minor amounts of halloysite. Goethite is the main Fe phase and is moderately pronounced. Illite, vermiculite, and smectite are present in minor to trace amounts. 


\section{Marine Sediment Parent Material - Abbott Claim Vineyard \\ Physical Characteristics}

Abbott Claim Vineyard, owned and operated by Ken Wright Cellars, is located in Carlton, Oregon. This vineyard is located on marine sedimentary rocks of the Coast Range. The Abbott Claim Vineyard soil pit is located on the shoulder of a south facing slope with vine rows running north and south (Lat. 45.291616 N, Long. -123.116963 W). The soil pit location was at 476 feet (145 meters) elevation, and the soil is mapped as the Wellsdale - Willakenzie - Dupee complex (previously Willakenzie) soil series (Figure 41). According to the vineyard manager, this vineyard was ripped about 2 feet $(0.61 \mathrm{~m})$ deep in 2000. The vines are Pinot Noir Dijon 777 clone planted in 2001 and are trellised as bilateral cordon in vertical shoot position. The vines are grafted onto 101-14 rootstock (Table 8).

The Wellsdale - Willakenzie - Dupee soil is characterized as an Aquultic Haploxeralf. The soil pit was $215+\mathrm{cm}$ deep, and I did reach the parent material but not refusal at that depth. The bedrock is part of the Spencer Formation of the Coast Range marine sediments (Figure 2). The $\mathrm{pH}$ decreases with depth from 6.4 in the Ap horizon. OM ranges from $6.5 \%$ to $9.4 \%$ and CEC is highest in the Bt1 horizon at $20.5 \mathrm{meq} / 100 \mathrm{~g}$ (Table 81). The sandstone parent material is found with depth to highly influence the texture of the soil. Clay percent is highest in the Bt horizon at $47 \%$ while percent sand increases in the $\mathrm{Bw}$ and $\mathrm{Cr} 1$ horizons from $51 \%$ to $58 \%$. 


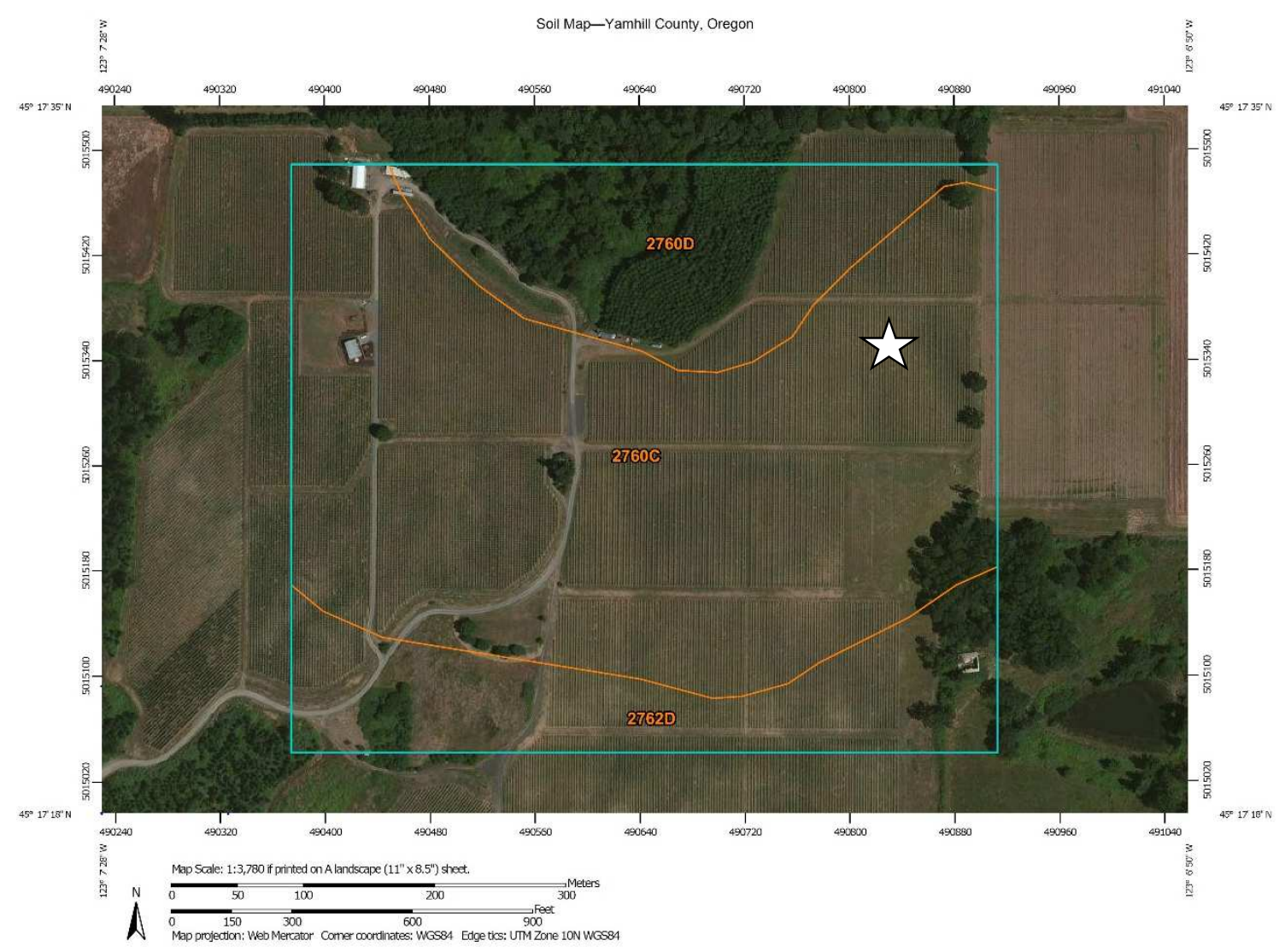

Figure 41. Soil map for Ken Wright Cellars, Abbott Claim Vineyard. Pit location marked. 2760C Wellsdale-Willakenzie-Dupee complex, 2 to 12 percent slopes. 2760D - Wellsdale-Willakenzie-Dupee complex, 2 to 12 percent slopes. 2762D - Willakenzie-Wellsdale complex, 12 to 20 percent slopes (NRCS, 2015). Previously mapped as WeC - Willakenzie silty clay loam, 2 to 12 percent slopes (NRCS, 2014).

Dry colors for the Ap horizon are yellowish brown (10 YR 5/4), Bt is strong brown (7.5 YR 5/6) and Bw is reddish yellow (7.5 YR 6/6). The parent material is multicolored in the $\mathrm{Cr} 1$ and $\mathrm{Cr} 2$ horizons including pale yellow (2.5 Y 8/2), strong brown (7.5 YR 4/6), and reddish yellow (7.5 YR 7/6) (Figure 42). The soil profile structure includes weak fine subangular blocky in the Ap horizon and moderate medium subangular block in the $\mathrm{Bt}$ with the $\mathrm{Bw}, \mathrm{Cr} 1$, and $\mathrm{Cr} 2$ horizons having more single grain fine structure. 
Texture is loam in the Ap horizon, clay in the Bt horizon and sandy clay loam, sandy loam, and loam with depth. Clay films are located on ped faces in the Bt horizon and are common and dominant. This soil contains abundant muscovite mica and quartz sand.

There are no pisolites found in this profile.

Table 81. Ken Wright Cellars, Abbott Claim Vineyard field and lab data.

\begin{tabular}{|c|c|c|c|c|c|c|}
\hline \multirow{3}{*}{$\begin{array}{l}\text { Depth } \\
\text { (cm) }\end{array}$} & \multirow{3}{*}{ Horizon } & \multicolumn{3}{|c|}{ Total } & \multirow[b]{2}{*}{$\begin{array}{c}\text { Coarse } \\
\text { Fragment } \\
(>2 \mathrm{~mm})\end{array}$} & \multirow{3}{*}{$\begin{array}{c}\text { Texture } \\
\text { Lab }\end{array}$} \\
\hline & & $\begin{array}{c}\text { Sand } \\
(2-0.05 \mathrm{~mm})\end{array}$ & $\begin{array}{c}\text { Silt } \\
(\mathbf{0 . 0 5 - 0 . 0 0 2} \\
\text { mm) }\end{array}$ & $\begin{array}{c}\text { Clay } \\
(<0.002 \\
\text { mm) }\end{array}$ & & \\
\hline & & \multicolumn{4}{|c|}{ 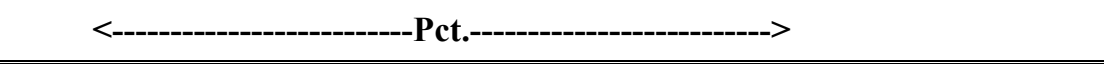 } & \\
\hline $0-24$ & Ap & 38.1 & 44.1 & 18.1 & 0.0 & $\mathrm{~L}$ \\
\hline $24-70$ & Bt1 & 27.8 & 24.5 & 47.0 & 0.0 & $\mathrm{C}$ \\
\hline $70-140$ & $\mathrm{Bw}$ & 51.4 & 27.4 & 21.7 & 0.0 & SCL \\
\hline $140-150$ & $\mathrm{Cr} 1$ & 57.6 & 28.9 & 14.6 & 0.0 & SL \\
\hline $150-215+$ & $\mathrm{Cr} 2$ & 40.2 & 34.3 & 22.4 & 0.9 & $\mathrm{~L}$ \\
\hline $\begin{array}{c}\text { Depth } \\
\text { (cm) }\end{array}$ & Horizon & Dry Color & Structure & $\begin{array}{c}\text { Organic } \\
\text { Matter } \\
\text { LOI (Pct.) } \\
\end{array}$ & $\begin{array}{c}\text { pH } \\
\left(1: 1 \mathbf{H}_{2} \mathrm{O}\right) \\
\end{array}$ & $\underset{(\mathrm{meq} / 100 \mathrm{~g})}{\mathrm{CEC}}$ \\
\hline $0-24$ & Ap & $10 \mathrm{YR} 5 / 4$ & $1, \mathrm{f}, \mathrm{sbk}$ & 6.5 & 6.4 & 11.7 \\
\hline $24-70$ & Bt1 & $\begin{array}{l}7.5 \text { YR 5/6 } \\
7.5 Y R 4 / 4\end{array}$ & $2, \mathrm{~m}, \mathrm{sbk}$ & 9.2 & 5.6 & 20.5 \\
\hline $70-140$ & $\mathrm{Bw}$ & $\begin{array}{l}7.5 \text { YR } 6 / 6 \\
7.5 Y R ~ 8 / 6\end{array}$ & sg to $1, f, s b k$ & 8.2 & 4.9 & 9.7 \\
\hline $140-150$ & $\mathrm{Cr} 1$ & $\begin{array}{c}7.5 \mathrm{YR} 4 / 6 \\
2.5 \mathrm{Y} 8 / 2\end{array}$ & sg to $f, g r$ & 9.4 & 4.7 & \\
\hline $150-215+$ & $\mathrm{Cr} 2$ & $\begin{array}{l}7.5 \text { YR 7/6 } \\
10 Y R \text { 8/4 }\end{array}$ & sg to $\mathrm{f}, \mathrm{gr}$ & 6.3 & 4.8 & \\
\hline
\end{tabular}



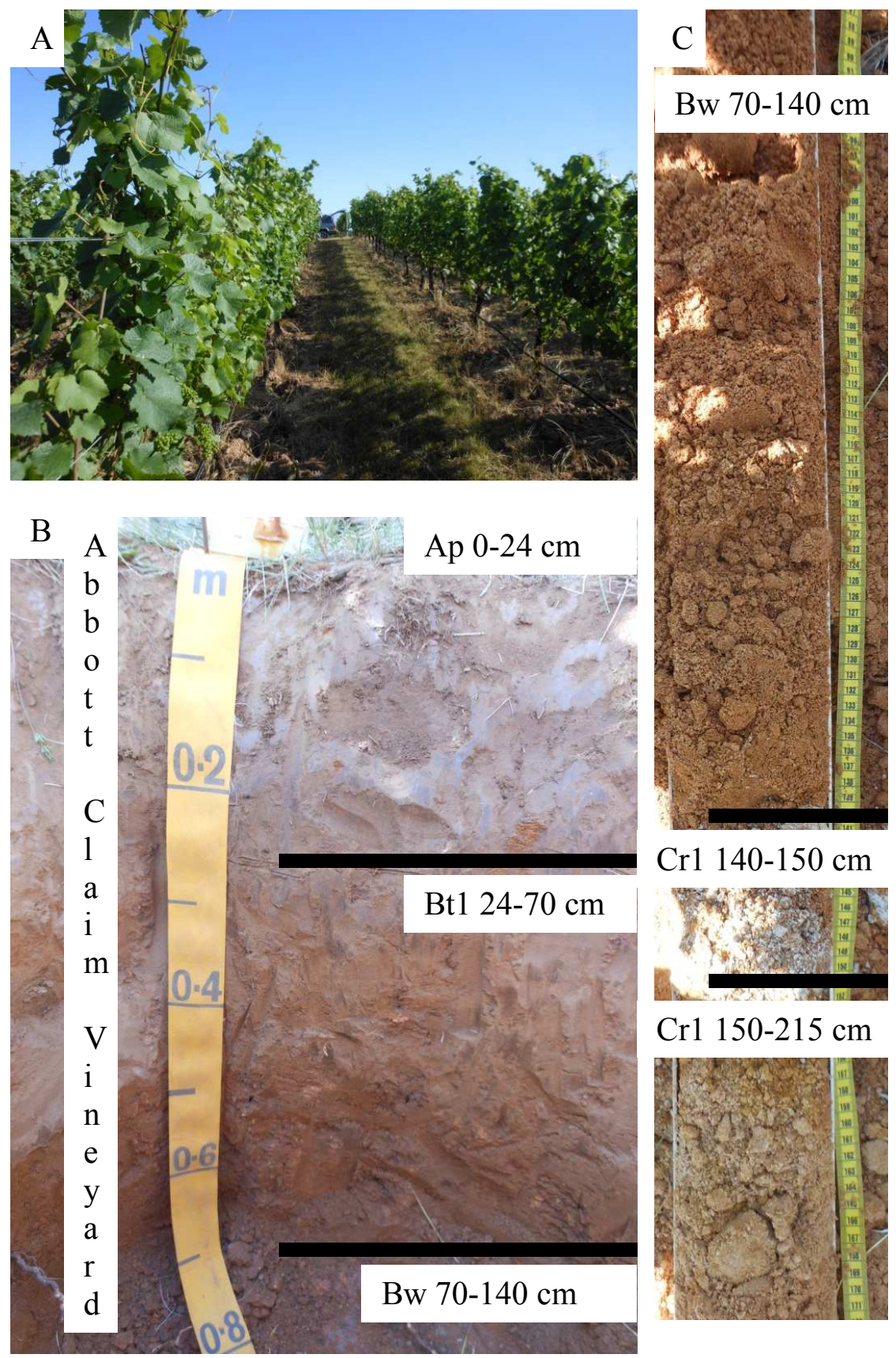

Bw $70-140 \mathrm{~cm}$
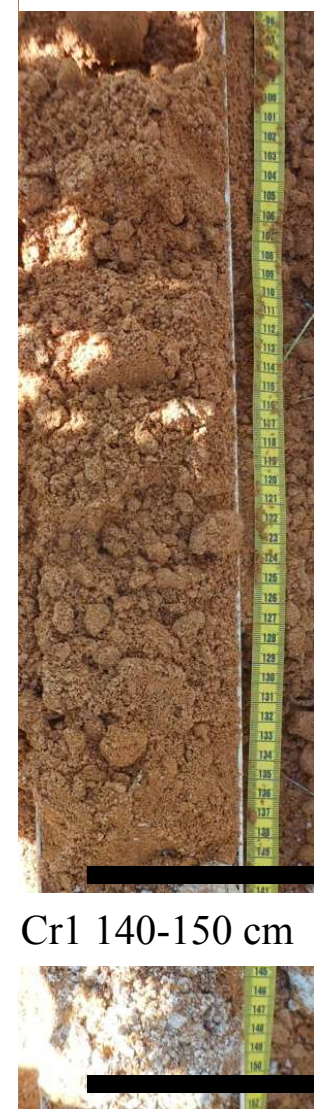

Cr1 $150-215 \mathrm{~cm}$

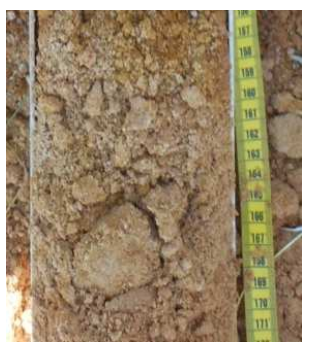

Figure 42. Sample soil pit at Ken Wright Cellars, Abbott Claim Vineyard. A - View of sample location, facing north. B - Picture of the face of the soil pit with horizon depths and boundaries marked. C - Soil retrieved using a hand auger with horizon depths and boundaries marked. 


\section{Soil Chemistry}

The Abbott Claim Vineyard soil pit was separated into five horizons, and samples of each horizon were sent for analysis (Table 82). The maximum concentrations of $\mathrm{P}, \mathrm{K}$, $\mathrm{Ca}$, and $\mathrm{S}$ are in the Ap horizon and the concentrations then decrease with depth. $\mathrm{S}$ is only detected in the Ap horizon. Mg concentrations bulge in the Bt horizon but has little trend. $\mathrm{Cl}$ is detected only in the $\mathrm{Cr} 1$ and $\mathrm{Cr} 2$ horizons. The micronutrient concentrations measured in the five soil horizons from the Abbott Claim Vineyard mostly decrease with depth. $\mathrm{Zn}, \mathrm{Ni}, \mathrm{Mn}, \mathrm{Cu}$ and $\mathrm{Co}$ are highest in the Ap horizon, decrease with depth, and have a small bulge in the $\mathrm{Cr} 1$ horizon. $\mathrm{Na}$ is highest in the Ap horizon with no trend below. Al bulges in the $\mathrm{Bt}$ horizon and Fe bulges in the $\mathrm{Cr} 1$ horizon before dropping significantly in the $\mathrm{Cr} 2$ horizon. Mo is non-detectable. Trace element concentrations for the five horizons of the Abbott Claim Vineyard show some trends. $\mathrm{Ba}$ and $\mathrm{Pb}$ are highest in the Ap horizon, decrease with depth, and have a small bulge in the $\mathrm{Cr}$ horizon. $\mathrm{Be}, \mathrm{Cr}$, $\mathrm{V}$ and As are variable at depth with the highest in the Cr1 horizon. Sr concentration bulges in the Bt horizon. Cd is highest in the Ap horizon and decreases with depth. $\mathrm{Hg}$ and Se are non-detectable.

\section{Grape Juice Chemistry}

The grape juice samples have concentrations of many elements that are below detection limits in this study, as seen in Table 83. All 24 elements were analyzed in the 
Table 82. Macronutrient, micronutrient and trace element concentrations (all values in $\mathrm{mg} / \mathrm{kg}$ ) for the Ken Wright Cellars, Abbott Claim Vineyard soil pit (ND - Non-detectable).

\begin{tabular}{|c|c|c|c|c|c|c|c|c|c|c|}
\hline Horizon (cm) & $\mathbf{P}$ & & $\mathbf{K}$ & \multicolumn{3}{|c|}{$\mathrm{Ca}$} & Mg & $\mathbf{S}$ & \multicolumn{2}{|r|}{$\mathbf{C l}$} \\
\hline Ap (0-24) & 521 & & 668 & \multicolumn{2}{|c|}{1610} & \multicolumn{2}{|c|}{653} & 135 & \multicolumn{2}{|r|}{ ND } \\
\hline $\mathrm{Bt}(24-70)$ & 504 & & 548 & \multicolumn{2}{|c|}{1270} & \multicolumn{2}{|c|}{955} & ND & \multicolumn{2}{|r|}{ ND } \\
\hline Bw (70-140) & 303 & & 238 & \multicolumn{2}{|c|}{428} & \multicolumn{2}{|c|}{615} & ND & \multicolumn{2}{|r|}{ ND } \\
\hline Cr1 (140-150) & 520 & & 400 & \multicolumn{2}{|c|}{524} & \multicolumn{2}{|c|}{879} & ND & \multicolumn{2}{|r|}{31.5} \\
\hline $\mathrm{Cr} 2(150-215+)$ & ND & & 295 & \multicolumn{2}{|c|}{286} & \multicolumn{2}{|c|}{611} & ND & \multicolumn{2}{|r|}{10.0} \\
\hline Mean & 462 & & 430 & \multicolumn{2}{|c|}{824} & \multicolumn{2}{|c|}{743} & 135 & \multicolumn{2}{|r|}{20.8} \\
\hline$S D$ & 106 & & 178 & \multicolumn{2}{|c|}{582} & \multicolumn{2}{|c|}{162} & 0 & \multicolumn{2}{|r|}{15.2} \\
\hline Maximum & 521 & & 668 & \multicolumn{2}{|c|}{1610} & \multicolumn{2}{|c|}{955} & 135 & \multicolumn{2}{|r|}{31.5} \\
\hline Horizon (cm) & $\mathrm{Fe}$ & Al & Co & \multicolumn{2}{|l|}{$\mathbf{C u}$} & \multicolumn{2}{|r|}{ Mo } & $\mathbf{N a}$ & $\mathbf{N i}$ & $\mathbf{Z n}$ \\
\hline Ap (0-24) & 12800 & 6410 & 7.37 & \multicolumn{2}{|c|}{8.44} & & ND & 141 & 2.42 & 17.8 \\
\hline $\mathrm{Bt}(24-70)$ & 25700 & 11800 & 4.45 & 8.13 & & & ND & 122 & 1.91 & 12.7 \\
\hline Bw (70-140) & 12600 & 6440 & 0.609 & 4.47 & & & ND & 132 & 1.14 & 9.12 \\
\hline Cr1 (140-150) & 30400 & 9490 & 0.661 & 8.40 & & & ND & 137 & 2.37 & 13.2 \\
\hline $\mathrm{Cr} 2(150-215+)$ & 5290 & 5160 & 0.523 & 2.48 & & & ND & 137 & 0.931 & 8.37 \\
\hline Mean & 17400 & 7860 & 2.72 & 6.38 & & & $N D$ & 134 & 1.75 & 12.2 \\
\hline$S D$ & 10400 & 2720 & 3.09 & 2.75 & & & $N D$ & 7.33 & 0.690 & 3.77 \\
\hline Maximum & 30400 & 11800 & 7.37 & 8.44 & & & $N D$ & 141 & 2.42 & 17.8 \\
\hline Horizon (cm) & As & $\mathbf{B a}$ & $\mathrm{Be}$ & Cd & $\mathrm{Cr}$ & Hg & $\mathbf{P b}$ & Se & $\mathrm{Sr}$ & V \\
\hline Ap $(0-24)$ & 1.99 & 92.2 & 0.309 & 0.192 & 10.5 & ND & 11.5 & ND & 7.41 & 35.4 \\
\hline $\mathrm{Bt}(24-70)$ & 1.42 & 83.4 & 0.518 & 0.143 & 14.4 & ND & 10.1 & ND & 11.3 & 48.9 \\
\hline Bw (70-140) & 2.48 & 52.6 & 0.379 & ND & 7.71 & ND & 8.11 & ND & 7.06 & 28.9 \\
\hline Cr1 (140-150) & 8.99 & 41.8 & 0.790 & 0.134 & 17.2 & ND & 9.39 & ND & 9.68 & 54.9 \\
\hline $\mathrm{Cr} 2(150-215+)$ & 0.69 & 44.1 & 0.222 & ND & 3.73 & ND & 6.04 & ND & 4.83 & 12.0 \\
\hline Mean & 3.11 & 62.8 & 0.444 & 0.156 & 10.7 & $N D$ & 9.03 & $N D$ & 8.06 & 36.0 \\
\hline$S D$ & 3.35 & 23.4 & 0.222 & 0.0312 & 5.33 & $N D$ & 2.07 & $N D$ & 2.50 & 17.0 \\
\hline Maximum & 8.99 & 92.2 & 0.790 & 0.192 & 17.2 & $N D$ & 11.5 & $N D$ & 11.3 & 54.9 \\
\hline
\end{tabular}

grape juice from grapes collected adjacent to the soil pits. The concentrations of $\mathrm{K}$ and $\mathrm{Na}$ in Abbott Claim Vineyard grape juice are $1730 \mathrm{mg} / \mathrm{kg}$ and $166 \mathrm{mg} / \mathrm{kg}$, respectively. 
Sr concentration, one of only three elements found in all grape juice samples, is measured as $0.844 \mathrm{mg} / \mathrm{kg}$, which is the $8^{\text {th }}$ highest concentration of $\mathrm{Sr}$ for the 20 vineyard samples (Table 105). Mean Sr concentration for all grape juice samples from the 20 different sites is $0.805 \pm 0.261 \mathrm{mg} / \mathrm{kg}$. P and Mn concentrations are non-detectable in this sample.

Table 83. Elemental concentrations measured by ICP-MS in the grape juice from clusters collected from vines immediately adjacent to the soil pit location at Ken Wright Cellars, Abbott Claim Vineyard (ND - Non-detectable).

\begin{tabular}{cccccccccc}
\hline Element & Sr & P & K & Na & Mg & Mn & Ca & Cu & Zn \\
\hline \hline Grape Juice $(\mathrm{mg} / \mathrm{kg})$ & 0.844 & ND & 1730 & 166 & ND & ND & ND & ND & ND \\
\hline
\end{tabular}

\section{Wine Chemistry}

Ken Wright provided a $750 \mathrm{ml}$ sample of the wine produced from the Abbott Claim Vineyard in 2012. Many of the 24 elements tested in the wine (same as the elements tested in the soil samples) were below detection limits. The 14 elements that were detected in the Abbott Claim Vineyard wine sample include $\mathrm{Ba}, \mathrm{Ca}, \mathrm{Co}, \mathrm{Cu}, \mathrm{Fe}, \mathrm{Pb}$, Mg, Mn, P, K, Na, Sr, S, and Zn (Table 84). K and P concentrations are the highest at $767 \mathrm{mg} / \mathrm{kg}$ and $403 \mathrm{mg} / \mathrm{kg}$, respectively. $\mathrm{S}$ is $77.2 \mathrm{mg} / \mathrm{kg}, \mathrm{Mg}$ is $60.4 \mathrm{mg} / \mathrm{kg}, \mathrm{Ca}$ is 30.6 $\mathrm{mg} / \mathrm{kg}$, and $\mathrm{Na}$ is $5.77 \mathrm{mg} / \mathrm{kg}$ for this wine. The concentration of $\mathrm{Mn}$ is $1.13 \mathrm{mg} / \mathrm{kg}$. The concentration of $\mathrm{Zn}$ is $0.965 \mathrm{mg} / \mathrm{kg}$, $\mathrm{Sr}$ is $0.912 \mathrm{mg} / \mathrm{kg}$, Fe is $0.517 \mathrm{mg} / \mathrm{kg}$ and $\mathrm{Ba}$ is 0.457 $\mathrm{mg} / \mathrm{kg}$. Trace amounts of $\mathrm{Cu}(0.075 \mathrm{mg} / \mathrm{kg}), \mathrm{Pb}(0.074 \mathrm{mg} / \mathrm{kg})$, and $\mathrm{Co}(0.0325 \mathrm{mg} / \mathrm{kg})$ are also detected in the Abbott Claim Vineyard wine sample. 
Table 84. Elemental concentrations measured by ICP-MS of a $750 \mathrm{ml}$ unblended wine sample from the 2012 Ken Wright, Abbott Claim Vineyard (ND - Non-detectable).

\begin{tabular}{cccc}
\hline Element & 2012 Wine Sample (mg/kg) & Element & 2012 Wine Sample (mg/kg) \\
\hline \hline $\mathrm{Al}$ & $\mathrm{ND}$ & $\mathrm{Mn}$ & 1.13 \\
$\mathrm{As}$ & $\mathrm{ND}$ & $\mathrm{Hg}$ & $\mathrm{ND}$ \\
$\mathrm{Ba}$ & 0.457 & $\mathrm{Mo}$ & $\mathrm{ND}$ \\
$\mathrm{Be}$ & $\mathrm{ND}$ & $\mathrm{Ni}$ & $\mathrm{ND}$ \\
$\mathrm{Cd}$ & $\mathrm{ND}$ & $\mathrm{P}$ & 403 \\
$\mathrm{Ca}$ & 30.6 & $\mathrm{~K}$ & 767 \\
$\mathrm{Cr}$ & $\mathrm{ND}$ & $\mathrm{Se}$ & $\mathrm{ND}$ \\
$\mathrm{Co}$ & $\mathrm{Na}$ & 5.77 \\
$\mathrm{Cu}$ & 0.0325 & $\mathrm{Sr}$ & 0.912 \\
$\mathrm{Fe}$ & 0.075 & $\mathrm{~S}$ & 77.2 \\
$\mathrm{~Pb}$ & 0.517 & $\mathrm{~V}$ & $\mathrm{ND}$ \\
$\mathrm{Mg}$ & 0.074 & $\mathrm{Zn}$ & 0.965 \\
\hline
\end{tabular}

\section{Clay Mineralogy}

The Abbot Claim clay mineral assemblage is considered very similar to the Lange Estate (volcanic parent material), Lange Yamhill (marine sediment parent material), and Rex Hill Sims (volcanic parent material) Vineyards. This soil is dominated by moderate amounts of disordered kaolinite with trace amounts of halloysite, chlorite, and smectite. Goethite is moderate, and minor amounts of gibbsite are present. These soils are indicative of deeply weathered material.

\section{Marine Sediment Parent Material - Freedom Hill Vineyard Physical Characteristics}

The Freedom Hill Vineyard, owned and operated by Dan and Helen Dusschee, is located in between Monmouth and Dallas, Oregon. This vineyard is located on marine 
sedimentary rocks of the Coast Range. Ken Wright's Freedom Hill Vineyard soil is located the midslope of a west facing slope with vine rows running north and south (Lat. 44.875343 N, Long. -123.293962 W). The soil pit location was at 466 feet (142 meters) elevation between rows 30 and 31, and the soil is mapped as the Jory soil series (Figure 43), but I determined that it is really the Bellpine soil series. The vines are Pinot Noir Wädenswil clone planted in 2002 and are trellised as bilateral cordon in vertical shoot position. The vines are grafted onto $44-53$ rootstock (Table 8 ). The Bellpine soil is characterized as a Xeric Haplohumult. The soil pit was $75+\mathrm{cm}$ deep, and I did reach the sandy parent material but not refusal at that depth. The bedrock is the Spencer Formation of the Coast Range marine sediments (Figure 2). Approximately 75 percent of the $\mathrm{Cr}$ horizon consisted of coarse fragments of sandstone parent material. Dry colors for the Ap horizon are yellowish brown (10 YR 5/4), and the Bt is dark yellowish brown (10 YR 4/4) (Figure 44).

Textures are silt loam in the Ap horizon and clay loam with depth. Structure is moderate medium subangular blocky. Clay percent is highest in the Bt horizon at 33\% but decreases with depth to $27 \%$ in the Cr horizon. Clay films are located on ped faces in the Ap and Bt horizons and are many and dominant. The soil contains muscovite mica and quartz sand. There are no pisolites in this profile. The $\mathrm{pH}$ decreases from 6.0 to 5.3 and CEC is around $20.3 \mathrm{meq} / 100 \mathrm{~g}$. OM ranges from $6.6 \%$ to $7.9 \%$ (Table 85 ). 


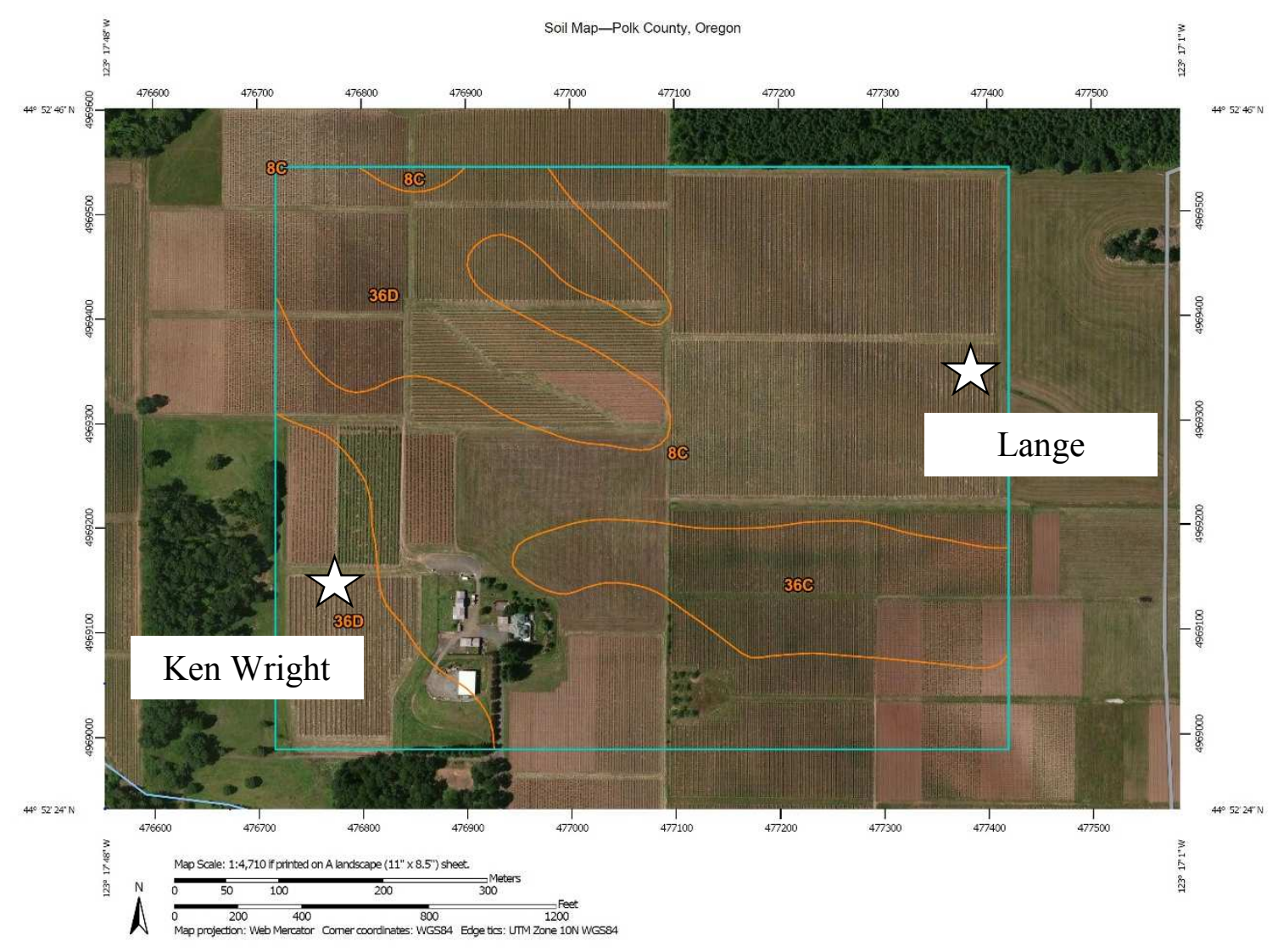

Figure 43. Soil map of Ken Wright Cellars, Freedom Hill Vineyard. Pit location marked. 36D - Jory silty clay loam, 12 to 20 percent slopes. 8C - Bellpine silty clay loam, 3 to 12 percent slopes. 36C Jory silty clay loam, 2 to 12 percent slopes (NRCS, 2014). Two sites were analyzed at the Freedom Hill Vineyard; one for Lange and one for Ken Wright.

\section{Soil Chemistry}

The Freedom Hill Vineyard soil pit was separated into four horizons, and samples of each horizon were sent for analysis (Table 86). $\mathrm{P}$ concentration bulges in the $\mathrm{Cr}$ horizon. $\mathrm{K}$ decreases with depth with the maximum in the Ap horizon. $\mathrm{Ca}$ is variable through the profile and is significantly higher in the $\mathrm{R}$ horizon. $\mathrm{Mg}$ increases with depth and is significantly higher in the $\mathrm{R}$ horizon as well. $\mathrm{S}$ is only detected in the Ap horizon. 
Table 85. Ken Wright Cellars, Freedom Hill Vineyard field and lab data.

\begin{tabular}{|c|c|c|c|c|c|c|}
\hline \multirow{3}{*}{$\begin{array}{l}\text { Depth } \\
\text { (cm) }\end{array}$} & \multirow{3}{*}{ Horizon } & \multicolumn{3}{|c|}{ Total } & \multirow[b]{2}{*}{$\begin{array}{c}\text { Coarse } \\
\text { Fragment } \\
(>2 \mathrm{~mm})\end{array}$} & \multirow[b]{2}{*}{$\begin{array}{c}\text { Texture } \\
\text { Lab }\end{array}$} \\
\hline & & $\begin{array}{c}\text { Sand } \\
(2-0.05 \\
\text { mm) }\end{array}$ & $\begin{array}{c}\text { Silt } \\
(0.05-0.002 \\
\text { mm) }\end{array}$ & $\begin{array}{c}\text { Clay } \\
(<0.002 \mathrm{~mm})\end{array}$ & & \\
\hline & & \multicolumn{5}{|c|}{ 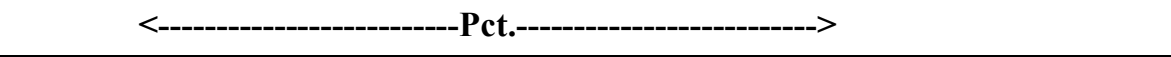 } \\
\hline $0-15$ & Ap & 22.2 & 56.8 & 21.7 & 0.0 & $\mathrm{SiL}$ \\
\hline $15-50$ & $\mathrm{Bt}$ & 21.0 & 45.8 & 32.9 & 0.0 & $\mathrm{CL}$ \\
\hline \multirow[t]{2}{*}{$50-75+$} & $\mathrm{Cr}$ & 36.1 & 33.4 & 27.0 & 0.7 & CL \\
\hline & $\mathrm{R}$ & & & & & \\
\hline $\begin{array}{l}\text { Depth } \\
\text { (cm) }\end{array}$ & Horizon & Dry Color & Structure & $\begin{array}{c}\text { Organic } \\
\text { Matter } \\
\text { LOI (Pct.) }\end{array}$ & $\begin{array}{c}\text { pH } \\
\left(1: 1 \mathrm{H}_{2} \mathrm{O}\right)\end{array}$ & $\begin{array}{c}\text { CEC } \\
\text { (meq/100g) }\end{array}$ \\
\hline $0-15$ & Ap & 10YR 5/4 & $2, \mathrm{~m}, \mathrm{sbk}$ & 7.2 & 6.0 & 20.3 \\
\hline $15-50$ & $\mathrm{Bt}$ & 10YR 4/4 & $2, \mathrm{~m}, \mathrm{sbk}$ & 6.6 & 5.6 & 21.5 \\
\hline \multirow[t]{2}{*}{$50-75+$} & $\mathrm{Cr}$ & $\begin{array}{l}\text { 10YR 5/4 } \\
10 Y R \text { 7/6 }\end{array}$ & $2, \mathrm{~m}, \mathrm{sbk}$ & 7.9 & 5.3 & \\
\hline & $\mathrm{R}$ & & & & & \\
\hline
\end{tabular}

The micronutrient concentrations measured in the four soil horizons from the Freedom Hill Vineyard mostly increase with depth. Al, $\mathrm{Fe}, \mathrm{Cu}, \mathrm{Na}, \mathrm{Ni}$ and zine all increase with depth in the profile with the maximum concentration in the $\mathrm{R}$ horizon that is significantly higher than the horizons above. Mn concentration bulges in the $\mathrm{Bt}$ horizon. Co concentration also bulges in the Bt horizon and is highest in the $\mathrm{R}$ horizon. Mo is non-detectable. $\mathrm{V}, \mathrm{Sr}$, and $\mathrm{Cr}$ are highest in the $\mathrm{R}$ horizon after increasing with depth. $\mathrm{Cd}$ and $\mathrm{Ba}$ decrease with depth and then bulge in the $\mathrm{R}$ horizon. $\mathrm{Pb}$ bulges slightly in the Bt horizon and decreases with depth. Be and As increase with depth and bulge in the $\mathrm{Cr}$ horizon. $\mathrm{Hg}$ and $\mathrm{Se}$ are non-detectable in this profile. 

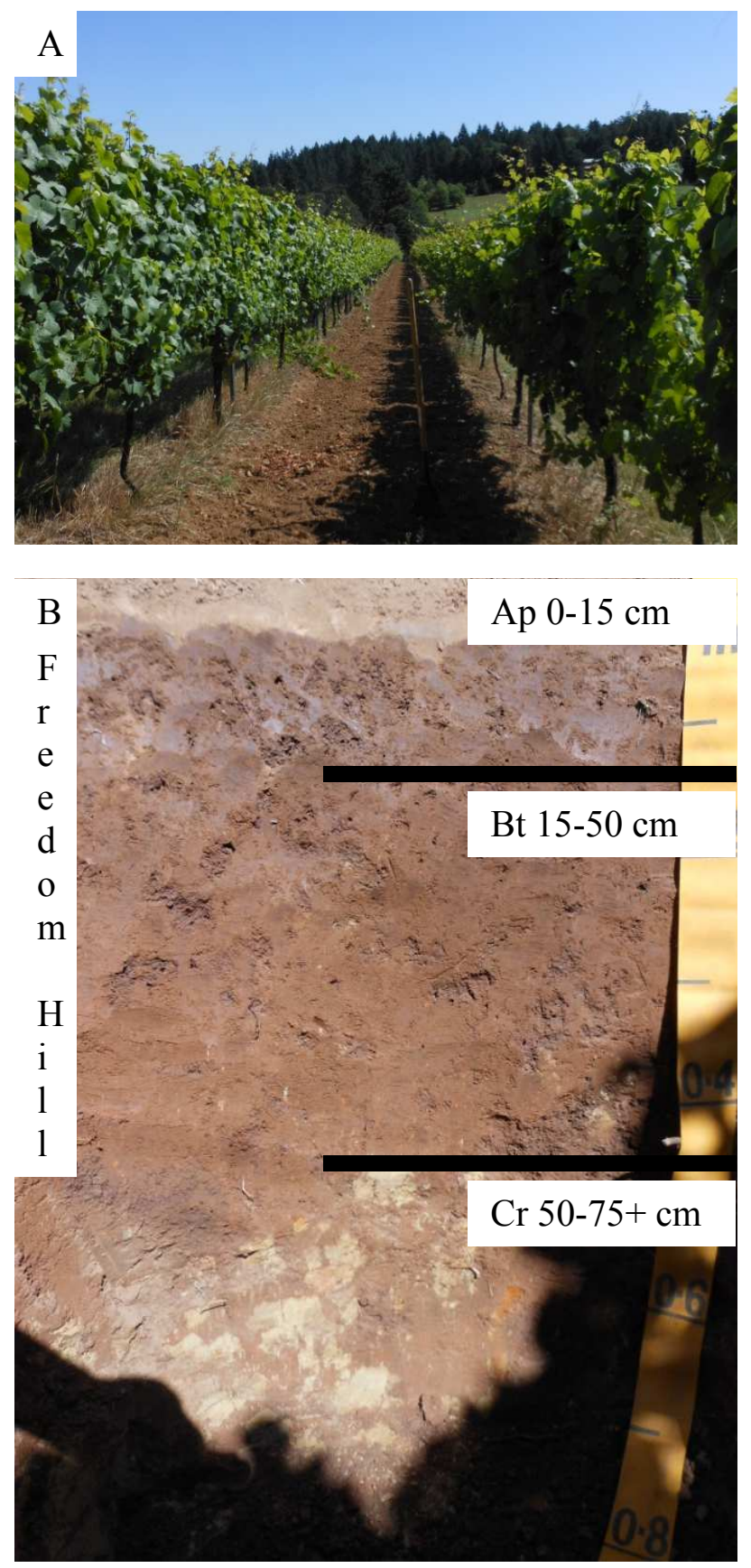

Figure 44. Sample soil pit at Ken Wright Cellars, Freedom Hill Vineyard. A - View of sample location, facing south. B - Picture of the face of the soil pit with horizon depths and boundaries marked. 
Table 86. Macronutrient, micronutrient and trace element concentrations (all values in $\mathrm{mg} / \mathrm{kg}$ ) for the Ken Wright Cellars, Freedom Hill Vineyard soil pit (ND - Non-detectable).

\begin{tabular}{|c|c|c|c|c|c|c|c|c|c|c|}
\hline Horizon (cm) & $\mathbf{P}$ & & $\mathbf{K}$ & \multicolumn{3}{|c|}{$\mathrm{Ca}$} & Mg & $\mathbf{S}$ & \multicolumn{2}{|r|}{ Cl } \\
\hline$A p(0-15)$ & 543 & & 1210 & \multicolumn{2}{|c|}{2070} & \multicolumn{2}{|c|}{1790} & 151 & \multicolumn{2}{|r|}{ ND } \\
\hline $\mathrm{Bt}(15-50)$ & 541 & & 1060 & \multicolumn{2}{|c|}{1860} & \multicolumn{2}{|c|}{1840} & ND & \multicolumn{2}{|r|}{ ND } \\
\hline $\mathrm{Cr}(50-75)$ & 614 & & 922 & \multicolumn{2}{|c|}{2100} & \multicolumn{2}{|c|}{2270} & ND & \multicolumn{2}{|r|}{ ND } \\
\hline $\mathrm{R}(75+)$ & 375 & & 132 & \multicolumn{2}{|c|}{21700} & \multicolumn{2}{|c|}{17700} & ND & \multicolumn{2}{|r|}{ ND } \\
\hline Mean & 518 & & 831 & \multicolumn{2}{|c|}{6930} & \multicolumn{2}{|c|}{5900} & 151 & \multicolumn{2}{|r|}{$N D$} \\
\hline$S D$ & 101 & & 481 & \multicolumn{2}{|c|}{9850} & \multicolumn{2}{|c|}{7870} & 0 & \multicolumn{2}{|r|}{$N D$} \\
\hline Maximum & 614 & & 1210 & \multicolumn{2}{|c|}{21700} & \multicolumn{2}{|c|}{17700} & 151 & \multicolumn{2}{|r|}{$N D$} \\
\hline Horizon (cm) & $\mathrm{Fe}$ & Al & Co & $\mathbf{C u}$ & & Mn & Mo & $\mathbf{N a}$ & $\mathbf{N i}$ & Zn \\
\hline Ap $(0-15)$ & 23600 & 12700 & 13.2 & 14.0 & & 819 & ND & 172 & 4.3 & 24.0 \\
\hline $\mathrm{Bt}(15-50)$ & 29700 & 13000 & 19.0 & 19.3 & & 869 & ND & 165 & 6.4 & 35.4 \\
\hline $\operatorname{Cr}(50-75)$ & 33100 & 15800 & 12.6 & 20.8 & & 444 & ND & 181 & 6.25 & 36.6 \\
\hline $\mathrm{R}(75+)$ & 59700 & 35100 & 29.5 & 114 & & 628 & ND & 3330 & 24.0 & 87.6 \\
\hline Mean & 36500 & 19200 & 18.6 & 42.0 & & 690 & $N D$ & 962 & 10.2 & 45.9 \\
\hline$S D$ & 15900 & 10700 & 7.83 & 48.1 & & 194 & $N D$ & 1580 & 9.22 & 28.4 \\
\hline Maximum & 59700 & 35100 & 29.5 & 114 & & 869 & $N D$ & 3330 & 24.0 & 87.6 \\
\hline Horizon (cm) & As & $\mathbf{B a}$ & $\mathrm{Be}$ & Cd & $\mathrm{Cr}$ & Hg & $\mathbf{P b}$ & Se & $\mathrm{Sr}$ & $\mathbf{V}$ \\
\hline Ap $(0-15)$ & 1.41 & 132 & 0.572 & 0.292 & 13.1 & ND & 9.29 & ND & 15.1 & 33.4 \\
\hline $\mathrm{Bt}(15-50)$ & 4.55 & 123 & 0.680 & 0.110 & 19.2 & ND & 9.46 & ND & 17.1 & 57.9 \\
\hline $\mathrm{Cr}(50-75)$ & 6.03 & 112 & 0.868 & ND & 23.9 & ND & 8.06 & ND & 23.5 & 57.9 \\
\hline $\mathrm{R}(75+)$ & ND & 201 & 0.681 & 0.319 & 24.9 & ND & 0.956 & ND & 452 & 150 \\
\hline Mean & 4.00 & 142 & 0.700 & 0.240 & 20.3 & $N D$ & 6.94 & $N D$ & 127 & 74.8 \\
\hline$S D$ & 2.36 & 40.2 & 0.123 & 0.114 & 5.39 & $N D$ & 4.04 & $N D$ & 217 & 51.4 \\
\hline Maximum & 6.03 & 201 & 0.868 & 0.319 & 24.9 & $N D$ & 9.46 & $N D$ & 452 & 150 \\
\hline
\end{tabular}

\section{Grape Juice Chemistry}

Grape juice from clusters of grapes collected from vines adjacent to the soil pit were analyzed for the same 24 elements as the soils. The majority of these elements are non-detectable using this method, therefore only the elements found in any sample are 
shown in Table 87. The highest elemental concentration measured in the Ken Wright Freedom Hill Vineyard grape juice is $\mathrm{K}$ at $1160 \mathrm{mg} / \mathrm{kg}$. P is below detection limits and $\mathrm{Na}$ is $126 \mathrm{mg} / \mathrm{kg}$. Sr, one of the only elements to be detected in all 20 grape juice samples, has a concentration of $0.816 \mathrm{mg} / \mathrm{kg}$ in this sample. It is the $9^{\text {th }}$ highest concentration where the mean concentration for all grape juice samples is $0.805 \pm 0.261$ $\mathrm{mg} / \mathrm{kg}$ (Table 105). No other elements were detected in the grape juice from this site.

Table 87. Elemental concentrations measured by ICP-MS in the grape juice from clusters collected from vines immediately adjacent to the soil pit location at Ken Wright Cellars, Freedom Hill Vineyard (ND - Non-detectable).

\begin{tabular}{cccccccccc}
\hline Element & Sr & $\mathbf{P}$ & $\mathbf{K}$ & Na & Mg & Mn & Ca & Cu & Zn \\
\hline \hline Grape Juice (mg/kg) & 0.816 & ND & 1160 & 126 & ND & ND & ND & ND & ND \\
\hline
\end{tabular}

\section{Wine Chemistry}

Ken Wright provided a $750 \mathrm{ml}$ sample of the wine produced from the Freedom Hill Vineyard in 2012. Many of the 24 elements tested in the wine (same as the elements tested in the soil samples) were below detection limits. The 12 elements that were detected in the Freedom Hill Vineyard wine sample include $\mathrm{Ba}, \mathrm{Ca}, \mathrm{Cu}, \mathrm{Fe}, \mathrm{Mg}, \mathrm{Mn}, \mathrm{P}$, $\mathrm{K}, \mathrm{Na}, \mathrm{Sr}, \mathrm{S}$, and $\mathrm{Zn}$ (Table 88). Co and $\mathrm{Pb}$, which were detected in many other wine samples in this study, were not detected in the wine sample from Freedom Hill Vineyard. $\mathrm{K}$ and $\mathrm{P}$ concentrations are the highest at $844 \mathrm{mg} / \mathrm{kg}$ and $297 \mathrm{mg} / \mathrm{kg}$, respectively. S is $100 \mathrm{mg} / \mathrm{kg}, \mathrm{Mg}$ is $96.8 \mathrm{mg} / \mathrm{kg}, \mathrm{Ca}$ is $43.5 \mathrm{mg} / \mathrm{kg}$, and $\mathrm{Na}$ is $5.4 \mathrm{mg} / \mathrm{kg}$ for this wine. The concentration of $\mathrm{Mn}$ is $1.73 \mathrm{mg} / \mathrm{kg}$. The concentration of $\mathrm{Sr}$ is $1.05 \mathrm{mg} / \mathrm{kg}, \mathrm{Zn}$ is 0.784 
$\mathrm{mg} / \mathrm{kg}, \mathrm{Fe}$ is $0.544 \mathrm{mg} / \mathrm{kg}$, and $\mathrm{Ba}$ is $0.47 \mathrm{mg} / \mathrm{kg}$. Trace amounts of $\mathrm{Cu}(0.054 \mathrm{mg} / \mathrm{kg})$ are detected in the Freedom Hill Vineyard wine sample.

Table 88. Elemental concentrations measured by ICP-MS of a $750 \mathrm{ml}$ unblended wine sample from the 2012 Ken Wright, Freedom Hill Vineyard (ND - Non-detectable).

\begin{tabular}{cccc}
\hline Element & $\mathbf{2 0 1 2}$ Wine Sample (mg/kg) & Element & 2012 Wine Sample (mg/kg) \\
\hline \hline $\mathrm{Al}$ & $\mathrm{ND}$ & $\mathrm{Mn}$ & 1.73 \\
$\mathrm{As}$ & $\mathrm{ND}$ & $\mathrm{Hg}$ & $\mathrm{ND}$ \\
$\mathrm{Ba}$ & 0.47 & $\mathrm{Mo}$ & $\mathrm{ND}$ \\
$\mathrm{Be}$ & $\mathrm{ND}$ & $\mathrm{Ni}$ & $\mathrm{ND}$ \\
$\mathrm{Cd}$ & $\mathrm{ND}$ & $\mathrm{P}$ & 297 \\
$\mathrm{Ca}$ & 43.5 & $\mathrm{~K}$ & 844 \\
$\mathrm{Cr}$ & $\mathrm{ND}$ & $\mathrm{Se}$ & $\mathrm{ND}$ \\
$\mathrm{Co}$ & $\mathrm{ND}$ & $\mathrm{Na}$ & 5.4 \\
$\mathrm{Cu}$ & $\mathrm{Sr}$ & 1.05 \\
$\mathrm{Fe}$ & 0.054 & $\mathrm{~S}$ & 100 \\
$\mathrm{~Pb}$ & 0.544 & $\mathrm{~V}$ & $\mathrm{ND}$ \\
$\mathrm{Mg}$ & $\mathrm{ND}$ & $\mathrm{Zn}$ & 0.784 \\
\hline
\end{tabular}

\section{Clay Mineralogy}

The Lange Freedom Hill and Ken Wright Freedom Hill are essentially the same when looking at the clay minerals. These two soils are separated by approximately 500 meters of vineyard at this estate. The expansive clay in the sample is moderately interlayered by $\mathrm{Al}$ and $\mathrm{Fe}$ oxides which shows moderate weathering. The soil contains trace amounts of mica and illite. The trace amount of chlorite is weakly developed. Minor hydroxy-interlayered smectite and vermiculite are also present with minor amounts of 
kaolinite. Cristobalite is also in this sample in minor amounts. The main Fe oxide is goethite and is well ordered and expressed.

\section{Volcanic Parent Material - Meredith Mitchell Vineyard, Martha Block Physical Characteristics}

Meredith Mitchell Vineyard, owned and operated by Susan Meredith and Frank Mitchell, is located in McMinnville, Oregon. This vineyard is unique in that it is located on Eocene-aged basaltic or diabase rocks that are part of the Coast Range. The Meredith Mitchell Vineyard soil pit was located at the summit of a southwest facing slope with vine rows running north and south (Lat. 45.156368 N, Long. -123.291720 W). The soil pit location was at 669 feet (204 meters) elevation between rows 60 and 61, and the soil is mapped as the Witzel - Dixonville (previously Yamhill) soil series (Figure 45). According to the vineyard owners, this vineyard was cultivated in 2010 and is farmed using LIVE Sustainable methods but is not currently certified (Appendix D). The rows at this location are 12 feet (3.6 meters) wide compared to most other vineyards that are 6 feet (1.83 meters) wide. The vines are Pinot Noir Pommard clone planted in 1988 and are trellised as bilateral cordon in hanging cane position. The vines are own-rooted (Table 8). 


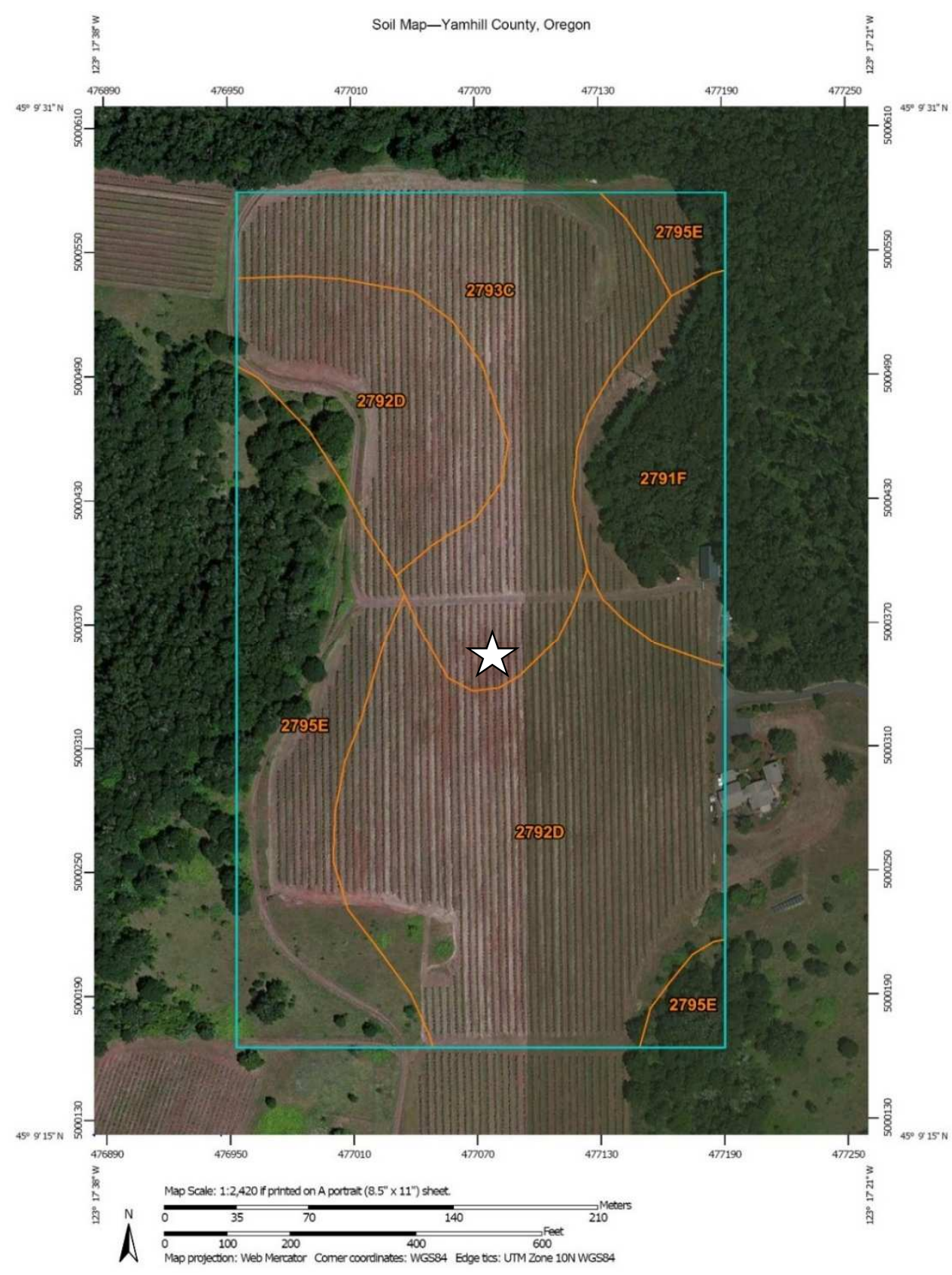

Figure 45. Soil map for Ken Wright Cellars, Meredith Mitchell Vineyard Martha Block. Pit location marked. 2793C - Witzel-Dixonville complex, 2 to 12 percent slopes. 2792D - Witzel-Dixonville complex, 12 to 20 percent slopes. $2795 \mathrm{E}$ - Gellatly-Dixonville complex, 20 to 30 percent slopes. $2791 \mathrm{~F}$ - Gellatly silty clay loam, 30 to 60 percent slopes (NRCS, 2015). Previously mapped as YhD Yamhill silt loam, moderately shallow, 7 to 20 percent slopes (NRCS, 2014). 
The Witzel - Dixonville soil is classified as a Lithic Ultic Haploxeroll. The soil pit was $204+\mathrm{cm}$ deep, reaching parent material but not refusal (Figure 46). The bedrock is mapped as Nestucca Formation that includes sedimentary sandstone and pillow basalt (Figure 2). The highly weathered basalt parent material is found from 121 to $204+\mathrm{cm}$ depth. The $\mathrm{pH}$ increases with depth to 6.7. CEC is the greatest in this profile, up to 80.0 meq/100 $\mathrm{g}$ in the Bt horizon. OM ranges from $10.1 \%$ at depth to $17.9 \%$ in the Ap horizon (Table 89). Coarse fragments also increase to $25 \%$ with depth. Percent sand increases with depth from $31 \%$ to $77 \%$ from Ap to $\mathrm{Cr}$ at $118 \mathrm{~cm}$. Dry colors for the Ap and $\mathrm{Bt}$ horizon are dark yellowish brown (10 YR 4/4).

Table 89. Ken Wright Cellars, Meredith Mitchell Vineyard Martha Block field and lab data.

\begin{tabular}{|c|c|c|c|c|c|c|}
\hline \multirow{3}{*}{$\begin{array}{l}\text { Depth } \\
\text { (cm) }\end{array}$} & \multirow{3}{*}{ Horizon } & \multicolumn{3}{|c|}{ Total } & \multirow[b]{2}{*}{$\begin{array}{c}\text { Coarse } \\
\text { Fragment } \\
(>2 \mathrm{~mm})\end{array}$} & \multirow{3}{*}{$\begin{array}{l}\text { Texture } \\
\text { Lab }\end{array}$} \\
\hline & & $\begin{array}{c}\text { Sand } \\
(2-0.05 \\
\text { mm) }\end{array}$ & $\begin{array}{c}\text { Silt } \\
(0.05-0.002 \\
\text { mm) }\end{array}$ & $\begin{array}{c}\text { Clay } \\
(<0.002 \mathrm{~mm})\end{array}$ & & \\
\hline & & \multicolumn{4}{|c|}{ 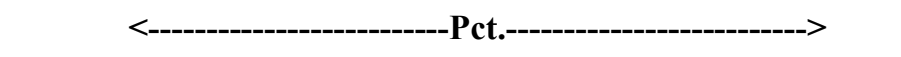 } & \\
\hline $0-10$ & Ap & 30.7 & 53.2 & 13.4 & 0.0 & $\mathrm{~L}$ \\
\hline $10-72$ & $\mathrm{Bt}$ & 21.3 & 54.1 & 20.2 & 0.5 & $\mathrm{SiL}$ \\
\hline $72-121$ & $\mathrm{Bw}$ & 62.4 & 21.2 & 9.3 & 0.0 & SL \\
\hline 121-204+ & $\mathrm{Cr}$ & 76.9 & 12.1 & 4.4 & 1.1 & LS \\
\hline $\begin{array}{c}\text { Depth } \\
\text { (cm) }\end{array}$ & Horizon & Dry Color & Structure & $\begin{array}{c}\text { Organic } \\
\text { Matter } \\
\text { LOI (Pct.) }\end{array}$ & $\begin{array}{c}\text { pH } \\
\left(1: 1 \mathrm{H}_{2} \mathrm{O}\right)\end{array}$ & $\begin{array}{c}\text { CEC } \\
(\mathrm{meq} / \mathbf{1 0 0 g})\end{array}$ \\
\hline $0-10$ & Ap & $10 \mathrm{YR} 4 / 4$ & $1, \mathrm{f}, \mathrm{sbk}$ & 17.9 & 6.0 & 48.5 \\
\hline $10-72$ & $\mathrm{Bt}$ & $10 Y R 53 / 4$ & $2, \mathrm{~m}, \mathrm{sbk}$ & 11.2 & 6.0 & 80.0 \\
\hline $72-121$ & $\mathrm{Bw}$ & $7.5 \mathrm{YR} 4 / 3$ & $2, \mathrm{~m}, \mathrm{sbk}$ & 11.1 & 6.3 & 61.0 \\
\hline $121-204+$ & $\mathrm{Cr}$ & 7.5YR 4/1 & $2, \mathrm{~m}, \mathrm{sbk}$ & 10.1 & 6.7 & \\
\hline
\end{tabular}



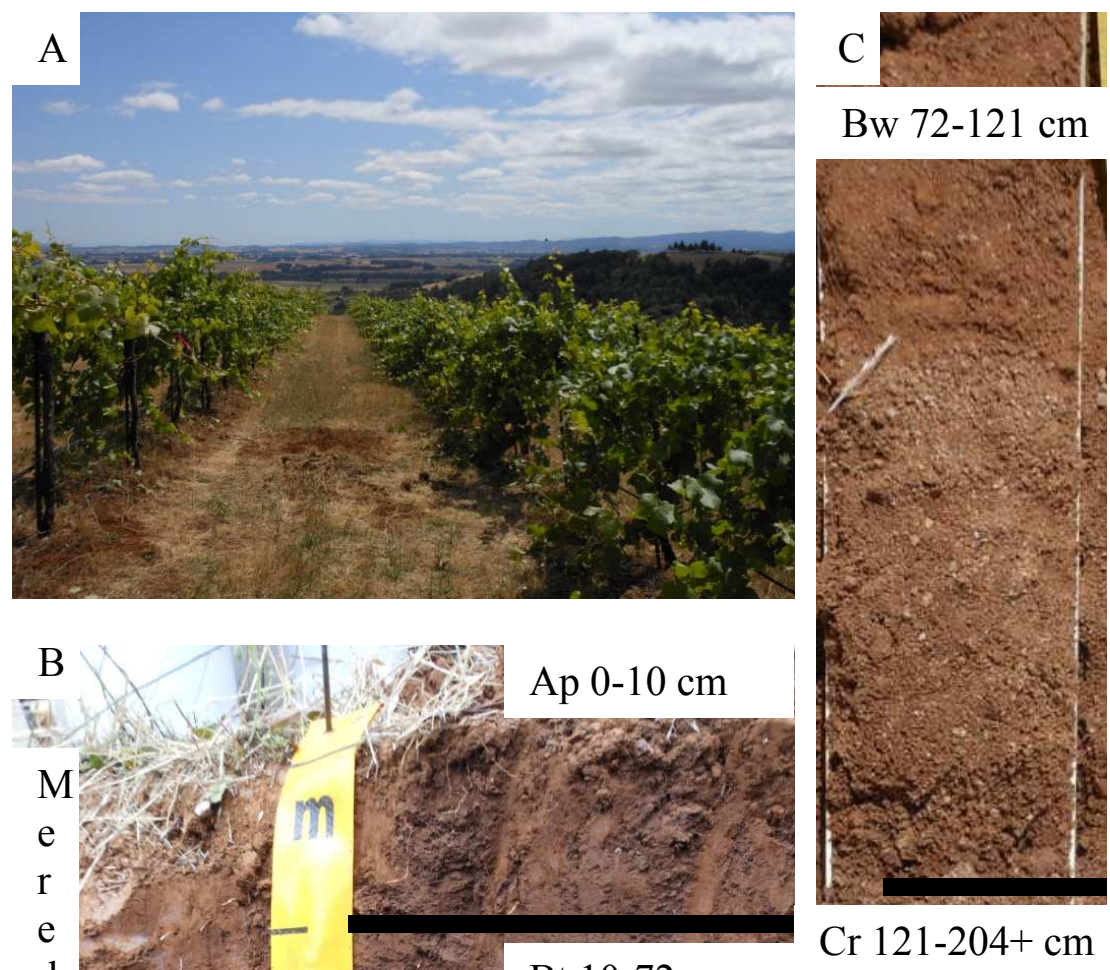

Bw $72-121 \mathrm{~cm}$

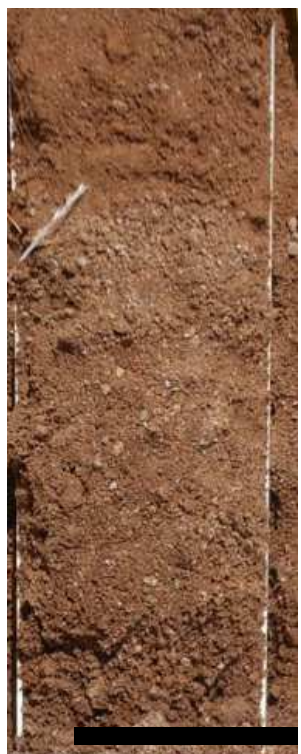

Cr $121-204+\mathrm{cm}$
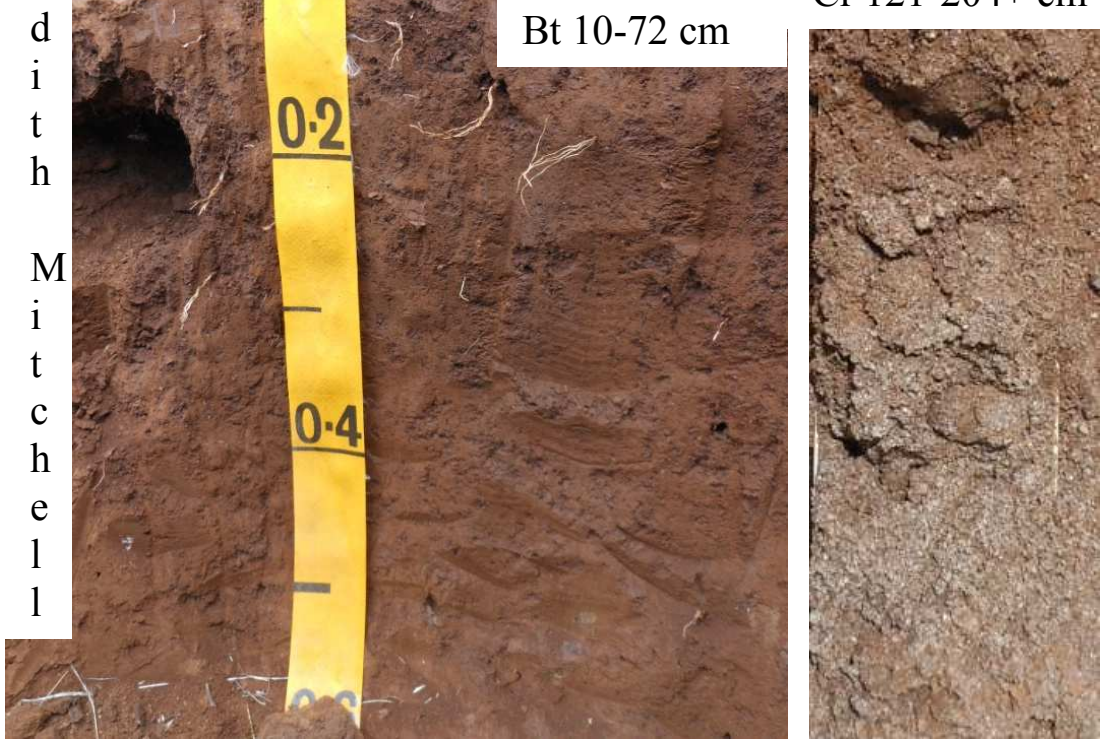

Figure 46. Sample soil pit at Ken Wright Cellars, Meredith Mitchell Vineyard Martha Block. A View of sample location, facing south. B - Picture of the face of the soil pit with horizon depths and boundaries marked. $\mathrm{C}$ - Soil retrieved using a hand auger with horizon depths and boundaries marked. 
Textures include loam and silt loam in the Ap horizon, sandy loam, and loamy fine sand with depth. Structures of the soil profile are medium subangular blocky with single grain texture in the $\mathrm{Bw}$ and $\mathrm{Cr}$ horizons. Clay percent is highest in the $\mathrm{Bt}$ horizon with $20 \%$ and lowers in the $\mathrm{Cr}$ to $4 \%$. Clay films are common and dominant on ped faces in the Bt horizon. There are no pisolites in this profile.

\section{Soil Chemistry}

The Meredith Mitchell Vineyard soil pit was separated into four horizons, and samples of each horizon were sent for analysis (Table 90). This is one of the deepest soil profiles in this study reaching weathered parent material at $121 \mathrm{~cm}$ and then coring to 204 $\mathrm{cm}$ because of the friability of the material. $\mathrm{P}$ and $\mathrm{K}$ decrease with depth and the maximum concentration is in the Ap horizon. $\mathrm{Ca}$ and $\mathrm{Mg}$ increase with depth with the maximum concentration in the $\mathrm{Cr}$ horizon. Ca increases dramatically in the $\mathrm{Cr}$ horizon compared to the horizons above and $\mathrm{Mg}$ is an order of magnitude higher for every horizon in this profile than all the other soil pits examined in this study. S is only detected at the surface and decreases with depth.

Some micronutrient concentrations measured in the four soil horizons from the Meredith Mitchell Vineyard decrease with depth and some increase with a slight bulge in the $\mathrm{Bt}$ or $\mathrm{Bw}$ horizons. Fe and $\mathrm{Mn}$ decrease with depth and the highest concentration is in the Ap horizon. Al increases with depth with the highest in the $\mathrm{Cr}$ horizon. Na decreases 
Table 90. Macronutrient, micronutrient and trace element concentrations (all values in $\mathrm{mg} / \mathrm{kg}$ ) for the Ken Wright Cellars, Meredith Mitchell Vineyard, Martha Block soil pit (ND - Non-detectable).

\begin{tabular}{|c|c|c|c|c|c|c|c|c|c|c|}
\hline Horizon (cm) & $\mathbf{P}$ & & $\mathbf{K}$ & \multicolumn{2}{|c|}{$\mathbf{C a}$} & \multicolumn{2}{|c|}{ Mg } & $\mathbf{S}$ & \multicolumn{2}{|r|}{ Cl } \\
\hline Ap (0-10) & 873 & & 2330 & \multicolumn{2}{|c|}{6530} & \multicolumn{2}{|c|}{12300} & 292 & \multicolumn{2}{|r|}{ ND } \\
\hline $\mathrm{Bt}(10-72)$ & 685 & & 1560 & \multicolumn{2}{|c|}{6060} & \multicolumn{2}{|c|}{14100} & 159 & \multicolumn{2}{|r|}{ ND } \\
\hline $\mathrm{Bw}(72-121)$ & 288 & & 220 & \multicolumn{2}{|c|}{9950} & \multicolumn{2}{|c|}{22300} & ND & \multicolumn{2}{|r|}{ ND } \\
\hline $\mathrm{Cr}(121-204+)$ & 304 & & 111 & \multicolumn{2}{|c|}{21900} & \multicolumn{2}{|c|}{22300} & ND & \multicolumn{2}{|r|}{ ND } \\
\hline Mean & 538 & & 1060 & \multicolumn{2}{|c|}{11100} & \multicolumn{2}{|c|}{17800} & 226 & \multicolumn{2}{|r|}{$N D$} \\
\hline$S D$ & 289 & & 1080 & \multicolumn{2}{|c|}{7400} & \multicolumn{2}{|c|}{5300} & 94.0 & \multicolumn{2}{|r|}{$N D$} \\
\hline Maximum & 873 & & 2330 & \multicolumn{2}{|c|}{21900} & \multicolumn{2}{|c|}{22300} & 292 & \multicolumn{2}{|r|}{$N D$} \\
\hline Horizon (cm) & $\mathbf{F e}$ & Al & Co & $\mathbf{C u}$ & & & Mo & $\mathbf{N a}$ & $\mathbf{N i}$ & Zn \\
\hline Ap $(0-10)$ & 92100 & 36100 & 46.8 & 110 & & & ND & 1130 & 14.5 & 93.0 \\
\hline Bt (10-72) & 91300 & 37100 & 48.4 & 116 & & & ND & 386 & 15.5 & 83.1 \\
\hline $\mathrm{Bw}(72-121)$ & 76300 & 40500 & 40.1 & 146 & & & ND & 344 & 27.3 & 104 \\
\hline $\mathrm{Cr}(121-204+)$ & 67300 & 41200 & 35.4 & 138 & & & ND & 1560 & 26.8 & 101 \\
\hline Mean & 81800 & 38700 & 42.7 & 128 & & & $N D$ & 855 & 21.0 & 95.3 \\
\hline$S D$ & 12100 & 2500 & 6.04 & 17.2 & & & $N D$ & 593 & 6.97 & 9.35 \\
\hline Maximum & 92100 & 41200 & 48.4 & 146 & & & $N D$ & 1560 & 27.3 & 104 \\
\hline Horizon (cm) & As & Ba & Be & Cd & $\mathrm{Cr}$ & Hg & $\mathbf{P b}$ & Se & $\mathrm{Sr}$ & $\mathbf{V}$ \\
\hline Ap $(0-10)$ & 0.426 & 162 & 0.863 & 1.11 & 40.7 & ND & 3.91 & ND & 196 & 255 \\
\hline Bt (10-72) & 0.341 & 179 & 0.954 & 0.912 & 40.1 & ND & 3.21 & 0.621 & 202 & 235 \\
\hline $\mathrm{Bw}(72-121)$ & ND & 214 & 0.863 & 0.542 & 35.9 & ND & 1.35 & ND & 396 & 181 \\
\hline $\mathrm{Cr}(121-204+)$ & ND & 177 & 0.800 & 0.634 & 29.6 & ND & 1.08 & ND & 555 & 221 \\
\hline Mean & 0.384 & 183 & 0.870 & 0.800 & 36.6 & $N D$ & 2.39 & 0.621 & 337 & 223 \\
\hline$S D$ & 0.0601 & 22.0 & 0.0634 & 0.260 & 5.12 & $N D$ & 1.39 & $N D$ & 172 & 31.3 \\
\hline Maximum & 0.426 & 214 & 0.954 & 1.11 & 40.7 & $N D$ & 3.91 & 0.621 & 555 & 255 \\
\hline
\end{tabular}

with depth, but increases significantly from the Bw horizon to the maximum in the $\mathrm{Cr}$ horizon. $\mathrm{Ni}$ and $\mathrm{Cu}$ increase with depth with a bulge in the $\mathrm{Bw}$ horizon. $\mathrm{Zn}$ is variable, with a bulge in the $\mathrm{Bw}$ horizon as well. Co bulges in the Bt horizon and decreases with depth. Mo is non-detectable. Trace element concentrations for the four horizons of the 
Meredith Mitchell Vineyard also varied greatly. As, $\mathrm{Cr}, \mathrm{Pb}$, and V decrease with depth the highest concentration in the Ap horizon. Cd decreases with depth from a maximum in the Ap horizon and a small bulge in the Cr horizon. Ba increases with depth and bulges in the $\mathrm{Bw}$ horizon. Be bulges in the Bt horizon and then decreases with depth. Se is only detected in the Bt horizon. Sr increases with depth. Hg was non-detectable.

\section{Grape Juice Chemistry}

The grape juice samples have concentrations of many elements that are below detection limits in this study, as seen in Table 91. All 24 elements were analyzed for in the grape juice from grapes collected adjacent to the soil pits. The concentrations of K and $\mathrm{Na}$ in Meredith Mitchell Vineyard grape juice are $883 \mathrm{mg} / \mathrm{kg}$ (3 ${ }^{\text {rd }}$ lowest) and 156 $\mathrm{mg} / \mathrm{kg}$, respectively (Table 105). Sr concentration, one of only three elements found in all grape juice samples, is measured as $0.332 \mathrm{mg} / \mathrm{kg}$, which is the lowest concentration of $\mathrm{Sr}$ for the 20 vineyard samples. Mean Sr concentration for all grape juice samples from the 20 different sites is $0.805 \pm 0.261 \mathrm{mg} / \mathrm{kg}$. P concentration is $328 \mathrm{mg} / \mathrm{kg}$ and $\mathrm{Mn}$ concentrations are non-detectable in this sample.

Table 91. Elemental concentrations measured by ICP-MS in the grape juice from clusters collected from vines immediately adjacent to the soil pit location at Ken Wright Cellars, Meredith Mitchell Vineyard, Martha Block (ND - Non-detectable).

\begin{tabular}{ccccccccccc}
\hline Element & Sr & $\mathbf{P}$ & $\mathbf{K}$ & $\mathbf{N a}$ & $\mathbf{M g}$ & $\mathbf{M n}$ & $\mathbf{C a}$ & $\mathbf{C u}$ & $\mathbf{Z n}$ \\
\hline \hline Grape Juice $(\mathrm{mg} / \mathrm{kg})$ & 0.332 & 328 & 883 & 156 & ND & ND & ND & ND & ND \\
\hline
\end{tabular}




\section{Wine Chemistry}

Ken Wright provided a $750 \mathrm{ml}$ sample of the wine produced from the Meredith Mitchell Vineyard in 2012. Many of the 24 elements tested in the wine (same as the elements tested in the soil samples) were below detection limits. The 11 elements that were detected in the Meredith Mitchell Vineyard wine sample include $\mathrm{Ba}, \mathrm{Ca}, \mathrm{Fe}, \mathrm{Mg}$, Mn, $\mathrm{P}, \mathrm{K}, \mathrm{Na}, \mathrm{Sr}, \mathrm{S}$, and $\mathrm{Zn}$ (Table 92). $\mathrm{Co}, \mathrm{Cu}$, and $\mathrm{Pb}$, which were detected in many other wine samples in this study, were not detected in the wine sample from Meredith Mitchell Vineyard. K and P concentrations are the highest at $538 \mathrm{mg} / \mathrm{kg}$ and $430 \mathrm{mg} / \mathrm{kg}$, respectively. $\mathrm{S}$ is $101 \mathrm{mg} / \mathrm{kg}, \mathrm{Mg}$ is $84.9 \mathrm{mg} / \mathrm{kg}, \mathrm{Ca}$ is $43.9 \mathrm{mg} / \mathrm{kg}$, and $\mathrm{Na}$ is $4.76 \mathrm{mg} / \mathrm{kg}$ for this wine. The concentration of Fe is $1.06 \mathrm{mg} / \mathrm{kg}$ and $\mathrm{Mn}$ is $0.952 \mathrm{mg} / \mathrm{kg}$. The concentration of $\mathrm{Zn}$ is $0.768 \mathrm{mg} / \mathrm{kg}$, $\mathrm{Sr}$ is $0.681 \mathrm{mg} / \mathrm{kg}$, and $\mathrm{Ba}$ is $0.188 \mathrm{mg} / \mathrm{kg}$.

\section{Clay Mineralogy}

The Meredith Mitchell Vineyard soil sample contains a distinct clay mineral assemblage that is not similar to any other pit in this study. There are minor amounts of smectite present in this sample, and the smectite present is not strongly interlayered with Al-Fe hydroxides. Some minor vermiculite and mixed layer kaolinite/smectite is present and expansive. No chlorite or chlorite intergrade is present. Trace amounts of kaolinite and dehydrate halloysite exists in this sample. The trace amount of goethite is also not strongly developed as compared to other samples. 
Table 92. Elemental concentrations measured by ICP-MS of a $750 \mathrm{ml}$ unblended wine sample from the 2012 Ken Wright, Meredith Mitchell Vineyard, Martha Block (ND - Non-detectable).

\begin{tabular}{cccc}
\hline Element & 2012 Wine Sample (mg/kg) & Element & 2012 Wine Sample ( $\mathbf{m g} / \mathbf{k g})$ \\
\hline \hline $\mathrm{Al}$ & $\mathrm{ND}$ & $\mathrm{Mn}$ & 0.952 \\
$\mathrm{As}$ & $\mathrm{ND}$ & $\mathrm{Hg}$ & $\mathrm{ND}$ \\
$\mathrm{Ba}$ & 0.188 & $\mathrm{Mo}$ & $\mathrm{ND}$ \\
$\mathrm{Be}$ & $\mathrm{ND}$ & $\mathrm{Ni}$ & $\mathrm{ND}$ \\
$\mathrm{Cd}$ & $\mathrm{ND}$ & $\mathrm{P}$ & 430 \\
$\mathrm{Ca}$ & 43.9 & $\mathrm{~K}$ & 538 \\
$\mathrm{Cr}$ & $\mathrm{ND}$ & $\mathrm{Se}$ & $\mathrm{ND}$ \\
$\mathrm{Co}$ & $\mathrm{ND}$ & $\mathrm{Na}$ & 4.76 \\
$\mathrm{Cu}$ & $\mathrm{ND}$ & $\mathrm{Sr}$ & 0.681 \\
$\mathrm{Fe}$ & 1.06 & $\mathrm{~S}$ & 101 \\
$\mathrm{~Pb}$ & $\mathrm{ND}$ & $\mathrm{V}$ & $\mathrm{ND}$ \\
$\mathrm{Mg}$ & 84.9 & $\mathrm{Zn}$ & 0.768 \\
\hline
\end{tabular}




\section{Chapter Ten - Data Analysis}

\section{Principal Component Analysis}

Principal Component Analysis (PCA) is a statistical method that converts the observations into vectors describing the variance in the data. These vectors are then placed on a new coordinate system using the first principal component and second principal coordinate to show correlations between data points in a space, allowing for correlation clusters to be observed. Because PCA does not handle data that varies greatly in magnitude, elements are analyzed according to the macronutrient, micronutrient, and trace element groups as discussed previously.

The soil horizon in each pit with the highest BW index (the most developed or "old") was selected. Each vineyard and data for the percent clay, mean OM, depth to $\mathrm{Cr}$ horizon, mean $\mathrm{pH}$, and CEC values were analyzed using PCA. The Meredith Mitchell vineyard is perceived as an outlier for many variables and is removed for some analyses. The null hypothesis is that there is no correlation significantly different from 0 between the variables. At least one of the correlations between the variables is significantly different from 0 for these data, and the computed p-value (0.022) is lower than the significance level (alpha $=0.05)$ in the Bartlett's sphericity test. Therefore, the null hypothesis is rejected. The eigenvectors indicate that $69.21 \%$ of the variability is explained using the F1 (40.60\%) and F2 (28.61\%) vectors (Figure 47). CEC, mean pH, 
and depth to $\mathrm{Cr}$ are related while the percent clay and mean $\mathrm{OM}$ are also related (indicating that the OM values in this study have been influenced by the high clay content of these soils).

Biplot (axes F1 and F2: 69.21\%)

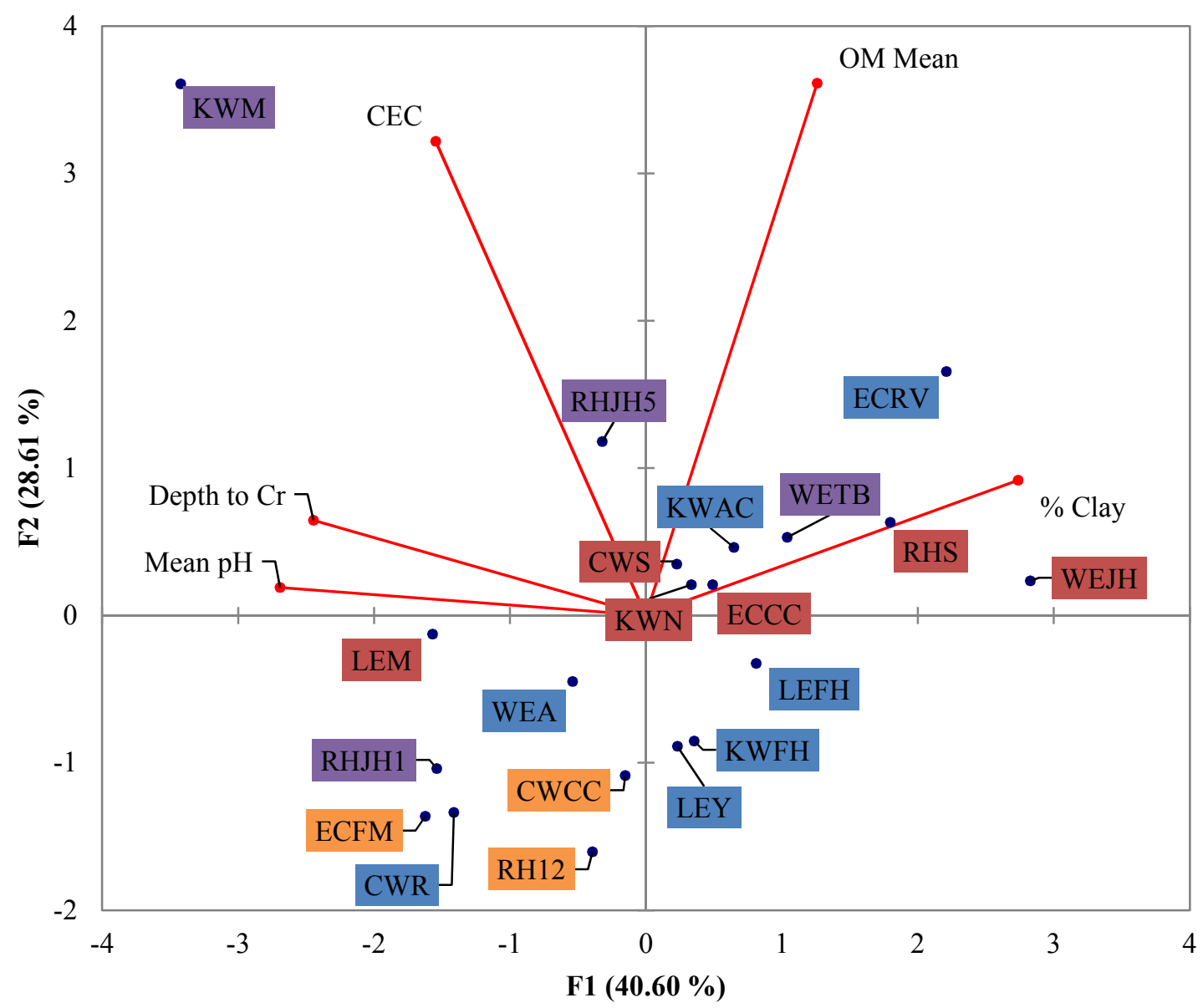

Figure 47. Principal component analysis of physical characteristics of vineyard soils in this study including \% Clay, Mean pH, Mean OM, Depth to $\mathrm{Cr}$, and $\mathrm{CEC}$ in comparison to vineyard soil parent materials $($ Red $=$ volcanic, Blue $=$ marine sediments, Orange $=$ loess $/$ volcanic, Purple $=$ other $)$. 
Macronutrients, CEC, and percent clay were plotted using PCA. The null hypothesis was again rejected because the computed p-value $(<0.0001)$ is lower than the significance level (alpha $=0.05)$. The risk in this case to reject the null hypothesis that there is no correlation between the variables is lower than $0.01 \%$. CEC is positively correlated with $\mathrm{Ca}$ and $\mathrm{Mg}$ and negatively correlated with percent clay. This result relates to the age of the soil, these soils being Ultisols and Ultic Alfisols with low CEC and high percent clay because of age and development. Vineyards are clustered based on soil parent material (Figure 48).

There is clustering of these data based on parent material. Vineyards with volcanic parent material plot together while vineyards with marine sediment parent material cluster separately. The loess/volcanic vineyards tend to plot in between the volcanic and the marine sediments. This indicates that these vineyards are influenced by both the volcanic bedrock which has similar chemistry and the loess parent material which has similar texture as the marine sediment soils. Ken Wright Meredith Mitchell vineyard is clearly an outlier, plotting nearest to $\mathrm{CEC}, \mathrm{Mg}$, and $\mathrm{Ca}$. This vineyard is removed for subsequent PCA analysis. The vineyards on other parent material, Terres Basses and Jacob-Hart, plat similarly to the vineyards loess/volcanic and marine sediment parent material. The Terres Basses vineyard is located on shale from the Coast Range sediments and Missoula Flood sediments, while the Jacob-Hart vineyard is located on a landslide on the south side of Chehalem Mountains, mostly consisting of basalt bedrock. 


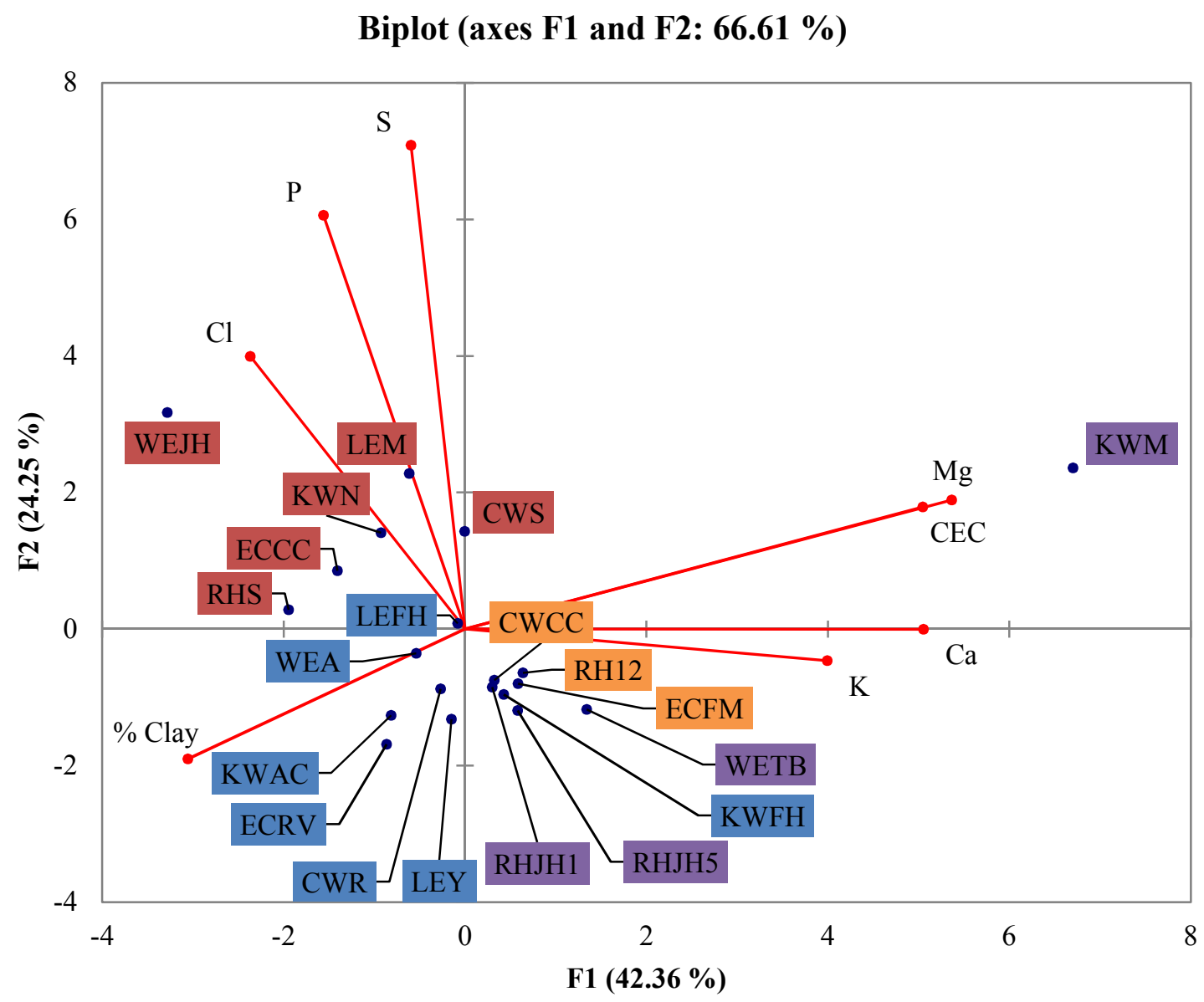

Figure 48. PCA biplot of soil macronutrients, CEC, and percent clay. Red labels - volcanic parent material. Blue labels - marine sediment parent material. Orange labels - loess/volcanic parent material. Purple labels - other parent material.

All soil elements (macronutrients, micronutrients, and trace elements) show a similar trend when PCA is done with outliers removed (Figure 49). This plot shows a separation based on soil parent material. The null hypothesis was again rejected because the computed $\mathrm{p}$-value $(<0.0001)$ is lower than the significance level (alpha $=0.05)$. The vineyards on volcanic parent material are more dispersed based on the soil elemental 
concentrations than the vineyards on marine sediment parent material. The vineyards on micronutrient concentrations in the soil, the volcanic soils cluster with $\mathrm{Fe}, \mathrm{Zn}, \mathrm{Mn}$, and $\mathrm{Al}$, while the loess/volcanic and marine sediment soils are separated from the volcanic soils by $\mathrm{Mo}, \mathrm{Cu}$, and $\mathrm{Na}$ (Figure 50). The null hypothesis was again rejected for the soil

Observations (axes F1 and F2: $47.92 \%$ )

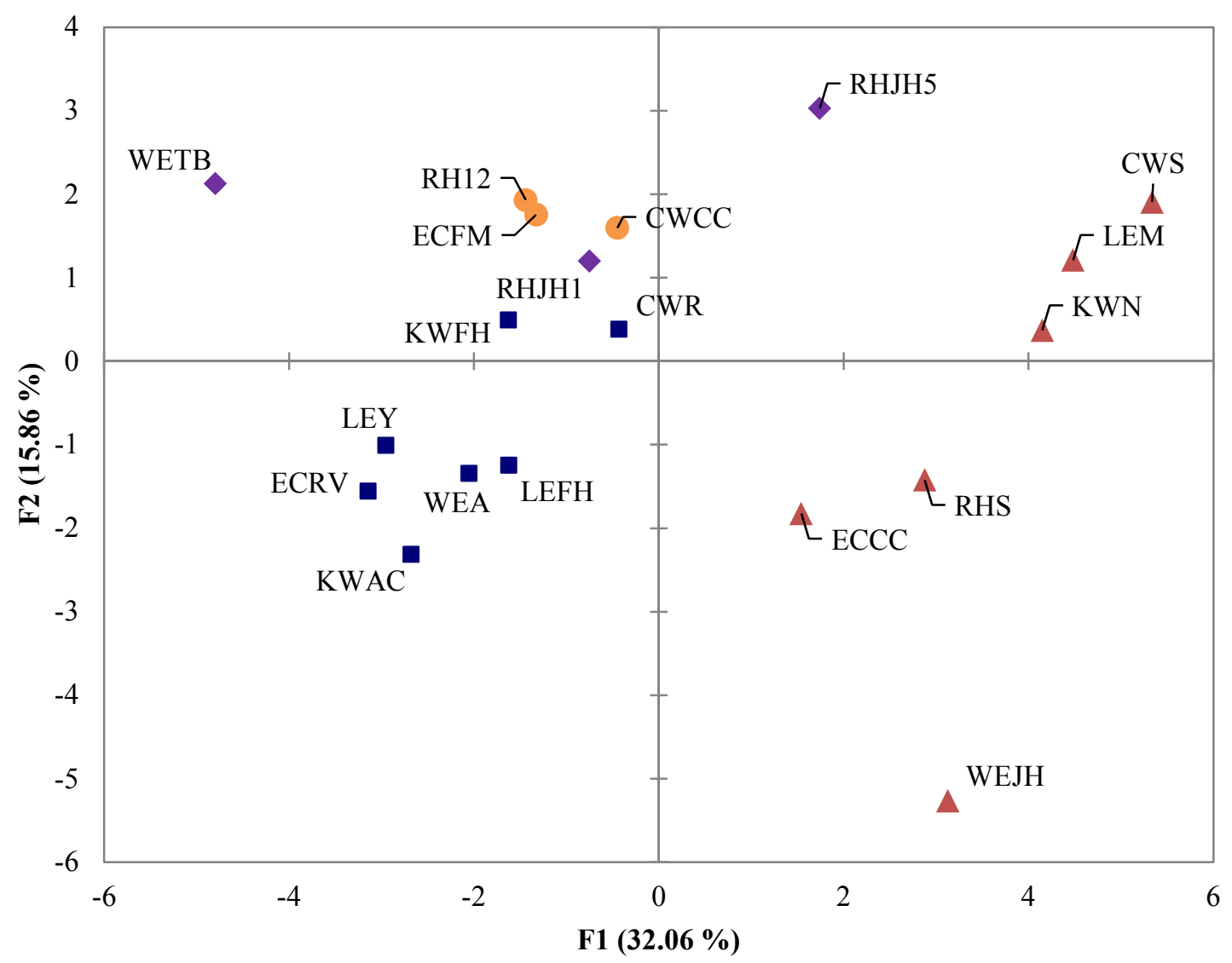

Figure 49. PCA plot of macronutrients, micronutrients and trace elements. Triangles - volcanic parent material. Squares - marine sediment parent material. Circles - loess/volcanic parent material. Diamonds - other parent material (Meredith Mitchell vineyard outlier data removed). 
Biplot (axes F1 and F2: $57.06 \%$ )

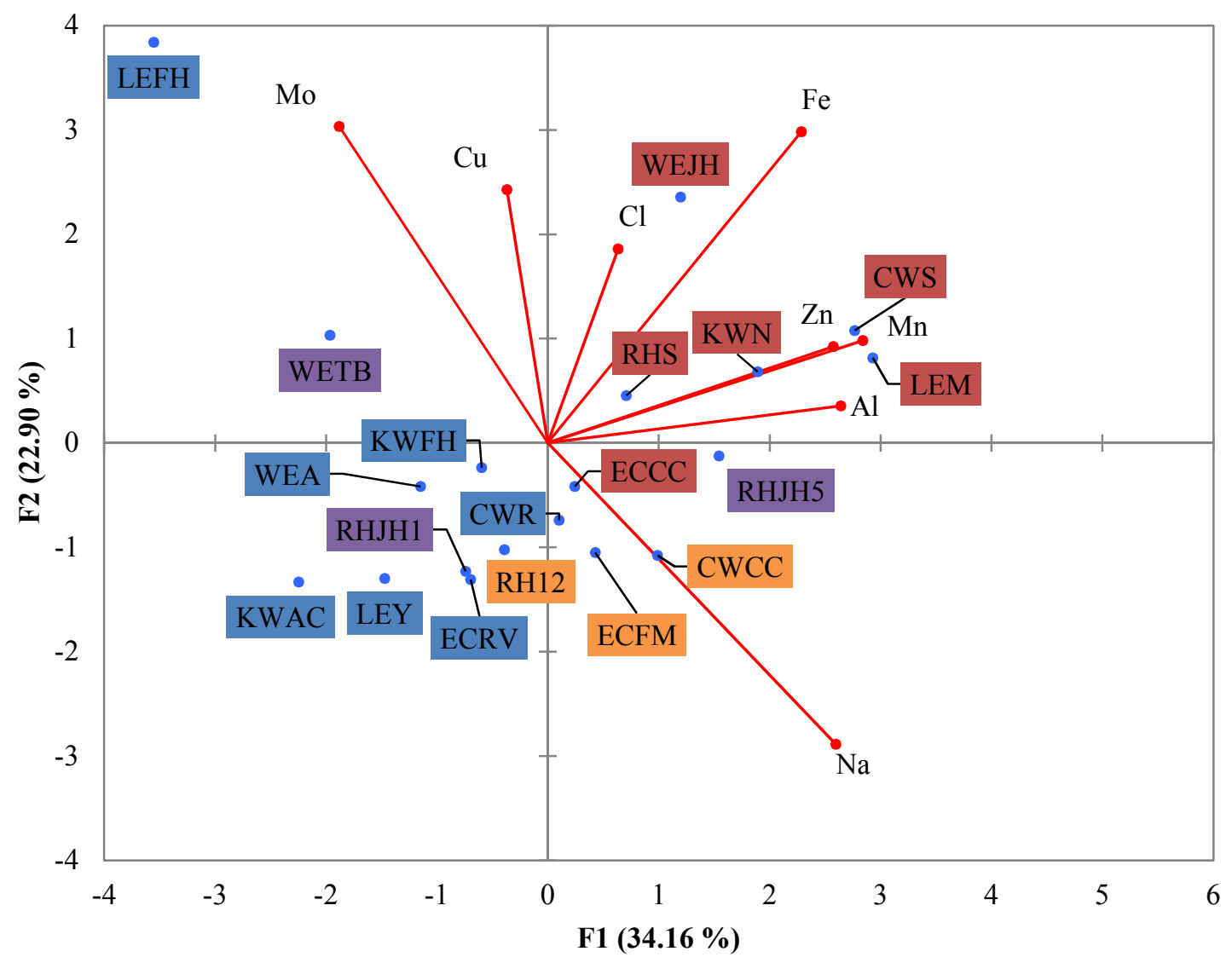

Figure 50. PCA biplot of the soil micronutrients grouping soil parent materials by color. Red labels volcanic parent material. Blue labels - marine sediment parent material. Orange labels loess/volcanic parent material. Purple labels - other parent material.

micronutrients because the computed p-value $(<0.0001)$ is lower than the significance level (alpha $=0.05$ ). The eigenvectors indicate that $57.06 \%$ of the variability is explained using the F1 (34.16\%) and F2 (22.90\%) vectors.

The vineyard soil parent materials to the trace element concentrations in the soil, the volcanic soils cluster nearest to $\mathrm{Ba}, \mathrm{Cd}, \mathrm{V}$, and $\mathrm{Be}$, while the loess/volcanic trend 
toward the As and Ni vectors (Figure 51). Marine sediment soils are separated from the volcanic soils by As and Se, and are clustered near Sr and Hg. The Jacob-Hart soils are most similar to the volcanic soil values and cluster near $\mathrm{Se}$ and $\mathrm{Ba}$. $\mathrm{Cr}$ and $\mathrm{Pb}$ vectors lie between the volcanic and the loess/volcanic soils. The null hypothesis was again rejected

Biplot (axes F1 and F2: $53.50 \%$ )

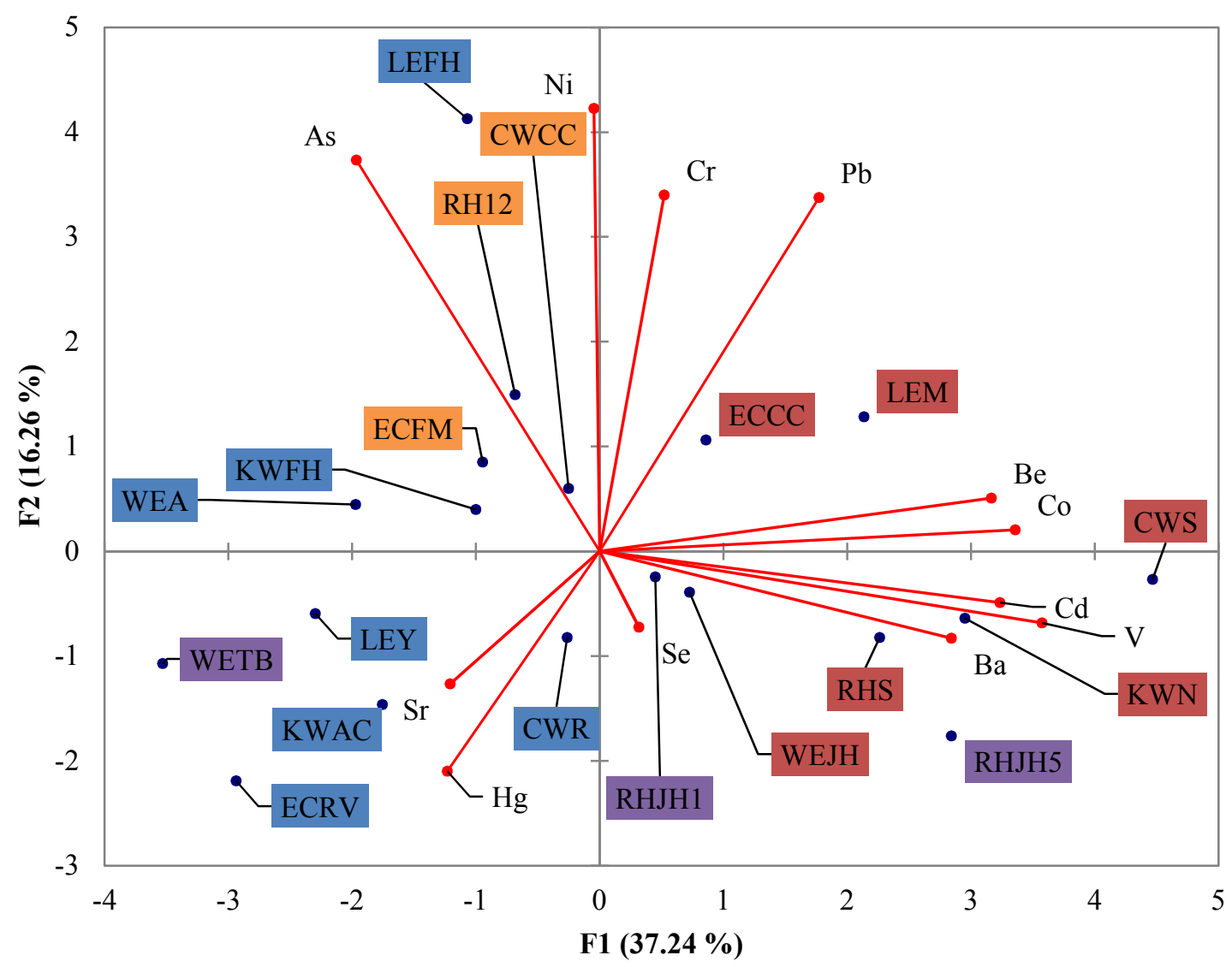

Figure 51. PCA biplot of the soil trace elements grouping soil parent materials by color. Red labels volcanic parent material. Blue labels - marine sediment parent material. Orange labels loess/volcanic parent material. Purple labels - other parent material. 
because the computed $\mathrm{p}$-value $(<0.0001)$ is lower than the significance level $($ alpha $=0.05)$. The eigenvectors indicate that $53.50 \%$ of the variability is explained using the F1 (37.24\%) and F2 (16.26\%) vectors. The Lange Estate Freedom Hill vineyard is an outlier when looking at these plots.

The grape analysis provided very little data but the nine elements that were detected are compared using PCA to the vineyard parent materials (Figure 52). The Jacob-Hart vineyards plot with the $\mathrm{P}, \mathrm{K}, \mathrm{Cu}$, and $\mathrm{Zn}$ while Yamhill, Nysa, and Ken Wright Freedom Hill plot with $\mathrm{Ca}, \mathrm{Mg}$, and Sr. One volcanic soil (Stoller) and one marine sediment soil (Aliette) plot with Na while all the rest of the vineyards, regardless of soil parent material cluster near the Mn vector. The null hypothesis was again rejected because the computed p-value $(<0.0001)$ is lower than the significance level (alpha $=0.05$ ). The eigenvectors indicate that $52.58 \%$ of the variability is explained using the F1 (28.20\%) and F2 (24.39\%) vectors.

Lastly, 15 elements were detected in the wine chemistry and the mean values are compared using PCA to the vineyard parent materials (Figure 53). The null hypothesis was again rejected because the computed $p$-value $(<0.0001)$ is lower than the significance level (alpha $=0.05$ ). The eigenvectors indicate that $42.91 \%$ of the variability is explained using the F1 (23.87\%) and F2 (19.04\%) vectors. Some vineyards from the marine 
sediments group with $\mathrm{Sr}$ and $\mathrm{Ba}$ (LEFH and WEA) and vineyards from volcanic parent material group with $\mathrm{Pb}, \mathrm{Co}, \mathrm{Ni}$, and $\mathrm{K}$ (KWN, CWS, LEM, and WEJH).

\section{Biplot (axes F1 and F2: $52.58 \%$ )}

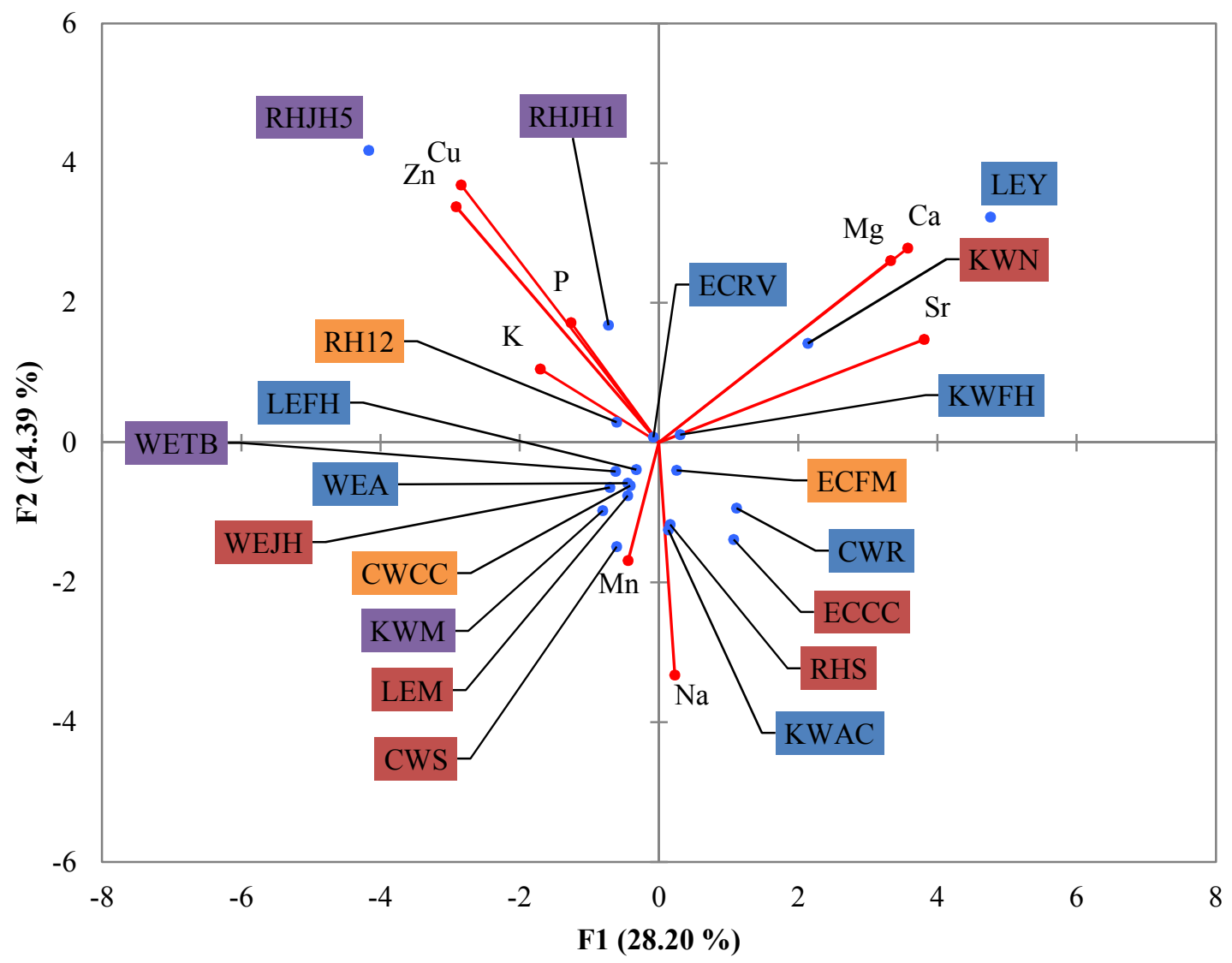

Figure 52. PCA biplot of grape chemistry by vineyard. Red labels - volcanic parent material. Blue labels - marine sediment parent material. Orange labels - loess/volcanic parent material. Purple labels - other parent material. 
Biplot (axes F1 and F2: $42.91 \%$ )

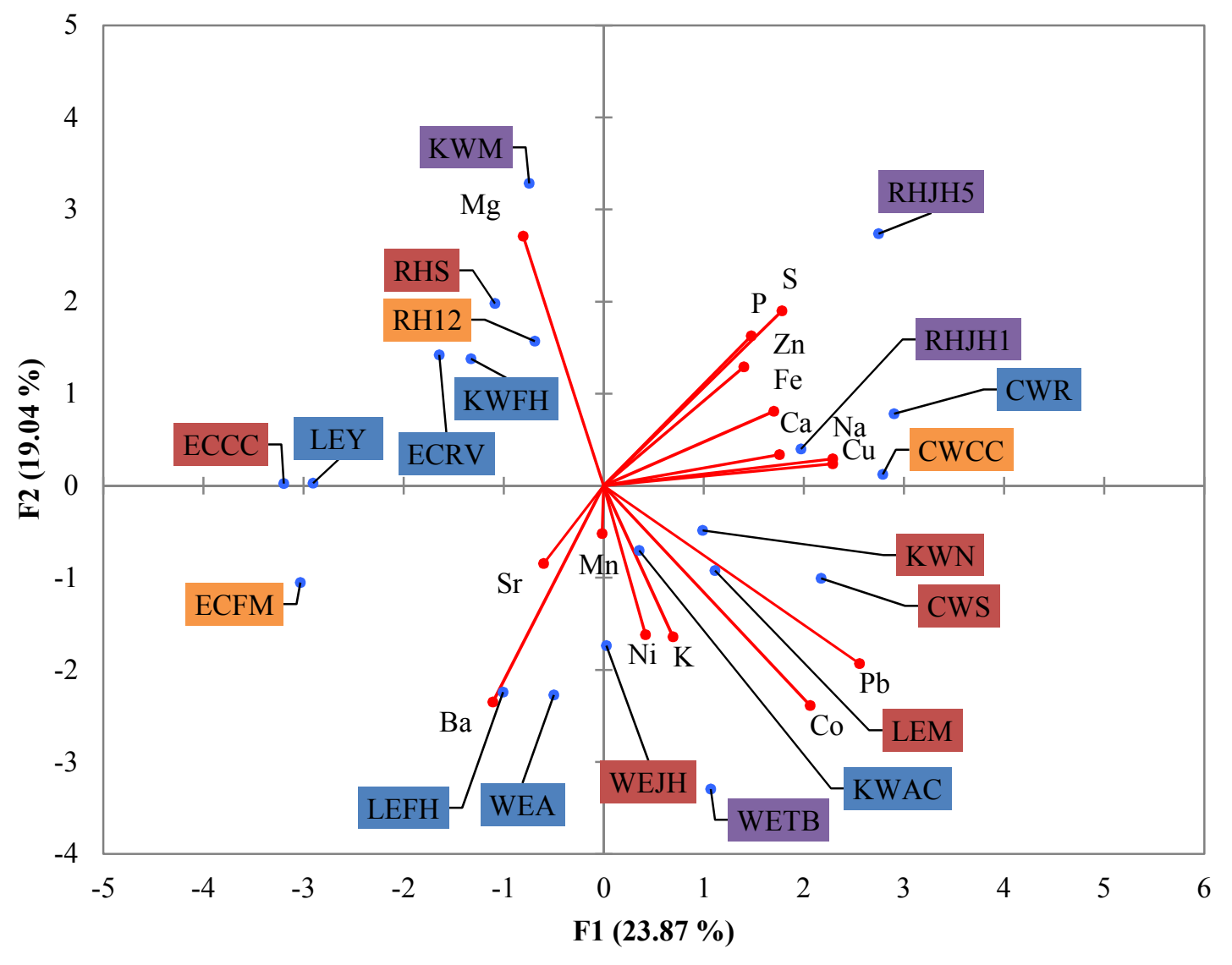

Figure 53. PCA biplot of mean wine chemistry by vineyard. Red labels - volcanic parent material. Blue labels - marine sediment parent material. Orange labels - loess/volcanic parent material. Purple labels - other parent material.

The results of this analysis support correlations between the $\mathrm{CEC}$, mean $\mathrm{pH}$, and depth to $\mathrm{Cr}$ and percent clay and OM (Figure 47). Volcanic soils have higher percent clay while marine sediment and loess soils clustered together and are more similar in texture, depth to $\mathrm{Cr}$, and $\mathrm{pH}$. Processing the data with macronutrients revealed $\mathrm{CEC}$ is positively 
correlated with $\mathrm{Ca}$ and $\mathrm{Mg}$ concentrations and negatively correlated with percent clay. All marine and volcanic soils have higher percent clay and loess and other soils have lower percent clay. Volcanic soils clustered more with $\mathrm{Cl}, \mathrm{P}$ and $\mathrm{S}$ while marine sediments mingled again with loess soils, some of which had higher $\mathrm{K}, \mathrm{Ca}, \mathrm{Mg}$, and $\mathrm{CEC}$ (Figure 48). The PCA revealed that the KWMM site was an outlier in many cases.

Concerning all the elements tested, marine, volcanic, and loess soils clustered with loess in between the volcanic and marine sediments. This clearly suggests similarities in the loess soil with both the volcanic (because the bedrock of the loess soil is also volcanic) and the marine sediments. These results were only observed with KWMM removed from the data set (Figure 49). Specifically, volcanic soils clustered with higher $\mathrm{Fe}, \mathrm{Zn}, \mathrm{Mn}$, and $\mathrm{Al}$ as well as $\mathrm{Mo}$, and $\mathrm{Cu}$. Loess soils clustered with $\mathrm{Na}$ and marine sediment soils are separated from the volcanic soils with lower values for all these elements (Figure 50). The clustering of trace elements is less pronounced, but the soil parent materials are still slightly clustered. Volcanic soils cluster with $\mathrm{Cr}$. $\mathrm{Pb}, \mathrm{Be}, \mathrm{Co}, \mathrm{Cd}$, $\mathrm{V}, \mathrm{Ba}$, and Se. Marine sediments cluster with $\mathrm{Hg}$, Sr, and loess soils cluster with As and Ni. Both marine sediments and loess are more similar to one another in terms of $\mathrm{Ni}, \mathrm{As}$, $\mathrm{Sr}$, and $\mathrm{Hg}$ while loess also shows similarities with volcanic soils concerning $\mathrm{Cr}$ and $\mathrm{Pb}$ (Figure 51). Clearly, there are similarities in soil chemistry and soil physical attributes causing each soil parent material to be clustered. 
There are few clear trends in the grape juice or wine chemistry as all three soil parent materials are mixed throughout the plot (Figure 52). The Rex Hill Jacob-Hart Vineyard Block 1 and Block 5 (RHJH1 and RHJH5) "other” soils both have similarly higher $\mathrm{Zn}$ and $\mathrm{Cu}$ concentrations in both grape juice and wine chemistry and had higher levels of $\mathrm{Zn}$ and $\mathrm{Cu}$ in the soils. The concentrations of $\mathrm{Sr}$ and $\mathrm{Ba}$ in the wine are correlated with a few marine sediment soils while the concentrations of $\mathrm{Pb}$ and $\mathrm{Co}$ in the wine are more correlated with volcanic soils (Figure 53). 


\section{Chapter Eleven - Discussion}

\section{Soil Physical Characteristics}

This study shows that there are trends in the physical, mineral, and chemical data that distinguish the soils that form on volcanic, marine sediments, and loess/volcanic parent material from one another. Soils from vineyards planted on the volcanic bedrock and loess sediments on volcanic bedrock are more similar to one another than to soils from vineyards planted on the marine sediment bedrock. Physical characteristics used to compare the various parent material in this study include texture, structure, depth, horizons, coarse fragments, and others (Table 93). The physical characteristics, clay mineralogy, and soil chemistry results (last chapter) from this study have demonstrated the need for and provided more focused research questions for future studies.

Table 93. Comparison of physical characteristics of vineyard soils in the Willamette Valley.

\begin{tabular}{cccc}
\hline Characteristic & Volcanic & Marine & Loess \\
\hline \hline Horizon Development & All have Bt Horizon & All have Bt Horizon & All have Bt Horizon \\
Bt Horizon Textures & SiL, SiCL, SiC, C & SiCL, CL, C & SiCL \\
Max Clay & $57 \%$ & $60 \%$ & $39 \%$ \\
Depth to Bt & $44 \pm 16 \mathrm{~cm}$ & $44 \pm 13 \mathrm{~cm}$ & $51 \pm 10 \mathrm{~cm}$ \\
$\begin{array}{c}\text { Depth to Bt } \\
\text { with Max Clay }\end{array}$ & $81 \pm 44 \mathrm{~cm}$ & $68 \pm 40 \mathrm{~cm}$ & $83 \pm 52 \mathrm{~cm}$ \\
Cr Horizon & $2 / 6$ & $6 / 7$ & $1 / 3$ \\
Coarse Fragments in & $\sim 25 \%$ & $\sim 2 \%$ & $\sim 5 \%$ \\
the Cr Horizon & $20 \pm 6.5$ & $19 \pm 7.3$ & $13 \pm 2.3$ \\
Max BW & $5.4 \pm 0.11$ & $5.4 \pm 0.25$ & $5.7 \pm 0.11$ \\
Mean Soil Acidity & $6 / 6$ & $0 / 7$ & $3 / 3$ \\
\hline
\end{tabular}


In general, 19 of the 20 soil pits analyzed in this study have developed a Bt horizon, the formation of which is dependent on time and moisture availability. A Bt horizon suggests a color change from the upper horizons to more red colors which is the result of oxidation occurring in a well-drained soil. Translocated clays from surface horizons have accumulated in the B horizon as fine-grained coatings on the peds and in the pore spaces. My soils with Bt horizons are old soils, as noted by the occurrence of a Bt horizon and other physical characteristics in the following discussion. The one soil without a Bt horizon was the Willakenzie Estate Terres Basses which is located on thin Missoula Flood sediments. The age of this soil must then be less than the age of the floods (approximately 15,000 years) (Allen et al., 2009) and not enough time has passed for a Bt horizon to form.

The idea that the majority of the vineyard soils examined in this study are old soils is supported also by the amount of clay present in each profile. The horizon with the maximum clay percentage for each profile based on parent material shows a major distinction between the soils on volcanic and marine sediments versus loess soils. For the soils on volcanic parent material the average maximum clay percentage is $57 \%$. Marine sediment soil has an average maximum clay percentage of $60 \%$. Loess soils have the least high average maximum clay percentage at $39 \%$. This is most likely due to the input of loess and resulting higher silt percentages in the soil profile. 
For all the Bt horizons in this study, the textures were determined from grain size analysis using the pipette method. The most common texture for these vineyard soils is silty clay loam in $28 \%$ of the horizons. The second most common textures were clay and silt loam in $21 \%$ of the horizons for each texture. Finally, $15 \%$ of the horizons were clay loam or silty clay in texture. Again, the accumulation of clay in these soils implies that they are old soils, and the presence of silt in almost all of the sites in this study is coming from the original loess parent material or an addition of loess over time. Many of the volcanic and all of the loess/volcanic soils are shown to contain a high percentage of silt. The many floods that brought sediment to the Willamette Valley provided silt to be blown from the valley bottoms onto the hillslopes where these sites are located. The silt in the marine sediments is coming from the sandstone and siltstone parent material directly from the Coast Range marine sediments.

Furthermore, many of the vineyard soils sampled in this study were shallow enough for the bedrock to be reached. In this study, 13 of 20 pits reached parent material. Many of these profiles were described as having a $\mathrm{Cr}$ or $\mathrm{R}$ horizon at depth. Marine sediment soil was most likely to have Cr horizon(s) sampled (six of seven pits), since the sandstone and siltstone parent material was friable and easily penetrated with the auger. Volcanic (two of six) and loess soils (one of three) were unable to reach basalt bedrock, but many contained basalt gravel at depth. Refusal at only a few sites was reached; The Jory Hills (volcanic), Stoller (volcanic), Corral Creek (loess), and Rex Hill Estate (loess) 
vineyards were dug to refusal at basalt bedrock. For the most part, the vine roots were also present in the $\mathrm{Cr}$ horizons, especially in the marine sediments.

In addition to reaching the bedrock or a $\mathrm{Cr}$ horizon, nine pits had $2.9 \%$ or less coarse fragments in the A horizon. Many quality vineyards in other places in the world have very little soil accumulation and are mostly gravel at the surface (White, 2009). This difference makes the soils of the Willamette Valley distinctive in that many vineyards have very little to no gravel at the surface. In contrast half of the sites in this study, 10 pits out of the 20, had coarse fragments in the Cr horizon. The majority of these coarse fragments were highly weathered basalt fragments from the bedrock below. The JacobHart vineyard contained the most gravel in the $\mathrm{Cr}$ horizon because this site is an ancient landslide deposit, consisting of a mix of sediment and basalt colluvium from the southwest slope of the Chehalem Mountains.

Of the 20 soil profiles, no vineyard had an O horizon present which is not uncommon for agricultural soils. An O horizon is an organic layer developed from leaves, needles, mosses, rushes, or woody material that is slightly decomposed and is mostly found in forested areas. These vineyards are well groomed and void of much debris left to decompose on the vineyard floor. The vineyard managers removed or till under the vine cuttings each season. Many have mown cover crops between vine rows and bare earth directly below the vines. Two of the profiles in this study had Bg horizons. 
$\mathrm{A} \mathrm{Bg}$ horizon indicates that there are periods of intense reduction in the soil meaning that it is poorly drained (Birkeland, 1999). The Bg horizon is characterized by gray colors and the presence of red mottling (redoximorphic features). The only sites in this study with Bg horizons were the Terres Basses vineyard on Missoula Flood deposits and the Yamhill vineyard on marine sediments. The cause of a Bg horizon at the Yamhill vineyard is most likely because of a clay layer within the siltstone parent material that inhibits drainage. The lack of many Bg horizons in the study indicates most vineyard soils in the study were well-drained.

An indication that these soils are old and have had plenty of time to develop is the structure of the peds. The majority of these soils had subangular blocky structure (Spohn and Giani, 2011). This structure is good for agriculture because pores and channels within the soil allow for the movement of air and fluids through the soil and creates a favorable environment for microbial activity and root growth (Barthès and Roose, 2002; Helgason et al., 2010). Structure is dependent on texture, clay, organic matter, and cementing substances like sesquioxides that coat and group the particles into aggregates (Colombo and Torrent, 1991). The presence of Fe and Al in many of the soils in this study, as well as the presence of macronutrients like $\mathrm{Ca}$ and $\mathrm{Mg}$, will aid in the formation of aggregates and the subangular structure. Bacteria, fungi, and mycorrhizae are also very important in the formation of aggregates and the structure of the soil (Barto et al., 2010; Rillig et al., 2010). Subangular blocky structure in these vineyards promotes aeration and 
soil permeability and, most likely, has a huge impact on the health of the vine and the quality of the wine. More research is needed into the role of soil structure in the vineyards of the Willamette Valley.

\section{Pisolites (Concretions)}

A major discovery in the physical characteristics is that both the volcanic and windblown soils, which form on the volcanic bedrock with the addition of loess, have concretions called pisolites (Miller, 1985) (Figure 54). These concretions were also described in 1985 in the Pre-Peoria loess in Northeastern Louisiana (Miller, 1985). I expected to find pisolites in the loess soils (mainly the Laurelwood series) because farmers have always called these "buckshot" soils, but finding them in the volcanic soils (at lower concentrations) was a surprise. The grain size of the volcanic and loess/volcanic soils have an unusually high percentage of sand-size grains in the upper horizons because of these secondary concretions of Fe and Mn similarly to the Pre-Peoria loess (Miller, 1985). These concretions are found in Alfisols and Ultisols in Louisiana, which is also the case in this study. The Pre-Peoria loess is dated at 60 to 25 Kya (Gillespie et al., 2004) suggesting that the soils with concretions in this study are likely soils on old weathered loess and not loess from the 15 Kya Missoula Flood sediment.

Therefore, many of the volcanic soils are closely related to the windblown soils in this study. These pisolites, discovered during the grain size analysis, exist in the soils that 
develop on volcanic bedrock that also have a loess input. Some of the volcanic soils have pisolites, implying they also have had an addition of loess in the past. Previous to this study, pisolites were only found in the old windblown soils in the Willamette Valley. Now, I know that volcanic soils sometimes also contain pisolites and must also have a windblown component. In this study, the marine sediment soils do not contain pisolites. The marine sediment soils do, on the other hand, contain visible muscovite mica and quartz sand where the volcanic soils are more likely to have dark rock fragments in the sand fraction and no quartz.

Pisolites are subrounded in shape and are sometimes referred to as Fe-Mn concretions (Manceau, 2003). Thin sections show that these pisolites usually contain a grain of quartz, feldspar, or mica that is surrounded by layers of Fe and Mn oxides and phyllosilicates. The similarity between the minerals available in the soil and the minerals found in the pisolites indicate that they form in place and are not transported. The mechanism of formation may involve wet and dry cycles and the enrichment of Fe, Mn, and other metals that are attracted to the nucleus and deposited in concentric layers during oxidation (Manceau, 2003). This process is most common in loess soils and may have an important impact on the availability of trace metals in the soils for uptake by the vines and result in lower Fe and Mn concentrations in the bulk soil. 


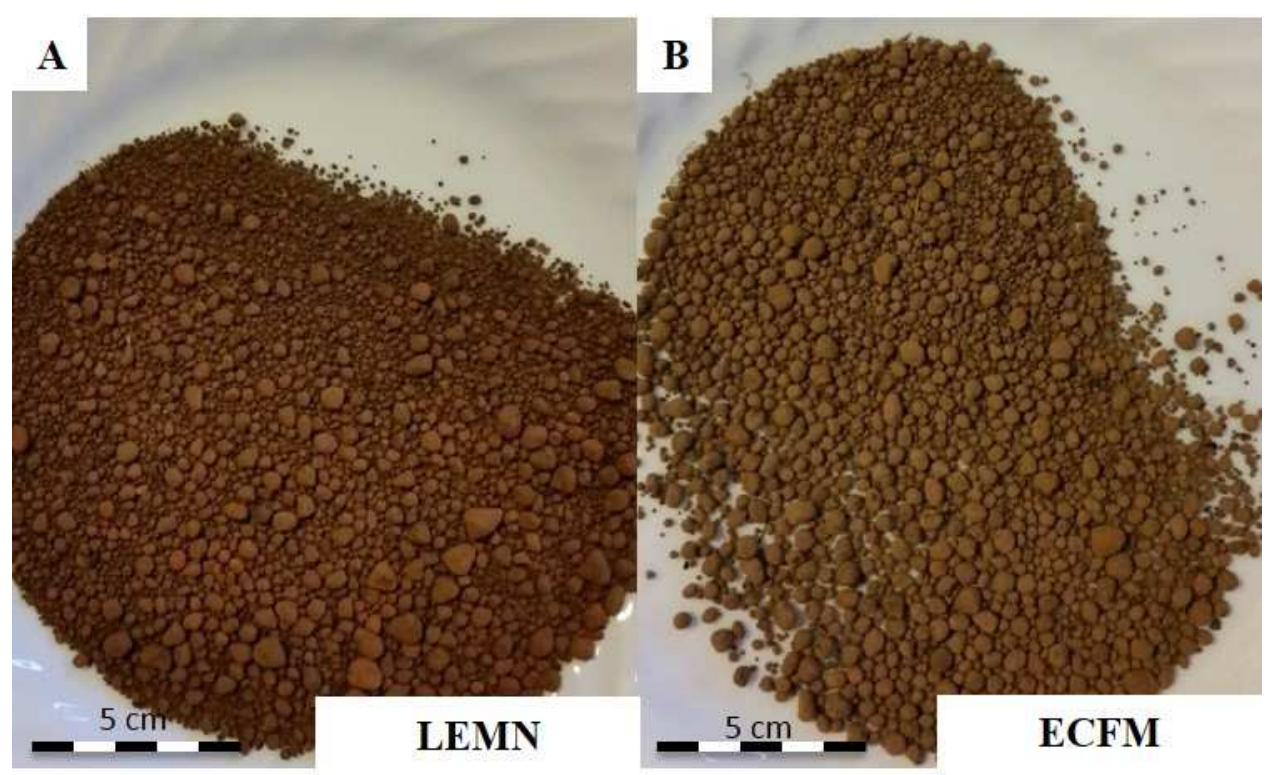

Figure 54. Pisolites from the Lange Estate, Mia Block (A - LEM) and Elk Cove, Five Mountain Vineyards (B - ECFM).

The pisolites were most significant in two vineyard sites in this study. The Lange Estate Vineyard, Mia Block and the Elk Cove, Five Mountain Vineyard both contain abundant pisolites throughout their profiles. I was expecting to find pisolites in the Five Mountain Vineyard, since it is one of my loess/volcanic sites, but did not expect to find pisolites in the Lange Estate, Mia Block. The pisolites were separated from the soil and powdered for X-ray diffraction at Portland State University in order to determine the mineralogy. Samples were also sent to Washington State University labs for analysis using X-ray fluorescence to determine elemental composition (Table 94). Trace elements were determined using ICP-MS (Figure 55). It is thought that the pisolites form mostly of 
Fe and Mn oxides while pulling many trace elements out of the soil. If this is true, it may relate to trends in the soil chemistry data for samples containing pisolites.

Table 94. Major elements measured in pisolites from soils formed on two different parent materials in the Willamette Valley using XRF. LEM - Lange Estate Mia vineyard on volcanic parent material. ECFM - Elk Cove Five Mountain vineyard on windblown and volcanic parent material.

\begin{tabular}{ccc}
\hline & $\begin{array}{c}\text { Normalized Major Elements (Weight \%) } \\
\text { Sample }\end{array}$ & \\
LEM (Volcanic) & ECFM (Loess/volcanic) \\
\hline $\mathrm{SiO}_{2}$ & 53.14 & 63.68 \\
$\mathrm{TiO}_{2}$ & 2.722 & 1.532 \\
$\mathrm{Al}_{2} \mathrm{O}_{3}$ & 20.60 & 16.82 \\
$\mathrm{FeO}^{*}$ & 16.95 & 9.23 \\
$\mathrm{MnO}$ & 0.972 & 0.670 \\
$\mathrm{MgO}$ & 0.83 & 1.11 \\
$\mathrm{CaO}$ & 0.73 & 1.33 \\
$\mathrm{Na}_{2} \mathrm{O}$ & 1.01 & 1.88 \\
$\mathrm{~K}_{2} \mathrm{O}$ & 1.44 & 1.99 \\
$\mathrm{P}_{2} \mathrm{O}_{5}$ & 1.618 & 1.759 \\
\hline $\mathrm{Total}$ & $\mathbf{1 0 0 . 0 0}$ & $\mathbf{1 0 0 . 0 0}$ \\
\hline \hline
\end{tabular}

The results from the XRF and ICP-MS analysis indicate that the pisolites do contain mostly silica, Al, and Fe oxides. Initial results of the x-ray diffraction also suggest the core of the pisolites is either quartz or feldspar as these peaks are the most distinguishing. The pisolites from the volcanic soil (LEM) actually have higher weight percent of $\mathrm{Al}, \mathrm{Fe}$, and $\mathrm{Mn}$ than the pisolites form the loess/volcanic soil (ECFM). $\mathrm{Mg}$, $\mathrm{Ca}, \mathrm{Na}, \mathrm{K}$, and $\mathrm{P}$ are higher weight percent in the loess soil pisolites, which correlates with the higher values of these elements in the soils of the loess pisolites (discussed in the 
soil chemistry section). Trace elements are similar between pisolites from the different parent materials with the exception of $\mathrm{Cr}, \mathrm{V}, \mathrm{Ba}, \mathrm{Sr}, \mathrm{Cu}$, and $\mathrm{Zn} . \mathrm{Cr}, \mathrm{V}$, and $\mathrm{Zn}$ are higher in the LEM (volcanic) pisolites while Ba and Sr are higher in the ECFM (loess/volcanic) pisolites.

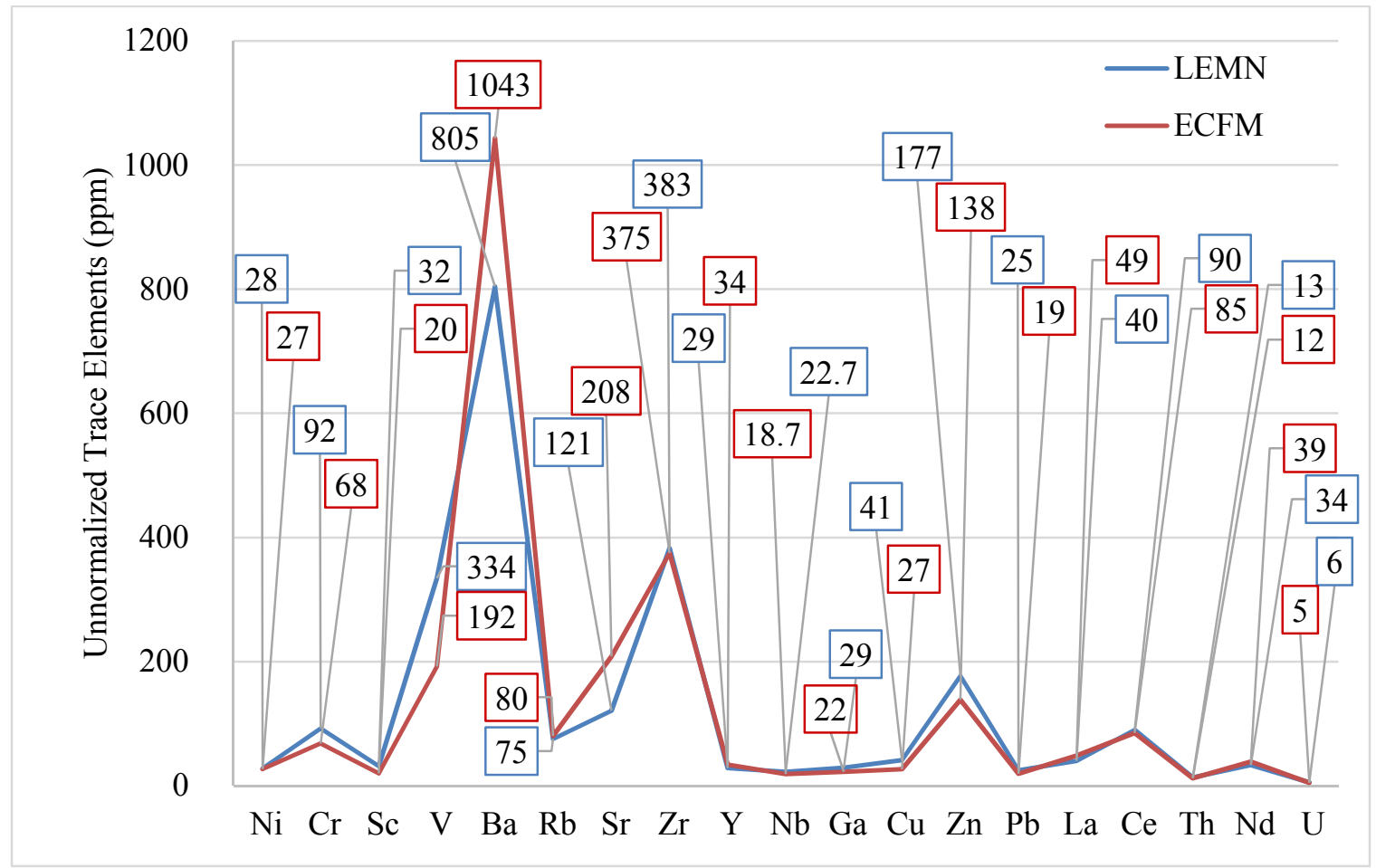

Figure 55. Trace elements of pisolites from soils formed on two different parent materials in the Willamette Valley using ICP-MS. LEM - Lange Estate Mia vineyard on volcanic parent material. ECFM - Elk Cove Five Mountain vineyard on windblown and volcanic parent material.

\section{Buntley-Westin Soil Development Index}

The soils in this study are mostly red soils, and this physical characteristic did vary between soils of different parent material and soil development. In general, the colors that have developed in the soils of the volcanic and loess parent material are more 
likely to be brown, strong brown, or reddish brown which coincides with the Munsell notations of 7.5YR or 5YR hue. The marine sediment soils are more yellowish brown in color which coincides with Munsell notations from the 10YR hue. This may be connected to the formation of different Fe-oxides, and the age of the soils, and the color of the parent material. In most cases, the marine sediments (sandstones and siltstones) have yellowish color which then influences the color of the soil above.

The Buntley-Westin (BW) soil development index (Buntley and Westin, 1965) utilizes soil colors determined by the Munsell notations to assess soil development which is based on redness of the soil (redder the soil the older the soil). The soils analyzed are grouped by parent material with their respective B horizon Buntley-Westin soil development index (Table 95). For each soil, the hue is given a value $(5 \mathrm{YR}=5 ; 7.5 \mathrm{YR}=$ $4 ; 10 \mathrm{YR}=3 ; 2.5 \mathrm{Y}=2$ ), which is multiplied by the chroma (Buntley and Westin, 1965 and Birkeland, 1999). According to Birkeland (1999), a BW Color Index greater than 15 coincides with soils greater than 10,000 years old in alpine soils (study by Miller and Birkland, 1974).

I know that the soils in this study are older than this, possibly a half to a million years old according to geologic history. The soils are at high enough elevations to have been protected from the catastrophic flooding that occurred approximately 15,000 to 18,000 calendar years ago (Allen et al., 2009) which would have deposited sediments to 
make the soils younger. Soils with volcanic parent material have a color index ranging from 12 to 30 with a mean of $20 \pm 6.5$ (Table 95). The soils with marine sediment parent material have $\mathrm{BW}$ color indices ranging from 12 to 30 with a mean of $19 \pm 7.3$. These soils are very similar in age as the soils that formed on the volcanic parent material in this study. The soils of loess/volcanic parent material have similar values ranging from 12 to 16 with a mean of $13 \pm 2.3$. These values are slightly lower due to the addition of loess.

Table 95. Soil development rating based on Buntley-Westin Color Index. Value is the maximum for each soil pit compared to all horizons sampled within that pit separated by parent material.

\begin{tabular}{|c|c|c|c|c|c|c|}
\hline \multicolumn{2}{|c|}{ Volcanic } & \multicolumn{2}{|c|}{ Marine } & \multicolumn{3}{|c|}{ Loess } \\
\hline ECCC & 20 & ECRV & 18 & \multicolumn{2}{|c|}{ ECFM } & 12 \\
\hline WEJH & 30 & WEAB & 30 & \multicolumn{2}{|c|}{ CWCC } & 16 \\
\hline CWS & 12 & CWR & 12 & \multicolumn{2}{|c|}{ RH12 } & 12 \\
\hline LEM & 16 & LEY & 24 & \multicolumn{2}{|c|}{ Mean } & 13 \\
\hline RHS & 24 & KWAC & 24 & \multicolumn{2}{|c|}{ St. Dev. } & 2.3 \\
\hline \multirow[t]{2}{*}{ KWN } & 16 & LEFH & 12 & \multirow{4}{*}{$\frac{\dot{\Xi}}{0}$} & WETB & 9 \\
\hline & & KWFH & 12 & & RHJH1 & 9 \\
\hline Mean & 20 & Mean & 19 & & RHJH5 & 9 \\
\hline St. Dev. & 6.5 & St. Dev. & 7.3 & & KWM & 12 \\
\hline
\end{tabular}

These results do not demonstrate a significant difference in soil development between these three parent materials, but it does imply all these vineyards in this study comparing three different parent materials are all well developed and old soils (Figure 56). My belief going into this study was that there would be a trend in the BW values with the Jory (volcanic parent material in the Dundee AVA) greater than the Willakenzie 


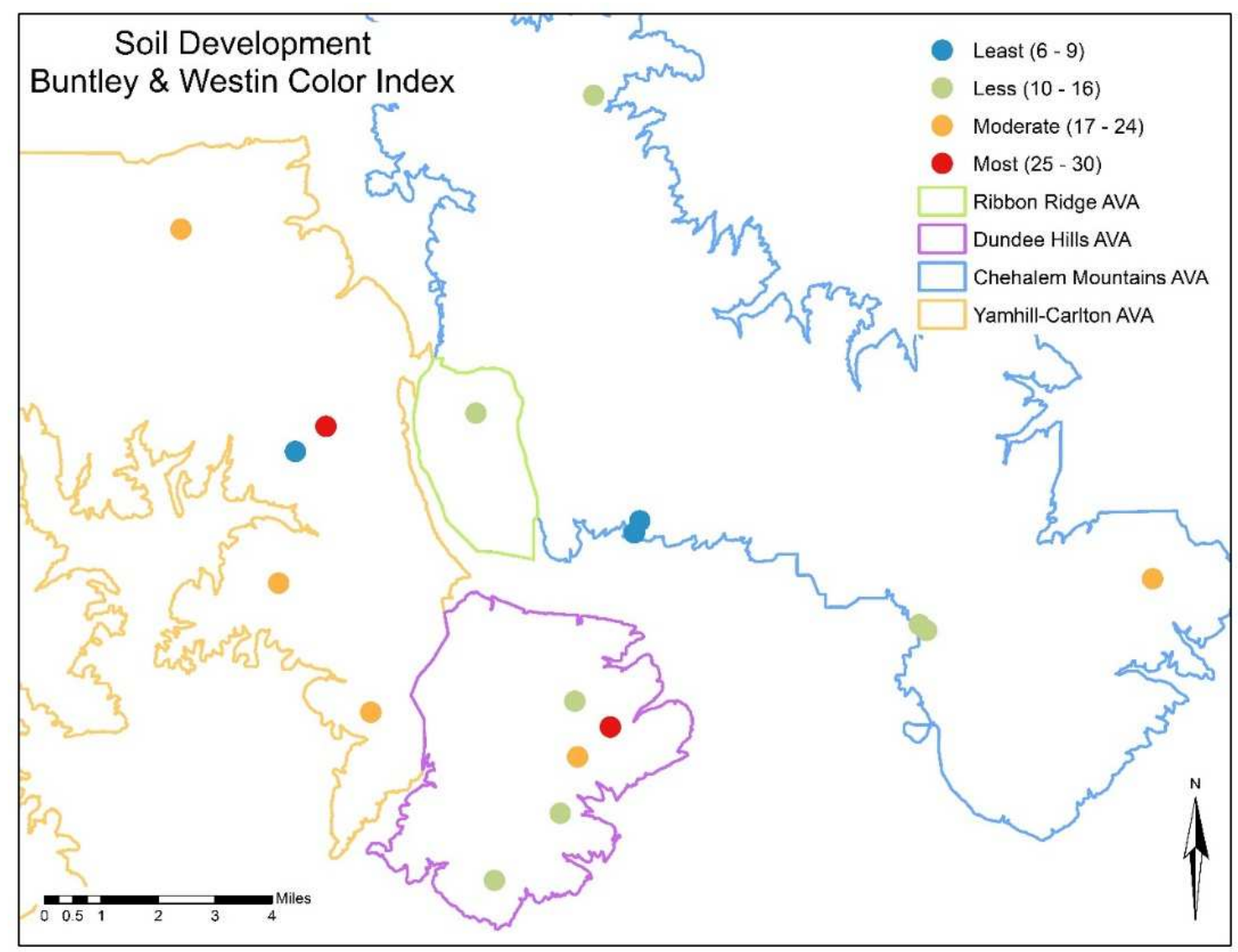

Figure 56. Map of the maximum Buntley \& Westin color from a B horizon in each soil pit for vineyards in this study that were located in the northern Willamette Valley AVAs.

(marine sediment parent material in the Yamhill-Carlton AVA) and both greater than the Laurelwood (loess/volcanic parent material in the Chehalem Mountains AVA) soil series. These data show this trend but are not statistically significant since I have so few data points (Scott Burns, per comm., 2015). It is notable that the vineyards on Missoula Flood Deposits (WETB) and the landslide deposits (RHJH1 and RHJH5) all have a BW color index of 9. This is the lowest soil development for all of my samples and correlates with what I know about these deposits being less than 15,000 years old and the youngest 
deposits in this study. The Meredith Mitchell vineyard is located on old volcanic bedrock in the Coast Range, and a value of 12 coincides with this being an older soil, similar to the other soils on marine sediments.

\section{Organic Matter}

The organic matter content of each horizon was determined using loss on ignition. Normally organic matter decreases with depth (Birkeland, 1999). The results using this method can be higher than normally seen at depth because of unusually high clay content in the soil. As the soil is heated, the moisture trapped in the clay lattice can be released, giving an incorrect value for the organic matter. As stated before, the average clay content of the volcanic soils is $57 \%$ and $60 \%$ for marine sediment soils so many of the horizons with these high amounts of clay also have high perceived percent organic matter values. Despite this issue with the deeper horizons, the organic matter in most of the A horizons are between $3 \%$ and $10 \%$, which is within the normal range for agricultural soils which is from 2 to $10 \%$ (Birkeland, 1999). The Stoller vineyard has the highest percent organic matter in the A horizon for these vineyards at $13.8 \%$. To compare the parent material in this study, the mean percent organic matter for the A horizon of each was calculated. The mean percent organic matter in volcanic soils is $11.3 \pm 1.3 \%$. The mean percent organic matter for the A horizons of the marine sediment soil is $6.9 \pm 1.8 \%$. The A horizons of the loess/volcanic soils have a mean percent organic matter of $7.5 \pm 0.7 \%$ (Table 96). There is enough of a distinction to believe the volcanic soils in this study do 
have higher organic matter in the surface horizons. This is most likely due to farming practices.

Table 96. Percent organic matter for the A horizon of each soil pit in this study separated by parent material. Organic matter determined using loss on ignition separated by parent material.

\begin{tabular}{|c|c|c|c|c|c|c|}
\hline \multicolumn{2}{|c|}{ Volcanic } & \multicolumn{2}{|c|}{ Marine } & \multicolumn{3}{|c|}{ Loess } \\
\hline ECCC & 10.3 & ECRV & 9.3 & & ECFM & 7.9 \\
\hline WEJH & 10.7 & WEAB & 8.0 & & CWCC & 6.7 \\
\hline CWS & 13.8 & CWAB & 3.9 & & RH12 & 8.0 \\
\hline LEM & 10.7 & LEY & 5.7 & & Mean & 7.5 \\
\hline RHS & 11.9 & KWAC & 6.5 & & St. Dev. & 0.7 \\
\hline \multirow[t]{2}{*}{ KWN } & 10.6 & LEFH & 7.6 & \multirow{4}{*}{$\frac{\dot{\Phi}}{\overline{0}}$} & WETB & 9.0 \\
\hline & & KWFH & 7.2 & & RHJH1 & 8.5 \\
\hline Mean & 11.3 & Mean & 6.9 & & RHJH5 & 9.0 \\
\hline St. Dev. & 1.3 & St. Dev. & 1.8 & & KWM & 17.9 \\
\hline
\end{tabular}

In order to assess the variation in percent organic matter by parent material, the mean for each soil pit was calculated and mapped according to AVA (Figure 57). The Dundee AVA (mostly volcanic soils) contains the sites with the highest organic matter content. Since organic matter is impacted by farming practices, it is necessary to note that the vineyard sites in all the AVAs have cover crop strategies and regular tilling schedules. It may be that these vineyards had been tilled more recently than others which increases the organic matter in the soils. Also, as stated before, the clay content in many of the sub-horizons of volcanic soils is higher than in the other soils. This high clay content most likely is the main reason these data are also high since loss on ignition tends 
to drive water out of the clays. Almost every site had increasing organic matter with depth, which is uncommon without evidence of translocation, which there is none in these sites. Organic matter translocation would leave behind OM coatings on ped faces among other visible evidence, and nothing of this kind was found. Percentages over 10\% for $\mathrm{OM}$ at depth are not common, and a comparison of various methods (other than LOI) to clay content is needed.

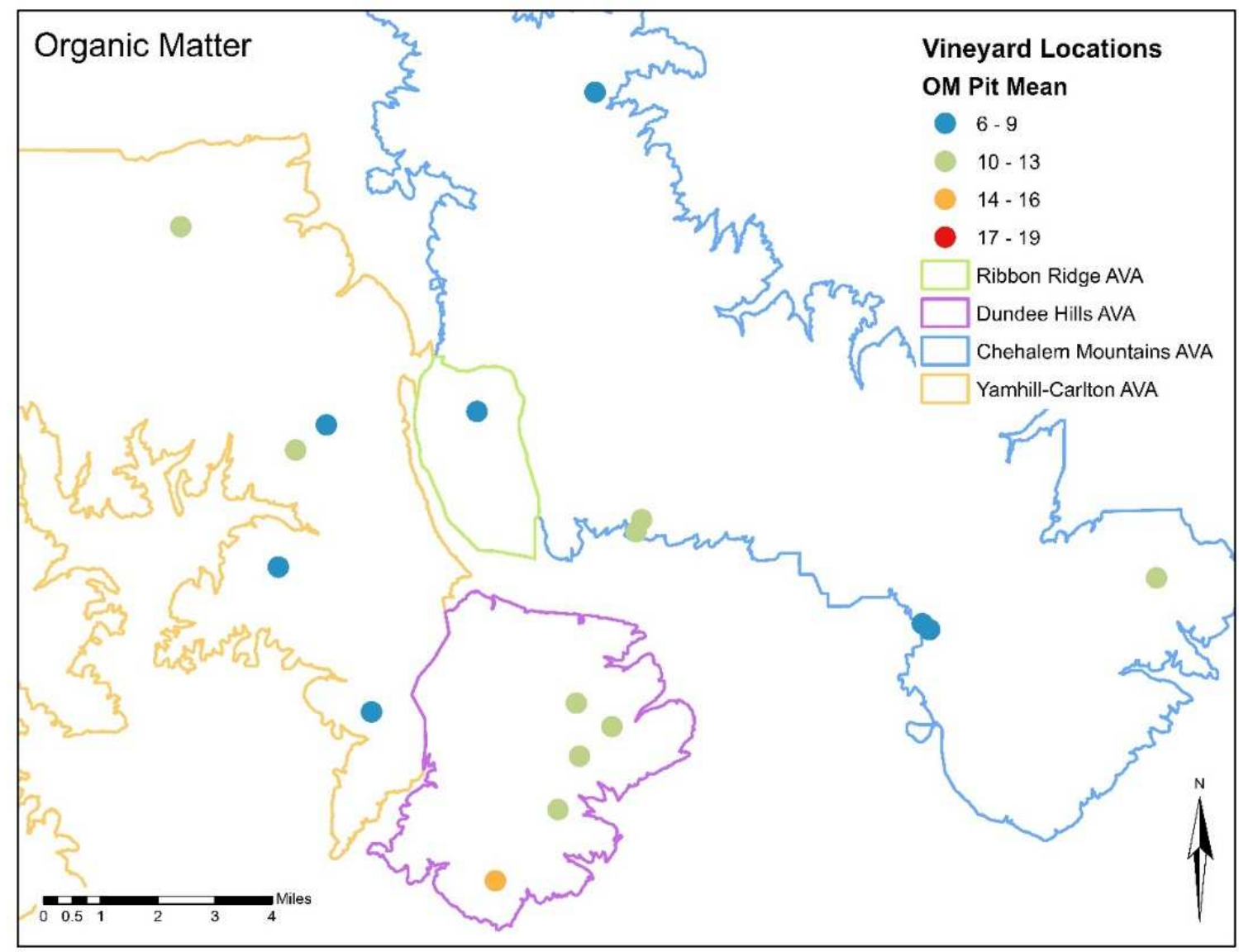

Figure 57. Map showing the mean organic matter determined using loss on ignition on each horizon in each soil pit for vineyards in this study that were located in the northern Willamette Valley AVAs. 


\section{Soil Acidity}

The $\mathrm{pH}$ values ranged from 4.7 to 6.7 for all 87 horizons tested in this study with a mean of $5.5 \pm 0.4$. The maximum soil $\mathrm{pH}$ of 6.7 was recorded in the Ken Wright Meredith Mitchell vineyard. This is correlated to the high organic matter, $\mathrm{CEC}$, and $\mathrm{Ca}$ content in this vineyard as compared to the other sites. The most acidic horizon was the Cr1 horizon of the Ken Wright Abbott Claim vineyard with a $\mathrm{pH}$ of 4.7. The minimum mean $\mathrm{pH}$ for soils with volcanic parent material is $5.2 \pm 0.2$, and the overall mean is $5.4 \pm$ 0.1 (Table 97).

Table 97. Minimum soil $\mathrm{pH}$ for each vineyard site according to parent material.

\begin{tabular}{|c|c|c|c|c|c|c|}
\hline \multicolumn{2}{|c|}{ Volcanic } & \multicolumn{2}{|c|}{ Marine } & \multicolumn{3}{|c|}{ Loess } \\
\hline ECCC & 5.0 & ECRV & 4.7 & & ECFM & 5.5 \\
\hline WEJH & 5.2 & WEAB & 5.8 & & CWCC & 5.7 \\
\hline CWS & 5.4 & CWAB & 5.0 & & RH12 & 5.6 \\
\hline LEM & 5.3 & LEY & 4.9 & & "Mean & $\bar{~} 5.6$ \\
\hline RHS & 5.0 & KWAC & 4.7 & & St. Dev. & 0.1 \\
\hline \multirow[t]{2}{*}{ KWN } & 5.4 & LEFH & 5.1 & \multirow{4}{*}{$\frac{\dot{\Xi}}{\tilde{\Xi}}$} & WETB & 5.3 \\
\hline & & KWFH & 5.3 & & RHJH1 & 5.7 \\
\hline Mean & 5.2 & Mean & 5.1 & & RHJH5 & 5.7 \\
\hline St. Dev. & 0.2 & St. Dev. & 0.4 & & KWM & 6.0 \\
\hline
\end{tabular}

The minimum mean $\mathrm{pH}$ for soils with marine sediment parent material is $5.1 \pm$ 0.4 , and the overall mean is $5.4 \pm 0.3$. Loess soils tend to have slightly higher $\mathrm{pH}$ with a minimum mean at $5.6 \pm 0.1$ and an overall mean at $5.7 \pm 0.1$. This is due to the input of young loess which also supplies nutrients to the soils. The majority of soil pits in this 
study have $\mathrm{pH}$ values that decrease with depth, usually from the moderately acid range (5.6 to 6.0$)$ to strongly acid (5.1 to 5.5). This was expected since these are old soils with low nutrients. Four soil pits were very consistent with depth considering $\mathrm{pH}$. These were Ken Wright Nysa vineyard, Willakenzie Estate Aliette vineyard, and Chehalem Corral Creek vineyard. These vineyards all have low $\mathrm{pH}$ because they are located on old soils.

A moderately low acidic soil is commonly used for quality vineyard sites. If the $\mathrm{pH}$ becomes too acidic or too alkaline, various key nutrients can become insoluble and unavailable to the plants (White, 2009). The soil $\mathrm{pH}$ has an important influence on the availability of nutrients and on the growth of different kinds of plants. If the soil $\mathrm{pH}$ is too low the $\mathrm{N}, \mathrm{P}$ and $\mathrm{K}$ are tied up in the soil and not available to plants. $\mathrm{Ca}$ and $\mathrm{Mg}$, which are essential plant nutrients, may be absent or deficient in low $\mathrm{pH}$ soils. Low $\mathrm{pH}$ also increases the toxicity of $\mathrm{Al}, \mathrm{Fe}$ and $\mathrm{Mn}$. Non-toxic elements like $\mathrm{S}, \mathrm{Ca}, \mathrm{Mg}$, and Mo will be available for plant uptake at the correct $\mathrm{pH}$. The decomposition of organic matter improves soil structure and is also impacted by the $\mathrm{pH}$. If soil $\mathrm{pH}$ is too low, the activity of soil organisms that break down organic matter is reduced (White, 2009). Proper soil $\mathrm{pH}$ increases microorganism activity which produces improved soil tilth (aggregation and readiness for crops), aeration and drainage. This is turn allows for better use of nutrients, increased root development, and drought tolerance. 


\section{Cation Exchange Capacity}

Cation exchange capacity can sometimes be estimated if the dominant clay minerals in the soil are known. The value of CEC relates to the elements that are available for uptake by the vine. From White (2003) kaolinite clays will have low CEC (3 to $20 \mathrm{meq} / 100 \mathrm{~g})$, illite (10 to $40 \mathrm{meq} / 100 \mathrm{~g})$, smectite (80 to $120 \mathrm{meq} / 100 \mathrm{~g}$ ) and vermiculite will have the highest CEC (100-150 meq/100g). In this study, volcanic soils have a mean CEC of $22.5 \mathrm{meq} / 100 \mathrm{~g}$ while the marine soils have a mean of $20.8 \mathrm{meq} / 100$ g. The loess soils have a slightly higher mean CEC at $28.0 \mathrm{meq} / 100 \mathrm{~g}$. All the sites in this study have very low CEC which correlates with the clay mineralogy since many sites are dominated by kaolinite and illite clay. The volcanic and marine sediments have slightly lower CEC than the loess/volcanic parent material. These low values also indicate that all soils in this study are old soils.

Table 98. Maximum CEC (meq/100g) for each soil pit by parent material.

\begin{tabular}{|c|c|c|c|c|c|c|}
\hline \multicolumn{2}{|c|}{ Volcanic } & \multicolumn{2}{|c|}{ Marine } & \multicolumn{3}{|c|}{ Loess } \\
\hline ECCC & 31.2 & ECRV & 20.7 & & ECFM & 18.6 \\
\hline WEJH & 15.4 & WEAB & 17.5 & & CWCC & 42.2 \\
\hline CWS & 23.5 & CWAB & 19.1 & & RH12 & 23.2 \\
\hline LEM & 22.6 & LEY & 26.1 & & Mean & 28.0 \\
\hline RHS & 20.2 & KWAC & 20.5 & & St. Dev. & 12.5 \\
\hline \multirow[t]{2}{*}{ KWN } & 21.7 & LEFH & 20.2 & \multirow{4}{*}{$\frac{\bar{\Xi}}{\overline{0}}$} & WETB & 38.1 \\
\hline & & KWFH & 21.5 & & RHJH1 & 22.3 \\
\hline Mean & 22.5 & Mean & 20.8 & & RHJH5 & 35.1 \\
\hline St. Dev. & 5.2 & St. Dev. & 2.7 & & KWM & 80.0 \\
\hline
\end{tabular}


With the exception of the Chehalem Corral Creek vineyard (loess soil) that has a CEC of $42.2 \mathrm{meq} / 100 \mathrm{~g}$, all other vineyards range from approximately 10 to $23 \mathrm{meq} / 100$ $\mathrm{g}$ (Figure 58). The marine sediment soils contain the most smectite clays, which generally means high CEC, but these data suggest that the method used was not satisfactory or that the percent of smectite clays in those soils are not high enough to influence the CEC. The higher CEC for the Corral Creek vineyard may be the result of the loess contribution of cations except for the fact that this vineyard is directly across the street from the Rex Hill Estate vineyard (loess soil) where the CEC is $23.2 \mathrm{meq} / 100 \mathrm{~g}$. This indicates an addition of cations to the soil as amendments by the vineyard manager resulting in higher CEC. This one vineyard increased the mean CEC for loess soils and, if taken out and regarded as an outlier, the loess soils would have similar values as the volcanic and marine soils in this study. One notable CEC value at $80.0 \mathrm{meq} / 100 \mathrm{~g}$ belongs to the Ken Wright Meredith Mitchell vineyard (old volcanic soil). This soil had visible calcium carbonate deposits in the parent material and a higher $\mathrm{pH}$. This, together with the higher concentration of $\mathrm{Ca}$, coincides with the higher $\mathrm{CEC}$ value.

\section{Clay Mineralogy}

Characterization of clay minerals as a product of weathering is important because they may best reflect the long-term effects of the chemical and leaching environment of the soil, and they influence many soil properties (Birkeland, 1999). The various clay minerals discussed here-in include illite, mica, chlorite, vermiculite, smectite, kaolinite, 
halloysite, and interlayered clays. These clay minerals could be the result of inheritance from the parent material, simple $\mathrm{K}$ ion exchange, or complex neo-formation and transformation from $\mathrm{Al}$ and silicon in the soil water solution (Birkeland, 1999).

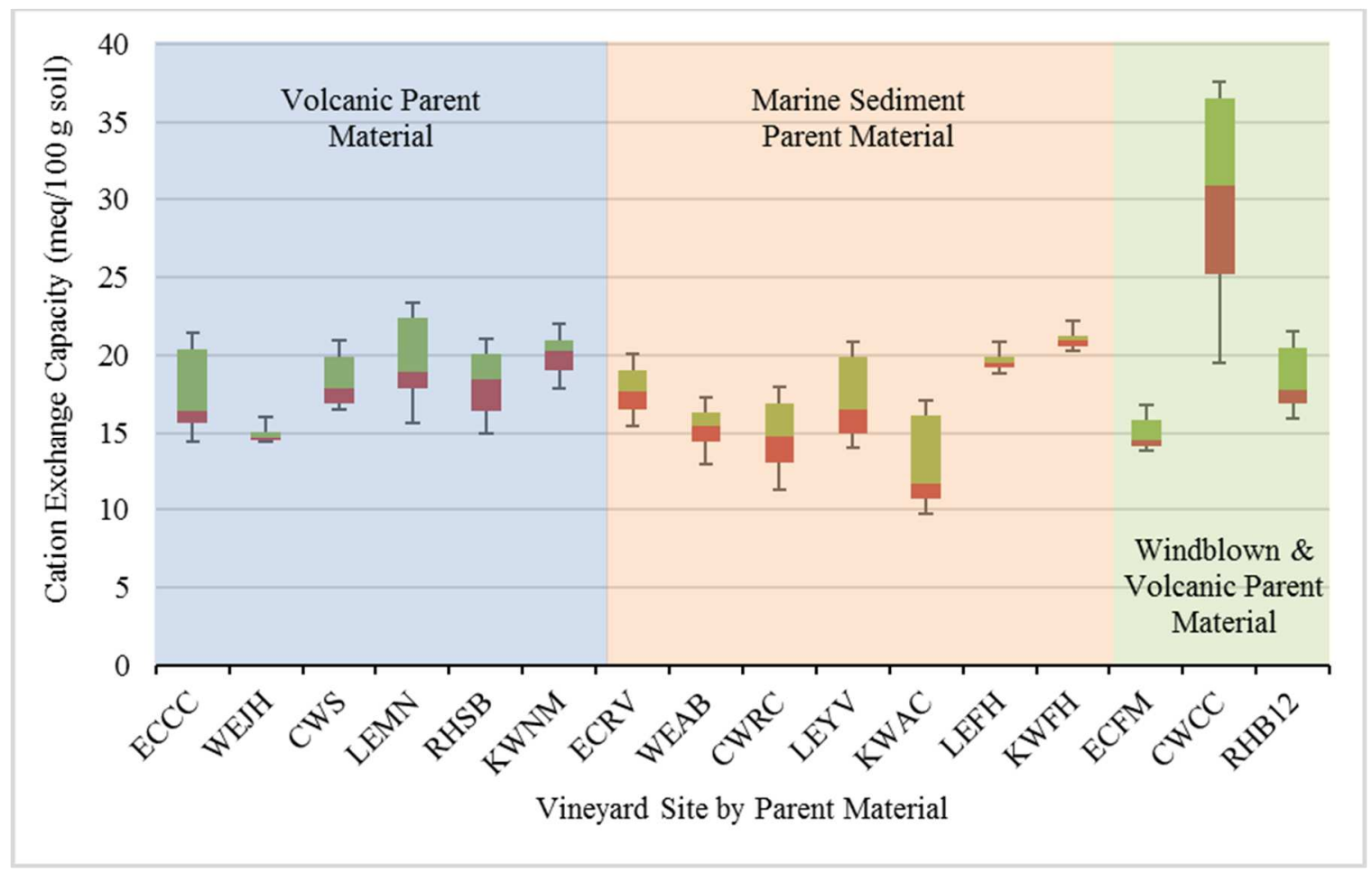

Figure 58. Cation Exchange Capacity (CEC) in meq/100 g soil for each vineyard sorted by parent material in a box and whisker plot.

The samples sent for analysis in this study were obtained during grain size analysis using the pipette method (Table 99). In this way, samples of the clay size fraction of the soil were collected, allowed to condense via evaporation, and then sent for analysis using x-ray diffraction of four different preparations that aid in differentiating between types of clay minerals. The selected sample for each soil profile was the horizon with the highest clay content based on the grain size analysis performed in this study. The 
suite of clay minerals determined in each soil sample can be used to infer details on age, development, and pedogenic history of the site (Birkeland, 1999). This study did not attempt to quantify clay minerals present in these soils because of the impracticality of methods that attempt to do so at any precision. Therefore, as commonly practiced, qualitative terms such as trace, minor, moderate, and abundant are used to differentiate between the relative abundance of certain clays in these samples.

Table 99. Clay mineralogy by parent material.

\begin{tabular}{c|ccc}
\hline \multicolumn{1}{c|}{ Parent Material } & Volcanic & Marine Sediment & Loess \\
\hline \hline Soil Series & Jory & Willakenzie \& Bellpine & Laurelwood \\
& Kaolinite & Smectite & Illite (All Sites) \\
Clays & Chlorite Intergrade & Kaolinite & Chlorite/Vermiculite \\
& Illite (Some sites) & Chlorite Intergrade & Kaolinite \\
Quartz Phase & Cristobalite & Trace Cristobalite & Cristobalite \\
Fe Phase & Goethite & Goethite & Moderate Goethite \\
Approximate Age & Old & Old & Mixed Ages \\
\hline
\end{tabular}

As background, clay minerals are mostly hydrous Al silicates. Table 100 is provided for reference to types of clays and other minerals associated with them (Klein and Dutrow, 2007). Clay minerals are classified as 1:1 or $2: 1$, in reference to their crystal structure, with some having interlayer cations. Kaolinite and halloysite are the most common 1:1layer clay minerals (Birkeland, 1999). Kaolinite clays show minimal shrinkage or swelling with change in water content. Water and solute molecules do not penetrate the interlayer spaces in kaolinite, therefore soils with kaolinite tend to have 
Table 100. Common clay minerals, chemical formulas, and notes concerning their formation in soils (Klein and Dutrow, 2007).

\begin{tabular}{|c|c|c|}
\hline Mineral & Chemical Formula & Notes \\
\hline Talc & $\mathrm{Mg}_{3} \mathrm{Si}_{4} \mathrm{O}_{10}(\mathrm{OH})_{2}$ & $\begin{array}{l}\text { Forms from alteration of } \mathrm{Mg} \\
\text { silicates (olivine, pyroxenes and } \\
\text { amphiboles) }\end{array}$ \\
\hline Feldspars & $\mathrm{KAlSi}_{3} \mathrm{O}_{8}$ or $\mathrm{NaAlSi}_{3} \mathrm{O}_{8}$ or $\mathrm{CaAl}_{2} \mathrm{Si}_{2} \mathrm{O}_{8}$ & $\begin{array}{l}\text { Al-silicate that weathers to } \\
\text { create kaolinite clay }\end{array}$ \\
\hline Muscovite & $\mathrm{KAl}_{2}\left(\mathrm{AlSi}_{3} \mathrm{O}_{10}\right)(\mathrm{F}, \mathrm{OH})_{2}$ & \\
\hline Biotite & $\mathrm{K}(\mathrm{Mg}, \mathrm{Fe}) \mathrm{Al}_{2}\left(\mathrm{AlSi}_{3} \mathrm{O}_{10}\right)(\mathrm{F}, \mathrm{OH})_{2}$ & \\
\hline Chlorite & $\begin{array}{l}\mathrm{Mg}_{3} \mathrm{Si}_{4} \mathrm{O}_{10}(\mathrm{OH})_{2} \cdot \mathrm{Mg}_{3}(\mathrm{OH})_{6} \text { or } \\
\left(\mathrm{Mg}, \mathrm{Fe}^{2+}, \mathrm{Fe}^{3+}, \mathrm{Al}\right)_{3}(\mathrm{Al}, \mathrm{Si})_{4} \mathrm{O}_{10}(\mathrm{OH})_{2} \cdot\left(\mathrm{Mg}, \mathrm{Fe}^{2+}, \mathrm{Fe}^{3+},\right. \\
\left.\mathrm{Al})_{3}(\mathrm{OH})_{6}\right)\end{array}$ & \\
\hline Illite & $\begin{array}{l}\left(\mathrm{K}, \mathrm{H}_{3} \mathrm{O}\right)(\mathrm{Al}, \mathrm{Mg}, \mathrm{Fe})_{2}(\mathrm{Si}, \mathrm{Al})_{4} \mathrm{O}_{10}\left[(\mathrm{OH})_{2},\left(\mathrm{H}_{2} \mathrm{O}\right)\right] \\
\text { Alkali-deficient mica near muscovite composition. }\end{array}$ & $\begin{array}{l}\text { Less substitution of } \mathrm{Al} \text { for } \mathrm{Si} \text {, } \\
\text { containing more water, } \mathrm{K} \text { partly } \\
\text { replaced by } \mathrm{Ca} \text { and } \mathrm{Mg} \text {. }\end{array}$ \\
\hline Vermiculite & $\mathrm{Mg}_{3}(\mathrm{Si}, \mathrm{Al})_{4} \mathrm{O}_{10}(\mathrm{OH})_{2} \cdot 4.5 \mathrm{H}_{2} \mathrm{O}[\mathrm{Mg}]_{0.35}$ & $\begin{array}{l}{[\mathrm{Mg}] \text { represents exchangeable }} \\
\text { ions in the structure }\end{array}$ \\
\hline Smectite & $\begin{array}{l}(\mathrm{Na}, \mathrm{Ca})_{0.3}(\mathrm{Al}, \mathrm{Mg})_{2} \mathrm{Si}_{4} \mathrm{O}_{10} \cdot \mathrm{nH}_{2} \mathrm{O} \text { (Montmorillonite) } \\
\text { Pyrophyllite }\left(\mathrm{Al}_{2} \mathrm{Si}_{4} \mathrm{O}_{10}(\mathrm{OH})_{2}\right) \text { with sheets of water } \\
\text { and exchangeable cations. }\end{array}$ & $\begin{array}{l}\text { Dioctahedral (gibbsite structure } \\
\text { - trivalent central cation) }\end{array}$ \\
\hline Kaolinite & $\begin{array}{l}\mathrm{Al}_{2} \mathrm{Si}_{2} \mathrm{O}_{5}(\mathrm{OH})_{4} \\
\mathrm{Si}_{2} \mathrm{O}_{5} \text { sheet bonded to a gibbsite sheet }\left(\mathrm{Al}(\mathrm{OH})_{3}\right)\end{array}$ & $\begin{array}{l}\text { Weathered or hydrothermal } \\
\text { alteration of Al-silicates } \\
\text { (feldspars) }\end{array}$ \\
\hline Halloysite & $\mathrm{Al}_{2} \mathrm{Si}_{2} \mathrm{O}_{5}(\mathrm{OH})_{4}$ or $\mathrm{Al}_{2} \mathrm{Si}_{2} \mathrm{O}_{5}(\mathrm{OH})_{4} \cdot 2 \mathrm{H}_{2} \mathrm{O}$ & $\begin{array}{l}\text { Kaolinite-group. Forms from } \\
\text { volcanic rocks. }\end{array}$ \\
\hline Goethite & $\alpha-\mathrm{FeO}(\mathrm{OH})$ & Oxides \\
\hline Hematite & $\alpha-\mathrm{Fe}_{2} \mathrm{O}_{3}$ & \\
\hline Brucite & $\mathrm{Mg}(\mathrm{OH})_{2}$ & \\
\hline Gibbsite & $\mathrm{Al}(\mathrm{OH})_{3}$ & \\
\hline
\end{tabular}


lower cation exchange capacity. Halloysite has the same structure as kaolinite, but two sheets of water molecules exist between crystal layers, and the clay shows expansion. Halloysite is mostly only found in weathered volcanic ash soils (Bednarz, 2002). According to Birkeland (1999), within the 2:1 clay minerals, differentiation is based on relative charge. Low charge (smectite), medium charge (vermiculite), high charge (mica and illite), and variable charge (chlorite) of the clay minerals in the soils will affect cation exchange capacity and soil chemistry as discussed in the previous section.

Many researchers (Jackson, 1964; Birkeland, 1999; Wilson, 1999) have formed a theory on the development of clay minerals over time due to different environments within the soil. These pathways of formation allow us to estimate relative ages of the soil based on clay mineral assemblage (Figure 59). Soils in the early stages of development will contain primary mica minerals, illite, and chlorite. The intergrade process (interlayering of illite, chlorite, vermiculite, or smectite) indicates more time has passed. Smectite will develop when the soils are wetter. With enough time, kaolinite forms and $\mathrm{Fe}$ and $\mathrm{Al}$ accumulates (due to insolubility) and goethite and gibbsite will accumulate in the soil. This general theory of soil development based on clay mineralogy is used in this study to discuss the age of these vineyard soils.

The existence of mica in a soil that formed on volcanic material indicates an eolian component, since the mica is most likely not from the parent material especially if 


\begin{tabular}{|c|c|c|c|c|c|c|c|c|}
\hline \multirow[t]{2}{*}{$\begin{array}{c}\text { Biotite } \\
\text { Muscovite } \\
\text { Illite }\end{array}$} & $\rightarrow$ & Vermiculite & $\rightarrow$ & $\begin{array}{l}\text { Montmorillonite } \\
\text { (Smectite) }\end{array}$ & $\leftrightarrow$ & $\begin{array}{l}\text { Pedogenic } \\
\text { intergrades }\end{array}$ & $\downarrow$ & \\
\hline & & & $\uparrow$ & $\uparrow$ & & & $\begin{array}{l}\text { Kaolinite } \\
\text { Halloysite }\end{array}$ & Gibbsite \\
\hline $\begin{array}{c}\text { Chlorite } \\
\text { (Mg, Fe, } \\
\text { Al) }\end{array}$ & $\rightarrow$ & $\begin{array}{l}\text { Secondary } \\
\text { Chlorite/ } \\
\text { Vermiculite }\end{array}$ & $\rightarrow$ & $\begin{array}{l}\text { Pedogenic } \\
\text { intergrades }\end{array}$ & $\rightarrow$ & Al-Chlorite & $\uparrow$ & \\
\hline
\end{tabular}

Figure 59. Pathways for the formation of soil clay minerals (adapted from Wilson, 1999 and Birkeland, 1999 after Jackson, 1964).

it is basalt. Similar studies on Hawaiian soils have also shown the presence of mica from eolian sources (Wilson, 1999). Micaceous minerals found in the clay fraction must either be inherited from the parent material or be added by some process, since there is very little evidence that mica forms pedogenically (and only in special circumstances) (Wilson, 1999). Illite clay is thin micromica with less $\mathrm{K}$ and less charge than the micromica found in soils. Therefore, illite is thought to have evolved from the weathering of mica minerals, losing $\mathrm{K}$ and layer charge because of the physical process of particle microdivision (Wilson, 1999). Vermiculite also forms from the weathering of mica minerals and therefore should be present where there is illite.

Chlorite is a group of minerals within the phyllosilicate group that consists of 2:1 sheets of talc (or pyrophyllite) separated by brucite- or gibbsite-like sheet. Al substitutes commonly for $\mathrm{Si}$ in the tetrahedral sites, and members of the chlorite group differ based on the amount of substitution of $\mathrm{Al}$ for $\mathrm{Si}$ and for $\mathrm{Mg}, \mathrm{Fe}$, or $\mathrm{Al}$ in the octahedral sites of both talc and brucite-like sheets (Klein and Dutrow, 2007). Illite is commonly associated 
with mica minerals. As illite weathers, the charge decreases as $\mathrm{K}$ is replaced by $\mathrm{Ca}$ and Mg in the interlayers (White, 2003). When the structure is hydrated, the chlorite becomes vermiculite by replacing $\mathrm{Ca}$ and $\mathrm{Mg}$ in the interlayers with $\mathrm{Al}$. When $\mathrm{Al}$ and other cations fill sites, the resulting mineral is somewhere in between clay and mica. When $\mathrm{K}$ rich, these clays are commonly referred to as illite (Wilson, 1999). When the pyrophyllite sheets are hydrated with water containing exchangeable cations, smectite (or montmorillonite) is formed.

Montmorillonite is the $\mathrm{Mg}$ variety of smectite with both $\mathrm{Al}$ and $\mathrm{Mg}$ in the octahedral sheet (Birkeland, 1999). These clays are expanding-lattice clays and result in visible shrinking and cracking when dry and swelling when wet (White, 2003). Some illite is mica intermixed with layers of smectite, vermiculite, and chlorite (Birkeland, 1999). Common interlayered clays are illite/smectite, chlorite/smectite, chlorite/vermiculite, and mica/vermiculite (Birkeland, 1999).

Fe oxides in the soil accumulate when highly weathered, indicating time and moisture available to remove other cations, leaving insoluble $\mathrm{Fe}$ and $\mathrm{Al}$ to migrate down through the profile and accumulate. This occurs in soils that form on volcanic parent material, like the soils in this study, over tens of thousands of years. Basalt rocks provide $\mathrm{Fe}, \mathrm{Al}$, and $\mathrm{Mn}$ for oxidation in soils that then become redder in color. With enough moisture, Fe will transform into goethite $(\mathrm{FeO}(\mathrm{OH}))$, which is the most common and stable Fe oxide in the soil. Over time and under dry conditions, the goethite will 
transform to hematite $\left(\mathrm{Fe}_{2} \mathrm{O}_{3}\right)$, indicating highly weathered soils (White, 2003). The principal $\mathrm{Al}$ oxide in soil is gibbsite $\left(\mathrm{Al}(\mathrm{OH})_{3}\right.$ which can be found in the interlayers of chlorite, vermiculite, and smectite and as coatings on these clay minerals (White, 2003). Black Mn dioxide coatings in the soil are common in soils that experience both wetting and drying (anaerobic and aerobic) conditions. These coatings on the surface have a tendency to attract $\mathrm{Co}$ and $\mathrm{Pb}$ (White, 2003).

Cristobalite, $\mathrm{SiO}_{2}$, is present in many siliceous volcanic rocks as a lining in cavities and as part of the fine-grained groundmass. Many times, cristobalite forms from the weathering of obsidian and glass in andic parent material and is associated with smectite clays (Wada, 1987; Van Rast et al., 2008). According to research on clay minerals in volcanic soils in Mexico, cristobalite in the soil was enriched in the clay fraction in mottles and were interpreted to be from the transformation of halloysite. This 1:1 clay mineral undergoes transformation into opal, then in turn is transformed into cristobalite (Elsass et al., 2000). Other research indicates that cristobalite can form from high or low temperatures or in place. High-temperature cristobalite is volcanic in origin (Mizota et al., 1987). This study suggests that the cristobalite accumulated in these soils as the result of precipitation of silica during prolonged dry summer conditions and is not necessarily from the parent material unless Cascadian ash deposits can be identified (Mizota et al., 1987). 
The occurrence of interlayered clays may be the result of $\mathrm{Al}$ weathered from feldspars in the parent material in acidic conditions. The soil in this study is mostly within the 4.0 to $5.8 \mathrm{pH}$ range, which has been shown as a favored $\mathrm{pH}$ for the stability of Al-hydroxy interlayers. My sites with higher amounts of $\mathrm{Al}$ (data in soil chemistry) may be associated with certain $\mathrm{pH}$ and the presence of Al-hydroxy-interlayered clays. These clays are common and are typical in highly weathered soils. Therefore, the presence of interlayered clays in the volcanic soils in this study support the idea that these soils are the oldest. Also, the application of fertilizers at these sites before they became vineyards have contributed to the formation of interlayers with the addition of K (Wilson, 1999).

The soils in this study are separated by parent material to discuss trends in the clay mineralogy for these vineyard sites (Table 101). Soils formed on marine sediments have different trends in the clay mineralogy than the volcanic and loess soils. Trace to moderate amounts of illite are found in these samples. This suggests a mica component that is weathering to illite in the marine sediments. There are trace amounts or more of chlorite in all soils that formed on marine sediments. Vermiculite/chlorite interlayers are moderately pronounced in the Aliette Vineyard, but vermiculite exists in trace or minor amounts in the others. Smectite clays are found in six of seven soils excluding Aliette Vineyard. Kaolinite is the most common clay in moderate amounts in the soils formed on marine sediment parent material. A minor amount of halloysite is present in a few of these marine sediment soils as well. Minor goethite is present in all soils. No sites other 
than Aliette Vineyard and Abbott Claim have gibbsite present. Ridgecrest Vineyard is the only site that has some hematite. The development of goethite in the marine sediment soils is less pronounced than in the volcanic soils.

The volcanic soils should not contain illite, but four of six sites contain trace to moderate amounts of illite clay. This suggests a mica component in these few volcanic soils that would have a regressive influence on the soil development. Soils with illite present must have a loess component if the parent material for the soil is volcanic basalt which does not contain mica. Trace amounts to abundant (Elk Cove Clay Court) chlorite intergrades are also present in the soils from volcanic parent material. Vermiculite was only present in the Elk Cove Clay Court soils. Trace amounts of smectite are found in two volcanic soils and two others have minor to moderate smectite present. It is most common to have moderate amounts of kaolinite clay with trace to moderate amounts of halloysite in the soils on volcanic parent material. Goethite is the main Fe phase in all volcanic soils; some also include gibbsite and hematite. Clay Court, Stoller, and Jory Hills vineyards all show minor to moderate amounts of cristobalite in the clay fraction as well. These soils also have moderate kaolinite and halloysite present, which suggests older soils, while illite suggests a younger soil. Therefore, the Stoller, Clay Court, Mia Block, and Jory Hills Vineyards all have some loess material that is causing to the presence of illite and a more mixed-age and development signature. 
The sites that were meant to be my only loess/volcanic parent material locations, having many similarities to the volcanic soils, suggest that some of the volcanic soils have a loess component I was not expecting. The loess/volcanic sites contain abundant illite clay and moderate chlorite intergrade and mixed-layer vermiculite and smectite clays. Mica is present in the clay sized fraction of these soils, also suggesting a more recent eolian input that has not weathered yet. Minor to moderate amounts of kaolinite and trace amounts of halloysite are also common in these soils suggesting an older soil while the illite suggests a younger soil. Therefore, these soils show mixed stages of development, similar to the four soils on volcanic parent material.

My youngest sites, according to the BW color index and other physical properties, include the Terres Basses (Missoula Flood sediment parent material) and the Jacob-Hart Vineyards (ancient landslide deposits). I assume that these sites are approximately less than 15,000 years old, according to the timing of the Missoula Floods (Allen et al., 2009). Terres Basses contains abundant smectite clay, minor vermiculite clays, and only trace amounts of kaolinite and goethite. This soil developed since the Missoula Flood sediments were deposited and the high clay content and poor drainage, is attributed to the shale parent material. The Jacob-Hart Vineyard soils contain minor to moderate amounts of smectite clay with trace amounts of goethite, vermiculite, and kaolinite. These assemblages suggest a geologic history that includes kaolinite that developed on an older 
Table 101. Clay mineral interpretation from x-ray diffraction. Key: - none present, o trace amounts, + minor amounts, ++ moderate amounts, +++ abundant amounts, bold grayscale $=$ interlayers.

\begin{tabular}{|c|c|c|c|c|c|c|c|c|c|c|c|}
\hline Vineyard & Parent Material & Mica & Illite & Chlorite & Vermiculite & Smectite & Kaolinite & Halloysite & Cristobalite & Goethite & Gibbsite \\
\hline ECRV & Marine Sediments & o & + & ++ & - & ++ & + & + & o & + & - \\
\hline WEAB & Marine Sediments & o & o & ++ & ++ & - & ++ & - & o & + & + \\
\hline CWR & Marine Sediments & ++ & ++ & + & o & + & ++ & + & + & + & - \\
\hline LEY & Marine Sediments & - & o & o & - & o & ++ & o & - & ++ & - \\
\hline KWAC & Marine Sediments & - & o & o & - & o & ++ & - & - & + & + \\
\hline LEFH & Marine Sediments & o & o & o & + & + & + & - & + & + & - \\
\hline KWFH & Marine Sediments & o & o & o & + & + & + & - & + & + & - \\
\hline ECCC & Volcanic & + & ++ & +++ & ++ & ++ & + & + & + & ++ & - \\
\hline WEJH & Volcanic & - & + & + & - & - & ++ & + & + & +++ & + \\
\hline CWS & Volcanic & ++ & ++ & + & - & + & ++ & ++ & ++ & ++ & - \\
\hline LEM & Volcanic & - & o & o & - & o & ++ & o & o & ++ & + \\
\hline RHS & Volcanic & - & - & o & - & o & ++ & o & o & ++ & + \\
\hline KWN & Volcanic & - & - & ++ & - & - & ++ & + & + & ++ & - \\
\hline ECFM & Loess & + & ++ & ++ & ++ & ++ & + & + & + & + & - \\
\hline CWCC & Loess & ++ & +++ & + & + & - & ++ & o & + & o & + \\
\hline RH12 & Loess & ++ & +++ & ++ & ++ & + & + & o & o & - & - \\
\hline WETB & Missoula Floods & o & - & - & + & +++ & o & - & - & - & - \\
\hline RHJH1 & Landslide & - & - & - & o & ++ & o & - & o & o & - \\
\hline RHJH5 & Landslide & - & - & - & o & ++ & o & - & o & o & - \\
\hline KWM & Ancient Volcanic & - & - & - & + & + & o & o & o & o & - \\
\hline
\end{tabular}


geomorphic surface of basalt bedrock before being disrupted with an event that supplied new material, like the floods or a landslide.

The final soil, on ancient volcanic bedrock parent material, is from the Meredith Mitchell Vineyard. This soil contains minor amounts of vermiculite, smectite and trace amounts of kaolinite, mixed interlayers, goethite, and halloysite. This is a soil with no loess component and moderate weathering and development. It is located in the Coast Range on older volcanic bedrock, possibly diabase or Tillamook basalts, and the clay minerals present suggest an older soil similar to the volcanic soils previously discussed.

The occurrence of smectite in the soils formed on marine sedimentary parent material is most likely the result of inheritance from weathering of these silts, sands, and shale. The Terres Basses Vineyard soil contains the most prominent amount of smectite clays, suggesting the presence of smectite in the parent material and from the formation from vermiculite in this poorly drained location from transformation or neo-formation. As illite and mica decrease in the sample, the vermiculite content increases (Figure 59). There is general acceptance that vermiculite forms from the weathering of mica by the release of K or during the oxidation of Fe (Wilson, 1999). The intergrades (interstratified) represent an intermediate stage in transformation and weathering of mica, chlorite, smectite, and vermiculite and are not expected to be found in highly weathered soils, but soils of intermediate or young age. 
According to prior studies by Reed Glasmann of OSU, the main difference between soils on basalt and on tuffaceous sandstone is that the clay-sized fraction over the sandstone contains quartz and that over the basalt does not. On both rock types, the clay minerals consist of halloysite and gibbsite, and the red to yellow Fe oxide coloring agents consist of hematite and goethite (Moore, 2002). Considering the soil series mentioned earlier that are associated with the different types of parent material in this study, the Jory and Laurelwood soils both form on volcanic bedrock of basalt and the Willakenzie soils form on marine sediments of sandstone and siltstone. In this study, the clay mineralogy associated with the basalt derived soil types consists mostly of kaolinite and chlorite interlayers with the presence of halloysite and goethite in the more weathered zones (Eggleton et al., 1987).

According to Nelson (2011), feldspar will commonly weather to kaolinite and therefore the soils with volcanic basalt parent material have more feldspars than marine sediment parent material. The Jory will have the highest goethite percentage of the three soils because it is the oldest and will have the highest percentage of available $\mathrm{Fe}$ available (Nelson, 2011). The Willakenzie and Bellpine soils will have similar amounts of kaolinite, chlorite, and goethite because of age, but will have more illite due to presence of mica in the parent material. The Laurelwood soils, and other volcanic soils with an eolian contribution of loess, will have a mixture of clays including kaolinite and goethite but substantial amounts of illite and chlorite/vermiculite. 


\section{Soil Chemistry}

Based on parent material the mean maximum values for most elements tested in this study, only a few had distinguishing differences. Concerning macronutrients, $\mathrm{P}$ values are higher in both volcanic and loess soils than marine sediment soils (Table 102). $\mathrm{K}$ is highest in loess soils and volcanic and marine sediment soils had similar values. All parent materials had similar values for $\mathrm{Ca}$. $\mathrm{Mg}$ was highest in loess soils, the marine sediment soils were the most variable (with the outlier value from Lange Estate Yamhill Vineyard of $4670 \mathrm{ppm}$ removed), and volcanic soils had the lowest concentration of $\mathrm{Mg}$. $\mathrm{S}$ was highest in volcanic soils while loess and marine sediments were similar. $\mathrm{Cl}$ was detected in marine sediment soil at higher concentrations than the few volcanic soils.

The composition of the Grande Ronde basalt, the bedrock and parent material for both the volcanic and loess/volcanic soils, has been widely studied. A summary of the chemical make-up of the Grande Ronde basalt flow indicates that Mn, P, titanium, K, Na, $\mathrm{Ca}, \mathrm{Mg}, \mathrm{Fe}$, and $\mathrm{Al}$ are most abundant in these rocks (Mangan et al., 1986; Swanson et al., 1989). Most of the CRB flows are tholeiitic basalt: High $\mathrm{MgO}$, relatively rich in silica, and poor in $\mathrm{Na}$. Average $\mathrm{SiO}_{2}$ is $53.84 \%, \mathrm{Al}_{2} \mathrm{O}_{3}$ is $14.37 \%, \mathrm{FeO}$ is $11.37 \%, \mathrm{CaO}$ is $8.97 \%$, and $\mathrm{MgO}$ is $5.25 \%$. Other elements include $\mathrm{Na}_{2} \mathrm{O}$ at $2.92 \%, \mathrm{~K}_{2} \mathrm{O}$ at $1.10 \%, \mathrm{TiO}_{2}$ at $1.75 \%, \mathrm{P}_{2} \mathrm{O}_{5}$ at $0.23 \%$, and $\mathrm{MnO}$ at $0.19 \%$ (Mangan et al., 1986; Swanson et al., 1989). The marine sediments in the Coast Range are mostly composed of quartz sand and muscovite mica, according to the grain size analysis in this study. These sandstones also 
contain high amounts of silt in some cases. Because of the marine depositional environment, higher amounts of $\mathrm{Na}, \mathrm{Ca}$, and $\mathrm{Mg}$ could be expected in this parent material.

Table 102. Maximum macronutrient values for vineyard soils separated by parent material (* Indicates value after removing outlier value of $4670 \mathrm{ppm}$ from the Lange Estate Yamhill Vineyard).

\begin{tabular}{ccccc}
\hline Element (ppm) & Volcanic & Marine & Loess/Volcanic & Trend \\
\hline $\mathrm{P}$ & $\mathbf{1 8 7 0} \pm \mathbf{3 4 1}$ & $642 \pm 195$ & $\mathbf{1 5 3 0} \pm \mathbf{2 1 1}$ & Volcanic \& Loess Highest \\
$\mathrm{K}$ & $926 \pm 472$ & $1040 \pm 373$ & $\mathbf{1 5 2 0} \pm \mathbf{7 5}$ & Loess Highest \\
$\mathrm{Ca}$ & $1660 \pm 716$ & $2070 \pm 526$ & $1780 \pm 284$ & All Similar \\
$\mathrm{Mg}$ & $1460 \pm 435$ & $1940 \pm 677^{*}$ & $\mathbf{3 1 4 0} \pm \mathbf{2 2 7}$ & Loess Highest \\
$\mathrm{S}$ & $\mathbf{2 4 5} \pm \mathbf{4 6 . 0}$ & $168 \pm 35.9$ & $172 \pm 22.7$ & Volcanic Highest \\
$\mathrm{Cl}$ & $17.7 \pm 0.07$ & $\mathbf{2 4 . 1} \pm \mathbf{1 1 . 3}$ & $\mathrm{ND}$ & Marine Highest \\
\hline
\end{tabular}

The parent material has little influence on many of the micronutrients tested and many values are similar (Table 103). Volcanic soils have the highest concentrations of $\mathrm{Fe}, \mathrm{Co}$, and $\mathrm{Mn}$. Al concentrations were very similar between the different parent materials. $\mathrm{Cu}$ values were highly variable, especially in the marine sediment soils. This is most likely due to the possible addition of $\mathrm{Cu}$ in practice as a fungicide, even in organic vineyards. Mo was not detected in loess soils and at very small concentrations for the others. Na concentrations were all similar when the outlier value of 3330 ppm for Ken Wright Freedom Hill Vineyard was removed. This high value of $\mathrm{Na}$ in the Freedom Hill Vineyard is most likely due to the Coast Range sediments being from a marine environment. 
Table 103. Maximum micronutrient values for vineyard soils separated by parent material (* Indicates value after removing Na outlier value of $3330 \mathrm{ppm}$ from Ken Wright Freedom Hill Vineyard).

\begin{tabular}{ccccc}
\hline Element $(\mathbf{p p m})$ & Volcanic & Marine & Loess/Volcanic & Trend \\
\hline \hline $\mathrm{Fe}$ & $\mathbf{5 8 9 0 0} \pm \mathbf{6 7 7 0}$ & $41500 \pm 10300$ & $38000 \pm 2820$ & Volcanic Highest \\
$\mathrm{Al}$ & $19500 \pm 1880$ & $20300 \pm 10800$ & $24300 \pm 10800$ & All Similar \\
$\mathrm{Co}$ & $\mathbf{3 5 . 6} \pm \mathbf{1 3 . 9}$ & $16.1 \pm 8.04$ & $20.7 \pm 1.40$ & Volcanic Highest \\
$\mathrm{Cu}$ & $22.4 \pm 5.53$ & $31.0 \pm 36.9$ & $20.3 \pm 7.40$ & All Similar \\
$\mathrm{Mn}$ & $\mathbf{2 5 3 0} \pm \mathbf{4 6 5}$ & $821 \pm 330$ & $1357 \pm 162$ & Volcanic Highest \\
$\mathrm{Mo}$ & $0.652 \pm 0.056$ & 0.678 & $\mathrm{ND}$ & All Similar \\
$\mathrm{Na}$ & $203 \pm 11.0$ & $205 \pm 43^{*}$ & $234 \pm 41.8$ & All Similar \\
$\mathrm{Ni}$ & $7.55 \pm 1.05$ & $11.0 \pm 7.14$ & $18.7 \pm 14.4$ & All Similar \\
$\mathrm{Zn}$ & $63.8 \pm 24.0$ & $49.8 \pm 27.3$ & $62.0 \pm 4.65$ & All Similar \\
\hline
\end{tabular}

Few trace elements can be used to distinguish the different vineyard soil parent material (Table 104). As is lowest in the volcanic soils and both marine sediment and loess soils have similar values. This makes sense since As in Oregon is attributed to tuffs and marine sediments from the Coast Range and not to basalts (Ricker, 2013). The As in the loess soils seems to be coming from the loess itself and not the volcanic bedrock. The loess was introduced to the Willamette Valley via multiple floods that brought sediment from eastern Washington (Allen et al., 2009). This sediment is more similar to the marine sediments (sandstones and siltstones) from the Coast Range than the volcanic bedrock. $\mathrm{Sr}$ concentration is also higher in the marine and loess soils than volcanic soils. V is highest in the volcanic soils with loess/volcanic soils second highest, most likely because the bedrock of the loess soils is the same volcanic material. Ba is lowest in the marine soils after an outlier of 669 ppm from Chehalem Coral Creek Vineyard was removed. All the 
rest of the trace elements are similar, despite parent material differences. $\mathrm{A} \mathrm{Pb}$ value of 47.1 ppm was removed as an outlier from the Rex Hill Estate Vineyard Block 12, making all parent materials have similar values.

Table 104. Maximum trace element values for vineyard soils separated by parent material (* Indicates value after removing outlier value of $669 \mathrm{ppm}$ Ba from Chehalem Coral Creek, $47.1 \mathrm{ppm}$ Pb from Rex Hill Estate, and 452 ppm Sr from Ken Wright Freedom Hill).

\begin{tabular}{|c|c|c|c|c|}
\hline Element (ppm) & Volcanic & Marine & Loess/Volcanic & Trend \\
\hline As & $2.15 \pm 0.56$ & $6.24 \pm 3.25$ & $6.24 \pm 5.16$ & $\begin{array}{c}\text { Marine \& Loess } \\
\text { Highest }\end{array}$ \\
\hline $\mathrm{Ba}$ & $308 \pm 0.22$ & $166 \pm 85.6$ & $245 \pm 1.00 *$ & $\begin{array}{c}\text { Volcanic \& Loess } \\
\text { Highest }\end{array}$ \\
\hline $\mathrm{Be}$ & $1.02 \pm 0.27$ & $0.856 \pm 0.181$ & $0.941 \pm 0.101$ & All Similar \\
\hline $\mathrm{Cd}$ & $0.456 \pm 0.196$ & $0.300 \pm .279$ & $0.421 \pm .278$ & All Similar \\
\hline $\mathrm{Cr}$ & $25.3 \pm 5.11$ & $22.2 \pm 3.41$ & $21.7 \pm 2.05$ & All Similar \\
\hline $\mathrm{Hg}$ & 0.0448 & $0.0462 \pm 0.007$ & 0.0426 & All Similar \\
\hline $\mathrm{Pb}$ & $12.3 \pm 1.57$ & $10.6 \pm 2.86$ & $10.8 \pm 2.37^{*}$ & All Similar \\
\hline $\mathrm{Se}$ & $0.715 \pm .136$ & $0.595 \pm 0.078$ & 0.686 & All Similar \\
\hline $\mathrm{Sr}$ & $17.4 \pm 5.48$ & $29.1 \pm 14^{*}$ & $27.5 \pm 7.03$ & $\begin{array}{c}\text { Marine \& Loess } \\
\text { Highest }\end{array}$ \\
\hline $\mathrm{V}$ & $175 \pm 29.3$ & $82.2 \pm 39.3$ & $123 \pm 10.2$ & Volcanic Highest \\
\hline
\end{tabular}

\section{Grape Juice Chemistry}

All 24 elements (similar to the soil samples) were analyzed for in the grape juice from grapes collected adjacent to the soil pits. K, $\mathrm{Na}$, and $\mathrm{Sr}$ are the only elements found in all 20 grape juice samples and $\mathrm{P}$ is detected in 15 of the 20 sites (Table 105). The majority of the elements analyzed were found to be non-detectable using just the grape juice. This suggests that much of the chemistry that influences the end flavor of the wine comes from the contact the juice has with the skin, seeds, and stems and not from the 
juice alone. Another possibility is that the methodology diluted the grape juice samples to the point that the elements were undetectable. It is also possible that wine flavor is not influenced by the elements taken up by the grapes since they occur in such low concentrations. Much more analysis will be done utilizing the grape samples that I have from these sites, but at this time I can present a few things including interesting discoveries previously unknown.

The average $\mathrm{K}$ concentrations were highest in loess soils, but volcanic and marine sediment soils had the highest maximum values (Table 106). $\mathrm{K}$ is the most mobile nutrient in the make-up of winegrapes, necessary for cell osmoregulation, turgor, and growth of the grape (White, 2003). $\mathrm{K}$ is concentrated in the berry skins until veraison (color change) when it then becomes concentrated in the pulp where fifty percent or more of the vine $\mathrm{K}$ is redistributed by harvest time (White, 2003). Soil $\mathrm{K}$ is the most important source for K found in the grapes (Boulton, 1980). Clay mineralogy has a great effect on the $\mathrm{K}$ availability in the soils. Kaolinite clays have the least sites for fixed $\mathrm{K}$ while vermiculitic clays have exchangeable $\mathrm{K}$ on the surfaces and edges like kaolinite but also has slowly released $\mathrm{K}$ available between clay sheets. Therefore, the loess soils have more vermiculite and smectite clays and also have slightly higher $\mathrm{K}$ available for uptake by the vine and incorporation into the grapes. $\mathrm{K}$ is also higher in soils formed on rocks containing mica, which is visible in the loess soils in this study (White, 2003). 
Table 105. Elemental concentration (ppm) for grape juice obtained from vines adjacent to soil pits in this study.

\begin{tabular}{|c|c|c|c|c|c|c|c|c|c|c|c|c|c|}
\hline Vineyard & $\mathbf{K}$ & Rank & $\mathrm{Na}$ & Rank & $\mathrm{Sr}$ & Rank & $\mathbf{P}$ & Rank & Mg & Mn & $\mathrm{Ca}$ & $\mathrm{Cu}$ & $\mathbf{Z n}$ \\
\hline ECCC & 530 & 20 & 161 & 3 & 0.973 & 6 & ND & & ND & ND & ND & ND & ND \\
\hline ECRV & 1240 & 12 & 144 & 12 & 0.852 & 7 & 361 & 1 & ND & ND & ND & ND & ND \\
\hline ECFM & 1340 & 11 & 145 & 11 & 1.02 & 5 & 232 & 14 & ND & 2.04 & ND & ND & ND \\
\hline WEJH & 1150 & 15 & 141 & 15 & 0.506 & 18 & 275 & 7 & ND & 2.14 & ND & ND & ND \\
\hline WEAB & 1680 & 5 & 158 & 6 & 0.716 & 11 & 267 & 9 & ND & ND & ND & ND & ND \\
\hline WETB & 1940 & 1 & 159 & 4 & 0.739 & 10 & 324 & 4 & ND & ND & ND & ND & ND \\
\hline CWS & 1400 & 9 & 153 & 9 & 0.633 & 17 & 213 & 15 & ND & 4.56 & ND & ND & ND \\
\hline CWR & 851 & 18 & 155 & 8 & 1.1 & 4 & ND & & ND & ND & ND & ND & ND \\
\hline CWCC & 1530 & 7 & 159 & 5 & 0.711 & 12 & 303 & 5 & ND & ND & ND & ND & ND \\
\hline LEM & 1730 & 4 & 162 & 2 & 0.711 & 13 & 248 & 12 & ND & ND & ND & ND & ND \\
\hline LEY & 1220 & 13 & 141 & 14 & 1.41 & 1 & 243 & 13 & 111 & ND & 115 & ND & ND \\
\hline LEFH & 1380 & 10 & 150 & 10 & 0.697 & 14 & 266 & 10 & ND & ND & ND & ND & ND \\
\hline RHS & 747 & 19 & 142 & 13 & 0.645 & 16 & ND & & ND & 2.02 & ND & ND & ND \\
\hline RH12 & 1600 & 6 & 139 & 17 & 0.696 & 15 & 361 & 2 & ND & ND & ND & ND & ND \\
\hline RHJH1 & 1880 & 2 & 140 & 16 & 1.12 & 3 & 297 & 6 & ND & ND & ND & 2.41 & ND \\
\hline RHJH5 & 1500 & 8 & 131 & 19 & 0.447 & 19 & 272 & 8 & ND & ND & ND & 4.19 & 2.2 \\
\hline KWN & 1070 & 16 & 138 & 18 & 1.14 & 2 & 257 & 11 & ND & ND & 102 & ND & ND \\
\hline KWAC & 1730 & 3 & 166 & 1 & 0.844 & 8 & ND & & ND & ND & ND & ND & ND \\
\hline KWFH & 1160 & 14 & 126 & 20 & 0.816 & 9 & ND & & ND & ND & ND & ND & ND \\
\hline KWM & 883 & 17 & 156 & 7 & 0.332 & 20 & 328 & 3 & $\mathrm{ND}$ & $\mathrm{ND}$ & $\mathrm{ND}$ & $\mathrm{ND}$ & $\mathrm{ND}$ \\
\hline Mean & 1328 & & 148 & & 0.805 & & 283 & & 111 & 2.69 & 109 & 3.30 & 2.2 \\
\hline$S D$ & 386 & & 11.1 & & 0.261 & & 44.9 & & $N D$ & 1.25 & 9.19 & 1.26 & $N D$ \\
\hline
\end{tabular}


Table 106. Mean and standard deviation values (with maximum in parentheses) for elemental concentrations in grape juice separated by parent material.

\begin{tabular}{|c|c|c|c|c|}
\hline Element (ppm) & Volcanic & Marine & Loess & Trend \\
\hline K & $\begin{array}{c}1110 \pm 434 \\
(1730)\end{array}$ & $\begin{array}{l}1320 \pm 306 \\
(1730)\end{array}$ & $\begin{array}{l}1490 \pm 135 \\
\quad(1600)\end{array}$ & All Similar \\
\hline $\mathrm{Na}$ & $\begin{array}{l}150 \pm 10.6 \\
\quad(162)\end{array}$ & $\begin{array}{l}149 \pm 13.1 \\
\quad(166)\end{array}$ & $\begin{array}{l}148 \pm 10.3 \\
\quad(159)\end{array}$ & All Similar \\
\hline $\mathrm{Sr}$ & $\begin{array}{c}0.768 \pm 0.239 \\
(1.14)\end{array}$ & $\begin{array}{c}0.919 \pm 0.253 \\
(1.41)\end{array}$ & $\begin{array}{c}0.809 \pm 0.183 \\
(1.02)\end{array}$ & Marine Highest \\
\hline $\mathrm{P}$ & $\begin{array}{l}248 \pm 26 \\
(275)\end{array}$ & $\begin{array}{l}284 \pm 52.4 \\
\quad(361)\end{array}$ & $\begin{array}{l}299 \pm 64.6 \\
\quad(361)\end{array}$ & All Similar \\
\hline $\mathrm{Mg}$ & ND & $\begin{array}{c}111 \pm 0 \\
(111)\end{array}$ & ND & $\begin{array}{l}\text { Only Marine } \\
\text { Detected }\end{array}$ \\
\hline $\mathrm{Mn}$ & $\begin{array}{l}2.91 \pm 1.43 \\
\quad(4.56)\end{array}$ & ND & $\begin{array}{c}2.04 \pm 0 \\
(2.04)\end{array}$ & $\begin{array}{c}\text { Only Volcanic and } \\
\text { Loess }\end{array}$ \\
\hline $\mathrm{Ca}$ & $\begin{array}{c}102 \pm 0 \\
(102)\end{array}$ & $\begin{array}{l}115 \pm 0 \\
(115)\end{array}$ & ND & $\begin{array}{l}\text { Very Few } \\
\text { Detected }\end{array}$ \\
\hline
\end{tabular}

The Sr levels were highest in the marine soils and in the grapes from marine soils. Though the averages are all similar, the maximum $\mathrm{Sr}$ value is in the marine soils. This element may be the only useful element when distinguishing juice from the various parent material in this study. $\mathrm{Sr}$ is not utilized by the grapevine in any particular manner, but is taken up by the vine from the soil (White, 2009). This element has been used to determine provenance in wines in Portugal (Almeida and Vasconcelos, 2001). In future studies, Sr isotopes should be used to determine geographical origin since this element is taken up by the vine in the same proportion in which they occur in the soils and precipitation (Almeida and Vasconcelos, 2001). 
The mean and maximum $\mathrm{Na}$ and $\mathrm{P}$ concentrations for each parent material are all similar and not useful for distinguishing between soil types. $\mathrm{Mg}$ was only detected in the Lange Yamhill vineyard grapes, though its concentration is highest in loess soils. This indicates that there is no direct relationship between soils $\mathrm{Mg}$ and $\mathrm{Mg}$ found in the grapes. $\mathrm{Mg}$ is mainly utilized in chlorophyll production and as an enzyme cofactor. $\mathrm{Ca}$ is only detected in two samples, Nysa (volcanic soils) and Yamhill (marine sediment soils) for unknown reasons. Ca is utilized in the making of cell walls in the vine and is not detected in many of the grape juice samples (White, 2003).

Interestingly, $\mathrm{Mn}$ is only picked up in grapes from volcanic and the loess/volcanic soils. This could be due to higher values of $\mathrm{Mn}$ in the soils because of the direct weathering of basaltic bedrock which contains minerals that may have Mn. There may be use in the future for determining volcanic versus marine sediment parent material in the Willamette Valley using Mn. Some elements were only detected in the grape juice from a few vineyards. $\mathrm{Zn}$ and $\mathrm{Cu}$ were only in the Jacob Hart grapes. This might be attributed to an application of these elements in the vineyard management program closer to the day of sampling than other vineyards. It is unlikely that the values are due to differences in vine uptake. 


\section{Wine Chemistry}

Almost all elements detected in the wines were similar to the concentration ratios measured in the soil parent material. More elements were detected in the wines than in the grape juice. It is very difficult to determine what elemental concentrations in the wine are determined by the winemaking equipment and process and what are determined by the soil concentrations. Because I included analysis of the grape juice, I can see that certain elements found in the wine are added during the winemaking process by the winemaker. Also, my methodology in analyzing the grape juice does not account for elements found in the wine due to extended contact with the skins, seeds, and stems. All data from the wines has been organized into macronutrient (Table 107), micronutrient (Table 108), and trace element (Table 109) groups and ranked from highest to lowest concentration for comparison. Maximum $\mathrm{P}$ and $\mathrm{K}$ concentrations are found in the Ken Wright Nysa vineyard, a volcanic soil. Chehalem Ridgecrest vineyard, a marine sediments soil, has the highest concentration of $\mathrm{Ca}$ in the wine. The highest concentration of $\mathrm{Mg}$ in the wine is in the Ken Wright Freedom Hill vineyard, also a marine sediment soil.

Rex Hill Sims vineyard has the highest concentration of Fe in the wine. Co and $\mathrm{Cu}$ are highest in the Rex Hill Jacob Hart vineyards block 1 and block 5, respectively. Willakenzie Estate Terres Basses has the highest concentration of Mn in the wine. Trace elements in the wine include $\mathrm{Ba}, \mathrm{Pb}$, and $\mathrm{Sr}$. The volcanic soil from Ken Wright Nysa 
Table 107. Macronutrient concentration (ppm) for wines obtained from vines adjacent to soil pits in this study (mean calculated from multiple runs of the same bottle of wine). ND - Non-detected.

\begin{tabular}{|c|c|c|c|c|c|c|c|c|c|c|}
\hline Vineyard \& Vintage & $\mathbf{P}$ & Rank & $\mathbf{K}$ & Rank & $\mathbf{C a}$ & Rank & Mg & Rank & $\mathbf{S}$ & Rank \\
\hline ECCC '11 (mean) & 73.0 & 20 & 436 & 20 & 33.2 & 16 & 46.2 & 19 & 51.6 & 20 \\
\hline ECRV '11 (mean) & 502 & 2 & 791 & 8 & 50.0 & 8 & 72.3 & 8 & 75.7 & 13 \\
\hline ECFM '11 (mean) & 247 & 11 & 816 & 6 & 42.3 & 12 & 61.5 & 11 & 62.1 & 19 \\
\hline WEJH '11 & 187 & 17 & 818 & 5 & 51.6 & 6 & 40.6 & 20 & 72.7 & 16 \\
\hline WEAB '11 & 222 & 13 & 835 & 4 & 55.8 & 3 & 47.9 & 18 & 71.3 & 18 \\
\hline WETB '11 (mean) & 207 & 14 & 908 & 2 & 50.5 & 7 & 52.7 & 15 & 90.7 & 9 \\
\hline CWS '11 (mean) & 233 & 12 & 785 & 9 & 52.3 & 5 & 50.1 & 17 & 75.1 & 14 \\
\hline CWR '11 (mean) & 364 & 9 & 673 & 16 & 61.6 & 1 & 61.5 & 10 & 86.0 & 11 \\
\hline CWCC '11 (mean) & 467 & 3 & 808 & 7 & 57.2 & 2 & 54.1 & 14 & 87.7 & 10 \\
\hline LEM '12 (mean) & 168 & 19 & 739 & 13 & 28.5 & 19 & 73.3 & 7 & 108 & 4 \\
\hline LEY '12 & 206 & 15 & 743 & 12 & 31.7 & 17 & 94.4 & 2 & 74.2 & 15 \\
\hline LEFH '12 & 199 & 16 & 676 & 15 & 27.6 & 20 & 51.6 & 16 & 72.1 & 17 \\
\hline RHS '12 (mean) & 186 & 18 & 453 & 19 & 35.1 & 15 & 79.9 & 6 & 115 & 3 \\
\hline RHB '12 & 447 & 4 & 713 & 14 & 42.9 & 11 & 80.4 & 5 & 97.0 & 8 \\
\hline RHJHB1 '12 & 412 & 6 & 563 & 17 & 35.2 & 14 & 59.2 & 13 & 119 & 2 \\
\hline RHJHB5 '12 (mean) & 368 & 8 & 745 & 11 & 54.5 & 4 & 85.4 & 3 & 145 & 1 \\
\hline KWN '12 & 542 & 1 & 917 & 1 & 37.4 & 13 & 65.7 & 9 & 106 & 5 \\
\hline KWAC '12 & 403 & 7 & 767 & 10 & 30.6 & 18 & 60.4 & 12 & 77.2 & 12 \\
\hline KWFH '12 & 297 & 10 & 844 & 3 & 43.5 & 10 & 96.8 & 1 & 100 & 7 \\
\hline KWM '12 & 430 & 5 & 538 & 18 & 43.9 & 9 & 84.9 & 4 & 101 & 6 \\
\hline
\end{tabular}


Table 108. Micronutrient concentration (ppm) for wines obtained from vines adjacent to soil pits in this study (mean calculated from multiple runs of the same bottle of wine). ND - Non-detected.

\begin{tabular}{ccccccccccccccc}
\hline Vineyard \& Vintage & Fe & Rank & Co & Rank & Cu & Rank & Mn & Rank & Na & Rank & Ni & Rank & Zn & Rank \\
\hline \hline ECCC '11 (mean) & 1.06 & 13 & 0.0262 & 11 & 0.120 & 5 & 1.29 & 11 & 3.82 & 19 & ND & \\
ECRV '11 (mean) & 0.711 & 17 & 0.0255 & 13 & 0.0830 & 11 & 1.04 & 16 & 3.35 & 20 & ND & 0.150 & 18 \\
ECFM '11 (mean) & 0.772 & 15 & ND & & 0.0918 & 9 & 0.986 & 18 & 4.12 & 17 & ND & 0.102 & 20 \\
WEJH '11 & 0.645 & 18 & 0.0310 & 6 & 0.0272 & 18 & 1.30 & 10 & 4.50 & 14 & ND & 0.189 & 16 \\
WEAB '11 & 0.768 & 16 & 0.0258 & 12 & 0.102 & 8 & 0.995 & 17 & 4.45 & 15 & ND & 0.164 & 17 \\
WETB '11 (mean) & 1.07 & 11 & 0.0315 & 4 & 0.127 & 4 & $\mathbf{2 . 5 6}$ & 1 & 4.04 & 18 & $\mathbf{0 . 0 2 6 0}$ & 1 & 0.208 & 15 \\
CWS '11 (mean) & 1.64 & 6 & 0.0282 & 9 & 0.0704 & 15 & 1.70 & 7 & $\mathbf{1 7 . 5}$ & 1 & ND & 0.436 & 8 \\
CWR '11 (mean) & 2.14 & 3 & 0.0298 & 7 & 0.162 & 2 & 1.31 & 9 & 9.94 & 3 & ND & $\mathbf{1 . 0 9}$ & 1 \\
CWCC '11 (mean) & 2.13 & 4 & 0.0312 & 5 & 0.116 & 6 & 0.865 & 20 & 8.91 & 4 & ND & 0.567 & 6 \\
LEM '12 (mean) & 1.75 & 5 & 0.0330 & 2 & 0.141 & 3 & 2.30 & 4 & 10.2 & 2 & ND & 0.274 & 14 \\
LEY '12 & 1.42 & 8 & ND & & ND & & 2.36 & 2 & 4.85 & 11 & ND & 0.334 & 12 \\
LEFH '12 & 0.966 & 14 & 0.0290 & 8 & 0.0865 & 10 & 1.25 & 12 & 4.30 & 16 & ND & 0.118 & 19 \\
RHS '12 (mean) & $\mathbf{2 . 3 6}$ & 1 & ND & & 0.0473 & 17 & 2.36 & 3 & 5.52 & 9 & ND & 0.343 & 10 \\
RHB '12 & 1.11 & 10 & ND & & 0.0810 & 12 & 1.06 & 15 & 7.74 & 7 & ND & 0.394 & 9 \\
RHJHB1 '12 & 2.22 & 2 & $\mathbf{0 . 0 3 3 8}$ & 1 & 0.111 & 7 & 1.07 & 14 & 8.42 & 5 & ND & 0.338 & 11 \\
RHJHB5 '12 (mean) & 1.23 & 9 & ND & & $\mathbf{0 . 3 0 3}$ & 1 & 1.78 & 5 & 7.93 & 6 & ND & 0.453 & 7 \\
KWN '12 & 1.58 & 7 & 0.0270 & 10 & 0.0742 & 14 & 1.67 & 8 & 4.50 & 13 & ND & 0.747 & 5 \\
KWAC '12 & 0.517 & 20 & 0.0325 & 3 & 0.0750 & 13 & 1.13 & 13 & 5.77 & 8 & ND & 0.965 & 2 \\
KWFH '12 & 0.544 & 19 & ND & & 0.0540 & 16 & 1.73 & 6 & 5.40 & 10 & ND & 0.784 & 3 \\
KWM '12 & 1.06 & 12 & ND & & ND & & 0.952 & 19 & 4.76 & 12 & ND & 0.768 & 4 \\
\hline
\end{tabular}


Table 109. Trace element concentration (ppm) for wines obtained from vines adjacent to soil pits in this study (mean calculated from multiple runs of the same bottle of wine). ND - Non-detected.

\begin{tabular}{ccccccc}
\hline Vineyard \& Vintage & Ba & Rank & Pb & Rank & Sr & Rank \\
\hline \hline ECCC '11 (mean) & 0.442 & 10 & 0.0598 & 14 & 0.982 & 12 \\
ECRV '11 (mean) & 0.511 & 4 & 0.0610 & 12 & 0.993 & 11 \\
ECFM '11 (mean) & 0.465 & 6 & ND & & 0.784 & 17 \\
WEJH '11 & 0.464 & 7 & 0.0615 & 11 & 0.954 & 14 \\
WEAB '11 & 0.439 & 11 & 0.0610 & 13 & 1.21 & 2 \\
WETB '11 (mean) & 0.419 & 12 & 0.0890 & 3 & 1.15 & 5 \\
CWS '11 (mean) & 0.408 & 13 & 0.0815 & 5 & 0.698 & 19 \\
CWR '11 (mean) & 0.288 & 18 & 0.0622 & 10 & 1.19 & 3 \\
CWCC '11 (mean) & 0.298 & 17 & 0.0845 & 4 & 0.880 & 16 \\
LEM '12 (mean) & 0.462 & 8 & $\mathbf{0 . 0 8 9 2}$ & 1 & 1.04 & 10 \\
LEY '12 & 0.540 & 3 & ND & & $\mathbf{1 . 6 2}$ & 1 \\
LEFH '12 & 0.577 & 2 & 0.0782 & 6 & 1.05 & 9 \\
RHS '12 (mean) & 0.369 & 15 & ND & & 0.965 & 13 \\
RHB '12 & 0.406 & 14 & ND & & 1.18 & 4 \\
RHJHB1 '12 & 0.327 & 16 & 0.0892 & 2 & 1.12 & 6 \\
RHJHB5 '12 (mean) & 0.177 & 20 & 0.0678 & 9 & 0.769 & 18 \\
KWN '12 & $\mathbf{0 . 5 8 4}$ & 1 & 0.0678 & 8 & 1.09 & 7 \\
KWAC '12 & 0.457 & 9 & 0.0740 & 7 & 0.912 & 15 \\
KWFH '12 & 0.470 & 5 & ND & & 1.05 & 8 \\
KWM '12 & 0.188 & 19 & ND & & 0.681 & 20 \\
\hline
\end{tabular}

vineyard has the highest concentration of $\mathrm{Ba}$ in the wine and the Lange Estate Mia vineyard has the highest $\mathrm{Pb}$ concentration in the wine. Lange Estate Yamhill vineyard has the highest $\mathrm{Sr}$ concentration. The mean and standard deviation of elemental concentrations grouped by parent material demonstrate that most elements in the wine 
have similar concentrations (Table 110). These data exhibit a starting point for future research and do not answer many of the questions about soil and wine chemistry.

$\mathrm{Ba}, \mathrm{Co}, \mathrm{Cu}, \mathrm{Fe}, \mathrm{Pb}, \mathrm{S}$, and $\mathrm{Zn}$ were not detected (or only detected in a few) in the grape juice samples in this study, Therefore, these elements found in the wine samples

Table 110. Mean and standard deviation values (with maximum in parentheses) for elemental concentrations in wines separated by parent material disregarding vintage.

\begin{tabular}{|c|c|c|c|c|}
\hline Element & Volcanic & $\begin{array}{c}\text { Marine } \\
\text { Sediments }\end{array}$ & Loess & Trend \\
\hline $\mathrm{Ba}$ & $\begin{array}{c}0.453 \pm 0.109 \\
(0.592)\end{array}$ & $\begin{array}{l}0.474 \pm 0.157 \\
\quad(0.754)\end{array}$ & $\begin{array}{c}0.422 \pm 0.115 \\
\quad(0.576)\end{array}$ & All Similar \\
\hline $\mathrm{Ca}$ & $\begin{array}{c}38.7 \pm 9.74 \\
\quad(52.3)\end{array}$ & $\begin{array}{c}43.8 \pm 12.8 \\
(61.6)\end{array}$ & $\begin{array}{c}44.8 \pm 10.9 \\
(57.2)\end{array}$ & All Similar \\
\hline $\mathrm{Co}$ & $\begin{array}{c}0.0291 \pm 0.00285 \\
(0.0330)\end{array}$ & $\begin{array}{c}0.0286 \pm 0.00295 \\
(0.0325)\end{array}$ & $\begin{array}{c}0.0312 \pm 0 \\
(0.0312)\end{array}$ & All Similar \\
\hline $\mathrm{Cu}$ & $\begin{array}{c}0.0800 \pm 0.0431 \\
(0.141)\end{array}$ & $\begin{array}{c}0.0922 \pm 0.0401 \\
(0.162)\end{array}$ & $\begin{array}{c}0.0938 \pm 0.0168 \\
(0.116)\end{array}$ & All Similar \\
\hline $\mathrm{Fe}$ & $\begin{array}{c}1.44 \pm 0.567 \\
(2.36)\end{array}$ & $\begin{array}{c}0.972 \pm 0.552 \\
(2.14)\end{array}$ & $\begin{array}{c}1.18 \pm 0.664 \\
(2.13)\end{array}$ & All Similar \\
\hline $\mathrm{Pb}$ & $\begin{array}{c}0.0720 \pm 0.129 \\
(0.0892)\end{array}$ & $\begin{array}{c}0.0673 \pm 0.00820 \\
(0.0782)\end{array}$ & $\begin{array}{c}0.0845 \pm 0 \\
(0.0845)\end{array}$ & All Similar \\
\hline $\mathrm{Mg}$ & $\begin{array}{c}57.4 \pm 15.9 \\
(79.9)\end{array}$ & $\begin{array}{c}69.7 \pm 19.5 \\
(96.8)\end{array}$ & $\begin{array}{l}64.0 \pm 11.5 \\
\quad(80.4)\end{array}$ & All Similar \\
\hline $\mathrm{Mn}$ & $\begin{array}{c}1.70 \pm 0.469 \\
(2.36)\end{array}$ & $\begin{array}{c}1.36 \pm 0.469 \\
(2.36)\end{array}$ & $\begin{array}{c}0.980 \pm 0.0864 \\
(1.06)\end{array}$ & $\begin{array}{l}\text { Volcanic and } \\
\text { Marine Highest }\end{array}$ \\
\hline $\mathrm{P}$ & $\begin{array}{c}209 \pm 159 \\
(542)\end{array}$ & $\begin{array}{c}337 \pm 129 \\
(560)\end{array}$ & $\begin{array}{c}344 \pm 137 \\
(467)\end{array}$ & All Similar \\
\hline $\mathrm{K}$ & $\begin{array}{c}655 \pm 207 \\
(917)\end{array}$ & $\begin{array}{c}765 \pm 67.9 \\
(844)\end{array}$ & $\begin{array}{c}790 \pm 52.1 \\
(828)\end{array}$ & All Similar \\
\hline $\mathrm{Na}$ & $\begin{array}{c}7.12 \pm 5.13 \\
(17.5)\end{array}$ & $\begin{array}{c}4.59 \pm 2.83 \\
(9.94)\end{array}$ & $\begin{array}{l}6.92 \pm 2.50 \\
(8.91)\end{array}$ & All Similar \\
\hline $\mathrm{Sr}$ & $\begin{array}{c}0.959 \pm 0.125 \\
(1.09)\end{array}$ & $\begin{array}{c}1.72 \pm 1.10 \\
(4.10)\end{array}$ & $\begin{array}{c}0.907 \pm 0.188 \\
(1.18)\end{array}$ & Marine Highest \\
\hline $\mathrm{S}$ & $\begin{array}{c}82.8 \pm 26.9 \\
(115)\end{array}$ & $\begin{array}{c}79.0 \pm 9.62 \\
(100)\end{array}$ & $\begin{array}{c}76.4 \pm 19.3 \\
(97)\end{array}$ & All Similar \\
\hline $\mathrm{Zn}$ & $\begin{array}{c}0.323 \pm 0.218 \\
(0.747)\end{array}$ & $\begin{array}{c}0.479 \pm 0.407 \\
(1.09)\end{array}$ & $\begin{array}{c}0.339 \pm 0.179 \\
(0.567)\end{array}$ & All Similar \\
\hline
\end{tabular}


must be a contribution from the winemaking process. $\mathrm{S}$ is added by the winemaker as a preservative while the metals found in the wine most likely came from the metallic equipment. Some elements may have come from the oak barrels. Sr is the only element that has a different concentration in the wine based on parent material. Sr is highest in marine soils and only slightly higher in the grape juice from marine soils. Sr is similar to $\mathrm{Ca}$, and therefore could be taken up by the vine and incorporated into the cell walls in the grapes in place of $\mathrm{Ca}$ (White, 2003). Because of this, increased amounts of Sr in soils may result in increased concentrations in the wine. Wine from volcanic and marine soils have higher concentrations of Mn than loess soils. This is intriguing since Mn was not detected in the grape juice from marine soils.

\section{Climate}

Climate seems to have had a factor in the grape juice and wine chemistry in this study. These samples were collected in 2011 for some samples and 2012 for others. High and low daily monthly temperatures as well as monthly cumulative rainfall for the two vintages from this study are shown in Figure 60. Note the earlier rainfall in 2012, which started in September, compared to 2011 where rainfall commenced in September but at a slower rate shown by the slope of the line. Temperatures varied between vintages as well. 2012 had a warmer spring than 2011 and reached higher temperatures in July and August. The NOAA weather site that I used for these data is centrally located in Newberg, Oregon, though it is at a lower elevation than my sample sites. In general, the vineyard 
owners and managers agree that 2011 was a cooler year (GDD $1966^{\circ} \mathrm{F} / 1092^{\circ} \mathrm{C}$ ) and that 2012 was warmer $\left(\mathrm{GDD} 2277^{\circ} \mathrm{F} / 1265^{\circ} \mathrm{C}\right)$ and more ideal.

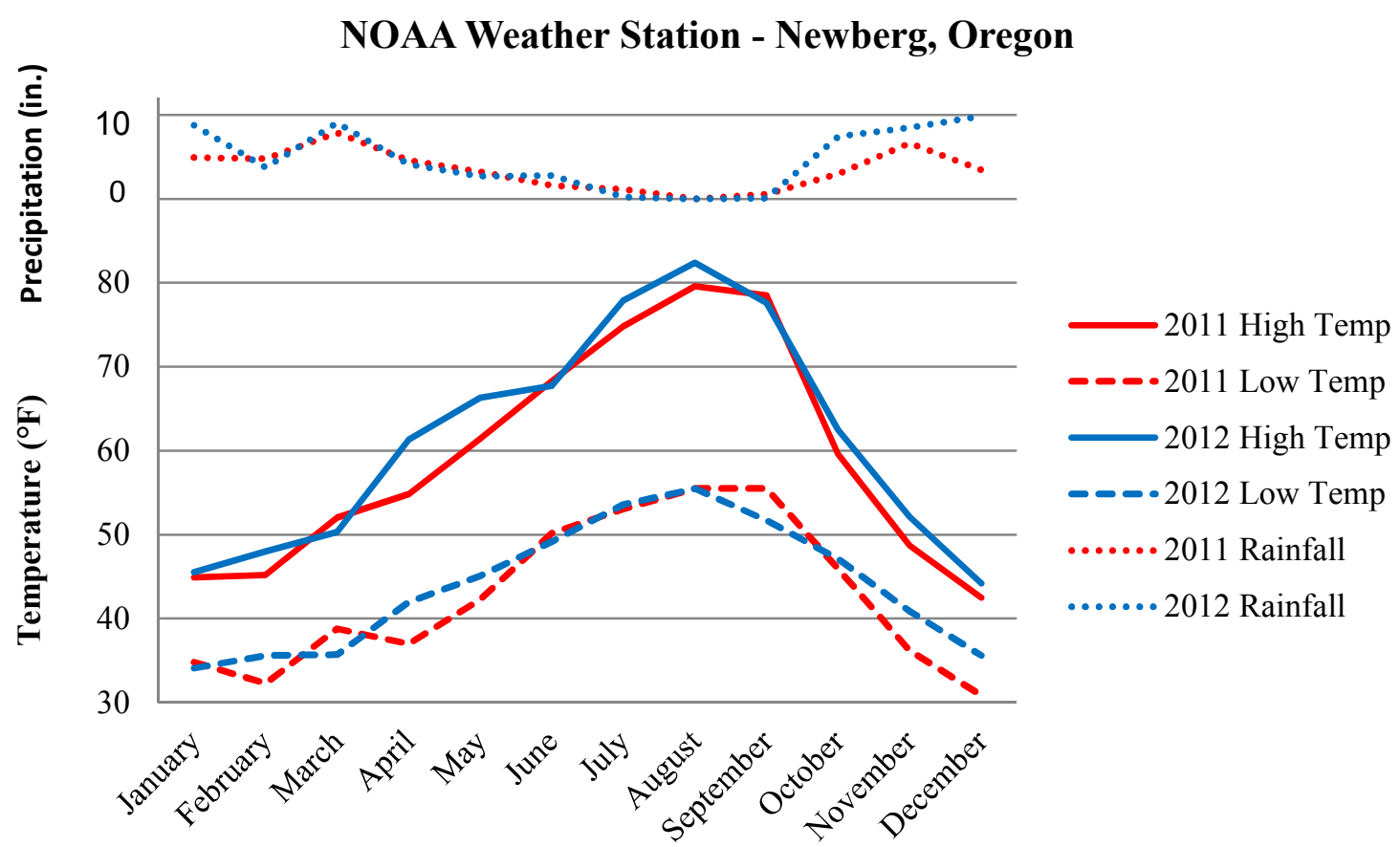

Figure 60. High and low average monthly temperatures as well as cumulative rainfall for the two vintages (2011 and 2012) included in this study (NOAA, 2013).

Elevation of the vineyards in this study differ because of the geology of the region. Volcanic and marine soils are located on the uplifted Columbia River Basalts and Coast Range sediments, respectively. Loess soils are located on Columbia River Basalts but at an elevation that accumulated windblown silt from the last ice age. Therefore, a difference in vineyard elevation between parent materials is evident (Table 111). The mean elevation of volcanic vineyards is $612 \pm 106$ feet (186 \pm 32 meters) and marine sediments vineyards $514 \pm 110$ feet $(157 \pm 34$ meters $)$. Loess vineyards have a mean 
elevation of $347 \pm 32$ feet (106 \pm 10 meters). This difference in elevation most definitely has an effect on the climate in each vineyard and on the uptake of water and nutrients from the soils into the wines.

Table 111. Elevations of soil pit locations for each vineyard, sorted by parent material (rounded to the nearest foot).

\begin{tabular}{|c|c|c|c|c|c|c|}
\hline \multicolumn{2}{|c|}{ Volcanic } & \multicolumn{2}{|c|}{ Marine } & \multicolumn{3}{|c|}{ Loess } \\
\hline $\mathrm{ECCC}$ & 610 & ECRV & 620 & & ECFM & 360 \\
\hline WEJH & 490 & WEAB & 600 & & CWCC & 370 \\
\hline CWS & 480 & CWR & 640 & & RH12 & 310 \\
\hline LEM & 720 & LEY & 450 & & Mean & 347 \\
\hline RHS & 660 & KWAC & 480 & & St. Dev. & 32 \\
\hline \multirow[t]{2}{*}{ KWN } & 710 & LEFH & 340 & \multirow{4}{*}{$\frac{\dot{\Xi}}{0}$} & WETB & 290 \\
\hline & & KWFH & 470 & & RHJHB1 & 320 \\
\hline Mean & 612 & Mean & 514 & & RHJHB5 & 380 \\
\hline St. Dev. & 106 & St. Dev. & 110 & & KWM & 670 \\
\hline
\end{tabular}

The elemental concentrations in the 2011 and 2012 wines show little variation from year to year (Table 112). Ca is slightly higher in the 2011 vintage of wines from the northern Willamette Valley disregarding parent material than in the 2012 vintage. Mn is slightly higher in the 2012 vintage of wines from the northern Willamette Valley (excluding the Freedom Hill vineyards since they are located farther south) disregarding parent material than in the 2011 vintage. Little variation is shown in the wine chemistry based on vintage, indicating that the previous discussion comparing parent material is valid even though this study was carried out over two seasons. In most cases, warmer 
Table 112. Mean and standard deviation values (with maximum in parentheses) for elemental concentrations in wines from the northern Willamette Valley separated vintage disregarding parent material.

\begin{tabular}{|c|c|c|c|}
\hline Element (ppm) & 2011 Vintage & 2012 Vintage & Trend \\
\hline $\mathrm{Ba}$ & $\begin{array}{c}0.399 \pm 0.133 \\
(0.754)\end{array}$ & $\begin{array}{c}0.456 \pm 0.0785 \\
(0.584)\end{array}$ & Similar \\
\hline $\mathrm{Ca}$ & $\begin{array}{l}50.8 \pm 10.2 \\
\quad(67.1)\end{array}$ & $\begin{array}{c}33.7 \pm 4.99 \\
\quad(42.9)\end{array}$ & 2011 Higher \\
\hline $\mathrm{Co}$ & $\begin{array}{c}0.0282 \pm 0.00246 \\
\quad(0.0312)\end{array}$ & $\begin{array}{c}0.0308 \pm 0.00333 \\
(0.033)\end{array}$ & Similar \\
\hline $\mathrm{Cu}$ & $\begin{array}{c}0.102 \pm 0.0454 \\
(0.191)\end{array}$ & $\begin{array}{c}0.0867 \pm 0.0416 \\
(0.164)\end{array}$ & Similar \\
\hline $\mathrm{Fe}$ & $\begin{array}{l}1.39 \pm 0.633 \\
(2.21)\end{array}$ & $\begin{array}{c}1.61 \pm 0.615 \\
(2.41)\end{array}$ & Similar \\
\hline $\mathrm{Pb}$ & $\begin{array}{c}0.0674 \pm 010107 \\
\quad(0.0845)\end{array}$ & $\begin{array}{c}0.0770 \pm 0.0110 \\
\quad(0.0892)\end{array}$ & Similar \\
\hline $\mathrm{Mg}$ & $\begin{array}{c}56.0 \pm 12.7 \\
\quad(85.7)\end{array}$ & $\begin{array}{l}75.9 \pm 11.9 \\
\quad(94.4)\end{array}$ & Similar \\
\hline $\mathrm{Mn}$ & $\begin{array}{c}1.20 \pm 0.291 \\
\quad(1.80)\end{array}$ & $\begin{array}{l}1.94 \pm 0.570 \\
\quad(2.36)\end{array}$ & 2012 Higher \\
\hline $\mathrm{P}$ & $\begin{array}{c}305 \pm 144 \\
(560)\end{array}$ & $\begin{array}{l}288 \pm 152 \\
\quad(542)\end{array}$ & Similar \\
\hline $\mathrm{K}$ & $\begin{array}{c}742 \pm 129 \\
(852)\end{array}$ & $\begin{array}{l}690 \pm 160 \\
(917)\end{array}$ & Similar \\
\hline $\mathrm{Na}$ & $\begin{array}{l}8.26 \pm 5.14 \\
\quad(18.7)\end{array}$ & $\begin{array}{c}6.80 \pm 2.33 \\
\quad(10.5)\end{array}$ & Similar \\
\hline $\mathrm{Sr}$ & $\begin{array}{c}0.932 \pm 0.182 \\
(1.26)\end{array}$ & $\begin{array}{c}1.10 \pm 0.228 \\
\quad(1.62)\end{array}$ & Similar \\
\hline $\mathrm{S}$ & $\begin{array}{l}74.0 \pm 12.6 \\
\quad(94.6)\end{array}$ & $\begin{array}{l}99.9 \pm 16.3 \\
\quad(118)\end{array}$ & Similar \\
\hline $\mathrm{Zn}$ & $\begin{array}{c}0.437 \pm 0.345 \\
(1.15)\end{array}$ & $\begin{array}{c}0.459 \pm 0.255 \\
(0.965)\end{array}$ & Similar \\
\hline
\end{tabular}

weather during veraison at the end of the season should increase uptake of groundwater and potentially dilute the elemental concentrations in the vines or, conversely, the 
increased uptake would provide more elements to be incorporated in the fruit and would increase the concentration of some elements. More study is needed to address this issue.

Chehalem also contributed multiple vintages of each vineyard to this study in order to look further into the possible influence of climate on the uptake of elements from the soil. Some of these variations in wine chemistry could be due to weather differences. The Stoller Vineyard 2007 vintage has higher concentrations of $\mathrm{Ba}, \mathrm{Cu}, \mathrm{Mn}$, and $\mathrm{Na}$ than the 2008 and 2009 vintages. The Ridgecrest Vineyard 2007 vintage has higher concentrations of $\mathrm{Ba}, \mathrm{Ca}, \mathrm{Co}, \mathrm{Cu}, \mathrm{Fe}, \mathrm{Pb}, \mathrm{P}, \mathrm{Na}, \mathrm{Sr}, \mathrm{S}$, and $\mathrm{Zn}$ than the 2008 vintage (2009 vintage not tested). The Ridgecrest Vineyard Ca, Na, Sr, S, Zn in the 2007 vintage are very similar to the concentrations in the 2008 vintage. In 2007, fall-like weather started early, including cool temperatures and wet fields. Growers reported issues with powdery mildew and low sugar levels (USDA, 2008). From July 2 to July 15, the longest warm period, with higher than average temperatures, was 14 days long in 2007. March had the most warmer than average days (NOAA, 2013). The 2007 vintage has aged well, with humble beginnings and a lighter overall flavor.

The Stoller Vineyard 2008 vintage has the highest concentration of Fe, S, and Co but the lowest concentration of Mg and Ca compared to 2007 and 2009. The Ridgecrest Vineyard 2008 vintage has the higher concentrations of Mg, Mn, and K than the 2007 vintage. Corral Creek Vineyard 2008 vintage has higher concentrations of $\mathrm{Ba}, \mathrm{Cu}, \mathrm{Fe}$, 
$\mathrm{Mg}, \mathrm{Mn}$, and $\mathrm{Sr}$ than the 2009 vintage (2007 vintage not tested). In 2008, growers reported a late start to the growing season. There were various sources of fruit loss but an overall warm growing season (USDA, 2009). The hottest month in 2008 was July with an average daily high temperature of $80^{\circ} \mathrm{F}$. The warmest month was September, with an average high temperature of $77^{\circ} \mathrm{F}$, compared to a typical value of $75^{\circ} \mathrm{F}$ which had an effect on the vintage. For 15 consecutive days from September 4 to September 18 there were higher than average high temperatures. The month of November had the largest fraction of warmer than average days with $70 \%$ days with higher than average high temperatures (NOAA, 2013). The 2008 vintage was well-balanced in regards to tannin and fruit.

The Stoller Vineyard bottle of the 2009 vintage has the highest concentration of $\mathrm{Ca}$ and $\mathrm{K}$, but the lowest concentration of $\mathrm{Ba}, \mathrm{Cu}, \mathrm{Fe}, \mathrm{Mn}, \mathrm{Na}$, and $\mathrm{Sr}$ compared to 2007 and 2008 vintages. The Mn and Sr concentrations are very similar to the concentrations in the Corral Creek Vineyard 2009 vintage. The Corral Creek Vineyard 2009 vintage has the higher concentrations of $\mathrm{Ca}, \mathrm{P}, \mathrm{K}, \mathrm{Na}, \mathrm{S}$, and $\mathrm{Zn}$ than the Corral Creek Vineyard 2008 vintage. The warmest month in 2009 was July, with an average high temperature of $86^{\circ} \mathrm{F}$, compared to a typical value of $80^{\circ} \mathrm{F}$. The longest warm spell was from May 21 to June 5, constituting 16 consecutive days with warmer than average high temperatures and an early start to the growing season. The month of July had the largest fraction of warmer than average days with $71 \%$ days with higher than average high temperatures (NOAA, 
2013). The 2009 vintage produced many full bodied wines with intense tannin and deep fruit flavor.

\section{New Soil Classifications}

During this study, the NRCS reclassified the soils of the Willamette Valley. For the most part, the Willakenzie soil series has been split into many soils, all with marine sediment parent material, but with slightly differing characteristics. As stated before, the Jory soil series (Xeric Palehumult) is similar to the Nekia soil series (Xeric Haplohumult) with the main difference in depth to bedrock; The Nekia soils series is shallower. Now, the Gelderman soils series is also a Xeric Haplohumult and is found near Jory soils and is very similar except for having an umbric epipedon (thicker A horizon) than the Jory Soil (base saturation still similar). There are, by NRCS mapping, five sites in this study that are Jory, zero Nekia (although the Willakenzie Estate Jory Hill soil was classified as a Nekia in the field and mapped as a Jory), and one Jory-Gelderman soil.

There are now few Willakenzie soil series (Ultic Haploxeralf) mapped by the NRCS, since it has been split into many different series. One site is now Wellsdale soil series (Aquultic Haploxeralf) which differs from Willakenzie because it has a Bg horizon at 20 to 30 inches. One site is now Goodin-Melbourne soil series (Ultic Haploxeralf-Ultic Palexeralf) and one site is now classified as Melbourne-Goodin. The Goodin has siltstone parent material and the Melbourne has mottles in the Cr horizon according to the official 
soil description (NRCS, 2015). Two sites are classified as being Wellsdale-WillakenzieDupee soil series (Dupee is an Aquultic Haploxeralf) that is similar to the Wellsdale with a Bg horizon at depth. Two sites are classified as Bellpine soil series (Xeric Haplohumult). The sites are located farthest south near Salem, which has a lower base saturation than most of the traditional Willakenzie Soils with an umbric epipedon.

The Laurelwood soil series (Ultic Haploxeralf) is still mapped at the three sites selected in this study. There are differences in the NRCS classification for the Terres Basses vineyard which is now a Witham soil series (Vertic Haploxeroll) which does not have a Bt horizon. It is the only site in the study that was sampled without the Bt horizon. The Meredith Mitchell vineyard is also now classified as Witzel-Dixonville. The Witzel is a Lithic Ultic Haploxeroll with a loamy skeletal structure and forms on colluvium from basalt with some loess input. The Jacob Hart vineyard is now classified as Dixonville soil series (Pachic Ultic Argixeroll) which is a superactive silty clay loam, well drained, clayey soil formed on basalt bedrock, sometimes forming on older basalts of the Siletz River Terrane. The Meredith Mitchell vineyard is most likely also on the Siletz River Terrane basalts. The reclassification and mapping done by the NRCS that occurred during this study does not influence the results of this study. The separation of vineyards based on parent material is still valid when looking at physical and chemical differences. 


\section{Chapter Twelve - Conclusions}

This study has given us the first in depth description of the volcanic, marine sediments, and loess/volcanic soils in the Willamette Valley that are used for growing Pinot Noir. Similar studies have not been carried out in this region before now. It is evident that there are many similarities between the vineyards in this study, despite the differences in parent material. The physical characteristics indicate that these vineyards are planted on old soils (over 50,000 years) based on red color, the presence of Bt horizons with subangular blocky structure, high clay content and clay textures, low CEC, and moderate acidity. This is relevant because old soils have few nutrients $(\mathrm{Ca}, \mathrm{Mg}, \mathrm{K}$, $\mathrm{Na}, \mathrm{P}$ ) and therefore reduce the vigor (vegetative growth) in grape plants. The idea is that the stress of growing on an old soil with less nutrients would cause the plant to focus more on creating flavor, color, or aroma compounds to attract pollinators and potential genetic dispersers. Young soils (under 20,000 years) have lots of nutrients and encourage vigor which leads to non-exciting wines because the fertile soils reduce the necessity for the vine to create enticing fruit (Andrés-de Prado et al., 2007; Bramley et al., 2011; Cortell et al., 2007; Goode, 2014; Jackson, 2008; Retallack and Burns, 2016).

Age of the Willamette Valley soils were qualitatively determined by clay content, $\mathrm{pH}$, cation exchange capacity, clay mineral assemblage, and color values. Maximum clay percentages are $57 \%$ for volcanic soils, $60 \%$ for loess/volcanic soils, and $39 \%$ for marine 
sediments. The $\mathrm{pH}$ is low with minimum average values for volcanic soils at $5.2 \pm 0.2$, marine sediment soil at $5.1 \pm 0.4$, and loess/volcanic soils at $5.6 \pm 0.1$. The range of $\mathrm{pH}$ in the study is from 4.7 to 6.7 with the highest at 6.7 for Meredith Mitchell Vineyard. The mean $\mathrm{pH}$ for all horizons for the study is $5.5 \pm 0.4$.

The average cation exchange capacity (CEC) for volcanic soils are 22.5 meq/100g, marine sediments are $20.8 \mathrm{meq} / 100 \mathrm{~g}$, and loess/volcanic soils are 28.0 meq/100g. Corral Creek Vineyard (42.2 meq/100g) and Meredith Mitchell (80.0 meq/100g) are outliers, and the rest are between 10 and $23 \mathrm{meq} / 100 \mathrm{~g}$. The clay mineral assemblage also indicates that these soils are well developed and old, but differ slightly based on parent material. The dominant clay minerals are kaolinite and chlorite intergrades, which require time for pedogenesis and indicate old soils (Jackson, 1964). The clay minerals also align with the low CEC values. Typical CEC values for finegrained micas and kaolinite clays are between 5 and 25 meq/100g (Weil and Brady, 1990). Illite dominates in soils with loess and smectite was more prevalent in marine sediment soils, but kaolinite, chlorite intergrades, and Fe oxides are still present, reducing the CEC values for these parent materials (Weil and Brady, 1990). In general, the soils in this study would be considered old, while also suggesting a slightly younger age for soils with illite clay because of the addition of loess to an already old and developed soil. This loess is old weathered loess that would have been deposited more than 50,000 years ago 
on soils that were already developing. The clay mineral assemblage has not been previously explored for the vineyard soils in the Willamette Valley.

The average organic matter $(\mathrm{OM})$ of volcanic soils at $11.3 \%$, marine sediment soils at $6.9 \%$ and loess/volcanic soils at 7.5\%. Ultisols and Ultic Alfisols, like those in this study, would be expected to have a range of OM from 1.5\% to 4\% (Weil and Brady, 1990). These high OM values are most likely due to water released from clays not organic matter on ignition. These high values occurred even after using a 2 stage heating method to drive off water from the clays before putting the samples in the oven for OM combustion (Dean et al., 1974; Heiri et al., 2001; Horneck et al., 1989). Other methods for determining OM were not available to confirm, or deny, this issue.

Another indication of old soils is the Buntley-Westin color values are $20 \pm 6.5$ for volcanic, $19 \pm 7.3$ for marine sediments, and $13 \pm 2.3$ for loess/volcanic soils This is an indication of very red soil colors and extensive weathering and age even for the loess/volcanic soils which have loess input and blurs the age with this more recent deposition of silt. The lowest values (9) for Buntley-Westin are for the Missoula Flood sediment soil and landslide soils. A Buntley-Westin value larger than 10 indicates the soil is at least 5000 years old and values larger than 15 indicate soils greater than 10,000 years old (Buntley and Westin, 1964; Miller and Birkeland, 1974). Volcanic soils have 7.5 YR and 5 YR hues in regards to soil color which are brown and reddish brown colors. 
The marine sediment soils mostly are 10 YR hues which are yellowish brown hues. The loess/volcanic soils have hues that are $10 \mathrm{YR}, 7.5 \mathrm{YR}$, and $5 \mathrm{YR}$, which includes brown, yellowish brown, and red hues. These red colors are due to high concentrations of Feoxides, which build up in soils over time. There is also very little gravel at the surface of these vineyard soils with the maximum at $2.9 \%$, and none had O horizons. Similarly, almost all the soils in the study are well drained, with only two out of 20 having $\mathrm{Bg}$ horizons.

Significant differences in depth to bedrock, presence of pisolites or mica and quartz, clay mineral assemblage, and chemistry exist between the soils founded on the three parent materials. These differences are correlated with the differences in grape juice and wine chemistry. Physically, many of the soils are shallow to bedrock with 13 out of the 20 pits reaching refusal within two meters. These shallowest soils are mainly found in the marine sediment parent material (six of seven) whereas for the other parent materials only one third of the soils were less than 2 meters to bedrock. Because of the friability of the marine sediment parent material, one would easily continue digging into the sandstone parent material, as would the vine roots, without realizing that the actual soil that had developed on the marine sediments is not very thick. This is one main physical difference between the marine sediment soils and the volcanic and loess/volcanic soils. 
Another major difference is that there are pisolites (concretions) in the volcanic and the loess soils and not in the marine sediments. This is the first study to point out that these pisolites exist in the soils formed on volcanic and loess/volcanic parent material, but not in the marine sediment soils. These pisolites formed in place based on chemistry, and mostly consist of silica, Al and Fe oxides. Excluding silica, volcanic soils contain pisolites with higher $\mathrm{Al}, \mathrm{Fe}, \mathrm{Mn}, \mathrm{Cr}, \mathrm{V}$, and $\mathrm{Zn}$ while the loess/volcanic soils have pisolites with higher $\mathrm{Mg}, \mathrm{Ca}, \mathrm{Na}, \mathrm{P}, \mathrm{Ba}$, and $\mathrm{Sr}$. The pisolites are composed of concentric layers of phyllosilicates and clays that are pulling trace elements directly out of the soil. The volcanic soils have higher Al, Fe, and Mn than the loess/volcanic soils and the loess/volcanic soils have higher $\mathrm{Mg}, \mathrm{Ca}, \mathrm{Na}$, and $\mathrm{P}$ concentrations. Therefore, the pisolites' elemental concentration reflects the chemistry of the soil they are from.

The marine sediments contain muscovite mica and quartz whereas the volcanic soils have little of those minerals implying that the development of pisolites is related to the volcanic bedrock and loess deposits and not related to the marine sediments. The volcanic soils that had pisolites, also were discovered to have illite clay, which suggests that they also had loess input. Other than removing some trace elements from soil, the pisolites change the texture of these clay rich soils. The clay content is still high, but pisolites increase the "sand" fraction and therefore increase soil permeability and root penetration. This deserves much more attention and research since the influence of the pisolites and how and under what conditions they form is still unknown. 
Volcanic soils have kaolinite clays with some chlorite intergrades and only a few locations have illite. Marine sediment soils have smectite clays with some kaolinite and chlorite intergrades but no illite. Loess/volcanic soils have mostly illite with some chlorite and only a little kaolinite. Illite dominates in loess/volcanic soils indicating that they are the youngest because of the loess addition. Illite was also found in the volcanic soils, therefore there is a windblown input even in the soils previously thought to not have any loess. The dominant silica phase is cristobalite quartz. Marine sediment soil, as stated before, contain quartz in the clay fraction when the other soils do not. Goethite is the dominant Fe phase, with some containing hematite. Goethite is less developed in marine sediment soils.

The chemistry was examined for the soil, juice from grapes next to the soil pit, and finished wine from the block of the soil pit. Soil chemistry varied between the marine, volcanic, and loess/volcanic soils and the PCA showed significant differences between the soils with the greatest differences between the marine and volcanic, and loess/volcanic in between. Volcanic soils have the highest mean and maximum concentrations of $\mathrm{P}, \mathrm{S}, \mathrm{Fe}, \mathrm{Co}, \mathrm{Mn}$, and $\mathrm{V}$ values and the lowest $\mathrm{As}$ and $\mathrm{Sr}$ values. Marine sediment soils are highest in $\mathrm{Cl}$ and $\mathrm{Sr}$ and lowest in $\mathrm{P}, \mathrm{Co}, \mathrm{Mn}, \mathrm{Ba}$, and $\mathrm{V}$. The loess/volcanic soils are highest in $\mathrm{K}, \mathrm{Mg}$, similar to volcanic soils with higher values of $\mathrm{P}$ and $\mathrm{V}$, and similar to marine sediment soils with higher values of Sr. According to the PCA, volcanic soils cluster with Fe, $\mathrm{Zn}, \mathrm{Mn}$, and $\mathrm{Al}$ while marine sediment soils cluster 
with the $\mathrm{Mo}, \mathrm{Cu}$, and $\mathrm{Na}$ and the loess/volcanic soils lie in between. The main elements found to be significant in determining one parent material from the other are V (volcanic soils), Mn (volcanic soils), Mg and K (loess soils), and $\mathrm{Sr}$ (marine sediment soil or loess soils). Low values of As (volcanic soils) and low values of $\mathrm{Ba}$ (marine sediment soils) could also help determine the parent material.

The relative concentration of elements in the grape juice are markedly different than the soil concentrations with selectivity towards more mobile elements and those that are incorporated into the grapes themselves rather than in other tissues of the grape vine. The PCA does not suggest a correlation between soil parent material and the chemistry of the grape juice. This is most likely because $\mathrm{K}, \mathrm{Na}$, and $\mathrm{Sr}$ are the only elements found in all 20 grape juice samples due to methodological errors in this study. $\mathrm{K}$ is incorporated into grape juice because it is an essential nutrient for living plant cells and membranes of plants are highly permeable to $\mathrm{K}$ (Kodur, 2011). Na is similarly easy for the grapevine to obtain from the soil and incorporate into various parts of the plant, including the grapes. As an element, $\mathrm{Sr}$ has similar properties as $\mathrm{Ca}$ and $\mathrm{Mg}$, allowing for it to also be mistaken as a nutrient and incorporated into the grapes. $\mathrm{P}$ was in 15 of 20 grape juice samples. $\mathrm{K}$ has the highest average concentration in loess/volcanic soils from the loess input but the highest peaks in the volcanic and marine sediment soils. Sr is highest in marine sediment soil and has been used to determine wine provenance in Portugal and other studies (Almeida and Vasconcelos, 2001). Na and P are similar in all soils. Sr is slightly higher 
in grape juice from plants living on marine sediment soils compared to volcanic or loess soils. $\mathrm{Mn}$ in the grape juice may be used to indicate a volcanic or loess soils instead of a marine sediment soils.

The wine elemental concentrations were also different than the soil and the grape juice as shown by PCA. Other research suggests this is because of filtering, precipitation, or co-precipitation during the wine making process (Castiñeira-Gómez et al., 2004). In this study, similar concentrations of elements were found in wines from all soil types and two minor conclusions can be made: $\mathrm{Mn}$ is highest in wine from volcanic and marine sediments soils contrary to the high Mn values in loess soils. Sr is highest in wine from marine sediment soil but not associated with the similarly higher values of Sr in the loess soils.

In conclusion, these results can be used to indicate the source of origin for Pinot Noir wine from the soils in the Willamette Valley of Oregon. The persistence of some elements from soil to grape juice to wine indicate that the soil has influence on the grape and wine chemistry. There are significant differences in the physical and chemical characteristics of the soils of the three major soil parent materials. 


\section{Chapter Thirteen - Future Work}

A comparison of the wines done by a tasting panel performed by Oregon State University will help determine how the elemental fingerprint from the soil changes the intensities of certain attributes of the wine. The tasting was completed in 2014 , but the results were not available at the time of publication of this dissertation. The tasting results should reveal that the soil differences truly produce wines that taste different from one another. The soil fingerprint based on physical characteristics and some chemical characteristics and wine fingerprint may then be correlated to specific wine flavors. In the future, these data may help shed light on the mechanisms by which winegrapes obtain certain flavors from the soil.

Other interesting questions evolved during this study concerning soil development in the Willamette Valley. When considering clay mineralogy, especially where there could be a windblown addition of parent material, what is the ratio of illite to kaolinite that could be expected in these old soils? In the windblown soils, there may be work in determining the differences between sources of loess between the Dundee Hills and the Chehalem Mountains. A spatial comparison of soils with an input of loess would indicate prehistoric wind directions in the Willamette Valley.

More vineyard soils in this region should be analyzed for $\mathrm{V}, \mathrm{Sr}$, and $\mathrm{Mn}$ in order to determine if these elements do separate vineyards on different parent materials. 
Testing of wines for these elements should also be done to determine the origin of the grapes and substantiate the results of this study in fingerprinting wines from different parent materials in the Willamette Valley. Further research into the creation and impact of pisolites in the soils, whether an increase in soil permeability or reduction in trace elements due to the formation of these concretions would also be an interesting direction to take this research.

As usual, more questions about the terroir of the Willamette Valley have developed due to this study on the soils of various parent materials than were answered. Further study into the impacts of various farming practices, soil microbiota, clay mineralogy, and climate all will satisfy some urge to understand this region and how it has become one of the most notable Pinot Noir wine producers in the world. Until then, I will have to continue to commiserate my unanswered questions over a glass or two of delicious wine. 


\section{References}

Allen, J.E., Burns, M., Burns, S.F., 2009, Cataclysms on the Columbia: The Great Missoula Floods (2 ${ }^{\text {nd }}$ ed.): Portland, Oregon, Ooligan Press, 204 p.

Almeida, C.M.R., and Vasconcelos, M.T.S.D., 1999, UV-irradiation and MW-digestion pre-treatment of Port wine suitable for the determination of $\mathrm{Pb}$ isotope ratios by inductively couple plasma mass spectrometry: Journal of Analytical Atomic Spectrometry, v. 14, p. 1815-1821.

Almeida, C.M.R., and Vasconcelos, M.T.S.D., 2001, ICP-MS determination of Sr isotope ratio in wine in order to be used as a fingerprint of its regional origin: Journal of Analytical Atomic Spectrometry, v. 16, p. 607-611.

Almeida, C.M.R., Vasconcelos, M.T.S.D., Barbaste, M., and Medina, B., 2002, ICP-MS multi-element analysis of wine samples - a comparative study of the methodologies used in two laboratories: Analytical and Bioanalytical Chemistry, v. 374, p. 314-322.

Almeida, C.M.R., and Vasconcelos, M.T.S.D., 2003, Multielement composition of wines and their precursors including provenance soil and their potentialities as fingerprints of wine origin: Journal of Agricultural and Food Chemistry, v., 51, p. 4788-4798.

Álvarez, M., Moreno, I.M., Jos, Á.M., Cameán, A.M., González, A.G., 2007, Study of mineral profile of Montilla-Moriles "fino" wines using inductively couple plasma atomic emission spectrometry methods: Journal of Food Composition and Analysis, v. 20, p. 391-395.

Andrés-de Prado, R. de, Yuste-Rojas, M., Sort, X., Andrés-Lacueva, C., Torres, M., and Lamuela-Raventós, R.M., 2007, Effect of soil type on wines produced from Vitis vinifera L. Cv. Grenache in commercial vineyards: Journal of Agricultural and Food Chemistry, v. 55, p. 779-786.

Atwater, B.F., 1984, Periodic floods from glacial Lake Missoula into the Sanpoil arm of glacial Lake Columbia, northeastern Washington: Geology, v. 12, p. 464-467.

Arrhenius, S.P., McCloskey, L.P., and Sylvan, M., 1996, Chemical markers for aroma of Vitis vinifera var. chardonnay region wines: Journal of Agricultural and Food Chemistry, v. 44, p. 1085-1090. 
Arvanitoyannis, I.S., Katsota, M.N., Psarra, E.P., Soufleros, E.H., and Kallithraka, S., 1999, Application of quality control methods for assessing wine authenticity: Use of multivariate analysis (chemometrics): Trends in Food Science \& Technology, v. 10, p. 321-336.

Augagneur, S., and Médina, B., 1996, Determination of rare earth elements in wine by inductively coupled plasma mass spectrometry using a microconcentric nebulizer: Journal of Analytical Atomic Spectrometry, v. 11, p. 713-721.

Bargmann, C.J., 2006, Geology and Wine 7. Geology and wine production in the coastal region, Western Cape Province, South Africa in Macqueen, R.W., and Meinert, L.D., eds., Fine Wine and Terroir - The Geoscience Perspective: Geological Association of Canada, St. John's, Newfoundland and Labrador, Canada, p. 93114.

Barham, E., 2002, Translating terroir: the global challenge of French AOC labeling: Journal of Rural Studies, v. 19, p. 127-138.

Barnard, K.B., 2009, Geology and Wine in Missouri: Spatial Analysis of Terroir Using a Geographic Information System and Remote Sensing: M.S. Thesis, Missouri State University, $204 \mathrm{p}$.

Barthès B. and Roose E., 2002. Aggregate stability as an indicator of soil susceptibility to runoff and erosion; validation at several levels: Catena, v. 47, p. 133-149.

Barto E.K., Alt F., Oelmann Y., Wilcke W. and Rillig M.C., 2010. Contributions of biotic and abiotic factors to soil aggregation across a land use gradient: Soil Biology and Biochemistry, v. 42, p. 2316-2324.

Baxter, M.J., Crews, H.M., Dennis, M.J., Goodall, I., and Anderson, D., 1996, The determination of the authenticity of wine from its trace element composition: Food Chemistry, v. 60, p. 443-450.

Bednarz, S., 2002, Influence of Halloysite on the Engineering Behavior of Basaltic Saprolites in Northwestern Oregon and Southwestern Washington, M.S. thesis: Portland, Portland State University, $30 \mathrm{p}$.

Berry, E.M.W., 1990, The importance of soil in fine wine production: Journal of Wine Research, v. 1, i. 2, p. 179-195. 
Birkeland, P.W., 1999, Soils and Geomorphology, $3^{\text {rd }}$ edition: New York, Oxford University Press, Inc., 430 p.

Bowen, P.A., Bogdanoff, C.P., Estergaard, B.F., Marsh, S.G., Usher, K.B., Smith, C.A.S., and Frank, G., 2006, Geology and Wine 10. Use of geographic information system technology to assess viticulture performance in the Okanagan and Similkameen Valleys, British Columbia in Macqueen, R.W., and Meinert, L.D., eds., Fine Wine and Terroir - The Geoscience Perspective: Geological Association of Canada, St. John's, Newfoundland and Labrador, Canada, p. 137152.

Bramley, R.G.V., Ouzman, J., and Boss, P.K., 2011, Variation in vine vigour, grape yield and vineyard soils and topography as indicators of variation in the chemical composition of grapes, wine and wine sensory attributes: Australian Journal of Grape and Wine Research, v. 17, p. 217-229.

Bretz, J.H., 1969, The Lake Missoula Floods and the Channeled Scabland; The Journal of Geology, v. 77, n. 5, p. 505-543.

Buntley, G.J., and Westin, F.C., 1965, A comparative study of developmental color in a Chestnut-Chernozem-Brunizem soil climosequence: Soil Science Society of America Procedures 29, p. 579-582.

Burns, S.F., 2012, The importance of soil and geology in tasting terroir with a case history from the Willamette Valley, Oregon, in Dougherty, P.H., ed., The Geography of Wine - Regions, Terroir and Techniques: Springer, Dordrecht, Heidelberg, London, New York, p. 95-108.

Busacca, A.J., Begét, J.E., Markewich, H.W., Muhs, D.R., Lancaster, N., and Sweeney, M.R., 2004, Eolian Sediments in Gillespie, A.R., Porter, S.C., and Atwater, B.F., eds., The Quaternary period in the United States: Elsevier, Netherlands, p. 275309.

Busacca, A.J., and Meinert, L.D., 2003, Wine and geology - the terroir of Washington State in Swanson, T.W., ed., Western Cordillera and Adjacent Areas, The Geological Society of America Field Guide 4: The Geological Society of America, Boulder, Colorado, p. 69-85.

Castiñeira, M.M., Brandt, R., von Bohlen, A., Jakubowski, N., 2001, Development of a procedure for the multi-element determination of trace elements in wine by ICPMS: Journal of Analytical Chemistry, v. 370, p. 553-558. 
Castiñeira-Gómez, M.M., Brandt, R., Jakubowski, N., and Anderson, J.T., 2004, Changes of the metal composition in German white wines through the winemaking process. A study of 63 elements by inductively coupled plasma-mass spectrometry: Journal of Agricultural and Food Chemistry, v. 52, p. 2953-2961.

Coetzee, P.P., Steffens, F.E., Eiselen, R.J., Augustyn, O.P., Balcaen, L., and Vanhaecke, F., 2005, Multi-element analysis of South African wines by ICP-MS and their classification according to geographical origin: Journal of Agricultural and Food Chemistry, v. 53, p. 5060-5066.

Colombo P.C. and Torrent C.J., 1991. Relationships between aggregation and Fe oxides in Terra Rossa soils from southern Italy: Catena, v. 18, p. 51-59.

Constantini, E.A.C., Bucelli, P., and Priori, S., 2012, Quaternary landscape history determines the soil functional characters of terroir: Quaternary International, v. 265 , p. 63-73.

Cortell, J.M., Halbleim, M., Gallagher, A.V., Righetti, T.L., and Kennedy, J.A., 2007, Influence of Viney Vigor on Grape (Vitis vinifera L. Cv. Pinot Noir) Anthocyanins. 2. Anthocyanins and Pigmented Polymers in Wine: Joural of Agricultural and Food Chemistry, v. 55, p. 6585-6595.

Dami, I., Bordelon, B., Ferree, D.C., Brown, M., Ellis, M.A., Williams, R.N., Doohan, D., 2005, Midwest Grape Production Guide, Bulletin 919: Ohio State University Extension, $155 \mathrm{p}$.

Dean, W. E. Jr., 1974, Determination of carbonate and organic matter in calcareous sediments and sedimentary rocks by loss on ignition: Comparison with other methods. Journal of Sedimentary Petrology, v. 44, p. 242-248.

Di Paola-Narajo, R.D., Baroni, M.V., Podio, N.S., Rubinstein, H.R., Fabani, M.P., Badini, R.G., Inga, M., Ostera, H.A., Cagnoni, M., Gallegos, E., Gautier, E., Peral-García, P., Hoogewerff, J., and Wunderlin, D.A., 2011, Fingerprints for main varieties of Argentinean wines: terroir differentiation by inorganic, organic, and stable isotopic analysis coupled to chemometrics: Journal of Agricultural and Food Chemistry, v. 59, p. 7854-7865.

Dougherty, P.H., 2012, Introduction to the geographical study of viticulture and wine production in Dougherty, P.H., ed., The Geography of Wine - Regions, Terroir and Techniques: Springer, Dordrecht, Heidelberg, London, New York, p. 3-36. 
Douglas, D., Cliff, M.A., and Reynolds, A.G., 2001, Canadian terroir: characterization of Riesling wines from the Niagara Peninsula: Food Research International, v. 34, p. 559-563.

Ebeler, S.E., 2001, Analytical chemistry: unlocking the secrets of wine flavor: Food Reviews International, v. 17, i. 1, p. 45-64.

Ebeler, S.E., and Thorngate, J.H., 2009, Wine chemistry and flavor: looking into the crystal glass: Journal of Agricultural and Food Chemistry, v. 57, p. 8098-8108.

Eggers, N.J., Greenough, J.D., and Cernak, T., 2006, Classification of British Columbia's Okanagan chardonnay wines by origin using volatile components in Macqueen, R.W. and Meinert, L.D., eds., Fine Wine and Terroir: The Geoscience Perspective, Newfoundland and Labrador, Geological Association of Canada c/o Department of Earth Sciences, Memorial University of Newfoundland, p. 183192.

Eggleton, R.A., Foudoulis, C., and Varkevisser, D., 1987, Weathering of basalt: changes in rock chemistry and mineralogy: Clays and Clay Minerals, v. 35, n. 3, p. 161169.

Elliott-Fisk, D.L., 1993, Viticultural soils of California, with special reference to the Napa Valley: Journal of Wine Research, v. 4, i. 2, p. 67-78.

Elsass, F., Dubroeucq, D., and Thiry, M., 2000, Diagenesis of silica minerals from clay minerals in volcanic soils of Mexico: Clay Minerals, v. 35, i. 3, p.477-489.

EPA, 1998, Method 6020A (SW-846): Inductively Coupled Plasma-Mass Spectrometry, Revision 1, 23 p.

EPA, 2007a, Method 3051A (SW-846): Microwave Assisted Acid Digestion of Sediments, Sludges, Soils, and Oils, Revision 1,30 p.

EPA, 2007b, Method 6010C (SW-846): Inductively Coupled Plasma-Atomic Emission Spectrometry, Revision 3, $30 \mathrm{p}$.

EPA, 2007c, Method 9056A (SW-846): Determination of Inorganic Anions by Ion Chromatography, $19 \mathrm{p}$.

Eschnauer, H., Jakob, L., Meierer, H., Neeb, R., 1989, Use and limitations of IP-OES in wine analysis: Mikrochimica Acta, v. 3, p. 291-298. 
Fabani, M.P., Toro, M.E., Vázquez, F., Diaz, M.P., and Wunderlin, D.A., 2009, Differential absorption of metals from soil to diverse vine varieties from the Valley of Tulum (Argentina): consequences to evaluate wine provenance: Journal of Agricultural and Food Chemistry, v. 57, p. 7409-7416.

Fabani, M.P., Arrúa, R.C., Vázquez, F., Diaz, M.P., Baroni, M.V., Wunderlin, D.A., 2010, Evaluation of elemental profile coupled to chemometrics to assess the geographical origin of Argentinean wines: Food Chemistry, v. 119, p. 372-379.

Fischer, U., Roth, D., and Christmann, M., 1999, The impact of geographic origin, vintage and wine estate on sensory properties of Vitis vinifera cv. Riesling wines: Food Quality and Preference, v. 10, p. 281-288.

Frías, S., Conde, J.E., Rodríguez-Bencomo, J.J., García-Montelongo, F., Pérez-Trujillo, J.P., 2003, Classification of commercial wines from the Canary Islands (Spain) by chemometric techniques using metallic content: Talanta, v. 59, p. 335-344.

Galani-Nikolakaki, S., Kallithrakas-Kontos, N., and Katsanos, A.A., 2002, Trace element analysis of Cretan wines and wine products: The Science of the Total Environment, v. 285, p. 155-163.

Galgano, F., Favati, F., Caruso, M., Scarpa, T., Palma, A., 2008, Analysis of trace elements in southern Italian wines and their classification according to provenance: LWT - Food Science and Technology, v. 41, p. 1808-1815.

Gee, G.W., and Bauder, J.W., 1986, Particle-size analysis in Klute, A., ed., Methods of soil analysis. Part 1: Physical and Mineralogical Methods, American Society of Agronomy, Soil Science Society of America, Series in Agronomy 9, Madison, WI, p. 383-409.

Gonzálvez, A., Llorens, A., Cervera, M.L., Armenta, S., and de la Guardia, M., 2009, Elemental fingerprint of wines from the protected designation of origin Valencia: Food Chemistry, v. 112, p. 26-34.

Greenough, J.D., Longerich, H.P., and Jackson, S.E., 1997, Element fingerprinting of Okanagan Valley wines using ICP-MS: Relationships between wine composition, vineyard and wine colour: Australian Journal of Grape and Wine Research, v. 3, p. $75-83$. 
Greenough, J.D., Mallory-Greenough, L.M., and Fryer, B.J., 2005, Geology and Wine 9. Regional trace element fingerprinting of Canadian wines: Geoscience Canada, v. 32, n. 3, p. 129-137.

Haynes, S.J., 2006a, Geology and Wine 1. Concept of terroir and the role of geology in Macqueen, R.W., and Meinert, L.D., eds., Fine Wine and Terroir - The Geoscience Perspective: Geological Association of Canada, St. John's, Newfoundland and Labrador, Canada, p. 3-7.

Haynes, S.J., 2006b, Geology and Wine 2. A geological foundation for terroirs and potential sub-appellations of Niagara Peninsula wines, Ontario, Canada in Macqueen, R.W., and Meinert, L.D., eds., Fine Wine and Terroir - The Geoscience Perspective: Geological Association of Canada, St. John's, Newfoundland and Labrador, Canada, p. 9-29.

Heiri, O., Lotter, A.F., Lemcke, G., 2001, Loss on ignition as a method for estimating organic and carbonate content in sediments: reproducibility and comparability of results: Journal of Paleolimnology, v. 25, p. 101-110.

Helgason, B.L., Walley, F.L., and Germida, J.J., 2010, No-till soil management increases microbial biomass and alters community profiles in soil aggregates: Applied Soil Ecology, v. 46, p. 390-397.

Heymann, H., and Noble, A.C., 1987, Descriptive analysis of commercial Cabernet Sauvignon wines from California: American Journal of Enology and Viticulture, v. 38, n. 1, p. 41-44.

Horneck, D.A., Hart, J.M., Topper, K., and Koepsell, B., 1989, Methods of Soil Analysis Used in the Soil Testing Laboratory at Oregon State University: Agricultural Experiment State, Oregon State University, SM 89:4, 21 p.

Jackson, M., 1964, Chemical composition of soils. in F.E. Bear, ed., Chemistry of the Soil: Reinhold Publishing Corp., New York, p. 71-141.

Jackson, R.S., 2008, Wine Science Principles and Applications, Third Edition: Academic Press, Burlington, MA, 776 p.

Jackson, R.S., 2009, Wine Tasting - A Professional Handbook, Second Edition: Academic Press, Burlington, MA, 512 p. 
Jones, G.V., Snead, N., and Nelson, P., 2006, Geology and Wine 8. Modeling viticultural landscapes: a GIS analysis of the terroir potential in the Umpqua Valley of Oregon in Macqueen, R.W., and Meinert, L.D., eds., Fine Wine and Terroir - The Geoscience Perspective: Geological Association of Canada, St. John's, Newfoundland and Labrador, Canada, p. 115-126.

Jones, G.V, Duff, A.A., Hall, A., and J. Myers, 2010, Spatial analysis of climate in winegrape growing regions in the western United States. American Journal of Enology and Viticulture, 61:313-326.

Jones, G.V., Reid, R., and Vilks, A., 2012, Climate, grapes and Wine: Structure and suitability in a variable and changing climate in Dougherty, P.H., ed., The Geography of Wine - Regions, Terroir and Techniques: Springer, Dordrecht, Heidelberg, London, New York, 109-136 p.

Joyce, E.B., 2004, Integrating soils, regolith and slope dynamics in the study of the terroir of wine regions in Central Victoria, Australia in Roach, I.C., ed., Regolith 2004: Cooperative Research Centre for Landscape Environments and Mineral Exploration, p. 157-160.

Klein, C., and Dutrow, B., 2007, The $23^{\text {rd }}$ edition of the manual of mineral science (after James D. Dana): Hoboken, John Wiley \& Sons, Inc., 675 p.

Kment, P., Mihaljevič, M., Ettler, V., Šebek, O., Strnad, L., and Rohlová, L., 2005, Differentiation of Czech wines using multielement composition - A comparison with vineyard soil: Food Chemistry, v. 91, p. 157-165.

Kontkanen, D., Reynolds, A.G., Cliff, M.A., King, M., 2005, Canadian terroir: sensory characterization of Bordeaux-style red wine varieties in the Niagara Peninsula: Food Research International, v. 38, p. 417-425.

Kodur, S, 2011, Effects of juice $\mathrm{pH}$ and $\mathrm{K}$ on juice and wine quality, and regulation of $\mathrm{K}$ in grapevines through rootstocks (Vitis): a short review: Vitis VEA, v. 50, n. 1, p. $1-6$.

Lara, R., Cerutti, S., Salonia, J.A., Olsina, R.A., Martinez, L.D., 2005, Trace element determination of Argentine wines using ETAAS and USN-ICP-OES: Food and Chemical Toxicology, v. 43, p. 293-297.

Latorre, M.J., García-Jares, C., Mèdina, B., Herrero, C., 1994, Pattern recognition analysis applied to classification of wines form Galicia (Northwestern Spain) with 
certified brand of origin: Journal of Agricultural and Food Chemistry, v. 42, p. 1451-1455.

Leeuwen, C.V., Friant, P., Choné, X., Tregoat, O., Koundouras, S., and Dubourdieu, D., 2004, Influence of climate, soil, and cultivar on terroir: American Journal of Enology and Viticulture, v. 55, i. 3, p. 207-217.

Lim, C.H., and Jackson M.L., 1982, Method of loss on ignition in Page, A.L., ed., Methods of Soil Analysis: Chemical and Microbiological Properties, $2^{\text {nd }}$ Edition: Soil Science Society of America, Madison Wisconsin, n. 9, part 2, p. 4.

Louw, L., Roux, K., Tredoux, A., Tomic, O., Naes, T., Nieuwoudt, H.H., and van Rensburg, P., 2009, Characterization of selected South African young cultivar wines using FTMIR spectroscopy, gas chromatography, and multivariate data analysis: Journal of Agricultural and Food Chemistry, v. 57, p. 2623-2632.

MacNeil, K., 2001, The Wine Bible: New York, Workman Publishing, 910 p.

Madin, I. P., 2009, Oregon: A Geologic History, Oregon Department of Geology and Mineral Industries Interpretive Series Map 28 [companion web page], http://www.oregongeology.org/sub/publications/IMS/ims-028/index.htm (accessed October 2015)

Manceau, A., Tamura, N., Celestre, R.S., Macdowell, A.A., Geoffroy, N., Sposito, G., and Padmore, H.A., 2003, Molecular-Scale Speciation of Zn and Ni in Soil Ferromanganese Nodules from Loess Soils of the Mississippi Basin:

Environmental Science and Technology, v. 37, p. 75-80.

Mangan, M.T., Wright, T.L., Swanson, D.A., Byerly, G.R., 1986, Regional correlation of Grande Ronde Basalt flows, Columbia River Basalt Group, Washington, Oregon, and Idaho: Geological Society of America Bulletin, v. 97, p. 1300-1318.

Medley. E., 2012, Ancient cataclysmic floods in the Pacific Northwest: ancestors to the Missoula Floods, M.S. thesis: Portland, Oregon, Portland State University, 185 p.

Meinert, L.D., and Busacca, A.J., 2006a, Geology and Wine 3. Terroirs of the Walla Walla Valley appellation, southeastern Washington State, USA in Macqueen, R.W., and Meinert, L.D., eds., Fine Wine and Terroir - The Geoscience Perspective: Geological Association of Canada, St. John's, Newfoundland and Labrador, Canada, p. 31-57. 
Meinert, L.D., and Busacca, A.J., 2006b, Geology and Wine 6. Terroir of the Red Mountain Appellation, Central Washington State, U.S.A. in Macqueen, R.W., and Meinert, L.D., eds., Fine Wine and Terroir - The Geoscience Perspective: Geological Association of Canada, St. John's, Newfoundland and Labrador, Canada, p. 73-92.

Miller, B.J., Lewis, G.C., Alford, J.J., and Day, W.J., 1985, Loesses in Louisiana and at Vicksburg, Mississippi: Guidebook for the Friends of the Pleistocene Field Trip, April 12-14: Louisiana State University and A \& M College, Baton Rouge, LA, $126 \mathrm{p}$.

Miller, C.D., and Birkeland, P.W., 1974, Probable pre-Neoglacial age of the type Temple Lake moraine, Wyoming: Discussion and additional relative-age data: Arctic and Alpine Research, v. 6, n. 3, p. 301-306.

Mizota, C., Toh, N., Matsuhisa, Y., 1987, Origin of cristobalite in soils derived from volcanic ash in temperate and tropical regions: Geoderma, v. 39, p. 323-330.

Moore, G.W., 2002, Geology of vineyards in the Willamette Valley, Oregon: Department of Geosciences, Oregon State University: http://www.cmug.com/chintimp/willamette.vineyards.htm (accessed January 2013).

Moore, G.W., 2005, Wine with a deep flavor: Nature, v. 434, p. 438.

NRCS, 2013, National Cooperative Soils Survey, National Cooperative Soil Characterization Database: http://ncsslabdatamart.sc.egov.usda.gov (accessed May 2013).

NRCS, 2014, National Cooperative Soils Survey, Web Soil Survey: http://websoilsurvey.nrcs.usda.gov/app/WebSoilSurvey.aspx (accessed September 2014).

NRCS, 2015, National Cooperative Soils Survey, Web Soil Survey: http://websoilsurvey.nrcs.usda.gov/app/WebSoilSurvey.aspx (accessed April 2015).

Nelson, S. A., 2011, Weathering and clay minerals: Tulane University, Mineralogy, http://www.tulane.edu/ sanelson/eens211/weathering\&clayminerals.htm (accessed May 2013). 
Noble, A.C., and Ebeler, S.E., 2002, Use of multivariate statistics in understanding wine flavor: Food Reviews International, v. 18, i. 1, p. 1-21.

NOAA, 2013, National Centers for Environmental Information, Climate Data Online, http://www.ncdc.noaa.gov (accessed October 2013).

Pérez-Magariño, S., Ortega-Heras, M., and González-San José, M.L., 2002, Multivariate classification of rosé wines from different Spanish protected designations of origin: Analytica Chimica Acta, v. 458, p. 187-190.

Perk, M. van der, 2006, Soil and Water Contamination from molecular to catchment scale: London, Taylor \& Francis, 389 p.

Peterson, C.D., Minor, R., Peterson, G.L., and Gates, E.B., 2011, Pre-and post-Missoula flood geomorphology of the Pre-Holocene ancestral Columbia River Valley in the Portland forearc basin, Oregon and Washington, USA: Geomorphology, v. 129, p. 276-293.

Pohl, P., 2007, What do metals tell us about wine?: Trends in Analytical Chemistry, v. 26, n. 9, p. 941-949.

Polášková, P., Herszage, J., and Ebeler, S.E., 2008, Wine flavor: chemistry in a glass: Chemical Society Reviews, v. 37, p. 2478-2489.

Pomeral, C., 1989, The Wines and Winelands of France: Geological Journeys: London, Robertson McCarta Limited, 370 p.

Retallack, G.J., and Burns, S.F., 2016, The effects of soils on the taste of wine: GSA Today, v. 26, n. 5, p. 4-9.

Ricker, T.R., 2013, As in the soils of Northwest Oregon: M.S. Thesis, Portland State University, $161 \mathrm{p}$.

Rillig, M.C., Mardatin, N.F., Leifheit, E.F., and Antunes, P.M., 2010, Mycelium of arbuscular mycorrhizal fungi increases soil water repellency and is sufficient to maintain water-stable soil aggregates: Soil Biology \& Biochemistry, v. 42, p. 1189-1191.

Robert, P., Rey-Debove, J., and Rey, A., 2008, Le nouveau petit Robert de la langue Francaise 2009: Educa Books/ Le Robert, 2838 p. 
Sabon, I., De Revel, G., Kotseridis, Y., and Bertrand, A., 2002, Determination of volatile compounds in Grenache wines in relation with different terroirs in the Rhone Valley: Journal of Agricultural and Food Chemistry, v. 50, p. 6341-6345.

Saurina, J., 2010, Characterization of wines using compositional profiles and chemometrics: Trends in Analytical Chemistry, v. 29, n. 3, p. 234-245.

Schlosser, J., Reynolds, A.G., King, M., and Cliff, M., 2005, Canadian terroir: sensory characterization of Chardonnay in the Niagara Peninsula: Food Research International, v. 38, p. 11-18.

Seguin, G., 1986, ‘Terroirs' and pedology of wine growing: Experientia, v. 42, p. 861873.

Soil Survey Staff, 1999, Soil taxonomy: A basic system of soil classification for making and interpreting soil surveys., 2nd edition.: Natural Resources Conservation Service, U.S. Department of Agriculture Handbook, 436 p.

Soil Survey Staff, 2010, Natural Resources Conservation Service, United States Department of Agriculture, Soil Survey Geographic (SSURGO) Database for Willamette Valley, Oregon: http://soildatamart.nrcs.usda.gov (accessed September 2010).

Spohn, M. and Giani, L., 2011, Impacts of land use change on soil aggregation and aggregate stabilizing compounds as dependent on time: Soil Biology \& Biochemistry, v. 43, p. 1081-1088.

Starr-Peace, D., 2005, The geography of vineyard soils and terroir in the North Willamette Valley, Oregon: M.A. Thesis, Portland State University, 93 p.

Stroh, A., Brückner, P., and Völlkopt, U., 1994, Multielement analysis of wine samples using ICP-MS: Atomic Spectroscopy, March/April, p. 100-106.

Swanson, D.A., Cameron, K.A., Evarts, R.C., Pringle, P.T., and Vance, J.A., 1989, Cenozoic volcanism in the Cascade Range and Columbia Plateau, southern Washington and northernmost Oregon: Field excursions to volcanic terranes in the western United States, Volume II: Cascades and Intermountain West, Chapin, C.E., and Zidek, J., eds., New Mexico Bureau of Mines \& Mineral Resources Memoir 47, p. 1-43. 
Szentmihályi, K., Csiktusnádi-Kiss, G.A., Keszler, Á., Kótai, L., Candeaias, M., Bronze, M.R., Boas, L.V., Spauger, I., and Forgács, E., 2000, Method development for measurement of elements in Hungarian red wines by Inductively Couple Plasma Optical Emission Spectrometry (ICP-OES): Acta Alimentaria, vol. 29, n. 2, p. 105-121.

Taylor, V.F., Longerich, H.P., and Greenough, J.D., 2003, Multielement Analysis of Canadian Wines by Inductively Coupled Plasma Mass Spectrometry (ICP-MS) and Multivariate Statistics: Journal of Agricultural and Food Chemistry, v. 51, p. 856-860.

Taylor, V.F., Longerich, H.P., and Greenough, J.D., 2006, Geology and Wine 5. Provenance of Okanagan Valley wines, British Columbia, using trace elements: promise and limitations in Macqueen, R.W., and Meinert, L.D., eds., Fine Wine and Terroir - The Geoscience Perspective: Geological Association of Canada, St. John's, Newfoundland and Labrador, Canada, p. 59-72.

Theil, G., Geisler, G., Blechschmidt, I., and Danzer, K., 2004, Determination of trace elements in wines and classification according to their provenance: Analytical and Bioanalytical Chemistry, v. 378, p. 1630-1636.

Tomasino, E., Harrison, R., Sedcole, R., Frost, A., and Sherlock, R., 2012a, characterizing regional New Zealand Pinot Noir: Australian \& New Zealand Grapegrower \& Winemaker, v. 581, p. 64-68.

Tomasino, E., Harrison, R., Sedcole, R., and Frost, A., 2012b, Regional Differentiation of New Zealand Pinot Noir wine by professionals using canonical variate analysis, Ph.D. Dissertation: Lincoln, Canterbury, New Zealand, Lincoln University, 25 p.

TTB - Alcohol and Tobacco Tax and Trade Bureau, 2007, Authorized wine appellations of origin - U.S. Viticultural Areas: U.S. Department of the Treasury, 9 p.

Unwin, T., 2012 Terroir: At the heart of geography in Dougherty, P.H., ed., The Geography of Wine - Regions, Terroir and Techniques: Springer, Dordrecht, Heidelberg, London, New York, p. 37-48.

USDA, 2012, 2011 Oregon Vineyard Report, National Agricultural Statistics Service, Oregon Field Office, Portland, Oregon, p. 1-2.

USDA, 2010, 2009 Oregon Vineyard Report, National Agricultural Statistics Service, Oregon Field Office, Portland, Oregon, p. 1-2. 
USDA, 2009, 2008 Oregon Vineyard Report, National Agricultural Statistics Service, Oregon Field Office, Portland, Oregon, p. 1-2.

USDA, 2008, 2007 Oregon Vineyard Report, National Agricultural Statistics Service, Oregon Field Office, Portland, Oregon, p. 1-2.

Van Ranst, E., Utami, S.R., Verdoodt, A., Qafoku, N.P., 2008, Mineralogy of a perudic Andisol in central Java, Indonesia: Geoderma, v. 144, p. 379-386.

Vilanova, M., Zamuz, S., Vilariño, F., and Sieiro, C., 2007, Effect of terroir on the volatiles of Vitis vinifera cv. Albariño: Journal of the Science of Food and Agriculture, v. 87, p. 1252-1256.

Vilanova, M., Genisheva, Z., Bescansa, L., Masa, A., and Oliveira, J.M., 2009, Volatile composition of wines from cvs. Blanco lexítimo, Agudelo and Serradelo (Vitis vinifera) grown in Betanzos (NW Spain): Journal of the Institute of Brewing, v. 115 , n. 1, p. 35-40.

Wada, K., 1987, Minerals formed and mineral formation from volcanic ash by weathering: Chemical Geology, v. 60, p. 17-28.

Weil, R.R., and Brady, N.C., 2016, The Nature and Properties of Soils, $15^{\text {th }}$ edition: New York, Pearson, $1104 \mathrm{p}$.

Wells, Ray, 2006, Oregon geology--Parent of the soil, foundation for the vine: U.S. Geological Survey Open-File Report 2006-1069: http://pubs.usgs.gov/of/2006/1069/ (accessed November 2010).

West, J.B., Ehleringer, J.R., and Cerling, T.E., 2007, Geography and vintage predicted by a novel GIS model of wine $\delta^{18} \mathrm{O}$ : Journal of Agriculture and Food Chemistry, v. 55, p. 7075-7083.

Watkins, R.L. and Meyer, V.F., 1997, Vineyard site suitability in eastern California: GeoJournal, v. 43, i. 3, p. 229-239.

White, R.E., 2003, Soils for Fine Wines: Oxford, University Press, 279 p.

White, R.E., 2009, Understanding Vineyard Soils: Oxford, University Press, 230 p.

Wilson, J.E., 1998, Terroir: The Role of Geology, Climate, and Culture in the Making of French Wines: London, Mitchell Beazley, 336 p. 
Wilson, M.J., 1999, The origin and formation of clay minerals in soils: past, present and future perspectives: Clay Minerals, v. 34, p. 7-25.

Yang, Y., 2010, Trace element and rare earth element profiles in berry tissues of three grape cultivars: American Journal of Enology and Viticulture, v. 61, i. 3, p. 401407. 


\section{Appendix A Vineyard Soil Descriptions}

\section{Elk Cove Vineyards, Clay Court Vineyard Block E}

Taxonomic Classification: Fine, mixed, active, mesic Xeric Palehumults

Soil Series: Jory

Lat/long Coordinates: 45¹9'31.7"N 122 ${ }^{\circ} 50^{\prime} 05.7^{\prime \prime} \mathrm{W}$ (45.325479, -122.834909)

UTM Coordinates: $512,947 \mathrm{mE}, 5,019,125 \mathrm{mN}$

Physiographic Position: Hill crest

MAT/MAP: 11 degrees C (52 degrees F)/152 cm (60 in.)

Elevation: 186 meters (611 feet)

Slope: 0-1 degree

Aspect: South

Vegetation: Pinot Noir Vineyard on trellis, permanent cover between rows

Parent Material: Basalt (soil contains pisolites)

Bedrock: Basalt

Ap $\quad$ 0-15 cm (0-6 in.); dark brown (7.5 YR 3/4), dark yellowish brown (10 YR 4/4) dry, silt loam; moderate medium granular to subangular blocky structure; very hard; very firm; slightly sticky and slightly plastic; common very fine roots; abundant fine concretions and dark staining; slightly acid (pH 6.4); gradual, wavy boundary.

Bt1 15-90 cm (6-35 in.); dark reddish brown (5 YR 3/4), brown (7.5 YR 4/4) dry, silty clay; weak medium subangular blocky structure; very hard, very firm, very sticky and very plastic; common prominent clay films on faces of peds; abundant fine concretions; strongly acid ( $\mathrm{pH} 5.4$ ); augured at $44 \mathrm{~cm}$.

Bt2 90-115 cm (35-45 in.); dark red (2.5 YR 3/6), brown (7.5 YR 4/4) dry, silty clay; weak medium subangular blocky structure; $10 \%$ gravel (basalt); hard, very firm, sticky and plastic; common faint clay films on faces of peds and interstitial pores; abundant fine concretions; strongly acid ( $\mathrm{pH} 5.4)$; augered.

Bt3 115-150+ cm (45-59+ in.); reddish brown (2.5 YR 5/4), dark reddish brown (5 YR 3/4) dry, clay; moderate medium subangular blocky structure; hard, firm, sticky and plastic; common distinct clay films on faces of peds; abundant fine concretions; strongly acid ( $\mathrm{pH} 5.1)$; augered. 


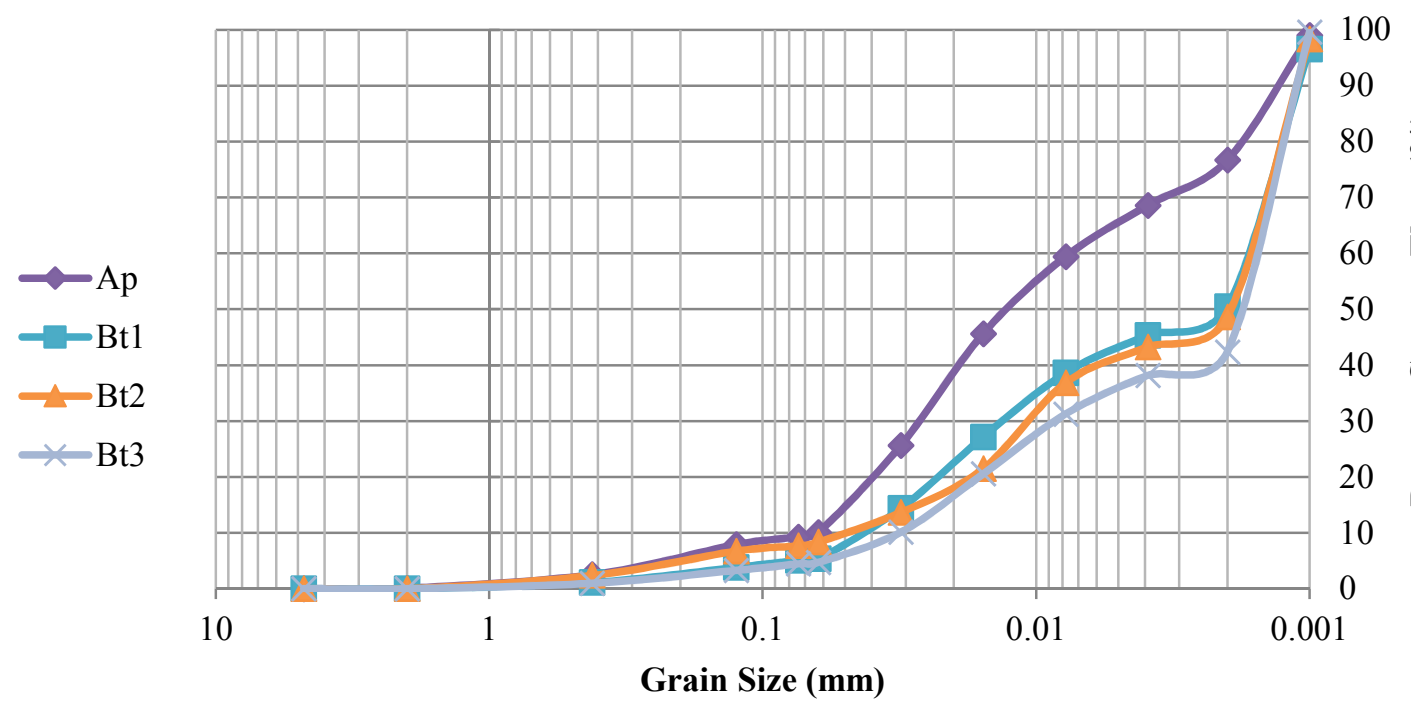

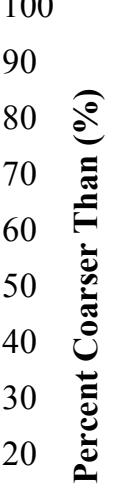

Figure 61. Particle size cumulative weight percent curve as determined by pipette analysis for each horizon of Elk Cove Vineyards, Clay Court Vineyard Block E soil.

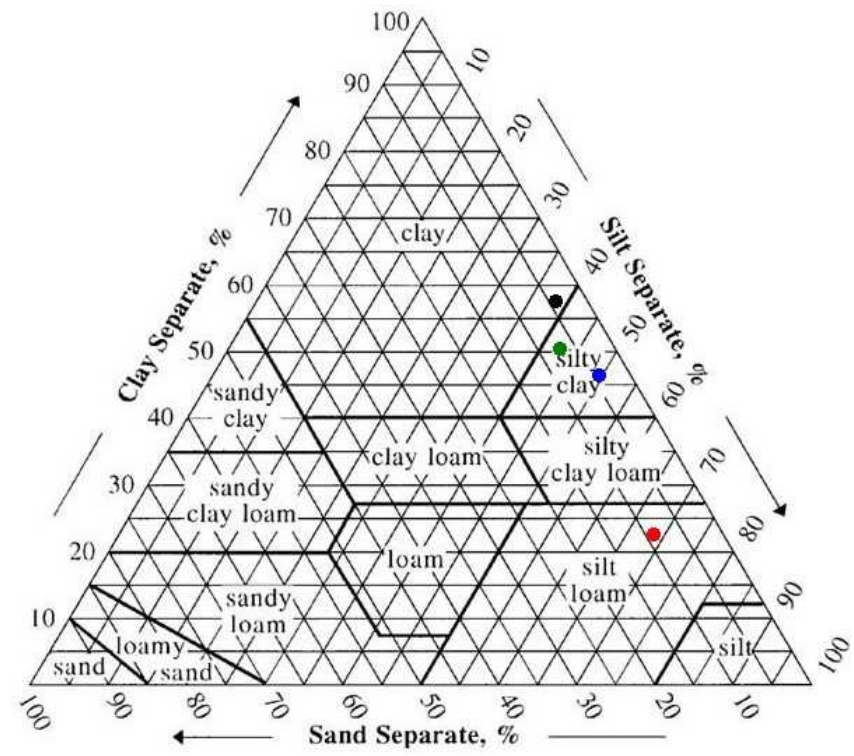

Figure 62. Elk Cove Vineyards, Clay Court Vineyard Block E soil pit horizon textures determined by pipette analysis. Red - Ap, Blue - Bt1, Green - Bt2, Black - Bt3. 


\section{Elk Cove Vineyards, Roosevelt Estate Vineyard}

Taxonomic Classification: Fine, mixed, superactive, mesic Ultic Haploxeralfs - Fine, mixed, superactive, mesic Ultic Palexeralfs (previously Fine-loamy, mixed, active, mesic Ultic Haploxeralfs)

Soil Series: Goodin - Melbourne (previously Willakenzie)

Lat/long Coordinates: 45²4'52.1"N 12311'08.8"W (45.414466, -123.185770)

UTM Coordinates: $485,460 \mathrm{mE}, 5,029,012 \mathrm{mN}$

Physiographic Position: Summit

MAT/MAP: 11 degrees C (52 degrees F)/152 cm (60 in.)

Elevation: 190 meters (623 feet)

Slope: 0-1 degree

Aspect: West

Vegetation: Pinot Noir Vineyard on trellis, cultivated between rows

Parent Material: Coast Range marine sediments (soil contains muscovite mica and quartz sand)

Bedrock: Spencer Formation

Ap 0-15 cm (0-6 in.); brown (10 YR 5/3), brown (10 YR 5/3) dry, silt loam; moderate medium subangular blocky structure; very hard, very firm, slightly sticky and slightly plastic; common very fine roots; strongly acid (pH 5.4); clear, wavy boundary; krotovina.

AB 15-25 cm (6-10 in.); yellowish brown (10 YR 5/4), brown (7.5 YR 5/3) dry, silt loam; moderate medium subangular blocky structure; extremely hard, extremely firm, sticky and plastic; strongly acid ( $\mathrm{pH} 5.5$ ); abrupt, wavy boundary.

Bt1 25-36 cm (10-14 in.); yellowish brown (10 YR 5/4), yellowish brown (10 YR 5/4) dry, silty clay loam; moderate medium subangular blocky structure; extremely hard, extremely firm, very sticky and very plastic; few faint clay films on faces of peds; strongly acid (pH 5.4); abrupt, wavy boundary.

Bt2 36-64 cm (14-25 in.); yellowish red (5 YR 4/6), brown (7.5 YR 4/4) dry, clay; moderate medium subangular blocky structure; very hard, very firm, very sticky and very plastic; few large roots; common distinct clay films on faces of peds and interstitial pores; strongly acid ( $\mathrm{pH} \mathrm{5.4)}$; augered at $45 \mathrm{~cm}$.

Bt3 64-84 cm (25-33 in.); dark reddish brown (5 YR 3/4), brown (7.5 YR 4/4) dry, silty clay; moderate medium subangular blocky structure; hard, firm, very sticky and very plastic; few large roots; few faint clay films on faces of peds; strongly acid ( $\mathrm{pH}$ 5.1); augered. 
Bt4 84-110 cm (33-43 in.); reddish yellow (7.5 YR 6/6), yellow (10 YR 7/6) dry, silty clay loam; moderate medium subangular blocky structure; firm, very sticky and very plastic; few very faint clay films on faces of peds; secondary colors, gray (10 YR 6/1) and pale yellow (2.5 Y 8/4) dry; very strongly acid ( $\mathrm{pH} 4.9)$; augered.

C1 110-144 cm (43-57 in.); brownish yellow (10 YR 6/6), yellow (10 YR 7/8) dry, silty clay loam; moderate fine subangular blocky structure; firm, slightly sticky and slightly plastic; secondary colors, gray (7.5 YR 5/1) and very pale brown (10 YR 8/4) dry; very strongly acid ( $\mathrm{pH} 4.9$ ); augered.

C2 144-161 cm (57-63 in.); strong brown (7.5 YR 5/8), yellowish brown (10 YR 5/6) dry, silty clay loam; single grain to massive structure; loose, friable, nonsticky and nonplastic (wet); very strongly acid ( $\mathrm{pH} 4.9)$; augured.

$\mathrm{Cr} \quad 161+\mathrm{cm}(63+$ in.); brownish yellow (10YR 6/8), pale yellow (2.5 Y 8/3) dry, silty clay loam; single grain to massive structure; loose, friable, slightly sticky and slightly plastic; secondary colors, pale brown (10 YR 6/3) and brownish yellow (10 YR 6/6) dry; very strongly acid (pH 4.7); augered (loose weathered sandstone).
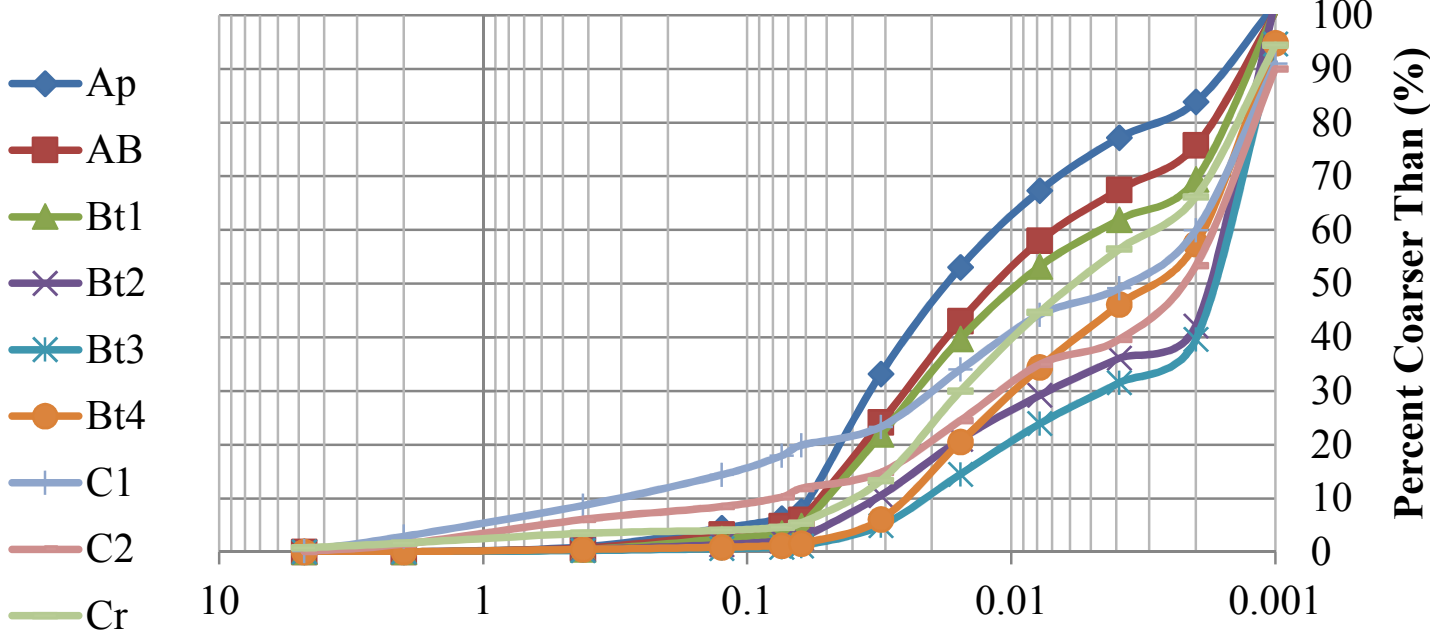

Figure 63. Particle size cumulative weight percent curve as determined by pipette analysis for each horizon of Elk Cove Vineyards, Roosevelt Estate Vineyard soil. 


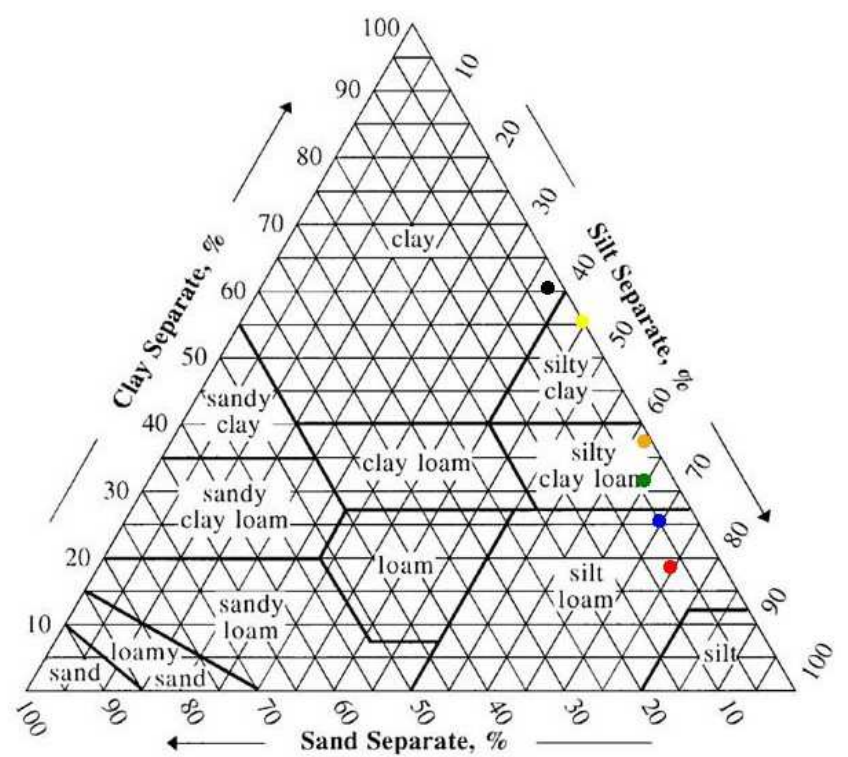

Figure 64. Elk Cove Vineyards, Roosevelt Estate Vineyard soil pit horizon textures determined by pipette analysis. Red - Ap, Blue - AB, Green - Bt1, Black - Bt2, Yellow - Bt3, Orange - Bt4.

\section{Elk Cove Vineyards, Five Mountain Vineyard}

Taxonomic Classification: Fine-silty, mixed, active, mesic Ultic Haploxeralfs Soil Series: Laurelwood

Lat/long Coordinates: 45²6'55.3"N 12302'11.6"W (45.448694, -123.036566)

UTM Coordinates: 497,134mE, 5,032,795mN

Physiographic Position: Midslope

MAT/MAP: 11 degrees C (52 degrees F)/152 cm (60 in.)

Elevation: 110 meters (362 feet)

Slope: Slight

Aspect: South

Vegetation: Pinot Noir Vineyard on trellis, permanent cover between rows

Parent Material: Basalt (soil contains pisolites)

Bedrock: Basalt

Ap $\quad$ 0-30 cm (0-12 in.); yellowish brown (10 YR 5/4), yellowish brown (10 YR 5/4) dry, silt loam; weak fine subangular blocky structure; hard; firm; slightly sticky and slightly plastic; common very fine roots; abundant fine concretions; moderately acid (pH 5.7); clear, wavy boundary. 
Bt1 30-61 cm (12-24 in.); dark yellowish brown (10 YR 3/4), yellowish brown (10 YR 5/4) dry, silty clay loam; moderate medium subangular blocky structure; hard, firm, very sticky and plastic; common distinct clay films on faces of peds; few fine concretions and dark staining; moderately acid ( $\mathrm{pH}$ 6.0); gradual, wavy boundary.

Bt2 61-114 cm (24-45 in.); dark yellowish brown (10 YR 4/4), yellowish brown (10 YR 5/4) dry, silty clay loam; moderate medium subangular blocky structure; hard, firm, very sticky and very plastic; few faint clay films on faces of peds and interstitial pores; few fine concretions; moderately acid ( $\mathrm{pH} 5.8)$; augered.

Bt3 114-171+ cm (45-67+ in.); dark brown (10 YR 3/3), dark yellowish brown (10 YR 4/4) dry, silty clay loam; moderate medium subangular blocky structure; very sticky and very plastic; few faint clay films on faces of peds; few fine concretions and rock fragments; strongly acid ( $\mathrm{pH} 5.5)$; augered.

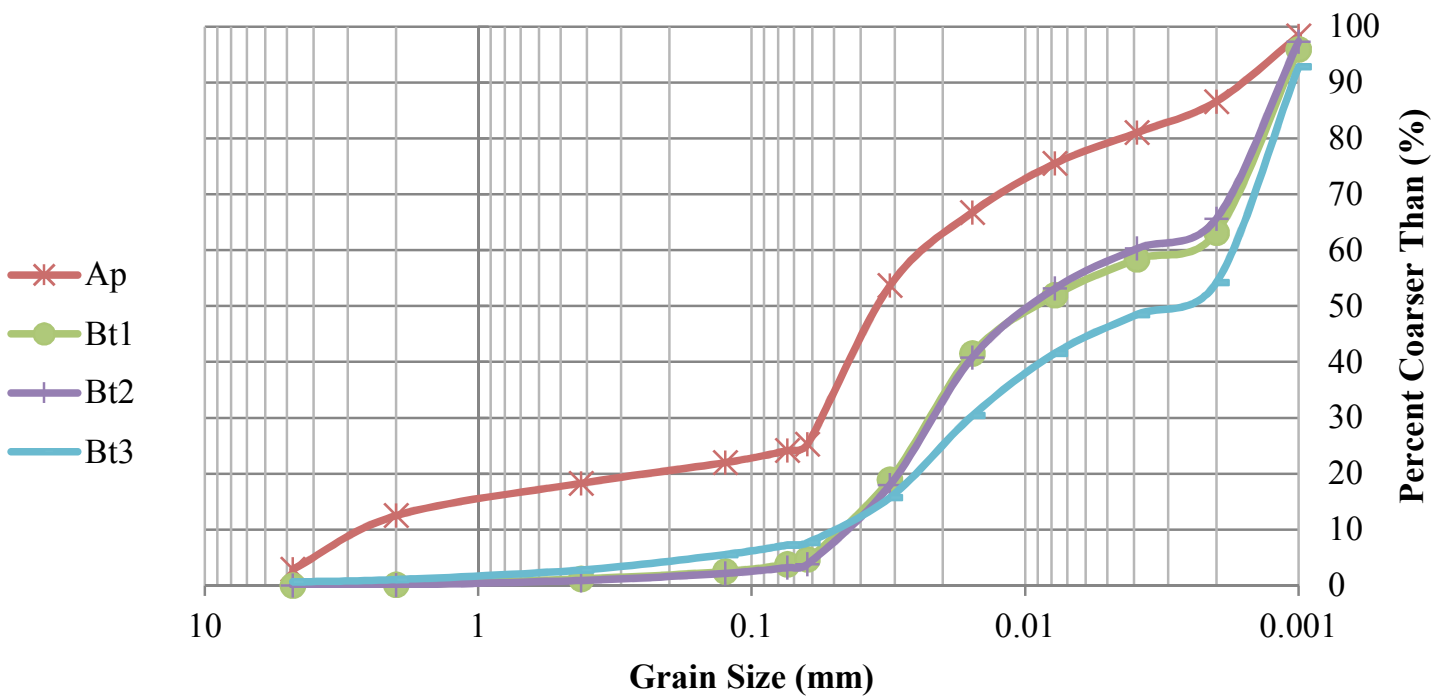

Figure 65. Particle size cumulative weight percent curve as determined by pipette analysis for each horizon of Elk Cove Vineyards, Five Mountain Vineyard soil. 


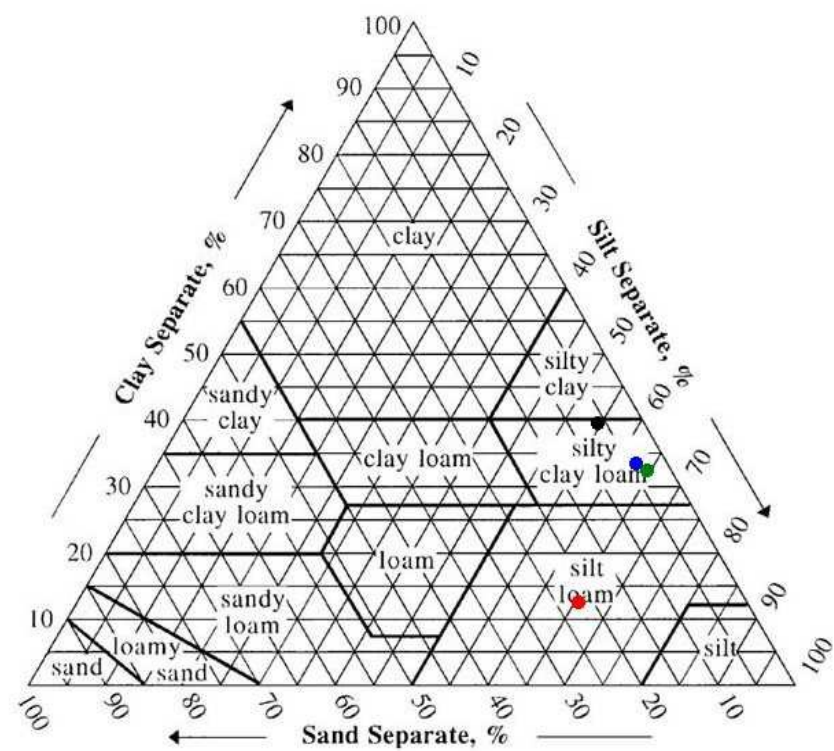

Figure 66. Elk Cove Vineyards, Five Mountain Vineyard soil pit horizon textures determined by pipette analysis. Red - Ap, Blue - Bt1, Green - Bt2, Black - Bt3.

\section{Willakenzie Estate Winery, The Jory Hills Vineyard Block 50c}

Taxonomic Classification: Fine, mixed, active, mesic Xeric Palehumults (previously Fine, mixed, active, mesic Xeric Haplohumults)

Soil Series: Jory (identified as Nekia) Lat/long Coordinates: $45^{\circ} 17^{\prime} 16.4^{\prime \prime} \mathrm{N} 123^{\circ} 01^{\prime} 49.7^{\prime \prime} \mathrm{W}(45.287902,-123.030467)$

UTM Coordinates: 497,608mE, 5,014,932mN

Physiographic Position: Midslope

MAT/MAP: 11 degrees $\mathrm{C}$ (52 degrees $\mathrm{F}) / 152 \mathrm{~cm}$ (60 in.)

Elevation: 150 meters (493 feet)

Slope: 10 degrees

Aspect: North?

Vegetation: Pinot Noir Vineyard on trellis

Parent Material: Basalt (soil contains pisolites)

Bedrock: Basalt

Ap 0-18 cm (0-7 in.); reddish brown (5 YR 4/4), reddish brown (7.5 YR 4/4) dry, silty clay; weak fine subangular blocky structure; very firm; sticky and plastic; many fine roots; many fine concretions; moderately acid (pH 5.6); abrupt, wavy boundary. 
Bt1 18-33 cm (7-13 in.); dark reddish brown (5 YR 3/3), dark brown (7.5 YR 4/4) dry, silty clay; weak medium subangular blocky structure; very firm, very sticky and very plastic; common distinct clay films on faces of peds; few coarse concretions; strongly acid (pH 5.5); abrupt, wavy boundary.

Bt2 33-43 cm (13-17 in.); dark reddish brown (2.5 YR 3/4), yellowish red (5 YR 4/6) dry, silty clay; weak very fine subangular blocky structure; firm, sticky and plastic; common distinct clay films on faces of peds; few fine concretions; strongly acid (pH 5.2); abrupt, wavy boundary.

Cr $43+\mathrm{cm}(17+$ in.); yellowish red (5 YR 4/6) dry, clay loam; $>75$ percent basalt rock fragments.

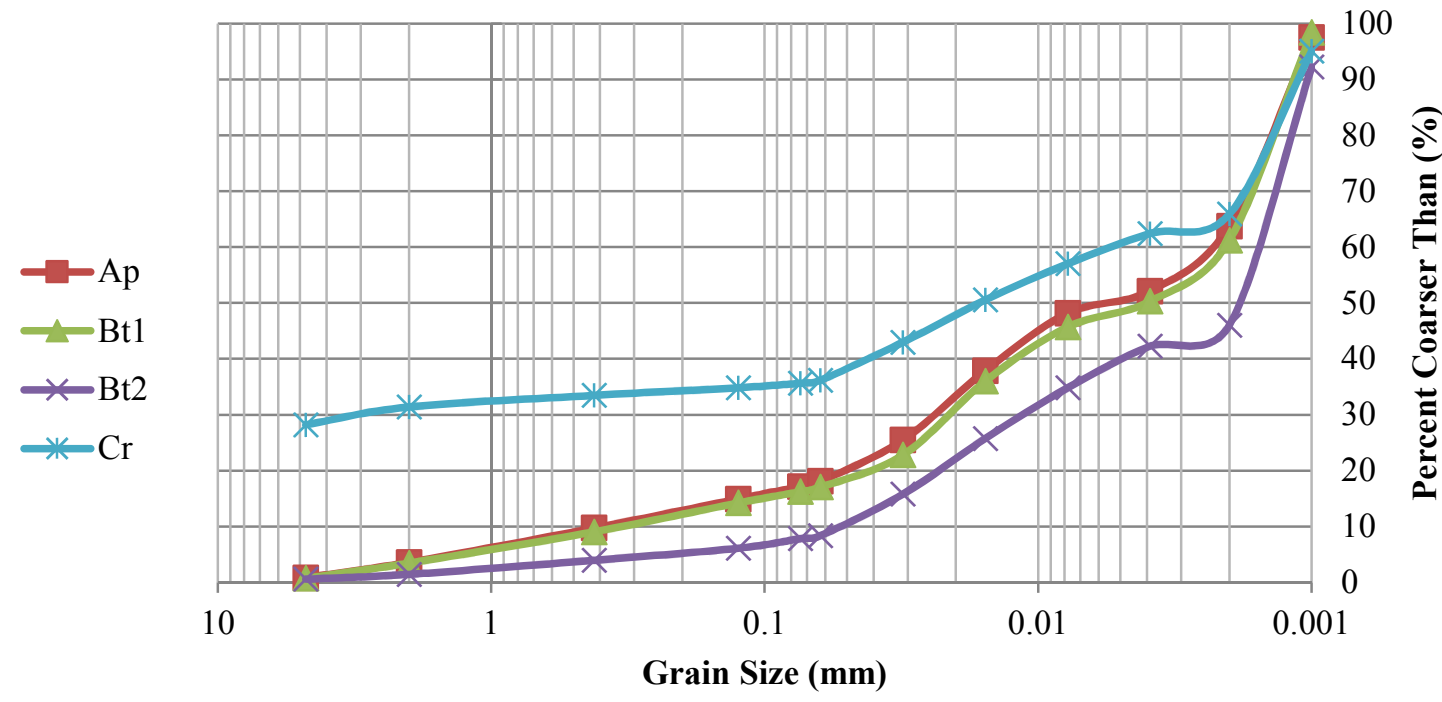

Figure 67. Particle size cumulative weight percent curve as determined by pipette analysis for each horizon of Willakenzie Estate Winery, The Jory Hills Vineyard Block 50c soil. 


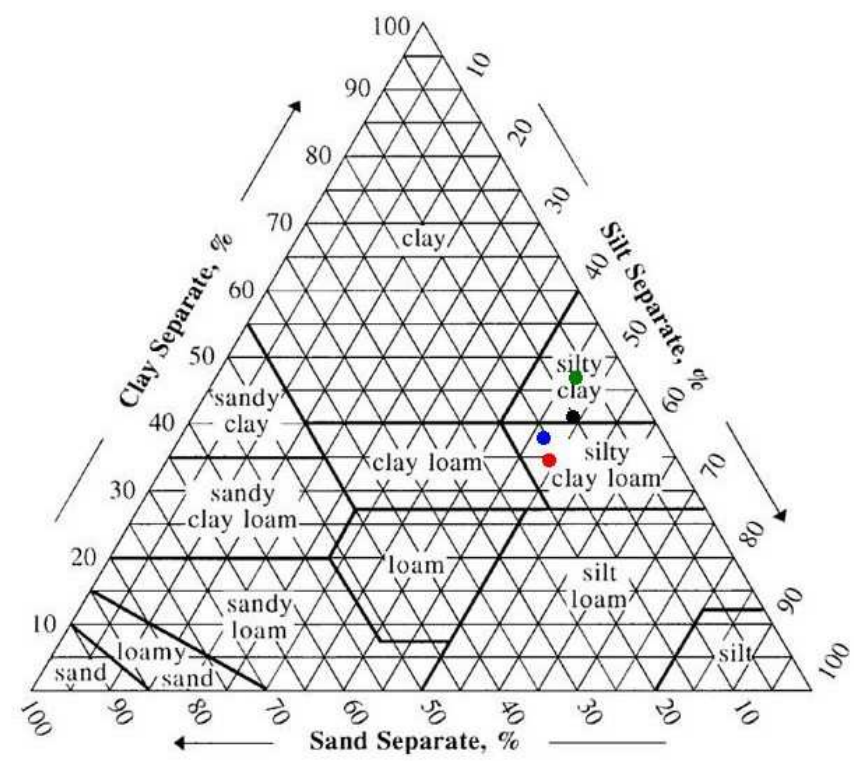

Figure 68. Willakenzie Estate Winery, The Jory Hills Vineyard Block 50c soil pit horizon textures determined by pipette analysis. Red - Ap, Blue - Bt1, Green - Bt2, Black - Cr.

\section{Willakenzie Estate Winery, Aliette Vineyard Block 2b}

Taxonomic Classification: Fine, mixed, superactive, mesic Ultic Palexeralfs - Fine, mixed, superactive, mesic Ultic Haploxeralfs (previously Fine-loamy, mixed, active, mesic Ultic Haploxeralfs)

Soil Series: Melbourne - Goodin (previously Willakenzie)

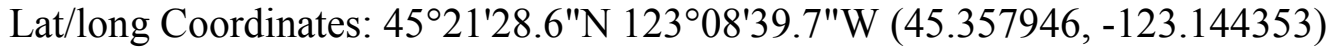

UTM Coordinates: $489,560 \mathrm{mE}, 5,023,434 \mathrm{mN}$

Physiographic Position: Upland

MAT/MAP: 11 degrees C (52 degrees F)/152 cm (60 in.)

Elevation: 185 meters (604 feet)

Slope: 2-3 degrees

Aspect: South

Vegetation: Pinot Noir Vineyard on trellis, permanent cover fescue between rows Parent Material: Sandstone (soil contains muscovite mica and quartz sand)

Bedrock: Pittsburg Bluff Sandstone

A/E 0-26 cm (0-10 in.); brown (7.5 YR 4/4), yellowish brown (10 YR 5/4) dry, loam; moderate medium subangular blocky structure; very firm; slightly sticky and slightly plastic; many fine roots; strongly acid ( $\mathrm{pH}$ 5.4); gradual, wavy boundary. 
AB 26-35 cm (10-14 in.); dark brown (7.5 YR 3/4), yellowish brown (10 YR 5/4) dry, loam; moderate medium subangular blocky structure; very firm; slightly sticky and slightly plastic; few fine roots; few faint clay films on faces of peds; moderately acid ( $\mathrm{pH} 5.9$ ); gradual, wavy boundary.

Bt1 35-100 cm (14-39 in.); dark brown (7.5 YR 3/4), dark yellowish brown (10 YR 4/6) dry, clay loam; moderate medium subangular blocky structure; extremely firm, very sticky and very plastic; few distinct clay films on faces of peds; moderately acid ( $\mathrm{pH} 5.3$ ); gradual, wavy boundary; charcoal pieces; auger.

Bt2 100-150 cm (39-60 in.); dark reddish brown (5 YR 3/4), strong brown (7.5 YR 4/6) with yellowish red (5 YR 5/6) dry, clay; moderate medium subangular blocky structure; very firm, very sticky and very plastic; few faint clay films on faces of peds; few fine concretions; strongly acid ( $\mathrm{pH}$ 5.4); gradual, wavy boundary; auger.

Bt3 150+ cm (60+ in.); yellowish red (5 YR 4/6) clay loam, strong brown (5 YR 4/6) dry; moderate medium subangular blocky structure; very firm, sticky and plastic; few distinct clay films on faces of peds; sandstone parent material rock fragments; moderately acid ( $\mathrm{pH}$ 5.7); auger.

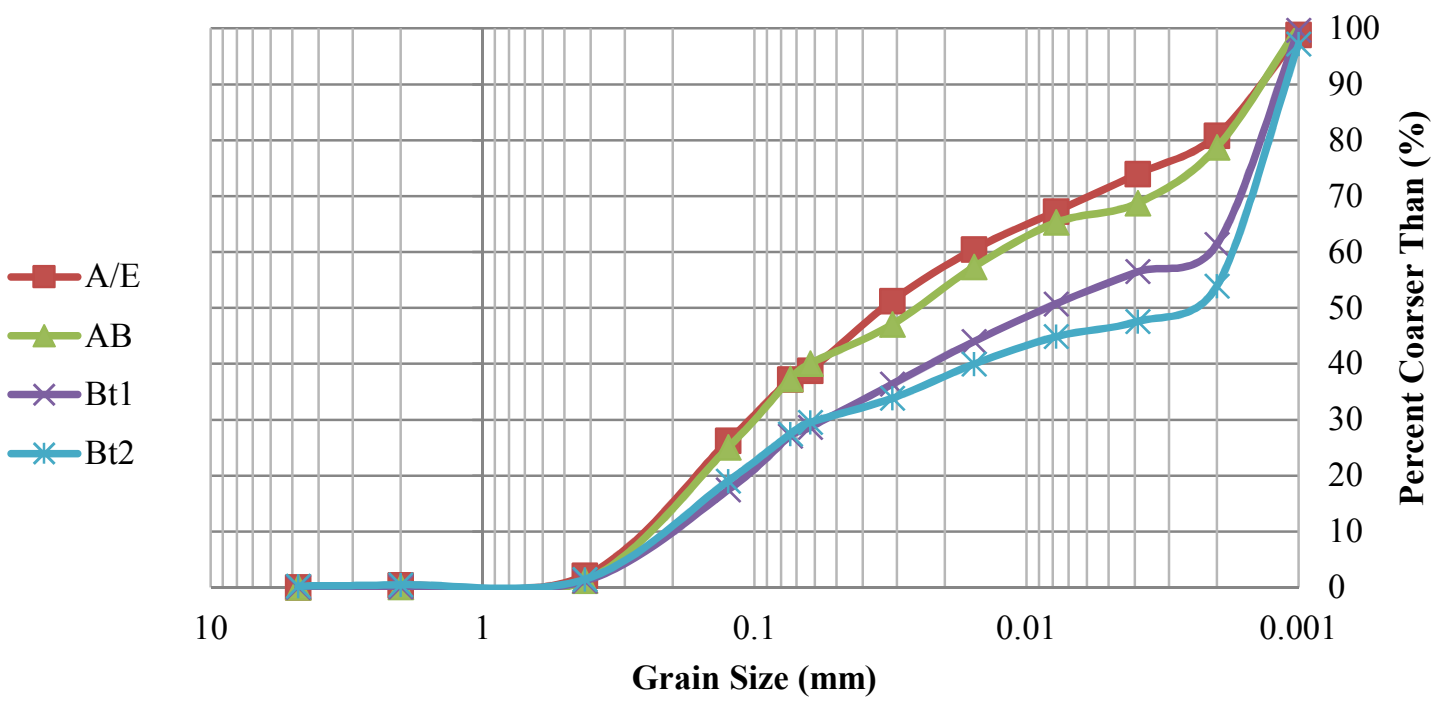

Figure 69. Particle size cumulative weight percent curve as determined by pipette analysis for each horizon of Willakenzie Estate Winery, Aliette Vineyard Block 2 b soil. 


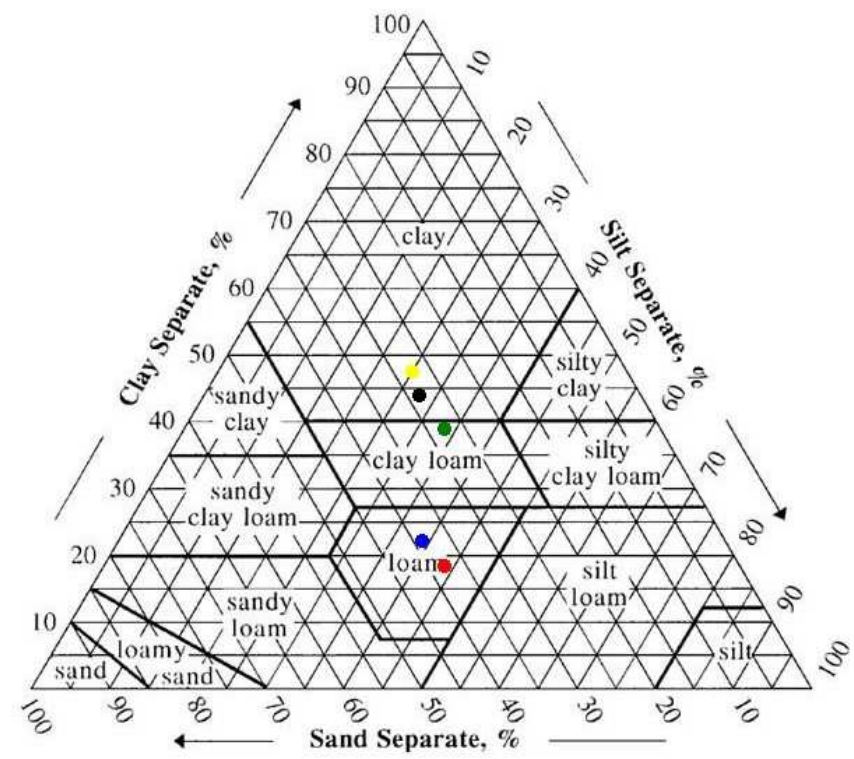

Figure 70. Willakenzie Estate Winery, Aliette Vineyard Block 2b soil pit horizon textures determined by pipette analysis. Red - A/E, Blue - AB, Green - Bt1, Black - Bt2, Yellow - Bt3.

\section{Willakenzie Estate Winery, Terres Basses Vineyard}

Taxonomic Classification: Fine, smectitic, mesic Vertic Haploxerolls (previously Veryfine, smectitic, mesic Vertic Haploxerolls)

Soil Series: Witham (previously Hazelair)

Lat/long Coordinates: $45^{\circ} 21^{\prime} 28.6^{\prime \prime} \mathrm{N} 123^{\circ} 08^{\prime} 39.7^{\prime \prime} \mathrm{W}(45.357946,-123.144353)$

UTM Coordinates: $488,693 \mathrm{mE}, 5,022,723 \mathrm{mN}$

Physiographic Position: Foot slope

MAT/MAP: 11 degrees $\mathrm{C}$ (52 degrees F)/152 cm (60 in.)

Elevation: 90 meters (293 feet)

Slope: 10 degrees

Aspect: West-Northwest

Vegetation: Pinot Noir Vineyard on trellis, permanent cover between rows

Parent Material: Missoula Flood sediments and Coast Range marine sediments (soil

contains quartz sand)

Bedrock: Shale

Ap $\quad 0-25 \mathrm{~cm}(0-10 \mathrm{in}$.); very dark grayish brown (10 YR 3/2), brown (10 YR 5/3) dry, silty clay loam; weak medium granular to subangular blocky structure; hard; firm; 
very sticky and very plastic; few fine roots; strongly acid ( $\mathrm{pH}$ 5.4); abrupt, wavy boundary.

AB 25-36 cm (10-14 in.); brown (10 YR 4/3), brown (10 YR 5/3) dry, silty clay loam; weak medium subangular blocky structure; hard; firm; very sticky and very plastic; common fine roots; moderately acid (pH 5.9); abrupt, wavy boundary.

Bg1 36-65 cm (14-26 in.); dark gray (5 YR 4/1), brown (10 YR 5/3) dry, clay; moderate medium subangular blocky structure; very hard, very firm, very sticky and very plastic; common distinct clay films on faces of peds and interstitial pores; common fine prominent redoximorphic features, yellowish red (5 YR 4/6) and yellowish red (5 YR 4/6) dry; moderately acid (pH 5.3); abrupt, wavy boundary.

Bg2 65-86 cm (26-34 in.); dark gray (5 YR 4/1), brown (10 YR 5/3) dry, clay loam; moderate medium subangular blocky structure; very hard, very firm very sticky and very plastic; common distinct clay films on faces of peds and interstitial pores; common fine prominent redoximorphic features, dark yellowish brown (10 YR 4/4) and yellowish red (5 YR 5/6) dry; few fine concretions; strongly acid (pH 5.4); abrupt, wavy boundary.

$\mathrm{Cg} \quad 86-102 \mathrm{~cm}(34-40$ in.); yellowish brown (10 YR 5/4) clay loam, dark yellowish brown (10 YR 4/4) dry; weak fine subangular blocky structure; very hard, very firm, sticky and plastic; rock fragments and dark staining; moderately acid $(\mathrm{pH}$ 5.7); augered.

$\mathrm{R} \quad 102-118+\mathrm{cm}(40-47+$ in. $)$; shale rock fragments and dark staining; augered. 


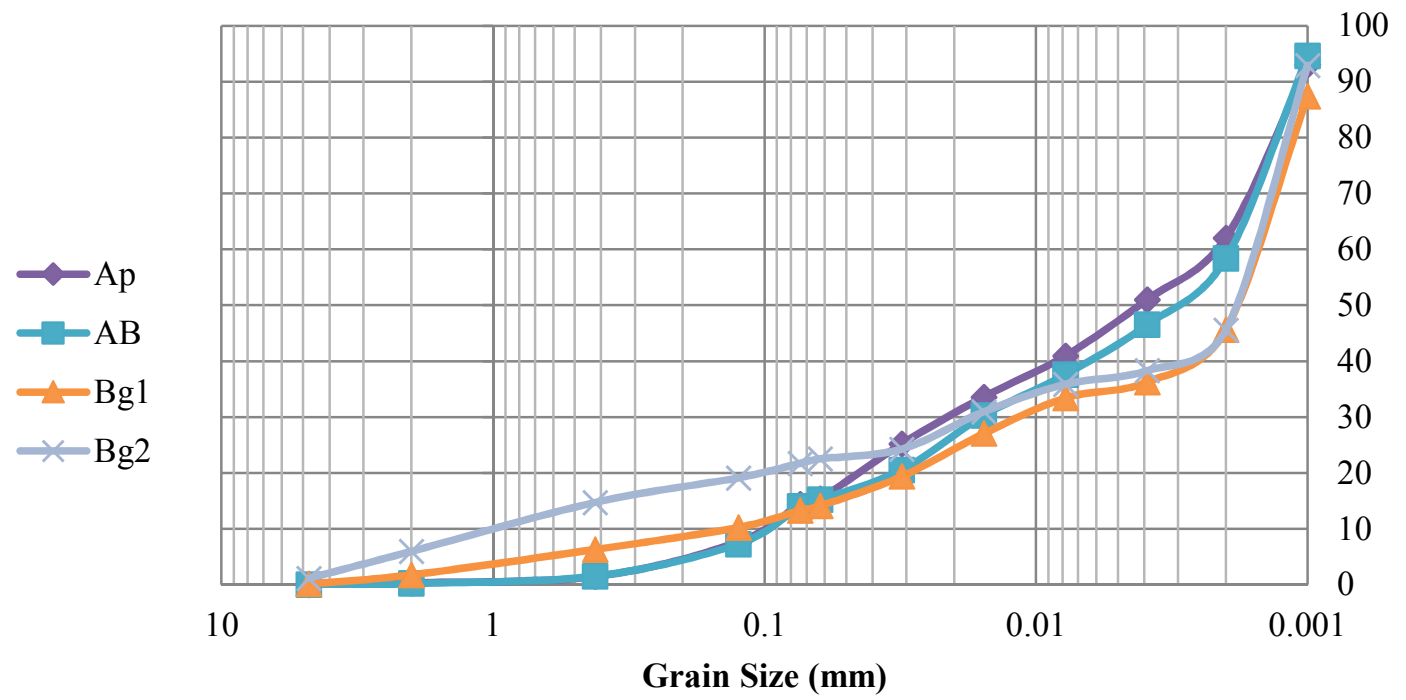

100
90
80
70
60
50
40
30
20
0

Figure 71. Particle size cumulative weight percent curve as determined by pipette analysis for each horizon of Willakenzie Estate Winery, Terres Basses Vineyard soil.

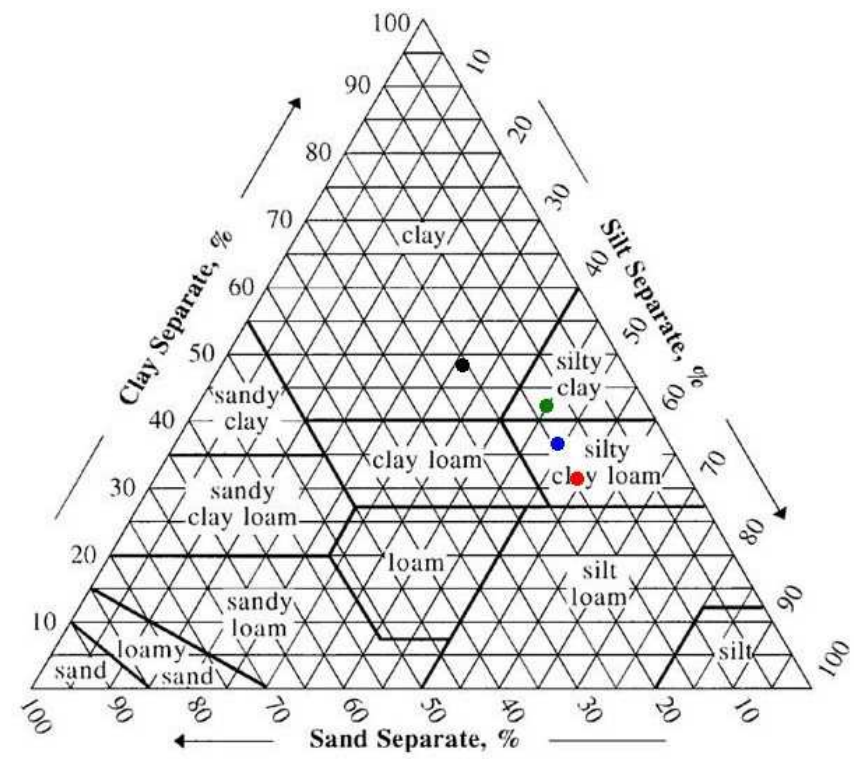

Figure 72. Willakenzie Estate Winery, Terres Basses Vineyard soil pit horizon textures determined by pipette analysis. Red - Ap, Blue - AB, Green - Bg1, Black - Bg2. 


\section{Chehalem, Stoller Vineyards}

Taxonomic Classification: Fine, mixed, active, mesic Xeric Palehumults

Soil Series: Jory

Lat/long Coordinates: $45^{\circ} 14^{\prime} 55.8^{\prime \prime} \mathrm{N} 123^{\circ} 04^{\prime} 20.4^{\prime \prime} \mathrm{W}$ (45.248827, -123.072347)

UTM Coordinates: $494,327 \mathrm{mE}, 5,010,596 \mathrm{mN}$

Physiographic Position: Midslope

MAT/MAP: 11 degrees C (52 degrees F)/152 cm (60 in.)

Elevation: 145 meters (475 feet)

Slope: 1 degree

Aspect: Southeast

Vegetation: Pinot Noir Vineyard on trellis

Parent Material: Basalt (soil contains pisolites)

Bedrock: Basalt

Ap 0-10 cm (0-4 in.); brown (7.5 YR 4/4), dark yellowish brown (10 YR 4/4) dry, silt loam; strong fine subangular blocky structure; very firm; slightly sticky and slightly plastic; many fine roots; few fine concretions; moderately acid ( $\mathrm{pH}$ 5.6); clear, smooth boundary.

Bt1 10-60 cm (4-24 in.); brown (7.5 YR 3/3), dark yellowish brown (10 YR 4/4) dry, silt loam; moderate fine subangular blocky structure; firm, sticky and plastic; few faint clay films on faces of peds; few fine concretions; moderately acid ( $\mathrm{pH} 5.4$ ); krotovina.

Bt2 60-100 cm (24-39 in.); dark reddish brown (5 YR 3/3), dark yellowish brown (10 YR 4/4) dry, silt loam; weak fine subangular blocky to loose structure; friable, sticky and plastic; few faint clay films on faces of peds; few fine concretions; strongly acid ( $\mathrm{pH} 5.4)$; auger.

Bt3 100-135 cm (39-53 in.); dark yellowish brown (10 YR 4/4), dark yellowish brown (10 YR 4/4) dry, silt loam; weak, fine subangular blocky to single grain, loose structure; friable, slightly sticky, slightly plastic $<10$ percent rock fragments; very few faint clay films on faces of peds; few fine concretions; moderately acid $(\mathrm{pH}$ 5.5); refusal. 


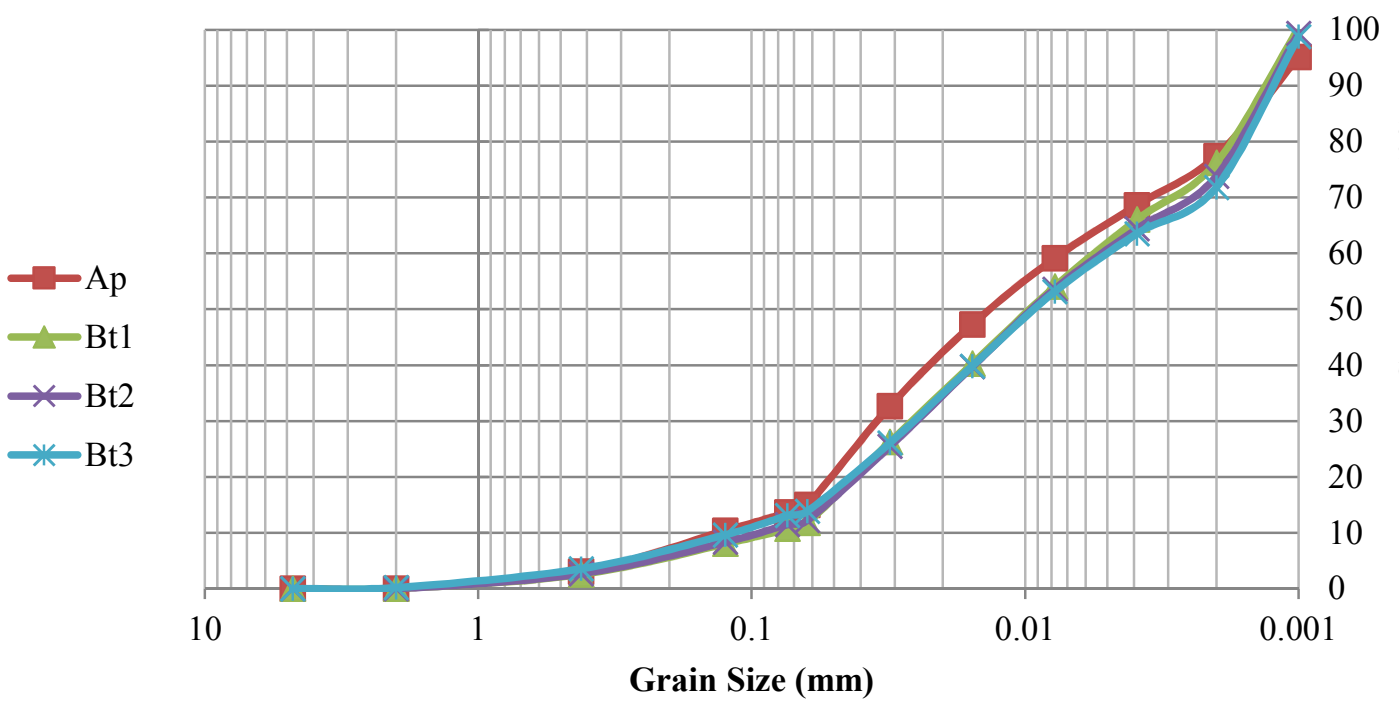

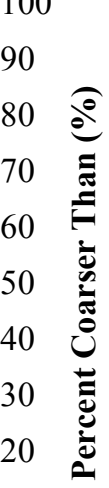

Figure 73. Particle size cumulative weight percent curve as determined by pipette analysis for each horizon of Chehalem, Stoller Vineyards soil.

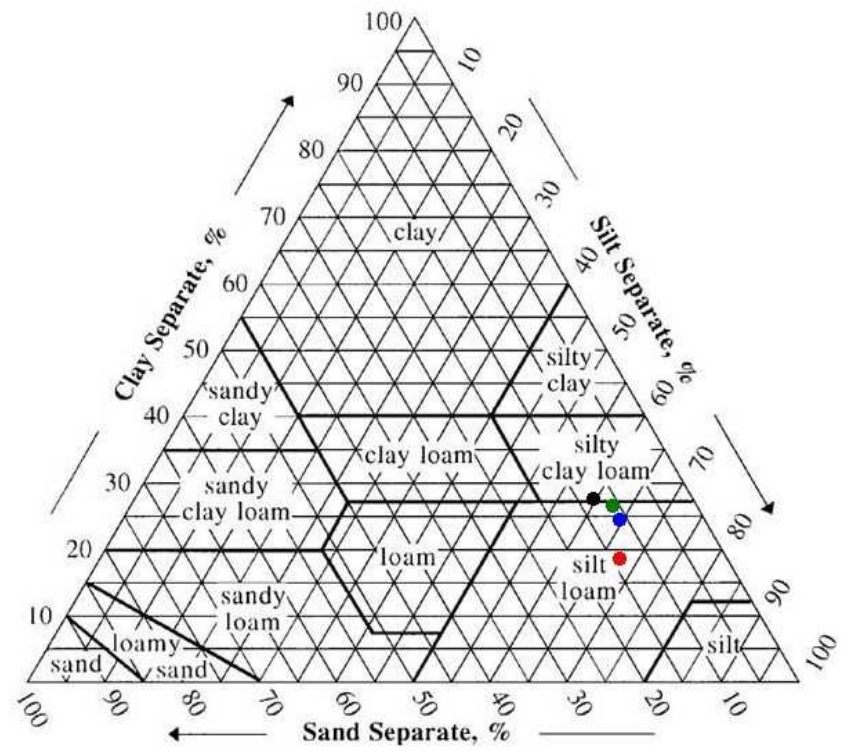

Figure 74. Chehalem, Stoller Vineyards soil pit horizon textures determined by pipette analysis. Red - Ap, Blue - Bt1, Green - Bt2, Black - Bt3. 


\section{Chehalem, Ridgecrest Vineyard}

Taxonomic Classification: Fine-loamy, mixed, active, mesic Aquultic Haploxeralfs (previously Fine-loamy, mixed, active, mesic Ultic Haploxeralfs)

Soil Series: Wellsdale (previously Willakenzie)

Lat/long Coordinates: $45^{\circ} 22^{\prime} 03.9^{\prime \prime} \mathrm{N} 123^{\circ} 04^{\prime} 44.8^{\prime \prime} \mathrm{W}$ (45.367757, -123.079108)

UTM Coordinates: 493,802mE, 5,023,809mN

Physiographic Position: Midslope

MAT/MAP: 11 degrees C (52 degrees F)/152 cm (60 in.)

Elevation: 195 meters (638 feet)

Slope: 10 degrees

Aspect: East

Vegetation: Pinot Noir Vineyard on trellis

Parent Material: Sandstone (soil contains quartz sand)

Bedrock: Sandstone

Ap $\quad 0-25 \mathrm{~cm}(0-10$ in.); yellowish brown (10 YR 5/4), yellowish brown (10 YR 5/4) dry, silt loam; weak fine granular structure; firm, nonsticky and nonplastic; many fine roots; strongly acid ( $\mathrm{pH}$ 5.5); clear, smooth boundary.

Bt1 25-65 cm (10-26 in.); strong brown (7.5 YR 4/6), dark yellowish brown (10 YR 4/4) dry, silt loam; moderate fine subangular blocky structure; firm, sticky and plastic; common faint clay films on faces of peds; moderately acid ( $\mathrm{pH} 5.6$ ); charcoal.

Bt2 65-115 cm (26-45 in.); strong brown (7.5 YR 4/6), dark yellowish brown (10 YR 5/4) dry, clay loam; moderate fine subangular blocky structure; firm, sticky and plastic; $<10$ percent rock fragments; strongly acid ( $\mathrm{pH} \mathrm{5.3);} \mathrm{auger.}$

C1 115-200 cm (45-79 in.); strong brown (7.5 YR 5/6) and red (2.5 YR 4/8), strong brown (7.5 YR 5/6) and light yellowish brown (2.5 Y 7/4) dry, loam; single grain fine structure; friable, sticky and plastic; 10 percent rock fragments; very few faint clay films on faces of peds; dark staining; strongly acid ( $\mathrm{pH} 5.1$ ); auger.

C2 200-220+ cm (79-87+ in.); reddish yellow (7.5 YR 6/8) and olive gray (5 Y 4/2), strong brown (7.5 YR 5/8) and light yellowish brown (2.5 Y 6/4) dry, loam; single grain to weak structure; $<10$ percent rock fragments; dark staining; very strongly acid (pH 5.0); auger. 


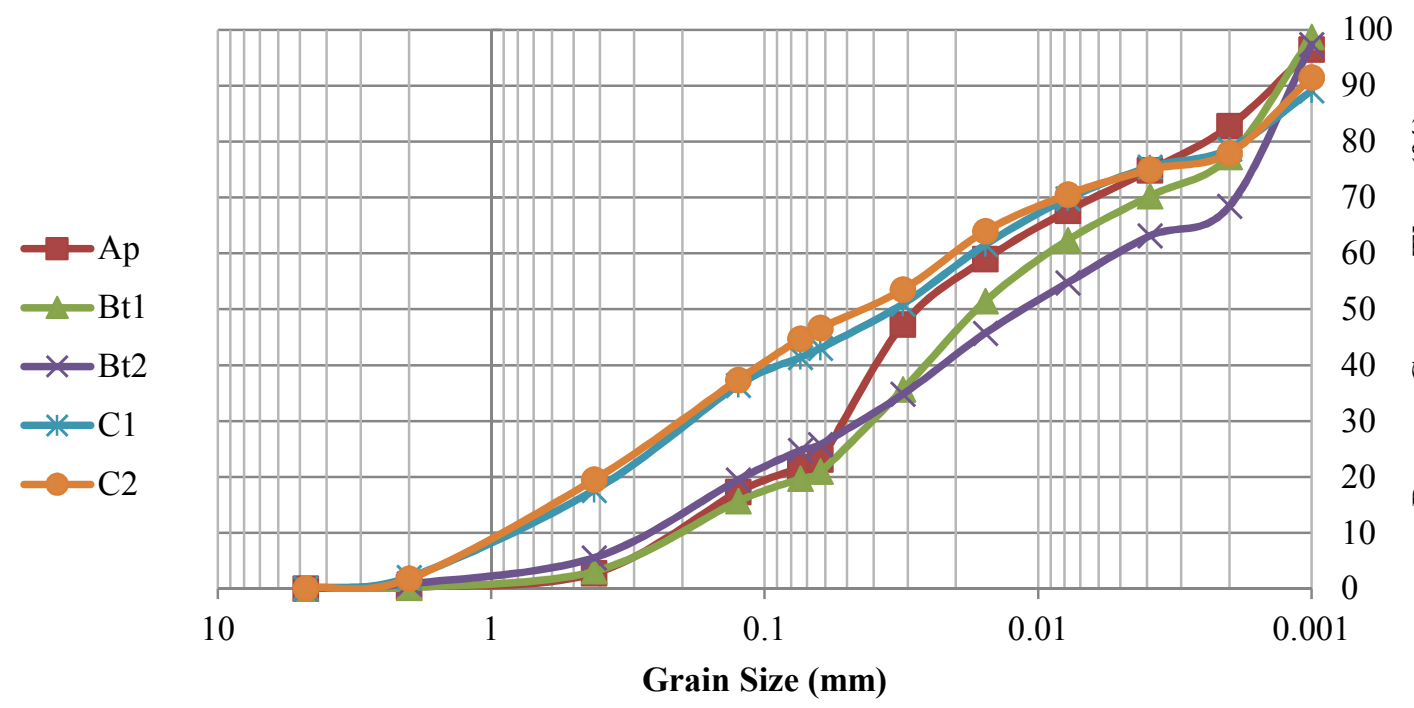



Figure 75. Particle size cumulative weight percent curve as determined by pipette analysis for each horizon of Chehalem, Ridgecrest Vineyard soil.

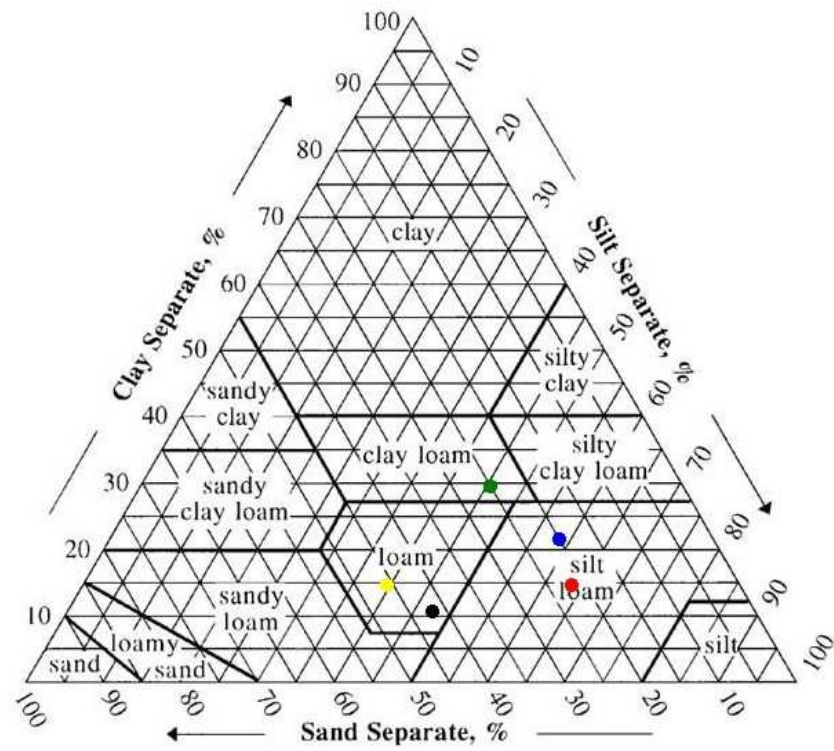

Figure 76. Chehalem, Ridgecrest Vineyard soil pit horizon textures determined by pipette analysis. Red - Ap, Blue - Bt1, Green - Bt2, Black - C1, Yellow - C2. 


\section{Chehalem, Corral Creek Vineyards Mid North Block}

Taxonomic Classification: Fine-silty, mixed, active, mesic Ultic Haploxeralfs

Soil Series: Laurelwood

Lat/long Coordinates: $45^{\circ} 18^{\prime} 45.0^{\prime \prime} \mathrm{N} 122^{\circ} 54^{\prime} 58.8^{\prime \prime} \mathrm{W}(45.312503,-122.916342)$

UTM Coordinates: $506,557 \mathrm{mE}, 5,017,665 \mathrm{mN}$

Physiographic Position: Midslope

MAT/MAP: 11 degrees C (52 degrees F)/152 cm (60 in.)

Elevation: 114 meters (373 feet)

Slope: 1 degree

Aspect: Northwest

Vegetation: Pinot Noir Vineyard on trellis

Parent Material: Loess \& Basalt (soil contains pisolites)

Bedrock: Basalt

Ap $\quad 0-35 \mathrm{~cm}(0-14$ in.); brown (7.5 YR 4/3), brown (10 YR 4/3) dry, silt loam; massive to weak fine subangular blocky structure; very firm; nonsticky and nonplastic; many fine roots; very few faint clay films on the faces of peds; few medium to coarse concretions; moderately acid ( $\mathrm{pH} 5.7$ ); clear, wavy boundary.

Bt $\quad 35-55 \mathrm{~cm}$ (14-22 in.); brown (7.5 YR 4/4), brown (7.5 YR 4/4) dry, silty clay loam; moderate medium subangular blocky structure; very firm, very sticky and very plastic; common distinct clay films on faces of peds and interstitial pores; few medium to coarse concretions; moderately acid ( $\mathrm{pH}$ 5.9); abrupt, wavy boundary.

Cr 55-65 cm (22-26 in.); dark yellowish brown (10 YR 4/6), brown (7.5 YR 5/4) dry, silty clay loam; sticky and plastic; 50 percent rock fragments; few faint clay films on faces of peds and interstitial pores; moderately acid ( $\mathrm{pH}$ 5.7); auger.

$\mathrm{R} \quad 65+\mathrm{cm}(26+$ in.); $>75$ percent basalt rock fragments. 


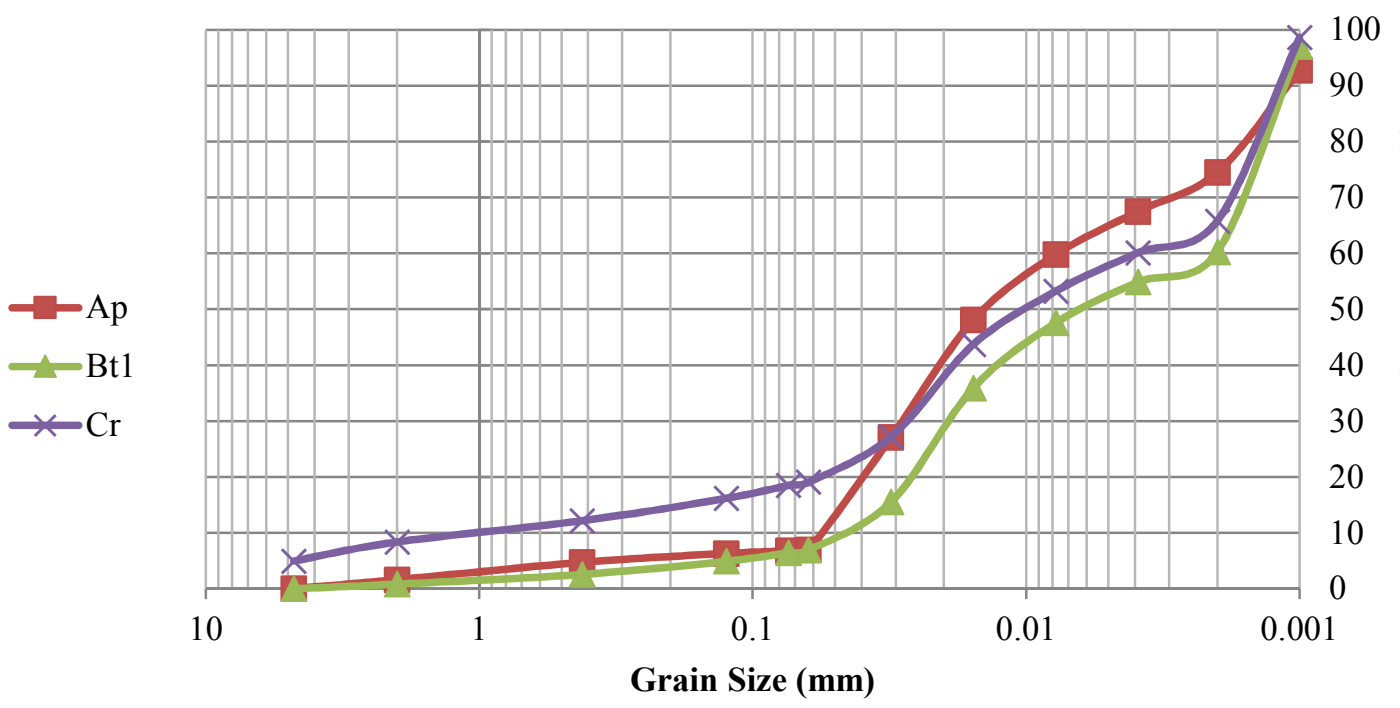

100
90
80
70
60
50
40
30
20
0

Figure 77. Particle size cumulative weight percent curve as determined by pipette analysis for each horizon of Chehalem, Corral Creek Vineyards Mid North Block soil.

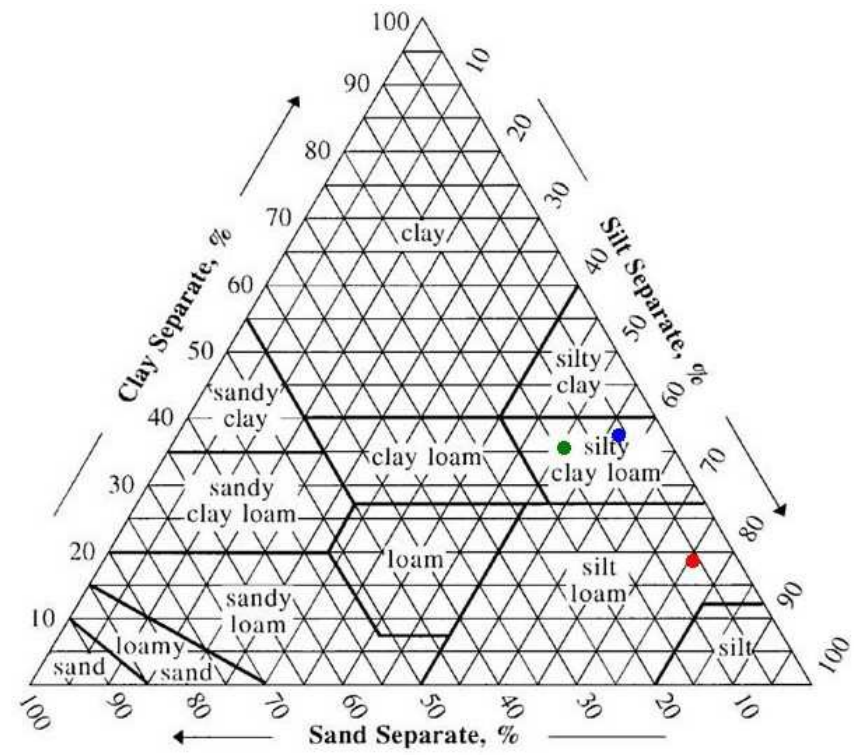

Figure 78. Chehalem, Corral Creek Vineyards Mid North Block soil pit horizon textures determined by pipette analysis. Red - Ap, Blue - Bt, Green - Cr. 


\section{Lange Estate Winery and Vineyards, Estate Vineyard Mia Block North}

Taxonomic Classification: Fine, mixed, active, mesic Xeric Palehumults - Fine, mixed, active, mesic Xeric Haplohumults (previously Fine, mixed, active, mesic Xeric

Palehumults)

Soil Series: Jory - Gelderman (previously Jory)

Lat/long Coordinates: $45^{\circ} 17^{\prime} 40.1^{\prime \prime} \mathrm{N} 123^{\circ} 02^{\prime} 35.8^{\prime \prime} \mathrm{W}(45.294480,-123.043289)$

UTM Coordinates: 496,695mE, 5,015,462mN

Physiographic Position: Midslope

MAT/MAP: 11 degrees C (52 degrees F)/152 cm (60 in.)

Elevation: 220 meters (719 feet)

Slope: 0 degrees

Aspect: South - Southeast

Vegetation: Pinot Noir Vineyard on trellis

Parent Material: Basalt (soil contains abundant pisolites)

Bedrock: Basalt

Ap $\quad$ 0-20 cm (0-8 in.); dark brown (7.5 YR 3/2), brown (7.5 YR 4/3) dry, silt loam; moderate medium granular to subangular blocky structure; firm, slightly sticky and slightly plastic; many fine roots; abundant fine to coarse concretions; moderately acid ( $\mathrm{pH}$ 5.6); clear, wavy boundary; krotovina.

A/B 20-50 cm (8-20 in.); dark brown (7.5 YR 3/3), brown (7.5 YR 4/3) dry, silt loam; moderate medium subangular blocky structure; firm, sticky and plastic; very few faint clay films on faces of peds; abundant fine to coarse concretions; moderately acid ( $\mathrm{pH}$ 5.8); clear wavy boundary; krotovina.

Bt1 50-80 cm (20-31 in.); dark reddish brown (5 YR 3/3), brown (7.5 YR 4/3) dry, silt loam; strong medium subangular blocky; firm, very sticky and very plastic; common distinct clay films on faces of peds and interstitial pores; abundant fine to coarse concretions; moderately acid ( $\mathrm{pH} 5.8)$; auger.

Bt2 80-140 cm (31-55 in.); reddish brown (5 YR 4/4), brown (7.5 YR 4/4) dry, silty clay; strong medium platy to subangular blocky structure; firm, very sticky and very plastic; common distinct clay films on faces of peds and interstitial pores; abundant fine to coarse concretions; strongly acid ( $\mathrm{pH} 5.5)$; auger.

Bt3 140-195+ cm (55-77+ in.); yellowish red (5 YR 4/6), brown (7.5 YR 4/4) dry, silty clay; strong medium subangular blocky structure; firm, very sticky and very plastic; many distinct clay films on faces of peds and interstitial pores; abundant fine to coarse concretions; strongly acid ( $\mathrm{pH}$ 5.3); charcoal; auger. 


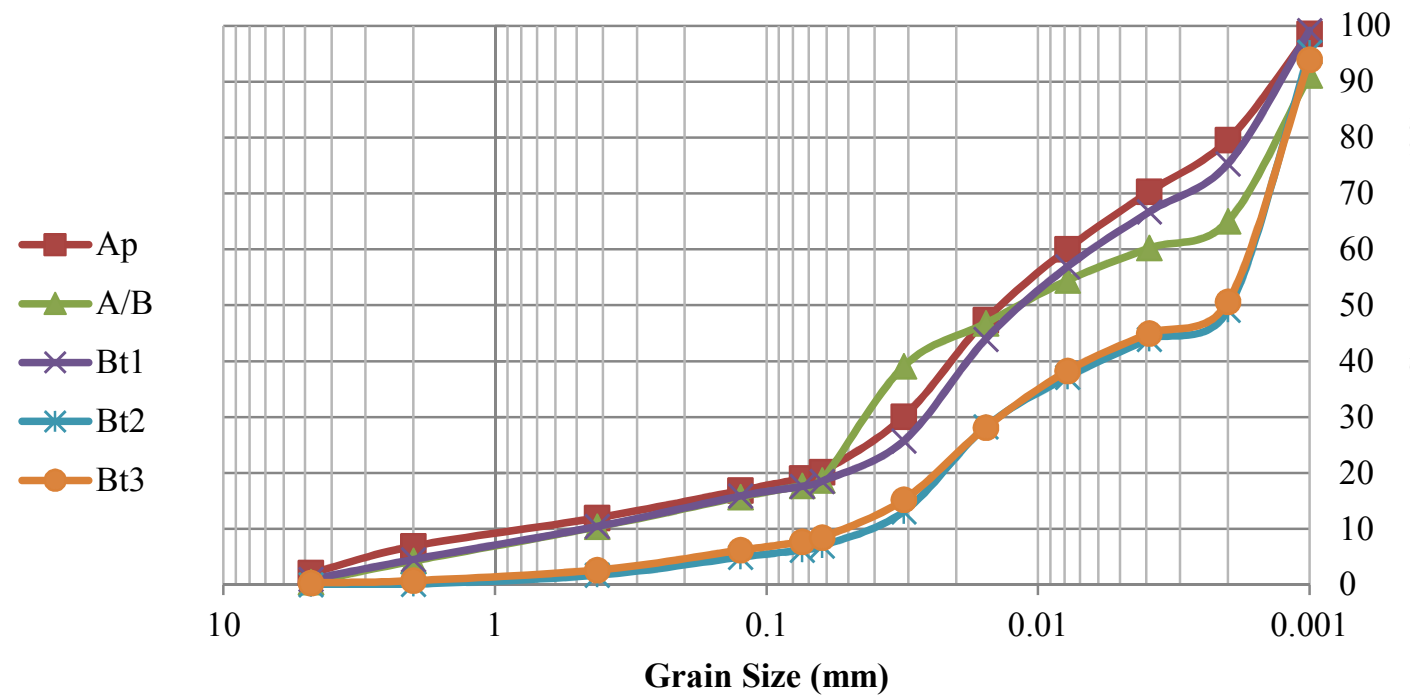

$$
60
$$

50

40

30

20

10

Grain Size (mm)

Figure 79. Particle size cumulative weight percent curve as determined by pipette analysis for each horizon of Lange Estate Winery and Vineyards, Estate Vineyard Mia Block North soil.

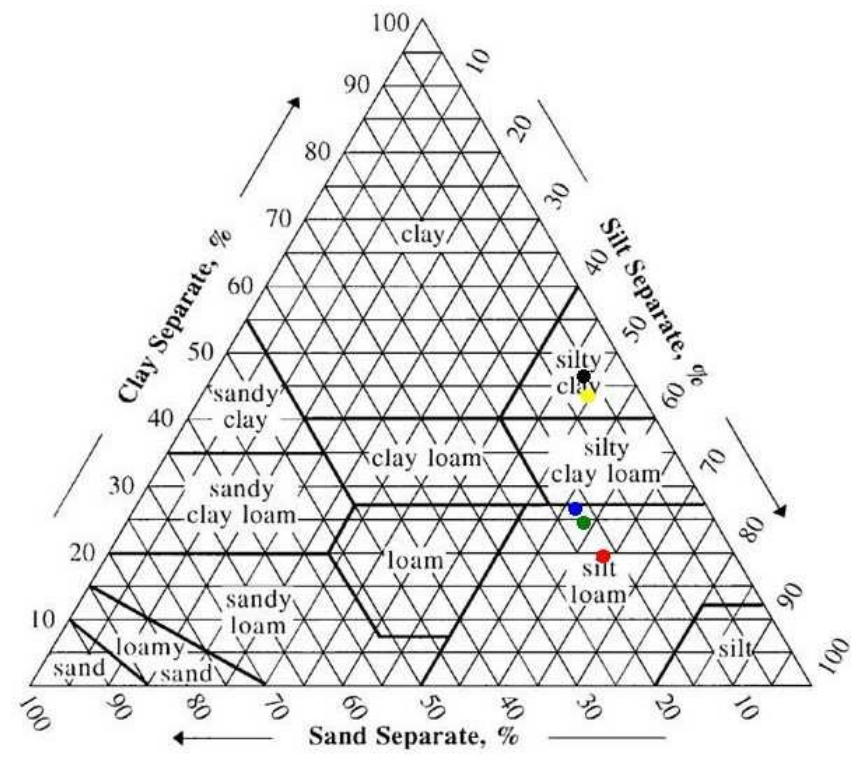

Figure 80. Lange Estate Winery and Vineyards, Estate Vineyard Mia Block North soil pit horizon textures determined by pipette analysis. Red - Ap, Blue - A/B, Green - Bt1, Black - Bt2, Yellow - Bt3. 


\section{Lange Estate Winery and Vineyards, Yamhill Vineyard}

Taxonomic Classification: Fine-loamy, mixed, active, mesic Aquultic Haploxeralfs Fine-loamy, mixed, active, mesic Ultic Haploxeralfs - Fine, mixed, superactive, mesic Aquultic Haploxeralfs (previously Fine-loamy, mixed, active, mesic Ultic Haploxeralfs) Soil Series: Wellsdale - Willakenzie - Dupee (previously Willakenzie) Lat/long Coordinates: $45^{\circ} 19^{\prime} 28.0^{\prime \prime} \mathrm{N} 123^{\circ} 09^{\prime} 00.8^{\prime \prime} \mathrm{W}$ (45.324441, -123.150227)

UTM Coordinates: $488,316 \mathrm{mE}, 5,018,802 \mathrm{mN}$

Physiographic Position: Summit

MAT/MAP: 11 degrees C (52 degrees F)/152 cm (60 in.)

Elevation: 138 meters (453 feet)

Slope: 0 degrees

Aspect: South

Vegetation: Pinot Noir Vineyard on trellis

Parent Material: Sandstone (soil contains muscovite mica and quartz sand)

Bedrock: Sandstone

Ap $\quad 0-26 \mathrm{~cm}(0-10$ in.); dark brown (7.5 YR 3/3), yellowish brown (10 YR 5/4) dry, loam; moderate fine granular to subangular blocky structure; many fine roots; few coarse sandstone concretions; moderately acid (pH 5.8); clear, wavy boundary.

Bt1 26-42 cm (10-17 in.); brownish yellow (10 YR 6/6), light yellowish brown (10 YR 6/4) dry, clay loam; moderate medium subangular blocky structure; extremely hard, extremely firm, very sticky and very plastic; common distinct clay films on faces of peds; few coarse sandstone concretions; strongly acid ( $\mathrm{pH}$ 5.5); abrupt, wavy boundary.

Bt2 42-75 cm (17-30 in.); strong brown (7.5 YR 4/6), strong brown (7.5 YR 5/6) dry, clay loam; moderate medium subangular blocky structure; firm, sticky and plastic; common distinct clay films on faces of peds; few coarse sandstone concretions; $<10$ percent rock fragments; strongly acid (pH 5.3); abrupt, wavy boundary; krotovina.

Bg $\quad 75-110 \mathrm{~cm}(30-43$ in.); yellowish brown (10 YR 5/8), reddish brown (2.5 YR 5/8), red (2.5 YR 5/8), and pale yellow (5 Y 7/3), brown (7.5 YR 5/4), reddish yellow (5 YR 6/6) and pink (5 YR 7/3) dry, clay loam; weak coarse platy to fine subangular blocky structure; friable, nonsticky and nonplastic; 10 percent rock fragments; very few faint clay films on faces of peds; mottling in plates; very strongly acid ( $\mathrm{pH} 4.9)$; clear, wavy boundary; auger. 
Cr1 110-160 cm (43-63 in.); pale yellow (5 Y 7/4), very pale brown (10 YR 7/4) dry, sandy loam; single grain to weak fine subangular blocky structure; loose, nonsticky and nonplastic; very strongly acid $(\mathrm{pH} 5.0)$; clear, wavy boundary; auger.

Cr2 160-200+ cm (63-79+ in.); yellowish brown (10 YR 5/8), very pale brown (10 YR 7/4) dry, sandy loam; single grain to weak fine subangular blocky structure; loose, nonsticky and nonplastic; strongly acid (pH 5.1); auger.

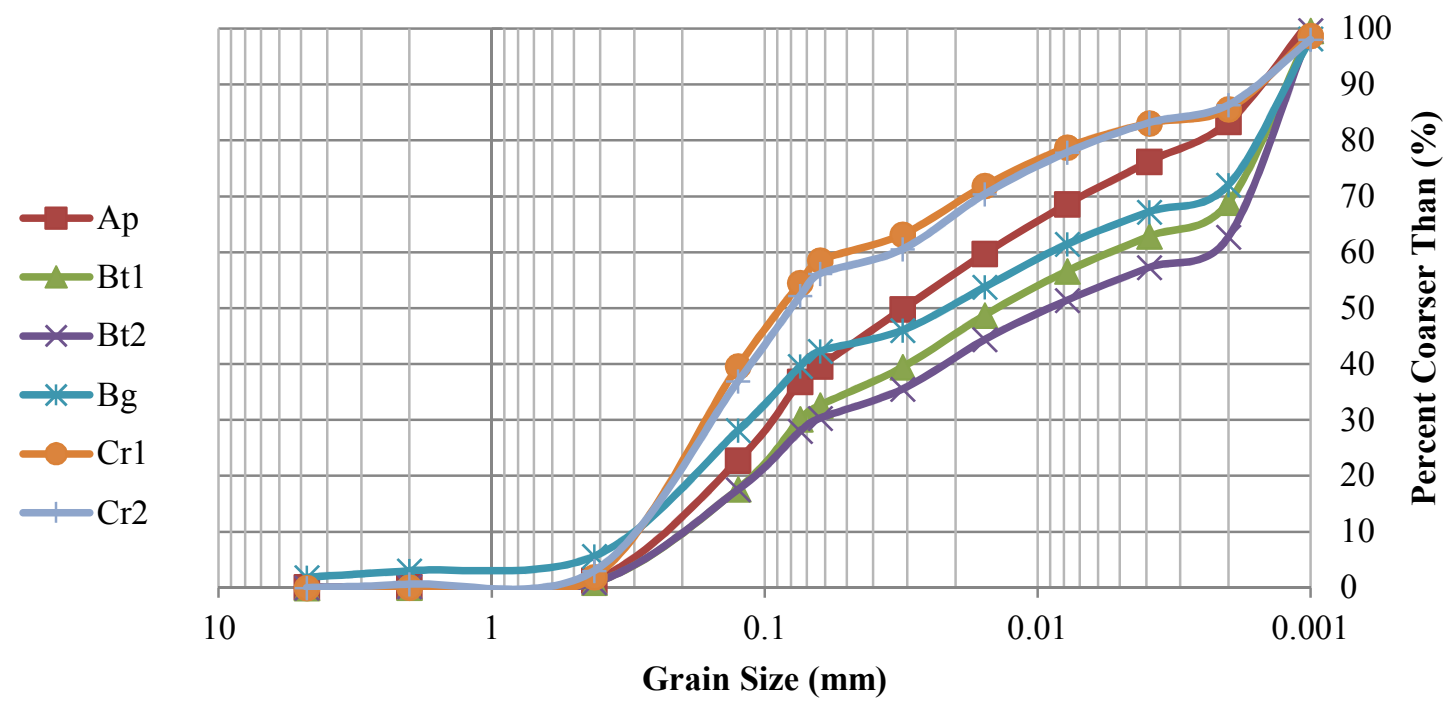

Figure 81. Particle size cumulative weight percent curve as determined by pipette analysis for each horizon of Lange Estate Winery and Vineyards, Yamhill Vineyard soil. 


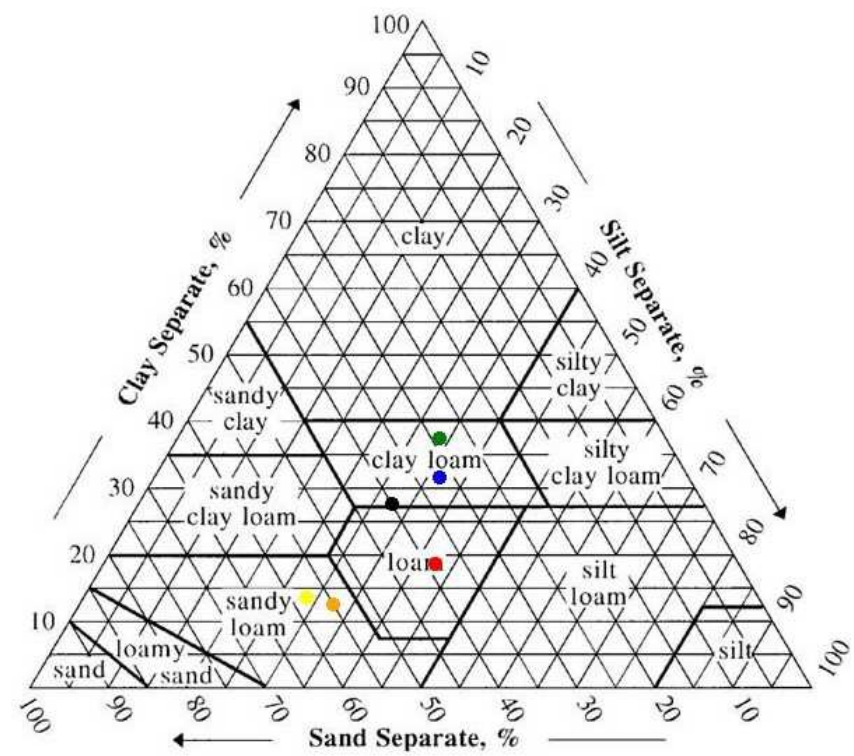

Figure 82. Lange Estate Winery and Vineyards, Yamhill Vineyard soil pit horizon textures determined by pipette analysis. Red - Ap, Blue - Bt1, Green - Bt2, Black - Bg, Yellow - Cr1, Orange Cr2.

\section{Lange Estate Winery and Vineyards, Freedom Hill Vineyard}

Taxonomic Classification: Fine, mixed, active, mesic Xeric Haplohumults Soil Series: Bellpine

Lat/long Coordinates: $44^{\circ} 52^{\prime} 38.2^{\prime \prime} \mathrm{N} 123^{\circ} 17^{\prime} 11.2^{\prime \prime} \mathrm{W}(44.877285,-123.286436)$

UTM coordinates: $477,378 \mathrm{mE}, 4,969,362 \mathrm{mN}$

Physiographic Position: Midslope

MAT/MAP: 11 degrees $\mathrm{C}$ (52 degrees F)/152 cm (60 in.)

Elevation: 105 meters (344 feet)

Slope: 2 degrees

Aspect: East

Vegetation: Pinot Noir Vineyard on trellis

Parent Material: Sandstone (soil contains muscovite mica and quartz sand)

Bedrock: Sandstone

Ap $\quad 0-34 \mathrm{~cm}(0-13$ in.); dark brown (7.5 YR 3/3), brown (10 YR 5/4) dry, silt loam; moderate very fine subangular blocky structure; firm, very sticky and very plastic; many fine roots; few distinct clay films on faces of peds; few coarse sandstone concretions; strongly acid ( $\mathrm{pH}$ 5.4); abrupt, wavy boundary; krotovina. 
Bt $\quad 34-63 \mathrm{~cm}$ (13-25 in.); dark brown (7.5 YR 3/4), light yellowish brown (10 YR 6/4) dry, silty clay loam; moderate medium subangular blocky structure; firm, sticky and plastic; common distinct clay films on faces of peds; few coarse sandstone concretions; $<10$ percent sandstone paragravel; strongly acid ( $\mathrm{pH} 5.3$ ); abrupt, wavy boundary.

Cr1 63-102 cm (25-40 in.); strong brown (7.5 YR 4/6) and light reddish brown (2.5 YR 6/3), light yellowish brown (10 YR 6/4) and yellowish red (5 YR 4/6) dry, silt loam; massive to strong medium platy structure; friable, nonsticky and nonplastic; strongly acid (pH 5.2); clear, wavy boundary; auger.

Cr2 102-157+ cm (40-62 in.); strong brown (7.5 YR 5/8), yellowish red (5 YR 4/6) and pink (2.5 YR 8/4), brownish yellow (10 YR 6/6), pale yellow (2.5 Y 8/2) and dark yellowish brown (10 YR 4/6) dry, sandy loam; massive to strong medium platy structure; friable, nonsticky and nonplastic; dark staining on ped surfaces; strongly acid ( $\mathrm{pH} 5.1$ ); auger.

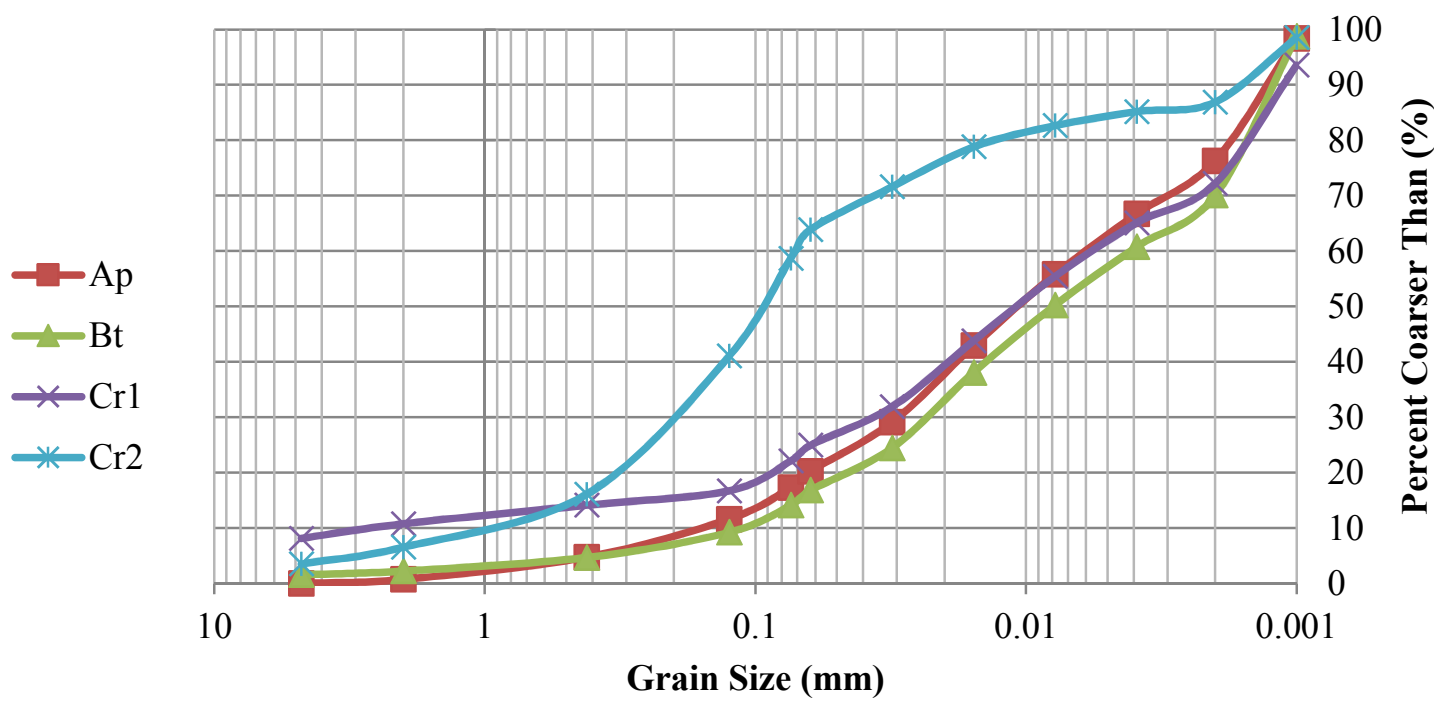

Figure 83. Particle size cumulative weight percent curve as determined by pipette analysis for each horizon of Lange Estate Winery and Vineyards, Freedom Hill Vineyard soil. 


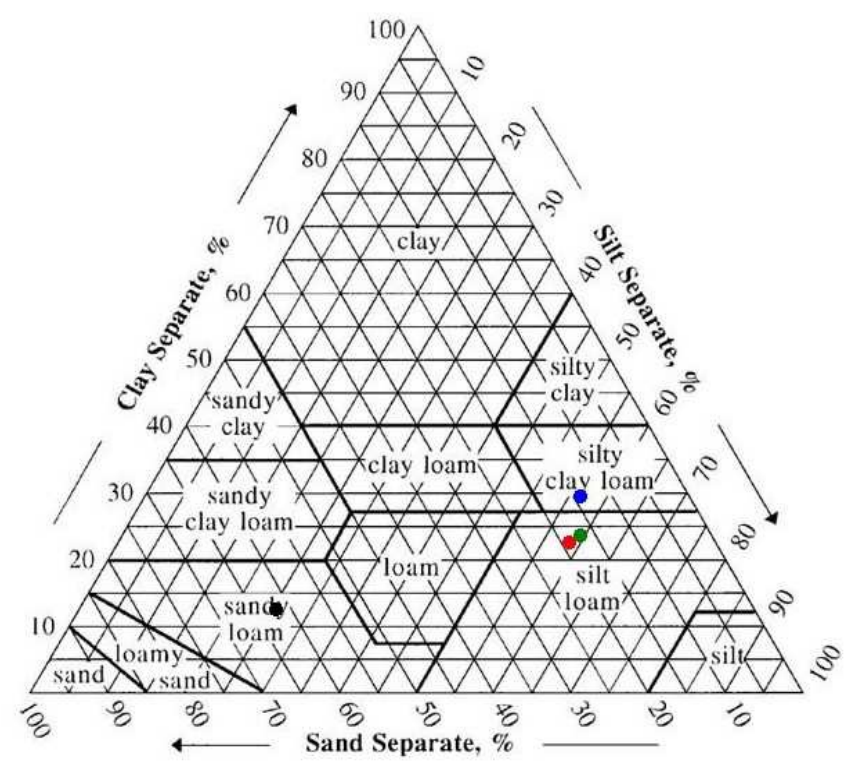

Figure 84. Lange Estate Winery and Vineyards, Freedom Hill Vineyard soil pit horizon textures determined by pipette analysis. Red - Ap, Blue - Bt, Green - Cr1, Black - Cr2.

\section{Rex Hill, Sims Vineyard Block 2}

Taxonomic Classification: Fine, mixed, active, mesic Xeric Palehumults

Soil Series: Jory

Lat/long Coordinates: $45^{\circ} 16^{\prime} 49.0^{\prime \prime} \mathrm{N} 123^{\circ} 02^{\prime} 32.6^{\prime \prime} \mathrm{W}(45.280286,-123.042398)$

UTM Coordinates: $496,773 \mathrm{mE}, 5,013,885 \mathrm{mN}$

Physiographic Position: Summit

MAT/MAP: 11 degrees C (52 degrees F)/152 cm (60 in.)

Elevation: 200 meters (656 feet)

Slope: 5 degrees

Aspect: West

Vegetation: Pinot Noir Vineyard on trellis, permanent fescue cover crop

Parent Material: Basalt (soil contains pisolites)

Bedrock: Basalt

Ap 0-12 cm (0-5 in.); brown (7.5 YR 4/4), brown (7.5 YR 4/4) dry, clay loam; moderate fine granular to subangular blocky structure; extremely firm, slightly sticky and slightly plastic; many fine roots; abundant medium concretions; strongly acid (pH 5.2); abrupt, wavy boundary. 
Bt1 12-50 cm (5-20 in.); reddish brown (5 YR 4/4), strong brown (7.5 YR 4/6) dry, clay; moderate medium subangular blocky structure; extremely firm, sticky and plastic; many prominent clay films on interstitial pores; few coarse concretions and dark staining on peds; strongly acid (pH 5.4); clear, wavy boundary.

Bt2 50-84 cm (20-33 in.); dark reddish brown (5 YR 3/4), brown (7.5 YR 4/4) dry, clay; moderate medium subangular blocky structure; extremely firm, sticky and plastic; common distinct clay films on faces of peds; few coarse concretions; dark staining on peds; $<10$ percent rock fragments; moderately acid ( $\mathrm{pH} 5.6$ ); clear, wavy boundary; auger.

Bt3 84-130+ cm (33-51+ in.); dark reddish brown (2.5 YR 3/4), brown (7.5 YR 4/4) dry, clay; weak medium subangular blocky structure; firm, sticky and plastic; common faint clay films on faces of peds; few coarse concretions; dark staining on ped surfaces; $<10$ percent rock fragments; very strongly acid ( $\mathrm{pH} 5.0$ ); auger.

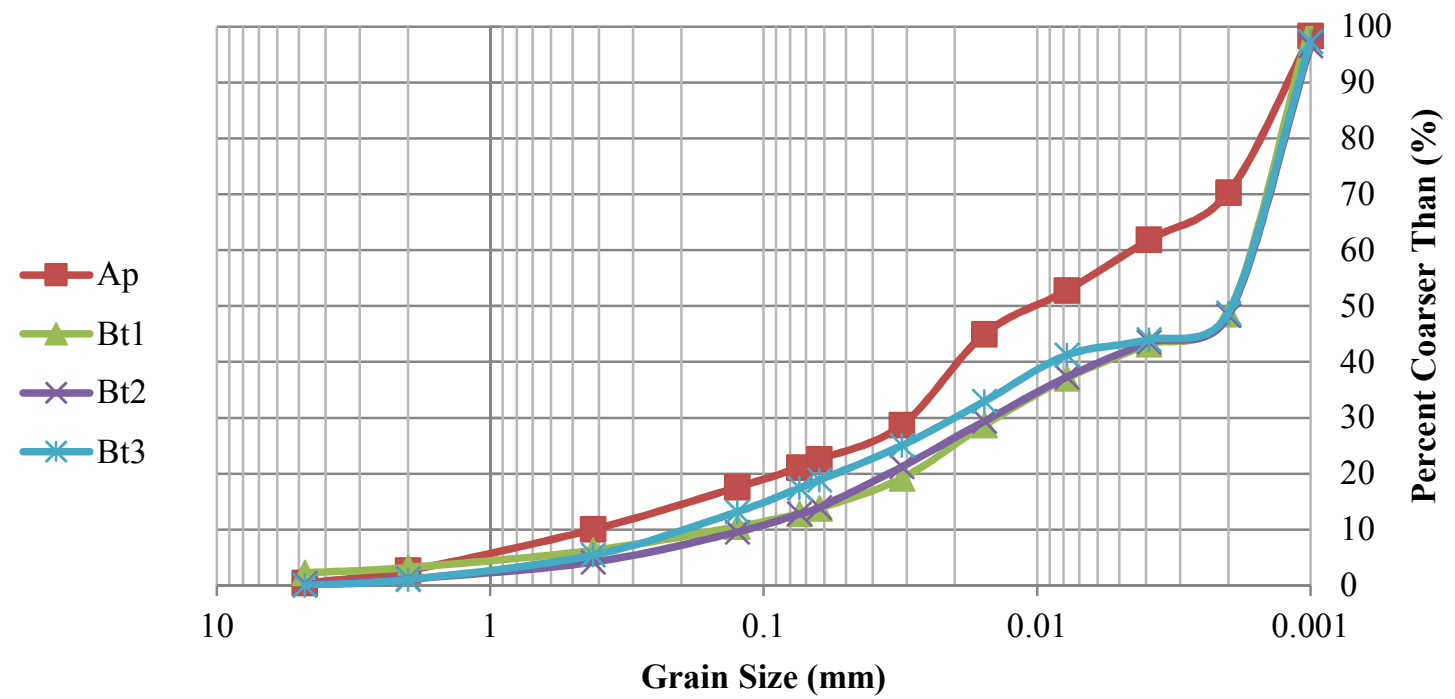

Figure 85. Particle size cumulative weight percent curve as determined by pipette analysis for each horizon of Rex Hill, Sims Vineyard Block 2 soil. 


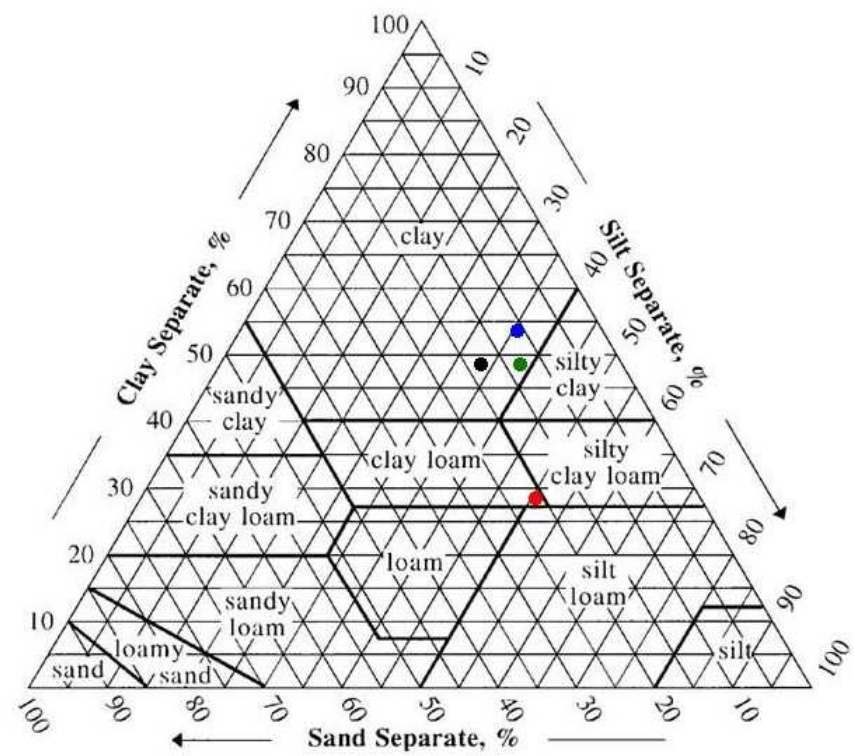

Figure 86. Rex Hill, Sims Vineyard Block 2 soil pit horizon textures determined by pipette analysis. Red - Ap, Blue - Bt1, Green - Bt2, Black - Bt3.

\section{Rex Hill, Estate Vineyard Block 12}

Taxonomic Classification: Fine-silty, mixed, active, mesic Ultic Haploxeralfs Soil Series: Laurelwood

Lat/long Coordinates: $45^{\circ} 18^{\prime} 50.3^{\prime \prime} \mathrm{N} 122^{\circ} 55^{\prime} 08.3^{\prime \prime} \mathrm{W}(45.313974,-122.918974)$

UTM Coordinates: $506,366 \mathrm{mE}, 5,017,831 \mathrm{mN}$

Physiographic Position: Midslope

MAT/MAP: 11 degrees C (52 degrees F)/152 cm (60 in.)

Elevation: 94 meters (308 feet)

Slope: 2 degrees

Aspect: Southeast

Vegetation: Pinot Noir Vineyard on trellis

Parent Material: Basalt and loess (soil contains pisolites)

Bedrock: Basalt

:

Ap $\quad 0-25 \mathrm{~cm}(0-10$ in.); brown (10 YR 4/3), brown (10 YR 5/3) dry, silt loam; moderate fine subangular blocky structure; firm, non-sticky and non-plastic; many fine roots; few distinct clay films on faces of peds; few coarse concretions; moderately acid (pH 5.8); abrupt, wavy boundary; krotovina. 
Bt1 25-100 cm (10-39 in.); dark brown (10 YR 3/3), yellowish brown (10 YR 5/4) dry, silty clay loam; strong medium subangular blocky structure; firm, very sticky and very plastic; many prominent clay films on faces of peds and on interstitial pores; few coarse concretions; moderately acid ( $\mathrm{pH}$ 5.6); abrupt, wavy boundary; auger started at $70 \mathrm{~cm}$.

Bt2 100-130 cm (39-51 in.); strong brown (7.5 YR 4/6) and dark yellowish brown (10 YR 4/6), yellowish brown (10 YR 5/4) and yellowish red (5 YR 5/8) dry, silt loam; strong medium subangular structure; firm, very sticky and very plastic; few medium roots; common distinct clay films on faces of peds; few coarse concretions; $<10$ percent basalt gravel; strongly acid ( $\mathrm{pH}$ 5.4); abrupt, wavy boundary; auger.

$\mathrm{R} \quad 130+\mathrm{cm}(51+$ in.); dark coatings on weathered basalt bedrock; refusal.

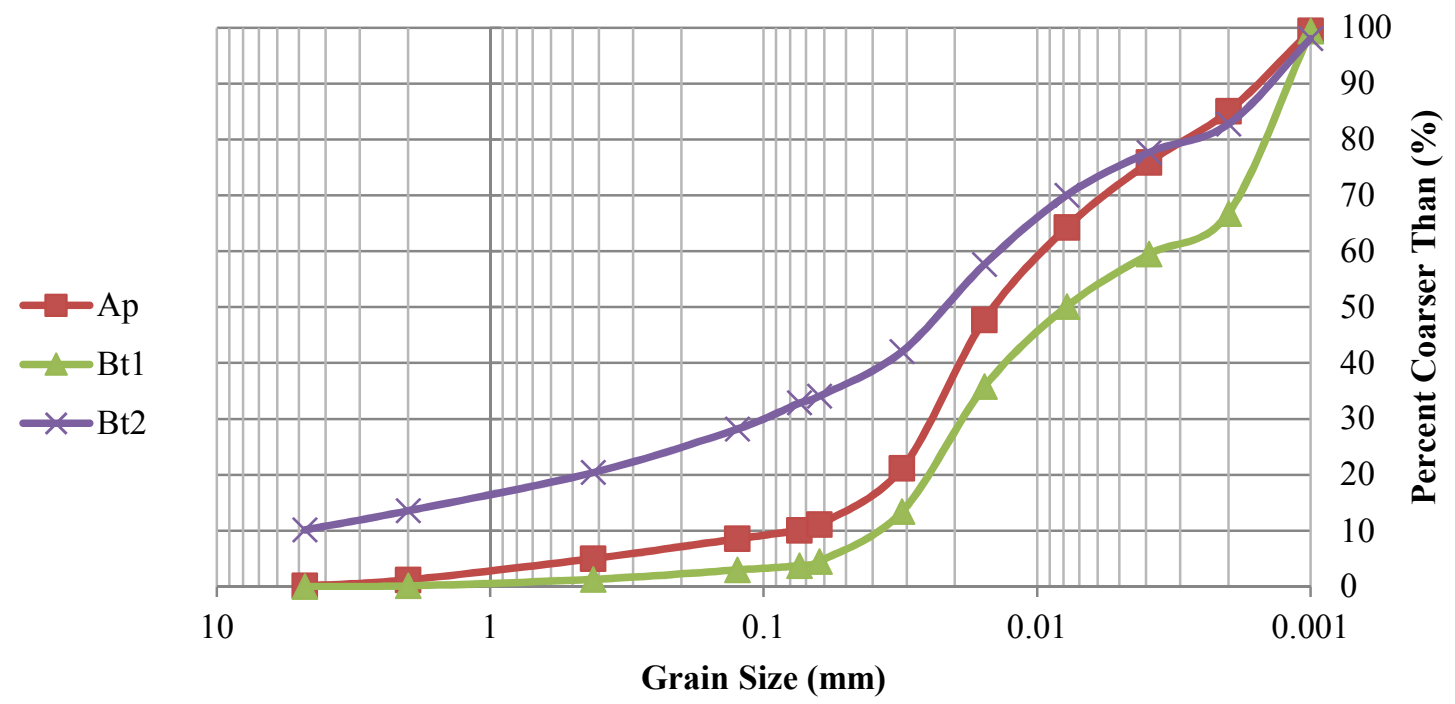

Figure 87. Particle size cumulative weight percent curve as determined by pipette analysis for each horizon of Rex Hill, Estate Vineyard Block 12 soil. 


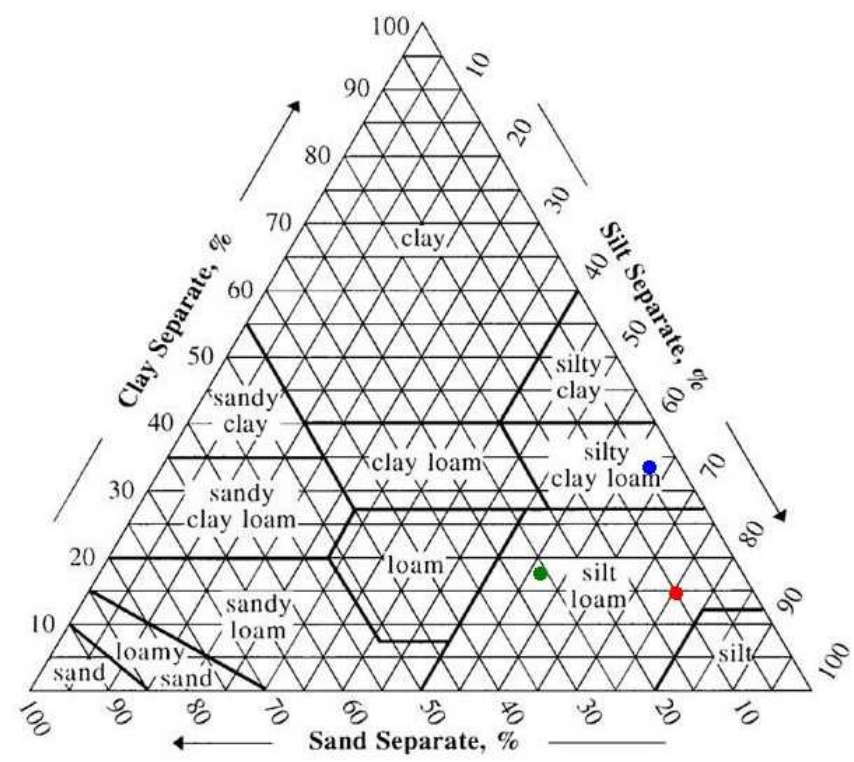

Figure 88. Rex Hill, Estate Vineyard Block 12 soil pit horizon textures determined by pipette analysis. Red - Ap, Blue - Bt1, Green - Bt2.

\section{Rex Hill, Jacob-Hart Vineyard Block 1}

Taxonomic Classification: Fine, mixed, superactive, mesic Pachic Ultic Argixerolls (previously Fine-loamy, mixed, superactive, mesic Ultic Haploxerolls)

Soil Series: Dixonville (previously Steiwer)

Lat/long Coordinates: $45^{\circ} 20^{\prime} 14.3^{\prime \prime N} 123^{\circ} 01^{\prime} 18.1 " \mathrm{~W}$ (45.337304, -123.021697)

UTM Coordinates: 498,298mE, 5,020,413mN

Physiographic Position: Toe of ancient landslide

MAT/MAP: 11 degrees C (52 degrees F)/152 cm (60 in.)

Elevation: 96 meters (315 feet)

Slope: 2 degrees

Aspect: South

Vegetation: Pinot Noir Vineyard on trellis

Parent Material: Colluvium (soil contains pisolites)

Bedrock: Basalt

Ap 0-30 cm (0-12 in.); dark brown (7.5 YR 3/2), brown (10 YR 5/3) dry, silt loam; moderate medium subangular blocky structure; $<10$ percent gravel; firm, sticky and plastic; many fine roots; common distinct clay films on faces of peds; moderately acid ( $\mathrm{pH}$ 5.7); gradual, wavy boundary; lots of worms. 
At $\quad 30-78 \mathrm{~cm}(12-31$ in.); dark reddish brown (5 YR 3/2), brown (10 YR 5/3) dry, silt loam; moderate medium subangular blocky structure; firm, very sticky and very plastic; many distinct clay films on faces of peds; moderately acid ( $\mathrm{pH} 5.7)$; abrupt, wavy boundary.

Bt $\quad 78-145 \mathrm{~cm}$ (31-57 in.); dark brown (7.5 YR 3/3), brown (10 YR 4/3) dry, silty clay loam; moderate medium subangular blocky structure; $<10$ percent basalt gravel; firm, very sticky and very plastic; many distinct clay films on faces of peds; few fine concretions; moderately acid ( $\mathrm{pH}$ 5.7); clear, wavy boundary; auger.

Cr 145-185+ cm (57-73+ in.); red (2.5 YR 4/6), very pale brown (10 YR 7/3) dry, clay loam; 75 percent basalt gravel; very firm; moderately acid ( $\mathrm{pH} 6.0)$; auger; basalt saprolite.

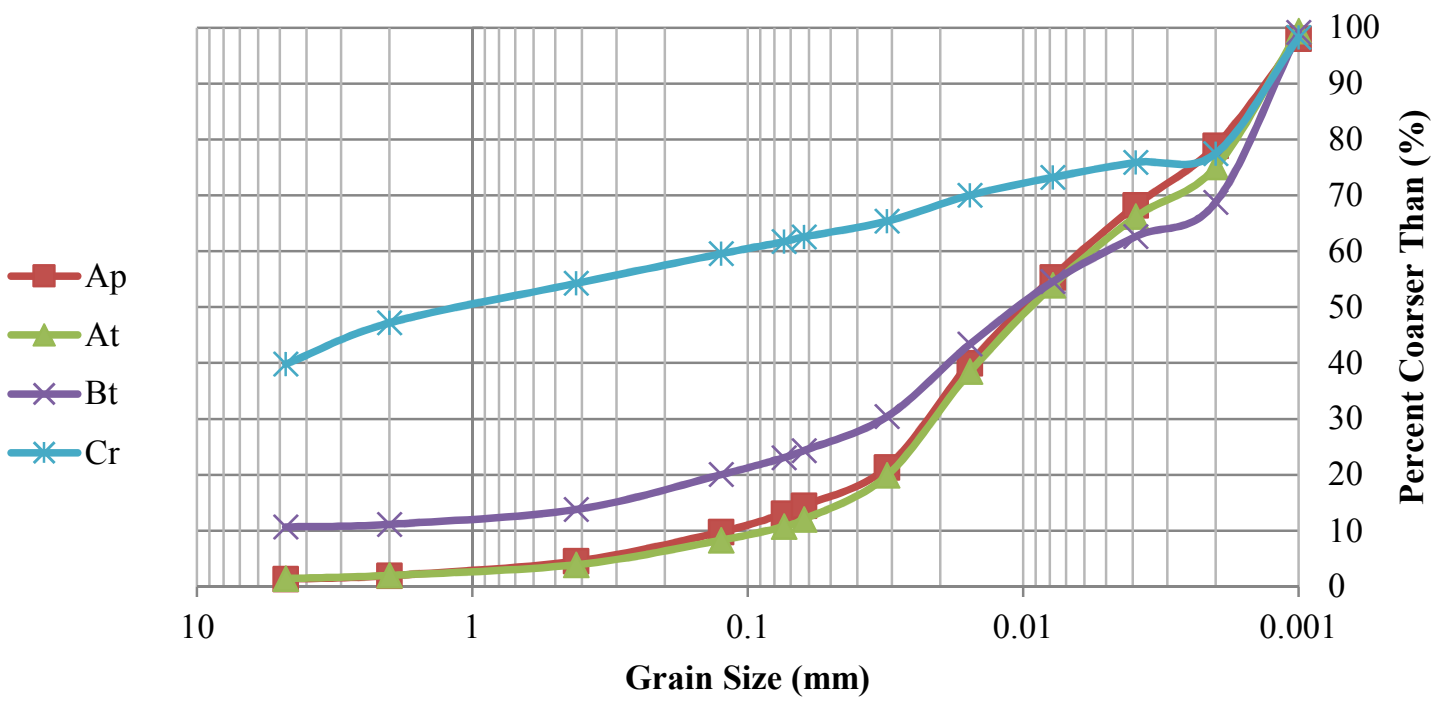

Figure 89. Particle size cumulative weight percent curve as determined by pipette analysis for each horizon of Rex Hill, Jacob-Hart Vineyard Block 1 soil. 


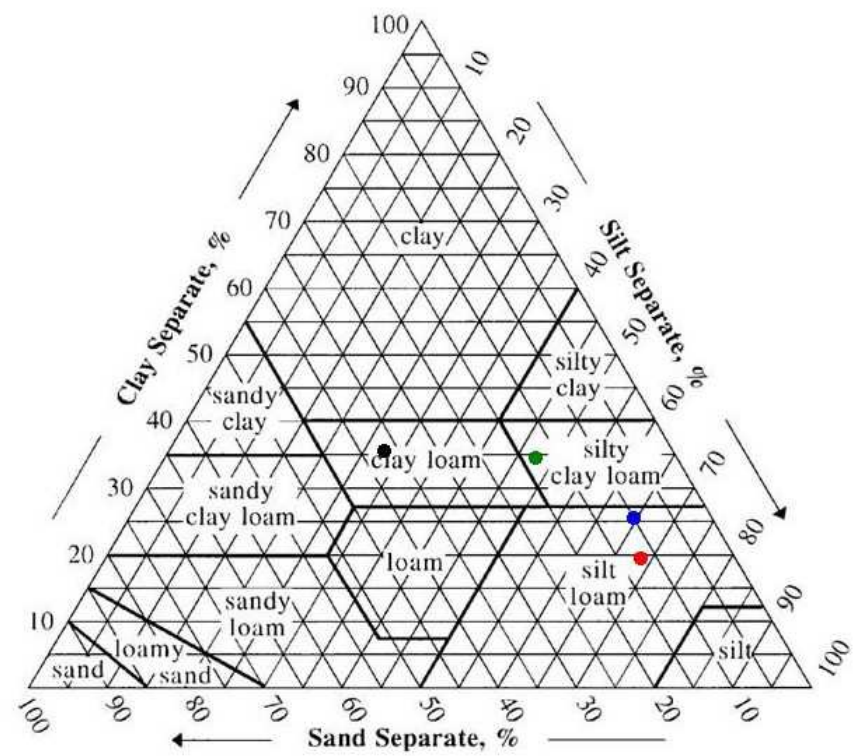

Figure 90. Rex Hill, Jacob-Hart Vineyard Block 1 soil pit horizon textures determined by pipette analysis. Red - Ap, Blue - At, Green - Bt, Black - Cr.

\section{Rex Hill, Jacob-Hart Vineyard Block 5}

Taxonomic Classification: Fine, mixed, superactive, mesic Pachic Ultic Argixerolls (previously Fine, mixed, superactive, mesic Pachic Ultic Haploxerolls)

Soil Series: Dixonville (previously Yamhill)

Lat/long Coordinates: $45^{\circ} 20^{\prime} 25.5^{\prime \prime} \mathrm{N} 123^{\circ} 01^{\prime} 11.6 " \mathrm{~W}(45.340408,-123.019881)$

UTM Coordinates: $498,465 \mathrm{mE}, 5,020,755 \mathrm{mN}$

Physiographic Position: Shoulder/summit of ancient landslide

MAT/MAP: 11 degrees C (52 degrees F)/152 cm (60 in.)

Elevation: 115 meters ( 377 feet)

Slope: 5 degrees

Aspect: South

Vegetation: Pinot Noir Vineyard on trellis

Parent Material: Colluvium (soil contains few pisolites)

Bedrock: Basalt

Apr $\quad 0-60 \mathrm{~cm}(0-24$ in.); dark brown (7.5 YR 3/2) and brown (7.5 YR 4/4), brown (10 YR 4/3) dry, silt loam; massive to moderate medium subangular blocky structure; very firm, sticky and plastic; many fine roots; common faint clay films on faces of peds; 20 percent basalt gravel; slightly acid ( $\mathrm{pH}$ 6.1); clear, wavy boundary; krotovina. 
Bt $\quad 60-80 \mathrm{~cm}(24-32$ in.); brown (10 YR 4/3), brown (10 YR 4/3) dry, silty clay; moderate medium subangular blocky structure; very firm, sticky and plastic; few medium roots; many distinct clay films on faces of peds; $<10$ percent basalt gravel; moderately acid ( $\mathrm{pH}$ 5.9); clear, wavy boundary; auger.

Btg 80-138+ cm (32-54+ in.); strong brown (7.5 YR 4/6) and light reddish brown (2.5 YR 6/3), dark yellowish brown (10 YR 4/4) dry, clay; moderate medium subangular blocky structure; firm, very sticky and very plastic; very few faint clay films on faces of peds; redoximorphic features, pale red (2.5 YR 6/2) and light brownish gray (10 YR 6/2) dry; few coarse concretions; dark staining on gravel and on ped faces; $<10$ percent basalt gravel; moderately acid ( $\mathrm{pH} 5.7)$; refusal.

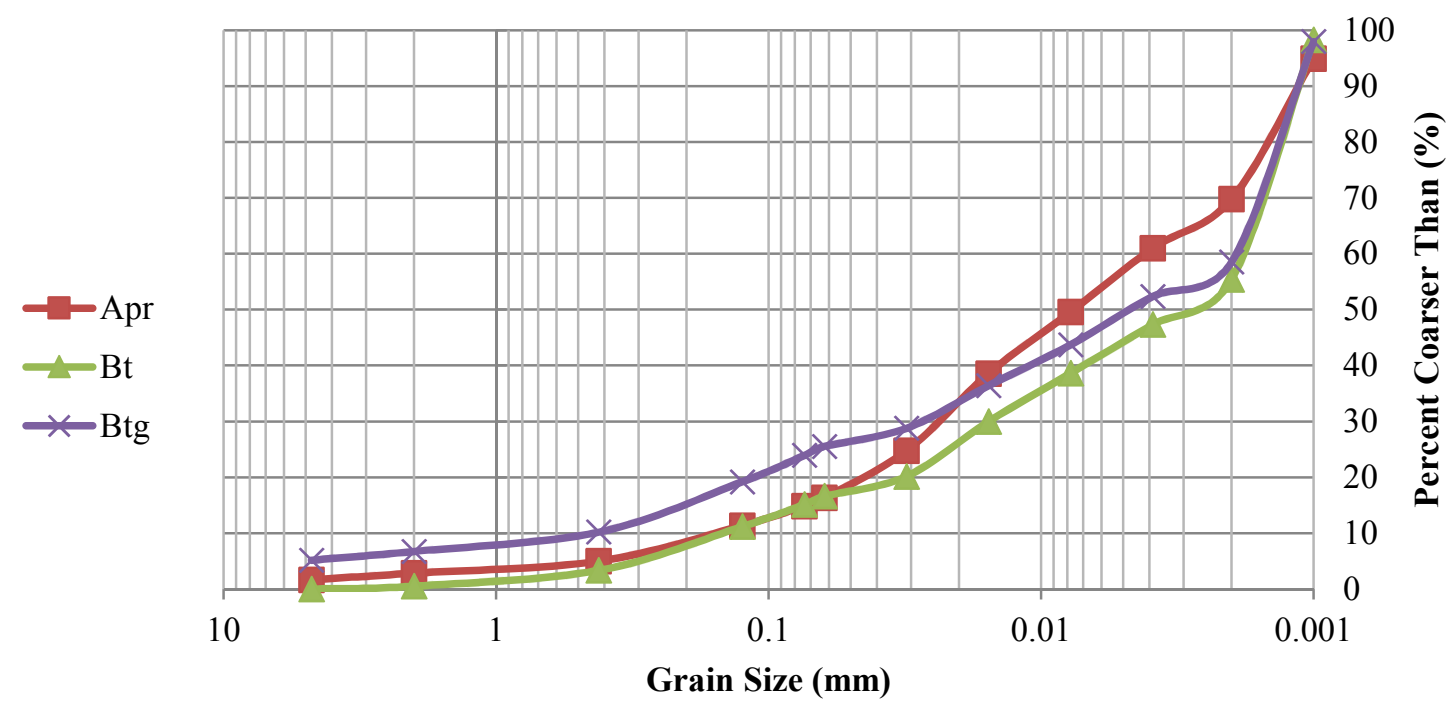

Figure 91. Particle size cumulative weight percent curve as determined by pipette analysis for each horizon of Rex Hill, Jacob-Hart Vineyard Block 5 soil. 


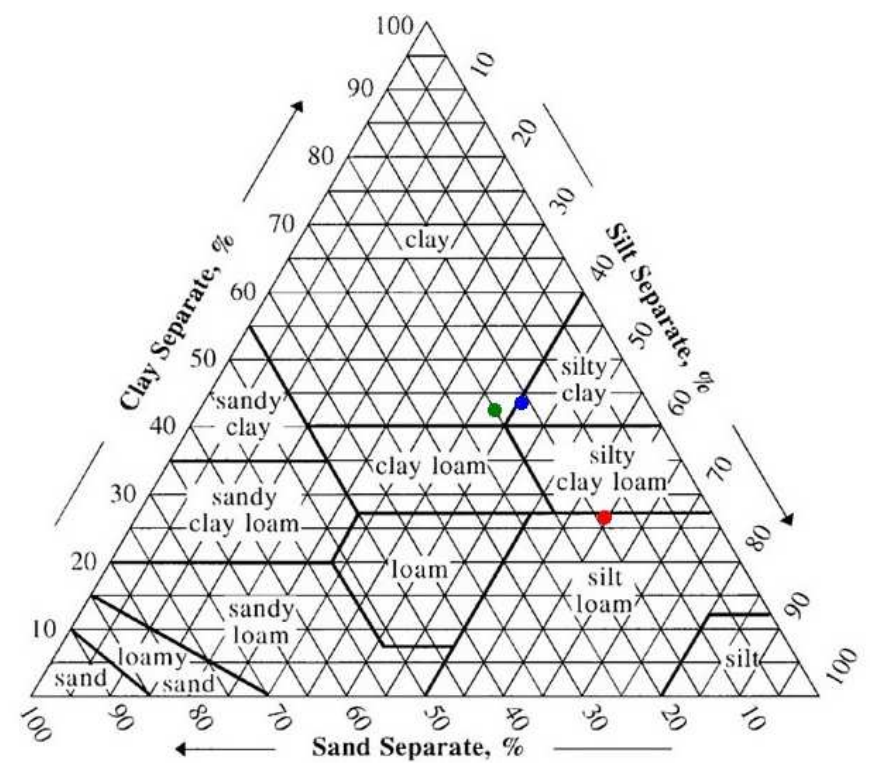

Figure 92. Rex Hill, Jacob-Hart Vineyard Block 5 soil pit horizon textures determined by pipette analysis. Red - Apr, Blue - Bt, Green - Btg.

\section{Ken Wright Cellars, Nysa Vineyard Midblock}

Taxonomic Classification: Fine, mixed, active, mesic Xeric Palehumults

Soil Series: Jory

Lat/long Coordinates: $45^{\circ} 15^{\prime} 57.6^{\prime \prime} \mathrm{N} 123^{\circ} 02^{\prime} 54.0^{\prime \prime} \mathrm{W}(45.265995,-123.048344)$

UTM Coordinates: 496,282mE, 5,012,292mN

Physiographic Position: Summit

MAT/MAP: 11 degrees C (52 degrees F)/152 cm (60 in.)

Elevation: 217 meters ( 712 feet)

Slope: 0 degrees

Aspect: East

Vegetation: Pinot Noir Vineyard on trellis

Parent Material: Basalt colluvium (soil contains pisolites)

Bedrock: Basalt

Ap $\quad 0-35 \mathrm{~cm}(0-14$ in.); dark brown (7.5 YR 3/3), brown (7.5 YR 4/3) dry, silt loam; strong medium subangular blocky structure; firm, slightly sticky and slightly plastic; many fine roots; many prominent clay films on faces of peds; abundant coarse concretions; strongly acid ( $\mathrm{pH} 5.4$ ); clear, wavy boundary. 
Bt1 35-80 cm (14-32 in.); dark reddish brown (5 YR 3/4), brown (7.5 YR 4/4) dry, silty clay loam; strong medium subangular blocky structure; firm, sticky and plastic; common distinct clay films on faces of peds; abundant fine to coarse concretions; 20 percent rock fragments and dark staining; strongly acid (pH 5.5); clear, wavy boundary.

Bt2 80-118 cm (31-47 in.); dark reddish brown (5 YR 3/3), brown (7.5 YR 4/4) dry, clay loam; weak medium subangular blocky structure; firm, sticky and plastic; few distinct clay films on faces of peds; few fine concretions; 70 percent rock fragments and dark staining; strongly acid ( $\mathrm{pH}$ 5.5); clear, wavy boundary; auger.

Cr 118-150+ cm (47-59+ in.); brown (7.5 YR 4/4) and dark grayish brown (2.5 YR 4/2), pale yellow (2.5 YR 7/4) and brownish yellow (10 YR 6/6) dry, loam; single grain to weak fine subangular blocky structure; firm, nonsticky and nonplastic; $>75$ percent basalt rock fragments and dark staining; strongly acid ( $\mathrm{pH} 5.4$ ); auger.

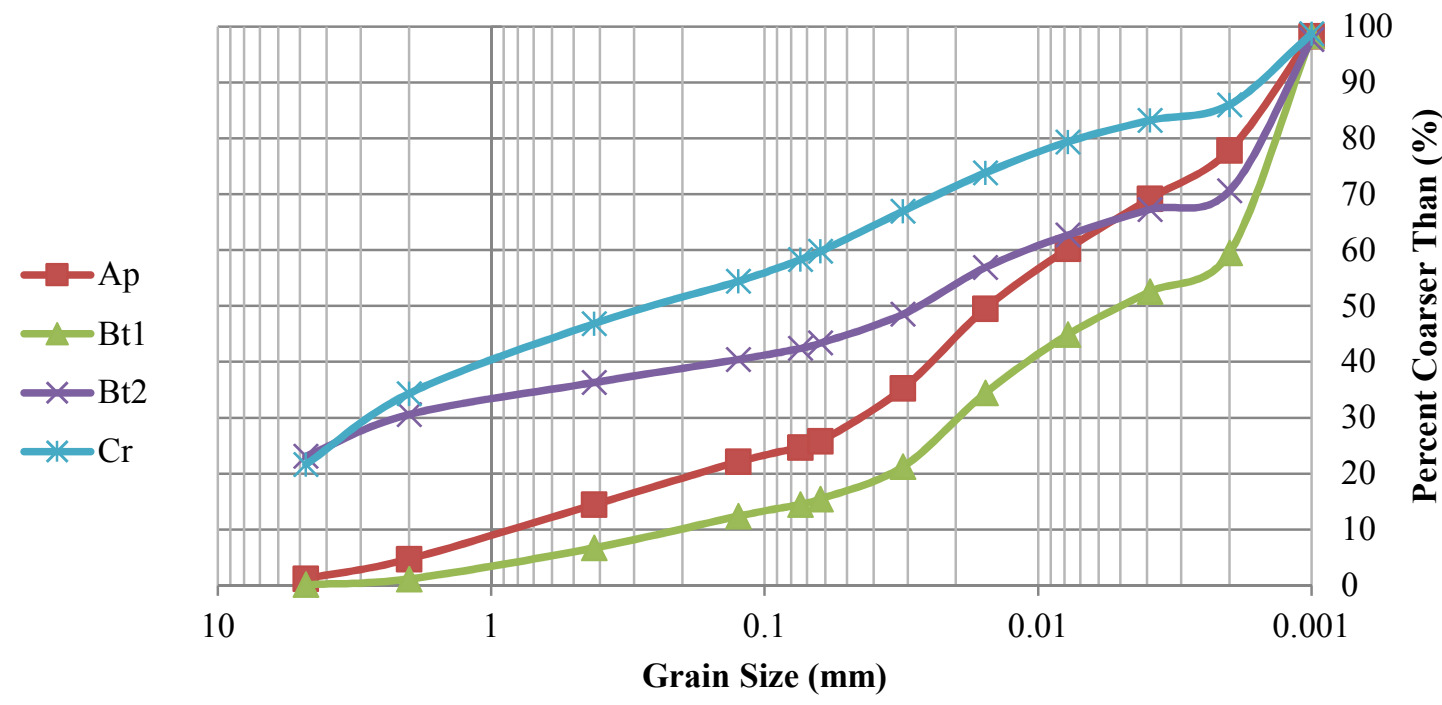

Figure 93. Particle size cumulative weight percent curve as determined by pipette analysis for each horizon of Ken Wright Cellars, Nysa Vineyard Midblock soil. 


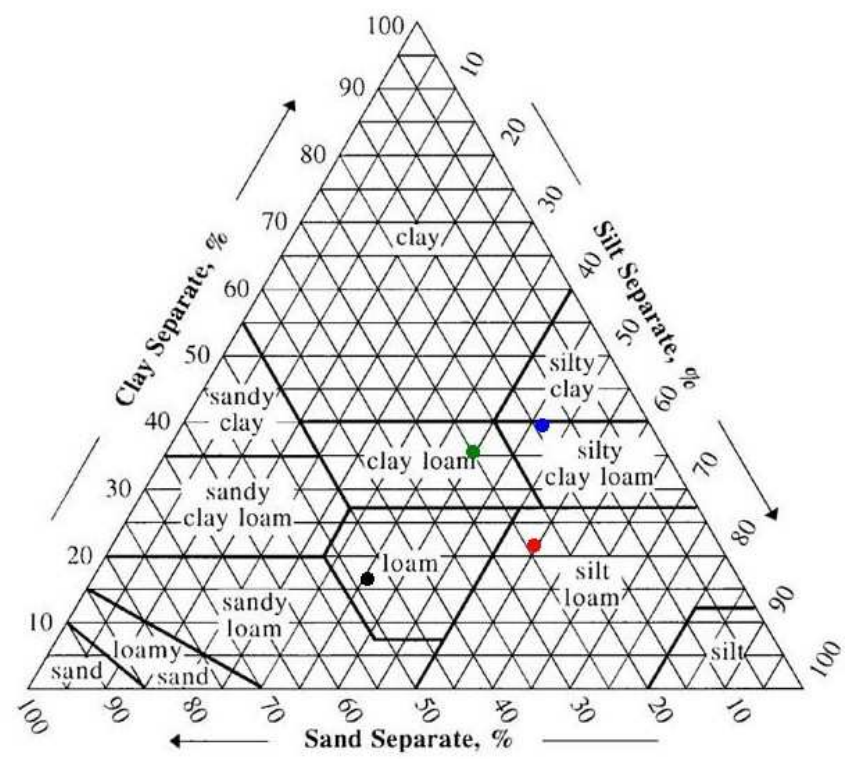

Figure 94. Ken Wright Cellars, Nysa Vineyard Midblock soil pit horizon textures determined by pipette analysis. Red - Ap, Blue - Bt1, Green - Bt2, Black - Cr.

\section{Ken Wright Cellars, Abbott Claim Vineyard}

Taxonomic Classification: Fine-loamy, mixed, active, mesic Aquultic Haploxeralfs Fine-loamy, mixed, active, mesic Ultic Haploxeralfs - Fine, mixed, superactive, mesic Aquultic Haploxeralfs (previously Fine-loamy, mixed, active, mesic Ultic Haploxeralfs) Soil Series: Wellsdale - Willakenzie - Dupee (previously Willakenzie)

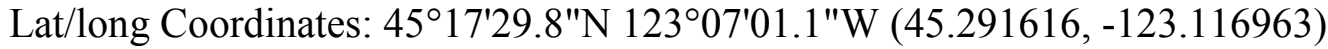

UTM Coordinates: $490,797 \mathrm{mE}, 5,015,352 \mathrm{mN}$

Physiographic Position: Summit/Shoulder MAT/MAP: 11 degrees C (52 degrees F)/152 cm (60 in.)

Elevation: 145 meters (476 feet)

Slope: 2 degrees

Aspect: South

Vegetation: Pinot Noir Vineyard on trellis (possibly ripped)

Parent Material: Sandstone (soil contains abundant muscovite and quartz sand)

Bedrock: Sandstone

Ap 0-24 cm (0-9 in.); dark brown (10 YR 3/3), yellowish brown (10 YR 5/4) dry, loam; weak fine subangular blocky structure; firm, slightly sticky and slightly plastic; many fine roots; slightly acid ( $\mathrm{pH}$ 6.4); abrupt, wavy boundary; krotovina. 
Bt1 24-70 cm (9-28 in.); strong brown (7.5 YR 4/6) and brown (10 YR 4/3), strong brown (7.5 YR 5/6) and brown (7.5 YR 4/4) dry, clay; moderate medium subangular blocky structure to massive; firm, very sticky and very plastic; few medium roots; few distinct clay films on faces of peds; very few fine sandstone concretions; moderately acid ( $\mathrm{pH} 5.6$ ); abrupt, wavy boundary; auger.

Bw 70-140 cm (28-55 in.); dark reddish brown (5 YR 3/4) and yellowish red (5 YR 5/8), reddish yellow (7.5 YR 6/6) and reddish yellow (7.5 YR 8/6) dry, sandy clay loam; single grain to weak fine subangular blocky structure; loose, slightly sticky and nonplastic; few medium roots; very few faint clay films on faces of peds and interstitial pores; very strongly acid ( $\mathrm{pH} 4.9$ ); abrupt, wavy boundary; auger.

Cr1 140-150 cm (55-59 in.); strong brown (7.5 YR 5/8) and light greenish gray (GLEY $18 / 10 \mathrm{Y})$, strong brown (7.5 YR 4/6) and pale yellow (2.5 Y 8/2) dry, sandy loam; single grain to fine granular structure; loose, nonsticky and nonplastic; few medium roots; very strongly acid ( $\mathrm{pH} 4.7$ ); abrupt, wavy boundary; auger.

Cr2 150-215+ cm (59-85+ in.); reddish yellow (7.5 YR 6/8) and reddish yellow (7.5 YR 7/6), reddish yellow (7.5 YR 7/6) and very pale brown (10 YR 8/4) dry, loam; single grain to fine granular structure; loose, nonsticky and nonplastic; few medium roots; very strongly acid ( $\mathrm{pH} 4.8)$; auger. 


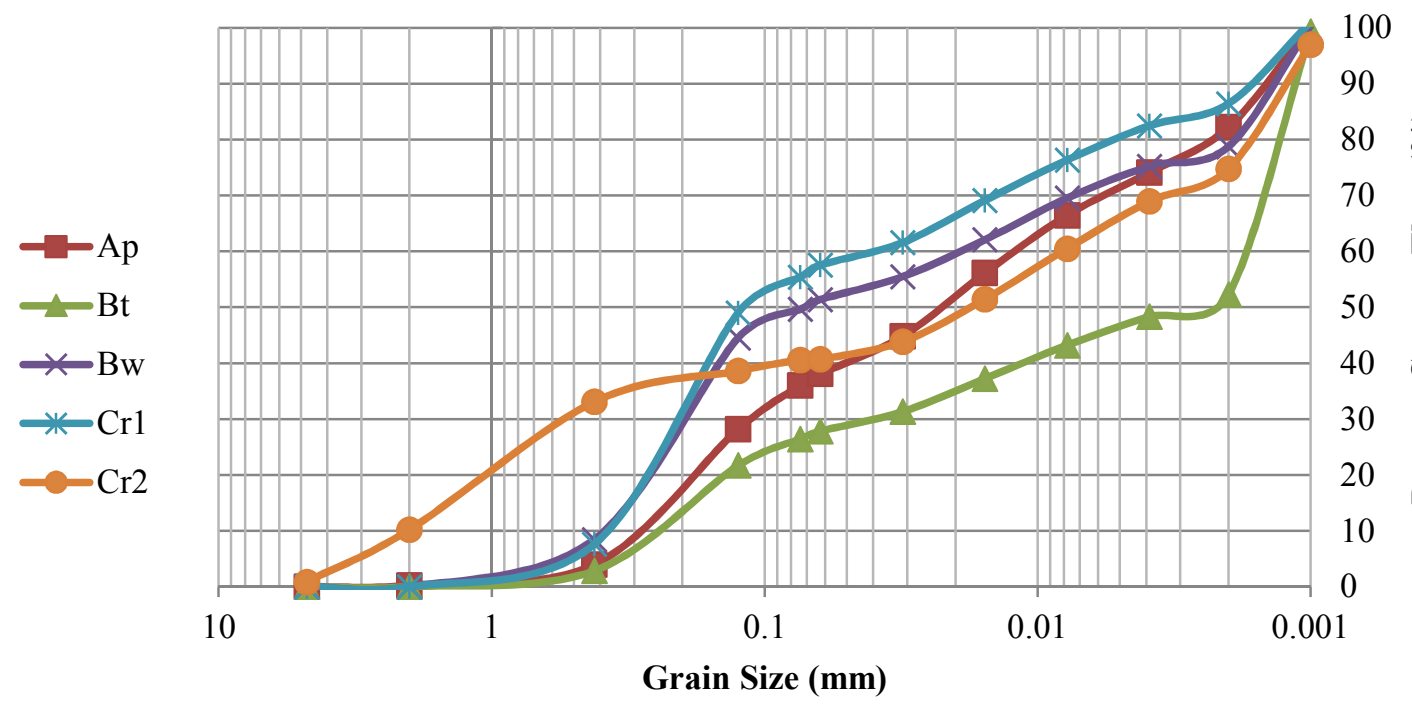

ฮี

Figure 95. Particle size cumulative weight percent curve as determined by pipette analysis for each horizon of Ken Wright Cellars, Abbott Claim Vineyard soil.

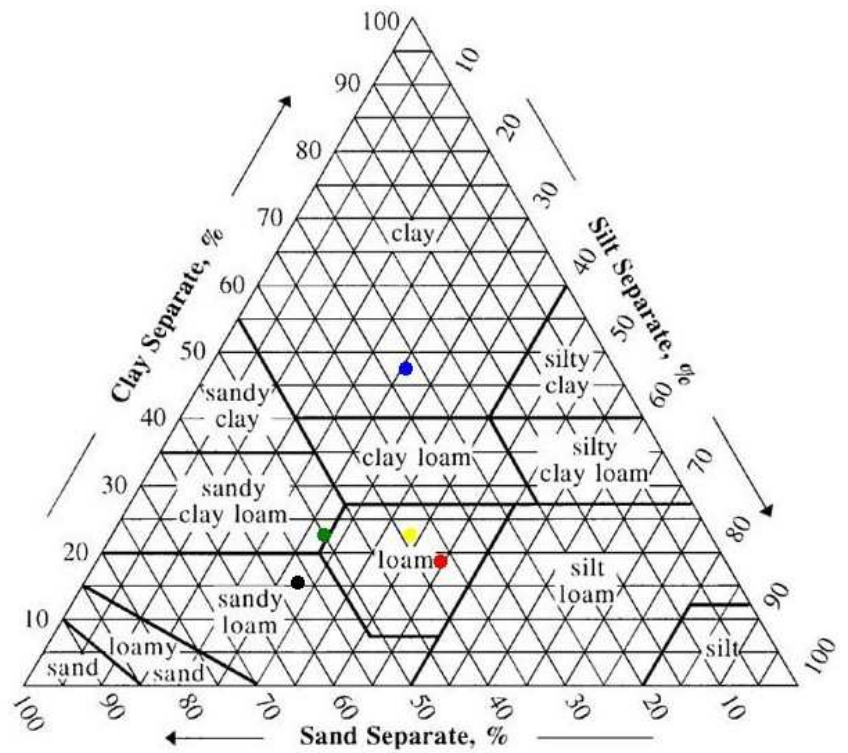

Figure 96. Ken Wright Cellars, Abbott Claim Vineyard soil pit horizon textures determined by pipette analysis. Red - Ap, Blue - Bt, Green - Bw, Black - Cr1, Yellow - Cr2. 


\section{Ken Wright Cellars, Freedom Hill Vineyard}

Taxonomic Classification: Fine, mixed, active, mesic Xeric Haplohumults (mapped as Fine, mixed, active, mesic Xeric Palehumults)

Soil Series: Bellpine (mapped as Jory)

Lat/long Coordinates: 4452'31.2"N 12317'38.3"W (44.875343, -123.293962)

UTM Coordinates: 476,874mE, 4,968,941mN

Physiographic Position: Midslope

MAT/MAP: 11 degrees C (52 degrees F)/152 cm (60 in.)

Elevation: 142 meters (466 feet)

Slope: 2 degrees

Aspect: Southwest

Vegetation: Pinot Noir Vineyard on trellis, ripped

Parent Material: Sandstone (soil contains muscovite mica and quartz sand)

Bedrock: Sandstone

Ap 0-15 cm (0-6 in.); brown (7.5 YR 4/3), yellowish brown (10 YR 5/4) dry, silt loam; moderate medium subangular blocky structure; firm, nonsticky and nonplastic; many fine roots; very few very fine sandstone concretions; moderately acid ( $\mathrm{pH} 6.0$ ); clear, wavy boundary.

Bt $\quad 15-50 \mathrm{~cm}$ (13-20 in.); brown (7.5 YR 4/4), dark yellowish brown (10 YR 4/4) dry, clay loam; moderate medium subangular blocky structure; firm, sticky and plastic; many prominent clay films on faces of peds and interstitial pores; moderately acid ( $\mathrm{pH}$ 5.6); clear, irregular boundary.

$\mathrm{Cr} \quad 50-75+\mathrm{cm}(20-30+$ in. $)$; light red (2.5 YR 7/6) and red (2.5 YR 4/6), dark yellowish brown (10 YR 4/6) and yellow (10 YR 7/6) dry, clay loam; moderate medium subangular blocky structure; firm, sticky and plastic; many prominent clay films on faces of peds and interstitial pores; 75 percent sandstone gravel; strongly acid ( $\mathrm{pH} 5.3)$; auger. 


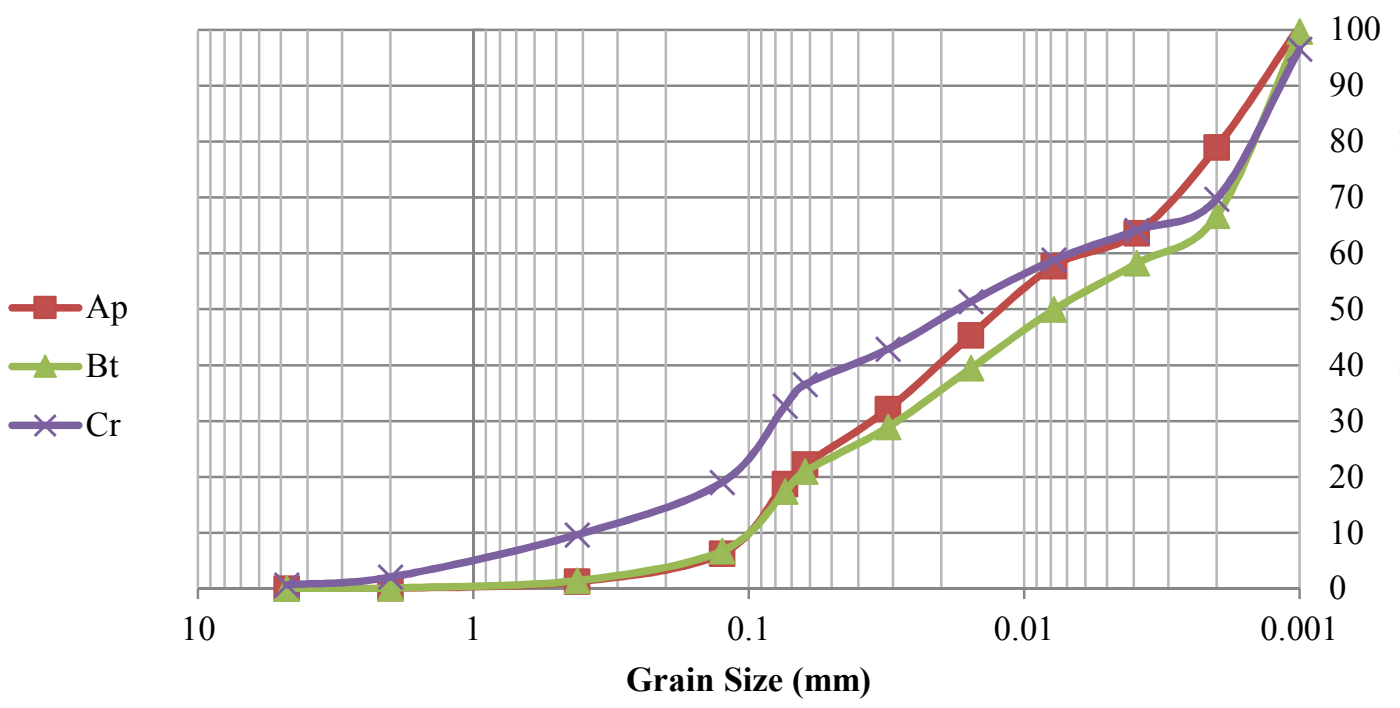



Figure 97. Particle size cumulative weight percent curve as determined by pipette analysis for each horizon of Ken Wright Cellars, Freedom Hill Vineyard soil.

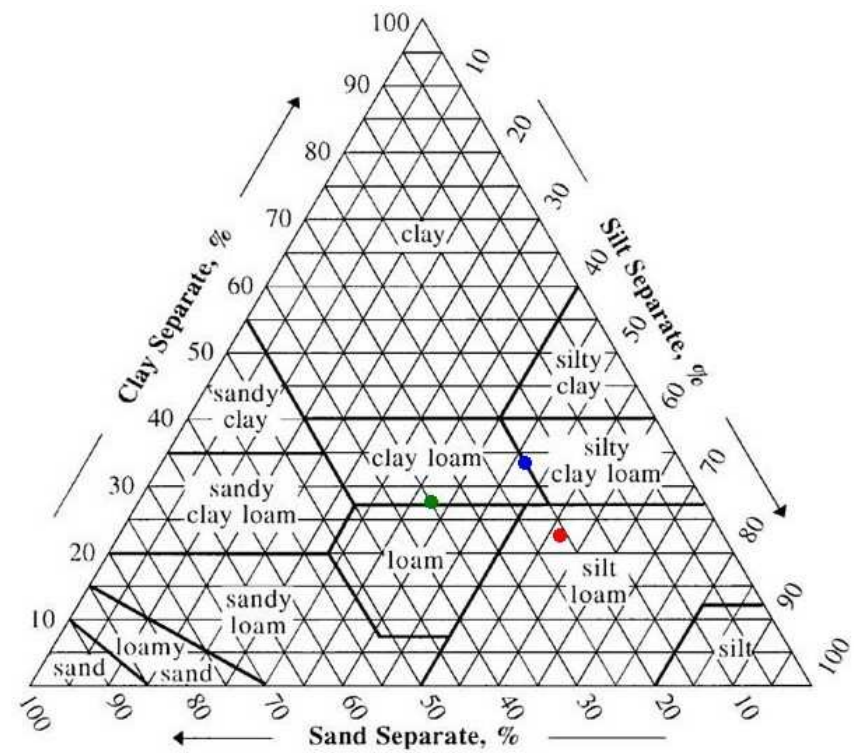

Figure 98. Ken Wright Cellars, Freedom Hill Vineyard soil pit horizon textures determined by pipette analysis. Red - Ap, Blue - Bt, Green - Cr. 


\section{Ken Wright Cellars, Meredith Mitchell Vineyard Martha Block}

Taxonomic Classification: Loamy-skeletal, mixed, superactive, mesic Lithic Ultic Haploxerolls - Fine, mixed, superactive, mesic Pachic Ultic Argixerolls (previously Fine, mixed, superactive, mesic Pachic Ultic Haploxerolls)

Soil Series: Witzel - Dixonville (previously Yamhill)

Lat/long Coordinates: 4509'22.9"N 12317'30.2"W (45.156368, -123.291720)

UTM Coordinates: 477,053mE, 5,000,364mN

Physiographic Position: Summit

MAT/MAP: 11 degrees C (52 degrees F)/152 cm (60 in.)

Elevation: 204 meters (669 feet)

Slope: 2 degrees

Aspect: Southwest

Vegetation: Pinot Noir Vineyard on trellis

Parent Material: Basalt (Soil contains fine pisolites)

Bedrock: Basalt (Tillamook or Siletz?)

Ap $\quad 0-10 \mathrm{~cm}(0-4$ in.); very dark brown (7.5 YR 2.5/2), dark yellowish brown (10 YR 4/4), dry loam; strong fine subangular blocky structure; very firm, nonsticky and nonplastic; many fine roots; few faint clay films on faces of peds; abundant concretions; moderately acid ( $\mathrm{pH}$ 6.0); clear, wavy boundary; krotovina.

Bt 10-72 cm (4-23 in.); dark brown (7.5 YR 3/4), dark yellowish brown (10 YR 3/4) dry, silt loam; moderate medium subangular blocky structure; firm, sticky and plastic; common distinct clay films on faces of peds; 20 percent weathered basalt gravel; moderately acid ( $\mathrm{pH} 6.0$ ); krotovina; auger at $60 \mathrm{~cm}$.

Bw 72-121 cm (23-48 in.); brown (7.5 YR 4/3), brown (7.5 YR 4/3) dry, sandy loam; single grain to weak fine subangular blocky structure; loose, nonsticky and nonplastic; $<10$ percent weathered basalt gravel; slightly acid ( $\mathrm{pH} 6.3$ ); abrupt, wavy boundary; auger; saprolite.

Cr 121-204+ cm (48-80+ in.); very dark grayish brown (10 YR 3/2), dark gray (7.5 YR 4/1) dry, loamy fine sand; single grain structure; loose, nonsticky and nonplastic; dark staining on ped surfaces; 25 percent weathered basalt gravel; neutral (pH 6.7); auger; saprolite; refusal. 


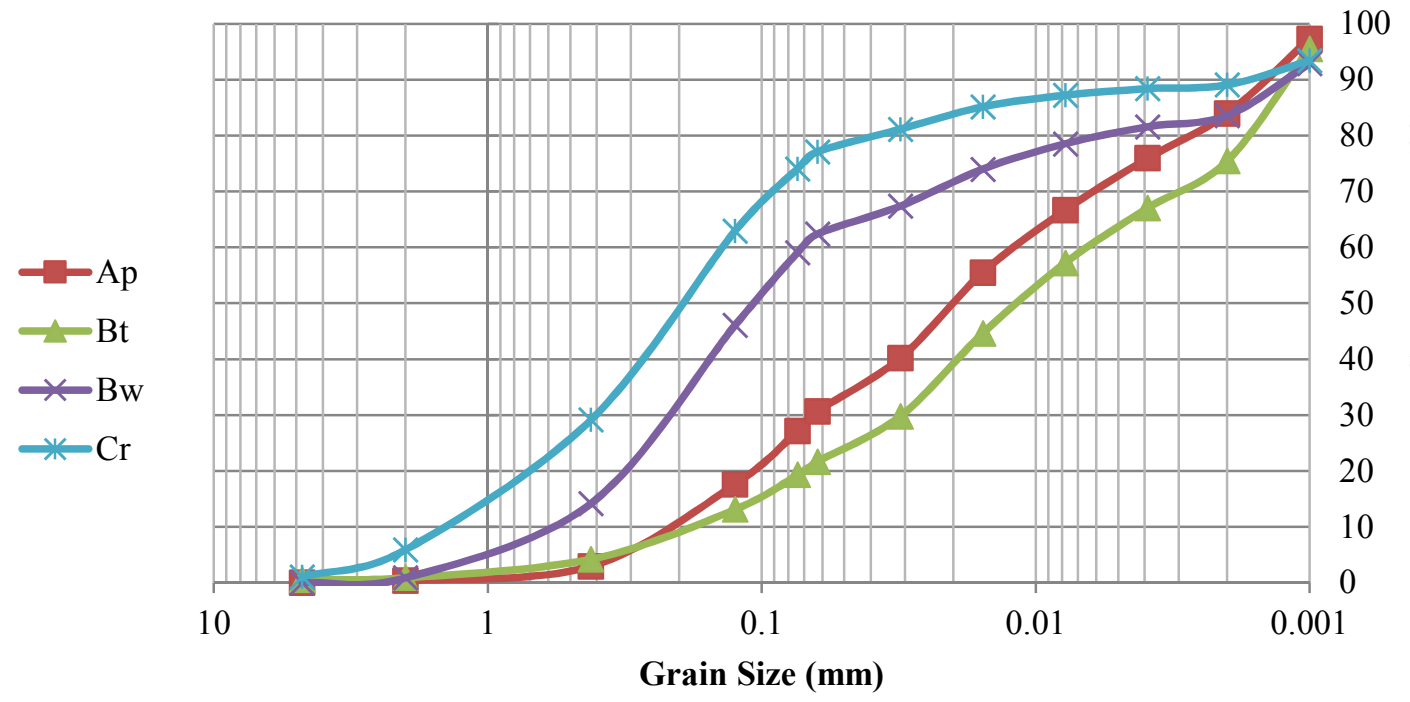

100
90
80
70
60
50
40
30
20
0

Figure 99. Particle size cumulative weight percent curve as determined by pipette analysis for each horizon of Ken Wright Cellars, Meredith Mitchell Vineyard Martha Block soil.

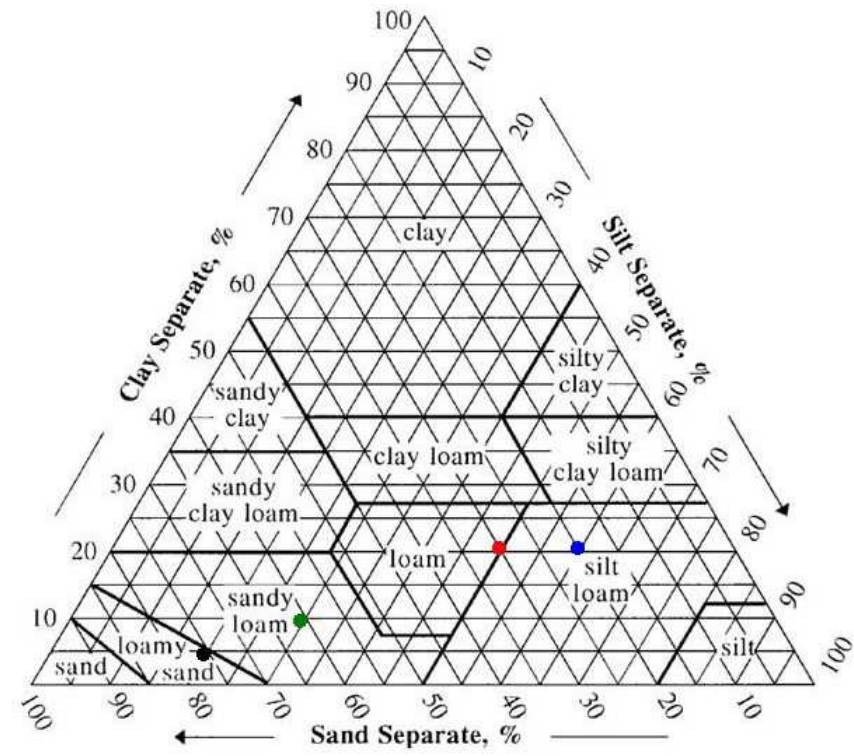

Figure 100. Ken Wright Cellars, Meredith Mitchell Vineyard Martha Block soil pit horizon textures determined by pipette analysis. Red - Ap, Blue - Bt, Green - Bw, Black - Cr. 


\section{Appendix B Clay Mineralogy}

XRD analyses performed by Reed Glasmann of Willamette Geological Service (descriptions in this Appendix are his direct words as quoted from his report unless in brackets). Clays were $\mathrm{Mg}$-saturated by rinsing several times with $0.5 \mathrm{~N} \mathrm{MgCl} 2$, then rinsing with distilled water. Clays were then K-saturated by washing several times with 1.0M KCl, then rinsing with 50\% methanol solution. The Mg-saturated slides were analyzed after air drying, then solvated with ethylene glycol and re-scanned. The Ksaturated slides were analyzed after air drying then rescanned after 6 hours in an 110C

oven. The scan conditions were shortened to try to limit re-hydration during analysis, but some minor re-expansion of smectitic clays is evident in the patterns.

\section{Elk Cove Vineyards, Clay Court Vineyard Block E}

The ECCC [Elk Cove Clay Court] Bt2 soil sample has a clay mineral assemblage that includes disordered kaolinite, illite, and hydroxy interlayered smectite (Figure 101). The smectitic phase shows significant resistance to expansion and collapse, indicating strong development of chloritic character due to the formation of interlayer sheets of Fe/Al hydroxy material. The kaolin phase probably includes a minor component of dehydrated halloysite, as suggested by the moderate peak in the range of 20 degrees 2 theta. The clay fraction also includes minor amounts of cristobalite. The Fe phase is 
dominated by goethite. The sample is probably too illitic to have formed from volcanic parent materials, unless windblown mica was a component of the parent material.

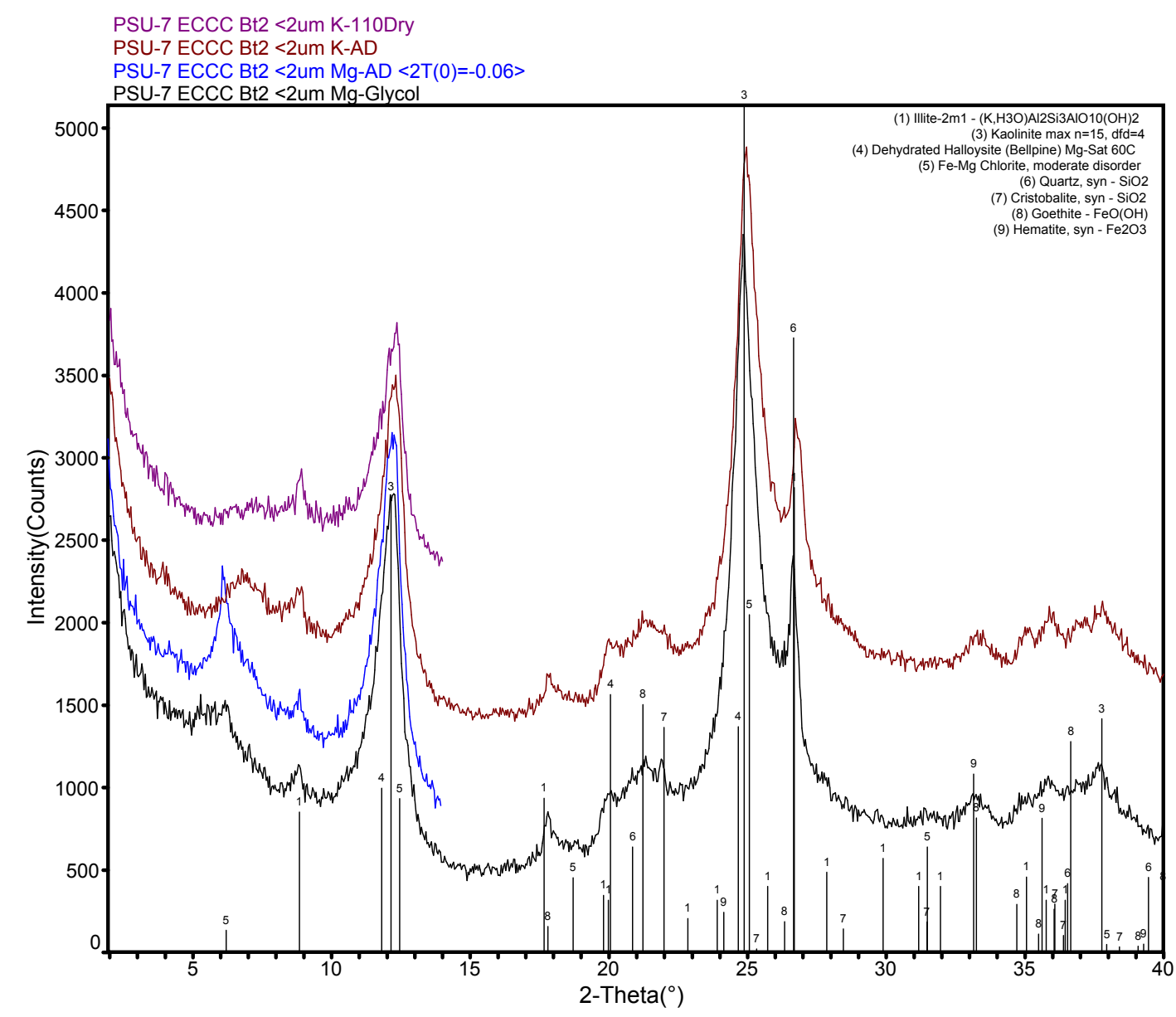

Figure 101. XRD patterns for the Bt2 soil horizon from Elk Cove Vineyards, Clay Court Vineyard Block E.

\section{Elk Cove Vineyards, Roosevelt Estate Vineyard}

This sample [ECRV Bt2] (Figure 102) may be genetically related to the WETB [Willakenzie Estate, Terres Basses] soil, given the occurrence of smectitic clay and 
general low abundance of mica. The smectitic component shows full expansion with glycol and the progressive collapse anticipated with K-saturation and heating; however, there is a definite chloritic intergrade component that causes a non-expansive 14A chlorite peak in the glycol pattern. This character persists in the K-air dry pattern, where a remnant $14 \mathrm{~A}$ phase causes the asymmetric character of the partially collapsed smectite. With heating, the 14A peak loses clarity and shows as a very weak peak remaining as the smectite has collapsed to ca 10A. The 7.3A peak doesn't show much variation during the 4 treatments shown, perhaps some weak broadening during glycol solvation (probably due to interference from the glycol 002 smectite peak). The kaolinite phase is dominated by disordered kaolinite, but may include a minor component of dehydrated halloysite. The absence of intensification of the 10A peak after K-saturation suggests that vermiculite is not present in the sample.

This sample does not show much cristobalite and has quartz as the main silica phase. If the cristobalite is an indicator of prolonged weathering and possible accumulation of plant opal (or primary cementation in paleosols affected by volcanic ash), then the general absence of cristobalite may suggest a less severe weathering history. This is also suggested by the occurrence of fully expansive smectite and the generally weak development of hydroxy interlayered clays. Perhaps the lower abundance of mica reduced the potential for vermiculitic/chloritic intergrade formation relative to the more micaceous clay mineral assemblages seen in this first set of soils. 


\section{Elk Cove Vineyards, Five Mountain Vineyard}

This sample [ECFM Bt3] is mineralogically almost identical to the ECCC [Elk Cove Clay Court] Bt2 sample (Figure 103). The clay mineral assemblage includes disordered kaolinite with a component of dehydrated halloysite, illite, and hydroxy interlayered smectite. It is possible that the smectitic component includes a bit of high

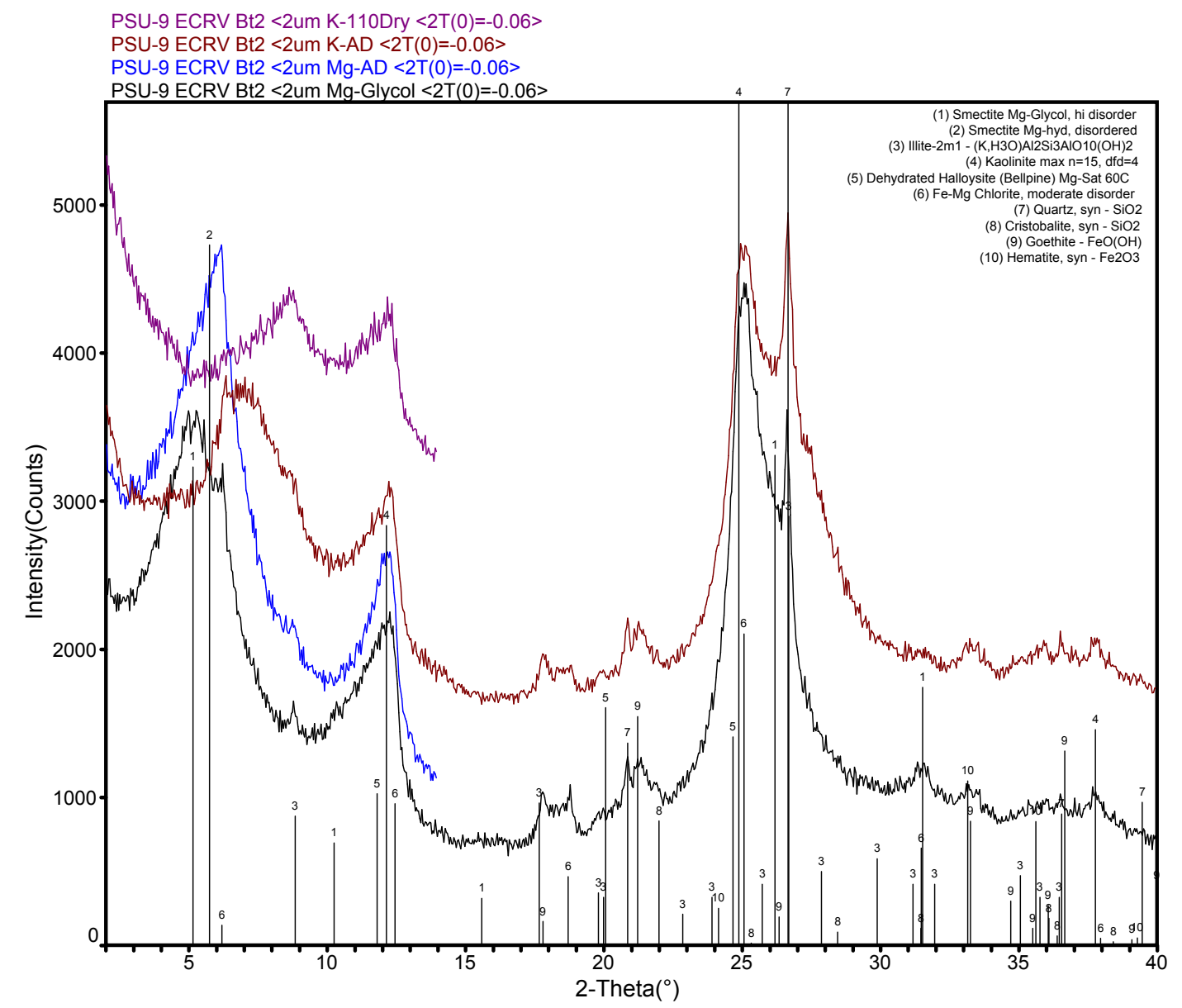

Figure 102. XRD patterns for the Bt2 soil horizon from Elk Cove Vineyards, Roosevelt Estate Vineyard. 
charge smectite/vermiculite, as there is slight intensification of the 10A component after K-saturation. The smectite component resists complete collapse with heating and Ksaturation and shows only weak expansion with glycol solvation. This is very characteristic behavior of hydroxy interlayered material (chloritic intergrade minerals). These chloritic intergrade clays are very common in Pacific Northwest soils that have a history of moderate weathering. The sample also contains a minor component of cristobalite and moderate amounts of goethite (probably both goethite and hematite).

\section{Willakenzie Estate Winery, The Jory Hills Vineyard Block 50c}

The clay mineral assemblage of this sample [WEJH Bt2] contains kaolinite (dehydrated halloysite) and chloritic intergrade clays (generally non-expansive, resists complete collapse, no intensification of the 10A peak with K-saturation suggests an absence of vermiculite). The halloysite peak at ca 20 degrees 2 -theta occurs and the sample shows abundant goethite (oxidized to hematite after oven drying). There is a minor cristobalite component. The sample looks a lot like the CWS Bt3 soil, but shows less cristobalite and is somewhat less illitic (Figure 104). Patterns of this character are common in buried paleosols from the southern Willamette Valley. This pattern is very similar to the ECFM [Elk Cove Five Mountain] Bt3 clay mineral assemblage.

\section{Willakenzie Estate Winery, Aliette Vineyard Block 2b}

This sample [WEAB Bt3] is the least illitic of the first 6 soils analyzed [Elk Cove, 


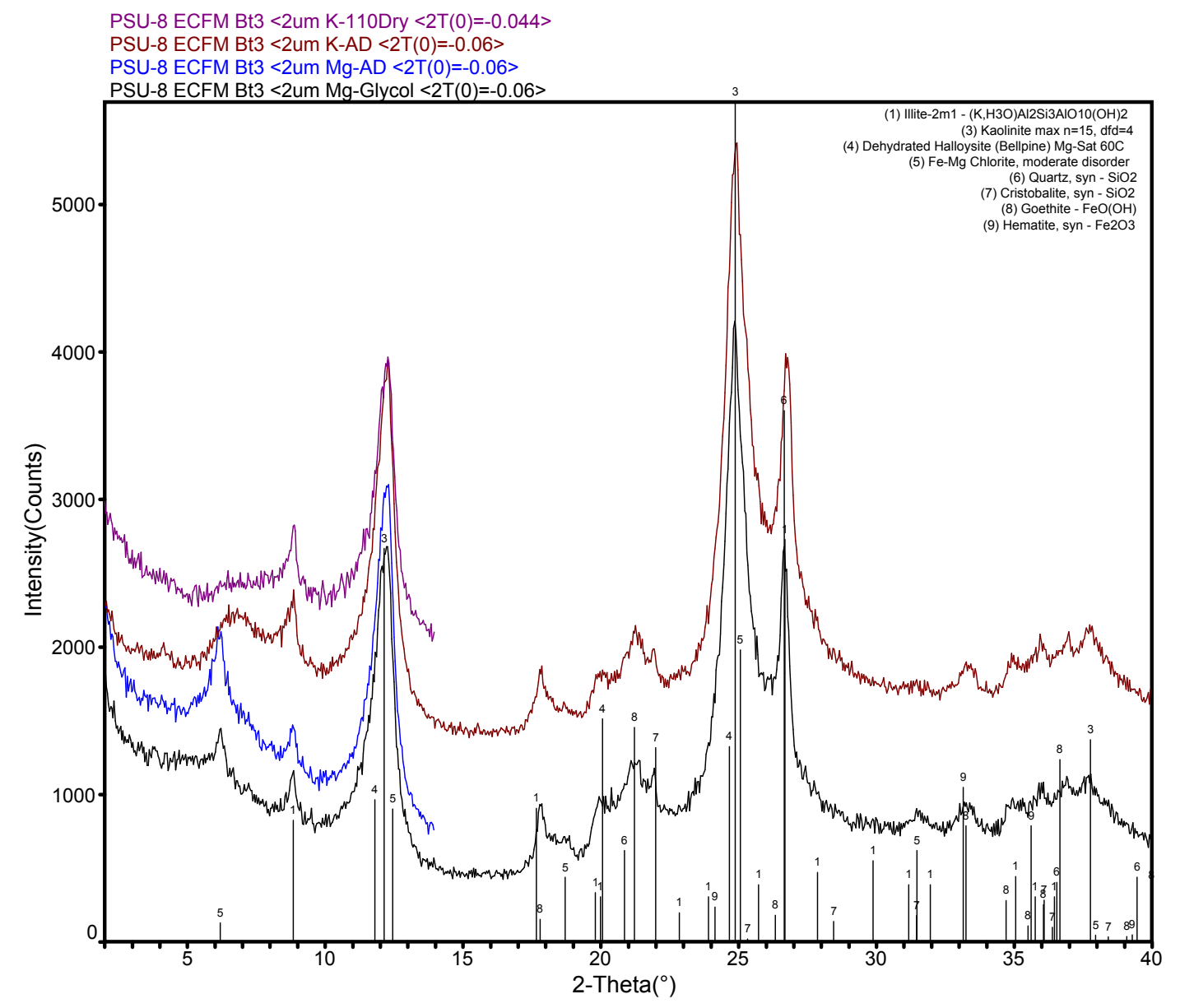

Figure 103. XRD patterns for the Bt3 soil horizon from Elk Cove Vineyards, Fine Mountain Vineyard.

Willakenzie, and Chehalem soils were the first to be analyzed]. The illitic component has probably been degraded to kaolinite and vermiculite. With $\mathrm{K}$-saturation, there is a component that shows complete collapse to $10 \mathrm{~A}$ (this indicates vermiculite). There is also a component that resists expansion with glycol and collapse with K-saturation and heating (this is well-developed chloritic intergrade). This sample looks very similar to 


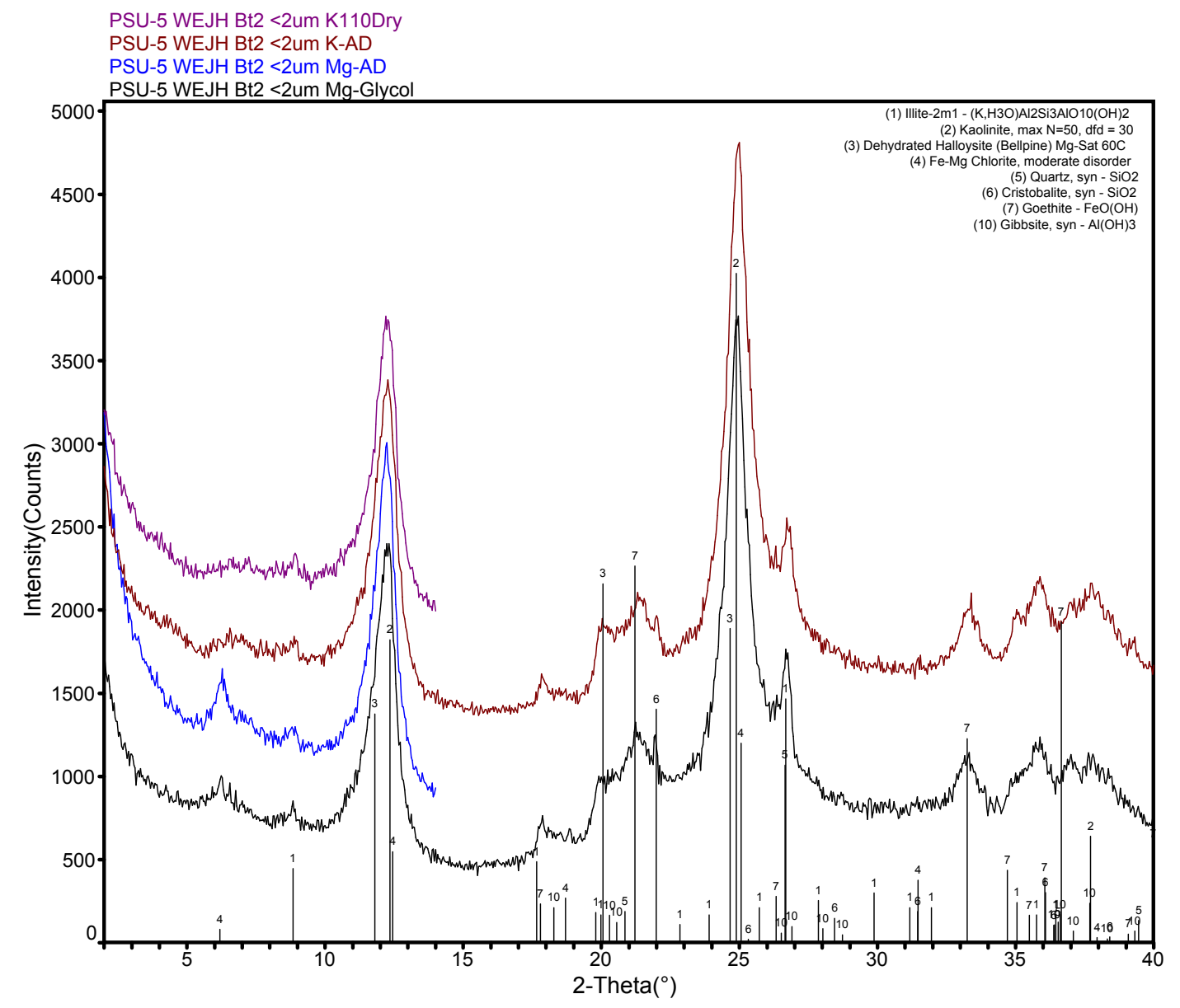

Figure 104. XRD patterns for the Bt2 soil horizon from Willakenzie Estate Winery, The Jory Hills Vineyard Block 50c.

buried/exhumed paleosols developed on basaltic and sedimentary materials in the southern Willamette Valley (Jory profile). There is not much indication of dehydrated halloysite, as the peak at ca 20 degrees 2-theta is very subdued (Figure 105). Most likely the sample consists of disordered kaolinite and vermiculitic chloritic intergrade possibly derived from strong weathering of mica. 


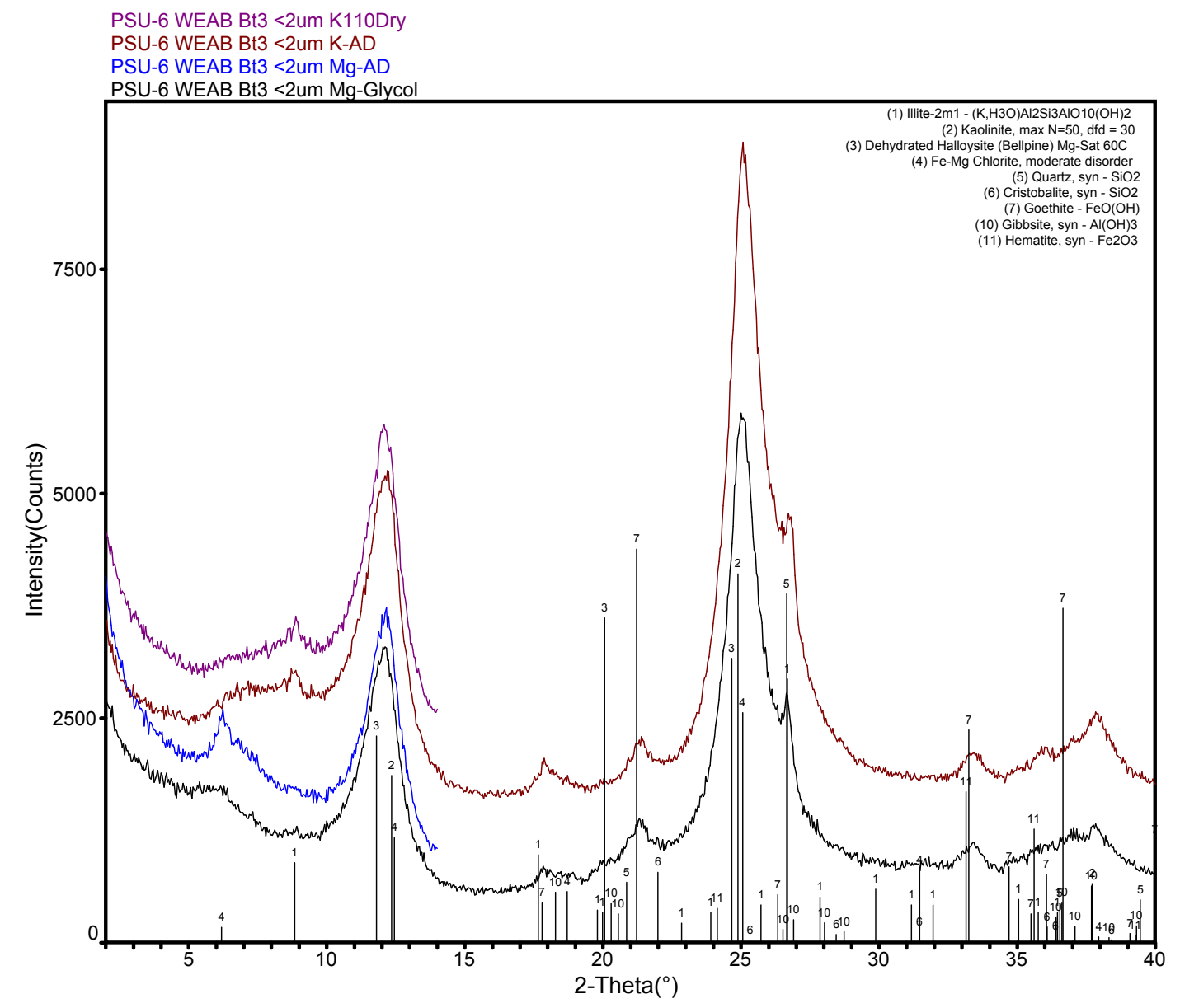

Figure 105. XRD patterns for the Bt3 soil horizon from Willakenzie Estate Winery, Aliette Vineyard Block 2b.

\section{Willakenzie Estate Winery, Terres Basses Vineyard}

The WETB Bg1 sample is highly smectitic and shows no evidence of the formation of hydroxy interlayer chloritic layers. The smectitic component expands fully with glycol and shows progressive collapse with K-saturation and heating. The slight shoulder in the K-air dry pattern at 10A suggests that some vermiculitic material is 
present (possibly a high-charge smectite component?) (Figure 106). The clay fraction contains only traces of mica and low amounts of kaolinitic clay. Instead of cristobalite, this sample shows minor amounts of quartz and very low amounts of Fe oxide (consistent with the gleyed color of the clay). It is hard for me to picture how this material might develop from a micaceous parent material without more significant preservation of mica

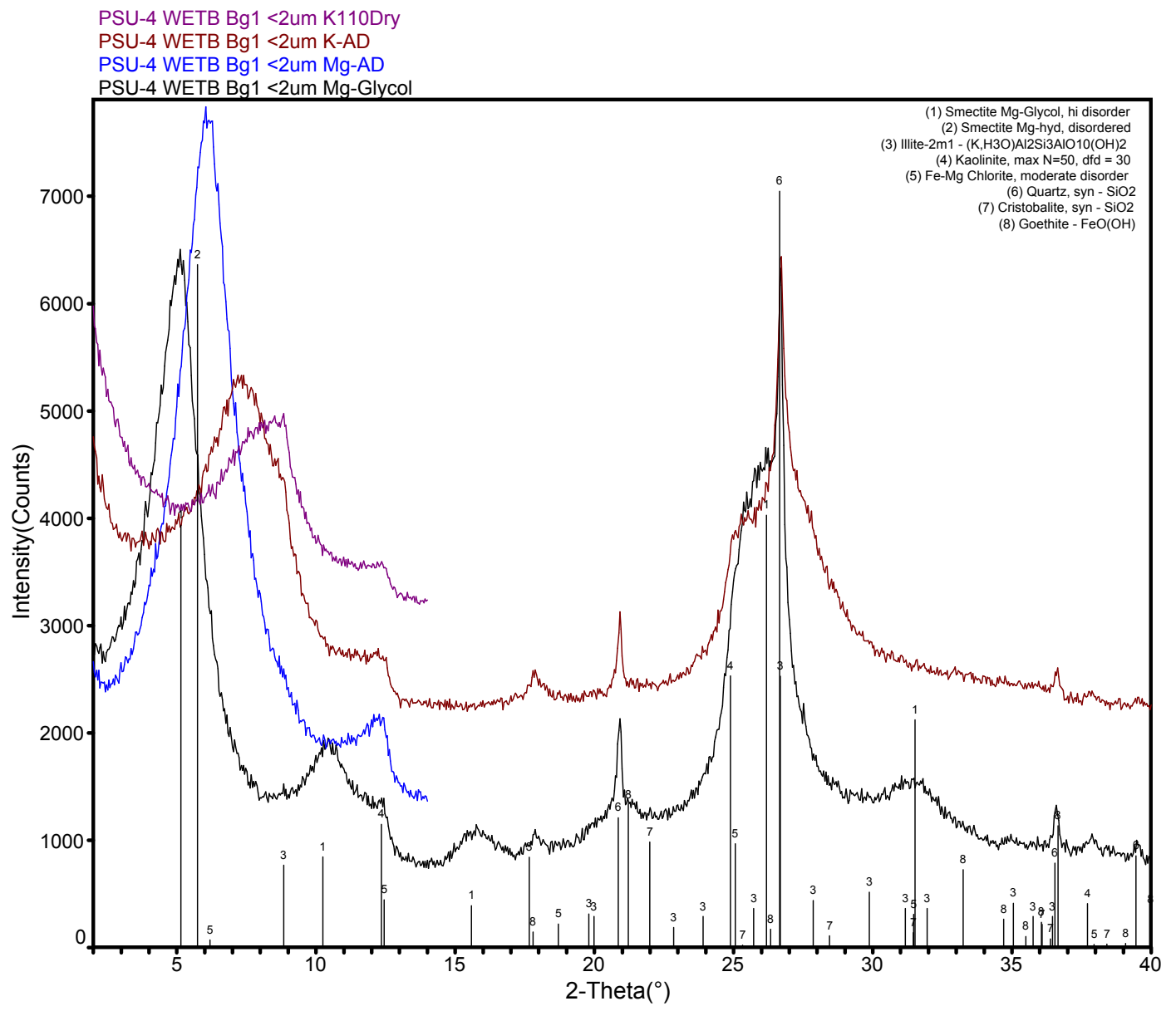

Figure 106. XRD patterns for the Bg1 soil horizon from Willakenzie Estate Winery, Terres Basses Vineyard. 
in the clay fraction. This probably represents a much wetter location than the highly oxidized soils with chloritic intergrade and kaolinite. It may be that this soil developed from alteration of tuffaceous material and reflects Cascadian provenance.

\section{Chehalem, Stoller Vineyards}

The CWS Bt3 sample could be genetically related to the CWR sample, showing similar illite-kaolinite-hydroxy interlayered smectite clay mineralogy. The sample contains quite a bit of cristobalite and has a much more halloysitic appearance than the CWR sample as indicated by intensification of the peak at around 20 degrees 2-theta (Figure 107). The smectite component is less expansive than the CWR [Chehalem Winery Ridgecrest] soil and shows greater resistance to collapse with K-saturation and heating, suggesting greater development of the hydroxy interlayer material and more chloritic character. The weathering of this soil has not yet caused complete degradation of the mica component. The presence of the strong mica component suggests that this soil was not derived from basaltic parent material, but represents weathered micaceous sedimentary material. The fairly strong cristobalite component may reflect accumulation of plant opal in the Bt3 horizon or could result from precipitation of silica during prolonged dry summer conditions. Goethite is the primary Fe phase.

\section{Chehalem, Ridgecrest Vineyard}

CWR Bt2 - This soil is potentially genetically related to the CWCC [Chehalem 


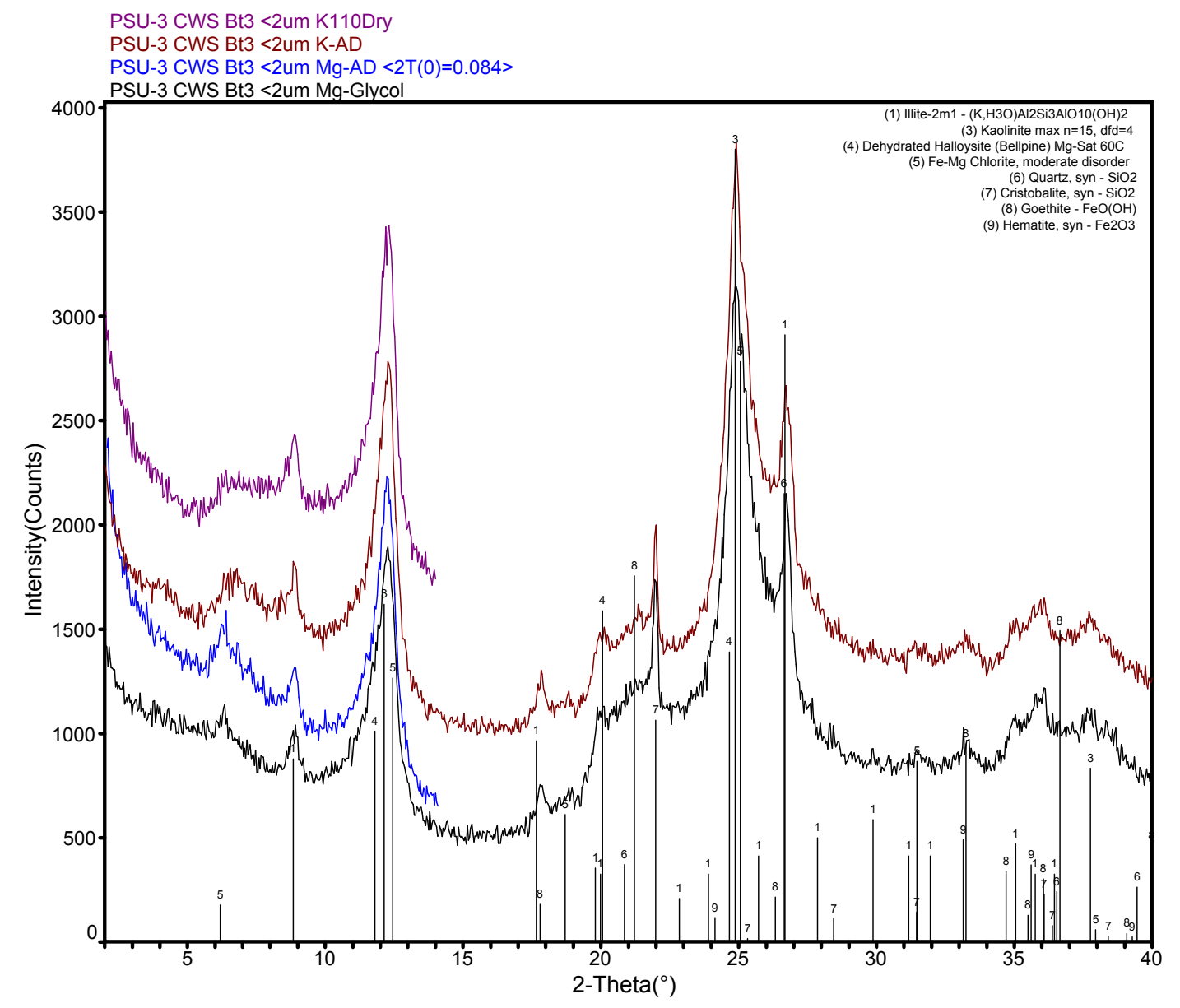

Figure 107. XRD patterns for the Bt3 soil horizon from Chehalem, Stoller Vineyard.

Winery Corral Creek] sample, showing fairly large amounts of illite in the clay fraction

(Figure 108). However, in contrast to the CWCC sample, the chloritic intergrade component of this sample shows moderate expansion and collapse behavior that suggests incomplete hydroxy sheet development. The expansive component showed moderate expansion with glycol solvation and weak collapse with K-saturation. It did not show a strong collapse typical of non-hydroxy interlayered vermiculite, but showed progressive 
collapse with heating that is more typical of hydroxy interlayered smectite. The "kaolinite" component does not show asymmetry development when K-saturated, further evidence that there is probably not much mixed-layered chlorite/vermiculite in this sample. The kaolinite must consist of very fine particles as the 7A peak is displaced to

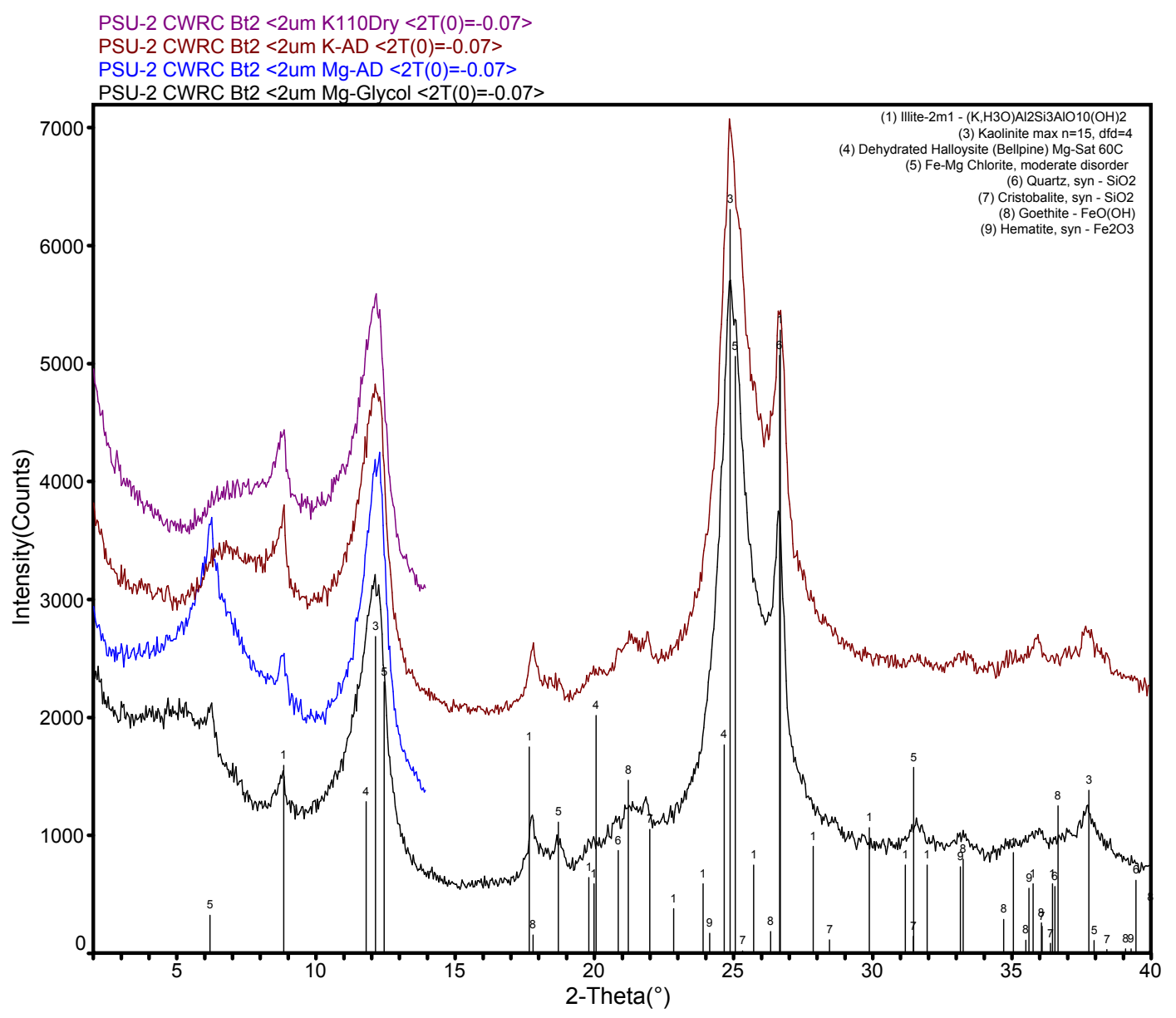

Figure 108. XRD patterns for the Bt3 soil horizon from Chehalem, Ridgecrest Vineyard. 
the left, typical of highly disordered kaolinite and some dehydrated halloysite. There is also a very minor amount of cristobalite in this sample. Goethite is the primary Fe phase.

\section{Chehalem, Corral Creek Vineyards Mid North Block}

CWCC Bt - This sample is the most illite-rich of the first group of soils [Elk Cove, Willakenzie, and Chehalem samples]. The clay mineral assemblage also contains non-expansive chloritic intergrade, suggesting mixed-layer chlorite/vermiculite. This phase does not expand with glycol solvation and resists complete collapse to $10 \mathrm{~A}$ with Ksaturation and heating. The odd character of the "kaolinite" component also indicates mixed-layer chlorite/vermiculite, as the collapse of vermiculitic layers causes the 7A component to drift towards $10 \mathrm{~A}$, causing the broad shoulder seen to the left of the kaolinite 7A peak (Figure 109). The vermiculite may have formed from degradation of the mica component, then experienced hydroxy interlayer chloritization during repeated wetting and drying cycles associated with soil weathering. The clay fraction also contains minor cristobalite that could be due to plant opal accumulating in the soil. Goethite is the primary Fe oxide.

\section{Lange Estate Winery and Vineyards, Estate Vineyard Mia Block North}

The remaining soil samples [Including LEM Bt3] were placed together at the bottom [of the report] because they share characteristics indicative of strongly weathered 


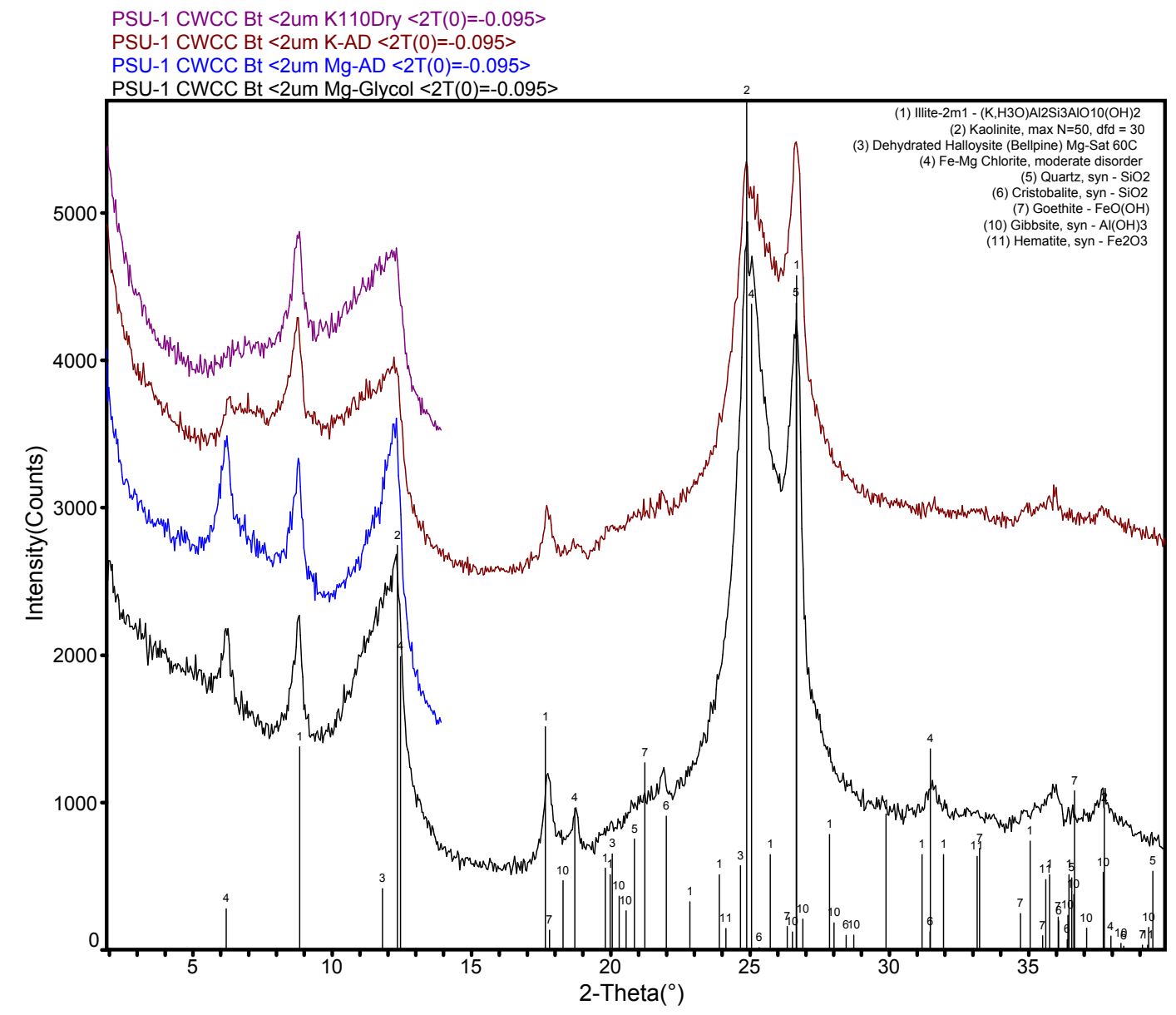

Figure 109. XRD patterns for the Bt3 soil horizon from Chehalem, Corral Creek Vineyard.

material. All of the soils are dominated by disordered kaolinite with low amounts of illite and hydroxy-interlayered smectite-vermiculite (chloritic-intergrade clays). The goethite component is fairly ordered and produces a relatively intense peak (Figure 110). Some of the samples include minor amounts of gibbsite. These patterns look much like the Jory series, or deeply weathered "red-hill" soils that have been exposed to prolonged weathering for 100,000's years+. There is some indication of dehydrated halloysite in a 
couple of the samples. The hydroxy interlayered material shows very weak expansion and strong resistance to collapse. These are highly pillared clays with lots of hydroxy AlFe interlayer material due to prolonged weathering.

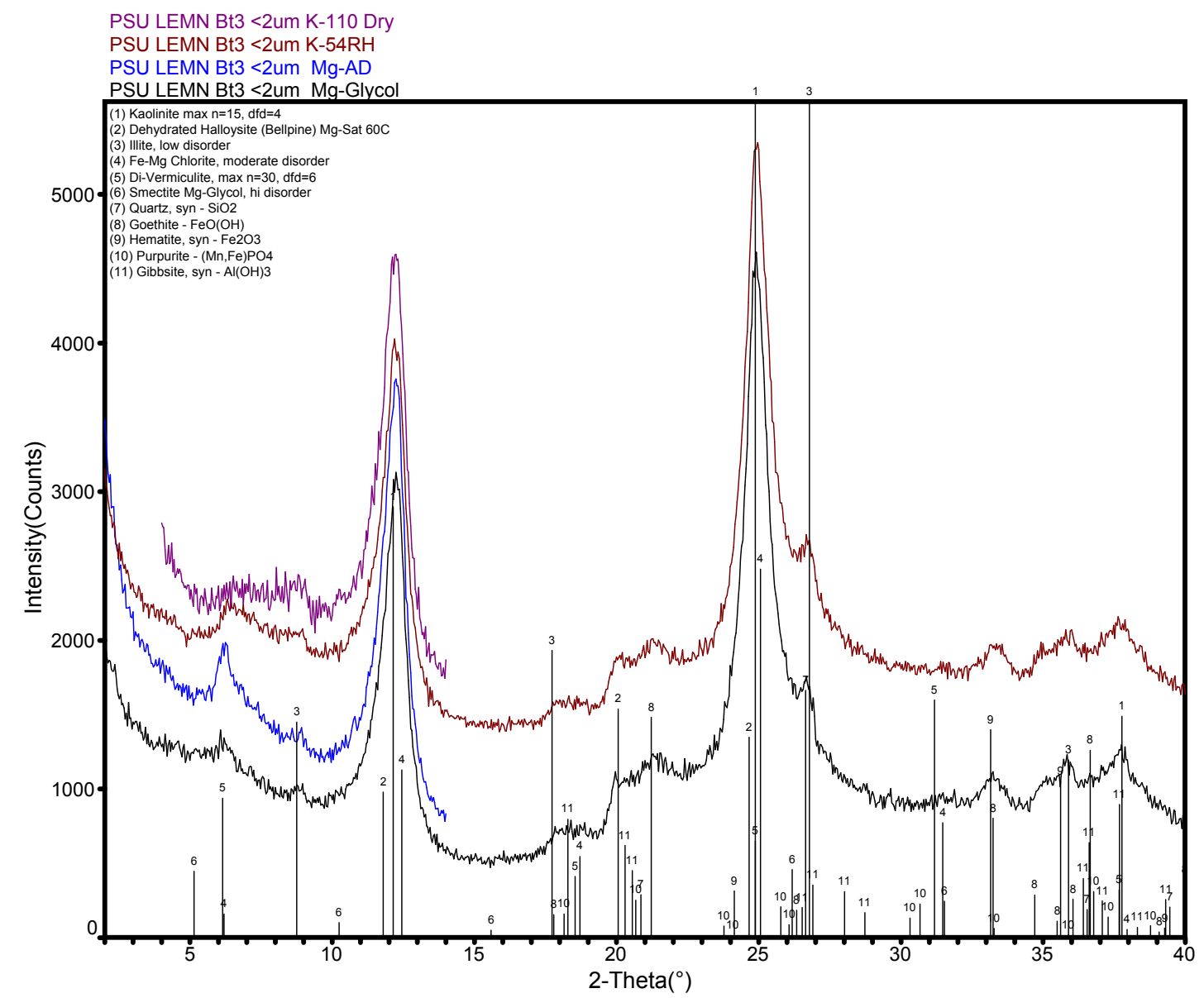

Figure 110. XRD patterns for the Bt3 soil horizon from Lange Estate Winery and Vineyards, Estate Vineyard Mia block. 


\section{Lange Estate Winery and Vineyards, Yamhill Vineyard}

LEY Bt2 - The remaining soil samples were placed together at the bottom [of the report] because they share characteristics indicative of strongly weathered material. All of the soils are dominated by disordered kaolinite with low amounts of illite and hydroxyinterlayered smectite-vermiculite (chloritic-intergrade clays) (Figure 111). The goethite component is fairly ordered and produces a relatively intense peak. Some of the samples include minor amounts of gibbsite. These patterns look much like the Jory series, or deeply weathered "red-hill" soils that have been exposed to prolonged weathering for 100,000 's years + . There is some indication of dehydrated halloysite in a couple of the samples. The hydroxy interlayered material shows very weak expansion and strong resistance to collapse. These are highly pillared clays with lots of hydroxy Al-Fe interlayer material due to prolonged weathering.

\section{Lange Estate Winery and Vineyards, Freedom Hill Vineyard}

This sample has much the same mineralogical character as the KWFH [Ken Wright Freedom Hill] Bt soil clay, right down to the well-ordered goethite (Figure 112). The parent materials and weathering history of these 2 samples must be related.

\section{Rex Hill, Sims Vineyard Block 2}

LEY Bt2 - The remaining soil samples [including RHS2 Bt1] were placed together at the bottom [of the report] because they share characteristics indicative of 
strongly weathered material. All of the soils are dominated by disordered kaolinite with low amounts of illite and hydroxy-interlayered smectite-vermiculite (chloritic-intergrade clays). The goethite component is fairly ordered and produces a relatively intense peak (Figure 113). Some of the samples include minor amounts of gibbsite. These patterns

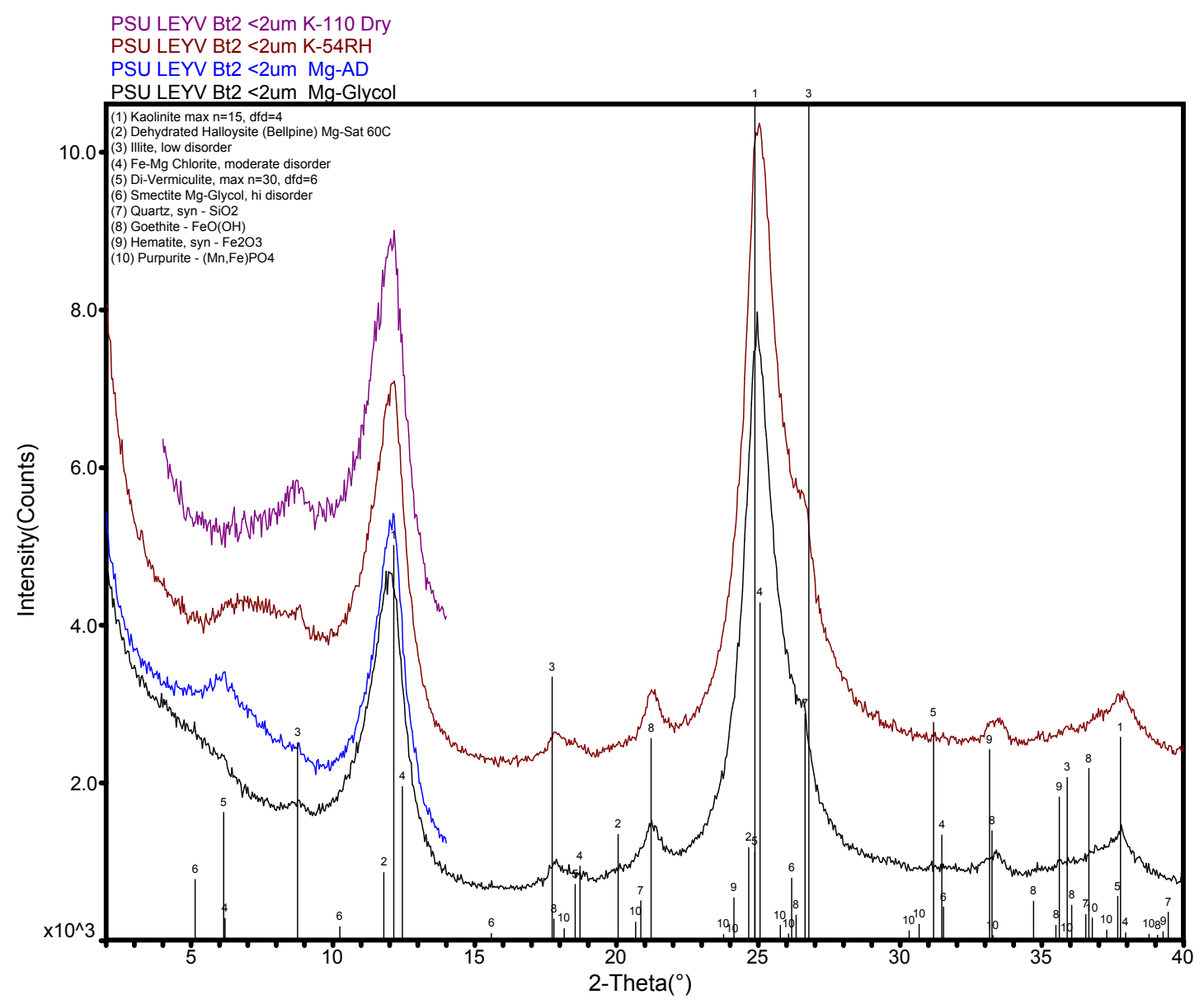

Figure 111. XRD patterns for the Bt3 soil horizon from Lange Estate Winery and Vineyards, Yamhill Vineyard. 


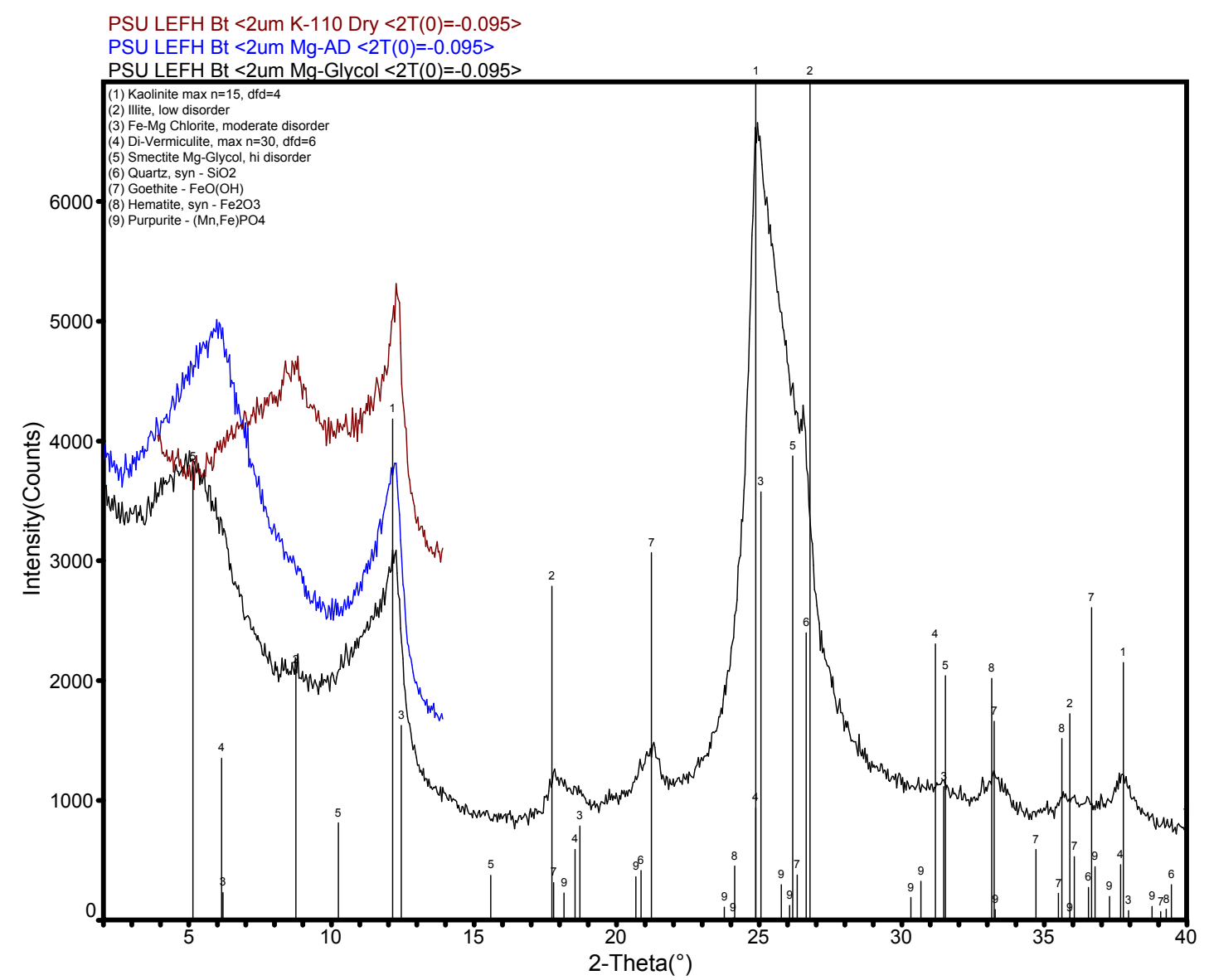

Figure 112. XRD patterns for the Bt3 soil horizon from Lange Estate Winery and Vineyards, Freedom Hill Vineyard.

look much like the Jory series, or deeply weathered "red-hill" soils that have been exposed to prolonged weathering for 100,000 's years+. There is some indication of dehydrated halloysite in a couple of the samples. The hydroxy interlayered material shows very weak expansion and strong resistance to collapse. These are highly pillared clays with lots of hydroxy Al-Fe interlayer material due to prolonged weathering. 


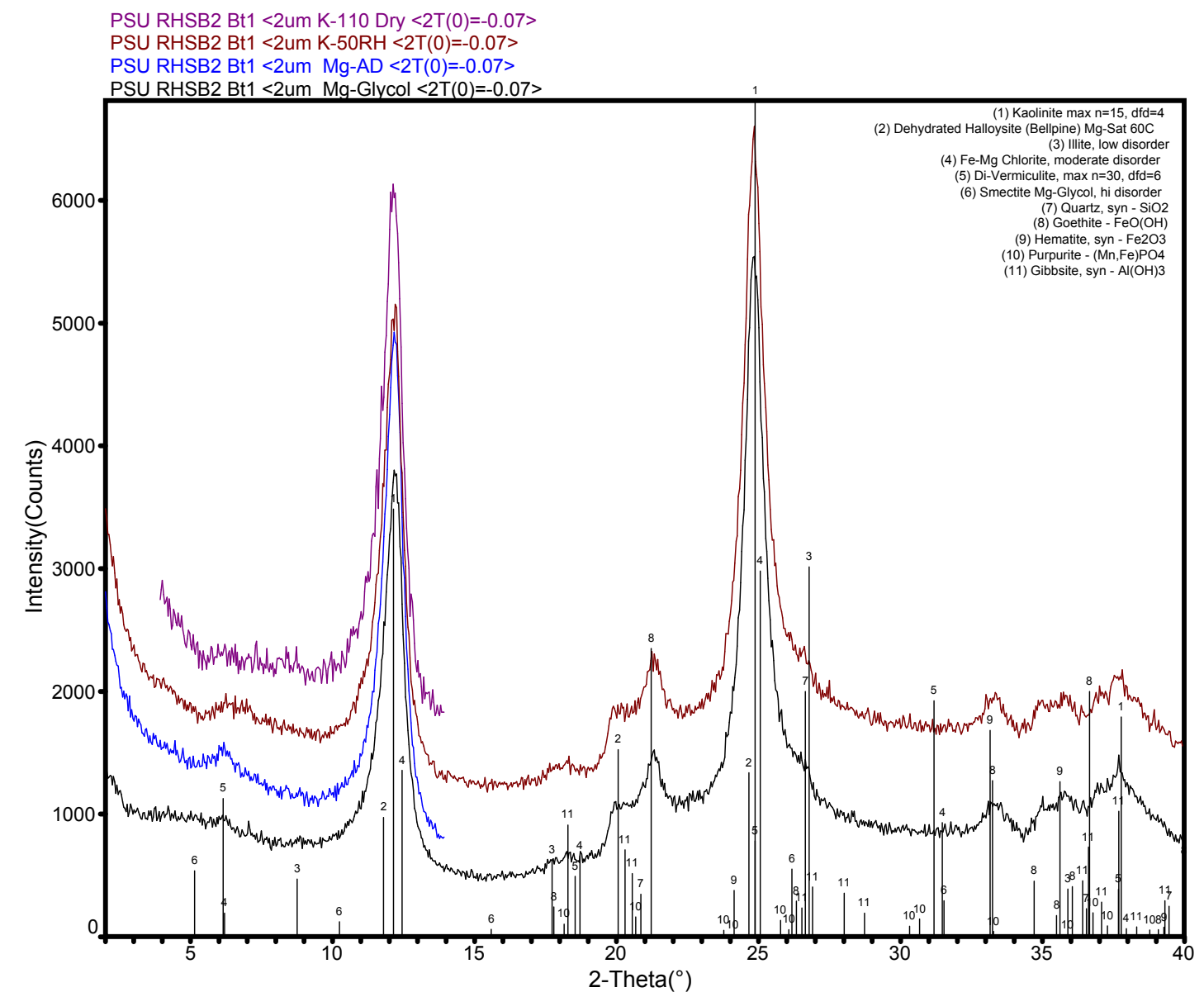

Figure 113. XRD patterns for the Bt3 soil horizon from Rex Hill, Sims Vineyard.

\section{Rex Hill, Estate Vineyard Block 12}

RH12 Bt1 - This is the "odd-ball" sample of the set [Lange, Rex Hill, and Ken

Wright]. The sample is strongly illitic and shows a mixture of chloritic intergrade, hydroxy-interlayered vermiculite, and mixed-layer kaolinite-vermiculite or smectite. The 0.7-nm peak does lots of funny things with the various sample treatments (Figure 114).

There is a component of expandable clay that gives a broad shoulder in the glycol 
treatment. With K-saturation, a peak between the illite 1.0-nm and kaolin 0.7-nm positions appears, suggesting mixed-layer vermiculite/kaolinite. This peak stays at about the same position with heating and drying, indicating a vermiculite-based mixed layer, as drying and collapse of smectite would have made this peak shift more towards illite. It is possible that this soil was derived from clays altered by intrusion of gabbro or basalt and

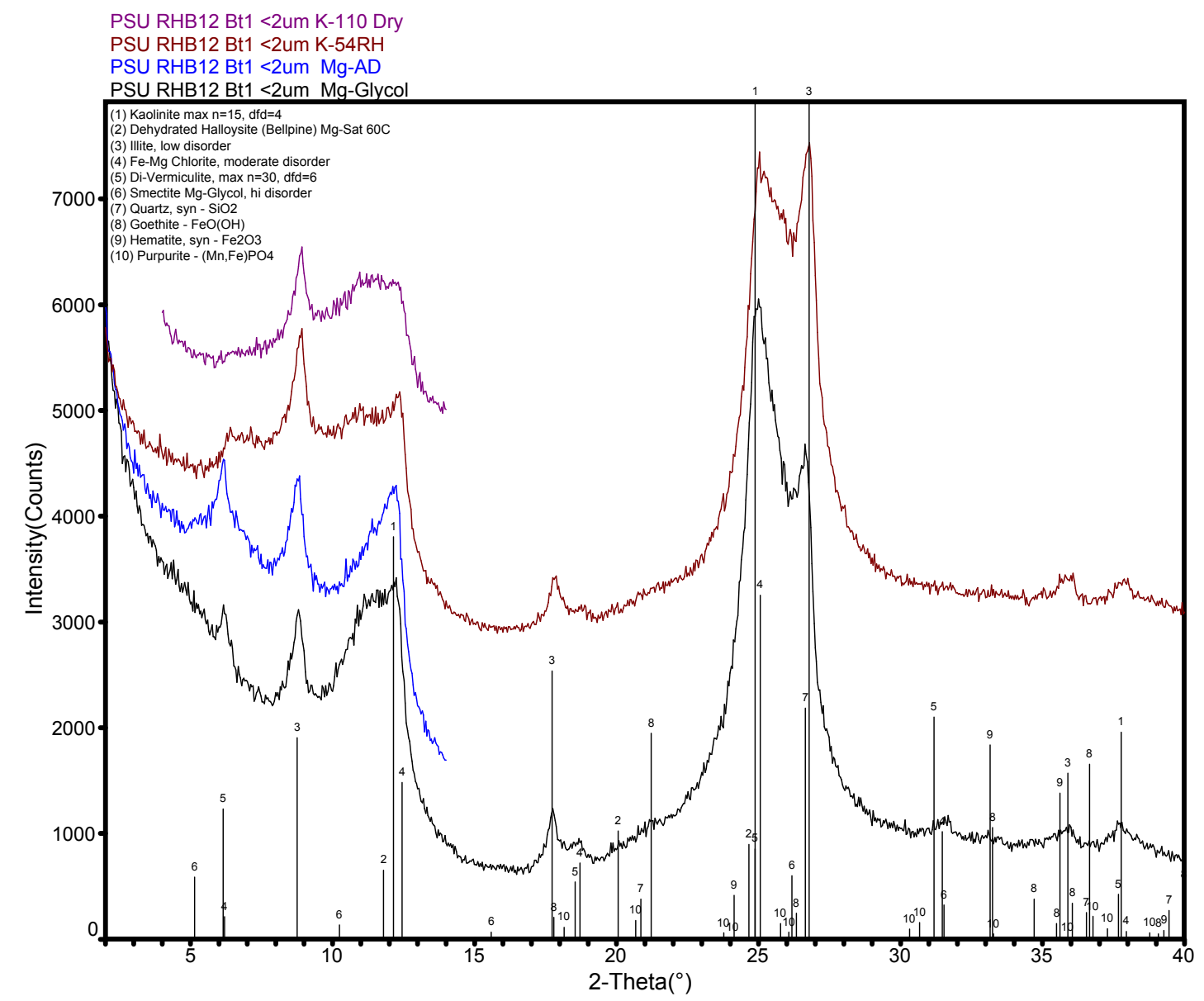

Figure 114. XRD patterns for the Bt3 soil horizon from Rex Hill, Estate Vineyard Block 12. 
represents a weathered, baked sedimentary section. This is about the only way to get the strong illite, unless the illite is associated with loess material off the Columbia (Missoula) River. Not much goethite in this sample, plenty of weatherable mica. Looks like loess to me.

\section{Rex Hill, Jacob-Hart Vineyard Block 1}

RHJHB1 Bt - This soil sample includes a component of non-hydroxy-interlayered smectitic clay, as indicated by the expansion and collapse of the 1.5-nm component (Figure 115). There is no indication of strongly developed chloritic-intergrade clay (no remnant 1.4-nm component after heating) and no strong plateauing of the $1.0-\mathrm{nm}$ peak in the direction of chlorite that would indicate irregular interstratified smectite/chlorite or chlorite/vermiculite. The disordered kaolinite peak shows no shifting with heat treatment, indicating an absence of mixed layer kaolinite/smectite. There may be some vermiculite in this sample, but I need the K-54\%RH pattern to be sure. Goethite is present, but in lower amounts than the previous 2 patterns. This sample is probably less weathered than the prior 2 samples, based upon the moderate preservation of un-encumbered expansion of the smectite phase, and the absence of strong hydroxy-interlayering of the smectite and/or vermiculite component.

\section{Rex Hill, Jacob-Hart Vineyard Block 5}

RHJHB5 Bt - This soil is genetically related to the RHJH B1 sample, but looks 


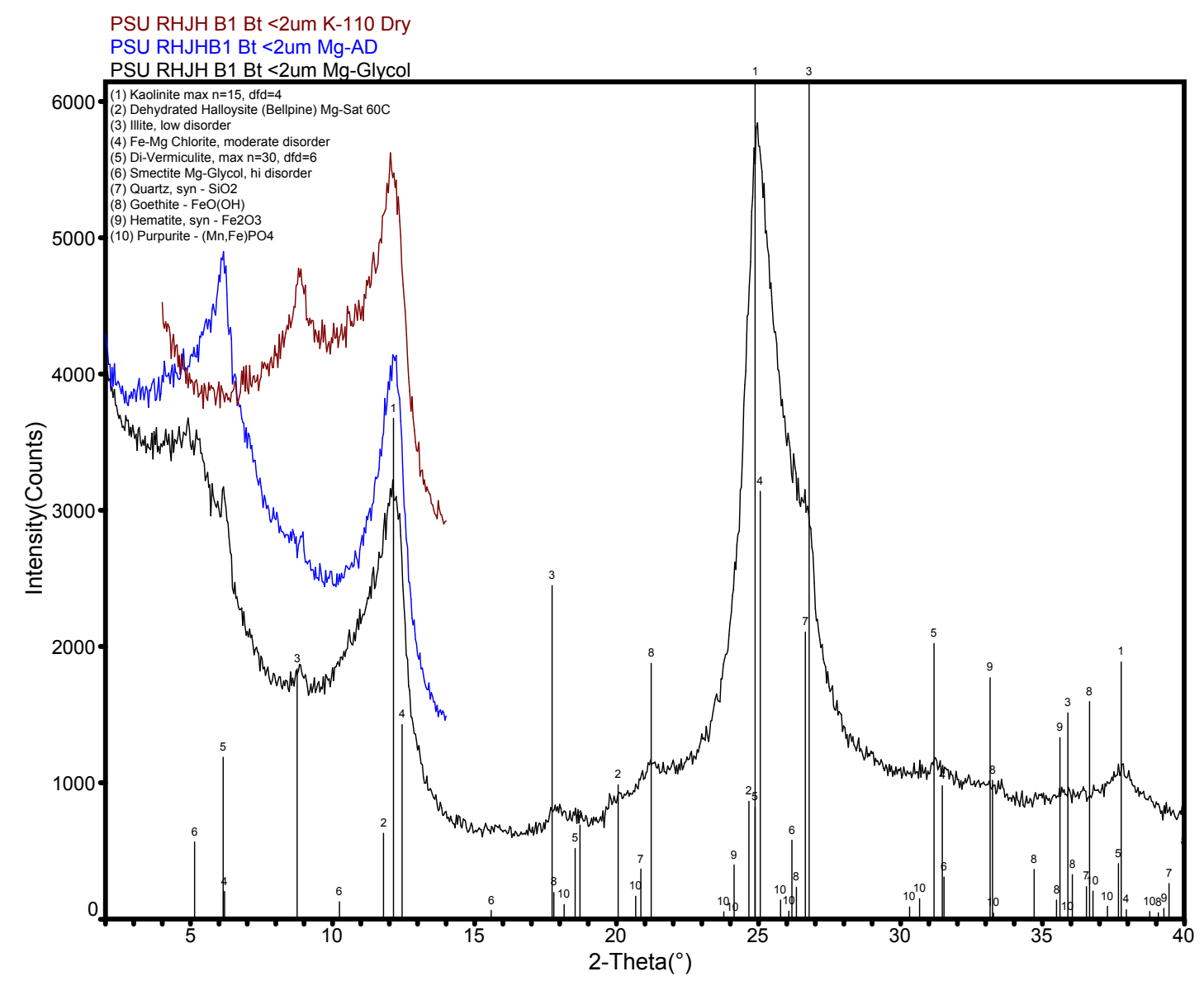

Figure 115. XRD patterns for the Bt3 soil horizon from Rex Hill, Jacob-Hart Vineyard Block 1.

like it represents a wetter site, perhaps deeper in the profile. The smectitic component is more strongly expressed, showing strong expansion and collapse (Figure 116). This suggests even less hydroxy-interlayering, much less pronounced effect of repeated wetting and drying cycles. This sample must maintain more uniform moisture content through the year that helps preserve the smectite expansion. This suggests that the sample could be from a younger geomorphic surface, a deeper part of a somewhat older surface, 
or represent mixed alluvium where expansive clay has been added to older parent material. I see patterns like this on the Mary's River floodplain, where old eroded material from the foothills has been mixed with smectite from basalt that is derived from stream down cutting into freshly weathered bedrock. The absence of illitic clays would be consistent with derivation from basaltic parent materials.

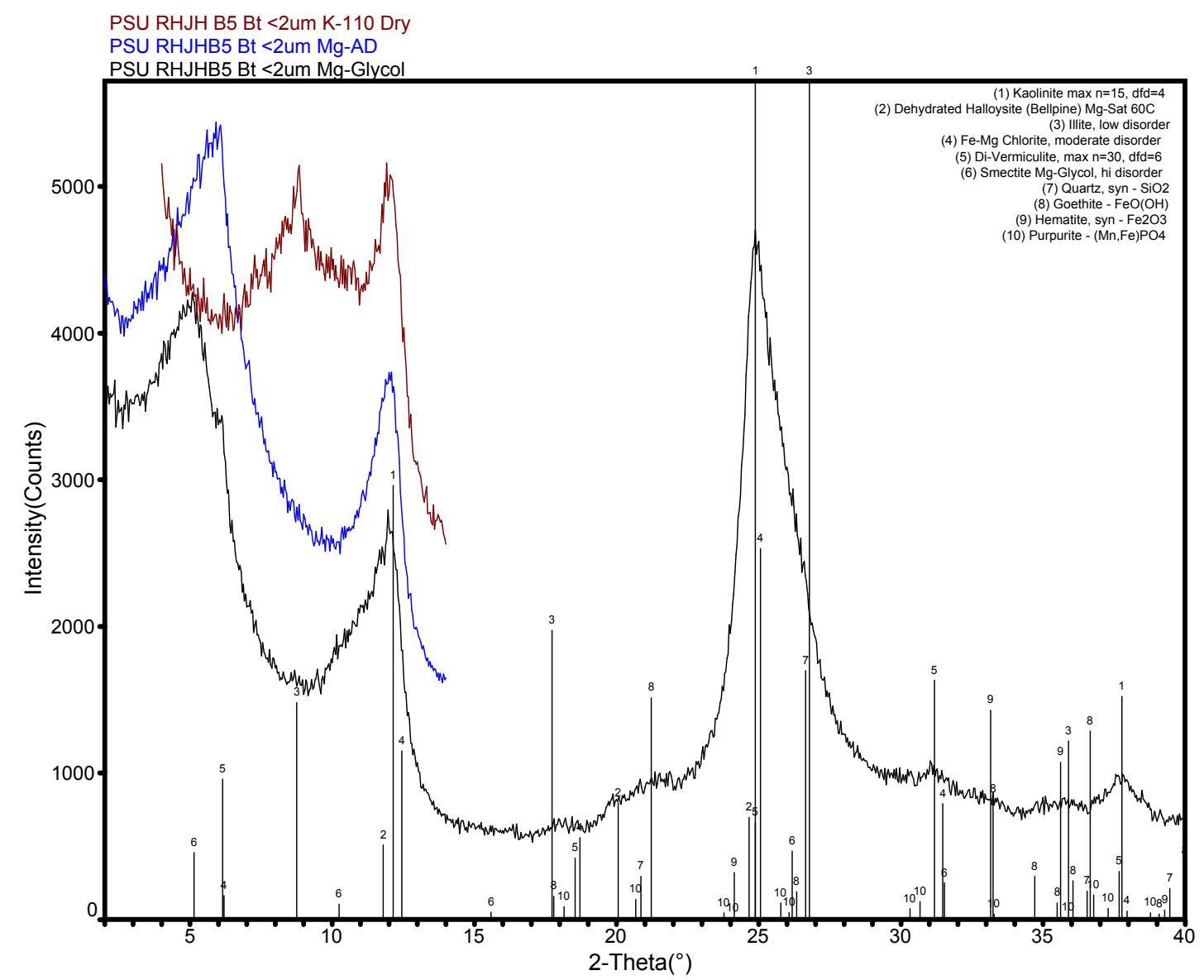

Figure 116. XRD patterns for the Bt3 soil horizon from Rex Hill, Jacob-Hart Vineyard Block 5. 


\section{Ken Wright Cellars, Nysa Vineyard Midblock}

The KWM and KWN patterns are fundamentally different, with the KWN pattern suggesting a much higher degree of weathering with essentially non-expansive chloritic intergrade clays, kaolin, and goethite as the dominant components of the clay fraction. The KWM sample has abundant expansive clay (smectite) and is much less kaolinitic (Figure 117).

\section{Ken Wright Cellars, Abbott Claim Vineyard}

The remaining soil samples [including KWAC Bt] were placed together at the bottom [of the report] because they share characteristics indicative of strongly weathered material. All of the soils are dominated by disordered kaolinite with low amounts of illite and hydroxy-interlayered smectite-vermiculite (chloritic-intergrade clays). The goethite component is fairly ordered and produces a relatively intense peak (Figure 118). Some of the samples include minor amounts of gibbsite. These patterns look much like the Jory series, or deeply weathered "red-hill" soils that have been exposed to prolonged weathering for 100,000 's years + . There is some indication of dehydrated halloysite in a couple of the samples. The hydroxy interlayered material shows very weak expansion and strong resistance to collapse. These are highly pillared clays with lots of hydroxy AlFe interlayer material due to prolonged weathering. 


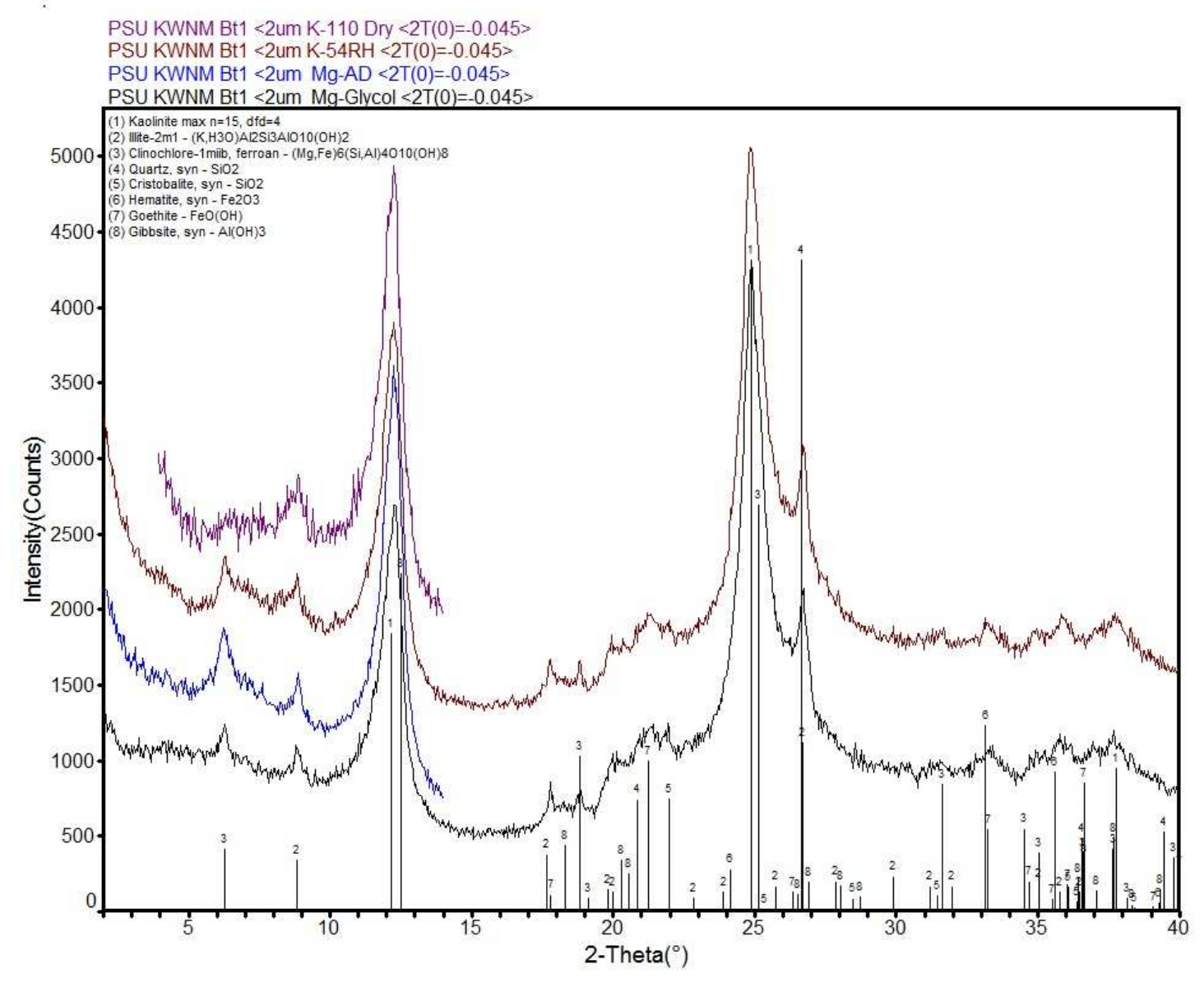

Figure 117. XRD patterns for the Bt3 soil horizon from Ken Wright Cellars, Nysa Vineyard. 


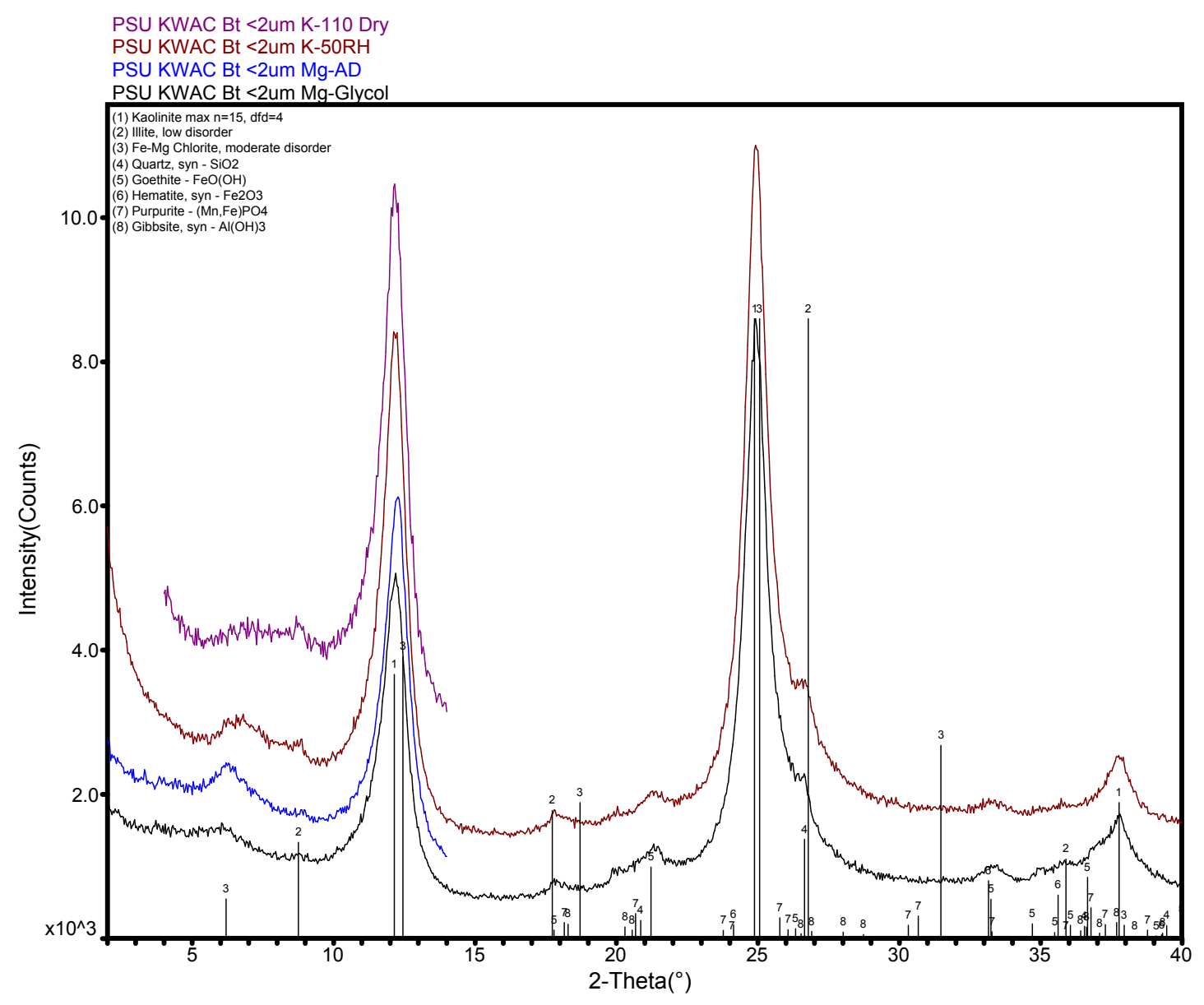

Figure 118. XRD patterns for the Bt3 soil horizon from Ken Wright Cellars, Abbott Claim Vineyard.

\section{Ken Wright Cellars, Freedom Hill Vineyard}

KWFH Bt - This sample peeled badly and is missing the K-54\%RH sample. I'll

try to re-run that treatment. The sample shows moderate expansion with glycol and intensification of the 1.0-nm with K-saturation and heating; however, there is a remnant of the 1.4-nm peak and a broad slope extending to the 1.0-nm peak (Figure 119). This indicates that the expansive clay is moderately interlayered by Al-Fe-oxides and indicates 


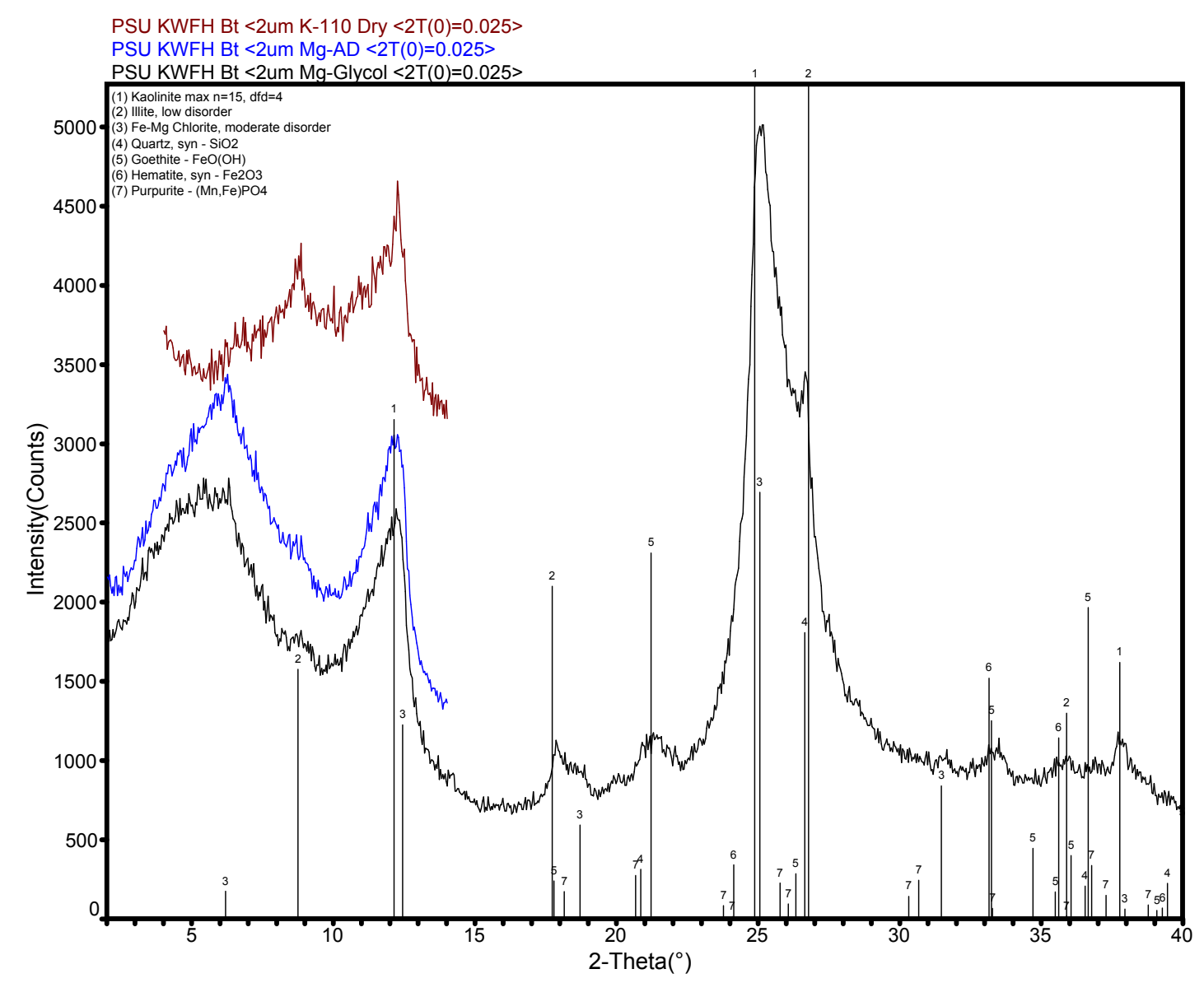

Figure 119. XRD patterns for the Bt3 soil horizon from Ken Wright Cellars, Freedom Hill Vineyard. a higher degree of weathering than the prior sample. The sample contains minor amounts of illitic clay, disordered kaolinite, hydroxy-interlayered smectite and vermiculite, and very weak development of chlorite. The goethite component is well expressed. This is a moderately weathered soil - not completely battered to the point that expandable clays are destroyed. Probably a bit wetter than some sites, keeping the smectitic clay component in a reduced state and preventing "pillaring" of the expansive clay. 


\section{Ken Wright Cellars, Meredith Mitchell Vineyard Martha Block}

The clay mineral assemblage includes minor amounts of smectitic clay that shows expansion with glycol and classic behavior with K-saturation and different humidity treatments (Figure 120). This indicates that the smectite is not strongly interlayered with Al-Fe-hydroxy material (i.e., not strongly weathered or exceptionally old). There is also

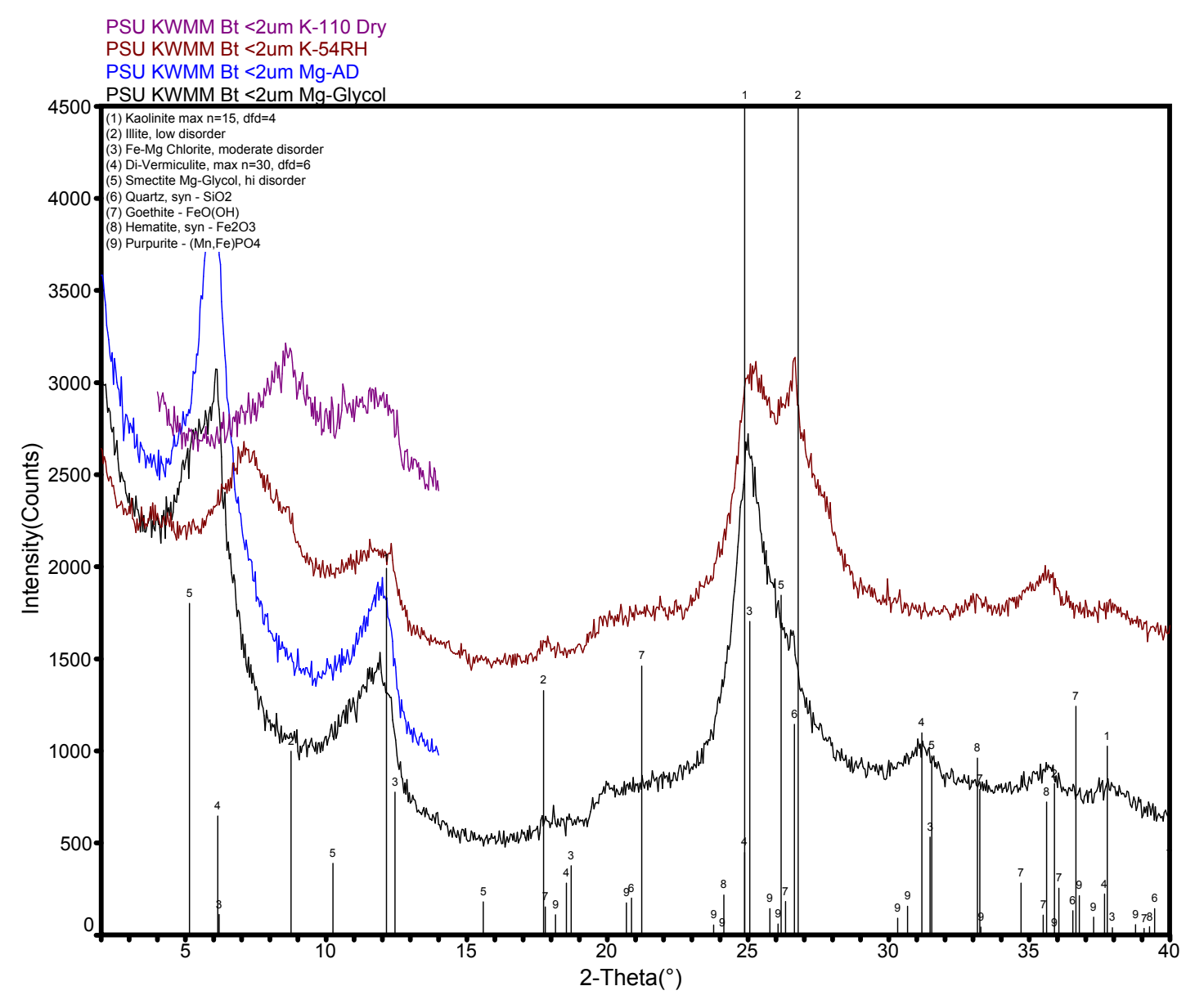

Figure 120. XRD patterns for the Bt3 soil horizon from Ken Wright Cellars, Meredith Mitchell Vineyard Martha block. 
minor vermiculite, reflected in the intensification of the 1.0-nm peak with K-saturation. It appears that this sample also has some mixed layer expansive material, possibly kaolinite/smectite, as indicated by the movement of the K-110 dry kaolin peak towards the 1.0-nm illite peak. As the smectite component decreases in d-spacing with heat treatment, the composite peak of the kaolinite/smectite mixed layer clay moves in the direction of the illite peak. The absence of a 1.4-nm peak with the $\mathrm{KCl}$ dry treatment indicates an absence of chlorite - so no strong chloritic intergrade clays - again, not a highly weathered, oxidized soil due to the absence of clays typical with long-term weathering. Looks like the kaolin component may include some dehydrated halloysite. Goethite is not strongly developed - another indicator of reduced weathering compared to some of the more Fe-rich soils. 


\section{Appendix C Soil Chemistry Data}

The soil chemistry was analyzed at Apex Laboratories using Environmental

Protection Agency (EPA) method 6020A for ICP-MS, 6010C for ICP-AES, and 9056A for ion chromatography were used (EPA, 1998; EPA, 2007; and EPA 2007c). These methods were preceded by acid digestion using EPA method 3051a (EPA, 2007a). Soil chemistry has been split into macronutrients, micronutrients, and trace elements according to the literature for vineyard soils (White, 2009). Because multiple horizons were analyzed for these elements, each vineyard site is presented here as a mean and maximum concentration of all horizons. From this data, the mean for each element separated by soil parent material is presented in the results section.

Using this appendix, one can see the mean and maximum soil element concentration and the mean, maximum, and standard deviation for the vineyards with the three main soil parent materials used for pinot noir vineyards in the Willamette Valley: volcanic, marine sediments, and loess/volcanic (Table 113 to Table 120). For individual soil pit values, see the results chapter for each winery. 
Table 113. Mean and maximum macronutrient concentration for vineyard sites with volcanic and marine sediment parent material.

\begin{tabular}{|c|c|c|c|c|c|c|}
\hline \multicolumn{2}{|c|}{ Vineyard } & \multirow{2}{*}{$\begin{array}{c}\mathbf{P} \\
1290\end{array}$} & \multirow{2}{*}{$\frac{\mathbf{K}}{366}$} & \multirow{2}{*}{$\begin{array}{c}\text { Ca } \\
1130\end{array}$} & \multirow{2}{*}{$\begin{array}{l}\text { Mg } \\
1020\end{array}$} & \multirow{2}{*}{$\begin{array}{c}S \\
173\end{array}$} \\
\hline $\mathrm{E} C \mathrm{CC}$ & Mean & & & & & \\
\hline ECCL & Max & 1740 & 591 & 2420 & 1910 & 191 \\
\hline \multirow{2}{*}{ WEJH } & Mean & 1450 & 342 & 695 & 535 & 212 \\
\hline & $\operatorname{Max}$ & 1580 & 685 & 1110 & 951 & 274 \\
\hline \multirow{2}{*}{ CWS } & Mean & 1380 & 1170 & 1620 & 1540 & 176 \\
\hline & $\operatorname{Max}$ & 2380 & 1800 & 2570 & 1850 & 309 \\
\hline \multirow{2}{*}{ LEM } & Mean & 1390 & 687 & 1250 & 1390 & 221 \\
\hline & Max & 1750 & 936 & 1790 & 1590 & 270 \\
\hline \multirow{2}{*}{ RHS2 } & Mean & 1210 & 226 & 752 & 591 & 165 \\
\hline & Max & 1560 & 515 & 892 & 907 & 213 \\
\hline \multirow{2}{*}{ KWN } & Mean & 1580 & 736 & 1150 & 1210 & 160 \\
\hline & $\operatorname{Max}$ & 2200 & 1030 & 1160 & 1550 & 212 \\
\hline \multirow{4}{*}{ 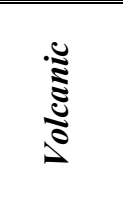 } & Mean & 1380 & 588 & 1100 & 1050 & 184 \\
\hline & $S D$ & 128 & 350 & 341 & 414 & 25.6 \\
\hline & Max Mean & 1870 & 926 & 1660 & 1460 & 245 \\
\hline & $\operatorname{Max} S D$ & 341 & 472 & 716 & 435 & 46.0 \\
\hline \multicolumn{2}{|c|}{ Vineyard } & $\mathbf{P}$ & $\mathbf{K}$ & $\mathbf{C a}$ & Mg & $\mathbf{S}$ \\
\hline \multirow{2}{*}{ ECRV } & Mean & 388 & 4887 & 1170 & 1520 & 130 \\
\hline & Max & 637 & 841 & 1760 & 1950 & 158 \\
\hline \multirow{2}{*}{ WEA } & Mean & 485 & 769 & 1440 & 1170 & 158 \\
\hline & Max & 594 & 1030 & 2240 & 1390 & 245 \\
\hline \multirow{2}{*}{ CWR } & Mean & 541 & 457 & 1780 & 1880 & 174 \\
\hline & Max & 1040 & 902 & 3050 & 2840 & 174 \\
\hline \multirow{2}{*}{ LEY } & Mean & 367 & 1270 & 1140 & 2610 & 154 \\
\hline & $\operatorname{Max}$ & 415 & 1790 & 1500 & 4670 & 154 \\
\hline \multirow{2}{*}{ KWAC } & Mean & 462 & 430 & 824 & 743 & 135 \\
\hline & $\operatorname{Max}$ & 521 & 668 & 1610 & 955 & 135 \\
\hline \multirow{2}{*}{ LEFH } & Mean & 540 & 677 & 1470 & 1740 & 131 \\
\hline & Max & 672 & 828 & 2260 & 2260 & 159 \\
\hline \multirow{2}{*}{ KWFH } & Mean & 518 & 831 & $2010^{*}$ & $1970^{*}$ & 151 \\
\hline & Max & 614 & 1210 & $2100^{*}$ & $2270^{*}$ & 151 \\
\hline \multirow{4}{*}{ हूँ } & Mean & 472 & 703 & 1410 & 1660 & 147 \\
\hline & $S D$ & 70.5 & 296 & 403 & 599 & 16.4 \\
\hline & Max Mean & 642 & 1040 & 2070 & 2330 & 168 \\
\hline & $\operatorname{Max} S D$ & 195 & 373 & 526 & 1200 & 35.9 \\
\hline
\end{tabular}


Table 114. Mean and maximum macronutrient concentrations for vineyard sites with loess/volcanic and other soil parent material.

\begin{tabular}{|c|c|c|c|c|c|c|}
\hline Vineyard & & $\mathbf{P}$ & $\mathbf{K}$ & $\mathrm{Ca}$ & Mg & $\mathbf{S}$ \\
\hline \multirow{2}{*}{ ECFM } & Mean & 825 & 1060 & 1360 & 2380 & 176 \\
\hline & Max & 1550 & 1430 & 1560 & 3380 & 176 \\
\hline \multirow{2}{*}{ CWCC } & Mean & 1030 & 1030 & 1690 & 2350 & 148 \\
\hline & Max & 1310 & 1560 & 2100 & 2930 & 148 \\
\hline \multirow{2}{*}{ RH12 } & Mean & 1090 & 1220 & 1550 & 2500 & 155 \\
\hline & Max & 1730 & 1560 & 1680 & 3100 & 193 \\
\hline \multirow{4}{*}{ 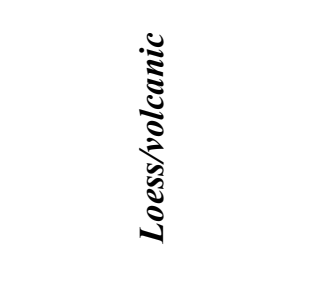 } & Mean & 982 & 1100 & 1530 & 2410 & 160 \\
\hline & $S D$ & 139 & 102 & 166 & 79.4 & 14.6 \\
\hline & Max Mean & 1530 & 1520 & 1780 & 3140 & 172 \\
\hline & $\operatorname{Max} S D$ & 211 & 75 & 284 & 227 & 22.7 \\
\hline \multicolumn{2}{|l|}{ Vineyard } & $\mathbf{P}$ & $\mathbf{K}$ & $\mathrm{Ca}$ & Mg & $\mathbf{S}$ \\
\hline \multirow{2}{*}{$\begin{array}{c}\text { WETB } \\
\text { (Missoula Floods) }\end{array}$} & Mean & 537 & 758 & 4365 & 2398 & 183 \\
\hline & Max & 758 & 970 & 6050 & 3330 & 270 \\
\hline \multirow{2}{*}{$\begin{array}{c}\text { RHJH1 } \\
\text { (Landslide Deposit) }\end{array}$} & Mean & 663 & 786 & 2005 & 2015 & 162 \\
\hline & Max & 1040 & 1390 & 2650 & 2600 & 216 \\
\hline \multirow{2}{*}{$\begin{array}{c}\text { RHJH5 } \\
\text { (Landslide Deposit) }\end{array}$} & Mean & 392 & 403 & 3443 & 1870 & 152 \\
\hline & Max & 515 & 718 & 3640 & 2030 & 152 \\
\hline \multirow{2}{*}{$\begin{array}{c}\text { KWM } \\
\text { (Coast Range Basalt) }\end{array}$} & Mean & 538 & 1060 & 11100 & 17800 & 226 \\
\hline & Max & 873 & 2330 & 21900 & 22300 & 292 \\
\hline
\end{tabular}


Table 115. S Mean and maximum micronutrient concentration for vineyard sites with volcanic parent material.

\begin{tabular}{|c|c|c|c|c|c|c|c|c|c|c|c|}
\hline & Vineyard & $\mathrm{Fe}$ & Al & $\mathrm{Cl}$ & Co & $\mathbf{C u}$ & Mn & Mo & $\mathbf{N a}$ & $\mathbf{N i}$ & $\mathbf{Z n}$ \\
\hline \multirow{2}{*}{ U } & Mean & 45000 & 17300 & ND & 22.0 & 16.3 & 1270 & 0.692 & 195 & 5.54 & 30.3 \\
\hline & Max & 61800 & 18200 & ND & 27.9 & 18.2 & 1730 & 0.692 & 210 & 8.36 & 46.5 \\
\hline \multirow{2}{*}{ 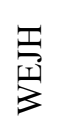 } & Mean & 54800 & 16500 & 13.8 & 21.8 & 17.6 & 1390 & ND & 178 & 5.23 & 35.6 \\
\hline & Max & 60000 & 19100 & 17.6 & 28.4 & 19.8 & 2580 & ND & 206 & 6.76 & 47.9 \\
\hline \multirow{2}{*}{$\stackrel{\pi}{3}$} & Mean & 32500 & 18900 & 17.7 & 42.0 & 19.7 & 2130 & 0.612 & 190 & 6.54 & 86.7 \\
\hline & $\operatorname{Max}$ & 60500 & 19500 & 17.7 & 60.3 & 33.4 & 3190 & 0.612 & 201 & 7.25 & 111 \\
\hline \multirow{2}{*}{$\sum_{\text {出 }}$} & Mean & 43000 & 17300 & ND & 19.3 & 18.4 & 1900 & ND & 174 & 7.672 & 49.9 \\
\hline & Max & 45700 & 19300 & ND & 21.1 & 22.3 & 2560 & ND & 199 & 9.25 & 63.1 \\
\hline \multirow{2}{*}{$\underset{\widetilde{\Omega}}{\stackrel{\widetilde{\Omega}}{\mathbb{Z}}}$} & Mean & 54100 & 15400 & ND & 34.6 & 15.9 & 1690 & ND & 172 & 4.36 & 36.7 \\
\hline & Max & 65300 & 17800 & ND & 41.2 & 20.6 & 2510 & ND & 184 & 6.49 & 53.9 \\
\hline \multirow{2}{*}{$\sum_{\Delta}^{z}$} & Mean & 51200 & 21900 & ND & 26.6 & 15.7 & 1250 & ND & 182 & 6.32 & 47.3 \\
\hline & Max & 60100 & 23100 & ND & 34.7 & 20.3 & 2590 & ND & 216 & 7.20 & 60.4 \\
\hline \multirow{4}{*}{ 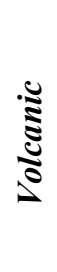 } & Mean & 46800 & 17900 & 15.8 & 27.7 & 17.3 & 1600 & 0.652 & 182 & 5.94 & 47.8 \\
\hline & $S D$ & 8470 & 2280 & 2.76 & 8.85 & 1.59 & 362 & 0.0566 & 8.99 & 1.16 & 20.5 \\
\hline & Max Mean & 58900 & 19500 & 17.7 & 35.6 & 22.4 & 2530 & 0.652 & 203 & 7.55 & 63.8 \\
\hline & $\operatorname{Max} S D$ & 6770 & 1880 & 0.0707 & 13.9 & 5.53 & 465 & 0.0566 & 11.0 & 1.05 & 24.0 \\
\hline
\end{tabular}


Table 116. Mean and maximum macronutrient concentration for vineyard sites with marine sediment parent material.

\begin{tabular}{|c|c|c|c|c|c|c|c|c|c|c|c|}
\hline & Vineyard & $\mathrm{Fe}$ & Al & $\mathrm{Cl}$ & Co & $\mathbf{C u}$ & Mn & Mo & $\mathbf{N a}$ & $\mathbf{N i}$ & $\mathbf{Z n}$ \\
\hline \multirow{2}{*}{$\underset{\text { 空 }}{\gtrsim}$} & Mean & 25900 & 16300 & 19.6 & 5.56 & 14.2 & 299 & ND & 195 & 3.70 & 20.7 \\
\hline & Max & 43600 & 20500 & 29.8 & 13.2 & 22.2 & 971 & ND & 223 & 6.45 & 33.3 \\
\hline \multirow{2}{*}{$\underset{3}{\mathbb{3}}$} & Mean & 25400 & 11100 & ND & 7.50 & 13.7 & 398 & ND & 159 & 5.95 & 28.8 \\
\hline & Max & 32000 & 14400 & ND & 12.0 & 17.0 & 751 & ND & 188 & 7.00 & 33.8 \\
\hline \multirow{2}{*}{$\frac{x}{3}$} & Mean & 35600 & 22700 & ND & 19.1 & 14.2 & 732 & ND & 209 & 7.55 & 61.6 \\
\hline & Max & 49000 & 36000 & ND & 24.6 & 19.2 & 1470 & ND & 267 & 15.9 & 85.8 \\
\hline \multirow{2}{*}{ 吉 } & Mean & 26300 & 10900 & 11.1 & 6.98 & 13.0 & 272 & ND & 190 & 6.78 & 36.0 \\
\hline & Max & 36900 & 13200 & 11.1 & 10.2 & 16.9 & 549 & ND & 222 & 11.9 & 53.5 \\
\hline \multirow{2}{*}{$\underset{\Delta}{\stackrel{U}{z}}$} & Mean & 17400 & 7860 & 20.8 & 2.72 & 6.38 & 170 & ND & 134 & 1.75 & 12.2 \\
\hline & Max & 30400 & 11800 & 31.5 & 7.37 & 8.44 & 552 & ND & 141 & 2.42 & 17.8 \\
\hline \multirow{2}{*}{$\begin{array}{l}\underset{I}{I} \\
\underset{I}{J}\end{array}$} & Mean & 30800 & 9660 & ND & 10.3 & 17.0 & 353 & 0.634 & 148 & 6.423 & 30.9 \\
\hline & Max & 38700 & 11300 & ND & 16.0 & 19.2 & 584 & 0.678 & 189 & 9.67 & 36.7 \\
\hline \multirow{2}{*}{$\sum_{1}^{\mathbb{T}}$} & Mean & 36500 & 19200 & ND & 18.6 & 42.0 & 690 & ND & 962 & 10.2 & 45.9 \\
\hline & Max & 59700 & 35100 & ND & 29.5 & 114 & 869 & ND & 3330 & 24.0 & 87.6 \\
\hline \multirow{4}{*}{ : } & Mean & 28300 & 14000 & 17.2 & 10.1 & 17.2 & 416 & 0.634 & 285 & 6.06 & 33.7 \\
\hline & $S D$ & 6630 & 5520 & 5.27 & 6.37 & 11.4 & 214 & 0 & 300 & 2.72 & 16.3 \\
\hline & Max Mean & 41500 & 20300 & 24.1 & 16.1 & 31.0 & 821 & 0.678 & 651 & 11.0 & 49.8 \\
\hline & $\operatorname{Max} S D$ & 10300 & 10800 & 11.3 & 8.04 & 36.9 & 330 & 0 & 1180 & 7.14 & 27.3 \\
\hline
\end{tabular}


Table 117. Mean and maximum macronutrient concentration for vineyard sites with loess/volcanic and other soil parent material.

\begin{tabular}{|c|c|c|c|c|c|c|c|c|c|c|c|}
\hline & Vineyard & $\mathrm{Fe}$ & Al & $\mathbf{C l}$ & Co & $\mathrm{Cu}$ & Mn & Mo & $\mathbf{N a}$ & $\mathbf{N i}$ & $\mathbf{Z n}$ \\
\hline \multirow{2}{*}{ 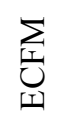 } & Mean & 28300 & 18700 & ND & 15.1 & 13.5 & 703 & ND & 187 & 8.80 & 42.8 \\
\hline & Max & 35400 & 20900 & ND & 20.1 & 15.3 & 1330 & ND & 220 & 10.5 & 56.9 \\
\hline \multirow{2}{*}{$\begin{array}{l}0 \\
0 \\
Z\end{array}$} & Mean & 34600 & 25700 & ND & 16.0 & 18.6 & 664 & ND & 234 & 16.9 & 54.3 \\
\hline & Max & 37600 & 36400 & ND & 19.7 & 28.8 & 1210 & ND & 281 & 35.3 & 66.0 \\
\hline \multirow{2}{*}{$\underset{\Omega}{\beth}$} & Mean & 29500 & 13800 & ND & 17.3 & 14.3 & 1003 & ND & 195 & 9.43 & 50.4 \\
\hline & Max & 41000 & 15700 & ND & 22.3 & 16.8 & 1530 & ND & 201 & 10.2 & 63.1 \\
\hline \multirow{4}{*}{ 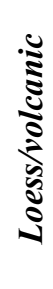 } & Mean & 30800 & 19400 & $N D$ & 16.1 & 15.5 & 790 & $N D$ & 205 & 11.7 & 49.2 \\
\hline & $S D$ & 3350 & 5980 & $N D$ & 1.13 & 2.73 & 186 & $N D$ & 25.3 & 4.51 & 5.81 \\
\hline & Max Mean & 38000 & 24300 & $N D$ & 20.7 & 20.3 & 1360 & $N D$ & 234 & 18.7 & 62.0 \\
\hline & $\operatorname{Max} S D$ & 2820 & 10800 & $N D$ & 1.40 & 7.40 & 162 & $N D$ & 41.8 & 14.4 & 4.65 \\
\hline & Vineyard & $\mathbf{F e}$ & Al & $\mathbf{C l}$ & Co & $\mathbf{C u}$ & Mn & Mo & $\mathbf{N a}$ & $\mathbf{N i}$ & $\mathbf{Z n}$ \\
\hline \multirow{2}{*}{$\begin{array}{l}\stackrel{n}{y} \\
\frac{1}{3}\end{array}$} & Mean & 25500 & 13700 & ND & 12.9 & 42.8 & 416 & ND & 183 & 11.7 & 43.7 \\
\hline & Max & 28600 & 18400 & ND & 24.4 & 64.4 & 849 & ND & 289 & 16.3 & 58.7 \\
\hline \multirow{2}{*}{ 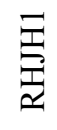 } & Mean & 36100 & 13400 & 24 & 23.7 & 16.8 & 851 & ND & 222 & 8.06 & 48.7 \\
\hline & Max & 51100 & 19500 & 24 & 28.0 & 19.3 & 1230 & ND & 299 & 8.89 & 63.2 \\
\hline \multirow{2}{*}{ 泾 } & Mean & 43100 & 13600 & ND & 48.0 & 14.9 & 1710 & ND & 192 & 6.06 & 61.8 \\
\hline & Max & 46000 & 14900 & ND & 67.4 & 15.8 & 2350 & ND & 212 & 8.03 & 64.1 \\
\hline \multirow{2}{*}{$\sum_{\Sigma}^{\sum}$} & Mean & 81800 & 38700 & ND & 42.7 & 128 & 1560 & ND & 855 & 21.0 & 95.3 \\
\hline & Max & 92100 & 41200 & ND & 48.4 & 146 & 1810 & ND & 1560 & 27.3 & 104 \\
\hline
\end{tabular}


Table 118. Mean and maximum macronutrient concentration for vineyard sites with volcanic parent material.

\begin{tabular}{|c|c|c|c|c|c|c|c|c|c|c|c|}
\hline & Vineyard & As & $\mathbf{B a}$ & Be & Cd & $\mathrm{Cr}$ & Hg & $\mathbf{P b}$ & Se & $\mathrm{Sr}$ & $\mathbf{V}$ \\
\hline \multirow{2}{*}{ U } & Mean & 2.10 & 103 & 0.800 & 0.226 & 25.6 & 0.0421 & 10.2 & 0.733 & 10.4 & 137 \\
\hline & Max & 2.78 & 190 & 0.828 & 0.267 & 30.0 & 0.0448 & 10.9 & 0.733 & 13.2 & 178 \\
\hline \multirow{2}{*}{$\begin{array}{l}\stackrel{ \pm}{1} \\
\stackrel{3}{3}\end{array}$} & Mean & 1.26 & 249 & 0.808 & 0.281 & 27.1 & ND & 9.67 & ND & 12.3 & 156 \\
\hline & Max & 1.62 & 430 & 0.910 & 0.346 & 31.8 & ND & 11.4 & ND & 15.4 & 195 \\
\hline \multirow{2}{*}{ z } & Mean & 1.75 & 235 & 1.44 & 0.419 & 16.9 & ND & 12.1 & 0.569 & 14.3 & 189 \\
\hline & Max & 2.40 & 310 & 1.52 & 0.558 & 18.3 & ND & 15.3 & 0.569 & 16.8 & 219 \\
\hline \multirow{2}{*}{$\sum_{\text {出 }}$} & Mean & 1.96 & 194 & 0.718 & 0.263 & 24.0 & ND & 11.3 & 0.564 & 18.5 & 127 \\
\hline & Max & 2.75 & 281 & 0.770 & 0.301 & 26.6 & ND & 12.4 & 0.604 & 24.8 & 139 \\
\hline \multirow{2}{*}{$\underset{\widetilde{N}}{\stackrel{N}{\widetilde{N}}}$} & Mean & 0.944 & 106 & 0.826 & 0.384 & 16.9 & ND & 9.26 & 0.630 & 8.86 & 135 \\
\hline & Max & 1.72 & 168 & 1.05 & 0.475 & 23.1 & ND & 12.0 & 0.759 & 11.1 & 171 \\
\hline \multirow{2}{*}{$\sum_{\Delta}^{z}$} & Mean & 1.31 & 264 & 1.04 & 0.634 & 15.8 & ND & 7.90 & 0.668 & 16.3 & 133 \\
\hline & Max & 1.61 & 467 & 1.05 & 0.787 & 22.0 & ND & 11.6 & 0.909 & 23.2 & 150 \\
\hline \multirow{4}{*}{ 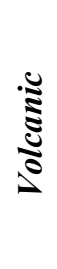 } & Mean & 1.55 & 192 & 0.938 & 0.368 & 21.0 & 0.0421 & 10.1 & 0.633 & 13.4 & 146 \\
\hline & $S D$ & 0.451 & 71.6 & 0.269 & 0.150 & 5.04 & 0 & 1.50 & 0.0707 & 3.63 & 23.0 \\
\hline & Max Mean & 2.15 & 308 & 1.02 & 0.456 & 25.3 & 0.0448 & 12.3 & 0.715 & 17.4 & 175 \\
\hline & $\operatorname{Max} S D$ & 0.562 & 122 & 0.270 & 0.196 & 5.11 & 0 & 1.57 & 0.136 & 5.48 & 29.3 \\
\hline
\end{tabular}


Table 119. Mean and maximum macronutrient concentration for vineyard sites with marine sediment parent material

\begin{tabular}{|c|c|c|c|c|c|c|c|c|c|c|c|}
\hline & Vineyard & As & Ba & $\mathrm{Be}$ & Cd & $\mathrm{Cr}$ & Hg & $\mathbf{P b}$ & Se & $\mathrm{Sr}$ & $\mathbf{V}$ \\
\hline \multirow{2}{*}{$\underset{\text { 空 }}{\gtrsim}$} & Mean & 4.40 & 96.1 & 0.568 & 0.125 & 16.7 & 0.0461 & 7.38 & 0.579 & 18.3 & 42.3 \\
\hline & Max & 6.17 & 205 & 0.661 & 0.174 & 21.6 & 0.0511 & 8.68 & 0.673 & 23.0 & 60.0 \\
\hline \multirow{2}{*}{$\underset{3}{\mathbb{1}}$} & Mean & 3.71 & 96.2 & 0.568 & 0.152 & 16.3 & ND & 7.02 & ND & 14.6 & 47.7 \\
\hline & Max & 4.92 & 125 & 0.711 & 0.233 & 19.4 & ND & 8.89 & ND & 18.4 & 59.4 \\
\hline \multirow{2}{*}{ su } & Mean & 1.34 & 207 & 0.817 & 0.338 & 13.9 & ND & 9.17 & 0.578 & 23.8 & 95.5 \\
\hline & Max & 2.34 & 328 & 1.220 & 0.916 & 23.8 & ND & 16.2 & 0.594 & 46.2 & 127 \\
\hline \multirow{2}{*}{ 㔛 } & Mean & 2.78 & 96.4 & 0.580 & 0.110 & 18.8 & ND & 6.82 & 0.517 & 21.6 & 43.2 \\
\hline & Max & 3.41 & 116 & 0.855 & 0.119 & 21.4 & ND & 7.88 & 0.517 & 36.9 & 55.5 \\
\hline \multirow{2}{*}{ 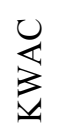 } & Mean & 3.11 & 62.8 & 0.444 & 0.156 & 10.7 & ND & 9.03 & ND & 8.06 & 36.0 \\
\hline & Max & 8.99 & 92.2 & 0.790 & 0.192 & 17.2 & ND & 11.5 & ND & 11.3 & 54.9 \\
\hline \multirow{2}{*}{ 壱 } & Mean & 9.78 & 75.6 & 0.723 & 0.134 & 20.1 & 0.0412 & 8.98 & ND & 24.3 & 47.3 \\
\hline & Max & 11.8 & 91.4 & 0.888 & 0.148 & 27.3 & 0.0412 & 11.9 & ND & 38.6 & 68.8 \\
\hline \multirow{2}{*}{$\sum_{\underline{V}}^{\mathbb{T}}$} & Mean & 4.00 & 142 & 0.700 & 0.240 & 20.3 & ND & 6.94 & ND & 127 & 74.8 \\
\hline & Max & 6.03 & 201 & 0.868 & 0.319 & 24.9 & ND & 9.46 & ND & 452 & 150 \\
\hline \multirow{4}{*}{ ב气 } & Mean & 4.16 & 111 & 0.629 & 0.179 & 16.7 & 0.0436 & 7.91 & 0.558 & 33.9 & 55.2 \\
\hline & $S D$ & 2.67 & 48.9 & 0.125 & 0.0816 & 3.47 & 0.00343 & 1.09 & 0.0355 & 41.4 & 21.6 \\
\hline & Max Mean & 6.24 & 166 & 0.856 & 0.300 & 22.2 & 0.0462 & 10.6 & 0.595 & 89.5 & 82.2 \\
\hline & $\operatorname{Max} S D$ & 3.25 & 85.8 & 0.181 & 0.279 & 3.41 & 0.00700 & 2.86 & 0.0780 & 160 & 39.3 \\
\hline
\end{tabular}


Table 120. Mean and maximum macronutrient concentration for vineyard sites with loess/volcanic and other soil parent material.

\begin{tabular}{|c|c|c|c|c|c|c|c|c|c|c|c|}
\hline \multicolumn{2}{|c|}{ Vineyard } & As & Ba & $\mathrm{Be}$ & Cd & $\mathrm{Cr}$ & Hg & $\mathbf{P b}$ & Se & $\mathrm{Sr}$ & $\mathbf{V}$ \\
\hline \multirow{2}{*}{$\sum_{\text {志 }}$} & Mean & 2.54 & 133 & 0.701 & 0.214 & 20.9 & 0.0426 & 8.78 & ND & 16.3 & 90.3 \\
\hline & Max & 3.51 & 244 & 0.827 & 0.244 & 24.1 & 0.0426 & 9.15 & ND & 20.1 & 127 \\
\hline \multirow{2}{*}{$\begin{array}{l}\text { U } \\
\text { Z }\end{array}$} & Mean & 2.33 & 316 & 0.847 & 0.379 & 19.4 & ND & 10.6 & 0.686 & 23.8 & 101 \\
\hline & Max & 3.02 & 669 & 1.02 & 0.741 & 20.6 & ND & 12.5 & 0.686 & 34.1 & 111 \\
\hline \multirow{2}{*}{$\underset{\widetilde{I}}{\stackrel{\sim}{z}}$} & Mean & 5.83 & 177 & 0.751 & 0.217 & 18.7 & ND & 22.1 & ND & 22.1 & 89.8 \\
\hline & Max & 12.2 & 246 & 0.975 & 0.277 & 20.5 & ND & 47.1 & ND & 28.2 & 130 \\
\hline \multirow{4}{*}{ 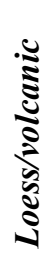 } & Mean & 3.57 & 209 & 0.766 & 0.270 & 19.7 & 0.0426 & 13.8 & 0.686 & 20.7 & 93.6 \\
\hline & $S D$ & 1.96 & 95.7 & 0.0740 & 0.0945 & 1.14 & $N D$ & 7.24 & $N D$ & 3.89 & 6.23 \\
\hline & Max Mean & 6.24 & 386 & 0.941 & 0.421 & 21.7 & 0.0426 & 22.9 & 0.686 & 27.5 & 123 \\
\hline & $\operatorname{Max} S D$ & 5.16 & 245 & 0.101 & 0.278 & 2.05 & $N D$ & 21.01 & $N D$ & 7.03 & 10.2 \\
\hline \multicolumn{2}{|c|}{ Vineyard } & As & $\mathbf{B a}$ & $\mathrm{Be}$ & Cd & $\mathrm{Cr}$ & Hg & $\mathbf{P b}$ & Se & $\mathbf{S r}$ & $\mathbf{V}$ \\
\hline \multirow{2}{*}{$\stackrel{n}{\underline{|r| r}}$} & Mean & 6.08 & 177 & 0.617 & 0.1 & 12.0 & ND & 6.94 & 0.560 & 54.1 & 45.5 \\
\hline & Max & 8.97 & 250 & 0.748 & 0.132 & 12.8 & ND & 9.00 & 0.638 & 81.5 & 58.5 \\
\hline \multirow{2}{*}{ 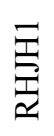 } & Mean & 2.64 & 303 & 0.813 & 0.236 & 16.9 & ND & 14.3 & ND & 25.8 & 134 \\
\hline & Max & 6.33 & 630 & 0.942 & 0.259 & 20.2 & ND & 25.9 & ND & 39.4 & 187 \\
\hline \multirow{2}{*}{ 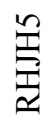 } & Mean & 0.937 & 227 & 1.07 & 0.345 & 12.8 & 0.0418 & 9.68 & 0.749 & 33.8 & 186 \\
\hline & Max & 1.04 & 290 & 1.15 & 0.413 & 13.4 & 0.0418 & 9.89 & 0.776 & 36.0 & 187 \\
\hline \multirow{2}{*}{ 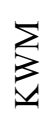 } & Mean & 0.384 & 183 & 0.870 & 0.800 & 36.6 & ND & 2.39 & 0.621 & 337 & 223 \\
\hline & Max & 0.426 & 214 & 0.954 & 1.11 & 40.7 & ND & 3.91 & 0.621 & 555 & 255 \\
\hline
\end{tabular}




\section{Appendix D Grape Chemistry Data}

All data from Apex Laboratories for the grape samples analyzed from vineyards in this study. Grapes were collected from vines, frozen, and delivered to the lab. The grape juice was analyzed using EPA method 6020A for ICP-MS (EPA, 1998). These methods were preceded by acid digestion using EPA method 3051a (EPA, 2007a). Analyst notes include B-02: Analyte detected in an associated blank at a level between one-half the minimum reporting limit (MRL) and the MRL, J: Estimated Result. Result detected below the lowest point of the calibration curve, but above the specified minimum detection limit (MDL), Q-29: Recovery for Lab Control Spike (LCS) is above the upper control limit. Data may be biased high, and Q-41: Estimated Results. Recovery of Continuing Calibration Verification sample above upper control limit for this analyte. Results are likely biased high. Quality control data follows (Table 121 to Table 140). 
Table 121. Chemical analysis using ICP-MS for the grape sample from Elk Cove Clay Court (ECCC) Vineyard. ND - Non-detect.

\begin{tabular}{|c|c|c|c|c|c|c|}
\hline \multicolumn{7}{|c|}{ Lab ID A4A0576-02 ECCC } \\
\hline Analyte & Result & Detection Limit & Reporting Limit & Units & Dilution & Analyst Notes \\
\hline S & ND & 106 & 211 & $\mathrm{mg} / \mathrm{kg}$ & 4 & \\
\hline $\mathrm{Hg}$ & ND & 0.0423 & 0.0846 & $\mathrm{mg} / \mathrm{kg}$ & 10 & Q-41 \\
\hline $\mathrm{Sr}$ & 0.973 & 0.211 & 0.423 & $\mathrm{mg} / \mathrm{kg}$ & 4 & \\
\hline $\mathrm{Al}$ & ND & 106 & 211 & $\mathrm{mg} / \mathrm{kg}$ & 4 & \\
\hline As & ND & 2.11 & 8.46 & $\mathrm{mg} / \mathrm{kg}$ & 4 & \\
\hline $\mathrm{Ba}$ & ND & 2.11 & 4.23 & $\mathrm{mg} / \mathrm{kg}$ & 4 & \\
\hline $\mathrm{Be}$ & ND & 2.11 & 4.23 & $\mathrm{mg} / \mathrm{kg}$ & 4 & \\
\hline $\mathrm{Cd}$ & ND & 2.11 & 4.23 & $\mathrm{mg} / \mathrm{kg}$ & 4 & \\
\hline $\mathrm{Ca}$ & ND & 106 & 211 & $\mathrm{mg} / \mathrm{kg}$ & 4 & \\
\hline $\mathrm{Cr}$ & ND & 2.11 & 4.23 & $\mathrm{mg} / \mathrm{kg}$ & 4 & \\
\hline Co & ND & 2.11 & 4.23 & $\mathrm{mg} / \mathrm{kg}$ & 4 & \\
\hline $\mathrm{Cu}$ & ND & 2.11 & 4.23 & $\mathrm{mg} / \mathrm{kg}$ & 4 & \\
\hline $\mathrm{Fe}$ & ND & 21.1 & 42.3 & $\mathrm{mg} / \mathrm{kg}$ & 4 & \\
\hline $\mathrm{Pb}$ & ND & 2.11 & 4.23 & $\mathrm{mg} / \mathrm{kg}$ & 4 & \\
\hline $\mathrm{P}$ & ND & 211 & 423 & $\mathrm{mg} / \mathrm{kg}$ & 4 & Q-29 \\
\hline $\mathrm{Mg}$ & ND & 106 & 211 & $\mathrm{mg} / \mathrm{kg}$ & 4 & \\
\hline $\mathrm{Mn}$ & ND & 2.11 & 4.23 & $\mathrm{mg} / \mathrm{kg}$ & 4 & \\
\hline Mo & ND & 2.11 & 4.23 & $\mathrm{mg} / \mathrm{kg}$ & 4 & \\
\hline $\mathrm{Ni}$ & ND & 2.11 & 4.23 & $\mathrm{mg} / \mathrm{kg}$ & 4 & \\
\hline $\mathrm{K}$ & 530 & 106 & 211 & $\mathrm{mg} / \mathrm{kg}$ & 4 & \\
\hline $\mathrm{Se}$ & ND & 2.11 & 8.46 & $\mathrm{mg} / \mathrm{kg}$ & 4 & \\
\hline $\mathrm{Na}$ & 161 & 106 & 211 & $\mathrm{mg} / \mathrm{kg}$ & 4 & B-02, J \\
\hline V & ND & 2.11 & 4.23 & $\mathrm{mg} / \mathrm{kg}$ & 4 & \\
\hline $\mathrm{Zn}$ & ND & 2.11 & 4.23 & $\mathrm{mg} / \mathrm{kg}$ & 4 & \\
\hline
\end{tabular}


Table 122. Chemical analysis using ICP-MS for the grape sample from Elk Cove Roosevelt Vineyard (ECRV). ND - Non-detect.

\begin{tabular}{|c|c|c|c|c|c|c|}
\hline \multicolumn{7}{|c|}{ Lab ID A4A0576-01 ECRV } \\
\hline Analyte & Result & Detection Limit & Reporting Limit & Units & Dilution & Analyst Notes \\
\hline $\mathrm{S}$ & ND & 101 & 203 & $\mathrm{mg} / \mathrm{kg}$ & 4 & \\
\hline $\mathrm{Hg}$ & ND & 0.0406 & 0.0811 & $\mathrm{mg} / \mathrm{kg}$ & 10 & Q-41 \\
\hline $\mathrm{Sr}$ & 0.852 & 0.203 & 0.406 & $\mathrm{mg} / \mathrm{kg}$ & 4 & \\
\hline $\mathrm{Al}$ & ND & 101 & 203 & $\mathrm{mg} / \mathrm{kg}$ & 4 & \\
\hline As & ND & 2.03 & 8.11 & $\mathrm{mg} / \mathrm{kg}$ & 4 & \\
\hline $\mathrm{Ba}$ & ND & 2.03 & 4.06 & $\mathrm{mg} / \mathrm{kg}$ & 4 & \\
\hline $\mathrm{Be}$ & ND & 2.03 & 4.06 & $\mathrm{mg} / \mathrm{kg}$ & 4 & \\
\hline $\mathrm{Cd}$ & ND & 2.03 & 4.06 & $\mathrm{mg} / \mathrm{kg}$ & 4 & \\
\hline $\mathrm{Ca}$ & ND & 101 & 203 & $\mathrm{mg} / \mathrm{kg}$ & 4 & \\
\hline $\mathrm{Cr}$ & ND & 2.03 & 4.06 & $\mathrm{mg} / \mathrm{kg}$ & 4 & \\
\hline Co & ND & 2.03 & 4.06 & $\mathrm{mg} / \mathrm{kg}$ & 4 & \\
\hline $\mathrm{Cu}$ & ND & 2.03 & 4.06 & $\mathrm{mg} / \mathrm{kg}$ & 4 & \\
\hline $\mathrm{Fe}$ & ND & 20.3 & 40.6 & $\mathrm{mg} / \mathrm{kg}$ & 4 & \\
\hline $\mathrm{Pb}$ & ND & 2.03 & 4.06 & $\mathrm{mg} / \mathrm{kg}$ & 4 & \\
\hline $\mathrm{P}$ & 361 & 203 & 406 & $\mathrm{mg} / \mathrm{kg}$ & 4 & Q-29, J \\
\hline $\mathrm{Mg}$ & ND & 101 & 203 & $\mathrm{mg} / \mathrm{kg}$ & 4 & \\
\hline $\mathrm{Mn}$ & ND & 2.03 & 4.06 & $\mathrm{mg} / \mathrm{kg}$ & 4 & \\
\hline Mo & ND & 2.03 & 4.06 & $\mathrm{mg} / \mathrm{kg}$ & 4 & \\
\hline $\mathrm{Ni}$ & ND & 2.03 & 4.06 & $\mathrm{mg} / \mathrm{kg}$ & 4 & \\
\hline K & 1240 & 101 & 203 & $\mathrm{mg} / \mathrm{kg}$ & 4 & \\
\hline $\mathrm{Se}$ & ND & 2.03 & 8.11 & $\mathrm{mg} / \mathrm{kg}$ & 4 & \\
\hline $\mathrm{Na}$ & 144 & 101 & 203 & $\mathrm{mg} / \mathrm{kg}$ & 4 & $\mathrm{~B}-02, \mathrm{~J}$ \\
\hline V & ND & 2.03 & 4.06 & $\mathrm{mg} / \mathrm{kg}$ & 4 & \\
\hline $\mathrm{Zn}$ & ND & 2.03 & 4.06 & $\mathrm{mg} / \mathrm{kg}$ & 4 & \\
\hline
\end{tabular}


Table 123. Chemical analysis using ICP-MS for the grape sample from Elk Cove Five Mountain (ECFM) Vineyard. ND - Non-detect.

\begin{tabular}{|c|c|c|c|c|c|c|}
\hline \multicolumn{7}{|c|}{ Lab ID A4A0576-03 ECFM } \\
\hline Analyte & Result & Detection Limit & Reporting Limit & Units & Dilution & Analyst Notes \\
\hline S & ND & 98.2 & 196 & $\mathrm{mg} / \mathrm{kg}$ & 4 & \\
\hline $\mathrm{Hg}$ & ND & 0.0393 & 0.0786 & $\mathrm{mg} / \mathrm{kg}$ & 10 & Q-41 \\
\hline $\mathrm{Sr}$ & 1.02 & 0.196 & 0.393 & $\mathrm{mg} / \mathrm{kg}$ & 4 & \\
\hline $\mathrm{Al}$ & ND & 98.2 & 196 & $\mathrm{mg} / \mathrm{kg}$ & 4 & \\
\hline As & ND & 1.96 & 7.86 & $\mathrm{mg} / \mathrm{kg}$ & 4 & \\
\hline $\mathrm{Ba}$ & ND & 1.96 & 3.93 & $\mathrm{mg} / \mathrm{kg}$ & 4 & \\
\hline $\mathrm{Be}$ & ND & 1.96 & 3.93 & $\mathrm{mg} / \mathrm{kg}$ & 4 & \\
\hline $\mathrm{Cd}$ & ND & 1.96 & 3.93 & $\mathrm{mg} / \mathrm{kg}$ & 4 & \\
\hline $\mathrm{Ca}$ & ND & 98.2 & 196 & $\mathrm{mg} / \mathrm{kg}$ & 4 & \\
\hline $\mathrm{Cr}$ & ND & 1.96 & 3.93 & $\mathrm{mg} / \mathrm{kg}$ & 4 & \\
\hline Co & ND & 1.96 & 3.93 & $\mathrm{mg} / \mathrm{kg}$ & 4 & \\
\hline $\mathrm{Cu}$ & ND & 1.96 & 3.93 & $\mathrm{mg} / \mathrm{kg}$ & 4 & \\
\hline $\mathrm{Fe}$ & ND & 19.6 & 39.3 & $\mathrm{mg} / \mathrm{kg}$ & 4 & \\
\hline $\mathrm{Pb}$ & ND & 1.96 & 3.93 & $\mathrm{mg} / \mathrm{kg}$ & 4 & \\
\hline $\mathrm{P}$ & 232 & 196 & 393 & $\mathrm{mg} / \mathrm{kg}$ & 4 & Q-29, J \\
\hline $\mathrm{Mg}$ & ND & 98.2 & 196 & $\mathrm{mg} / \mathrm{kg}$ & 4 & \\
\hline $\mathrm{Mn}$ & 2.04 & 1.96 & 3.93 & $\mathrm{mg} / \mathrm{kg}$ & 4 & $\mathrm{~J}$ \\
\hline Mo & ND & 1.96 & 3.93 & $\mathrm{mg} / \mathrm{kg}$ & 4 & \\
\hline $\mathrm{Ni}$ & ND & 1.96 & 3.93 & $\mathrm{mg} / \mathrm{kg}$ & 4 & \\
\hline $\mathrm{K}$ & 1340 & 98.2 & 196 & $\mathrm{mg} / \mathrm{kg}$ & 4 & \\
\hline $\mathrm{Se}$ & ND & 1.96 & 7.86 & $\mathrm{mg} / \mathrm{kg}$ & 4 & \\
\hline $\mathrm{Na}$ & 145 & 98.2 & 196 & $\mathrm{mg} / \mathrm{kg}$ & 4 & B- $02, \mathrm{~J}$ \\
\hline V & ND & 1.96 & 3.93 & $\mathrm{mg} / \mathrm{kg}$ & 4 & \\
\hline $\mathrm{Zn}$ & ND & 1.96 & 3.93 & $\mathrm{mg} / \mathrm{kg}$ & 4 & \\
\hline
\end{tabular}


Table 124. Chemical analysis using ICP-MS for the grape sample from Willakenzie Jory Hill (WEJH) Vineyard. ND - Non-detect.

\begin{tabular}{|c|c|c|c|c|c|c|}
\hline \multicolumn{7}{|c|}{ Lab ID A4A0576-06 WEJH } \\
\hline Analyte & Result & Detection Limit & Reporting Limit & Units & Dilution & Analyst Notes \\
\hline $\mathrm{S}$ & ND & 97.3 & 195 & $\mathrm{mg} / \mathrm{kg}$ & 4 & \\
\hline $\mathrm{Hg}$ & ND & 0.0389 & 0.0778 & $\mathrm{mg} / \mathrm{kg}$ & 10 & Q-41 \\
\hline $\mathrm{Sr}$ & 0.506 & 0.195 & 0.389 & $\mathrm{mg} / \mathrm{kg}$ & 4 & \\
\hline $\mathrm{Al}$ & ND & 97.3 & 195 & $\mathrm{mg} / \mathrm{kg}$ & 4 & \\
\hline As & ND & 1.95 & 7.78 & $\mathrm{mg} / \mathrm{kg}$ & 4 & \\
\hline $\mathrm{Ba}$ & ND & 1.95 & 3.89 & $\mathrm{mg} / \mathrm{kg}$ & 4 & \\
\hline $\mathrm{Be}$ & ND & 1.95 & 3.89 & $\mathrm{mg} / \mathrm{kg}$ & 4 & \\
\hline $\mathrm{Cd}$ & ND & 1.95 & 3.89 & $\mathrm{mg} / \mathrm{kg}$ & 4 & \\
\hline $\mathrm{Ca}$ & ND & 97.3 & 195 & $\mathrm{mg} / \mathrm{kg}$ & 4 & \\
\hline $\mathrm{Cr}$ & ND & 1.95 & 3.89 & $\mathrm{mg} / \mathrm{kg}$ & 4 & \\
\hline Co & ND & 1.95 & 3.89 & $\mathrm{mg} / \mathrm{kg}$ & 4 & \\
\hline $\mathrm{Cu}$ & ND & 1.95 & 3.89 & $\mathrm{mg} / \mathrm{kg}$ & 4 & \\
\hline $\mathrm{Fe}$ & ND & 19.5 & 38.9 & $\mathrm{mg} / \mathrm{kg}$ & 4 & \\
\hline $\mathrm{Pb}$ & ND & 1.95 & 3.89 & $\mathrm{mg} / \mathrm{kg}$ & 4 & \\
\hline $\mathrm{P}$ & 275 & 195 & 389 & $\mathrm{mg} / \mathrm{kg}$ & 4 & $\mathrm{~J}$ \\
\hline $\mathrm{Mg}$ & ND & 97.3 & 195 & $\mathrm{mg} / \mathrm{kg}$ & 4 & \\
\hline $\mathrm{Mn}$ & 2.14 & 1.95 & 3.89 & $\mathrm{mg} / \mathrm{kg}$ & 4 & $\mathrm{~J}$ \\
\hline Mo & ND & 1.95 & 3.89 & $\mathrm{mg} / \mathrm{kg}$ & 4 & \\
\hline $\mathrm{Ni}$ & ND & 1.95 & 3.89 & $\mathrm{mg} / \mathrm{kg}$ & 4 & \\
\hline K & 1150 & 97.3 & 195 & $\mathrm{mg} / \mathrm{kg}$ & 4 & \\
\hline $\mathrm{Se}$ & ND & 1.95 & 7.78 & $\mathrm{mg} / \mathrm{kg}$ & 4 & \\
\hline $\mathrm{Na}$ & 141 & 97.3 & 195 & $\mathrm{mg} / \mathrm{kg}$ & 4 & B-02, J \\
\hline V & ND & 1.95 & 3.89 & $\mathrm{mg} / \mathrm{kg}$ & 4 & \\
\hline $\mathrm{Zn}$ & ND & 1.95 & 3.89 & $\mathrm{mg} / \mathrm{kg}$ & 4 & \\
\hline
\end{tabular}


Table 125. Chemical analysis using ICP-MS for the grape sample from Willakenzie Estate Aliette (WEAB) Vineyard. ND - Non-detect.

\begin{tabular}{|c|c|c|c|c|c|c|}
\hline \multicolumn{7}{|c|}{ Lab ID A4A0576-05 WEAB } \\
\hline Analyte & Result & Detection Limit & Reporting Limit & Units & Dilution & Analyst Notes \\
\hline S & ND & 105 & 211 & $\mathrm{mg} / \mathrm{kg}$ & 4 & \\
\hline $\mathrm{Hg}$ & ND & 0.0421 & 0.0842 & $\mathrm{mg} / \mathrm{kg}$ & 10 & Q-41 \\
\hline $\mathrm{Sr}$ & 0.716 & 0.211 & 0.421 & $\mathrm{mg} / \mathrm{kg}$ & 4 & \\
\hline $\mathrm{Al}$ & ND & 105 & 211 & $\mathrm{mg} / \mathrm{kg}$ & 4 & \\
\hline As & ND & 2.11 & 8.42 & $\mathrm{mg} / \mathrm{kg}$ & 4 & \\
\hline $\mathrm{Ba}$ & ND & 2.11 & 4.21 & $\mathrm{mg} / \mathrm{kg}$ & 4 & \\
\hline $\mathrm{Be}$ & ND & 2.11 & 4.21 & $\mathrm{mg} / \mathrm{kg}$ & 4 & \\
\hline $\mathrm{Cd}$ & ND & 2.11 & 4.21 & $\mathrm{mg} / \mathrm{kg}$ & 4 & \\
\hline $\mathrm{Ca}$ & ND & 105 & 211 & $\mathrm{mg} / \mathrm{kg}$ & 4 & \\
\hline $\mathrm{Cr}$ & ND & 2.11 & 4.21 & $\mathrm{mg} / \mathrm{kg}$ & 4 & \\
\hline Co & ND & 2.11 & 4.21 & $\mathrm{mg} / \mathrm{kg}$ & 4 & \\
\hline $\mathrm{Cu}$ & ND & 2.11 & 4.21 & $\mathrm{mg} / \mathrm{kg}$ & 4 & \\
\hline $\mathrm{Fe}$ & ND & 21.1 & 42.1 & $\mathrm{mg} / \mathrm{kg}$ & 4 & \\
\hline $\mathrm{Pb}$ & ND & 2.11 & 4.21 & $\mathrm{mg} / \mathrm{kg}$ & 4 & \\
\hline $\mathrm{P}$ & 267 & 211 & 421 & $\mathrm{mg} / \mathrm{kg}$ & 4 & $\mathrm{~J}$ \\
\hline $\mathrm{Mg}$ & ND & 105 & 211 & $\mathrm{mg} / \mathrm{kg}$ & 4 & \\
\hline $\mathrm{Mn}$ & ND & 2.11 & 4.21 & $\mathrm{mg} / \mathrm{kg}$ & 4 & \\
\hline Mo & ND & 2.11 & 4.21 & $\mathrm{mg} / \mathrm{kg}$ & 4 & \\
\hline $\mathrm{Ni}$ & ND & 2.11 & 4.21 & $\mathrm{mg} / \mathrm{kg}$ & 4 & \\
\hline K & 1680 & 105 & 211 & $\mathrm{mg} / \mathrm{kg}$ & 4 & \\
\hline $\mathrm{Se}$ & ND & 2.11 & 8.42 & $\mathrm{mg} / \mathrm{kg}$ & 4 & \\
\hline $\mathrm{Na}$ & 158 & 105 & 211 & $\mathrm{mg} / \mathrm{kg}$ & 4 & B-02, J \\
\hline V & ND & 2.11 & 4.21 & $\mathrm{mg} / \mathrm{kg}$ & 4 & \\
\hline $\mathrm{Zn}$ & ND & 2.11 & 4.21 & $\mathrm{mg} / \mathrm{kg}$ & 4 & \\
\hline
\end{tabular}


Table 126. Chemical analysis using ICP-MS for the grape sample from Willakenzie Estate Terres Basses (WETB) Vineyard. ND - Non-detect.

\begin{tabular}{|c|c|c|c|c|c|c|}
\hline \multicolumn{7}{|c|}{ Lab ID A4A0576-04 WETB } \\
\hline Analyte & Result & Detection Limit & Reporting Limit & Units & Dilution & Analyst Notes \\
\hline S & ND & 103 & 205 & $\mathrm{mg} / \mathrm{kg}$ & 4 & \\
\hline $\mathrm{Hg}$ & ND & 0.0411 & 0.0821 & $\mathrm{mg} / \mathrm{kg}$ & 10 & Q-41 \\
\hline $\mathrm{Sr}$ & 0.739 & 0.205 & 0.411 & $\mathrm{mg} / \mathrm{kg}$ & 4 & \\
\hline $\mathrm{Al}$ & ND & 103 & 205 & $\mathrm{mg} / \mathrm{kg}$ & 4 & \\
\hline As & ND & 2.05 & 8.21 & $\mathrm{mg} / \mathrm{kg}$ & 4 & \\
\hline $\mathrm{Ba}$ & ND & 2.05 & 4.11 & $\mathrm{mg} / \mathrm{kg}$ & 4 & \\
\hline $\mathrm{Be}$ & ND & 2.05 & 4.11 & $\mathrm{mg} / \mathrm{kg}$ & 4 & \\
\hline $\mathrm{Cd}$ & ND & 2.05 & 4.11 & $\mathrm{mg} / \mathrm{kg}$ & 4 & \\
\hline $\mathrm{Ca}$ & ND & 103 & 205 & $\mathrm{mg} / \mathrm{kg}$ & 4 & \\
\hline $\mathrm{Cr}$ & ND & 2.05 & 4.11 & $\mathrm{mg} / \mathrm{kg}$ & 4 & \\
\hline Co & ND & 2.05 & 4.11 & $\mathrm{mg} / \mathrm{kg}$ & 4 & \\
\hline $\mathrm{Cu}$ & ND & 2.05 & 4.11 & $\mathrm{mg} / \mathrm{kg}$ & 4 & \\
\hline $\mathrm{Fe}$ & ND & 20.5 & 41.1 & $\mathrm{mg} / \mathrm{kg}$ & 4 & \\
\hline $\mathrm{Pb}$ & ND & 2.05 & 4.11 & $\mathrm{mg} / \mathrm{kg}$ & 4 & \\
\hline $\mathrm{P}$ & 324 & 205 & 411 & $\mathrm{mg} / \mathrm{kg}$ & 4 & Q-29, J \\
\hline $\mathrm{Mg}$ & ND & 103 & 205 & $\mathrm{mg} / \mathrm{kg}$ & 4 & \\
\hline $\mathrm{Mn}$ & ND & 2.05 & 4.11 & $\mathrm{mg} / \mathrm{kg}$ & 4 & \\
\hline Mo & ND & 2.05 & 4.11 & $\mathrm{mg} / \mathrm{kg}$ & 4 & \\
\hline $\mathrm{Ni}$ & ND & 2.05 & 4.11 & $\mathrm{mg} / \mathrm{kg}$ & 4 & \\
\hline $\mathrm{K}$ & 1940 & 103 & 205 & $\mathrm{mg} / \mathrm{kg}$ & 4 & \\
\hline $\mathrm{Se}$ & ND & 2.05 & 8.21 & $\mathrm{mg} / \mathrm{kg}$ & 4 & \\
\hline $\mathrm{Na}$ & 159 & 103 & 205 & $\mathrm{mg} / \mathrm{kg}$ & 4 & $\mathrm{~B}-02, \mathrm{~J}$ \\
\hline V & ND & 2.05 & 4.11 & $\mathrm{mg} / \mathrm{kg}$ & 4 & \\
\hline $\mathrm{Zn}$ & ND & 2.05 & 4.11 & $\mathrm{mg} / \mathrm{kg}$ & 4 & \\
\hline
\end{tabular}


Table 127. Chemical analysis using ICP-MS for the grape sample from Chehalem, Stoller Vineyard (CWS). ND - Non-detect.

\begin{tabular}{|c|c|c|c|c|c|c|}
\hline \multicolumn{7}{|c|}{ Lab ID A4A0576-07 CWS } \\
\hline Analyte & Result & Detection Limit & Reporting Limit & Units & Dilution & Analyst Notes \\
\hline $\mathrm{S}$ & ND & 105 & 211 & $\mathrm{mg} / \mathrm{kg}$ & 4 & \\
\hline $\mathrm{Hg}$ & ND & 0.0422 & 0.0844 & $\mathrm{mg} / \mathrm{kg}$ & 10 & Q-41 \\
\hline $\mathrm{Sr}$ & 0.633 & 0.211 & 0.422 & $\mathrm{mg} / \mathrm{kg}$ & 4 & \\
\hline $\mathrm{Al}$ & ND & 105 & 211 & $\mathrm{mg} / \mathrm{kg}$ & 4 & \\
\hline As & ND & 2.11 & 8.44 & $\mathrm{mg} / \mathrm{kg}$ & 4 & \\
\hline $\mathrm{Ba}$ & ND & 2.11 & 4.22 & $\mathrm{mg} / \mathrm{kg}$ & 4 & \\
\hline $\mathrm{Be}$ & ND & 2.11 & 4.22 & $\mathrm{mg} / \mathrm{kg}$ & 4 & \\
\hline $\mathrm{Cd}$ & ND & 2.11 & 4.22 & $\mathrm{mg} / \mathrm{kg}$ & 4 & \\
\hline $\mathrm{Ca}$ & ND & 105 & 211 & $\mathrm{mg} / \mathrm{kg}$ & 4 & \\
\hline $\mathrm{Cr}$ & ND & 2.11 & 4.22 & $\mathrm{mg} / \mathrm{kg}$ & 4 & \\
\hline Co & ND & 2.11 & 4.22 & $\mathrm{mg} / \mathrm{kg}$ & 4 & \\
\hline $\mathrm{Cu}$ & ND & 2.11 & 4.22 & $\mathrm{mg} / \mathrm{kg}$ & 4 & \\
\hline $\mathrm{Fe}$ & ND & 21.1 & 42.2 & $\mathrm{mg} / \mathrm{kg}$ & 4 & \\
\hline $\mathrm{Pb}$ & ND & 2.11 & 4.22 & $\mathrm{mg} / \mathrm{kg}$ & 4 & \\
\hline $\mathrm{P}$ & 213 & 211 & 422 & $\mathrm{mg} / \mathrm{kg}$ & 4 & $\mathrm{~J}$ \\
\hline $\mathrm{Mg}$ & ND & 105 & 211 & $\mathrm{mg} / \mathrm{kg}$ & 4 & \\
\hline $\mathrm{Mn}$ & 4.56 & 2.11 & 4.22 & $\mathrm{mg} / \mathrm{kg}$ & 4 & \\
\hline Mo & ND & 2.11 & 4.22 & $\mathrm{mg} / \mathrm{kg}$ & 4 & \\
\hline $\mathrm{Ni}$ & ND & 2.11 & 4.22 & $\mathrm{mg} / \mathrm{kg}$ & 4 & \\
\hline K & 1400 & 105 & 211 & $\mathrm{mg} / \mathrm{kg}$ & 4 & \\
\hline $\mathrm{Se}$ & ND & 2.11 & 8.44 & $\mathrm{mg} / \mathrm{kg}$ & 4 & \\
\hline $\mathrm{Na}$ & 153 & 105 & 211 & $\mathrm{mg} / \mathrm{kg}$ & 4 & $\mathrm{~B}-02, \mathrm{~J}$ \\
\hline V & ND & 2.11 & 4.22 & $\mathrm{mg} / \mathrm{kg}$ & 4 & \\
\hline $\mathrm{Zn}$ & ND & 2.11 & 4.22 & $\mathrm{mg} / \mathrm{kg}$ & 4 & \\
\hline
\end{tabular}


Table 128. Chemical analysis using ICP-MS for the grape sample from Chehalem, Ridgecrest Vineyard (CWRC). ND - Non-detect.

\begin{tabular}{|c|c|c|c|c|c|c|}
\hline \multicolumn{7}{|c|}{ Lab ID A4A0576-08 CWRC } \\
\hline Analyte & Result & Detection Limit & Reporting Limit & Units & Dilution & Analyst Notes \\
\hline $\mathrm{S}$ & ND & 106 & 212 & $\mathrm{mg} / \mathrm{kg}$ & 4 & \\
\hline $\mathrm{Hg}$ & ND & 0.0424 & 0.0847 & $\mathrm{mg} / \mathrm{kg}$ & 10 & Q-41 \\
\hline $\mathrm{Sr}$ & 1.10 & 0.212 & 0.424 & $\mathrm{mg} / \mathrm{kg}$ & 4 & \\
\hline $\mathrm{Al}$ & ND & 106 & 212 & $\mathrm{mg} / \mathrm{kg}$ & 4 & \\
\hline As & ND & 2.12 & 8.47 & $\mathrm{mg} / \mathrm{kg}$ & 4 & \\
\hline $\mathrm{Ba}$ & ND & 2.12 & 4.24 & $\mathrm{mg} / \mathrm{kg}$ & 4 & \\
\hline $\mathrm{Be}$ & ND & 2.12 & 4.24 & $\mathrm{mg} / \mathrm{kg}$ & 4 & \\
\hline $\mathrm{Cd}$ & ND & 2.12 & 4.24 & $\mathrm{mg} / \mathrm{kg}$ & 4 & \\
\hline $\mathrm{Ca}$ & ND & 106 & 212 & $\mathrm{mg} / \mathrm{kg}$ & 4 & \\
\hline $\mathrm{Cr}$ & ND & 2.12 & 4.24 & $\mathrm{mg} / \mathrm{kg}$ & 4 & \\
\hline Co & ND & 2.12 & 4.24 & $\mathrm{mg} / \mathrm{kg}$ & 4 & \\
\hline $\mathrm{Cu}$ & ND & 2.12 & 4.24 & $\mathrm{mg} / \mathrm{kg}$ & 4 & \\
\hline $\mathrm{Fe}$ & ND & 21.2 & 42.4 & $\mathrm{mg} / \mathrm{kg}$ & 4 & \\
\hline $\mathrm{Pb}$ & ND & 2.12 & 4.24 & $\mathrm{mg} / \mathrm{kg}$ & 4 & \\
\hline $\mathrm{P}$ & ND & 212 & 424 & $\mathrm{mg} / \mathrm{kg}$ & 4 & \\
\hline $\mathrm{Mg}$ & ND & 106 & 212 & $\mathrm{mg} / \mathrm{kg}$ & 4 & \\
\hline $\mathrm{Mn}$ & ND & 2.12 & 4.24 & $\mathrm{mg} / \mathrm{kg}$ & 4 & \\
\hline Mo & ND & 2.12 & 4.24 & $\mathrm{mg} / \mathrm{kg}$ & 4 & \\
\hline $\mathrm{Ni}$ & ND & 2.12 & 4.24 & $\mathrm{mg} / \mathrm{kg}$ & 4 & \\
\hline $\mathrm{K}$ & 851 & 106 & 212 & $\mathrm{mg} / \mathrm{kg}$ & 4 & \\
\hline $\mathrm{Se}$ & ND & 2.12 & 8.47 & $\mathrm{mg} / \mathrm{kg}$ & 4 & \\
\hline $\mathrm{Na}$ & 155 & 106 & 212 & $\mathrm{mg} / \mathrm{kg}$ & 4 & B-02, J \\
\hline $\mathrm{V}$ & ND & 2.12 & 4.24 & $\mathrm{mg} / \mathrm{kg}$ & 4 & \\
\hline $\mathrm{Zn}$ & ND & 2.12 & 4.24 & $\mathrm{mg} / \mathrm{kg}$ & 4 & \\
\hline
\end{tabular}


Table 129. Chemical analysis using ICP-MS for the grape sample from Chehalem, Corral Creek Vineyard (CWCC). ND - Non-detect.

\begin{tabular}{|c|c|c|c|c|c|c|}
\hline \multicolumn{7}{|c|}{ Lab ID A4A0576-09 CWCC } \\
\hline Analyte & Result & Detection Limit & Reporting Limit & Units & Dilution & Analyst Notes \\
\hline $\mathrm{S}$ & ND & 98.8 & 198 & $\mathrm{mg} / \mathrm{kg}$ & 4 & \\
\hline $\mathrm{Hg}$ & ND & 0.0395 & 0.0791 & $\mathrm{mg} / \mathrm{kg}$ & 10 & Q-41 \\
\hline $\mathrm{Sr}$ & 0.711 & 0.198 & 0.395 & $\mathrm{mg} / \mathrm{kg}$ & 4 & \\
\hline $\mathrm{Al}$ & ND & 98.8 & 198 & $\mathrm{mg} / \mathrm{kg}$ & 4 & \\
\hline As & ND & 1.98 & 7.91 & $\mathrm{mg} / \mathrm{kg}$ & 4 & \\
\hline $\mathrm{Ba}$ & ND & 1.98 & 3.95 & $\mathrm{mg} / \mathrm{kg}$ & 4 & \\
\hline $\mathrm{Be}$ & ND & 1.98 & 3.95 & $\mathrm{mg} / \mathrm{kg}$ & 4 & \\
\hline $\mathrm{Cd}$ & ND & 1.98 & 3.95 & $\mathrm{mg} / \mathrm{kg}$ & 4 & \\
\hline $\mathrm{Ca}$ & ND & 98.8 & 198 & $\mathrm{mg} / \mathrm{kg}$ & 4 & \\
\hline $\mathrm{Cr}$ & ND & 1.98 & 3.95 & $\mathrm{mg} / \mathrm{kg}$ & 4 & \\
\hline Co & ND & 1.98 & 3.95 & $\mathrm{mg} / \mathrm{kg}$ & 4 & \\
\hline $\mathrm{Cu}$ & ND & 1.98 & 3.95 & $\mathrm{mg} / \mathrm{kg}$ & 4 & \\
\hline $\mathrm{Fe}$ & ND & 19.8 & 39.5 & $\mathrm{mg} / \mathrm{kg}$ & 4 & \\
\hline $\mathrm{Pb}$ & ND & 1.98 & 3.95 & $\mathrm{mg} / \mathrm{kg}$ & 4 & \\
\hline $\mathrm{P}$ & 303 & 198 & 395 & $\mathrm{mg} / \mathrm{kg}$ & 4 & $\mathrm{~J}$ \\
\hline $\mathrm{Mg}$ & ND & 98.8 & 198 & $\mathrm{mg} / \mathrm{kg}$ & 4 & \\
\hline $\mathrm{Mn}$ & ND & 1.98 & 3.95 & $\mathrm{mg} / \mathrm{kg}$ & 4 & \\
\hline Mo & ND & 1.98 & 3.95 & $\mathrm{mg} / \mathrm{kg}$ & 4 & \\
\hline $\mathrm{Ni}$ & ND & 1.98 & 3.95 & $\mathrm{mg} / \mathrm{kg}$ & 4 & \\
\hline $\mathrm{K}$ & 1530 & 98.8 & 198 & $\mathrm{mg} / \mathrm{kg}$ & 4 & \\
\hline $\mathrm{Se}$ & ND & 1.98 & 7.91 & $\mathrm{mg} / \mathrm{kg}$ & 4 & \\
\hline $\mathrm{Na}$ & 159 & 98.8 & 198 & $\mathrm{mg} / \mathrm{kg}$ & 4 & $\mathrm{~B}-02, \mathrm{~J}$ \\
\hline $\mathrm{V}$ & ND & 1.98 & 3.95 & $\mathrm{mg} / \mathrm{kg}$ & 4 & \\
\hline $\mathrm{Zn}$ & ND & 1.98 & 3.95 & $\mathrm{mg} / \mathrm{kg}$ & 4 & \\
\hline
\end{tabular}


Table 130. Chemical analysis using ICP-MS for the grape sample from Lange Estate, Estate Vineyard (LEMN). ND - Non-detect.

\begin{tabular}{|c|c|c|c|c|c|c|}
\hline \multicolumn{7}{|c|}{ Lab ID A4A0576-11 LEMN } \\
\hline Analyte & Result & Detection Limit & Reporting Limit & Units & Dilution & Analyst Notes \\
\hline $\mathrm{S}$ & ND & 111 & 222 & $\mathrm{mg} / \mathrm{kg}$ & 4 & \\
\hline $\mathrm{Hg}$ & ND & 0.0444 & 0.0889 & $\mathrm{mg} / \mathrm{kg}$ & 10 & Q-41 \\
\hline $\mathrm{Sr}$ & 0.711 & 0.222 & 0.444 & $\mathrm{mg} / \mathrm{kg}$ & 4 & \\
\hline $\mathrm{Al}$ & ND & 111 & 222 & $\mathrm{mg} / \mathrm{kg}$ & 4 & \\
\hline As & ND & 2.22 & 8.89 & $\mathrm{mg} / \mathrm{kg}$ & 4 & \\
\hline $\mathrm{Ba}$ & ND & 2.22 & 4.44 & $\mathrm{mg} / \mathrm{kg}$ & 4 & \\
\hline $\mathrm{Be}$ & ND & 2.22 & 4.44 & $\mathrm{mg} / \mathrm{kg}$ & 4 & \\
\hline $\mathrm{Cd}$ & ND & 2.22 & 4.44 & $\mathrm{mg} / \mathrm{kg}$ & 4 & \\
\hline $\mathrm{Ca}$ & ND & 111 & 222 & $\mathrm{mg} / \mathrm{kg}$ & 4 & \\
\hline $\mathrm{Cr}$ & ND & 2.22 & 4.44 & $\mathrm{mg} / \mathrm{kg}$ & 4 & \\
\hline Co & ND & 2.22 & 4.44 & $\mathrm{mg} / \mathrm{kg}$ & 4 & \\
\hline $\mathrm{Cu}$ & ND & 2.22 & 4.44 & $\mathrm{mg} / \mathrm{kg}$ & 4 & \\
\hline $\mathrm{Fe}$ & ND & 22.2 & 44.4 & $\mathrm{mg} / \mathrm{kg}$ & 4 & \\
\hline $\mathrm{Pb}$ & ND & 2.22 & 4.44 & $\mathrm{mg} / \mathrm{kg}$ & 4 & \\
\hline $\mathrm{P}$ & 248 & 222 & 444 & $\mathrm{mg} / \mathrm{kg}$ & 4 & $\mathrm{~J}$ \\
\hline $\mathrm{Mg}$ & ND & 111 & 222 & $\mathrm{mg} / \mathrm{kg}$ & 4 & \\
\hline $\mathrm{Mn}$ & ND & 2.22 & 4.44 & $\mathrm{mg} / \mathrm{kg}$ & 4 & \\
\hline Mo & ND & 2.22 & 4.44 & $\mathrm{mg} / \mathrm{kg}$ & 4 & \\
\hline $\mathrm{Ni}$ & ND & 2.22 & 4.44 & $\mathrm{mg} / \mathrm{kg}$ & 4 & \\
\hline $\mathrm{K}$ & 1730 & 111 & 222 & $\mathrm{mg} / \mathrm{kg}$ & 4 & \\
\hline $\mathrm{Se}$ & ND & 2.22 & 8.89 & $\mathrm{mg} / \mathrm{kg}$ & 4 & \\
\hline $\mathrm{Na}$ & 162 & 111 & 222 & $\mathrm{mg} / \mathrm{kg}$ & 4 & $\mathrm{~B}-02, \mathrm{~J}$ \\
\hline $\mathrm{V}$ & ND & 2.22 & 4.44 & $\mathrm{mg} / \mathrm{kg}$ & 4 & \\
\hline $\mathrm{Zn}$ & ND & 2.22 & 4.44 & $\mathrm{mg} / \mathrm{kg}$ & 4 & \\
\hline
\end{tabular}


Table 131. Chemical analysis using ICP-MS for the grape sample from Lange Estate, Yamhill Vineyard (LEYV). ND - Non-detect.

\begin{tabular}{|c|c|c|c|c|c|c|}
\hline \multicolumn{7}{|c|}{ Lab ID A4A0576-12 LEYV } \\
\hline Analyte & Result & Detection Limit & Reporting Limit & Units & Dilution & Analyst Notes \\
\hline $\mathrm{S}$ & ND & 107 & 213 & $\mathrm{mg} / \mathrm{kg}$ & 4 & \\
\hline $\mathrm{Hg}$ & ND & 0.0426 & 0.0853 & $\mathrm{mg} / \mathrm{kg}$ & 10 & Q-41 \\
\hline $\mathrm{Sr}$ & 1.41 & 0.213 & 0.426 & $\mathrm{mg} / \mathrm{kg}$ & 4 & \\
\hline $\mathrm{Al}$ & ND & 107 & 213 & $\mathrm{mg} / \mathrm{kg}$ & 4 & \\
\hline As & ND & 2.13 & 8.53 & $\mathrm{mg} / \mathrm{kg}$ & 4 & \\
\hline $\mathrm{Ba}$ & ND & 2.13 & 4.26 & $\mathrm{mg} / \mathrm{kg}$ & 4 & \\
\hline $\mathrm{Be}$ & ND & 2.13 & 4.26 & $\mathrm{mg} / \mathrm{kg}$ & 4 & \\
\hline $\mathrm{Cd}$ & ND & 2.13 & 4.26 & $\mathrm{mg} / \mathrm{kg}$ & 4 & \\
\hline $\mathrm{Ca}$ & 115 & 107 & 213 & $\mathrm{mg} / \mathrm{kg}$ & 4 & $\mathrm{~J}$ \\
\hline $\mathrm{Cr}$ & ND & 2.13 & 4.26 & $\mathrm{mg} / \mathrm{kg}$ & 4 & \\
\hline Co & ND & 2.13 & 4.26 & $\mathrm{mg} / \mathrm{kg}$ & 4 & \\
\hline $\mathrm{Cu}$ & ND & 2.13 & 4.26 & $\mathrm{mg} / \mathrm{kg}$ & 4 & \\
\hline $\mathrm{Fe}$ & ND & 21.3 & 42.6 & $\mathrm{mg} / \mathrm{kg}$ & 4 & \\
\hline $\mathrm{Pb}$ & ND & 2.13 & 4.26 & $\mathrm{mg} / \mathrm{kg}$ & 4 & \\
\hline $\mathrm{P}$ & 243 & 213 & 426 & $\mathrm{mg} / \mathrm{kg}$ & 4 & $\mathrm{~J}$ \\
\hline $\mathrm{Mg}$ & 111 & 107 & 213 & $\mathrm{mg} / \mathrm{kg}$ & 4 & $\mathrm{~J}$ \\
\hline $\mathrm{Mn}$ & ND & 2.13 & 4.26 & $\mathrm{mg} / \mathrm{kg}$ & 4 & \\
\hline Mo & ND & 2.13 & 4.26 & $\mathrm{mg} / \mathrm{kg}$ & 4 & \\
\hline $\mathrm{Ni}$ & ND & 2.13 & 4.26 & $\mathrm{mg} / \mathrm{kg}$ & 4 & \\
\hline $\mathrm{K}$ & 1220 & 107 & 213 & $\mathrm{mg} / \mathrm{kg}$ & 4 & \\
\hline $\mathrm{Se}$ & ND & 2.13 & 8.53 & $\mathrm{mg} / \mathrm{kg}$ & 4 & \\
\hline $\mathrm{Na}$ & 141 & 107 & 213 & $\mathrm{mg} / \mathrm{kg}$ & 4 & B-02, J \\
\hline $\mathrm{V}$ & ND & 2.13 & 4.26 & $\mathrm{mg} / \mathrm{kg}$ & 4 & \\
\hline $\mathrm{Zn}$ & ND & 2.13 & 4.26 & $\mathrm{mg} / \mathrm{kg}$ & 4 & \\
\hline
\end{tabular}


Table 132. Chemical analysis using ICP-MS for the grape sample from Lange Estate, Freedom Hill Vineyard (LEFH). ND - Non-detect.

\begin{tabular}{|c|c|c|c|c|c|c|}
\hline \multicolumn{7}{|c|}{ Lab ID A4A0576-10 LEFH } \\
\hline Analyte & Result & Detection Limit & Reporting Limit & Units & Dilution & Analyst Notes \\
\hline S & ND & 102 & 205 & $\mathrm{mg} / \mathrm{kg}$ & 4 & \\
\hline $\mathrm{Hg}$ & ND & 0.0410 & 0.0820 & $\mathrm{mg} / \mathrm{kg}$ & 10 & Q-41 \\
\hline $\mathrm{Sr}$ & 0.697 & 0.205 & 0.410 & $\mathrm{mg} / \mathrm{kg}$ & 4 & \\
\hline $\mathrm{Al}$ & ND & 102 & 205 & $\mathrm{mg} / \mathrm{kg}$ & 4 & \\
\hline As & ND & 2.05 & 8.20 & $\mathrm{mg} / \mathrm{kg}$ & 4 & \\
\hline $\mathrm{Ba}$ & ND & 2.05 & 4.10 & $\mathrm{mg} / \mathrm{kg}$ & 4 & \\
\hline $\mathrm{Be}$ & ND & 2.05 & 4.10 & $\mathrm{mg} / \mathrm{kg}$ & 4 & \\
\hline $\mathrm{Cd}$ & ND & 2.05 & 4.10 & $\mathrm{mg} / \mathrm{kg}$ & 4 & \\
\hline $\mathrm{Ca}$ & ND & 102 & 205 & $\mathrm{mg} / \mathrm{kg}$ & 4 & \\
\hline $\mathrm{Cr}$ & ND & 2.05 & 4.10 & $\mathrm{mg} / \mathrm{kg}$ & 4 & \\
\hline Co & ND & 2.05 & 4.10 & $\mathrm{mg} / \mathrm{kg}$ & 4 & \\
\hline $\mathrm{Cu}$ & ND & 2.05 & 4.10 & $\mathrm{mg} / \mathrm{kg}$ & 4 & \\
\hline $\mathrm{Fe}$ & ND & 20.5 & 41.0 & $\mathrm{mg} / \mathrm{kg}$ & 4 & \\
\hline $\mathrm{Pb}$ & ND & 2.05 & 4.10 & $\mathrm{mg} / \mathrm{kg}$ & 4 & \\
\hline $\mathrm{P}$ & 266 & 205 & 410 & $\mathrm{mg} / \mathrm{kg}$ & 4 & $\mathrm{~J}$ \\
\hline $\mathrm{Mg}$ & ND & 102 & 205 & $\mathrm{mg} / \mathrm{kg}$ & 4 & \\
\hline $\mathrm{Mn}$ & ND & 2.05 & 4.10 & $\mathrm{mg} / \mathrm{kg}$ & 4 & \\
\hline Mo & ND & 2.05 & 4.10 & $\mathrm{mg} / \mathrm{kg}$ & 4 & \\
\hline $\mathrm{Ni}$ & ND & 2.05 & 4.10 & $\mathrm{mg} / \mathrm{kg}$ & 4 & \\
\hline $\mathrm{K}$ & 1380 & 102 & 205 & $\mathrm{mg} / \mathrm{kg}$ & 4 & \\
\hline $\mathrm{Se}$ & ND & 2.05 & 8.20 & $\mathrm{mg} / \mathrm{kg}$ & 4 & \\
\hline $\mathrm{Na}$ & 150 & 102 & 205 & $\mathrm{mg} / \mathrm{kg}$ & 4 & B-02, J \\
\hline V & ND & 2.05 & 4.10 & $\mathrm{mg} / \mathrm{kg}$ & 4 & \\
\hline $\mathrm{Zn}$ & ND & 2.05 & 4.10 & $\mathrm{mg} / \mathrm{kg}$ & 4 & \\
\hline
\end{tabular}


Table 133. Chemical analysis using ICP-MS for the grape sample from Rex Hill, Sims Vineyard (RHSB). ND - Non-detect.

\begin{tabular}{|c|c|c|c|c|c|c|}
\hline \multicolumn{7}{|c|}{ Lab ID A4A0576-17 RHSB } \\
\hline Analyte & Result & Detection Limit & Reporting Limit & Units & Dilution & Analyst Notes \\
\hline S & ND & 101 & 202 & $\mathrm{mg} / \mathrm{kg}$ & 4 & \\
\hline $\mathrm{Hg}$ & ND & 0.0403 & 0.0806 & $\mathrm{mg} / \mathrm{kg}$ & 10 & Q-41 \\
\hline $\mathrm{Sr}$ & 0.645 & 0.202 & 0.403 & $\mathrm{mg} / \mathrm{kg}$ & 4 & \\
\hline $\mathrm{Al}$ & ND & 101 & 202 & $\mathrm{mg} / \mathrm{kg}$ & 4 & \\
\hline As & ND & 2.02 & 8.06 & $\mathrm{mg} / \mathrm{kg}$ & 4 & \\
\hline $\mathrm{Ba}$ & ND & 2.02 & 4.03 & $\mathrm{mg} / \mathrm{kg}$ & 4 & \\
\hline $\mathrm{Be}$ & ND & 2.02 & 4.03 & $\mathrm{mg} / \mathrm{kg}$ & 4 & \\
\hline $\mathrm{Cd}$ & ND & 2.02 & 4.03 & $\mathrm{mg} / \mathrm{kg}$ & 4 & \\
\hline $\mathrm{Ca}$ & ND & 101 & 202 & $\mathrm{mg} / \mathrm{kg}$ & 4 & \\
\hline $\mathrm{Cr}$ & ND & 2.02 & 4.03 & $\mathrm{mg} / \mathrm{kg}$ & 4 & \\
\hline Co & ND & 2.02 & 4.03 & $\mathrm{mg} / \mathrm{kg}$ & 4 & \\
\hline $\mathrm{Cu}$ & ND & 2.02 & 4.03 & $\mathrm{mg} / \mathrm{kg}$ & 4 & \\
\hline $\mathrm{Fe}$ & ND & 20.2 & 40.3 & $\mathrm{mg} / \mathrm{kg}$ & 4 & \\
\hline $\mathrm{Pb}$ & ND & 2.02 & 4.03 & $\mathrm{mg} / \mathrm{kg}$ & 4 & \\
\hline $\mathrm{P}$ & ND & 202 & 403 & $\mathrm{mg} / \mathrm{kg}$ & 4 & \\
\hline $\mathrm{Mg}$ & ND & 101 & 202 & $\mathrm{mg} / \mathrm{kg}$ & 4 & \\
\hline $\mathrm{Mn}$ & 2.02 & 2.02 & 4.03 & $\mathrm{mg} / \mathrm{kg}$ & 4 & $\mathrm{~J}$ \\
\hline Mo & ND & 2.02 & 4.03 & $\mathrm{mg} / \mathrm{kg}$ & 4 & \\
\hline $\mathrm{Ni}$ & ND & 2.02 & 4.03 & $\mathrm{mg} / \mathrm{kg}$ & 4 & \\
\hline K & 747 & 101 & 202 & $\mathrm{mg} / \mathrm{kg}$ & 4 & \\
\hline $\mathrm{Se}$ & ND & 2.02 & 8.06 & $\mathrm{mg} / \mathrm{kg}$ & 4 & \\
\hline $\mathrm{Na}$ & 142 & 101 & 202 & $\mathrm{mg} / \mathrm{kg}$ & 4 & B-02, J \\
\hline $\mathrm{V}$ & ND & 2.02 & 4.03 & $\mathrm{mg} / \mathrm{kg}$ & 4 & \\
\hline $\mathrm{Zn}$ & ND & 2.02 & 4.03 & $\mathrm{mg} / \mathrm{kg}$ & 4 & \\
\hline
\end{tabular}


Table 134. Chemical analysis using ICP-MS for the grape sample from Rex Hill, Estate Vineyard (RHB12). ND - Non-detect.

\begin{tabular}{|c|c|c|c|c|c|c|}
\hline \multicolumn{7}{|c|}{ Lab ID A4A0576-18 RHB12 } \\
\hline Analyte & Result & Detection Limit & Reporting Limit & Units & Dilution & Analyst Notes \\
\hline S & ND & 96.7 & 193 & $\mathrm{mg} / \mathrm{kg}$ & 4 & \\
\hline $\mathrm{Hg}$ & ND & 0.0387 & 0.0774 & $\mathrm{mg} / \mathrm{kg}$ & 10 & Q-41 \\
\hline $\mathrm{Sr}$ & 0.696 & 0.193 & 0.387 & $\mathrm{mg} / \mathrm{kg}$ & 4 & \\
\hline $\mathrm{Al}$ & ND & 96.7 & 193 & $\mathrm{mg} / \mathrm{kg}$ & 4 & \\
\hline As & ND & 1.93 & 7.74 & $\mathrm{mg} / \mathrm{kg}$ & 4 & \\
\hline $\mathrm{Ba}$ & ND & 1.93 & 3.87 & $\mathrm{mg} / \mathrm{kg}$ & 4 & \\
\hline $\mathrm{Be}$ & ND & 1.93 & 3.87 & $\mathrm{mg} / \mathrm{kg}$ & 4 & \\
\hline $\mathrm{Cd}$ & ND & 1.93 & 3.87 & $\mathrm{mg} / \mathrm{kg}$ & 4 & \\
\hline $\mathrm{Ca}$ & ND & 96.7 & 193 & $\mathrm{mg} / \mathrm{kg}$ & 4 & \\
\hline $\mathrm{Cr}$ & ND & 1.93 & 3.87 & $\mathrm{mg} / \mathrm{kg}$ & 4 & \\
\hline Co & ND & 1.93 & 3.87 & $\mathrm{mg} / \mathrm{kg}$ & 4 & \\
\hline $\mathrm{Cu}$ & ND & 1.93 & 3.87 & $\mathrm{mg} / \mathrm{kg}$ & 4 & \\
\hline $\mathrm{Fe}$ & ND & 19.3 & 38.7 & $\mathrm{mg} / \mathrm{kg}$ & 4 & \\
\hline $\mathrm{Pb}$ & ND & 1.93 & 3.87 & $\mathrm{mg} / \mathrm{kg}$ & 4 & \\
\hline $\mathrm{P}$ & 361 & 193 & 387 & $\mathrm{mg} / \mathrm{kg}$ & 4 & $\mathrm{~J}$ \\
\hline $\mathrm{Mg}$ & ND & 96.7 & 193 & $\mathrm{mg} / \mathrm{kg}$ & 4 & \\
\hline $\mathrm{Mn}$ & ND & 1.93 & 3.87 & $\mathrm{mg} / \mathrm{kg}$ & 4 & \\
\hline Mo & ND & 1.93 & 3.87 & $\mathrm{mg} / \mathrm{kg}$ & 4 & \\
\hline $\mathrm{Ni}$ & ND & 1.93 & 3.87 & $\mathrm{mg} / \mathrm{kg}$ & 4 & \\
\hline $\mathrm{K}$ & 1600 & 96.7 & 193 & $\mathrm{mg} / \mathrm{kg}$ & 4 & \\
\hline $\mathrm{Se}$ & ND & 1.93 & 7.74 & $\mathrm{mg} / \mathrm{kg}$ & 4 & \\
\hline $\mathrm{Na}$ & 139 & 96.7 & 193 & $\mathrm{mg} / \mathrm{kg}$ & 4 & B-02, J \\
\hline V & ND & 1.93 & 3.87 & $\mathrm{mg} / \mathrm{kg}$ & 4 & \\
\hline $\mathrm{Zn}$ & ND & 1.93 & 3.87 & $\mathrm{mg} / \mathrm{kg}$ & 4 & \\
\hline
\end{tabular}


Table 135. Chemical analysis using ICP-MS for the grape sample from Rex Hill, Jacob-Hart Vineyard Block 1 (RHJH1). ND - Non-detect.

\begin{tabular}{|c|c|c|c|c|c|c|}
\hline \multicolumn{7}{|c|}{ Lab ID A4A0576-15 RHJH1 } \\
\hline Analyte & Result & Detection Limit & Reporting Limit & Units & Dilution & Analyst Notes \\
\hline S & ND & 108 & 216 & $\mathrm{mg} / \mathrm{kg}$ & 4 & \\
\hline $\mathrm{Hg}$ & ND & 0.0431 & 0.0862 & $\mathrm{mg} / \mathrm{kg}$ & 10 & Q-41 \\
\hline $\mathrm{Sr}$ & 1.12 & 0.216 & 0.431 & $\mathrm{mg} / \mathrm{kg}$ & 4 & \\
\hline $\mathrm{Al}$ & ND & 108 & 216 & $\mathrm{mg} / \mathrm{kg}$ & 4 & \\
\hline As & ND & 2.16 & 8.62 & $\mathrm{mg} / \mathrm{kg}$ & 4 & \\
\hline $\mathrm{Ba}$ & ND & 2.16 & 4.31 & $\mathrm{mg} / \mathrm{kg}$ & 4 & \\
\hline $\mathrm{Be}$ & ND & 2.16 & 4.31 & $\mathrm{mg} / \mathrm{kg}$ & 4 & \\
\hline $\mathrm{Cd}$ & ND & 2.16 & 4.31 & $\mathrm{mg} / \mathrm{kg}$ & 4 & \\
\hline $\mathrm{Ca}$ & ND & 108 & 216 & $\mathrm{mg} / \mathrm{kg}$ & 4 & \\
\hline $\mathrm{Cr}$ & ND & 2.16 & 4.31 & $\mathrm{mg} / \mathrm{kg}$ & 4 & \\
\hline Co & ND & 2.16 & 4.31 & $\mathrm{mg} / \mathrm{kg}$ & 4 & \\
\hline $\mathrm{Cu}$ & 2.41 & 2.16 & 4.31 & $\mathrm{mg} / \mathrm{kg}$ & 4 & $\mathrm{~J}$ \\
\hline $\mathrm{Fe}$ & ND & 21.6 & 43.1 & $\mathrm{mg} / \mathrm{kg}$ & 4 & \\
\hline $\mathrm{Pb}$ & ND & 2.16 & 4.31 & $\mathrm{mg} / \mathrm{kg}$ & 4 & \\
\hline $\mathrm{P}$ & 297 & 216 & 431 & $\mathrm{mg} / \mathrm{kg}$ & 4 & $\mathrm{~J}$ \\
\hline $\mathrm{Mg}$ & ND & 108 & 216 & $\mathrm{mg} / \mathrm{kg}$ & 4 & \\
\hline $\mathrm{Mn}$ & ND & 2.16 & 4.31 & $\mathrm{mg} / \mathrm{kg}$ & 4 & \\
\hline Mo & ND & 2.16 & 4.31 & $\mathrm{mg} / \mathrm{kg}$ & 4 & \\
\hline $\mathrm{Ni}$ & ND & 2.16 & 4.31 & $\mathrm{mg} / \mathrm{kg}$ & 4 & \\
\hline $\mathrm{K}$ & 1880 & 108 & 216 & $\mathrm{mg} / \mathrm{kg}$ & 4 & \\
\hline $\mathrm{Se}$ & ND & 2.16 & 8.62 & $\mathrm{mg} / \mathrm{kg}$ & 4 & \\
\hline $\mathrm{Na}$ & 140 & 108 & 216 & $\mathrm{mg} / \mathrm{kg}$ & 4 & B-02, J \\
\hline V & ND & 2.16 & 4.31 & $\mathrm{mg} / \mathrm{kg}$ & 4 & \\
\hline $\mathrm{Zn}$ & ND & 2.16 & 4.31 & $\mathrm{mg} / \mathrm{kg}$ & 4 & \\
\hline
\end{tabular}


Table 136. Chemical analysis using ICP-MS for the grape sample from Rex Hill, Jacob-Hart Vineyard Block 5 (RHJH5). ND - Non-detect.

\begin{tabular}{|c|c|c|c|c|c|c|}
\hline \multicolumn{7}{|c|}{ Lab ID A4A0576-16 RHJH5 } \\
\hline Analyte & Result & Detection Limit & Reporting Limit & Units & Dilution & Analyst Notes \\
\hline $\mathrm{S}$ & ND & 102 & 203 & $\mathrm{mg} / \mathrm{kg}$ & 4 & \\
\hline $\mathrm{Hg}$ & ND & 0.0407 & 0.0813 & $\mathrm{mg} / \mathrm{kg}$ & 10 & Q-41 \\
\hline $\mathrm{Sr}$ & 0.447 & 0.203 & 0.407 & $\mathrm{mg} / \mathrm{kg}$ & 4 & \\
\hline $\mathrm{Al}$ & ND & 102 & 203 & $\mathrm{mg} / \mathrm{kg}$ & 4 & \\
\hline As & ND & 2.03 & 8.13 & $\mathrm{mg} / \mathrm{kg}$ & 4 & \\
\hline $\mathrm{Ba}$ & ND & 2.03 & 4.07 & $\mathrm{mg} / \mathrm{kg}$ & 4 & \\
\hline $\mathrm{Be}$ & ND & 2.03 & 4.07 & $\mathrm{mg} / \mathrm{kg}$ & 4 & \\
\hline $\mathrm{Cd}$ & ND & 2.03 & 4.07 & $\mathrm{mg} / \mathrm{kg}$ & 4 & \\
\hline $\mathrm{Ca}$ & ND & 102 & 203 & $\mathrm{mg} / \mathrm{kg}$ & 4 & \\
\hline $\mathrm{Cr}$ & ND & 2.03 & 4.07 & $\mathrm{mg} / \mathrm{kg}$ & 4 & \\
\hline Co & ND & 2.03 & 4.07 & $\mathrm{mg} / \mathrm{kg}$ & 4 & \\
\hline $\mathrm{Cu}$ & 4.19 & 2.03 & 4.07 & $\mathrm{mg} / \mathrm{kg}$ & 4 & \\
\hline $\mathrm{Fe}$ & ND & 20.3 & 40.7 & $\mathrm{mg} / \mathrm{kg}$ & 4 & \\
\hline $\mathrm{Pb}$ & ND & 2.03 & 4.07 & $\mathrm{mg} / \mathrm{kg}$ & 4 & \\
\hline $\mathrm{P}$ & 272 & 203 & 407 & $\mathrm{mg} / \mathrm{kg}$ & 4 & $\mathrm{~J}$ \\
\hline $\mathrm{Mg}$ & ND & 102 & 203 & $\mathrm{mg} / \mathrm{kg}$ & 4 & \\
\hline $\mathrm{Mn}$ & ND & 2.03 & 4.07 & $\mathrm{mg} / \mathrm{kg}$ & 4 & \\
\hline Mo & ND & 2.03 & 4.07 & $\mathrm{mg} / \mathrm{kg}$ & 4 & \\
\hline $\mathrm{Ni}$ & ND & 2.03 & 4.07 & $\mathrm{mg} / \mathrm{kg}$ & 4 & \\
\hline $\mathrm{K}$ & 1500 & 102 & 203 & $\mathrm{mg} / \mathrm{kg}$ & 4 & \\
\hline $\mathrm{Se}$ & ND & 2.03 & 8.13 & $\mathrm{mg} / \mathrm{kg}$ & 4 & \\
\hline $\mathrm{Na}$ & 131 & 102 & 203 & $\mathrm{mg} / \mathrm{kg}$ & 4 & B-02, J \\
\hline V & ND & 2.03 & 4.07 & $\mathrm{mg} / \mathrm{kg}$ & 4 & \\
\hline $\mathrm{Zn}$ & 2.20 & 2.03 & 4.07 & $\mathrm{mg} / \mathrm{kg}$ & 4 & $\mathrm{~J}$ \\
\hline
\end{tabular}


Table 137. Chemical analysis using ICP-MS for the grape sample from Ken Wright Cellars, Nysa Vineyard (KWNM). ND - Non-detect.

\begin{tabular}{|c|c|c|c|c|c|c|}
\hline \multicolumn{7}{|c|}{ Lab ID A4A0576-19 KWNM } \\
\hline Analyte & Result & Detection Limit & Reporting Limit & Units & Dilution & Analyst Notes \\
\hline S & ND & 102 & 204 & $\mathrm{mg} / \mathrm{kg}$ & 4 & \\
\hline $\mathrm{Hg}$ & ND & 0.0407 & 0.0815 & $\mathrm{mg} / \mathrm{kg}$ & 10 & Q-41 \\
\hline $\mathrm{Sr}$ & 1.14 & 0.204 & 0.407 & $\mathrm{mg} / \mathrm{kg}$ & 4 & \\
\hline $\mathrm{Al}$ & ND & 102 & 204 & $\mathrm{mg} / \mathrm{kg}$ & 4 & \\
\hline As & ND & 2.04 & 8.15 & $\mathrm{mg} / \mathrm{kg}$ & 4 & \\
\hline $\mathrm{Ba}$ & ND & 2.04 & 4.07 & $\mathrm{mg} / \mathrm{kg}$ & 4 & \\
\hline $\mathrm{Be}$ & ND & 2.04 & 4.07 & $\mathrm{mg} / \mathrm{kg}$ & 4 & \\
\hline $\mathrm{Cd}$ & ND & 2.04 & 4.07 & $\mathrm{mg} / \mathrm{kg}$ & 4 & \\
\hline $\mathrm{Ca}$ & 102 & 102 & 204 & $\mathrm{mg} / \mathrm{kg}$ & 4 & $\mathrm{~J}$ \\
\hline $\mathrm{Cr}$ & ND & 2.04 & 4.07 & $\mathrm{mg} / \mathrm{kg}$ & 4 & \\
\hline Co & ND & 2.04 & 4.07 & $\mathrm{mg} / \mathrm{kg}$ & 4 & \\
\hline $\mathrm{Cu}$ & ND & 2.04 & 4.07 & $\mathrm{mg} / \mathrm{kg}$ & 4 & \\
\hline $\mathrm{Fe}$ & ND & 20.4 & 40.7 & $\mathrm{mg} / \mathrm{kg}$ & 4 & \\
\hline $\mathrm{Pb}$ & ND & 2.04 & 4.07 & $\mathrm{mg} / \mathrm{kg}$ & 4 & \\
\hline $\mathrm{P}$ & 257 & 204 & 407 & $\mathrm{mg} / \mathrm{kg}$ & 4 & $\mathrm{~J}$ \\
\hline $\mathrm{Mg}$ & ND & 102 & 204 & $\mathrm{mg} / \mathrm{kg}$ & 4 & \\
\hline $\mathrm{Mn}$ & ND & 2.04 & 4.07 & $\mathrm{mg} / \mathrm{kg}$ & 4 & \\
\hline Mo & ND & 2.04 & 4.07 & $\mathrm{mg} / \mathrm{kg}$ & 4 & \\
\hline $\mathrm{Ni}$ & ND & 2.04 & 4.07 & $\mathrm{mg} / \mathrm{kg}$ & 4 & \\
\hline $\mathrm{K}$ & 1070 & 102 & 204 & $\mathrm{mg} / \mathrm{kg}$ & 4 & \\
\hline $\mathrm{Se}$ & ND & 2.04 & 8.15 & $\mathrm{mg} / \mathrm{kg}$ & 4 & \\
\hline $\mathrm{Na}$ & 138 & 102 & 204 & $\mathrm{mg} / \mathrm{kg}$ & 4 & B-02, J \\
\hline V & ND & 2.04 & 4.07 & $\mathrm{mg} / \mathrm{kg}$ & 4 & \\
\hline $\mathrm{Zn}$ & ND & 2.04 & 4.07 & $\mathrm{mg} / \mathrm{kg}$ & 4 & \\
\hline
\end{tabular}


Table 138. Chemical analysis using ICP-MS for the grape sample from Ken Wright Cellars, Abbott Claim Vineyard (KWAC). ND - Non-detect.

\begin{tabular}{|c|c|c|c|c|c|c|}
\hline \multicolumn{7}{|c|}{ Lab ID A4A0576-20 KWAC } \\
\hline Analyte & Result & Detection Limit & Reporting Limit & Units & Dilution & Analyst Notes \\
\hline $\mathrm{S}$ & ND & 111 & 222 & $\mathrm{mg} / \mathrm{kg}$ & 4 & \\
\hline $\mathrm{Hg}$ & ND & 0.0444 & 0.0889 & $\mathrm{mg} / \mathrm{kg}$ & 10 & Q-41 \\
\hline $\mathrm{Sr}$ & 0.844 & 0.222 & 0.444 & $\mathrm{mg} / \mathrm{kg}$ & 4 & \\
\hline $\mathrm{Al}$ & ND & 111 & 222 & $\mathrm{mg} / \mathrm{kg}$ & 4 & \\
\hline As & ND & 2.22 & 8.89 & $\mathrm{mg} / \mathrm{kg}$ & 4 & \\
\hline $\mathrm{Ba}$ & ND & 2.22 & 4.44 & $\mathrm{mg} / \mathrm{kg}$ & 4 & \\
\hline $\mathrm{Be}$ & ND & 2.22 & 4.44 & $\mathrm{mg} / \mathrm{kg}$ & 4 & \\
\hline $\mathrm{Cd}$ & ND & 2.22 & 4.44 & $\mathrm{mg} / \mathrm{kg}$ & 4 & \\
\hline $\mathrm{Ca}$ & ND & 111 & 222 & $\mathrm{mg} / \mathrm{kg}$ & 4 & \\
\hline $\mathrm{Cr}$ & ND & 2.22 & 4.44 & $\mathrm{mg} / \mathrm{kg}$ & 4 & \\
\hline Co & ND & 2.22 & 4.44 & $\mathrm{mg} / \mathrm{kg}$ & 4 & \\
\hline $\mathrm{Cu}$ & ND & 2.22 & 4.44 & $\mathrm{mg} / \mathrm{kg}$ & 4 & \\
\hline $\mathrm{Fe}$ & ND & 22.2 & 44.4 & $\mathrm{mg} / \mathrm{kg}$ & 4 & \\
\hline $\mathrm{Pb}$ & ND & 2.22 & 4.44 & $\mathrm{mg} / \mathrm{kg}$ & 4 & \\
\hline $\mathrm{P}$ & ND & 222 & 444 & $\mathrm{mg} / \mathrm{kg}$ & 4 & \\
\hline $\mathrm{Mg}$ & ND & 111 & 222 & $\mathrm{mg} / \mathrm{kg}$ & 4 & \\
\hline $\mathrm{Mn}$ & ND & 2.22 & 4.44 & $\mathrm{mg} / \mathrm{kg}$ & 4 & \\
\hline Mo & ND & 2.22 & 4.44 & $\mathrm{mg} / \mathrm{kg}$ & 4 & \\
\hline $\mathrm{Ni}$ & ND & 2.22 & 4.44 & $\mathrm{mg} / \mathrm{kg}$ & 4 & \\
\hline $\mathrm{K}$ & 1730 & 111 & 222 & $\mathrm{mg} / \mathrm{kg}$ & 4 & \\
\hline $\mathrm{Se}$ & ND & 2.22 & 8.89 & $\mathrm{mg} / \mathrm{kg}$ & 4 & \\
\hline $\mathrm{Na}$ & 166 & 111 & 222 & $\mathrm{mg} / \mathrm{kg}$ & 4 & B- $02, \mathrm{~J}$ \\
\hline V & ND & 2.22 & 4.44 & $\mathrm{mg} / \mathrm{kg}$ & 4 & \\
\hline $\mathrm{Zn}$ & ND & 2.22 & 4.44 & $\mathrm{mg} / \mathrm{kg}$ & 4 & \\
\hline
\end{tabular}


Table 139. Chemical analysis using ICP-MS for the grape sample from Ken Wright Cellars, Freedom Hill Vineyard (KWFH). ND - Non-detect.

\begin{tabular}{|c|c|c|c|c|c|c|}
\hline \multicolumn{7}{|c|}{ Lab ID A4A0576-14 KWFH } \\
\hline Analyte & Result & Detection Limit & Reporting Limit & Units & Dilution & Analyst Notes \\
\hline S & ND & 97.1 & 194 & $\mathrm{mg} / \mathrm{kg}$ & 4 & \\
\hline $\mathrm{Hg}$ & ND & 0.0388 & 0.0777 & $\mathrm{mg} / \mathrm{kg}$ & 10 & Q-41 \\
\hline $\mathrm{Sr}$ & 0.816 & 0.194 & 0.388 & $\mathrm{mg} / \mathrm{kg}$ & 4 & \\
\hline $\mathrm{Al}$ & ND & 97.1 & 194 & $\mathrm{mg} / \mathrm{kg}$ & 4 & \\
\hline As & ND & 1.94 & 7.77 & $\mathrm{mg} / \mathrm{kg}$ & 4 & \\
\hline $\mathrm{Ba}$ & ND & 1.94 & 3.88 & $\mathrm{mg} / \mathrm{kg}$ & 4 & \\
\hline $\mathrm{Be}$ & ND & 1.94 & 3.88 & $\mathrm{mg} / \mathrm{kg}$ & 4 & \\
\hline $\mathrm{Cd}$ & ND & 1.94 & 3.88 & $\mathrm{mg} / \mathrm{kg}$ & 4 & \\
\hline $\mathrm{Ca}$ & ND & 97.1 & 194 & $\mathrm{mg} / \mathrm{kg}$ & 4 & \\
\hline $\mathrm{Cr}$ & ND & 1.94 & 3.88 & $\mathrm{mg} / \mathrm{kg}$ & 4 & \\
\hline Co & ND & 1.94 & 3.88 & $\mathrm{mg} / \mathrm{kg}$ & 4 & \\
\hline $\mathrm{Cu}$ & ND & 1.94 & 3.88 & $\mathrm{mg} / \mathrm{kg}$ & 4 & \\
\hline $\mathrm{Fe}$ & ND & 19.4 & 38.8 & $\mathrm{mg} / \mathrm{kg}$ & 4 & \\
\hline $\mathrm{Pb}$ & ND & 1.94 & 3.88 & $\mathrm{mg} / \mathrm{kg}$ & 4 & \\
\hline $\mathrm{P}$ & ND & 194 & 388 & $\mathrm{mg} / \mathrm{kg}$ & 4 & \\
\hline $\mathrm{Mg}$ & ND & 97.1 & 194 & $\mathrm{mg} / \mathrm{kg}$ & 4 & \\
\hline $\mathrm{Mn}$ & ND & 1.94 & 3.88 & $\mathrm{mg} / \mathrm{kg}$ & 4 & \\
\hline Mo & ND & 1.94 & 3.88 & $\mathrm{mg} / \mathrm{kg}$ & 4 & \\
\hline $\mathrm{Ni}$ & ND & 1.94 & 3.88 & $\mathrm{mg} / \mathrm{kg}$ & 4 & \\
\hline $\mathrm{K}$ & 1160 & 97.1 & 194 & $\mathrm{mg} / \mathrm{kg}$ & 4 & \\
\hline $\mathrm{Se}$ & ND & 1.94 & 7.77 & $\mathrm{mg} / \mathrm{kg}$ & 4 & \\
\hline $\mathrm{Na}$ & 126 & 97.1 & 194 & $\mathrm{mg} / \mathrm{kg}$ & 4 & B-02, J \\
\hline V & ND & 1.94 & 3.88 & $\mathrm{mg} / \mathrm{kg}$ & 4 & \\
\hline $\mathrm{Zn}$ & ND & 1.94 & 3.88 & $\mathrm{mg} / \mathrm{kg}$ & 4 & \\
\hline
\end{tabular}


Table 140. Chemical analysis using ICP-MS for the grape sample from Ken Wright Cellars, Meredith Mitchell Vineyard (KWMM). ND - Non-detect.

\begin{tabular}{|c|c|c|c|c|c|c|}
\hline \multicolumn{7}{|c|}{ Lab ID A4A0576-13 KWMM } \\
\hline Analyte & Result & Detection Limit & Reporting Limit & Units & Dilution & Analyst Notes \\
\hline $\mathrm{S}$ & ND & 104 & 207 & $\mathrm{mg} / \mathrm{kg}$ & 4 & \\
\hline $\mathrm{Hg}$ & ND & 0.0415 & 0.0830 & $\mathrm{mg} / \mathrm{kg}$ & 10 & Q-41 \\
\hline $\mathrm{Sr}$ & 0.332 & 0.207 & 0.415 & $\mathrm{mg} / \mathrm{kg}$ & 4 & $\mathrm{~J}$ \\
\hline $\mathrm{Al}$ & ND & 104 & 207 & $\mathrm{mg} / \mathrm{kg}$ & 4 & \\
\hline As & ND & 2.07 & 8.30 & $\mathrm{mg} / \mathrm{kg}$ & 4 & \\
\hline $\mathrm{Ba}$ & ND & 2.07 & 4.15 & $\mathrm{mg} / \mathrm{kg}$ & 4 & \\
\hline $\mathrm{Be}$ & ND & 2.07 & 4.15 & $\mathrm{mg} / \mathrm{kg}$ & 4 & \\
\hline $\mathrm{Cd}$ & ND & 2.07 & 4.15 & $\mathrm{mg} / \mathrm{kg}$ & 4 & \\
\hline $\mathrm{Ca}$ & ND & 104 & 207 & $\mathrm{mg} / \mathrm{kg}$ & 4 & \\
\hline $\mathrm{Cr}$ & ND & 2.07 & 4.15 & $\mathrm{mg} / \mathrm{kg}$ & 4 & \\
\hline Co & ND & 2.07 & 4.15 & $\mathrm{mg} / \mathrm{kg}$ & 4 & \\
\hline $\mathrm{Cu}$ & ND & 2.07 & 4.15 & $\mathrm{mg} / \mathrm{kg}$ & 4 & \\
\hline $\mathrm{Fe}$ & ND & 20.7 & 41.5 & $\mathrm{mg} / \mathrm{kg}$ & 4 & \\
\hline $\mathrm{Pb}$ & ND & 2.07 & 4.15 & $\mathrm{mg} / \mathrm{kg}$ & 4 & \\
\hline $\mathrm{P}$ & 328 & 207 & 415 & $\mathrm{mg} / \mathrm{kg}$ & 4 & $\mathrm{~J}$ \\
\hline $\mathrm{Mg}$ & ND & 104 & 207 & $\mathrm{mg} / \mathrm{kg}$ & 4 & \\
\hline $\mathrm{Mn}$ & ND & 2.07 & 4.15 & $\mathrm{mg} / \mathrm{kg}$ & 4 & \\
\hline Mo & ND & 2.07 & 4.15 & $\mathrm{mg} / \mathrm{kg}$ & 4 & \\
\hline $\mathrm{Ni}$ & ND & 2.07 & 4.15 & $\mathrm{mg} / \mathrm{kg}$ & 4 & \\
\hline K & 883 & 104 & 207 & $\mathrm{mg} / \mathrm{kg}$ & 4 & \\
\hline $\mathrm{Se}$ & ND & 2.07 & 8.30 & $\mathrm{mg} / \mathrm{kg}$ & 4 & \\
\hline $\mathrm{Na}$ & 156 & 104 & 207 & $\mathrm{mg} / \mathrm{kg}$ & 4 & B-02, J \\
\hline V & ND & 2.07 & 4.15 & $\mathrm{mg} / \mathrm{kg}$ & 4 & \\
\hline $\mathrm{Zn}$ & ND & 2.07 & 4.15 & $\mathrm{mg} / \mathrm{kg}$ & 4 & \\
\hline
\end{tabular}




\section{Appendix E Wine Chemistry Data}

All data from Apex Laboratories for the wine samples analyzed from vineyards in this study (Table 141 to Table 183). Wines were collected from vineyard owners or winemakers, stored until sensory analysis, then sampled when opened and delivered to the lab. The wine was analyzed using EPA method 6020A for ICP-MS (EPA, 1998). These methods were preceded by acid digestion using EPA method 3051a (EPA, 2007a). Analyst notes include E: Estimated value. The result is above the calibration range of the instrument, E-03: Result is reported as an estimated value. QA protocols have not been met for this analyte, $\mathrm{H}-01$ : This sample was analyzed outside the recommended holding time, Q-41: Estimated results. Recover of continuing calibration verification sample above upper control limit. Results are likely biased high, Q-01: Spike recovery and/or RPD is outside acceptance limits, Q-02: Spike recovery is outside of established control limits due to matrix interference, Q-05: Analyses are not controlled on RPD values from sample or duplicate concentrations below 5 times the reporting limit, R-01: The reporting limit for this analyte has been raised to account for matrix interference, R-03: Elevated reporting limits due to limited sample volume, R-04: Reporting levels elevated due to dilution necessary for analysis. Multiple vintages were available from Chehalem and many wines were analyzed multiple times from the same bottle, unless otherwise noted. 
Table 141. Chemical analysis using ICP-MS for the small sample of the 2011 wine from Elk Cove Clay Court (ECCC) Vineyard. ND - Non-detect.

\begin{tabular}{|c|c|c|c|c|c|c|}
\hline \multicolumn{7}{|c|}{ Lab ID A4B0164-13-27 ECCC 11S } \\
\hline Analyte & Result & Detection Limit & Reporting Limit & Units & Dilution & Analyst Notes \\
\hline S & 50.4 & 2.25 & 2.25 & $\mathrm{mg} / \mathrm{L}$ & 1 & \\
\hline $\mathrm{Hg}$ & ND & 0.00180 & 0.00180 & $\mathrm{mg} / \mathrm{L}$ & 5 & H-01, R-04 \\
\hline $\mathrm{Sr}$ & 0.990 & 0.00405 & 0.00405 & $\mathrm{mg} / \mathrm{L}$ & 1 & \\
\hline $\mathrm{Al}$ & ND & 2.25 & 2.25 & $\mathrm{mg} / \mathrm{L}$ & 1 & \\
\hline As & ND & 4.50 & 4.50 & $\mathrm{mg} / \mathrm{L}$ & 1 & $\mathrm{R}-01$ \\
\hline $\mathrm{Ba}$ & 0.292 & 0.0450 & 0.0450 & $\mathrm{mg} / \mathrm{L}$ & 1 & \\
\hline $\mathrm{Be}$ & ND & 0.0450 & 0.0450 & $\mathrm{mg} / \mathrm{L}$ & 1 & \\
\hline $\mathrm{Cd}$ & ND & 0.0450 & 0.0450 & $\mathrm{mg} / \mathrm{L}$ & 1 & \\
\hline $\mathrm{Ca}$ & 37.5 & 2.25 & 2.25 & $\mathrm{mg} / \mathrm{L}$ & 1 & \\
\hline $\mathrm{Cr}$ & ND & 0.450 & 0.450 & $\mathrm{mg} / \mathrm{L}$ & 1 & $\mathrm{R}-01$ \\
\hline $\mathrm{Co}$ & ND & 0.0450 & 0.0450 & $\mathrm{mg} / \mathrm{L}$ & 1 & \\
\hline $\mathrm{Cu}$ & ND & 0.0450 & 0.0450 & $\mathrm{mg} / \mathrm{L}$ & 1 & \\
\hline $\mathrm{Fe}$ & 1.06 & 0.450 & 0.450 & $\mathrm{mg} / \mathrm{L}$ & 1 & \\
\hline $\mathrm{Pb}$ & ND & 0.0450 & 0.0450 & $\mathrm{mg} / \mathrm{L}$ & 1 & \\
\hline $\mathrm{Mg}$ & 53.4 & 2.25 & 2.25 & $\mathrm{mg} / \mathrm{L}$ & 1 & \\
\hline $\mathrm{Mn}$ & 1.38 & 0.0450 & 0.0450 & $\mathrm{mg} / \mathrm{L}$ & 1 & \\
\hline Mo & ND & 0.225 & 0.225 & $\mathrm{mg} / \mathrm{L}$ & 1 & \\
\hline $\mathrm{Ni}$ & ND & 0.0450 & 0.0450 & $\mathrm{mg} / \mathrm{L}$ & 1 & \\
\hline $\mathrm{P}$ & 46.7 & 2.25 & 2.25 & $\mathrm{mg} / \mathrm{L}$ & 1 & \\
\hline $\mathrm{K}$ & 413 & 2.25 & 2.25 & $\mathrm{mg} / \mathrm{L}$ & 1 & \\
\hline $\mathrm{Se}$ & ND & 9.00 & 9.00 & $\mathrm{mg} / \mathrm{L}$ & 1 & \\
\hline $\mathrm{Na}$ & 2.72 & 2.25 & 2.25 & $\mathrm{mg} / \mathrm{L}$ & 1 & \\
\hline V & ND & 0.0450 & 0.0450 & $\mathrm{mg} / \mathrm{L}$ & 1 & \\
\hline $\mathrm{Zn}$ & 0.0960 & 0.0450 & 0.0450 & $\mathrm{mg} / \mathrm{L}$ & 1 & \\
\hline
\end{tabular}


Table 142. Chemical analysis using ICP-MS for the bottle of the 2011 wine from Elk Cove Clay Court (ECCC) Vineyard. ND - Non-detect.

\begin{tabular}{|c|c|c|c|c|c|c|}
\hline \multicolumn{7}{|c|}{ Lab ID A4B0164-04-18 ECCC 11} \\
\hline Analyte & Result & Detection Limit & Reporting Limit & Units & Dilution & Analyst Notes \\
\hline S & 52.7 & 1.12 & 1.12 & $\mathrm{mg} / \mathrm{L}$ & 1 & \\
\hline $\mathrm{Hg}$ & ND & 0.000900 & 0.000900 & $\mathrm{mg} / \mathrm{L}$ & 5 & E-03, R-04 \\
\hline $\mathrm{Sr}$ & 0.973 & 0.00202 & 0.00202 & $\mathrm{mg} / \mathrm{L}$ & 1 & \\
\hline $\mathrm{Al}$ & ND & 1.12 & 1.12 & $\mathrm{mg} / \mathrm{L}$ & 1 & \\
\hline As & ND & 2.25 & 2.25 & $\mathrm{mg} / \mathrm{L}$ & 1 & R-01 \\
\hline $\mathrm{Ba}$ & 0.592 & 0.0225 & 0.0225 & $\mathrm{mg} / \mathrm{L}$ & 1 & \\
\hline $\mathrm{Be}$ & ND & 0.0225 & 0.0225 & $\mathrm{mg} / \mathrm{L}$ & 1 & \\
\hline $\mathrm{Cd}$ & ND & 0.0225 & 0.0225 & $\mathrm{mg} / \mathrm{L}$ & 1 & \\
\hline $\mathrm{Ca}$ & 28.8 & 1.12 & 1.12 & $\mathrm{mg} / \mathrm{L}$ & 1 & \\
\hline $\mathrm{Cr}$ & ND & 0.225 & 0.225 & $\mathrm{mg} / \mathrm{L}$ & 1 & R-01 \\
\hline Co & 0.0262 & 0.0225 & 0.0225 & $\mathrm{mg} / \mathrm{L}$ & 1 & \\
\hline $\mathrm{Cu}$ & 0.120 & 0.0225 & 0.0225 & $\mathrm{mg} / \mathrm{L}$ & 1 & \\
\hline $\mathrm{Fe}$ & 1.05 & 0.225 & 0.225 & $\mathrm{mg} / \mathrm{L}$ & 1 & \\
\hline $\mathrm{Pb}$ & 0.0598 & 0.0225 & 0.0225 & $\mathrm{mg} / \mathrm{L}$ & 1 & \\
\hline $\mathrm{Mg}$ & 39.0 & 1.12 & 1.12 & $\mathrm{mg} / \mathrm{L}$ & 1 & \\
\hline $\mathrm{Mn}$ & 1.19 & 0.0225 & 0.0225 & $\mathrm{mg} / \mathrm{L}$ & 1 & \\
\hline Mo & ND & 0.112 & 0.112 & $\mathrm{mg} / \mathrm{L}$ & 1 & \\
\hline $\mathrm{Ni}$ & ND & 0.0225 & 0.0225 & $\mathrm{mg} / \mathrm{L}$ & 1 & \\
\hline $\mathrm{P}$ & 99.3 & 1.12 & 1.12 & $\mathrm{mg} / \mathrm{L}$ & 1 & Q-41 \\
\hline $\mathrm{K}$ & 458 & 1.12 & 1.12 & $\mathrm{mg} / \mathrm{L}$ & 1 & \\
\hline $\mathrm{Se}$ & ND & 4.50 & 4.50 & $\mathrm{mg} / \mathrm{L}$ & 1 & Q-41 \\
\hline $\mathrm{Na}$ & 4.92 & 1.12 & 1.12 & $\mathrm{mg} / \mathrm{L}$ & 1 & \\
\hline V & ND & 0.0225 & 0.0225 & $\mathrm{mg} / \mathrm{L}$ & 1 & \\
\hline $\mathrm{Zn}$ & 0.204 & 0.0225 & 0.0225 & $\mathrm{mg} / \mathrm{L}$ & 1 & \\
\hline
\end{tabular}


Table 143. Chemical analysis using ICP-MS for the small sample of the 2011 wine from Elk Cove Roosevelt (ECRV) Vineyard. ND - Non-detect.

\begin{tabular}{|c|c|c|c|c|c|c|}
\hline \multicolumn{7}{|c|}{ Lab ID A4B0164-14 28 ECRV 11S } \\
\hline Analyte & Result & Detection Limit & Reporting Limit & Units & Dilution & Analyst Notes \\
\hline S & 76.8 & 2.25 & 2.25 & $\mathrm{mg} / \mathrm{L}$ & 1 & \\
\hline $\mathrm{Hg}$ & ND & 0.00180 & 0.00180 & $\mathrm{mg} / \mathrm{L}$ & 5 & H-01, R-04 \\
\hline $\mathrm{Sr}$ & 0.915 & 0.00405 & 0.00405 & $\mathrm{mg} / \mathrm{L}$ & 1 & \\
\hline $\mathrm{Al}$ & ND & 2.25 & 2.25 & $\mathrm{mg} / \mathrm{L}$ & 1 & \\
\hline As & ND & 4.50 & 4.50 & $\mathrm{mg} / \mathrm{L}$ & 1 & $\mathrm{R}-01$ \\
\hline $\mathrm{Ba}$ & 0.268 & 0.0450 & 0.0450 & $\mathrm{mg} / \mathrm{L}$ & 1 & \\
\hline $\mathrm{Be}$ & ND & 0.0450 & 0.0450 & $\mathrm{mg} / \mathrm{L}$ & 1 & \\
\hline $\mathrm{Cd}$ & ND & 0.0450 & 0.0450 & $\mathrm{mg} / \mathrm{L}$ & 1 & \\
\hline $\mathrm{Ca}$ & 46.1 & 2.25 & 2.25 & $\mathrm{mg} / \mathrm{L}$ & 1 & \\
\hline $\mathrm{Cr}$ & ND & 0.450 & 0.450 & $\mathrm{mg} / \mathrm{L}$ & 1 & R-01 \\
\hline Co & ND & 0.0450 & 0.0450 & $\mathrm{mg} / \mathrm{L}$ & 1 & \\
\hline $\mathrm{Cu}$ & 0.0460 & 0.0450 & 0.0450 & $\mathrm{mg} / \mathrm{L}$ & 1 & \\
\hline $\mathrm{Fe}$ & 0.738 & 0.450 & 0.450 & $\mathrm{mg} / \mathrm{L}$ & 1 & \\
\hline $\mathrm{Pb}$ & ND & 0.0450 & 0.0450 & $\mathrm{mg} / \mathrm{L}$ & 1 & \\
\hline $\mathrm{Mg}$ & 85.7 & 2.25 & 2.25 & $\mathrm{mg} / \mathrm{L}$ & 1 & \\
\hline $\mathrm{Mn}$ & 1.09 & 0.0450 & 0.0450 & $\mathrm{mg} / \mathrm{L}$ & 1 & \\
\hline Mo & ND & 0.225 & 0.225 & $\mathrm{mg} / \mathrm{L}$ & 1 & \\
\hline $\mathrm{Ni}$ & ND & 0.0450 & 0.0450 & $\mathrm{mg} / \mathrm{L}$ & 1 & \\
\hline $\mathrm{P}$ & 443 & 2.25 & 2.25 & $\mathrm{mg} / \mathrm{L}$ & 1 & \\
\hline $\mathrm{K}$ & 829 & 2.25 & 2.25 & $\mathrm{mg} / \mathrm{L}$ & 1 & \\
\hline $\mathrm{Se}$ & ND & 9.00 & 9.00 & $\mathrm{mg} / \mathrm{L}$ & 1 & \\
\hline $\mathrm{Na}$ & 2.59 & 2.25 & 2.25 & $\mathrm{mg} / \mathrm{L}$ & 1 & \\
\hline $\mathrm{V}$ & ND & 0.0450 & 0.0450 & $\mathrm{mg} / \mathrm{L}$ & 1 & \\
\hline $\mathrm{Zn}$ & 0.0785 & 0.0450 & 0.0450 & $\mathrm{mg} / \mathrm{L}$ & 1 & \\
\hline
\end{tabular}


Table 144. Chemical analysis using ICP-MS for the bottle of the 2011 wine from Elk Cove Roosevelt (ECRV) Vineyard. ND - Non-detect.

\begin{tabular}{|c|c|c|c|c|c|c|}
\hline \multicolumn{7}{|c|}{ Lab ID A4B0052-05 ECRV 2011} \\
\hline Analyte & Result & Detection Limit & Reporting Limit & Units & Dilution & Analyst Notes \\
\hline S & 74.6 & 1.12 & 1.12 & $\mathrm{mg} / \mathrm{L}$ & 1 & \\
\hline $\mathrm{Hg}$ & ND & 0.000900 & 0.000900 & $\mathrm{mg} / \mathrm{L}$ & 5 & H-01, R-04 \\
\hline $\mathrm{Sr}$ & 1.07 & 0.00202 & 0.00202 & $\mathrm{mg} / \mathrm{L}$ & 1 & \\
\hline $\mathrm{Al}$ & ND & 1.12 & 1.12 & $\mathrm{mg} / \mathrm{L}$ & 1 & \\
\hline As & ND & 2.25 & 2.25 & $\mathrm{mg} / \mathrm{L}$ & 1 & $\mathrm{R}-01$ \\
\hline $\mathrm{Ba}$ & 0.754 & 0.0225 & 0.0225 & $\mathrm{mg} / \mathrm{L}$ & 1 & \\
\hline $\mathrm{Be}$ & ND & 0.0225 & 0.0225 & $\mathrm{mg} / \mathrm{L}$ & 1 & \\
\hline $\mathrm{Cd}$ & ND & 0.0225 & 0.0225 & $\mathrm{mg} / \mathrm{L}$ & 1 & \\
\hline $\mathrm{Ca}$ & 53.8 & 1.12 & 1.12 & $\mathrm{mg} / \mathrm{L}$ & 1 & \\
\hline $\mathrm{Cr}$ & ND & 0.225 & 0.225 & $\mathrm{mg} / \mathrm{L}$ & 1 & R-01 \\
\hline Co & 0.0255 & 0.0225 & 0.0225 & $\mathrm{mg} / \mathrm{L}$ & 1 & \\
\hline $\mathrm{Cu}$ & 0.120 & 0.0225 & 0.0225 & $\mathrm{mg} / \mathrm{L}$ & 1 & \\
\hline $\mathrm{Fe}$ & 0.684 & 0.225 & 0.225 & $\mathrm{mg} / \mathrm{L}$ & 1 & \\
\hline $\mathrm{Pb}$ & 0.0610 & 0.0225 & 0.0225 & $\mathrm{mg} / \mathrm{L}$ & 1 & \\
\hline $\mathrm{Mg}$ & 58.9 & 1.12 & 1.12 & $\mathrm{mg} / \mathrm{L}$ & 1 & \\
\hline $\mathrm{Mn}$ & 0.996 & 0.0225 & 0.0225 & $\mathrm{mg} / \mathrm{L}$ & 1 & \\
\hline Mo & ND & 0.112 & 0.112 & $\mathrm{mg} / \mathrm{L}$ & 1 & \\
\hline $\mathrm{Ni}$ & ND & 0.0225 & 0.0225 & $\mathrm{mg} / \mathrm{L}$ & 1 & \\
\hline $\mathrm{P}$ & 560 & 1.12 & 1.12 & $\mathrm{mg} / \mathrm{L}$ & 1 & $\mathrm{E}$ \\
\hline $\mathrm{K}$ & 752 & 1.12 & 1.12 & $\mathrm{mg} / \mathrm{L}$ & 1 & $\mathrm{E}$ \\
\hline $\mathrm{Se}$ & ND & 4.50 & 4.50 & $\mathrm{mg} / \mathrm{L}$ & 1 & Q-41 \\
\hline $\mathrm{Na}$ & 4.10 & 1.12 & 1.12 & $\mathrm{mg} / \mathrm{L}$ & 1 & \\
\hline $\mathrm{V}$ & ND & 0.0225 & 0.0225 & $\mathrm{mg} / \mathrm{L}$ & 1 & \\
\hline $\mathrm{Zn}$ & 0.126 & 0.0225 & 0.0225 & $\mathrm{mg} / \mathrm{L}$ & 1 & \\
\hline
\end{tabular}


Table 145. Chemical analysis using ICP-MS for the small sample of the 2011 wine from Elk Cove Five Mountain (ECFM) Vineyard. ND - Non-detect.

\begin{tabular}{|c|c|c|c|c|c|c|}
\hline \multicolumn{7}{|c|}{ Lab ID A4B0432-03 31 ECFM 11S } \\
\hline Analyte & Result & Detection Limit & Reporting Limit & Units & Dilution & Analyst Notes \\
\hline S & 55.1 & 2.25 & 2.25 & $\mathrm{mg} / \mathrm{L}$ & 1 & \\
\hline $\mathrm{Hg}$ & ND & 0.00180 & 0.00180 & $\mathrm{mg} / \mathrm{L}$ & 5 & $\mathrm{R}-04$ \\
\hline $\mathrm{Sr}$ & 0.779 & 0.00405 & 0.00405 & $\mathrm{mg} / \mathrm{L}$ & 1 & \\
\hline $\mathrm{Al}$ & ND & 2.25 & 2.25 & $\mathrm{mg} / \mathrm{L}$ & 1 & \\
\hline As & ND & 4.50 & 4.50 & $\mathrm{mg} / \mathrm{L}$ & 1 & R-01 \\
\hline $\mathrm{Ba}$ & 0.576 & 0.0450 & 0.0450 & $\mathrm{mg} / \mathrm{L}$ & 1 & \\
\hline $\mathrm{Be}$ & ND & 0.0450 & 0.0450 & $\mathrm{mg} / \mathrm{L}$ & 1 & \\
\hline $\mathrm{Cd}$ & ND & 0.0450 & 0.0450 & $\mathrm{mg} / \mathrm{L}$ & 1 & \\
\hline $\mathrm{Ca}$ & 31.1 & 2.25 & 2.25 & $\mathrm{mg} / \mathrm{L}$ & 1 & \\
\hline $\mathrm{Cr}$ & ND & 0.450 & 0.450 & $\mathrm{mg} / \mathrm{L}$ & 1 & R-01 \\
\hline Co & ND & 0.0450 & 0.0450 & $\mathrm{mg} / \mathrm{L}$ & 1 & \\
\hline $\mathrm{Cu}$ & 0.0805 & 0.0450 & 0.0450 & $\mathrm{mg} / \mathrm{L}$ & 1 & \\
\hline $\mathrm{Fe}$ & 0.630 & 0.450 & 0.450 & $\mathrm{mg} / \mathrm{L}$ & 1 & \\
\hline $\mathrm{Pb}$ & ND & 0.0450 & 0.0450 & $\mathrm{mg} / \mathrm{L}$ & 1 & \\
\hline $\mathrm{Mg}$ & 58.6 & 2.25 & 2.25 & $\mathrm{mg} / \mathrm{L}$ & 1 & \\
\hline $\mathrm{Mn}$ & 1.03 & 0.0450 & 0.0450 & $\mathrm{mg} / \mathrm{L}$ & 1 & \\
\hline Mo & ND & 0.225 & 0.225 & $\mathrm{mg} / \mathrm{L}$ & 1 & \\
\hline $\mathrm{Ni}$ & ND & 0.0450 & 0.0450 & $\mathrm{mg} / \mathrm{L}$ & 1 & \\
\hline $\mathrm{P}$ & 180 & 2.25 & 2.25 & $\mathrm{mg} / \mathrm{L}$ & 1 & \\
\hline $\mathrm{K}$ & 828 & 2.25 & 2.25 & $\mathrm{mg} / \mathrm{L}$ & 1 & \\
\hline $\mathrm{Se}$ & ND & 9.00 & 9.00 & $\mathrm{mg} / \mathrm{L}$ & 1 & \\
\hline $\mathrm{Na}$ & ND & 2.25 & 2.25 & $\mathrm{mg} / \mathrm{L}$ & 1 & \\
\hline V & ND & 0.0450 & 0.0450 & $\mathrm{mg} / \mathrm{L}$ & 1 & \\
\hline $\mathrm{Zn}$ & 0.222 & 0.0450 & 0.0450 & $\mathrm{mg} / \mathrm{L}$ & 1 & \\
\hline
\end{tabular}


Table 146. Chemical analysis using ICP-MS for the 1st bottle of the 2011 wine from Elk Cove Five Mountain (ECFM) Vineyard. ND - Non-detect.

\begin{tabular}{|c|c|c|c|c|c|c|}
\hline \multicolumn{7}{|c|}{ Lab ID A4B0432-02 30 ECFM 11} \\
\hline Analyte & Result & Detection Limit & Reporting Limit & Units & Dilution & Analyst Notes \\
\hline S & 63.0 & 2.25 & 2.25 & $\mathrm{mg} / \mathrm{L}$ & 1 & \\
\hline $\mathrm{Hg}$ & ND & 0.00180 & 0.00180 & $\mathrm{mg} / \mathrm{L}$ & 5 & R-04 \\
\hline $\mathrm{Sr}$ & 0.774 & 0.00405 & 0.00405 & $\mathrm{mg} / \mathrm{L}$ & 1 & \\
\hline $\mathrm{Al}$ & ND & 2.25 & 2.25 & $\mathrm{mg} / \mathrm{L}$ & 1 & \\
\hline As & ND & 4.50 & 4.50 & $\mathrm{mg} / \mathrm{L}$ & 1 & $\mathrm{R}-01$ \\
\hline $\mathrm{Ba}$ & 0.404 & 0.0450 & 0.0450 & $\mathrm{mg} / \mathrm{L}$ & 1 & \\
\hline $\mathrm{Be}$ & ND & 0.0450 & 0.0450 & $\mathrm{mg} / \mathrm{L}$ & 1 & \\
\hline $\mathrm{Cd}$ & ND & 0.0450 & 0.0450 & $\mathrm{mg} / \mathrm{L}$ & 1 & \\
\hline $\mathrm{Ca}$ & 46.5 & 2.25 & 2.25 & $\mathrm{mg} / \mathrm{L}$ & 1 & \\
\hline $\mathrm{Cr}$ & ND & 0.450 & 0.450 & $\mathrm{mg} / \mathrm{L}$ & 1 & $\mathrm{R}-01$ \\
\hline Co & ND & 0.0450 & 0.0450 & $\mathrm{mg} / \mathrm{L}$ & 1 & \\
\hline $\mathrm{Cu}$ & 0.102 & 0.0450 & 0.0450 & $\mathrm{mg} / \mathrm{L}$ & 1 & \\
\hline $\mathrm{Fe}$ & 0.829 & 0.450 & 0.450 & $\mathrm{mg} / \mathrm{L}$ & 1 & \\
\hline $\mathrm{Pb}$ & ND & 0.0450 & 0.0450 & $\mathrm{mg} / \mathrm{L}$ & 1 & \\
\hline $\mathrm{Mg}$ & 59.4 & 2.25 & 2.25 & $\mathrm{mg} / \mathrm{L}$ & 1 & \\
\hline $\mathrm{Mn}$ & 0.942 & 0.0450 & 0.0450 & $\mathrm{mg} / \mathrm{L}$ & 1 & \\
\hline Mo & ND & 0.225 & 0.225 & $\mathrm{mg} / \mathrm{L}$ & 1 & \\
\hline $\mathrm{Ni}$ & ND & 0.0450 & 0.0450 & $\mathrm{mg} / \mathrm{L}$ & 1 & \\
\hline $\mathrm{P}$ & 282 & 2.25 & 2.25 & $\mathrm{mg} / \mathrm{L}$ & 1 & \\
\hline $\mathrm{K}$ & 775 & 2.25 & 2.25 & $\mathrm{mg} / \mathrm{L}$ & 1 & \\
\hline $\mathrm{Se}$ & ND & 9.00 & 9.00 & $\mathrm{mg} / \mathrm{L}$ & 1 & \\
\hline $\mathrm{Na}$ & 4.34 & 2.25 & 2.25 & $\mathrm{mg} / \mathrm{L}$ & 1 & \\
\hline V & ND & 0.0450 & 0.0450 & $\mathrm{mg} / \mathrm{L}$ & 1 & \\
\hline $\mathrm{Zn}$ & 0.172 & 0.0450 & 0.0450 & $\mathrm{mg} / \mathrm{L}$ & 1 & \\
\hline
\end{tabular}


Table 147. Chemical analysis using ICP-MS for the 2nd bottle of the 2011 wine from Elk Cove Five Mountain (ECFM) Vineyard. ND - Non-detect.

\begin{tabular}{|c|c|c|c|c|c|c|}
\hline \multicolumn{7}{|c|}{ Lab ID A4B0432-16 45 ECFM11N } \\
\hline Analyte & Result & Detection Limit & Reporting Limit & Units & Dilution & Analyst Notes \\
\hline S & 68.1 & 2.25 & 2.25 & $\mathrm{mg} / \mathrm{L}$ & 1 & \\
\hline $\mathrm{Hg}$ & ND & 0.00180 & 0.00180 & $\mathrm{mg} / \mathrm{L}$ & 5 & R-04 \\
\hline $\mathrm{Sr}$ & 0.800 & 0.00405 & 0.00405 & $\mathrm{mg} / \mathrm{L}$ & 1 & \\
\hline $\mathrm{Al}$ & ND & 2.25 & 2.25 & $\mathrm{mg} / \mathrm{L}$ & 1 & $\mathrm{R}-03$ \\
\hline As & ND & 4.50 & 4.50 & $\mathrm{mg} / \mathrm{L}$ & 1 & $\mathrm{R}-01$ \\
\hline $\mathrm{Ba}$ & 0.414 & 0.0450 & 0.0450 & $\mathrm{mg} / \mathrm{L}$ & 1 & \\
\hline $\mathrm{Be}$ & ND & 0.0450 & 0.0450 & $\mathrm{mg} / \mathrm{L}$ & 1 & $\mathrm{R}-03$ \\
\hline $\mathrm{Cd}$ & ND & 0.0450 & 0.0450 & $\mathrm{mg} / \mathrm{L}$ & 1 & $\mathrm{R}-03$ \\
\hline $\mathrm{Ca}$ & 49.4 & 2.25 & 2.25 & $\mathrm{mg} / \mathrm{L}$ & 1 & \\
\hline $\mathrm{Cr}$ & ND & 0.0450 & 0.0450 & $\mathrm{mg} / \mathrm{L}$ & 1 & $\mathrm{R}-03$ \\
\hline $\mathrm{Co}$ & ND & 0.0450 & 0.0450 & $\mathrm{mg} / \mathrm{L}$ & 1 & R-03 \\
\hline $\mathrm{Cu}$ & 0.0930 & 0.0450 & 0.0450 & $\mathrm{mg} / \mathrm{L}$ & 1 & \\
\hline $\mathrm{Fe}$ & 0.858 & 0.450 & 0.450 & $\mathrm{mg} / \mathrm{L}$ & 1 & \\
\hline $\mathrm{Pb}$ & ND & 0.0450 & 0.0450 & $\mathrm{mg} / \mathrm{L}$ & 1 & $\mathrm{R}-03$ \\
\hline $\mathrm{Mg}$ & 66.6 & 2.25 & 2.25 & $\mathrm{mg} / \mathrm{L}$ & 1 & \\
\hline $\mathrm{Mn}$ & 0.986 & 0.0450 & 0.0450 & $\mathrm{mg} / \mathrm{L}$ & 1 & \\
\hline Mo & ND & 0.0450 & 0.0450 & $\mathrm{mg} / \mathrm{L}$ & 1 & $\mathrm{R}-03$ \\
\hline $\mathrm{Ni}$ & ND & 0.0450 & 0.0450 & $\mathrm{mg} / \mathrm{L}$ & 1 & $\mathrm{R}-03$ \\
\hline $\mathrm{P}$ & 280 & 2.25 & 2.25 & $\mathrm{mg} / \mathrm{L}$ & 1 & \\
\hline $\mathrm{K}$ & 846 & 2.25 & 2.25 & $\mathrm{mg} / \mathrm{L}$ & 1 & \\
\hline $\mathrm{Se}$ & ND & 4.50 & 4.50 & $\mathrm{mg} / \mathrm{L}$ & 1 & $\mathrm{R}-01$ \\
\hline $\mathrm{Na}$ & 3.89 & 2.25 & 2.25 & $\mathrm{mg} / \mathrm{L}$ & 1 & \\
\hline V & ND & 0.0450 & 0.0450 & $\mathrm{mg} / \mathrm{L}$ & 1 & $\mathrm{R}-03$ \\
\hline $\mathrm{Zn}$ & 0.172 & 0.0450 & 0.0450 & $\mathrm{mg} / \mathrm{L}$ & 1 & \\
\hline
\end{tabular}


Table 148. Chemical analysis using ICP-MS for the bottle of the 2011 wine from Willakenzie Estate Jory Hill (WEJH) Vineyard. ND - Non-detect.

\begin{tabular}{|c|c|c|c|c|c|c|}
\hline \multicolumn{7}{|c|}{ Lab ID A4B0164-05 19 WEJH 11} \\
\hline Analyte & Result & Detection Limit & Reporting Limit & Units & Dilution & Analyst Notes \\
\hline $\mathrm{S}$ & 72.7 & 1.12 & 1.12 & $\mathrm{mg} / \mathrm{L}$ & 1 & \\
\hline $\mathrm{Hg}$ & ND & 0.000900 & 0.000900 & $\mathrm{mg} / \mathrm{L}$ & 5 & E-03, R-04 \\
\hline $\mathrm{Sr}$ & 0.954 & 0.00202 & 0.00202 & $\mathrm{mg} / \mathrm{L}$ & 1 & \\
\hline $\mathrm{Al}$ & ND & 1.12 & 1.12 & $\mathrm{mg} / \mathrm{L}$ & 1 & \\
\hline As & ND & 2.25 & 2.25 & $\mathrm{mg} / \mathrm{L}$ & 1 & $\mathrm{R}-01$ \\
\hline $\mathrm{Ba}$ & 0.464 & 0.0225 & 0.0225 & $\mathrm{mg} / \mathrm{L}$ & 1 & \\
\hline $\mathrm{Be}$ & ND & 0.0225 & 0.0225 & $\mathrm{mg} / \mathrm{L}$ & 1 & \\
\hline $\mathrm{Cd}$ & ND & 0.0225 & 0.0225 & $\mathrm{mg} / \mathrm{L}$ & 1 & \\
\hline $\mathrm{Ca}$ & 51.6 & 1.12 & 1.12 & $\mathrm{mg} / \mathrm{L}$ & 1 & \\
\hline $\mathrm{Cr}$ & ND & 0.225 & 0.225 & $\mathrm{mg} / \mathrm{L}$ & 1 & $\mathrm{R}-01$ \\
\hline Co & 0.0310 & 0.0225 & 0.0225 & $\mathrm{mg} / \mathrm{L}$ & 1 & \\
\hline $\mathrm{Cu}$ & 0.0272 & 0.0225 & 0.0225 & $\mathrm{mg} / \mathrm{L}$ & 1 & \\
\hline $\mathrm{Fe}$ & 0.645 & 0.225 & 0.225 & $\mathrm{mg} / \mathrm{L}$ & 1 & \\
\hline $\mathrm{Pb}$ & 0.0615 & 0.0225 & 0.0225 & $\mathrm{mg} / \mathrm{L}$ & 1 & \\
\hline $\mathrm{Mg}$ & 40.6 & 1.12 & 1.12 & $\mathrm{mg} / \mathrm{L}$ & 1 & \\
\hline $\mathrm{Mn}$ & 1.30 & 0.0225 & 0.0225 & $\mathrm{mg} / \mathrm{L}$ & 1 & \\
\hline Mo & ND & 0.112 & 0.112 & $\mathrm{mg} / \mathrm{L}$ & 1 & \\
\hline $\mathrm{Ni}$ & ND & 0.0225 & 0.0225 & $\mathrm{mg} / \mathrm{L}$ & 1 & \\
\hline $\mathrm{P}$ & 187 & 1.12 & 1.12 & $\mathrm{mg} / \mathrm{L}$ & 1 & Q-41 \\
\hline $\mathrm{K}$ & 818 & 1.12 & 1.12 & $\mathrm{mg} / \mathrm{L}$ & 1 & $\mathrm{E}$ \\
\hline $\mathrm{Se}$ & ND & 4.50 & 4.50 & $\mathrm{mg} / \mathrm{L}$ & 1 & Q-41 \\
\hline $\mathrm{Na}$ & 4.50 & 1.12 & 1.12 & $\mathrm{mg} / \mathrm{L}$ & 1 & \\
\hline $\mathrm{V}$ & ND & 0.0225 & 0.0225 & $\mathrm{mg} / \mathrm{L}$ & 1 & \\
\hline $\mathrm{Zn}$ & 0.164 & 0.0225 & 0.0225 & $\mathrm{mg} / \mathrm{L}$ & 1 & \\
\hline
\end{tabular}


Table 149. Chemical analysis using ICP-MS for the bottle of the 2011 wine from Willakenzie Estate Aliette Block (WEAB) Vineyard. ND - Non-detect.

\begin{tabular}{|c|c|c|c|c|c|c|}
\hline \multicolumn{7}{|c|}{ Lab ID A4B0052-01 1 WEAB 2011} \\
\hline Analyte & Result & Detection Limit & Reporting Limit & Units & Dilution & Analyst Notes \\
\hline $\mathrm{S}$ & 71.3 & 1.12 & 1.12 & $\mathrm{mg} / \mathrm{L}$ & 1 & \\
\hline $\mathrm{Hg}$ & ND & 0.000900 & 0.000900 & $\mathrm{mg} / \mathrm{L}$ & 5 & $\mathrm{H}-01, \mathrm{R}-04$ \\
\hline $\mathrm{Sr}$ & 1.21 & 0.00202 & 0.00202 & $\mathrm{mg} / \mathrm{L}$ & 1 & \\
\hline $\mathrm{Al}$ & ND & 1.12 & 1.12 & $\mathrm{mg} / \mathrm{L}$ & 1 & \\
\hline As & ND & 2.25 & 2.25 & $\mathrm{mg} / \mathrm{L}$ & 1 & $\mathrm{R}-01$ \\
\hline $\mathrm{Ba}$ & 0.439 & 0.0225 & 0.0225 & $\mathrm{mg} / \mathrm{L}$ & 1 & \\
\hline $\mathrm{Be}$ & ND & 0.0225 & 0.0225 & $\mathrm{mg} / \mathrm{L}$ & 1 & \\
\hline $\mathrm{Cd}$ & ND & 0.0225 & 0.0225 & $\mathrm{mg} / \mathrm{L}$ & 1 & \\
\hline $\mathrm{Ca}$ & 55.8 & 1.12 & 1.12 & $\mathrm{mg} / \mathrm{L}$ & 1 & \\
\hline $\mathrm{Cr}$ & ND & 0.225 & 0.225 & $\mathrm{mg} / \mathrm{L}$ & 1 & $\mathrm{R}-01$ \\
\hline Co & 0.0258 & 0.0225 & 0.0225 & $\mathrm{mg} / \mathrm{L}$ & 1 & \\
\hline $\mathrm{Cu}$ & 0.102 & 0.0225 & 0.0225 & $\mathrm{mg} / \mathrm{L}$ & 1 & \\
\hline $\mathrm{Fe}$ & 0.768 & 0.225 & 0.225 & $\mathrm{mg} / \mathrm{L}$ & 1 & \\
\hline $\mathrm{Pb}$ & 0.0610 & 0.0225 & 0.0225 & $\mathrm{mg} / \mathrm{L}$ & 1 & \\
\hline $\mathrm{Mg}$ & 47.9 & 1.12 & 1.12 & $\mathrm{mg} / \mathrm{L}$ & 1 & \\
\hline $\mathrm{Mn}$ & 0.995 & 0.0225 & 0.0225 & $\mathrm{mg} / \mathrm{L}$ & 1 & \\
\hline Mo & ND & 0.112 & 0.112 & $\mathrm{mg} / \mathrm{L}$ & 1 & \\
\hline $\mathrm{Ni}$ & ND & 0.0225 & 0.0225 & $\mathrm{mg} / \mathrm{L}$ & 1 & \\
\hline $\mathrm{P}$ & 222 & 1.12 & 1.12 & $\mathrm{mg} / \mathrm{L}$ & 1 & \\
\hline $\mathrm{K}$ & 835 & 1.12 & 1.12 & $\mathrm{mg} / \mathrm{L}$ & 1 & $\mathrm{E}$ \\
\hline $\mathrm{Se}$ & ND & 4.50 & 4.50 & $\mathrm{mg} / \mathrm{L}$ & 1 & Q-41 \\
\hline $\mathrm{Na}$ & 4.45 & 1.12 & 1.12 & $\mathrm{mg} / \mathrm{L}$ & 1 & \\
\hline $\mathrm{V}$ & ND & 0.0225 & 0.0225 & $\mathrm{mg} / \mathrm{L}$ & 1 & \\
\hline $\mathrm{Zn}$ & 0.333 & 0.0225 & 0.0225 & $\mathrm{mg} / \mathrm{L}$ & 1 & \\
\hline
\end{tabular}


Table 150. Chemical analysis using ICP-MS for the bottle of the 2011 wine from Willakenzie Estate Terres Basses (WETB) Vineyard. ND - Non-detect.

\begin{tabular}{|c|c|c|c|c|c|c|}
\hline \multicolumn{7}{|c|}{ Lab ID A4B0164-11 25 WETB 11} \\
\hline Analyte & Result & Detection Limit & Reporting Limit & Units & Dilution & Analyst Notes \\
\hline $\mathrm{S}$ & 92.5 & 2.25 & 2.25 & $\mathrm{mg} / \mathrm{L}$ & 1 & \\
\hline $\mathrm{Hg}$ & ND & 0.00180 & 0.00180 & $\mathrm{mg} / \mathrm{L}$ & 5 & H-01, R-04 \\
\hline $\mathrm{Sr}$ & 1.13 & 0.00405 & 0.00405 & $\mathrm{mg} / \mathrm{L}$ & 1 & \\
\hline $\mathrm{Al}$ & ND & 2.25 & 2.25 & $\mathrm{mg} / \mathrm{L}$ & 1 & \\
\hline As & ND & 4.50 & 4.50 & $\mathrm{mg} / \mathrm{L}$ & 1 & $\mathrm{R}-01$ \\
\hline $\mathrm{Ba}$ & 0.406 & 0.0450 & 0.0450 & $\mathrm{mg} / \mathrm{L}$ & 1 & \\
\hline $\mathrm{Be}$ & ND & 0.0450 & 0.0450 & $\mathrm{mg} / \mathrm{L}$ & 1 & \\
\hline $\mathrm{Cd}$ & ND & 0.0450 & 0.0450 & $\mathrm{mg} / \mathrm{L}$ & 1 & \\
\hline $\mathrm{Ca}$ & 55.4 & 2.25 & 2.25 & $\mathrm{mg} / \mathrm{L}$ & 1 & \\
\hline $\mathrm{Cr}$ & ND & 0.450 & 0.450 & $\mathrm{mg} / \mathrm{L}$ & 1 & $\mathrm{R}-01$ \\
\hline Co & ND & 0.0450 & 0.0450 & $\mathrm{mg} / \mathrm{L}$ & 1 & \\
\hline $\mathrm{Cu}$ & 0.108 & 0.0450 & 0.0450 & $\mathrm{mg} / \mathrm{L}$ & 1 & \\
\hline $\mathrm{Fe}$ & 1.15 & 0.450 & 0.450 & $\mathrm{mg} / \mathrm{L}$ & 1 & \\
\hline $\mathrm{Pb}$ & 0.0630 & 0.0450 & 0.0450 & $\mathrm{mg} / \mathrm{L}$ & 1 & \\
\hline $\mathrm{Mg}$ & 63.8 & 2.25 & 2.25 & $\mathrm{mg} / \mathrm{L}$ & 1 & \\
\hline $\mathrm{Mn}$ & 2.74 & 0.0450 & 0.0450 & $\mathrm{mg} / \mathrm{L}$ & 1 & \\
\hline Mo & ND & 0.225 & 0.225 & $\mathrm{mg} / \mathrm{L}$ & 1 & \\
\hline $\mathrm{Ni}$ & ND & 0.0450 & 0.0450 & $\mathrm{mg} / \mathrm{L}$ & 1 & \\
\hline $\mathrm{P}$ & 184 & 2.25 & 2.25 & $\mathrm{mg} / \mathrm{L}$ & 1 & \\
\hline $\mathrm{K}$ & 975 & 2.25 & 2.25 & $\mathrm{mg} / \mathrm{L}$ & 1 & \\
\hline $\mathrm{Se}$ & ND & 9.00 & 9.00 & $\mathrm{mg} / \mathrm{L}$ & 1 & \\
\hline $\mathrm{Na}$ & 4.18 & 2.25 & 2.25 & $\mathrm{mg} / \mathrm{L}$ & 1 & \\
\hline $\mathrm{V}$ & ND & 0.0450 & 0.0450 & $\mathrm{mg} / \mathrm{L}$ & 1 & \\
\hline $\mathrm{Zn}$ & 0.204 & 0.0450 & 0.0450 & $\mathrm{mg} / \mathrm{L}$ & 1 & \\
\hline
\end{tabular}


Table 151. Chemical analysis using ICP-MS for the $2^{\text {nd }}$ sample from the same bottle of the 2011 wine from Willakenzie Estate Terres Basses (WETB) Vineyard. ND - Non-detect.

\begin{tabular}{|c|c|c|c|c|c|c|}
\hline \multicolumn{7}{|c|}{ Lab ID A4B0164-03 17 WETB 11} \\
\hline Analyte & Result & Detection Limit & Reporting Limit & Units & Dilution & Analyst Notes \\
\hline S & 88.8 & 1.12 & 1.12 & $\mathrm{mg} / \mathrm{L}$ & 1 & \\
\hline $\mathrm{Hg}$ & ND & 0.000900 & 0.000900 & $\mathrm{mg} / \mathrm{L}$ & 5 & E-03, R-04 \\
\hline $\mathrm{Sr}$ & 1.16 & 0.00202 & 0.00202 & $\mathrm{mg} / \mathrm{L}$ & 1 & \\
\hline $\mathrm{Al}$ & ND & 1.12 & 1.12 & $\mathrm{mg} / \mathrm{L}$ & 1 & \\
\hline As & ND & 2.25 & 2.25 & $\mathrm{mg} / \mathrm{L}$ & 1 & $\mathrm{R}-01$ \\
\hline $\mathrm{Ba}$ & 0.431 & 0.0225 & 0.0225 & $\mathrm{mg} / \mathrm{L}$ & 1 & \\
\hline $\mathrm{Be}$ & ND & 0.0225 & 0.0225 & $\mathrm{mg} / \mathrm{L}$ & 1 & \\
\hline $\mathrm{Cd}$ & ND & 0.0225 & 0.0225 & $\mathrm{mg} / \mathrm{L}$ & 1 & \\
\hline $\mathrm{Ca}$ & 45.6 & 1.12 & 1.12 & $\mathrm{mg} / \mathrm{L}$ & 1 & \\
\hline $\mathrm{Cr}$ & ND & 0.225 & 0.225 & $\mathrm{mg} / \mathrm{L}$ & 1 & R-01 \\
\hline Co & 0.0315 & 0.0225 & 0.0225 & $\mathrm{mg} / \mathrm{L}$ & 1 & \\
\hline $\mathrm{Cu}$ & 0.146 & 0.0225 & 0.0225 & $\mathrm{mg} / \mathrm{L}$ & 1 & \\
\hline $\mathrm{Fe}$ & 0.991 & 0.225 & 0.225 & $\mathrm{mg} / \mathrm{L}$ & 1 & \\
\hline $\mathrm{Pb}$ & 0.115 & 0.0225 & 0.0225 & $\mathrm{mg} / \mathrm{L}$ & 1 & \\
\hline $\mathrm{Mg}$ & 41.5 & 1.12 & 1.12 & $\mathrm{mg} / \mathrm{L}$ & 1 & \\
\hline $\mathrm{Mn}$ & 2.38 & 0.0225 & 0.0225 & $\mathrm{mg} / \mathrm{L}$ & 1 & \\
\hline Mo & ND & 0.112 & 0.112 & $\mathrm{mg} / \mathrm{L}$ & 1 & \\
\hline $\mathrm{Ni}$ & 0.0260 & 0.0225 & 0.0225 & $\mathrm{mg} / \mathrm{L}$ & 1 & \\
\hline $\mathrm{P}$ & 230 & 1.12 & 1.12 & $\mathrm{mg} / \mathrm{L}$ & 1 & Q-41 \\
\hline $\mathrm{K}$ & 840 & 1.12 & 1.12 & $\mathrm{mg} / \mathrm{L}$ & 1 & E \\
\hline $\mathrm{Se}$ & ND & 4.50 & 4.50 & $\mathrm{mg} / \mathrm{L}$ & 1 & Q-41 \\
\hline $\mathrm{Na}$ & 3.89 & 1.12 & 1.12 & $\mathrm{mg} / \mathrm{L}$ & 1 & \\
\hline $\mathrm{V}$ & ND & 0.0225 & 0.0225 & $\mathrm{mg} / \mathrm{L}$ & 1 & \\
\hline $\mathrm{Zn}$ & 0.212 & 0.0225 & 0.0225 & $\mathrm{mg} / \mathrm{L}$ & 1 & \\
\hline
\end{tabular}


Table 152. Chemical analysis using ICP-MS for the bottle of the 2007 wine from Chehalem Stoller (CWS) Vineyard. ND - Non-detect.

\begin{tabular}{|c|c|c|c|c|c|c|}
\hline \multicolumn{7}{|c|}{ Lab ID A4B0432-08 36 CWS 07} \\
\hline Analyte & Result & Detection Limit & Reporting Limit & Units & Dilution & Analyst Notes \\
\hline $\mathrm{S}$ & 68.4 & 2.25 & 2.25 & $\mathrm{mg} / \mathrm{L}$ & 1 & \\
\hline $\mathrm{Hg}$ & ND & 0.00180 & 0.00180 & $\mathrm{mg} / \mathrm{L}$ & 5 & R-04 \\
\hline $\mathrm{Sr}$ & 0.858 & 0.00405 & 0.00405 & $\mathrm{mg} / \mathrm{L}$ & 1 & \\
\hline $\mathrm{Al}$ & ND & 2.25 & 2.25 & $\mathrm{mg} / \mathrm{L}$ & 1 & \\
\hline As & ND & 4.50 & 4.50 & $\mathrm{mg} / \mathrm{L}$ & 1 & $\mathrm{R}-01$ \\
\hline $\mathrm{Ba}$ & 0.557 & 0.0450 & 0.0450 & $\mathrm{mg} / \mathrm{L}$ & 1 & \\
\hline $\mathrm{Be}$ & ND & 0.0450 & 0.0450 & $\mathrm{mg} / \mathrm{L}$ & 1 & \\
\hline $\mathrm{Cd}$ & ND & 0.0450 & 0.0450 & $\mathrm{mg} / \mathrm{L}$ & 1 & \\
\hline $\mathrm{Ca}$ & 49.0 & 2.25 & 2.25 & $\mathrm{mg} / \mathrm{L}$ & 1 & \\
\hline $\mathrm{Cr}$ & ND & 0.450 & 0.450 & $\mathrm{mg} / \mathrm{L}$ & 1 & R-01 \\
\hline $\mathrm{Co}$ & ND & 0.0450 & 0.0450 & $\mathrm{mg} / \mathrm{L}$ & 1 & \\
\hline $\mathrm{Cu}$ & 0.298 & 0.0450 & 0.0450 & $\mathrm{mg} / \mathrm{L}$ & 1 & \\
\hline $\mathrm{Fe}$ & 2.68 & 0.450 & 0.450 & $\mathrm{mg} / \mathrm{L}$ & 1 & \\
\hline $\mathrm{Pb}$ & ND & 0.0450 & 0.0450 & $\mathrm{mg} / \mathrm{L}$ & 1 & \\
\hline $\mathrm{Mg}$ & 71.5 & 2.25 & 2.25 & $\mathrm{mg} / \mathrm{L}$ & 1 & \\
\hline $\mathrm{Mn}$ & 2.12 & 0.0450 & 0.0450 & $\mathrm{mg} / \mathrm{L}$ & 1 & \\
\hline Mo & ND & 0.225 & 0.225 & $\mathrm{mg} / \mathrm{L}$ & 1 & \\
\hline $\mathrm{Ni}$ & ND & 0.0450 & 0.0450 & $\mathrm{mg} / \mathrm{L}$ & 1 & \\
\hline $\mathrm{P}$ & 327 & 2.25 & 2.25 & $\mathrm{mg} / \mathrm{L}$ & 1 & \\
\hline $\mathrm{K}$ & 774 & 2.25 & 2.25 & $\mathrm{mg} / \mathrm{L}$ & 1 & \\
\hline $\mathrm{Se}$ & ND & 9.00 & 9.00 & $\mathrm{mg} / \mathrm{L}$ & 1 & \\
\hline $\mathrm{Na}$ & 3.93 & 2.25 & 2.25 & $\mathrm{mg} / \mathrm{L}$ & 1 & \\
\hline $\mathrm{V}$ & ND & 0.0450 & 0.0450 & $\mathrm{mg} / \mathrm{L}$ & 1 & \\
\hline $\mathrm{Zn}$ & 0.702 & 0.0450 & 0.0450 & $\mathrm{mg} / \mathrm{L}$ & 1 & \\
\hline
\end{tabular}


Table 153. Chemical analysis using ICP-MS for the bottle of the 2008 wine from Chehalem Stoller (CWS) Vineyard. ND - Non-detect.

\begin{tabular}{|c|c|c|c|c|c|c|}
\hline \multicolumn{7}{|c|}{ Lab ID A4B0052-02 2 CWS 2008} \\
\hline Analyte & Result & Detection Limit & Reporting Limit & Units & Dilution & Analyst Notes \\
\hline S & 88.1 & 1.12 & 1.12 & $\mathrm{mg} / \mathrm{L}$ & 1 & \\
\hline $\mathrm{Hg}$ & ND & 0.000900 & 0.000900 & $\mathrm{mg} / \mathrm{L}$ & 5 & H-01, R-04 \\
\hline $\mathrm{Sr}$ & 0.812 & 0.00202 & 0.00202 & $\mathrm{mg} / \mathrm{L}$ & 1 & \\
\hline $\mathrm{Al}$ & ND & 1.12 & 1.12 & $\mathrm{mg} / \mathrm{L}$ & 1 & \\
\hline As & ND & 2.25 & 2.25 & $\mathrm{mg} / \mathrm{L}$ & 1 & $\mathrm{R}-01$ \\
\hline $\mathrm{Ba}$ & 0.393 & 0.0225 & 0.0225 & $\mathrm{mg} / \mathrm{L}$ & 1 & \\
\hline $\mathrm{Be}$ & ND & 0.0225 & 0.0225 & $\mathrm{mg} / \mathrm{L}$ & 1 & \\
\hline $\mathrm{Cd}$ & ND & 0.0225 & 0.0225 & $\mathrm{mg} / \mathrm{L}$ & 1 & \\
\hline $\mathrm{Ca}$ & 32.5 & 1.12 & 1.12 & $\mathrm{mg} / \mathrm{L}$ & 1 & \\
\hline $\mathrm{Cr}$ & ND & 0.225 & 0.225 & $\mathrm{mg} / \mathrm{L}$ & 1 & R-01 \\
\hline Co & 0.0358 & 0.0225 & 0.0225 & $\mathrm{mg} / \mathrm{L}$ & 1 & \\
\hline $\mathrm{Cu}$ & 0.213 & 0.0225 & 0.0225 & $\mathrm{mg} / \mathrm{L}$ & 1 & \\
\hline $\mathrm{Fe}$ & 2.82 & 0.225 & 0.225 & $\mathrm{mg} / \mathrm{L}$ & 1 & \\
\hline $\mathrm{Pb}$ & 0.0812 & 0.0225 & 0.0225 & $\mathrm{mg} / \mathrm{L}$ & 1 & \\
\hline $\mathrm{Mg}$ & 46.8 & 1.12 & 1.12 & $\mathrm{mg} / \mathrm{L}$ & 1 & \\
\hline $\mathrm{Mn}$ & 1.95 & 0.0225 & 0.0225 & $\mathrm{mg} / \mathrm{L}$ & 1 & \\
\hline Mo & ND & 0.112 & 0.112 & $\mathrm{mg} / \mathrm{L}$ & 1 & \\
\hline $\mathrm{Ni}$ & ND & 0.0225 & 0.0225 & $\mathrm{mg} / \mathrm{L}$ & 1 & \\
\hline $\mathrm{P}$ & 289 & 1.12 & 1.12 & $\mathrm{mg} / \mathrm{L}$ & 1 & $\mathrm{E}$ \\
\hline $\mathrm{K}$ & 710 & 1.12 & 1.12 & $\mathrm{mg} / \mathrm{L}$ & 1 & $\mathrm{E}$ \\
\hline $\mathrm{Se}$ & ND & 4.50 & 4.50 & $\mathrm{mg} / \mathrm{L}$ & 1 & Q-41 \\
\hline $\mathrm{Na}$ & 3.87 & 1.12 & 1.12 & $\mathrm{mg} / \mathrm{L}$ & 1 & \\
\hline $\mathrm{V}$ & ND & 0.0225 & 0.0225 & $\mathrm{mg} / \mathrm{L}$ & 1 & \\
\hline $\mathrm{Zn}$ & 0.550 & 0.0225 & 0.0225 & $\mathrm{mg} / \mathrm{L}$ & 1 & \\
\hline
\end{tabular}


Table 154. Chemical analysis using ICP-MS for the bottle of the 2009 wine from Chehalem Stoller (CWS) Vineyard. ND - Non-detect.

\begin{tabular}{|c|c|c|c|c|c|c|}
\hline \multicolumn{7}{|c|}{ Lab ID A4B0164-06 20 CWS 09} \\
\hline Analyte & Result & Detection Limit & Reporting Limit & Units & Dilution & Analyst Notes \\
\hline $\mathrm{S}$ & 77.4 & 2.25 & 2.25 & $\mathrm{mg} / \mathrm{L}$ & 1 & \\
\hline $\mathrm{Hg}$ & ND & 0.00180 & 0.00180 & $\mathrm{mg} / \mathrm{L}$ & 5 & H-01, R-04 \\
\hline $\mathrm{Sr}$ & 0.732 & 0.00405 & 0.00405 & $\mathrm{mg} / \mathrm{L}$ & 1 & \\
\hline $\mathrm{Al}$ & ND & 2.25 & 2.25 & $\mathrm{mg} / \mathrm{L}$ & 1 & \\
\hline As & ND & 4.50 & 4.50 & $\mathrm{mg} / \mathrm{L}$ & 1 & $\mathrm{R}-01$ \\
\hline $\mathrm{Ba}$ & 0.358 & 0.0450 & 0.0450 & $\mathrm{mg} / \mathrm{L}$ & 1 & \\
\hline $\mathrm{Be}$ & ND & 0.0450 & 0.0450 & $\mathrm{mg} / \mathrm{L}$ & 1 & \\
\hline $\mathrm{Cd}$ & ND & 0.0450 & 0.0450 & $\mathrm{mg} / \mathrm{L}$ & 1 & \\
\hline $\mathrm{Ca}$ & 51.6 & 2.25 & 2.25 & $\mathrm{mg} / \mathrm{L}$ & 1 & \\
\hline $\mathrm{Cr}$ & ND & 0.450 & 0.450 & $\mathrm{mg} / \mathrm{L}$ & 1 & R-01 \\
\hline $\mathrm{Co}$ & ND & 0.0450 & 0.0450 & $\mathrm{mg} / \mathrm{L}$ & 1 & \\
\hline $\mathrm{Cu}$ & 0.140 & 0.0450 & 0.0450 & $\mathrm{mg} / \mathrm{L}$ & 1 & \\
\hline $\mathrm{Fe}$ & 1.70 & 0.450 & 0.450 & $\mathrm{mg} / \mathrm{L}$ & 1 & \\
\hline $\mathrm{Pb}$ & 0.0475 & 0.0450 & 0.0450 & $\mathrm{mg} / \mathrm{L}$ & 1 & \\
\hline $\mathrm{Mg}$ & 60.8 & 2.25 & 2.25 & $\mathrm{mg} / \mathrm{L}$ & 1 & \\
\hline $\mathrm{Mn}$ & 1.91 & 0.0450 & 0.0450 & $\mathrm{mg} / \mathrm{L}$ & 1 & \\
\hline Mo & ND & 0.225 & 0.225 & $\mathrm{mg} / \mathrm{L}$ & 1 & \\
\hline $\mathrm{Ni}$ & ND & 0.0450 & 0.0450 & $\mathrm{mg} / \mathrm{L}$ & 1 & \\
\hline $\mathrm{P}$ & 319 & 2.25 & 2.25 & $\mathrm{mg} / \mathrm{L}$ & 1 & \\
\hline $\mathrm{K}$ & 860 & 2.25 & 2.25 & $\mathrm{mg} / \mathrm{L}$ & 1 & \\
\hline $\mathrm{Se}$ & ND & 9.00 & 9.00 & $\mathrm{mg} / \mathrm{L}$ & 1 & \\
\hline $\mathrm{Na}$ & 3.32 & 2.25 & 2.25 & $\mathrm{mg} / \mathrm{L}$ & 1 & \\
\hline $\mathrm{V}$ & ND & 0.0450 & 0.0450 & $\mathrm{mg} / \mathrm{L}$ & 1 & \\
\hline $\mathrm{Zn}$ & 0.356 & 0.0450 & 0.0450 & $\mathrm{mg} / \mathrm{L}$ & 1 & \\
\hline
\end{tabular}


Table 155. Chemical analysis using ICP-MS for the bottle of the 2011 wine from Chehalem Stoller (CWS) Vineyard. ND - Non-detect.

\begin{tabular}{|c|c|c|c|c|c|c|}
\hline \multicolumn{7}{|c|}{ Lab ID A4B052-03 3 CWS 2011} \\
\hline Analyte & Result & Detection Limit & Reporting Limit & Units & Dilution & Analyst Notes \\
\hline $\mathrm{S}$ & 74.6 & 1.12 & 1.12 & $\mathrm{mg} / \mathrm{L}$ & 1 & \\
\hline $\mathrm{Hg}$ & ND & 0.000900 & 0.000900 & $\mathrm{mg} / \mathrm{L}$ & 5 & H-01, R-04 \\
\hline $\mathrm{Sr}$ & 0.758 & 0.00202 & 0.00202 & $\mathrm{mg} / \mathrm{L}$ & 1 & \\
\hline $\mathrm{Al}$ & ND & 1.12 & 1.12 & $\mathrm{mg} / \mathrm{L}$ & 1 & \\
\hline As & ND & 2.25 & 2.25 & $\mathrm{mg} / \mathrm{L}$ & 1 & R-01 \\
\hline $\mathrm{Ba}$ & 0.446 & 0.0225 & 0.0225 & $\mathrm{mg} / \mathrm{L}$ & 1 & \\
\hline $\mathrm{Be}$ & ND & 0.0225 & 0.0225 & $\mathrm{mg} / \mathrm{L}$ & 1 & \\
\hline $\mathrm{Cd}$ & ND & 0.0225 & 0.0225 & $\mathrm{mg} / \mathrm{L}$ & 1 & \\
\hline $\mathrm{Ca}$ & 47.2 & 1.12 & 1.12 & $\mathrm{mg} / \mathrm{L}$ & 1 & \\
\hline $\mathrm{Cr}$ & ND & 0.225 & 0.225 & $\mathrm{mg} / \mathrm{L}$ & 1 & R-01 \\
\hline Co & 0.0282 & 0.0225 & 0.0225 & $\mathrm{mg} / \mathrm{L}$ & 1 & \\
\hline $\mathrm{Cu}$ & 0.0998 & 0.0225 & 0.0225 & $\mathrm{mg} / \mathrm{L}$ & 1 & \\
\hline $\mathrm{Fe}$ & 1.58 & 0.225 & 0.225 & $\mathrm{mg} / \mathrm{L}$ & 1 & \\
\hline $\mathrm{Pb}$ & 0.0815 & 0.0225 & 0.0225 & $\mathrm{mg} / \mathrm{L}$ & 1 & \\
\hline $\mathrm{Mg}$ & 37.8 & 1.12 & 1.12 & $\mathrm{mg} / \mathrm{L}$ & 1 & \\
\hline $\mathrm{Mn}$ & 1.62 & 0.0225 & 0.0225 & $\mathrm{mg} / \mathrm{L}$ & 1 & \\
\hline Mo & ND & 0.112 & 0.112 & $\mathrm{mg} / \mathrm{L}$ & 1 & \\
\hline $\mathrm{Ni}$ & ND & 0.0225 & 0.0225 & $\mathrm{mg} / \mathrm{L}$ & 1 & \\
\hline $\mathrm{P}$ & 286 & 1.12 & 1.12 & $\mathrm{mg} / \mathrm{L}$ & 1 & E \\
\hline $\mathrm{K}$ & 740 & 1.12 & 1.12 & $\mathrm{mg} / \mathrm{L}$ & 1 & E \\
\hline $\mathrm{Se}$ & ND & 4.50 & 4.50 & $\mathrm{mg} / \mathrm{L}$ & 1 & Q-41 \\
\hline $\mathrm{Na}$ & 17.3 & 1.12 & 1.12 & $\mathrm{mg} / \mathrm{L}$ & 1 & \\
\hline V & ND & 0.0225 & 0.0225 & $\mathrm{mg} / \mathrm{L}$ & 1 & \\
\hline $\mathrm{Zn}$ & 0.463 & 0.0225 & 0.0225 & $\mathrm{mg} / \mathrm{L}$ & 1 & \\
\hline
\end{tabular}


Table 156. Chemical analysis using ICP-MS for the $2^{\text {nd }}$ sample from the same bottle of the 2011 wine from Chehalem Stoller (CWS) Vineyard. ND - Non-detect.

\begin{tabular}{|c|c|c|c|c|c|c|}
\hline \multicolumn{7}{|c|}{ Lab ID A4B0432-10 38 CWS 11} \\
\hline Analyte & Result & Detection Limit & Reporting Limit & Units & Dilution & Analyst Notes \\
\hline $\mathrm{S}$ & 70.0 & 2.25 & 2.25 & $\mathrm{mg} / \mathrm{L}$ & 1 & \\
\hline $\mathrm{Hg}$ & ND & 0.00180 & 0.00180 & $\mathrm{mg} / \mathrm{L}$ & 5 & $\mathrm{R}-04$ \\
\hline $\mathrm{Sr}$ & 0.648 & 0.00405 & 0.00405 & $\mathrm{mg} / \mathrm{L}$ & 1 & \\
\hline $\mathrm{Al}$ & ND & 2.25 & 2.25 & $\mathrm{mg} / \mathrm{L}$ & 1 & \\
\hline As & ND & 4.50 & 4.50 & $\mathrm{mg} / \mathrm{L}$ & 1 & $\mathrm{R}-01$ \\
\hline $\mathrm{Ba}$ & 0.386 & 0.0450 & 0.0450 & $\mathrm{mg} / \mathrm{L}$ & 1 & \\
\hline $\mathrm{Be}$ & ND & 0.0450 & 0.0450 & $\mathrm{mg} / \mathrm{L}$ & 1 & \\
\hline $\mathrm{Cd}$ & ND & 0.0450 & 0.0450 & $\mathrm{mg} / \mathrm{L}$ & 1 & \\
\hline $\mathrm{Ca}$ & 52.6 & 2.25 & 2.25 & $\mathrm{mg} / \mathrm{L}$ & 1 & \\
\hline $\mathrm{Cr}$ & ND & 0.450 & 0.450 & $\mathrm{mg} / \mathrm{L}$ & 1 & $\mathrm{R}-01$ \\
\hline $\mathrm{Co}$ & ND & 0.0450 & 0.0450 & $\mathrm{mg} / \mathrm{L}$ & 1 & \\
\hline $\mathrm{Cu}$ & 0.0545 & 0.0450 & 0.0450 & $\mathrm{mg} / \mathrm{L}$ & 1 & \\
\hline $\mathrm{Fe}$ & 1.65 & 0.450 & 0.450 & $\mathrm{mg} / \mathrm{L}$ & 1 & \\
\hline $\mathrm{Pb}$ & ND & 0.0450 & 0.0450 & $\mathrm{mg} / \mathrm{L}$ & 1 & \\
\hline $\mathrm{Mg}$ & 51.7 & 2.25 & 2.25 & $\mathrm{mg} / \mathrm{L}$ & 1 & \\
\hline $\mathrm{Mn}$ & 1.68 & 0.0450 & 0.0450 & $\mathrm{mg} / \mathrm{L}$ & 1 & \\
\hline Mo & ND & 0.225 & 0.225 & $\mathrm{mg} / \mathrm{L}$ & 1 & \\
\hline $\mathrm{Ni}$ & ND & 0.0450 & 0.0450 & $\mathrm{mg} / \mathrm{L}$ & 1 & \\
\hline $\mathrm{P}$ & 204 & 2.25 & 2.25 & $\mathrm{mg} / \mathrm{L}$ & 1 & \\
\hline $\mathrm{K}$ & 762 & 2.25 & 2.25 & $\mathrm{mg} / \mathrm{L}$ & 1 & \\
\hline $\mathrm{Se}$ & ND & 9.00 & 9.00 & $\mathrm{mg} / \mathrm{L}$ & 1 & \\
\hline $\mathrm{Na}$ & 16.4 & 2.25 & 2.25 & $\mathrm{mg} / \mathrm{L}$ & 1 & \\
\hline $\mathrm{V}$ & ND & 0.0450 & 0.0450 & $\mathrm{mg} / \mathrm{L}$ & 1 & \\
\hline $\mathrm{Zn}$ & 0.400 & 0.0450 & 0.0450 & $\mathrm{mg} / \mathrm{L}$ & 1 & \\
\hline
\end{tabular}


Table 157. Chemical analysis using ICP-MS for the 3rd sample from the same bottle of the 2011 wine from Chehalem Stoller (CWS) Vineyard. ND - Non-detect.

\begin{tabular}{|c|c|c|c|c|c|c|}
\hline \multicolumn{7}{|c|}{ Lab ID A4B0432-13 41 CWS 11} \\
\hline Analyte & Result & Detection Limit & Reporting Limit & Units & Dilution & Analyst Notes \\
\hline S & 80.7 & 2.25 & 2.25 & $\mathrm{mg} / \mathrm{L}$ & 1 & \\
\hline $\mathrm{Hg}$ & ND & 0.00180 & 0.00180 & $\mathrm{mg} / \mathrm{L}$ & 5 & $\mathrm{R}-04$ \\
\hline $\mathrm{Sr}$ & 0.688 & 0.00405 & 0.00405 & $\mathrm{mg} / \mathrm{L}$ & 1 & \\
\hline $\mathrm{Al}$ & ND & 2.25 & 2.25 & $\mathrm{mg} / \mathrm{L}$ & 1 & $\mathrm{R}-03$ \\
\hline As & ND & 4.50 & 4.50 & $\mathrm{mg} / \mathrm{L}$ & 1 & $\mathrm{R}-01$ \\
\hline $\mathrm{Ba}$ & 0.392 & 0.0450 & 0.0450 & $\mathrm{mg} / \mathrm{L}$ & 1 & \\
\hline $\mathrm{Be}$ & ND & 0.0450 & 0.0450 & $\mathrm{mg} / \mathrm{L}$ & 1 & $\mathrm{R}-03$ \\
\hline $\mathrm{Cd}$ & ND & 0.0450 & 0.0450 & $\mathrm{mg} / \mathrm{L}$ & 1 & $\mathrm{R}-03$ \\
\hline $\mathrm{Ca}$ & 57.1 & 2.25 & 2.25 & $\mathrm{mg} / \mathrm{L}$ & 1 & \\
\hline $\mathrm{Cr}$ & ND & 0.0450 & 0.0450 & $\mathrm{mg} / \mathrm{L}$ & 1 & R-03 \\
\hline Co & ND & 0.0450 & 0.0450 & $\mathrm{mg} / \mathrm{L}$ & 1 & R-03 \\
\hline $\mathrm{Cu}$ & 0.0570 & 0.0450 & 0.0450 & $\mathrm{mg} / \mathrm{L}$ & 1 & \\
\hline $\mathrm{Fe}$ & 1.69 & 0.450 & 0.450 & $\mathrm{mg} / \mathrm{L}$ & 1 & \\
\hline $\mathrm{Pb}$ & ND & 0.0450 & 0.0450 & $\mathrm{mg} / \mathrm{L}$ & 1 & $\mathrm{R}-03$ \\
\hline $\mathrm{Mg}$ & 60.7 & 2.25 & 2.25 & $\mathrm{mg} / \mathrm{L}$ & 1 & \\
\hline $\mathrm{Mn}$ & 1.80 & 0.0450 & 0.0450 & $\mathrm{mg} / \mathrm{L}$ & 1 & \\
\hline Mo & ND & 0.0450 & 0.0450 & $\mathrm{mg} / \mathrm{L}$ & 1 & R-03 \\
\hline $\mathrm{Ni}$ & ND & 0.0450 & 0.0450 & $\mathrm{mg} / \mathrm{L}$ & 1 & R-03 \\
\hline $\mathrm{P}$ & 210 & 2.25 & 2.25 & $\mathrm{mg} / \mathrm{L}$ & 1 & \\
\hline $\mathrm{K}$ & 852 & 2.25 & 2.25 & $\mathrm{mg} / \mathrm{L}$ & 1 & \\
\hline $\mathrm{Se}$ & ND & 4.50 & 4.50 & $\mathrm{mg} / \mathrm{L}$ & 1 & R-01 \\
\hline $\mathrm{Na}$ & 18.7 & 2.25 & 2.25 & $\mathrm{mg} / \mathrm{L}$ & 1 & \\
\hline $\mathrm{V}$ & ND & 0.0450 & 0.0450 & $\mathrm{mg} / \mathrm{L}$ & 1 & R-03 \\
\hline $\mathrm{Zn}$ & 0.446 & 0.0450 & 0.0450 & $\mathrm{mg} / \mathrm{L}$ & 1 & \\
\hline
\end{tabular}


Table 158. Chemical analysis using ICP-MS for the bottle of the 2007 wine from Chehalem Ridgecrest (CWRC) Vineyard. ND - Non-detect.

\begin{tabular}{|c|c|c|c|c|c|c|}
\hline \multicolumn{7}{|c|}{ Lab ID A4B0052-11 11 CWRC 2007} \\
\hline Analyte & Result & Detection Limit & Reporting Limit & Units & Dilution & Analyst Notes \\
\hline $\mathrm{S}$ & 106 & 1.12 & 1.12 & $\mathrm{mg} / \mathrm{L}$ & 1 & \\
\hline $\mathrm{Hg}$ & ND & 0.000900 & 0.000900 & $\mathrm{mg} / \mathrm{L}$ & 5 & E-03, H-01, R-04 \\
\hline $\mathrm{Sr}$ & 1.49 & 0.00202 & 0.00202 & $\mathrm{mg} / \mathrm{L}$ & 1 & \\
\hline $\mathrm{Al}$ & ND & 1.12 & 1.12 & $\mathrm{mg} / \mathrm{L}$ & 1 & \\
\hline As & ND & 2.25 & 2.25 & $\mathrm{mg} / \mathrm{L}$ & 1 & $\mathrm{R}-01$ \\
\hline $\mathrm{Ba}$ & 0.366 & 0.0225 & 0.0225 & $\mathrm{mg} / \mathrm{L}$ & 1 & \\
\hline $\mathrm{Be}$ & ND & 0.0225 & 0.0225 & $\mathrm{mg} / \mathrm{L}$ & 1 & \\
\hline $\mathrm{Cd}$ & ND & 0.0225 & 0.0225 & $\mathrm{mg} / \mathrm{L}$ & 1 & \\
\hline $\mathrm{Ca}$ & 40.5 & 1.12 & 1.12 & $\mathrm{mg} / \mathrm{L}$ & 1 & \\
\hline $\mathrm{Cr}$ & ND & 0.225 & 0.225 & $\mathrm{mg} / \mathrm{L}$ & 1 & R-01 \\
\hline Co & 0.0345 & 0.0225 & 0.0225 & $\mathrm{mg} / \mathrm{L}$ & 1 & \\
\hline $\mathrm{Cu}$ & 0.553 & 0.0225 & 0.0225 & $\mathrm{mg} / \mathrm{L}$ & 1 & \\
\hline $\mathrm{Fe}$ & 3.84 & 0.225 & 0.225 & $\mathrm{mg} / \mathrm{L}$ & 1 & \\
\hline $\mathrm{Pb}$ & 0.0822 & 0.0225 & 0.0225 & $\mathrm{mg} / \mathrm{L}$ & 1 & \\
\hline $\mathrm{Mg}$ & 49.5 & 1.12 & 1.12 & $\mathrm{mg} / \mathrm{L}$ & 1 & \\
\hline $\mathrm{Mn}$ & 1.34 & 0.0225 & 0.0225 & $\mathrm{mg} / \mathrm{L}$ & 1 & \\
\hline Mo & ND & 0.112 & 0.112 & $\mathrm{mg} / \mathrm{L}$ & 1 & \\
\hline $\mathrm{Ni}$ & ND & 0.0225 & 0.0225 & $\mathrm{mg} / \mathrm{L}$ & 1 & \\
\hline $\mathrm{P}$ & 326 & 1.12 & 1.12 & $\mathrm{mg} / \mathrm{L}$ & 1 & E, Q-41 \\
\hline $\mathrm{K}$ & 700 & 1.12 & 1.12 & $\mathrm{mg} / \mathrm{L}$ & 1 & E \\
\hline $\mathrm{Se}$ & ND & 4.50 & 4.50 & $\mathrm{mg} / \mathrm{L}$ & 1 & Q-41 \\
\hline $\mathrm{Na}$ & 8.54 & 1.12 & 1.12 & $\mathrm{mg} / \mathrm{L}$ & 1 & \\
\hline $\mathrm{V}$ & ND & 0.0225 & 0.0225 & $\mathrm{mg} / \mathrm{L}$ & 1 & \\
\hline $\mathrm{Zn}$ & 0.644 & 0.0225 & 0.0225 & $\mathrm{mg} / \mathrm{L}$ & 1 & \\
\hline
\end{tabular}


Table 159. Chemical analysis using ICP-MS for the bottle of the 2008 wine from Chehalem Ridgecrest (CWRC) Vineyard. ND - Non-detect.

\begin{tabular}{|c|c|c|c|c|c|c|}
\hline \multicolumn{7}{|c|}{ Lab ID A4B0432-18 47 CWRC 08} \\
\hline Analyte & Result & Detection Limit & Reporting Limit & Units & Dilution & Analyst Notes \\
\hline S & 95.8 & 2.25 & 2.25 & $\mathrm{mg} / \mathrm{L}$ & 1 & \\
\hline $\mathrm{Hg}$ & ND & 0.00180 & 0.00180 & $\mathrm{mg} / \mathrm{L}$ & 5 & $\mathrm{R}-04$ \\
\hline $\mathrm{Sr}$ & 1.43 & 0.00405 & 0.00405 & $\mathrm{mg} / \mathrm{L}$ & 1 & \\
\hline $\mathrm{Al}$ & ND & 2.25 & 2.25 & $\mathrm{mg} / \mathrm{L}$ & 1 & $\mathrm{R}-03$ \\
\hline As & ND & 4.50 & 4.50 & $\mathrm{mg} / \mathrm{L}$ & 1 & $\mathrm{R}-01$ \\
\hline $\mathrm{Ba}$ & 0.248 & 0.0450 & 0.0450 & $\mathrm{mg} / \mathrm{L}$ & 1 & \\
\hline $\mathrm{Be}$ & ND & 0.0450 & 0.0450 & $\mathrm{mg} / \mathrm{L}$ & 1 & R-03 \\
\hline $\mathrm{Cd}$ & ND & 0.0450 & 0.0450 & $\mathrm{mg} / \mathrm{L}$ & 1 & $\mathrm{R}-03$ \\
\hline $\mathrm{Ca}$ & 39.2 & 2.25 & 2.25 & $\mathrm{mg} / \mathrm{L}$ & 1 & \\
\hline $\mathrm{Cr}$ & ND & 0.0450 & 0.0450 & $\mathrm{mg} / \mathrm{L}$ & 1 & R-03 \\
\hline $\mathrm{Co}$ & ND & 0.0450 & 0.0450 & $\mathrm{mg} / \mathrm{L}$ & 1 & R-03 \\
\hline $\mathrm{Cu}$ & 0.350 & 0.0450 & 0.0450 & $\mathrm{mg} / \mathrm{L}$ & 1 & \\
\hline $\mathrm{Fe}$ & 2.70 & 0.450 & 0.450 & $\mathrm{mg} / \mathrm{L}$ & 1 & \\
\hline $\mathrm{Pb}$ & ND & 0.0450 & 0.0450 & $\mathrm{mg} / \mathrm{L}$ & 1 & R-03 \\
\hline $\mathrm{Mg}$ & 87.0 & 2.25 & 2.25 & $\mathrm{mg} / \mathrm{L}$ & 1 & \\
\hline $\mathrm{Mn}$ & 1.57 & 0.0450 & 0.0450 & $\mathrm{mg} / \mathrm{L}$ & 1 & \\
\hline Mo & ND & 0.0450 & 0.0450 & $\mathrm{mg} / \mathrm{L}$ & 1 & R-03 \\
\hline $\mathrm{Ni}$ & ND & 0.0450 & 0.0450 & $\mathrm{mg} / \mathrm{L}$ & 1 & R-03 \\
\hline $\mathrm{P}$ & 211 & 2.25 & 2.25 & $\mathrm{mg} / \mathrm{L}$ & 1 & \\
\hline $\mathrm{K}$ & 722 & 2.25 & 2.25 & $\mathrm{mg} / \mathrm{L}$ & 1 & \\
\hline $\mathrm{Se}$ & ND & 4.50 & 4.50 & $\mathrm{mg} / \mathrm{L}$ & 1 & R-01 \\
\hline $\mathrm{Na}$ & 8.37 & 2.25 & 2.25 & $\mathrm{mg} / \mathrm{L}$ & 1 & \\
\hline $\mathrm{V}$ & ND & 0.0450 & 0.0450 & $\mathrm{mg} / \mathrm{L}$ & 1 & R-03 \\
\hline $\mathrm{Zn}$ & 0.604 & 0.0450 & 0.0450 & $\mathrm{mg} / \mathrm{L}$ & 1 & \\
\hline
\end{tabular}


Table 160. Chemical analysis using ICP-MS for the $2^{\text {nd }}$ sample from the same bottle of the 2008 wine from Chehalem Ridgecrest (CWRC) Vineyard. ND - Non-detect.

\begin{tabular}{|c|c|c|c|c|c|c|}
\hline \multicolumn{7}{|c|}{ Lab ID A4B0432-12 40 CWRC 08} \\
\hline Analyte & Result & Detection Limit & Reporting Limit & Units & Dilution & Analyst Notes \\
\hline S & 103 & 2.25 & 2.25 & $\mathrm{mg} / \mathrm{L}$ & 1 & \\
\hline $\mathrm{Hg}$ & ND & 0.00180 & 0.00180 & $\mathrm{mg} / \mathrm{L}$ & 5 & $\mathrm{R}-04$ \\
\hline $\mathrm{Sr}$ & 1.36 & 0.00405 & 0.00405 & $\mathrm{mg} / \mathrm{L}$ & 1 & \\
\hline $\mathrm{Al}$ & ND & 2.25 & 2.25 & $\mathrm{mg} / \mathrm{L}$ & 1 & $\mathrm{R}-03$ \\
\hline As & ND & 4.50 & 4.50 & $\mathrm{mg} / \mathrm{L}$ & 1 & $\mathrm{R}-01$ \\
\hline $\mathrm{Ba}$ & 0.275 & 0.0450 & 0.0450 & $\mathrm{mg} / \mathrm{L}$ & 1 & \\
\hline $\mathrm{Be}$ & ND & 0.0450 & 0.0450 & $\mathrm{mg} / \mathrm{L}$ & 1 & \\
\hline $\mathrm{Cd}$ & ND & 0.0450 & 0.0450 & $\mathrm{mg} / \mathrm{L}$ & 1 & $\mathrm{R}-03$ \\
\hline $\mathrm{Ca}$ & 40.1 & 2.25 & 2.25 & $\mathrm{mg} / \mathrm{L}$ & 1 & \\
\hline $\mathrm{Cr}$ & ND & 0.0450 & 0.0450 & $\mathrm{mg} / \mathrm{L}$ & 1 & R-03 \\
\hline Co & ND & 0.0450 & 0.0450 & $\mathrm{mg} / \mathrm{L}$ & 1 & R-03 \\
\hline $\mathrm{Cu}$ & 0.404 & 0.0450 & 0.0450 & $\mathrm{mg} / \mathrm{L}$ & 1 & \\
\hline $\mathrm{Fe}$ & 2.83 & 0.450 & 0.450 & $\mathrm{mg} / \mathrm{L}$ & 1 & \\
\hline $\mathrm{Pb}$ & ND & 0.0450 & 0.0450 & $\mathrm{mg} / \mathrm{L}$ & 1 & R-03 \\
\hline $\mathrm{Mg}$ & 93.0 & 2.25 & 2.25 & $\mathrm{mg} / \mathrm{L}$ & 1 & \\
\hline $\mathrm{Mn}$ & 1.58 & 0.0450 & 0.0450 & $\mathrm{mg} / \mathrm{L}$ & 1 & \\
\hline Mo & ND & 0.0450 & 0.0450 & $\mathrm{mg} / \mathrm{L}$ & 1 & R-03 \\
\hline $\mathrm{Ni}$ & ND & 0.0450 & 0.0450 & $\mathrm{mg} / \mathrm{L}$ & 1 & R-03 \\
\hline $\mathrm{P}$ & 205 & 2.25 & 2.25 & $\mathrm{mg} / \mathrm{L}$ & 1 & \\
\hline $\mathrm{K}$ & 724 & 2.25 & 2.25 & $\mathrm{mg} / \mathrm{L}$ & 1 & \\
\hline $\mathrm{Se}$ & ND & 4.50 & 4.50 & $\mathrm{mg} / \mathrm{L}$ & 1 & R-01 \\
\hline $\mathrm{Na}$ & 8.26 & 2.25 & 2.25 & $\mathrm{mg} / \mathrm{L}$ & 1 & \\
\hline $\mathrm{V}$ & ND & 0.0450 & 0.0450 & $\mathrm{mg} / \mathrm{L}$ & 1 & R-03 \\
\hline $\mathrm{Zn}$ & 0.632 & 0.0450 & 0.0450 & $\mathrm{mg} / \mathrm{L}$ & 1 & \\
\hline
\end{tabular}


Table 161. Chemical analysis using ICP-MS for the bottle of the 2011 wine from Chehalem Ridgecrest (CWRC) Vineyard. ND - Non-detect.

\begin{tabular}{|c|c|c|c|c|c|c|}
\hline \multicolumn{7}{|c|}{ Lab ID A4B0052-06 6 CWRC 2011} \\
\hline Analyte & Result & Detection Limit & Reporting Limit & Units & Dilution & Analyst Notes \\
\hline S & 83.4 & 1.12 & 1.12 & $\mathrm{mg} / \mathrm{L}$ & 1 & \\
\hline $\mathrm{Hg}$ & ND & 0.000900 & 0.000900 & $\mathrm{mg} / \mathrm{L}$ & 5 & $\mathrm{H}-01, \mathrm{R}-04$ \\
\hline $\mathrm{Sr}$ & 1.26 & 0.00202 & 0.00202 & $\mathrm{mg} / \mathrm{L}$ & 1 & \\
\hline $\mathrm{Al}$ & ND & 1.12 & 1.12 & $\mathrm{mg} / \mathrm{L}$ & 1 & \\
\hline As & ND & 2.25 & 2.25 & $\mathrm{mg} / \mathrm{L}$ & 1 & $\mathrm{R}-01$ \\
\hline $\mathrm{Ba}$ & 0.312 & 0.0225 & 0.0225 & $\mathrm{mg} / \mathrm{L}$ & 1 & \\
\hline $\mathrm{Be}$ & ND & 0.0225 & 0.0225 & $\mathrm{mg} / \mathrm{L}$ & 1 & \\
\hline $\mathrm{Cd}$ & ND & 0.0225 & 0.0225 & $\mathrm{mg} / \mathrm{L}$ & 1 & \\
\hline $\mathrm{Ca}$ & 55.6 & 1.12 & 1.12 & $\mathrm{mg} / \mathrm{L}$ & 1 & \\
\hline $\mathrm{Cr}$ & ND & 0.225 & 0.225 & $\mathrm{mg} / \mathrm{L}$ & 1 & R-01 \\
\hline $\mathrm{Co}$ & 0.0298 & 0.0225 & 0.0225 & $\mathrm{mg} / \mathrm{L}$ & 1 & \\
\hline $\mathrm{Cu}$ & 0.191 & 0.0225 & 0.0225 & $\mathrm{mg} / \mathrm{L}$ & 1 & \\
\hline $\mathrm{Fe}$ & 2.10 & 0.225 & 0.225 & $\mathrm{mg} / \mathrm{L}$ & 1 & \\
\hline $\mathrm{Pb}$ & 0.0622 & 0.0225 & 0.0225 & $\mathrm{mg} / \mathrm{L}$ & 1 & \\
\hline $\mathrm{Mg}$ & 46.4 & 1.12 & 1.12 & $\mathrm{mg} / \mathrm{L}$ & 1 & \\
\hline $\mathrm{Mn}$ & 1.23 & 0.0225 & 0.0225 & $\mathrm{mg} / \mathrm{L}$ & 1 & \\
\hline Mo & ND & 0.112 & 0.112 & $\mathrm{mg} / \mathrm{L}$ & 1 & \\
\hline $\mathrm{Ni}$ & ND & 0.0225 & 0.0225 & $\mathrm{mg} / \mathrm{L}$ & 1 & \\
\hline $\mathrm{P}$ & 425 & 1.12 & 1.12 & $\mathrm{mg} / \mathrm{L}$ & 1 & $\mathrm{E}$ \\
\hline $\mathrm{K}$ & 620 & 1.12 & 1.12 & $\mathrm{mg} / \mathrm{L}$ & 1 & $\mathrm{E}$ \\
\hline $\mathrm{Se}$ & ND & 4.50 & 4.50 & $\mathrm{mg} / \mathrm{L}$ & 1 & Q-41 \\
\hline $\mathrm{Na}$ & 9.55 & 1.12 & 1.12 & $\mathrm{mg} / \mathrm{L}$ & 1 & \\
\hline $\mathrm{V}$ & ND & 0.0225 & 0.0225 & $\mathrm{mg} / \mathrm{L}$ & 1 & \\
\hline $\mathrm{Zn}$ & 1.11 & 0.0225 & 0.0225 & $\mathrm{mg} / \mathrm{L}$ & 1 & \\
\hline
\end{tabular}


Table 162. Chemical analysis using ICP-MS for the $2^{\text {nd }}$ sample from the same bottle of the 2011 wine from Chehalem Ridgecrest (CWRC) Vineyard. ND - Non-detect.

\begin{tabular}{|c|c|c|c|c|c|c|}
\hline \multicolumn{7}{|c|}{ Lab ID A4B0432-04 32 CWRC 11} \\
\hline Analyte & Result & Detection Limit & Reporting Limit & Units & Dilution & Analyst Notes \\
\hline $\mathrm{S}$ & 80.1 & 2.25 & 2.25 & $\mathrm{mg} / \mathrm{L}$ & 1 & \\
\hline $\mathrm{Hg}$ & ND & 0.00180 & 0.00180 & $\mathrm{mg} / \mathrm{L}$ & 5 & $\mathrm{R}-04$ \\
\hline $\mathrm{Sr}$ & 1.15 & 0.00405 & 0.00405 & $\mathrm{mg} / \mathrm{L}$ & 1 & \\
\hline $\mathrm{Al}$ & ND & 2.25 & 2.25 & $\mathrm{mg} / \mathrm{L}$ & 1 & \\
\hline As & ND & 4.50 & 4.50 & $\mathrm{mg} / \mathrm{L}$ & 1 & $\mathrm{R}-01$ \\
\hline $\mathrm{Ba}$ & 0.273 & 0.0450 & 0.0450 & $\mathrm{mg} / \mathrm{L}$ & 1 & \\
\hline $\mathrm{Be}$ & ND & 0.0450 & 0.0450 & $\mathrm{mg} / \mathrm{L}$ & 1 & \\
\hline $\mathrm{Cd}$ & ND & 0.0450 & 0.0450 & $\mathrm{mg} / \mathrm{L}$ & 1 & \\
\hline $\mathrm{Ca}$ & 62.0 & 2.25 & 2.25 & $\mathrm{mg} / \mathrm{L}$ & 1 & \\
\hline $\mathrm{Cr}$ & ND & 0.450 & 0.450 & $\mathrm{mg} / \mathrm{L}$ & 1 & R-01 \\
\hline Co & ND & 0.0450 & 0.0450 & $\mathrm{mg} / \mathrm{L}$ & 1 & \\
\hline $\mathrm{Cu}$ & 0.150 & 0.0450 & 0.0450 & $\mathrm{mg} / \mathrm{L}$ & 1 & \\
\hline $\mathrm{Fe}$ & 2.10 & 0.450 & 0.450 & $\mathrm{mg} / \mathrm{L}$ & 1 & \\
\hline $\mathrm{Pb}$ & ND & 0.0450 & 0.0450 & $\mathrm{mg} / \mathrm{L}$ & 1 & \\
\hline $\mathrm{Mg}$ & 62.4 & 2.25 & 2.25 & $\mathrm{mg} / \mathrm{L}$ & 1 & \\
\hline $\mathrm{Mn}$ & 1.31 & 0.0450 & 0.0450 & $\mathrm{mg} / \mathrm{L}$ & 1 & \\
\hline Mo & ND & 0.225 & 0.225 & $\mathrm{mg} / \mathrm{L}$ & 1 & \\
\hline $\mathrm{Ni}$ & ND & 0.0450 & 0.0450 & $\mathrm{mg} / \mathrm{L}$ & 1 & \\
\hline $\mathrm{P}$ & 341 & 2.25 & 2.25 & $\mathrm{mg} / \mathrm{L}$ & 1 & \\
\hline $\mathrm{K}$ & 659 & 2.25 & 2.25 & $\mathrm{mg} / \mathrm{L}$ & 1 & \\
\hline $\mathrm{Se}$ & ND & 9.00 & 9.00 & $\mathrm{mg} / \mathrm{L}$ & 1 & \\
\hline $\mathrm{Na}$ & 9.46 & 2.25 & 2.25 & $\mathrm{mg} / \mathrm{L}$ & 1 & \\
\hline $\mathrm{V}$ & ND & 0.0450 & 0.0450 & $\mathrm{mg} / \mathrm{L}$ & 1 & \\
\hline $\mathrm{Zn}$ & 1.02 & 0.0450 & 0.0450 & $\mathrm{mg} / \mathrm{L}$ & 1 & \\
\hline
\end{tabular}


Table 163. Chemical analysis using ICP-MS for the $3^{\text {rd }}$ sample from the same bottle of the 2011 wine from Chehalem Ridgecrest (CWRC) Vineyard. ND - Non-detect.

\begin{tabular}{|c|c|c|c|c|c|c|}
\hline \multicolumn{7}{|c|}{ Lab ID A4B0432-14 42 CWRC 11} \\
\hline Analyte & Result & Detection Limit & Reporting Limit & Units & Dilution & Analyst Notes \\
\hline S & 94.6 & 2.25 & 2.25 & $\mathrm{mg} / \mathrm{L}$ & 1 & \\
\hline $\mathrm{Hg}$ & ND & 0.00180 & 0.00180 & $\mathrm{mg} / \mathrm{L}$ & 5 & $\mathrm{R}-04$ \\
\hline $\mathrm{Sr}$ & 1.17 & 0.00405 & 0.00405 & $\mathrm{mg} / \mathrm{L}$ & 1 & \\
\hline $\mathrm{Al}$ & ND & 2.25 & 2.25 & $\mathrm{mg} / \mathrm{L}$ & 1 & $\mathrm{R}-03$ \\
\hline As & ND & 4.50 & 4.50 & $\mathrm{mg} / \mathrm{L}$ & 1 & $\mathrm{R}-01$ \\
\hline $\mathrm{Ba}$ & 0.278 & 0.0450 & 0.0450 & $\mathrm{mg} / \mathrm{L}$ & 1 & \\
\hline $\mathrm{Be}$ & ND & 0.0450 & 0.0450 & $\mathrm{mg} / \mathrm{L}$ & 1 & $\mathrm{R}-03$ \\
\hline $\mathrm{Cd}$ & ND & 0.0450 & 0.0450 & $\mathrm{mg} / \mathrm{L}$ & 1 & $\mathrm{R}-03$ \\
\hline $\mathrm{Ca}$ & 67.1 & 2.25 & 2.25 & $\mathrm{mg} / \mathrm{L}$ & 1 & \\
\hline $\mathrm{Cr}$ & ND & 0.0450 & 0.0450 & $\mathrm{mg} / \mathrm{L}$ & 1 & R-03 \\
\hline Co & ND & 0.0450 & 0.0450 & $\mathrm{mg} / \mathrm{L}$ & 1 & R-03 \\
\hline $\mathrm{Cu}$ & 0.146 & 0.0450 & 0.0450 & $\mathrm{mg} / \mathrm{L}$ & 1 & \\
\hline $\mathrm{Fe}$ & 2.21 & 0.450 & 0.450 & $\mathrm{mg} / \mathrm{L}$ & 1 & \\
\hline $\mathrm{Pb}$ & ND & 0.0450 & 0.0450 & $\mathrm{mg} / \mathrm{L}$ & 1 & $\mathrm{R}-03$ \\
\hline $\mathrm{Mg}$ & 75.8 & 2.25 & 2.25 & $\mathrm{mg} / \mathrm{L}$ & 1 & \\
\hline $\mathrm{Mn}$ & 1.40 & 0.0450 & 0.0450 & $\mathrm{mg} / \mathrm{L}$ & 1 & \\
\hline Mo & ND & 0.0450 & 0.0450 & $\mathrm{mg} / \mathrm{L}$ & 1 & R-03 \\
\hline $\mathrm{Ni}$ & ND & 0.0450 & 0.0450 & $\mathrm{mg} / \mathrm{L}$ & 1 & R-03 \\
\hline $\mathrm{P}$ & 325 & 2.25 & 2.25 & $\mathrm{mg} / \mathrm{L}$ & 1 & \\
\hline $\mathrm{K}$ & 739 & 2.25 & 2.25 & $\mathrm{mg} / \mathrm{L}$ & 1 & \\
\hline $\mathrm{Se}$ & ND & 4.50 & 4.50 & $\mathrm{mg} / \mathrm{L}$ & 1 & R-01 \\
\hline $\mathrm{Na}$ & 10.8 & 2.25 & 2.25 & $\mathrm{mg} / \mathrm{L}$ & 1 & \\
\hline $\mathrm{V}$ & ND & 0.0450 & 0.0450 & $\mathrm{mg} / \mathrm{L}$ & 1 & R-03 \\
\hline $\mathrm{Zn}$ & 1.15 & 0.0450 & 0.0450 & $\mathrm{mg} / \mathrm{L}$ & 1 & \\
\hline
\end{tabular}


Table 164. Chemical analysis using ICP-MS for the bottle of the 2008 wine from Chehalem Corral Creek (CWCC) Vineyard. ND - Non-detect.

\begin{tabular}{|c|c|c|c|c|c|c|}
\hline \multicolumn{7}{|c|}{ Lab ID A4B0432-06 34 CWCC 08} \\
\hline Analyte & Result & Detection Limit & Reporting Limit & Units & Dilution & Analyst Notes \\
\hline S & 74.8 & 2.25 & 2.25 & $\mathrm{mg} / \mathrm{L}$ & 1 & \\
\hline $\mathrm{Hg}$ & ND & 0.00180 & 0.00180 & $\mathrm{mg} / \mathrm{L}$ & 5 & $\mathrm{R}-04$ \\
\hline $\mathrm{Sr}$ & 1.07 & 0.00405 & 0.00405 & $\mathrm{mg} / \mathrm{L}$ & 1 & \\
\hline $\mathrm{Al}$ & ND & 2.25 & 2.25 & $\mathrm{mg} / \mathrm{L}$ & 1 & \\
\hline As & ND & 4.50 & 4.50 & $\mathrm{mg} / \mathrm{L}$ & 1 & $\mathrm{R}-01$ \\
\hline $\mathrm{Ba}$ & 0.465 & 0.0450 & 0.0450 & $\mathrm{mg} / \mathrm{L}$ & 1 & \\
\hline $\mathrm{Be}$ & ND & 0.0450 & 0.0450 & $\mathrm{mg} / \mathrm{L}$ & 1 & \\
\hline $\mathrm{Cd}$ & ND & 0.0450 & 0.0450 & $\mathrm{mg} / \mathrm{L}$ & 1 & \\
\hline $\mathrm{Ca}$ & 39.0 & 2.25 & 2.25 & $\mathrm{mg} / \mathrm{L}$ & 1 & \\
\hline $\mathrm{Cr}$ & ND & 0.450 & 0.450 & $\mathrm{mg} / \mathrm{L}$ & 1 & R-01 \\
\hline Co & ND & 0.0450 & 0.0450 & $\mathrm{mg} / \mathrm{L}$ & 1 & \\
\hline $\mathrm{Cu}$ & 0.166 & 0.0450 & 0.0450 & $\mathrm{mg} / \mathrm{L}$ & 1 & \\
\hline $\mathrm{Fe}$ & 2.70 & 0.450 & 0.450 & $\mathrm{mg} / \mathrm{L}$ & 1 & \\
\hline $\mathrm{Pb}$ & ND & 0.0450 & 0.0450 & $\mathrm{mg} / \mathrm{L}$ & 1 & \\
\hline $\mathrm{Mg}$ & 79.3 & 2.25 & 2.25 & $\mathrm{mg} / \mathrm{L}$ & 1 & \\
\hline $\mathrm{Mn}$ & 1.08 & 0.0450 & 0.0450 & $\mathrm{mg} / \mathrm{L}$ & 1 & \\
\hline Mo & ND & 0.225 & 0.225 & $\mathrm{mg} / \mathrm{L}$ & 1 & \\
\hline $\mathrm{Ni}$ & ND & 0.0450 & 0.0450 & $\mathrm{mg} / \mathrm{L}$ & 1 & \\
\hline $\mathrm{P}$ & 252 & 2.25 & 2.25 & $\mathrm{mg} / \mathrm{L}$ & 1 & \\
\hline $\mathrm{K}$ & 748 & 2.25 & 2.25 & $\mathrm{mg} / \mathrm{L}$ & 1 & \\
\hline $\mathrm{Se}$ & ND & 9.00 & 9.00 & $\mathrm{mg} / \mathrm{L}$ & 1 & \\
\hline $\mathrm{Na}$ & 4.69 & 2.25 & 2.25 & $\mathrm{mg} / \mathrm{L}$ & 1 & \\
\hline $\mathrm{V}$ & ND & 0.0450 & 0.0450 & $\mathrm{mg} / \mathrm{L}$ & 1 & \\
\hline $\mathrm{Zn}$ & 0.414 & 0.0450 & 0.0450 & $\mathrm{mg} / \mathrm{L}$ & 1 & \\
\hline
\end{tabular}


Table 165. Chemical analysis using ICP-MS for the $2^{\text {nd }}$ sample from the bottle of the 2008 wine from Chehalem Corral Creek (CWCC) Vineyard. ND - Non-detect.

\begin{tabular}{|c|c|c|c|c|c|c|}
\hline \multicolumn{7}{|c|}{ Lab ID A4B0432-17 46 CWCC 08} \\
\hline Analyte & Result & Detection Limit & Reporting Limit & Units & Dilution & Analyst Notes \\
\hline $\mathrm{S}$ & 76.9 & 2.25 & 2.25 & $\mathrm{mg} / \mathrm{L}$ & 1 & \\
\hline $\mathrm{Hg}$ & ND & 0.00180 & 0.00180 & $\mathrm{mg} / \mathrm{L}$ & 5 & $\mathrm{R}-04$ \\
\hline $\mathrm{Sr}$ & 1.09 & 0.00405 & 0.00405 & $\mathrm{mg} / \mathrm{L}$ & 1 & \\
\hline $\mathrm{Al}$ & ND & 2.25 & 2.25 & $\mathrm{mg} / \mathrm{L}$ & 1 & $\mathrm{R}-03$ \\
\hline As & ND & 4.50 & 4.50 & $\mathrm{mg} / \mathrm{L}$ & 1 & $\mathrm{R}-01$ \\
\hline $\mathrm{Ba}$ & 0.472 & 0.0450 & 0.0450 & $\mathrm{mg} / \mathrm{L}$ & 1 & \\
\hline $\mathrm{Be}$ & ND & 0.0450 & 0.0450 & $\mathrm{mg} / \mathrm{L}$ & 1 & $\mathrm{R}-03$ \\
\hline $\mathrm{Cd}$ & ND & 0.0450 & 0.0450 & $\mathrm{mg} / \mathrm{L}$ & 1 & $\mathrm{R}-03$ \\
\hline $\mathrm{Ca}$ & 39.7 & 2.25 & 2.25 & $\mathrm{mg} / \mathrm{L}$ & 1 & \\
\hline $\mathrm{Cr}$ & ND & 0.0450 & 0.0450 & $\mathrm{mg} / \mathrm{L}$ & 1 & $\mathrm{R}-03$ \\
\hline Co & ND & 0.0450 & 0.0450 & $\mathrm{mg} / \mathrm{L}$ & 1 & $\mathrm{R}-03$ \\
\hline $\mathrm{Cu}$ & 0.176 & 0.0450 & 0.0450 & $\mathrm{mg} / \mathrm{L}$ & 1 & \\
\hline $\mathrm{Fe}$ & 2.66 & 0.450 & 0.450 & $\mathrm{mg} / \mathrm{L}$ & 1 & \\
\hline $\mathrm{Pb}$ & ND & 0.0450 & 0.0450 & $\mathrm{mg} / \mathrm{L}$ & 1 & R-03 \\
\hline $\mathrm{Mg}$ & 85.8 & 2.25 & 2.25 & $\mathrm{mg} / \mathrm{L}$ & 1 & \\
\hline $\mathrm{Mn}$ & 1.11 & 0.0450 & 0.0450 & $\mathrm{mg} / \mathrm{L}$ & 1 & \\
\hline Mo & ND & 0.0450 & 0.0450 & $\mathrm{mg} / \mathrm{L}$ & 1 & R-03 \\
\hline $\mathrm{Ni}$ & ND & 0.0450 & 0.0450 & $\mathrm{mg} / \mathrm{L}$ & 1 & R-03 \\
\hline $\mathrm{P}$ & 240 & 2.25 & 2.25 & $\mathrm{mg} / \mathrm{L}$ & 1 & \\
\hline $\mathrm{K}$ & 793 & 2.25 & 2.25 & $\mathrm{mg} / \mathrm{L}$ & 1 & \\
\hline $\mathrm{Se}$ & ND & 4.50 & 4.50 & $\mathrm{mg} / \mathrm{L}$ & 1 & R-01 \\
\hline $\mathrm{Na}$ & 5.04 & 2.25 & 2.25 & $\mathrm{mg} / \mathrm{L}$ & 1 & \\
\hline $\mathrm{V}$ & ND & 0.0450 & 0.0450 & $\mathrm{mg} / \mathrm{L}$ & 1 & R-03 \\
\hline $\mathrm{Zn}$ & 0.418 & 0.0450 & 0.0450 & $\mathrm{mg} / \mathrm{L}$ & 1 & \\
\hline
\end{tabular}


Table 166. Chemical analysis using ICP-MS for the bottle of the 2009 wine from Chehalem Corral Creek (CWCC) Vineyard. ND - Non-detect.

\begin{tabular}{|c|c|c|c|c|c|c|}
\hline \multicolumn{7}{|c|}{ Lab ID A4B0164-08 22 CWCC 09} \\
\hline Analyte & Result & Detection Limit & Reporting Limit & Units & Dilution & Analyst Notes \\
\hline $\mathrm{S}$ & 84.8 & 2.25 & 2.25 & $\mathrm{mg} / \mathrm{L}$ & 1 & \\
\hline $\mathrm{Hg}$ & ND & 0.00180 & 0.00180 & $\mathrm{mg} / \mathrm{L}$ & 5 & H-01, R-04 \\
\hline $\mathrm{Sr}$ & 0.992 & 0.00405 & 0.00405 & $\mathrm{mg} / \mathrm{L}$ & 1 & \\
\hline $\mathrm{Al}$ & ND & 2.25 & 2.25 & $\mathrm{mg} / \mathrm{L}$ & 1 & \\
\hline As & ND & 4.50 & 4.50 & $\mathrm{mg} / \mathrm{L}$ & 1 & $\mathrm{R}-01$ \\
\hline $\mathrm{Ba}$ & 0.272 & 0.0450 & 0.0450 & $\mathrm{mg} / \mathrm{L}$ & 1 & \\
\hline $\mathrm{Be}$ & ND & 0.0450 & 0.0450 & $\mathrm{mg} / \mathrm{L}$ & 1 & \\
\hline $\mathrm{Cd}$ & ND & 0.0450 & 0.0450 & $\mathrm{mg} / \mathrm{L}$ & 1 & \\
\hline $\mathrm{Ca}$ & 49.0 & 2.25 & 2.25 & $\mathrm{mg} / \mathrm{L}$ & 1 & \\
\hline $\mathrm{Cr}$ & ND & 0.450 & 0.450 & $\mathrm{mg} / \mathrm{L}$ & 1 & $\mathrm{R}-01$ \\
\hline Co & ND & 0.0450 & 0.0450 & $\mathrm{mg} / \mathrm{L}$ & 1 & \\
\hline $\mathrm{Cu}$ & 0.102 & 0.0450 & 0.0450 & $\mathrm{mg} / \mathrm{L}$ & 1 & \\
\hline $\mathrm{Fe}$ & 2.18 & 0.450 & 0.450 & $\mathrm{mg} / \mathrm{L}$ & 1 & \\
\hline $\mathrm{Pb}$ & ND & 0.0450 & 0.0450 & $\mathrm{mg} / \mathrm{L}$ & 1 & \\
\hline $\mathrm{Mg}$ & 68.2 & 2.25 & 2.25 & $\mathrm{mg} / \mathrm{L}$ & 1 & \\
\hline $\mathrm{Mn}$ & 0.926 & 0.0450 & 0.0450 & $\mathrm{mg} / \mathrm{L}$ & 1 & \\
\hline Mo & ND & 0.225 & 0.225 & $\mathrm{mg} / \mathrm{L}$ & 1 & \\
\hline $\mathrm{Ni}$ & ND & 0.0450 & 0.0450 & $\mathrm{mg} / \mathrm{L}$ & 1 & \\
\hline $\mathrm{P}$ & 384 & 2.25 & 2.25 & $\mathrm{mg} / \mathrm{L}$ & 1 & \\
\hline $\mathrm{K}$ & 828 & 2.25 & 2.25 & $\mathrm{mg} / \mathrm{L}$ & 1 & \\
\hline $\mathrm{Se}$ & ND & 9.00 & 9.00 & $\mathrm{mg} / \mathrm{L}$ & 1 & \\
\hline $\mathrm{Na}$ & 5.32 & 2.25 & 2.25 & $\mathrm{mg} / \mathrm{L}$ & 1 & \\
\hline $\mathrm{V}$ & ND & 0.0450 & 0.0450 & $\mathrm{mg} / \mathrm{L}$ & 1 & \\
\hline $\mathrm{Zn}$ & 0.478 & 0.0450 & 0.0450 & $\mathrm{mg} / \mathrm{L}$ & 1 & \\
\hline
\end{tabular}


Table 167. Chemical analysis using ICP-MS for the bottle of the 2011 wine from Chehalem Corral Creek (CWCC) Vineyard. ND - Non-detect.

\begin{tabular}{|c|c|c|c|c|c|c|}
\hline \multicolumn{7}{|c|}{ Lab ID A4B0164-08 8 CWCC 2011} \\
\hline Analyte & Result & Detection Limit & Reporting Limit & Units & Dilution & Analyst Notes \\
\hline $\mathrm{S}$ & 88.2 & 1.12 & 1.12 & $\mathrm{mg} / \mathrm{L}$ & 1 & \\
\hline $\mathrm{Hg}$ & ND & 0.000900 & 0.000900 & $\mathrm{mg} / \mathrm{L}$ & 5 & H-01, R-04 \\
\hline $\mathrm{Sr}$ & 0.914 & 0.00202 & 0.00202 & $\mathrm{mg} / \mathrm{L}$ & 1 & \\
\hline $\mathrm{Al}$ & ND & 1.12 & 1.12 & $\mathrm{mg} / \mathrm{L}$ & 1 & \\
\hline As & ND & 2.25 & 2.25 & $\mathrm{mg} / \mathrm{L}$ & 1 & $\mathrm{R}-01$ \\
\hline $\mathrm{Ba}$ & 0.338 & 0.0225 & 0.0225 & $\mathrm{mg} / \mathrm{L}$ & 1 & \\
\hline $\mathrm{Be}$ & ND & 0.0225 & 0.0225 & $\mathrm{mg} / \mathrm{L}$ & 1 & \\
\hline $\mathrm{Cd}$ & ND & 0.0225 & 0.0225 & $\mathrm{mg} / \mathrm{L}$ & 1 & \\
\hline $\mathrm{Ca}$ & 51.3 & 1.12 & 1.12 & $\mathrm{mg} / \mathrm{L}$ & 1 & \\
\hline $\mathrm{Cr}$ & ND & 0.225 & 0.225 & $\mathrm{mg} / \mathrm{L}$ & 1 & $\mathrm{R}-01$ \\
\hline Co & 0.0312 & 0.0225 & 0.0225 & $\mathrm{mg} / \mathrm{L}$ & 1 & \\
\hline $\mathrm{Cu}$ & 0.178 & 0.0225 & 0.0225 & $\mathrm{mg} / \mathrm{L}$ & 1 & \\
\hline $\mathrm{Fe}$ & 2.05 & 0.225 & 0.225 & $\mathrm{mg} / \mathrm{L}$ & 1 & \\
\hline $\mathrm{Pb}$ & 0.0845 & 0.0225 & 0.0225 & $\mathrm{mg} / \mathrm{L}$ & 1 & \\
\hline $\mathrm{Mg}$ & 42.4 & 1.12 & 1.12 & $\mathrm{mg} / \mathrm{L}$ & 1 & \\
\hline $\mathrm{Mn}$ & 0.816 & 0.0225 & 0.0225 & $\mathrm{mg} / \mathrm{L}$ & 1 & \\
\hline Mo & ND & 0.112 & 0.112 & $\mathrm{mg} / \mathrm{L}$ & 1 & \\
\hline $\mathrm{Ni}$ & ND & 0.0225 & 0.0225 & $\mathrm{mg} / \mathrm{L}$ & 1 & \\
\hline $\mathrm{P}$ & 523 & 1.12 & 1.12 & $\mathrm{mg} / \mathrm{L}$ & 1 & E, Q-41 \\
\hline $\mathrm{K}$ & 761 & 1.12 & 1.12 & $\mathrm{mg} / \mathrm{L}$ & 1 & $\mathrm{E}$ \\
\hline $\mathrm{Se}$ & ND & 4.50 & 4.50 & $\mathrm{mg} / \mathrm{L}$ & 1 & Q-41 \\
\hline $\mathrm{Na}$ & 8.79 & 1.12 & 1.12 & $\mathrm{mg} / \mathrm{L}$ & 1 & \\
\hline $\mathrm{V}$ & ND & 0.0225 & 0.0225 & $\mathrm{mg} / \mathrm{L}$ & 1 & \\
\hline $\mathrm{Zn}$ & 0.596 & 0.0225 & 0.0225 & $\mathrm{mg} / \mathrm{L}$ & 1 & \\
\hline
\end{tabular}


Table 168. Chemical analysis using ICP-MS for the $2^{\text {nd }}$ sample from the same bottle of the 2011 wine from Chehalem Corral Creek (CWCC) Vineyard. ND - Non-detect.

\begin{tabular}{|c|c|c|c|c|c|c|}
\hline \multicolumn{7}{|c|}{ Lab ID A4B0164-0 21 CWCC 11} \\
\hline Analyte & Result & Detection Limit & Reporting Limit & Units & Dilution & Analyst Notes \\
\hline S & 86.2 & 2.25 & 2.25 & $\mathrm{mg} / \mathrm{L}$ & 1 & \\
\hline $\mathrm{Hg}$ & ND & 0.00180 & 0.00180 & $\mathrm{mg} / \mathrm{L}$ & 5 & H-01, R-04 \\
\hline $\mathrm{Sr}$ & 0.858 & 0.00405 & 0.00405 & $\mathrm{mg} / \mathrm{L}$ & 1 & \\
\hline $\mathrm{Al}$ & ND & 2.25 & 2.25 & $\mathrm{mg} / \mathrm{L}$ & 1 & \\
\hline As & ND & 4.50 & 4.50 & $\mathrm{mg} / \mathrm{L}$ & 1 & $\mathrm{R}-01$ \\
\hline $\mathrm{Ba}$ & 0.274 & 0.0450 & 0.0450 & $\mathrm{mg} / \mathrm{L}$ & 1 & \\
\hline $\mathrm{Be}$ & ND & 0.0450 & 0.0450 & $\mathrm{mg} / \mathrm{L}$ & 1 & \\
\hline $\mathrm{Cd}$ & ND & 0.0450 & 0.0450 & $\mathrm{mg} / \mathrm{L}$ & 1 & \\
\hline $\mathrm{Ca}$ & 59.0 & 2.25 & 2.25 & $\mathrm{mg} / \mathrm{L}$ & 1 & \\
\hline $\mathrm{Cr}$ & ND & 0.450 & 0.450 & $\mathrm{mg} / \mathrm{L}$ & 1 & R-01 \\
\hline Co & ND & 0.0450 & 0.0450 & $\mathrm{mg} / \mathrm{L}$ & 1 & \\
\hline $\mathrm{Cu}$ & 0.0750 & 0.0450 & 0.0450 & $\mathrm{mg} / \mathrm{L}$ & 1 & \\
\hline $\mathrm{Fe}$ & 2.20 & 0.450 & 0.450 & $\mathrm{mg} / \mathrm{L}$ & 1 & \\
\hline $\mathrm{Pb}$ & ND & 0.0450 & 0.0450 & $\mathrm{mg} / \mathrm{L}$ & 1 & \\
\hline $\mathrm{Mg}$ & 57.9 & 2.25 & 2.25 & $\mathrm{mg} / \mathrm{L}$ & 1 & \\
\hline $\mathrm{Mn}$ & 0.869 & 0.0450 & 0.0450 & $\mathrm{mg} / \mathrm{L}$ & 1 & \\
\hline Mo & ND & 0.225 & 0.225 & $\mathrm{mg} / \mathrm{L}$ & 1 & \\
\hline $\mathrm{Ni}$ & ND & 0.0450 & 0.0450 & $\mathrm{mg} / \mathrm{L}$ & 1 & \\
\hline $\mathrm{P}$ & 444 & 2.25 & 2.25 & $\mathrm{mg} / \mathrm{L}$ & 1 & \\
\hline $\mathrm{K}$ & 814 & 2.25 & 2.25 & $\mathrm{mg} / \mathrm{L}$ & 1 & \\
\hline $\mathrm{Se}$ & ND & 9.00 & 9.00 & $\mathrm{mg} / \mathrm{L}$ & 1 & \\
\hline $\mathrm{Na}$ & 8.94 & 2.25 & 2.25 & $\mathrm{mg} / \mathrm{L}$ & 1 & \\
\hline $\mathrm{V}$ & ND & 0.0450 & 0.0450 & $\mathrm{mg} / \mathrm{L}$ & 1 & \\
\hline $\mathrm{Zn}$ & 0.550 & 0.0450 & 0.0450 & $\mathrm{mg} / \mathrm{L}$ & 1 & \\
\hline
\end{tabular}


Table 169. Chemical analysis using ICP-MS for the $3^{\text {rd }}$ sample from the same bottle of the 2011 wine from Chehalem Corral Creek (CWCC) Vineyard. ND - Non-detect.

\begin{tabular}{|c|c|c|c|c|c|c|}
\hline \multicolumn{7}{|c|}{ Lab ID A4B0164-12 26 CWCC 11} \\
\hline Analyte & Result & Detection Limit & Reporting Limit & Units & Dilution & Analyst Notes \\
\hline $\mathrm{S}$ & 88.6 & 2.25 & 2.25 & $\mathrm{mg} / \mathrm{L}$ & 1 & \\
\hline $\mathrm{Hg}$ & ND & 0.00180 & 0.00180 & $\mathrm{mg} / \mathrm{L}$ & 5 & H-01, R-04 \\
\hline $\mathrm{Sr}$ & 0.867 & 0.00405 & 0.00405 & $\mathrm{mg} / \mathrm{L}$ & 1 & \\
\hline $\mathrm{Al}$ & ND & 2.25 & 2.25 & $\mathrm{mg} / \mathrm{L}$ & 1 & \\
\hline As & ND & 4.50 & 4.50 & $\mathrm{mg} / \mathrm{L}$ & 1 & $\mathrm{R}-01$ \\
\hline $\mathrm{Ba}$ & 0.282 & 0.0450 & 0.0450 & $\mathrm{mg} / \mathrm{L}$ & 1 & \\
\hline $\mathrm{Be}$ & ND & 0.0450 & 0.0450 & $\mathrm{mg} / \mathrm{L}$ & 1 & \\
\hline $\mathrm{Cd}$ & ND & 0.0450 & 0.0450 & $\mathrm{mg} / \mathrm{L}$ & 1 & \\
\hline $\mathrm{Ca}$ & 61.3 & 2.25 & 2.25 & $\mathrm{mg} / \mathrm{L}$ & 1 & \\
\hline $\mathrm{Cr}$ & ND & 0.450 & 0.450 & $\mathrm{mg} / \mathrm{L}$ & 1 & $\mathrm{R}-01$ \\
\hline Co & ND & 0.0450 & 0.0450 & $\mathrm{mg} / \mathrm{L}$ & 1 & \\
\hline $\mathrm{Cu}$ & 0.0940 & 0.0450 & 0.0450 & $\mathrm{mg} / \mathrm{L}$ & 1 & \\
\hline $\mathrm{Fe}$ & 2.15 & 0.450 & 0.450 & $\mathrm{mg} / \mathrm{L}$ & 1 & \\
\hline $\mathrm{Pb}$ & ND & 0.0450 & 0.0450 & $\mathrm{mg} / \mathrm{L}$ & 1 & \\
\hline $\mathrm{Mg}$ & 62.0 & 2.25 & 2.25 & $\mathrm{mg} / \mathrm{L}$ & 1 & \\
\hline $\mathrm{Mn}$ & 0.910 & 0.0450 & 0.0450 & $\mathrm{mg} / \mathrm{L}$ & 1 & \\
\hline Mo & ND & 0.225 & 0.225 & $\mathrm{mg} / \mathrm{L}$ & 1 & \\
\hline $\mathrm{Ni}$ & ND & 0.0450 & 0.0450 & $\mathrm{mg} / \mathrm{L}$ & 1 & \\
\hline $\mathrm{P}$ & 435 & 2.25 & 2.25 & $\mathrm{mg} / \mathrm{L}$ & 1 & \\
\hline $\mathrm{K}$ & 850 & 2.25 & 2.25 & $\mathrm{mg} / \mathrm{L}$ & 1 & \\
\hline $\mathrm{Se}$ & ND & 9.00 & 9.00 & $\mathrm{mg} / \mathrm{L}$ & 1 & \\
\hline $\mathrm{Na}$ & 8.99 & 2.25 & 2.25 & $\mathrm{mg} / \mathrm{L}$ & 1 & \\
\hline $\mathrm{V}$ & ND & 0.0450 & 0.0450 & $\mathrm{mg} / \mathrm{L}$ & 1 & \\
\hline $\mathrm{Zn}$ & 0.556 & 0.0450 & 0.0450 & $\mathrm{mg} / \mathrm{L}$ & 1 & \\
\hline
\end{tabular}


Table 170. Chemical analysis using ICP-MS for the bottle of the 2012 wine from Lange Estate Mia North (LEMN) Vineyard. ND - Non-detect.

\begin{tabular}{|c|c|c|c|c|c|c|}
\hline \multicolumn{7}{|c|}{ Lab ID A4B0164-01 15 LEMN 12} \\
\hline Analyte & Result & Detection Limit & Reporting Limit & Units & Dilution & Analyst Notes \\
\hline $\mathrm{S}$ & 113 & 1.12 & 1.12 & $\mathrm{mg} / \mathrm{L}$ & 1 & \\
\hline $\mathrm{Hg}$ & ND & 0.000900 & 0.000900 & $\mathrm{mg} / \mathrm{L}$ & 5 & E-03, R-04 \\
\hline $\mathrm{Sr}$ & 1.09 & 0.00202 & 0.00202 & $\mathrm{mg} / \mathrm{L}$ & 1 & \\
\hline $\mathrm{Al}$ & ND & 1.12 & 1.12 & $\mathrm{mg} / \mathrm{L}$ & 1 & \\
\hline As & ND & 2.25 & 2.25 & $\mathrm{mg} / \mathrm{L}$ & 1 & $\mathrm{R}-01$ \\
\hline $\mathrm{Ba}$ & 0.492 & 0.0225 & 0.0225 & $\mathrm{mg} / \mathrm{L}$ & 1 & \\
\hline $\mathrm{Be}$ & ND & 0.0225 & 0.0225 & $\mathrm{mg} / \mathrm{L}$ & 1 & \\
\hline $\mathrm{Cd}$ & ND & 0.0225 & 0.0225 & $\mathrm{mg} / \mathrm{L}$ & 1 & \\
\hline $\mathrm{Ca}$ & 27.2 & 1.12 & 1.12 & $\mathrm{mg} / \mathrm{L}$ & 1 & \\
\hline $\mathrm{Cr}$ & ND & 0.225 & 0.225 & $\mathrm{mg} / \mathrm{L}$ & 1 & $\mathrm{R}-01$ \\
\hline $\mathrm{Co}$ & 0.0330 & 0.0225 & 0.0225 & $\mathrm{mg} / \mathrm{L}$ & 1 & \\
\hline $\mathrm{Cu}$ & 0.164 & 0.0225 & 0.0225 & $\mathrm{mg} / \mathrm{L}$ & 1 & \\
\hline $\mathrm{Fe}$ & 1.76 & 0.225 & 0.225 & $\mathrm{mg} / \mathrm{L}$ & 1 & \\
\hline $\mathrm{Pb}$ & 0.0892 & 0.0225 & 0.0225 & $\mathrm{mg} / \mathrm{L}$ & 1 & \\
\hline $\mathrm{Mg}$ & 63.2 & 1.12 & 1.12 & $\mathrm{mg} / \mathrm{L}$ & 1 & \\
\hline $\mathrm{Mn}$ & 2.27 & 0.0225 & 0.0225 & $\mathrm{mg} / \mathrm{L}$ & 1 & \\
\hline Mo & ND & 0.112 & 0.112 & $\mathrm{mg} / \mathrm{L}$ & 1 & \\
\hline $\mathrm{Ni}$ & ND & 0.0225 & 0.0225 & $\mathrm{mg} / \mathrm{L}$ & 1 & \\
\hline $\mathrm{P}$ & 192 & 1.12 & 1.12 & $\mathrm{mg} / \mathrm{L}$ & 1 & Q-41 \\
\hline K & 735 & 1.12 & 1.12 & $\mathrm{mg} / \mathrm{L}$ & 1 & E \\
\hline $\mathrm{Se}$ & ND & 4.50 & 4.50 & $\mathrm{mg} / \mathrm{L}$ & 1 & Q-41 \\
\hline $\mathrm{Na}$ & 10.5 & 1.12 & 1.12 & $\mathrm{mg} / \mathrm{L}$ & 1 & \\
\hline $\mathrm{V}$ & ND & 0.0225 & 0.0225 & $\mathrm{mg} / \mathrm{L}$ & 1 & \\
\hline $\mathrm{Zn}$ & 0.294 & 0.0225 & 0.0225 & $\mathrm{mg} / \mathrm{L}$ & 1 & \\
\hline
\end{tabular}


Table 171. Chemical analysis using ICP-MS for the $2^{\text {nd }}$ sample from the same bottle of the 2012 wine from Lange Estate Mia North (LEMN) Vineyard. ND - Non-detect.

\begin{tabular}{|c|c|c|c|c|c|c|}
\hline \multicolumn{7}{|c|}{ Lab ID A4B0164-1024 LEMN 12} \\
\hline Analyte & Result & Detection Limit & Reporting Limit & Units & Dilution & Analyst Notes \\
\hline S & 103 & 2.25 & 2.25 & $\mathrm{mg} / \mathrm{L}$ & 1 & \\
\hline $\mathrm{Hg}$ & ND & 0.00180 & 0.00180 & $\mathrm{mg} / \mathrm{L}$ & 5 & H-01, R-04 \\
\hline $\mathrm{Sr}$ & 0.980 & 0.00405 & 0.00405 & $\mathrm{mg} / \mathrm{L}$ & 1 & \\
\hline $\mathrm{Al}$ & ND & 2.25 & 2.25 & $\mathrm{mg} / \mathrm{L}$ & 1 & \\
\hline As & ND & 4.50 & 4.50 & $\mathrm{mg} / \mathrm{L}$ & 1 & $\mathrm{R}-01$ \\
\hline $\mathrm{Ba}$ & 0.432 & 0.0450 & 0.0450 & $\mathrm{mg} / \mathrm{L}$ & 1 & \\
\hline $\mathrm{Be}$ & ND & 0.0450 & 0.0450 & $\mathrm{mg} / \mathrm{L}$ & 1 & \\
\hline $\mathrm{Cd}$ & ND & 0.0450 & 0.0450 & $\mathrm{mg} / \mathrm{L}$ & 1 & \\
\hline $\mathrm{Ca}$ & 29.7 & 2.25 & 2.25 & $\mathrm{mg} / \mathrm{L}$ & 1 & \\
\hline $\mathrm{Cr}$ & ND & 0.450 & 0.450 & $\mathrm{mg} / \mathrm{L}$ & 1 & R-01 \\
\hline Co & ND & 0.0450 & 0.0450 & $\mathrm{mg} / \mathrm{L}$ & 1 & \\
\hline $\mathrm{Cu}$ & 0.118 & 0.0450 & 0.0450 & $\mathrm{mg} / \mathrm{L}$ & 1 & \\
\hline $\mathrm{Fe}$ & 1.74 & 0.450 & 0.450 & $\mathrm{mg} / \mathrm{L}$ & 1 & \\
\hline $\mathrm{Pb}$ & ND & 0.0450 & 0.0450 & $\mathrm{mg} / \mathrm{L}$ & 1 & \\
\hline $\mathrm{Mg}$ & 83.4 & 2.25 & 2.25 & $\mathrm{mg} / \mathrm{L}$ & 1 & \\
\hline $\mathrm{Mn}$ & 2.32 & 0.0450 & 0.0450 & $\mathrm{mg} / \mathrm{L}$ & 1 & \\
\hline Mo & ND & 0.225 & 0.225 & $\mathrm{mg} / \mathrm{L}$ & 1 & \\
\hline $\mathrm{Ni}$ & ND & 0.0450 & 0.0450 & $\mathrm{mg} / \mathrm{L}$ & 1 & \\
\hline $\mathrm{P}$ & 144 & 2.25 & 2.25 & $\mathrm{mg} / \mathrm{L}$ & 1 & \\
\hline $\mathrm{K}$ & 742 & 2.25 & 2.25 & $\mathrm{mg} / \mathrm{L}$ & 1 & \\
\hline $\mathrm{Se}$ & ND & 9.00 & 9.00 & $\mathrm{mg} / \mathrm{L}$ & 1 & \\
\hline $\mathrm{Na}$ & 9.98 & 2.25 & 2.25 & $\mathrm{mg} / \mathrm{L}$ & 1 & \\
\hline $\mathrm{V}$ & ND & 0.0450 & 0.0450 & $\mathrm{mg} / \mathrm{L}$ & 1 & \\
\hline $\mathrm{Zn}$ & 0.253 & 0.0450 & 0.0450 & $\mathrm{mg} / \mathrm{L}$ & 1 & \\
\hline
\end{tabular}


Table 172. Chemical analysis using ICP-MS for the bottle of the 2012 wine from Lange Estate Yamhill (LEYV) Vineyard. ND - Non-detect.

\begin{tabular}{|c|c|c|c|c|c|c|}
\hline \multicolumn{7}{|c|}{ Lab ID A4B0432-05 33 LEYV 12} \\
\hline Analyte & Result & Detection Limit & Reporting Limit & Units & Dilution & Analyst Notes \\
\hline S & 74.2 & 2.25 & 2.25 & $\mathrm{mg} / \mathrm{L}$ & 1 & \\
\hline $\mathrm{Hg}$ & ND & 0.00180 & 0.00180 & $\mathrm{mg} / \mathrm{L}$ & 5 & $\mathrm{R}-04$ \\
\hline $\mathrm{Sr}$ & 1.62 & 0.00405 & 0.00405 & $\mathrm{mg} / \mathrm{L}$ & 1 & \\
\hline $\mathrm{Al}$ & ND & 2.25 & 2.25 & $\mathrm{mg} / \mathrm{L}$ & 1 & \\
\hline As & ND & 4.50 & 4.50 & $\mathrm{mg} / \mathrm{L}$ & 1 & $\mathrm{R}-01$ \\
\hline $\mathrm{Ba}$ & 0.540 & 0.0450 & 0.0450 & $\mathrm{mg} / \mathrm{L}$ & 1 & \\
\hline $\mathrm{Be}$ & ND & 0.0450 & 0.0450 & $\mathrm{mg} / \mathrm{L}$ & 1 & \\
\hline $\mathrm{Cd}$ & ND & 0.0450 & 0.0450 & $\mathrm{mg} / \mathrm{L}$ & 1 & \\
\hline $\mathrm{Ca}$ & 31.7 & 2.25 & 2.25 & $\mathrm{mg} / \mathrm{L}$ & 1 & \\
\hline $\mathrm{Cr}$ & ND & 0.450 & 0.450 & $\mathrm{mg} / \mathrm{L}$ & 1 & R-01 \\
\hline Co & ND & 0.0450 & 0.0450 & $\mathrm{mg} / \mathrm{L}$ & 1 & \\
\hline $\mathrm{Cu}$ & ND & 0.0450 & 0.0450 & $\mathrm{mg} / \mathrm{L}$ & 1 & \\
\hline $\mathrm{Fe}$ & 1.42 & 0.450 & 0.450 & $\mathrm{mg} / \mathrm{L}$ & 1 & \\
\hline $\mathrm{Pb}$ & ND & 0.0450 & 0.0450 & $\mathrm{mg} / \mathrm{L}$ & 1 & \\
\hline $\mathrm{Mg}$ & 94.4 & 2.25 & 2.25 & $\mathrm{mg} / \mathrm{L}$ & 1 & \\
\hline $\mathrm{Mn}$ & 2.36 & 0.0450 & 0.0450 & $\mathrm{mg} / \mathrm{L}$ & 1 & \\
\hline Mo & ND & 0.225 & 0.225 & $\mathrm{mg} / \mathrm{L}$ & 1 & \\
\hline $\mathrm{Ni}$ & ND & 0.0450 & 0.0450 & $\mathrm{mg} / \mathrm{L}$ & 1 & \\
\hline $\mathrm{P}$ & 206 & 2.25 & 2.25 & $\mathrm{mg} / \mathrm{L}$ & 1 & \\
\hline $\mathrm{K}$ & 743 & 2.25 & 2.25 & $\mathrm{mg} / \mathrm{L}$ & 1 & \\
\hline $\mathrm{Se}$ & ND & 9.00 & 9.00 & $\mathrm{mg} / \mathrm{L}$ & 1 & \\
\hline $\mathrm{Na}$ & 4.85 & 2.25 & 2.25 & $\mathrm{mg} / \mathrm{L}$ & 1 & \\
\hline $\mathrm{V}$ & ND & 0.0450 & 0.0450 & $\mathrm{mg} / \mathrm{L}$ & 1 & \\
\hline $\mathrm{Zn}$ & 0.334 & 0.0450 & 0.0450 & $\mathrm{mg} / \mathrm{L}$ & 1 & \\
\hline
\end{tabular}


Table 173. Chemical analysis using ICP-MS for the bottle of the 2012 wine from Lange Estate Freedom Hill (LEFH) Vineyard. ND - Non-detect.

\begin{tabular}{|c|c|c|c|c|c|c|}
\hline \multicolumn{7}{|c|}{ Lab ID A4B0052-07 7 LEFH 2012} \\
\hline Analyte & Result & Detection Limit & Reporting Limit & Units & Dilution & Analyst Notes \\
\hline S & 72.1 & 1.12 & 1.12 & $\mathrm{mg} / \mathrm{L}$ & 1 & \\
\hline $\mathrm{Hg}$ & ND & 0.000900 & 0.000900 & $\mathrm{mg} / \mathrm{L}$ & 5 & H-01, R-04 \\
\hline $\mathrm{Sr}$ & 1.05 & 0.00202 & 0.00202 & $\mathrm{mg} / \mathrm{L}$ & 1 & \\
\hline $\mathrm{Al}$ & ND & 1.12 & 1.12 & $\mathrm{mg} / \mathrm{L}$ & 1 & \\
\hline As & ND & 2.25 & 2.25 & $\mathrm{mg} / \mathrm{L}$ & 1 & $\mathrm{R}-01$ \\
\hline $\mathrm{Ba}$ & 0.577 & 0.0225 & 0.0225 & $\mathrm{mg} / \mathrm{L}$ & 1 & \\
\hline $\mathrm{Be}$ & ND & 0.0225 & 0.0225 & $\mathrm{mg} / \mathrm{L}$ & 1 & \\
\hline $\mathrm{Cd}$ & ND & 0.0225 & 0.0225 & $\mathrm{mg} / \mathrm{L}$ & 1 & \\
\hline $\mathrm{Ca}$ & 27.6 & 1.12 & 1.12 & $\mathrm{mg} / \mathrm{L}$ & 1 & \\
\hline $\mathrm{Cr}$ & ND & 0.225 & 0.225 & $\mathrm{mg} / \mathrm{L}$ & 1 & R-01 \\
\hline $\mathrm{Co}$ & 0.0290 & 0.0225 & 0.0225 & $\mathrm{mg} / \mathrm{L}$ & 1 & \\
\hline $\mathrm{Cu}$ & 0.0865 & 0.0225 & 0.0225 & $\mathrm{mg} / \mathrm{L}$ & 1 & \\
\hline $\mathrm{Fe}$ & 0.966 & 0.225 & 0.225 & $\mathrm{mg} / \mathrm{L}$ & 1 & \\
\hline $\mathrm{Pb}$ & 0.0782 & 0.0225 & 0.0225 & $\mathrm{mg} / \mathrm{L}$ & 1 & \\
\hline $\mathrm{Mg}$ & 51.6 & 1.12 & 1.12 & $\mathrm{mg} / \mathrm{L}$ & 1 & \\
\hline $\mathrm{Mn}$ & 1.25 & 0.0225 & 0.0225 & $\mathrm{mg} / \mathrm{L}$ & 1 & \\
\hline Mo & ND & 0.112 & 0.112 & $\mathrm{mg} / \mathrm{L}$ & 1 & \\
\hline $\mathrm{Ni}$ & ND & 0.0225 & 0.0225 & $\mathrm{mg} / \mathrm{L}$ & 1 & \\
\hline $\mathrm{P}$ & 199 & 1.12 & 1.12 & $\mathrm{mg} / \mathrm{L}$ & 1 & \\
\hline $\mathrm{K}$ & 676 & 1.12 & 1.12 & $\mathrm{mg} / \mathrm{L}$ & 1 & E \\
\hline $\mathrm{Se}$ & ND & 4.50 & 4.50 & $\mathrm{mg} / \mathrm{L}$ & 1 & Q-41 \\
\hline $\mathrm{Na}$ & 4.30 & 1.12 & 1.12 & $\mathrm{mg} / \mathrm{L}$ & 1 & \\
\hline $\mathrm{V}$ & ND & 0.0225 & 0.0225 & $\mathrm{mg} / \mathrm{L}$ & 1 & \\
\hline $\mathrm{Zn}$ & 0.118 & 0.0225 & 0.0225 & $\mathrm{mg} / \mathrm{L}$ & 1 & \\
\hline
\end{tabular}


Table 174. Chemical analysis using ICP-MS for the bottle of the 2012 wine from Rex Hill Sims (RHSB) Vineyard. ND - Non-detect.

\begin{tabular}{|c|c|c|c|c|c|c|}
\hline \multicolumn{7}{|c|}{ Lab ID A4B0432-01 29 RHSB 12} \\
\hline Analyte & Result & Detection Limit & Reporting Limit & Units & Dilution & Analyst Notes \\
\hline S & 111 & 2.25 & 2.25 & $\mathrm{mg} / \mathrm{L}$ & 1 & \\
\hline $\mathrm{Hg}$ & ND & 0.00180 & 0.00180 & $\mathrm{mg} / \mathrm{L}$ & 5 & $\mathrm{R}-04$ \\
\hline $\mathrm{Sr}$ & 0.978 & 0.00405 & 0.00405 & $\mathrm{mg} / \mathrm{L}$ & 1 & \\
\hline $\mathrm{Al}$ & ND & 2.25 & 2.25 & $\mathrm{mg} / \mathrm{L}$ & 1 & \\
\hline As & ND & 4.50 & 4.50 & $\mathrm{mg} / \mathrm{L}$ & 1 & $\mathrm{R}-01$ \\
\hline $\mathrm{Ba}$ & 0.378 & 0.0450 & 0.0450 & $\mathrm{mg} / \mathrm{L}$ & 1 & \\
\hline $\mathrm{Be}$ & ND & 0.0450 & 0.0450 & $\mathrm{mg} / \mathrm{L}$ & 1 & \\
\hline $\mathrm{Cd}$ & ND & 0.0450 & 0.0450 & $\mathrm{mg} / \mathrm{L}$ & 1 & \\
\hline $\mathrm{Ca}$ & 34.7 & 2.25 & 2.25 & $\mathrm{mg} / \mathrm{L}$ & 1 & \\
\hline $\mathrm{Cr}$ & ND & 0.450 & 0.450 & $\mathrm{mg} / \mathrm{L}$ & 1 & R-01 \\
\hline Co & ND & 0.0450 & 0.0450 & $\mathrm{mg} / \mathrm{L}$ & 1 & \\
\hline $\mathrm{Cu}$ & 0.0470 & 0.0450 & 0.0450 & $\mathrm{mg} / \mathrm{L}$ & 1 & \\
\hline $\mathrm{Fe}$ & 2.41 & 0.450 & 0.450 & $\mathrm{mg} / \mathrm{L}$ & 1 & \\
\hline $\mathrm{Pb}$ & ND & 0.0450 & 0.0450 & $\mathrm{mg} / \mathrm{L}$ & 1 & \\
\hline $\mathrm{Mg}$ & 75.9 & 2.25 & 2.25 & $\mathrm{mg} / \mathrm{L}$ & 1 & \\
\hline $\mathrm{Mn}$ & 2.36 & 0.0450 & 0.0450 & $\mathrm{mg} / \mathrm{L}$ & 1 & \\
\hline Mo & ND & 0.225 & 0.225 & $\mathrm{mg} / \mathrm{L}$ & 1 & \\
\hline $\mathrm{Ni}$ & ND & 0.0450 & 0.0450 & $\mathrm{mg} / \mathrm{L}$ & 1 & \\
\hline $\mathrm{P}$ & 192 & 2.25 & 2.25 & $\mathrm{mg} / \mathrm{L}$ & 1 & \\
\hline K & 445 & 2.25 & 2.25 & $\mathrm{mg} / \mathrm{L}$ & 1 & \\
\hline $\mathrm{Se}$ & ND & 9.00 & 9.00 & $\mathrm{mg} / \mathrm{L}$ & 1 & \\
\hline $\mathrm{Na}$ & 5.40 & 2.25 & 2.25 & $\mathrm{mg} / \mathrm{L}$ & 1 & \\
\hline V & ND & 0.0450 & 0.0450 & $\mathrm{mg} / \mathrm{L}$ & 1 & \\
\hline $\mathrm{Zn}$ & 0.336 & 0.0450 & 0.0450 & $\mathrm{mg} / \mathrm{L}$ & 1 & \\
\hline
\end{tabular}


Table 175. Chemical analysis using ICP-MS for the $2^{\text {nd }}$ sample from the same bottle of the 2012 wine from Rex Hill Sims (RHSB) Vineyard. ND - Non-detect.

\begin{tabular}{|c|c|c|c|c|c|c|}
\hline \multicolumn{7}{|c|}{ Lab ID A4B0432-19 44 RHSB 12} \\
\hline Analyte & Result & Detection Limit & Reporting Limit & Units & Dilution & Analyst Notes \\
\hline S & 118 & 2.25 & 2.25 & $\mathrm{mg} / \mathrm{L}$ & 1 & \\
\hline $\mathrm{Hg}$ & ND & 0.00180 & 0.00180 & $\mathrm{mg} / \mathrm{L}$ & 5 & $\mathrm{R}-04$ \\
\hline $\mathrm{Sr}$ & 0.951 & 0.00405 & 0.00405 & $\mathrm{mg} / \mathrm{L}$ & 1 & \\
\hline $\mathrm{Al}$ & ND & 2.25 & 2.25 & $\mathrm{mg} / \mathrm{L}$ & 1 & $\mathrm{R}-03$ \\
\hline As & ND & 4.50 & 4.50 & $\mathrm{mg} / \mathrm{L}$ & 1 & $\mathrm{R}-01$ \\
\hline $\mathrm{Ba}$ & 0.360 & 0.0450 & 0.0450 & $\mathrm{mg} / \mathrm{L}$ & 1 & \\
\hline $\mathrm{Be}$ & ND & 0.0450 & 0.0450 & $\mathrm{mg} / \mathrm{L}$ & 1 & $\mathrm{R}-03$ \\
\hline $\mathrm{Cd}$ & ND & 0.0450 & 0.0450 & $\mathrm{mg} / \mathrm{L}$ & 1 & $\mathrm{R}-03$ \\
\hline $\mathrm{Ca}$ & 35.4 & 2.25 & 2.25 & $\mathrm{mg} / \mathrm{L}$ & 1 & \\
\hline $\mathrm{Cr}$ & ND & 0.0450 & 0.0450 & $\mathrm{mg} / \mathrm{L}$ & 1 & R-03 \\
\hline Co & ND & 0.0450 & 0.0450 & $\mathrm{mg} / \mathrm{L}$ & 1 & R-03 \\
\hline $\mathrm{Cu}$ & 0.0475 & 0.0450 & 0.0450 & $\mathrm{mg} / \mathrm{L}$ & 1 & \\
\hline $\mathrm{Fe}$ & 2.31 & 0.450 & 0.450 & $\mathrm{mg} / \mathrm{L}$ & 1 & \\
\hline $\mathrm{Pb}$ & ND & 0.0450 & 0.0450 & $\mathrm{mg} / \mathrm{L}$ & 1 & R-03 \\
\hline $\mathrm{Mg}$ & 83.9 & 2.25 & 2.25 & $\mathrm{mg} / \mathrm{L}$ & 1 & \\
\hline $\mathrm{Mn}$ & 2.35 & 0.0450 & 0.0450 & $\mathrm{mg} / \mathrm{L}$ & 1 & \\
\hline Mo & ND & 0.0450 & 0.0450 & $\mathrm{mg} / \mathrm{L}$ & 1 & R-03 \\
\hline $\mathrm{Ni}$ & ND & 0.0450 & 0.0450 & $\mathrm{mg} / \mathrm{L}$ & 1 & R-03 \\
\hline $\mathrm{P}$ & 179 & 2.25 & 2.25 & $\mathrm{mg} / \mathrm{L}$ & 1 & \\
\hline $\mathrm{K}$ & 460 & 2.25 & 2.25 & $\mathrm{mg} / \mathrm{L}$ & 1 & \\
\hline $\mathrm{Se}$ & ND & 4.50 & 4.50 & $\mathrm{mg} / \mathrm{L}$ & 1 & R-01 \\
\hline $\mathrm{Na}$ & 5.64 & 2.25 & 2.25 & $\mathrm{mg} / \mathrm{L}$ & 1 & \\
\hline $\mathrm{V}$ & ND & 0.0450 & 0.0450 & $\mathrm{mg} / \mathrm{L}$ & 1 & R-03 \\
\hline $\mathrm{Zn}$ & 0.350 & 0.0450 & 0.0450 & $\mathrm{mg} / \mathrm{L}$ & 1 & \\
\hline
\end{tabular}


Table 176. Chemical analysis using ICP-MS for the bottle of the 2012 wine from Rex Hill Estate (RHB12) Vineyard. ND - Non-detect.

\begin{tabular}{|c|c|c|c|c|c|c|}
\hline \multicolumn{7}{|c|}{ Lab ID A4B0164-09 23 RHB12 } \\
\hline Analyte & Result & Detection Limit & Reporting Limit & Units & Dilution & Analyst Notes \\
\hline S & 97.0 & 2.25 & 2.25 & $\mathrm{mg} / \mathrm{L}$ & 1 & \\
\hline $\mathrm{Hg}$ & ND & 0.00180 & 0.00180 & $\mathrm{mg} / \mathrm{L}$ & 5 & $\mathrm{H}-01, \mathrm{R}-04$ \\
\hline $\mathrm{Sr}$ & 1.18 & 0.00405 & 0.00405 & $\mathrm{mg} / \mathrm{L}$ & 1 & \\
\hline $\mathrm{Al}$ & ND & 2.25 & 2.25 & $\mathrm{mg} / \mathrm{L}$ & 1 & \\
\hline As & ND & 4.50 & 4.50 & $\mathrm{mg} / \mathrm{L}$ & 1 & $\mathrm{R}-01$ \\
\hline $\mathrm{Ba}$ & 0.406 & 0.0450 & 0.0450 & $\mathrm{mg} / \mathrm{L}$ & 1 & \\
\hline $\mathrm{Be}$ & ND & 0.0450 & 0.0450 & $\mathrm{mg} / \mathrm{L}$ & 1 & \\
\hline $\mathrm{Cd}$ & ND & 0.0450 & 0.0450 & $\mathrm{mg} / \mathrm{L}$ & 1 & \\
\hline $\mathrm{Ca}$ & 42.9 & 2.25 & 2.25 & $\mathrm{mg} / \mathrm{L}$ & 1 & \\
\hline $\mathrm{Cr}$ & ND & 0.450 & 0.450 & $\mathrm{mg} / \mathrm{L}$ & 1 & R-01 \\
\hline Co & ND & 0.0450 & 0.0450 & $\mathrm{mg} / \mathrm{L}$ & 1 & \\
\hline $\mathrm{Cu}$ & 0.0810 & 0.0450 & 0.0450 & $\mathrm{mg} / \mathrm{L}$ & 1 & \\
\hline $\mathrm{Fe}$ & 1.11 & 0.450 & 0.450 & $\mathrm{mg} / \mathrm{L}$ & 1 & \\
\hline $\mathrm{Pb}$ & ND & 0.0450 & 0.0450 & $\mathrm{mg} / \mathrm{L}$ & 1 & \\
\hline $\mathrm{Mg}$ & 80.4 & 2.25 & 2.25 & $\mathrm{mg} / \mathrm{L}$ & 1 & \\
\hline $\mathrm{Mn}$ & 1.06 & 0.0450 & 0.0450 & $\mathrm{mg} / \mathrm{L}$ & 1 & \\
\hline Mo & ND & 0.225 & 0.225 & $\mathrm{mg} / \mathrm{L}$ & 1 & \\
\hline $\mathrm{Ni}$ & ND & 0.0450 & 0.0450 & $\mathrm{mg} / \mathrm{L}$ & 1 & \\
\hline $\mathrm{P}$ & 447 & 2.25 & 2.25 & $\mathrm{mg} / \mathrm{L}$ & 1 & \\
\hline $\mathrm{K}$ & 713 & 2.25 & 2.25 & $\mathrm{mg} / \mathrm{L}$ & 1 & \\
\hline $\mathrm{Se}$ & ND & 9.00 & 9.00 & $\mathrm{mg} / \mathrm{L}$ & 1 & \\
\hline $\mathrm{Na}$ & 7.74 & 2.25 & 2.25 & $\mathrm{mg} / \mathrm{L}$ & 1 & \\
\hline $\mathrm{V}$ & ND & 0.0450 & 0.0450 & $\mathrm{mg} / \mathrm{L}$ & 1 & \\
\hline $\mathrm{Zn}$ & 0.394 & 0.0450 & 0.0450 & $\mathrm{mg} / \mathrm{L}$ & 1 & \\
\hline
\end{tabular}


Table 177. Chemical analysis using ICP-MS for the bottle of the 2012 wine from Rex Hill Jacob-Hart Block 1 (RHJHB1) Vineyard. ND - Non-detect.

\begin{tabular}{|c|c|c|c|c|c|c|}
\hline \multicolumn{7}{|c|}{ Lab ID A4B0052-10 10 RHJHB1 2012} \\
\hline Analyte & Result & Detection Limit & Reporting Limit & Units & Dilution & Analyst Notes \\
\hline S & 119 & 1.12 & 1.12 & $\mathrm{mg} / \mathrm{L}$ & 1 & \\
\hline $\mathrm{Hg}$ & ND & 0.000900 & 0.000900 & $\mathrm{mg} / \mathrm{L}$ & 5 & H-01, R-04 \\
\hline $\mathrm{Sr}$ & 1.12 & 0.00202 & 0.00202 & $\mathrm{mg} / \mathrm{L}$ & 1 & \\
\hline $\mathrm{Al}$ & ND & 1.12 & 1.12 & $\mathrm{mg} / \mathrm{L}$ & 1 & \\
\hline As & ND & 2.25 & 2.25 & $\mathrm{mg} / \mathrm{L}$ & 1 & $\mathrm{R}-01$ \\
\hline $\mathrm{Ba}$ & 0.327 & 0.0225 & 0.0225 & $\mathrm{mg} / \mathrm{L}$ & 1 & \\
\hline $\mathrm{Be}$ & ND & 0.0225 & 0.0225 & $\mathrm{mg} / \mathrm{L}$ & 1 & \\
\hline $\mathrm{Cd}$ & ND & 0.0225 & 0.0225 & $\mathrm{mg} / \mathrm{L}$ & 1 & \\
\hline $\mathrm{Ca}$ & 35.2 & 1.12 & 1.12 & $\mathrm{mg} / \mathrm{L}$ & 1 & \\
\hline $\mathrm{Cr}$ & ND & 0.225 & 0.225 & $\mathrm{mg} / \mathrm{L}$ & 1 & R-01 \\
\hline $\mathrm{Co}$ & 0.0338 & 0.0225 & 0.0225 & $\mathrm{mg} / \mathrm{L}$ & 1 & \\
\hline $\mathrm{Cu}$ & 0.111 & 0.0225 & 0.0225 & $\mathrm{mg} / \mathrm{L}$ & 1 & \\
\hline $\mathrm{Fe}$ & 2.22 & 0.225 & 0.225 & $\mathrm{mg} / \mathrm{L}$ & 1 & \\
\hline $\mathrm{Pb}$ & 0.0892 & 0.0225 & 0.0225 & $\mathrm{mg} / \mathrm{L}$ & 1 & \\
\hline $\mathrm{Mg}$ & 59.2 & 1.12 & 1.12 & $\mathrm{mg} / \mathrm{L}$ & 1 & \\
\hline $\mathrm{Mn}$ & 1.07 & 0.0225 & 0.0225 & $\mathrm{mg} / \mathrm{L}$ & 1 & \\
\hline Mo & ND & 0.112 & 0.112 & $\mathrm{mg} / \mathrm{L}$ & 1 & \\
\hline $\mathrm{Ni}$ & ND & 0.0225 & 0.0225 & $\mathrm{mg} / \mathrm{L}$ & 1 & \\
\hline $\mathrm{P}$ & 412 & 1.12 & 1.12 & $\mathrm{mg} / \mathrm{L}$ & 1 & E, Q-41 \\
\hline K & 563 & 1.12 & 1.12 & $\mathrm{mg} / \mathrm{L}$ & 1 & $\mathrm{E}$ \\
\hline $\mathrm{Se}$ & ND & 4.50 & 4.50 & $\mathrm{mg} / \mathrm{L}$ & 1 & Q-41 \\
\hline $\mathrm{Na}$ & 8.42 & 1.12 & 1.12 & $\mathrm{mg} / \mathrm{L}$ & 1 & \\
\hline $\mathrm{V}$ & ND & 0.0225 & 0.0225 & $\mathrm{mg} / \mathrm{L}$ & 1 & \\
\hline $\mathrm{Zn}$ & 0.338 & 0.0225 & 0.0225 & $\mathrm{mg} / \mathrm{L}$ & 1 & \\
\hline
\end{tabular}


Table 178. Chemical analysis using ICP-MS for the bottle of the 2012 wine from Rex Hill Jacob-Hart Block 5 (RHJHB5) Vineyard. ND - Non-detect.

\begin{tabular}{|c|c|c|c|c|c|c|}
\hline \multicolumn{7}{|c|}{ Lab ID A4B0432-09 37 RHJHB5 12} \\
\hline Analyte & Result & Detection Limit & Reporting Limit & Units & Dilution & Analyst Notes \\
\hline S & 139 & 2.25 & 2.25 & $\mathrm{mg} / \mathrm{L}$ & 1 & \\
\hline $\mathrm{Hg}$ & ND & 0.00180 & 0.00180 & $\mathrm{mg} / \mathrm{L}$ & 5 & $\mathrm{R}-04$ \\
\hline $\mathrm{Sr}$ & 0.766 & 0.00405 & 0.00405 & $\mathrm{mg} / \mathrm{L}$ & 1 & \\
\hline $\mathrm{Al}$ & ND & 2.25 & 2.25 & $\mathrm{mg} / \mathrm{L}$ & 1 & \\
\hline As & ND & 4.50 & 4.50 & $\mathrm{mg} / \mathrm{L}$ & 1 & $\mathrm{R}-01$ \\
\hline $\mathrm{Ba}$ & 0.170 & 0.0450 & 0.0450 & $\mathrm{mg} / \mathrm{L}$ & 1 & \\
\hline $\mathrm{Be}$ & ND & 0.0450 & 0.0450 & $\mathrm{mg} / \mathrm{L}$ & 1 & \\
\hline $\mathrm{Cd}$ & ND & 0.0450 & 0.0450 & $\mathrm{mg} / \mathrm{L}$ & 1 & \\
\hline $\mathrm{Ca}$ & 53.0 & 2.25 & 2.25 & $\mathrm{mg} / \mathrm{L}$ & 1 & \\
\hline $\mathrm{Cr}$ & ND & 0.450 & 0.450 & $\mathrm{mg} / \mathrm{L}$ & 1 & R-01 \\
\hline Co & ND & 0.0450 & 0.0450 & $\mathrm{mg} / \mathrm{L}$ & 1 & \\
\hline $\mathrm{Cu}$ & 0.286 & 0.0450 & 0.0450 & $\mathrm{mg} / \mathrm{L}$ & 1 & \\
\hline $\mathrm{Fe}$ & 1.23 & 0.450 & 0.450 & $\mathrm{mg} / \mathrm{L}$ & 1 & \\
\hline $\mathrm{Pb}$ & 0.0625 & 0.0450 & 0.0450 & $\mathrm{mg} / \mathrm{L}$ & 1 & \\
\hline $\mathrm{Mg}$ & 80.3 & 2.25 & 2.25 & $\mathrm{mg} / \mathrm{L}$ & 1 & \\
\hline $\mathrm{Mn}$ & 1.75 & 0.0450 & 0.0450 & $\mathrm{mg} / \mathrm{L}$ & 1 & \\
\hline Mo & ND & 0.225 & 0.225 & $\mathrm{mg} / \mathrm{L}$ & 1 & \\
\hline $\mathrm{Ni}$ & ND & 0.0450 & 0.0450 & $\mathrm{mg} / \mathrm{L}$ & 1 & \\
\hline $\mathrm{P}$ & 378 & 2.25 & 2.25 & $\mathrm{mg} / \mathrm{L}$ & 1 & \\
\hline $\mathrm{K}$ & 721 & 2.25 & 2.25 & $\mathrm{mg} / \mathrm{L}$ & 1 & \\
\hline $\mathrm{Se}$ & ND & 9.00 & 9.00 & $\mathrm{mg} / \mathrm{L}$ & 1 & \\
\hline $\mathrm{Na}$ & 7.58 & 2.25 & 2.25 & $\mathrm{mg} / \mathrm{L}$ & 1 & \\
\hline $\mathrm{V}$ & ND & 0.0450 & 0.0450 & $\mathrm{mg} / \mathrm{L}$ & 1 & \\
\hline $\mathrm{Zn}$ & 0.443 & 0.0450 & 0.0450 & $\mathrm{mg} / \mathrm{L}$ & 1 & \\
\hline
\end{tabular}


Table 179. Chemical analysis using ICP-MS for the $2^{\text {nd }}$ sample from the same bottle of the 2012 wine from Rex Hill Jacob-Hart Block 5 (RHJHB5) Vineyard. ND - Non-detect.

\begin{tabular}{|c|c|c|c|c|c|c|}
\hline \multicolumn{7}{|c|}{ Lab ID A4B0432-15 43 RHJHB5 12} \\
\hline Analyte & Result & Detection Limit & Reporting Limit & Units & Dilution & Analyst Notes \\
\hline S & 151 & 2.25 & 2.25 & $\mathrm{mg} / \mathrm{L}$ & 1 & \\
\hline $\mathrm{Hg}$ & ND & 0.00180 & 0.00180 & $\mathrm{mg} / \mathrm{L}$ & 5 & $\mathrm{R}-04$ \\
\hline $\mathrm{Sr}$ & 0.772 & 0.00405 & 0.00405 & $\mathrm{mg} / \mathrm{L}$ & 1 & \\
\hline $\mathrm{Al}$ & ND & 2.25 & 2.25 & $\mathrm{mg} / \mathrm{L}$ & 1 & $\mathrm{R}-03$ \\
\hline As & ND & 4.50 & 4.50 & $\mathrm{mg} / \mathrm{L}$ & 1 & $\mathrm{R}-01$ \\
\hline $\mathrm{Ba}$ & 0.183 & 0.0450 & 0.0450 & $\mathrm{mg} / \mathrm{L}$ & 1 & \\
\hline $\mathrm{Be}$ & ND & 0.0450 & 0.0450 & $\mathrm{mg} / \mathrm{L}$ & 1 & $\mathrm{R}-03$ \\
\hline $\mathrm{Cd}$ & ND & 0.0450 & 0.0450 & $\mathrm{mg} / \mathrm{L}$ & 1 & $\mathrm{R}-03$ \\
\hline $\mathrm{Ca}$ & 56.0 & 2.25 & 2.25 & $\mathrm{mg} / \mathrm{L}$ & 1 & \\
\hline $\mathrm{Cr}$ & ND & 0.0450 & 0.0450 & $\mathrm{mg} / \mathrm{L}$ & 1 & R-03 \\
\hline Co & ND & 0.0450 & 0.0450 & $\mathrm{mg} / \mathrm{L}$ & 1 & R-03 \\
\hline $\mathrm{Cu}$ & 0.320 & 0.0450 & 0.0450 & $\mathrm{mg} / \mathrm{L}$ & 1 & \\
\hline $\mathrm{Fe}$ & 1.23 & 0.450 & 0.450 & $\mathrm{mg} / \mathrm{L}$ & 1 & \\
\hline $\mathrm{Pb}$ & 0.0730 & 0.0450 & 0.0450 & $\mathrm{mg} / \mathrm{L}$ & 1 & \\
\hline $\mathrm{Mg}$ & 90.4 & 2.25 & 2.25 & $\mathrm{mg} / \mathrm{L}$ & 1 & \\
\hline $\mathrm{Mn}$ & 1.81 & 0.0450 & 0.0450 & $\mathrm{mg} / \mathrm{L}$ & 1 & \\
\hline Mo & ND & 0.0450 & 0.0450 & $\mathrm{mg} / \mathrm{L}$ & 1 & R-03 \\
\hline $\mathrm{Ni}$ & ND & 0.0450 & 0.0450 & $\mathrm{mg} / \mathrm{L}$ & 1 & R-03 \\
\hline $\mathrm{P}$ & 357 & 2.25 & 2.25 & $\mathrm{mg} / \mathrm{L}$ & 1 & \\
\hline $\mathrm{K}$ & 769 & 2.25 & 2.25 & $\mathrm{mg} / \mathrm{L}$ & 1 & \\
\hline $\mathrm{Se}$ & ND & 4.50 & 4.50 & $\mathrm{mg} / \mathrm{L}$ & 1 & R-01 \\
\hline $\mathrm{Na}$ & 8.28 & 2.25 & 2.25 & $\mathrm{mg} / \mathrm{L}$ & 1 & \\
\hline $\mathrm{V}$ & ND & 0.0450 & 0.0450 & $\mathrm{mg} / \mathrm{L}$ & 1 & R-03 \\
\hline $\mathrm{Zn}$ & 0.462 & 0.0450 & 0.0450 & $\mathrm{mg} / \mathrm{L}$ & 1 & \\
\hline
\end{tabular}


Table 180. Chemical analysis using ICP-MS for the bottle of the 2012 wine from Ken Wright Nysa (KWNM) Vineyard. ND - Non-detect.

\begin{tabular}{|c|c|c|c|c|c|c|}
\hline \multicolumn{7}{|c|}{ Lab ID A4B0052-09 9 KWNM 2012} \\
\hline Analyte & Result & Detection Limit & Reporting Limit & Units & Dilution & Analyst Notes \\
\hline S & 106 & 1.12 & 1.12 & $\mathrm{mg} / \mathrm{L}$ & 1 & \\
\hline $\mathrm{Hg}$ & ND & 0.000900 & 0.000900 & $\mathrm{mg} / \mathrm{L}$ & 5 & $\mathrm{H}-01, \mathrm{R}-04$ \\
\hline $\mathrm{Sr}$ & 1.09 & 0.00202 & 0.00202 & $\mathrm{mg} / \mathrm{L}$ & 1 & \\
\hline $\mathrm{Al}$ & ND & 1.12 & 1.12 & $\mathrm{mg} / \mathrm{L}$ & 1 & \\
\hline As & ND & 2.25 & 2.25 & $\mathrm{mg} / \mathrm{L}$ & 1 & $\mathrm{R}-01$ \\
\hline $\mathrm{Ba}$ & 0.584 & 0.0225 & 0.0225 & $\mathrm{mg} / \mathrm{L}$ & 1 & \\
\hline $\mathrm{Be}$ & ND & 0.0225 & 0.0225 & $\mathrm{mg} / \mathrm{L}$ & 1 & \\
\hline $\mathrm{Cd}$ & ND & 0.0225 & 0.0225 & $\mathrm{mg} / \mathrm{L}$ & 1 & \\
\hline $\mathrm{Ca}$ & 37.4 & 1.12 & 1.12 & $\mathrm{mg} / \mathrm{L}$ & 1 & \\
\hline $\mathrm{Cr}$ & ND & 0.225 & 0.225 & $\mathrm{mg} / \mathrm{L}$ & 1 & $\mathrm{R}-01$ \\
\hline Co & 0.0270 & 0.0225 & 0.0225 & $\mathrm{mg} / \mathrm{L}$ & 1 & \\
\hline $\mathrm{Cu}$ & 0.0742 & 0.0225 & 0.0225 & $\mathrm{mg} / \mathrm{L}$ & 1 & \\
\hline $\mathrm{Fe}$ & 1.58 & 0.225 & 0.225 & $\mathrm{mg} / \mathrm{L}$ & 1 & \\
\hline $\mathrm{Pb}$ & 0.0678 & 0.0225 & 0.0225 & $\mathrm{mg} / \mathrm{L}$ & 1 & \\
\hline $\mathrm{Mg}$ & 65.7 & 1.12 & 1.12 & $\mathrm{mg} / \mathrm{L}$ & 1 & \\
\hline $\mathrm{Mn}$ & 1.67 & 0.0225 & 0.0225 & $\mathrm{mg} / \mathrm{L}$ & 1 & \\
\hline Mo & ND & 0.112 & 0.112 & $\mathrm{mg} / \mathrm{L}$ & 1 & \\
\hline $\mathrm{Ni}$ & ND & 0.0225 & 0.0225 & $\mathrm{mg} / \mathrm{L}$ & 1 & \\
\hline $\mathrm{P}$ & 542 & 1.12 & 1.12 & $\mathrm{mg} / \mathrm{L}$ & 1 & E, Q-41 \\
\hline K & 917 & 1.12 & 1.12 & $\mathrm{mg} / \mathrm{L}$ & 1 & $\mathrm{E}$ \\
\hline $\mathrm{Se}$ & ND & 4.50 & 4.50 & $\mathrm{mg} / \mathrm{L}$ & 1 & Q-41 \\
\hline $\mathrm{Na}$ & 4.50 & 1.12 & 1.12 & $\mathrm{mg} / \mathrm{L}$ & 1 & \\
\hline $\mathrm{V}$ & ND & 0.0225 & 0.0225 & $\mathrm{mg} / \mathrm{L}$ & 1 & \\
\hline $\mathrm{Zn}$ & 0.747 & 0.0225 & 0.0225 & $\mathrm{mg} / \mathrm{L}$ & 1 & \\
\hline
\end{tabular}


Table 181. Chemical analysis using ICP-MS for the bottle of the 2012 wine from Ken Wright Abbott Claim (KWAC) Vineyard. ND - Non-detect.

\begin{tabular}{|c|c|c|c|c|c|c|}
\hline \multicolumn{7}{|c|}{ Lab ID A4B0052-04 4 KWAC 2012} \\
\hline Analyte & Result & Detection Limit & Reporting Limit & Units & Dilution & Analyst Notes \\
\hline S & 77.2 & 1.12 & 1.12 & $\mathrm{mg} / \mathrm{L}$ & 1 & \\
\hline $\mathrm{Hg}$ & ND & 0.000900 & 0.000900 & $\mathrm{mg} / \mathrm{L}$ & 5 & $\mathrm{H}-01, \mathrm{R}-04$ \\
\hline $\mathrm{Sr}$ & 0.912 & 0.00202 & 0.00202 & $\mathrm{mg} / \mathrm{L}$ & 1 & \\
\hline $\mathrm{Al}$ & ND & 1.12 & 1.12 & $\mathrm{mg} / \mathrm{L}$ & 1 & \\
\hline As & ND & 2.25 & 2.25 & $\mathrm{mg} / \mathrm{L}$ & 1 & $\mathrm{R}-01$ \\
\hline $\mathrm{Ba}$ & 0.457 & 0.0225 & 0.0225 & $\mathrm{mg} / \mathrm{L}$ & 1 & \\
\hline $\mathrm{Be}$ & ND & 0.0225 & 0.0225 & $\mathrm{mg} / \mathrm{L}$ & 1 & \\
\hline $\mathrm{Cd}$ & ND & 0.0225 & 0.0225 & $\mathrm{mg} / \mathrm{L}$ & 1 & \\
\hline $\mathrm{Ca}$ & 30.6 & 1.12 & 1.12 & $\mathrm{mg} / \mathrm{L}$ & 1 & \\
\hline $\mathrm{Cr}$ & ND & 0.225 & 0.225 & $\mathrm{mg} / \mathrm{L}$ & 1 & R-01 \\
\hline Co & 0.0325 & 0.0225 & 0.0225 & $\mathrm{mg} / \mathrm{L}$ & 1 & \\
\hline $\mathrm{Cu}$ & 0.0750 & 0.0225 & 0.0225 & $\mathrm{mg} / \mathrm{L}$ & 1 & \\
\hline $\mathrm{Fe}$ & 0.517 & 0.225 & 0.225 & $\mathrm{mg} / \mathrm{L}$ & 1 & \\
\hline $\mathrm{Pb}$ & 0.0740 & 0.0225 & 0.0225 & $\mathrm{mg} / \mathrm{L}$ & 1 & \\
\hline $\mathrm{Mg}$ & 60.4 & 1.12 & 1.12 & $\mathrm{mg} / \mathrm{L}$ & 1 & \\
\hline $\mathrm{Mn}$ & 1.13 & 0.0225 & 0.0225 & $\mathrm{mg} / \mathrm{L}$ & 1 & \\
\hline Mo & ND & 0.112 & 0.112 & $\mathrm{mg} / \mathrm{L}$ & 1 & \\
\hline $\mathrm{Ni}$ & ND & 0.0225 & 0.0225 & $\mathrm{mg} / \mathrm{L}$ & 1 & \\
\hline $\mathrm{P}$ & 403 & 1.12 & 1.12 & $\mathrm{mg} / \mathrm{L}$ & 1 & $\mathrm{E}$ \\
\hline $\mathrm{K}$ & 767 & 1.12 & 1.12 & $\mathrm{mg} / \mathrm{L}$ & 1 & $\mathrm{E}$ \\
\hline $\mathrm{Se}$ & ND & 4.50 & 4.50 & $\mathrm{mg} / \mathrm{L}$ & 1 & Q-41 \\
\hline $\mathrm{Na}$ & 5.77 & 1.12 & 1.12 & $\mathrm{mg} / \mathrm{L}$ & 1 & \\
\hline $\mathrm{V}$ & ND & 0.0225 & 0.0225 & $\mathrm{mg} / \mathrm{L}$ & 1 & \\
\hline $\mathrm{Zn}$ & 0.965 & 0.0225 & 0.0225 & $\mathrm{mg} / \mathrm{L}$ & 1 & \\
\hline
\end{tabular}


Table 182. Chemical analysis using ICP-MS for the bottle of the 2012 wine from Ken Wright Freedom Hill (KWFH) Vineyard. ND - Non-detect.

\begin{tabular}{|c|c|c|c|c|c|c|}
\hline \multicolumn{7}{|c|}{ Lab ID A4B0432-11 39 KWFH 12} \\
\hline Analyte & Result & Detection Limit & Reporting Limit & Units & Dilution & Analyst Notes \\
\hline S & 100 & 2.25 & 2.25 & $\mathrm{mg} / \mathrm{L}$ & 1 & \\
\hline $\mathrm{Hg}$ & ND & 0.00180 & 0.00180 & $\mathrm{mg} / \mathrm{L}$ & 5 & $\mathrm{R}-04$ \\
\hline $\mathrm{Sr}$ & 1.05 & 0.00405 & 0.00405 & $\mathrm{mg} / \mathrm{L}$ & 1 & \\
\hline $\mathrm{Al}$ & ND & 2.25 & 2.25 & $\mathrm{mg} / \mathrm{L}$ & 1 & \\
\hline As & ND & 4.50 & 4.50 & $\mathrm{mg} / \mathrm{L}$ & 1 & $\mathrm{R}-01$ \\
\hline $\mathrm{Ba}$ & 0.470 & 0.0450 & 0.0450 & $\mathrm{mg} / \mathrm{L}$ & 1 & \\
\hline $\mathrm{Be}$ & ND & 0.0450 & 0.0450 & $\mathrm{mg} / \mathrm{L}$ & 1 & \\
\hline $\mathrm{Cd}$ & ND & 0.0450 & 0.0450 & $\mathrm{mg} / \mathrm{L}$ & 1 & \\
\hline $\mathrm{Ca}$ & 43.5 & 2.25 & 2.25 & $\mathrm{mg} / \mathrm{L}$ & 1 & \\
\hline $\mathrm{Cr}$ & ND & 0.450 & 0.450 & $\mathrm{mg} / \mathrm{L}$ & 1 & R-01 \\
\hline Co & ND & 0.0450 & 0.0450 & $\mathrm{mg} / \mathrm{L}$ & 1 & \\
\hline $\mathrm{Cu}$ & 0.0540 & 0.0450 & 0.0450 & $\mathrm{mg} / \mathrm{L}$ & 1 & \\
\hline $\mathrm{Fe}$ & 0.544 & 0.450 & 0.450 & $\mathrm{mg} / \mathrm{L}$ & 1 & \\
\hline $\mathrm{Pb}$ & ND & 0.0450 & 0.0450 & $\mathrm{mg} / \mathrm{L}$ & 1 & \\
\hline $\mathrm{Mg}$ & 96.8 & 2.25 & 2.25 & $\mathrm{mg} / \mathrm{L}$ & 1 & \\
\hline $\mathrm{Mn}$ & 1.73 & 0.0450 & 0.0450 & $\mathrm{mg} / \mathrm{L}$ & 1 & \\
\hline Mo & ND & 0.225 & 0.225 & $\mathrm{mg} / \mathrm{L}$ & 1 & \\
\hline $\mathrm{Ni}$ & ND & 0.0450 & 0.0450 & $\mathrm{mg} / \mathrm{L}$ & 1 & \\
\hline $\mathrm{P}$ & 297 & 2.25 & 2.25 & $\mathrm{mg} / \mathrm{L}$ & 1 & \\
\hline $\mathrm{K}$ & 844 & 2.25 & 2.25 & $\mathrm{mg} / \mathrm{L}$ & 1 & \\
\hline $\mathrm{Se}$ & ND & 9.00 & 9.00 & $\mathrm{mg} / \mathrm{L}$ & 1 & \\
\hline $\mathrm{Na}$ & 5.40 & 2.25 & 2.25 & $\mathrm{mg} / \mathrm{L}$ & 1 & \\
\hline $\mathrm{V}$ & ND & 0.0450 & 0.0450 & $\mathrm{mg} / \mathrm{L}$ & 1 & \\
\hline $\mathrm{Zn}$ & 0.784 & 0.0450 & 0.0450 & $\mathrm{mg} / \mathrm{L}$ & 1 & \\
\hline
\end{tabular}


Table 183. Chemical analysis using ICP-MS for the bottle of the 2012 wine from Ken Wright Meredith Mitchell (KWMM) Vineyard. ND - Non-detect.

\begin{tabular}{|c|c|c|c|c|c|c|}
\hline \multicolumn{7}{|c|}{ Lab ID A4B0432-07 35 KWMM 12} \\
\hline Analyte & Result & Detection Limit & Reporting Limit & Units & Dilution & Analyst Notes \\
\hline S & 101 & 2.25 & 2.25 & $\mathrm{mg} / \mathrm{L}$ & 1 & \\
\hline $\mathrm{Hg}$ & ND & 0.00180 & 0.00180 & $\mathrm{mg} / \mathrm{L}$ & 5 & $\mathrm{R}-04$ \\
\hline $\mathrm{Sr}$ & 0.681 & 0.00405 & 0.00405 & $\mathrm{mg} / \mathrm{L}$ & 1 & \\
\hline $\mathrm{Al}$ & ND & 2.25 & 2.25 & $\mathrm{mg} / \mathrm{L}$ & 1 & \\
\hline As & ND & 4.50 & 4.50 & $\mathrm{mg} / \mathrm{L}$ & 1 & $\mathrm{R}-01$ \\
\hline $\mathrm{Ba}$ & 0.188 & 0.0450 & 0.0450 & $\mathrm{mg} / \mathrm{L}$ & 1 & \\
\hline $\mathrm{Be}$ & ND & 0.0450 & 0.0450 & $\mathrm{mg} / \mathrm{L}$ & 1 & \\
\hline $\mathrm{Cd}$ & ND & 0.0450 & 0.0450 & $\mathrm{mg} / \mathrm{L}$ & 1 & \\
\hline $\mathrm{Ca}$ & 43.9 & 2.25 & 2.25 & $\mathrm{mg} / \mathrm{L}$ & 1 & \\
\hline $\mathrm{Cr}$ & ND & 0.450 & 0.450 & $\mathrm{mg} / \mathrm{L}$ & 1 & R-01 \\
\hline Co & ND & 0.0450 & 0.0450 & $\mathrm{mg} / \mathrm{L}$ & 1 & \\
\hline $\mathrm{Cu}$ & ND & 0.0450 & 0.0450 & $\mathrm{mg} / \mathrm{L}$ & 1 & \\
\hline $\mathrm{Fe}$ & 1.06 & 0.450 & 0.450 & $\mathrm{mg} / \mathrm{L}$ & 1 & \\
\hline $\mathrm{Pb}$ & ND & 0.0450 & 0.0450 & $\mathrm{mg} / \mathrm{L}$ & 1 & \\
\hline $\mathrm{Mg}$ & 84.9 & 2.25 & 2.25 & $\mathrm{mg} / \mathrm{L}$ & 1 & \\
\hline $\mathrm{Mn}$ & 0.952 & 0.0450 & 0.0450 & $\mathrm{mg} / \mathrm{L}$ & 1 & \\
\hline Mo & ND & 0.225 & 0.225 & $\mathrm{mg} / \mathrm{L}$ & 1 & \\
\hline $\mathrm{Ni}$ & ND & 0.0450 & 0.0450 & $\mathrm{mg} / \mathrm{L}$ & 1 & \\
\hline $\mathrm{P}$ & 430 & 2.25 & 2.25 & $\mathrm{mg} / \mathrm{L}$ & 1 & \\
\hline $\mathrm{K}$ & 538 & 2.25 & 2.25 & $\mathrm{mg} / \mathrm{L}$ & 1 & \\
\hline $\mathrm{Se}$ & ND & 9.00 & 9.00 & $\mathrm{mg} / \mathrm{L}$ & 1 & \\
\hline $\mathrm{Na}$ & 4.76 & 2.25 & 2.25 & $\mathrm{mg} / \mathrm{L}$ & 1 & \\
\hline $\mathrm{V}$ & ND & 0.0450 & 0.0450 & $\mathrm{mg} / \mathrm{L}$ & 1 & \\
\hline $\mathrm{Zn}$ & 0.768 & 0.0450 & 0.0450 & $\mathrm{mg} / \mathrm{L}$ & 1 & \\
\hline
\end{tabular}




\section{Appendix F Quality Assurance/Quality Control}

The following tables were duplicated from the elemental analysis report from Apex Laboratories for the soil samples (Table 184 to Table 189). Similar data were obtained for the grape juice and wine analysis. When analyte is not detected at or above reporting limit, ND is used. RPD means Relative Percent Difference and Minimum Detection Limit is MDL. Analyst notes include A-01: High Iron value in sample plus non-regulatory sample. No Post Spike performed, J: Estimated Results. Result detected below the lowest point of the calibration curve, but above the specified MDL, Q-03:

Spike recover and/or RPD is outside acceptance limits, Q-16: Reanalysis of an original Batch QC sample. 
Table 184. Batch 3090668 data from Apex Laboratories of Quality Assurance/Quality Control data for various elements using EPA 3051A sample prep and EPA 6020A analysis.

\begin{tabular}{|c|c|c|c|c|c|c|c|c|c|c|c|c|}
\hline Analyte & Result & MDL & $\begin{array}{c}\text { Rep. } \\
\text { Limit }\end{array}$ & Units & Dil. & $\begin{array}{c}\text { Spike } \\
\text { Amount } \\
\end{array}$ & $\begin{array}{l}\text { Source } \\
\text { Result } \\
\end{array}$ & \% Rec. & $\begin{array}{l}\% \text { Rec. } \\
\text { Limits } \\
\end{array}$ & RPD & $\begin{array}{c}\text { RPD } \\
\text { Limit } \\
\end{array}$ & Notes \\
\hline As & ND & 0.250 & 1.00 & $\mathrm{mg} / \mathrm{kg}$ & 10 & Blank & - & - & - & - & - & - \\
\hline $\mathrm{Ba}$ & ND & 0.500 & 1.00 & $\mathrm{mg} / \mathrm{kg}$ & 10 & Blank & - & - & - & - & - & - \\
\hline $\mathrm{Cd}$ & ND & 0.100 & 0.200 & $\mathrm{mg} / \mathrm{kg}$ & 10 & Blank & - & - & - & - & - & - \\
\hline $\mathrm{Cr}$ & ND & 0.500 & 1.00 & $\mathrm{mg} / \mathrm{kg}$ & 10 & Blank & - & - & - & - & - & - \\
\hline $\mathrm{Co}$ & ND & 0.100 & 0.200 & $\mathrm{mg} / \mathrm{kg}$ & 10 & Blank & - & - & - & - & - & - \\
\hline $\mathrm{Cu}$ & ND & 0.500 & 1.00 & $\mathrm{mg} / \mathrm{kg}$ & 10 & Blank & - & - & - & - & - & - \\
\hline $\mathrm{Pb}$ & ND & 0.100 & 0.200 & $\mathrm{mg} / \mathrm{kg}$ & 10 & Blank & - & - & - & - & - & - \\
\hline $\mathrm{Mn}$ & ND & 0.500 & 1.00 & $\mathrm{mg} / \mathrm{kg}$ & 10 & Blank & - & - & - & - & - & - \\
\hline Mo & ND & 0.500 & 1.00 & $\mathrm{mg} / \mathrm{kg}$ & 10 & Blank & - & - & - & - & - & - \\
\hline $\mathrm{Ni}$ & ND & 0.500 & 1.00 & $\mathrm{mg} / \mathrm{kg}$ & 10 & Blank & - & - & - & - & - & - \\
\hline $\mathrm{Se}$ & ND & 0.500 & 1.00 & $\mathrm{mg} / \mathrm{kg}$ & 10 & Blank & - & - & - & - & - & - \\
\hline $\mathrm{V}$ & ND & 0.500 & 1.00 & $\mathrm{mg} / \mathrm{kg}$ & 10 & Blank & - & - & - & - & - & - \\
\hline $\mathrm{Zn}$ & ND & 2.00 & 1.00 & $\mathrm{mg} / \mathrm{kg}$ & 10 & Blank & - & - & - & - & - & - \\
\hline $\mathrm{Hg}$ & ND & 0.0400 & 4.00 & $\mathrm{mg} / \mathrm{kg}$ & 10 & Blank & - & - & - & - & - & Q-16 \\
\hline \multicolumn{13}{|c|}{ Matrix Spike - QC Source Sample: KWFH Ap } \\
\hline As & 46.4 & 0.247 & 0.986 & $\mathrm{mg} / \mathrm{kg}$ & 10 & 49.3 & 1.41 & 91 & $75-125 \%$ & - & - & - \\
\hline
\end{tabular}


Table 185. continued from Table 153. Batch 3090668 data from Apex Laboratories of Quality Assurance/Quality Control data for various elements using EPA 3051A sample prep and EPA 6020A analysis.

\begin{tabular}{|c|c|c|c|c|c|c|c|c|c|c|c|c|}
\hline Analyte & Result & MDL & $\begin{array}{c}\text { Rep. } \\
\text { Limit } \\
\end{array}$ & Units & Dil. & $\begin{array}{c}\text { Spike } \\
\text { Amount } \\
\end{array}$ & $\begin{array}{c}\text { Source } \\
\text { Result } \\
\end{array}$ & \% Rec. & $\begin{array}{c}\text { \% Rec. } \\
\text { Limits } \\
\end{array}$ & RPD & $\begin{array}{c}\text { RPD } \\
\text { Limit } \\
\end{array}$ & Notes \\
\hline $\mathrm{Ba}$ & 183 & 0.493 & 0.986 & $\mathrm{mg} / \mathrm{kg}$ & 10 & 49.3 & 132 & 105 & $75-125 \%$ & - & - & - \\
\hline $\mathrm{Cd}$ & 51.5 & 0.0986 & 0.197 & $\mathrm{mg} / \mathrm{kg}$ & 10 & 49.3 & 0.292 & 104 & $75-125 \%$ & - & - & - \\
\hline $\mathrm{Cr}$ & 64.0 & 0.493 & 0.986 & $\mathrm{mg} / \mathrm{kg}$ & 10 & 49.3 & 13.1 & 103 & $75-125 \%$ & - & - & - \\
\hline $\mathrm{Co}$ & 62.6 & 0.0986 & 0.197 & $\mathrm{mg} / \mathrm{kg}$ & 10 & 49.3 & 13.2 & 100 & $75-125 \%$ & - & - & - \\
\hline $\mathrm{Pb}$ & 60.2 & 0.0986 & 0.197 & $\mathrm{mg} / \mathrm{kg}$ & 10 & 49.3 & 9.29 & 103 & $75-125 \%$ & - & - & - \\
\hline $\mathrm{Mn}$ & 881 & 0.493 & 0.986 & $\mathrm{mg} / \mathrm{kg}$ & 10 & 49.3 & 819 & 125 & $75-125 \%$ & - & - & - \\
\hline $\mathrm{Hg}$ & 1.04 & 0.0394 & 0.158 & $\mathrm{mg} / \mathrm{kg}$ & 10 & 0.986 & ND & 105 & $75-125 \%$ & - & - & - \\
\hline Mo & 21.6 & 0.493 & 0.986 & $\mathrm{mg} / \mathrm{kg}$ & 10 & 24.6 & ND & 88 & $75-125 \%$ & - & - & - \\
\hline $\mathrm{Ni}$ & 52.9 & 0.493 & 0.986 & $\mathrm{mg} / \mathrm{kg}$ & 10 & 49.3 & 4.30 & 98 & $75-125 \%$ & - & - & - \\
\hline V & 90.6 & 0.493 & 0.986 & $\mathrm{mg} / \mathrm{kg}$ & 10 & 49.3 & 33.4 & 116 & $75-125 \%$ & - & - & - \\
\hline $\mathrm{Zn}$ & 80.7 & 1.970 & 3.94 & $\mathrm{mg} / \mathrm{kg}$ & 10 & 49.3 & 24.0 & 115 & $75-125 \%$ & - & - & - \\
\hline \multicolumn{13}{|c|}{ Post Spike } \\
\hline $\mathrm{Mn}$ & 5830 & - & - & $\mu \mathrm{g} / \mathrm{L}$ & 10 & 2860 & 3110 & 95 & $80-120 \%$ & - & - & - \\
\hline
\end{tabular}


Table 186. Batch 3100753 data from Apex Laboratories of Quality Assurance/Quality Control data for various elements using EPA 3051A sample prep and EPA $6010 \mathrm{C}$ analysis.

\begin{tabular}{|c|c|c|c|c|c|c|c|c|c|c|c|c|}
\hline Analyte & Result & MDL & $\begin{array}{c}\text { Rep. } \\
\text { Limit }\end{array}$ & Units & Dil. & $\begin{array}{c}\text { Spike } \\
\text { Amount }\end{array}$ & $\begin{array}{l}\text { Source } \\
\text { Result } \\
\end{array}$ & \% Rec. & $\begin{array}{l}\% \text { Rec. } \\
\text { Limits } \\
\end{array}$ & RPD & $\begin{array}{c}\text { RPD } \\
\text { Limit } \\
\end{array}$ & Notes \\
\hline $\mathrm{Sr}$ & ND & 0.200 & 0.400 & $\mathrm{mg} / \mathrm{kg}$ & 4 & Blank & - & - & - & - & - & - \\
\hline $\mathrm{Al}$ & ND & 100 & 200 & $\mathrm{mg} / \mathrm{kg}$ & 4 & Blank & - & - & - & - & - & - \\
\hline $\mathrm{Ca}$ & ND & 100 & 200 & $\mathrm{mg} / \mathrm{kg}$ & 4 & Blank & - & - & - & - & - & - \\
\hline $\mathrm{Fe}$ & ND & 20.0 & 40.0 & $\mathrm{mg} / \mathrm{kg}$ & 4 & Blank & - & - & - & - & - & - \\
\hline $\mathrm{P}$ & ND & 200 & 400 & $\mathrm{mg} / \mathrm{kg}$ & 4 & Blank & - & - & - & - & - & - \\
\hline $\mathrm{Sr}$ & ND & 100 & 200 & $\mathrm{mg} / \mathrm{kg}$ & 4 & Blank & - & - & - & - & - & - \\
\hline $\mathrm{Mg}$ & ND & 100 & 200 & $\mathrm{mg} / \mathrm{kg}$ & 4 & Blank & - & - & - & - & - & - \\
\hline $\mathrm{K}$ & ND & 100 & 200 & $\mathrm{mg} / \mathrm{kg}$ & 4 & Blank & - & - & - & - & - & - \\
\hline $\mathrm{Na}$ & ND & 100 & 200 & $\mathrm{mg} / \mathrm{kg}$ & 4 & Blank & - & - & - & - & - & - \\
\hline \multicolumn{13}{|c|}{ LCS } \\
\hline $\mathrm{Sr}$ & 103 & 0.200 & 0.400 & $\mathrm{mg} / \mathrm{kg}$ & 4 & 100 & - & 103 & $80-120 \%$ & - & - & - \\
\hline $\mathrm{Al}$ & 5150 & 100 & 200 & $\mathrm{mg} / \mathrm{kg}$ & 4 & 5000 & - & 103 & $80-120 \%$ & - & - & - \\
\hline $\mathrm{Ca}$ & 5080 & 100 & 200 & $\mathrm{mg} / \mathrm{kg}$ & 4 & 5000 & - & 102 & $80-120 \%$ & - & - & - \\
\hline $\mathrm{Fe}$ & 5420 & 20.0 & 40.0 & $\mathrm{mg} / \mathrm{kg}$ & 4 & 5000 & - & 109 & $80-120 \%$ & - & - & - \\
\hline $\mathrm{P}$ & 4670 & 200 & 400 & $\mathrm{mg} / \mathrm{kg}$ & 4 & 4000 & - & 117 & $80-120 \%$ & - & - & - \\
\hline $\mathrm{Sr}$ & 4360 & 100 & 200 & $\mathrm{mg} / \mathrm{kg}$ & 4 & 4000 & - & 109 & $80-120 \%$ & - & - & - \\
\hline $\mathrm{Mg}$ & 4990 & 100 & 200 & $\mathrm{mg} / \mathrm{kg}$ & 4 & 5000 & - & 100 & $80-120 \%$ & - & - & - \\
\hline
\end{tabular}


Table 187. continued Batch 3100753 data from Apex Laboratories of Quality Assurance/Quality Control data for various elements using EPA 3051A sample prep and EPA 6010C analysis.

\begin{tabular}{|c|c|c|c|c|c|c|c|c|c|c|c|c|}
\hline Analyte & Result & MDL & $\begin{array}{l}\text { Rep. } \\
\text { Limit }\end{array}$ & Units & Dil. & $\begin{array}{c}\text { Spike } \\
\text { Amount }\end{array}$ & $\begin{array}{l}\text { Source } \\
\text { Result } \\
\end{array}$ & $\%$ Rec. & $\begin{array}{l}\% \text { Rec. } \\
\text { Limits }\end{array}$ & RPD & $\begin{array}{c}\text { RPD } \\
\text { Limit } \\
\end{array}$ & Notes \\
\hline $\mathrm{K}$ & 5160 & 100 & 200 & $\mathrm{mg} / \mathrm{kg}$ & 4 & 5000 & - & 103 & $80-120 \%$ & - & - & - \\
\hline $\mathrm{Na}$ & 5340 & 100 & 200 & $\mathrm{mg} / \mathrm{kg}$ & 4 & 5000 & - & 107 & $80-120 \%$ & - & - & - \\
\hline \multicolumn{13}{|c|}{ Duplicate - QC Source Sample: KWFH Bt } \\
\hline $\mathrm{Sr}$ & 17.7 & 0.217 & 0.435 & $\mathrm{mg} / \mathrm{kg}$ & 4 & - & 17.1 & - & - & 3 & $40 \%$ & - \\
\hline $\mathrm{Al}$ & 16500 & 109 & 217 & $\mathrm{mg} / \mathrm{kg}$ & 4 & - & 16300 & - & - & 1 & $40 \%$ & - \\
\hline $\mathrm{Fe}$ & 33200 & 21.7 & 43.5 & $\mathrm{mg} / \mathrm{kg}$ & 4 & - & 33200 & - & - & 0.06 & $40 \%$ & - \\
\hline $\mathrm{P}$ & 561 & 217 & 43.5 & $\mathrm{mg} / \mathrm{kg}$ & 4 & - & 541 & - & - & 4 & $40 \%$ & - \\
\hline $\mathrm{Sr}$ & ND & 109 & 435 & $\mathrm{mg} / \mathrm{kg}$ & 4 & - & ND & - & - & - & $40 \%$ & - \\
\hline $\mathrm{Mg}$ & 2140 & 109 & 217 & $\mathrm{mg} / \mathrm{kg}$ & 4 & - & 2100 & - & - & 2 & $40 \%$ & - \\
\hline $\mathrm{K}$ & 1240 & 109 & 217 & $\mathrm{mg} / \mathrm{kg}$ & 4 & - & 1230 & - & - & 0.8 & $40 \%$ & - \\
\hline $\mathrm{Na}$ & 182 & 109 & 217 & $\mathrm{mg} / \mathrm{kg}$ & 4 & - & 165 & - & - & 10 & $40 \%$ & $\mathrm{~J}$ \\
\hline \multicolumn{13}{|c|}{ Matrix Spike QC Source Sample: KWFH Bt } \\
\hline $\mathrm{Sr}$ & 123 & 0.213 & 0.426 & $\mathrm{mg} / \mathrm{kg}$ & 4 & 107 & 17.1 & 99 & $75-125 \%$ & - & - & - \\
\hline $\mathrm{Al}$ & 21300 & 107 & 213 & $\mathrm{mg} / \mathrm{kg}$ & 4 & 5330 & 16300 & 94 & $75-125 \%$ & - & - & - \\
\hline $\mathrm{Ca}$ & 7210 & 107 & 213 & $\mathrm{mg} / \mathrm{kg}$ & 4 & 5330 & 1920 & 99 & $75-125 \%$ & - & - & - \\
\hline $\mathrm{Fe}$ & 36000 & 21.3 & 42.6 & $\mathrm{mg} / \mathrm{kg}$ & 4 & 5330 & 33200 & 51 & $75-125 \%$ & - & - & A-01, Q-03 \\
\hline $\mathrm{P}$ & 5410 & 21.3 & 426 & $\mathrm{mg} / \mathrm{kg}$ & 4 & 4260 & 541 & 114 & $75-125 \%$ & - & - & - \\
\hline
\end{tabular}


Table 188. continued Batch 3100753 data from Apex Laboratories of Quality Assurance/Quality Control data for various elements using EPA 3051A sample prep and EPA 6010C analysis.

\begin{tabular}{|c|c|c|c|c|c|c|c|c|c|c|c|c|}
\hline Analyte & Result & MDL & $\begin{array}{c}\text { Rep. } \\
\text { Limit }\end{array}$ & Units & Dil. & $\begin{array}{c}\text { Spike } \\
\text { Amount }\end{array}$ & $\begin{array}{l}\text { Source } \\
\text { Result } \\
\end{array}$ & \% Rec. & $\begin{array}{l}\text { \% Rec. } \\
\text { Limits }\end{array}$ & RPD & $\begin{array}{c}\text { RPD } \\
\text { Limit } \\
\end{array}$ & Notes \\
\hline $\mathrm{Sr}$ & 4750 & 107 & 213 & $\mathrm{mg} / \mathrm{kg}$ & 4 & 4260 & ND & 112 & $75-125 \%$ & - & - & - \\
\hline $\mathrm{Mg}$ & 7260 & 107 & 213 & $\mathrm{mg} / \mathrm{kg}$ & 4 & 5330 & 2100 & 97 & $75-125 \%$ & - & - & - \\
\hline $\mathrm{K}$ & 6480 & 107 & 213 & $\mathrm{mg} / \mathrm{kg}$ & 4 & 5330 & 1230 & 99 & $75-125 \%$ & - & - & - \\
\hline $\mathrm{Na}$ & 5590 & 107 & 213 & $\mathrm{mg} / \mathrm{kg}$ & 4 & 5330 & 165 & 102 & $75-125 \%$ & - & - & - \\
\hline \multicolumn{13}{|c|}{ Matrix Spike - QC Source Sample: RHJHB5 Btg } \\
\hline $\mathrm{Sr}$ & 137 & 0.202 & 0.404 & $\mathrm{mg} / \mathrm{kg}$ & 4 & 101 & 36 & 100 & $75-125 \%$ & - & - & - \\
\hline $\mathrm{Al}$ & 20900 & 101 & 202 & $\mathrm{mg} / \mathrm{kg}$ & 4 & 5050 & 16800 & 81 & $75-125 \%$ & - & - & - \\
\hline $\mathrm{Ca}$ & 8960 & 101 & 202 & $\mathrm{mg} / \mathrm{kg}$ & 4 & 5050 & 3590 & 106 & $75-125 \%$ & - & - & - \\
\hline $\mathrm{Fe}$ & 51700 & 20.2 & 40.4 & $\mathrm{mg} / \mathrm{kg}$ & 4 & 5050 & 53500 & -37 & $75-125 \%$ & - & - & A-01, Q-03 \\
\hline $\mathrm{P}$ & 4640 & 20.2 & 40.4 & $\mathrm{mg} / \mathrm{kg}$ & 4 & 4040 & 314 & 107 & $75-125 \%$ & - & - & - \\
\hline $\mathrm{Sr}$ & 4300 & 101 & 202 & $\mathrm{mg} / \mathrm{kg}$ & 4 & 4040 & ND & 106 & $75-125 \%$ & - & - & - \\
\hline $\mathrm{Mg}$ & 7270 & 101 & 202 & $\mathrm{mg} / \mathrm{kg}$ & 4 & 5050 & 2160 & 101 & $75-125 \%$ & - & - & - \\
\hline $\mathrm{K}$ & 5280 & 101 & 202 & $\mathrm{mg} / \mathrm{kg}$ & 4 & 5050 & 245 & 100 & $75-125 \%$ & - & - & - \\
\hline $\mathrm{Na}$ & 5360 & 101 & 202 & $\mathrm{mg} / \mathrm{kg}$ & 4 & 5050 & 193 & 102 & $75-125 \%$ & - & - & - \\
\hline
\end{tabular}


Table 189. Sample data table from Apex Laboratories with Quality Assurance/Quality Control data for Chloride analysis using EPA 3051A sample prep and EPA 9056A analysis.

\begin{tabular}{|c|c|c|c|c|c|c|c|c|c|c|c|c|}
\hline $\begin{array}{l}\text { Chloride } \\
\text { Analyte } \\
\end{array}$ & Result & MDL & $\begin{array}{c}\text { Rep. } \\
\text { Limit }\end{array}$ & Units & Dil. & $\begin{array}{c}\text { Spike } \\
\text { Amount }\end{array}$ & $\begin{array}{l}\text { Source } \\
\text { Result } \\
\end{array}$ & \% Rec. & $\begin{array}{l}\text { \% Rec. } \\
\text { Limits } \\
\end{array}$ & RPD & $\begin{array}{c}\text { RPD } \\
\text { Limit }\end{array}$ & Notes \\
\hline Blank & ND & 9.81 & 9.81 & $\mathrm{mg} / \mathrm{kg}$ & 1 & - & - & - & - & - & - & - \\
\hline LCS & 39 & 9.95 & 9.95 & $\mathrm{mg} / \mathrm{kg}$ & 1 & 39.8 & - & 98 & $\begin{array}{c}90- \\
110 \%\end{array}$ & - & - & - \\
\hline $\begin{array}{l}\text { LCS } \\
\text { Dup. }\end{array}$ & 38.6 & 9.81 & 9.81 & $\mathrm{mg} / \mathrm{kg}$ & 1 & 39.3 & - & 98 & $\begin{array}{c}90- \\
110 \%\end{array}$ & 0.9 & $15 \%$ & - \\
\hline
\end{tabular}




\section{Appendix G Cation Exchange Capacity Data}

Oregon State University, Crop and Soil Science lab conducted the CEC analysis for this study using methods derived from the Methods of Soil Analysis Used in the Soil Testing Laboratory at Oregon State University (Hormeck et al., 1989). CEC was obtained using the Ammonium Acetate Method as described in the manual. This method determines of the $\mathrm{NH}_{4} \cdot \mathrm{N}$ spectrophotometrically rather than by Kjeldahl distillation and titration (Hormeck et al., 1989).

Equation 2. Equation for the calculation of Cation Exchange Capacity.

$$
\text { CEC } \frac{\mathrm{meq}}{100 \mathrm{~g} \text { of soil }}=\left(\mathrm{ppm} \mathrm{NH} \mathrm{H}_{4} \cdot \mathrm{N} \text { in leachate }\right) \times \frac{0.25}{14} \times \frac{100}{\text { sample size } g}
$$


Table 190. Cation Exchange Capacity (CEC) results from the Oregon State University Crop and Soil Science lab.

\begin{tabular}{|c|c|c|c|c|c|c|c|c|c|}
\hline $\begin{array}{c}\text { Sample } \\
\text { Number }\end{array}$ & Vineyard & Horizon & $\begin{array}{c}\text { Lab } \\
\text { Number }\end{array}$ & $\begin{array}{c}\mathrm{CEC} \\
\mathrm{meq} / 100 \mathrm{~g}\end{array}$ & $\begin{array}{c}\text { Sample } \\
\text { Number }\end{array}$ & Vineyard & Horizon & $\begin{array}{c}\text { Lab } \\
\text { Number }\end{array}$ & $\begin{array}{c}\text { CEC } \\
\text { meq/100g }\end{array}$ \\
\hline 1 & ECR & Ap & 140128.01 & 18.5 & 35 & LEM & $\mathrm{Bt} 2$ & 140128.35 & 18.9 \\
\hline 2 & ECR & $\mathrm{AB}$ & 140128.02 & 15.4 & 36 & LEM & $\mathrm{Bt} 3$ & 140128.36 & 15.6 \\
\hline 3 & ECR & Bt1 & 140128.03 & 16.9 & 37 & LEF & Ap & 140128.37 & 17.8 \\
\hline 4 & ECR & Bt2 & 140128.04 & 20.7 & 38 & LEF & $\mathrm{Bt}$ & 140128.38 & 18.9 \\
\hline 5 & ECC & Ap & 140128.05 & 31.2 & 39 & LEY & Ap & 140128.39 & 20.2 \\
\hline 6 & ECC & Bt1 & 140128.06 & 16.1 & 40 & LEY & Bt1 & 140128.40 & 14.0 \\
\hline 7 & ECC & $\mathrm{Bt} 2$ & 140128.07 & 16.8 & 41 & LEY & $\mathrm{Bt} 2$ & 140128.41 & 15.3 \\
\hline 8 & ECC & Bt3 & 140128.08 & 14.4 & 42 & LEY & $\mathrm{Bg}$ & 140128.42 & 17.8 \\
\hline 9 & $\mathrm{ECF}$ & Ap & 140128.09 & 18.6 & 43 & RH1 & Ap & 140128.43 & 26.1 \\
\hline 10 & ECF & Bt1 & 140128.10 & 14.2 & 44 & RH1 & At & 140128.44 & 20.3 \\
\hline 11 & $\mathrm{ECF}$ & $\mathrm{Bt} 2$ & 140128.11 & 14.9 & 45 & RH1 & $\mathrm{Bt}$ & 140128.45 & 16.3 \\
\hline 12 & ECF & $\mathrm{Bt} 3$ & 140128.12 & 13.8 & 46 & RH5 & Ap & 140128.46 & 22.3 \\
\hline 13 & WET & Ap & 140128.13 & 25.3 & 47 & RH5 & $\mathrm{Bt}$ & 140128.47 & 28.2 \\
\hline 14 & WET & $\mathrm{AB}$ & 140128.14 & 23.1 & 48 & RH5 & Btg & 140128.48 & 32.9 \\
\hline 15 & WET & $\mathrm{Bg} 1$ & 140128.15 & 38.1 & 49 & RHB & Ap & 140128.49 & 35.1 \\
\hline 16 & WET & $\mathrm{Bg} 2$ & 140128.16 & 34.6 & 50 & RHB & Bt1 & 140128.50 & 17.8 \\
\hline 17 & WEA & $\mathrm{A}$ & 140128.17 & 15.9 & 51 & RHB & Bt2 & 140128.51 & 15.9 \\
\hline 18 & WEA & $\mathrm{AB}$ & 140128.18 & 12.9 & 52 & RHS & Ap & 140128.52 & 23.2 \\
\hline 19 & WEA & Bt1 & 140128.19 & 17.5 & 53 & RHS & Bt1 & 140128.53 & 20.2 \\
\hline 20 & WEA & Bt2 & 140128.20 & 14.9 & 54 & RHS & Bt2 & 140128.54 & 15.0 \\
\hline 21 & WEJ & Ap & 140128.21 & 14.4 & 55 & RHS & $\mathrm{Bt} 3$ & 140128.55 & 20.0 \\
\hline 22 & WEJ & Bt1 & 140128.22 & 15.4 & 56 & KWA & Ap & 140128.56 & 16.9 \\
\hline 23 & WEJ & $\mathrm{Bt} 2$ & 140128.23 & 14.6 & 57 & KWA & $\mathrm{Bt}$ & 140128.57 & 11.7 \\
\hline 24 & CWS & Ap & 140128.24 & 23.5 & 58 & KWA & $\mathrm{Bw}$ & 140128.58 & 20.5 \\
\hline 25 & CWS & Bt1 & 140128.25 & 18.7 & 59 & KWF & Ap & 140128.59 & 9.7 \\
\hline 26 & CWS & Bt2 & 140128.26 & 17.0 & 60 & KWF & $\mathrm{Bt}$ & 140128.60 & 20.3 \\
\hline 27 & CWS & $\mathrm{Bt} 3$ & 140128.27 & 16.5 & 61 & KWM & Ap & 140128.61 & 21.5 \\
\hline 28 & CWR & Ap & 140128.28 & 14.8 & 62 & KWM & $\mathrm{Bt}$ & 140128.62 & 48.5 \\
\hline 29 & CWR & Bt1 & 140128.29 & 11.2 & 63 & KWM & $\mathrm{Bw}$ & 140128.63 & 80.0 \\
\hline 30 & CWR & Bt2 & 140128.30 & 19.1 & 64 & KWN & Ap & 140128.64 & 61.0 \\
\hline 31 & CWC & $\mathrm{Ap}$ & 140128.31 & 42.2 & 65 & KWN & Bt1 & 140128.65 & 20.2 \\
\hline 32 & CWC & $\mathrm{Bt}$ & 140128.32 & 19.5 & 66 & KWN & Bt2 & 140128.66 & 17.8 \\
\hline 33 & LEM & Ap & 140128.33 & 22.6 & 67 & LEM & Bt2 & 140128.67 & 21.7 \\
\hline 34 & LEM & $\mathrm{A} / \mathrm{B}$ & 140128.34 & 22.4 & & & & & \\
\hline
\end{tabular}




\section{Appendix H NSF Cascades to Coast GK-12 Fellowship Requirement}

\section{Created Curriculum - Radon Gas from the Missoula Floods}

Fellow: Kat Barnard (Geology)

Teacher: Brie Bui (Dexter McCarty School)

Advisor: Dr. Scott Burns (Geology)

Learning goals: After learning about Missoula floods, and their impact on the creation of the Willamette Valley, this lesson ties the science of radon produced from the flood deposits to human health concerns, i.e. lung cancer. This lesson tries to impress the usefulness of the geological sciences to everyday life and how data collection for a government agency, like the Oregon Health Authority, is a community responsibility.

Prior lessons: Willamette Valley crops grown on Missoula Flood sediments like hazelnuts, grass seed, clover, and wheat. Missoula Flood gravels were included in a rock identification lesson about Oregon rocks. Upland Willamette Valley soils were used in a soil horizon and soil color lesson.

Target Grade: $8^{\text {th }}$ grade Integrated Science. Earth and Physical emphasis.

State Standards: 6.1P.1 Describe physical and chemical properties of matter and how they can be measured. 7.2E.4 Explain how landforms change over time at various rates in terms of constructive and destructive forces. 8.2E.2 Describe the processes of Earth's geosphere and the resulting major geological events.

Activity Summary: Show presentation reviewing the Missoula Floods, watch video from Oregon Public Broadcasting - Oregon Field Guide, and pass out radon kits with Radon brochures from the Oregon Health Authority.

Activity Plan:

30 minutes' total -

- 5 minutes for first 4 slides

- Slide 1 
- Question posed to class: What ecoregion was affected by the Missoula Floods? (Willamette Valley)

- Question posed to class: How long ago did this occur? (The last ice age, about $15000-18000$ years ago)

- "An ice dam from the iced sheet blocked and backed up a river that made a huge lake in Montana called Glacial Lake Missoula. When the dam breached, a giant flood came across Washington and caused scouring and erosion. The flood came down the Columbia Gorge, carrying the soil and rock into the Willamette Valley."

- Slide 2

- Question posed to class: On this elevation map can you see the flat areas in NE Portland and down into the valley? (Yes)

- Question posed to class: What are the rough and bumpy areas called? (Uplands)

- Question posed to class: Did these areas get covered by the floods? (No)

- "Where do you live on this map? Dexter McCarty is here in the flat areas so it is possible that this land was covered by the Missoula Floods and rocks were deposited here that were carried down from Washington."

- Slide 3

- Go down the bullet points

- Question posed to class: What radioactive elements have you heard of? (Uranium, K, Thorium...)

- "In the natural decay of Uranium all the elements that are made are solids except for one, which is a gas... RADON."

- Slide 4

- Question posed to class: Have you ever heard of Oregon Public Broadcasting, OPB? 
- Question posed to class: Have you ever watched Oregon Field Guide?

- "They make cool videos about interesting things but put in the science behind it. For example, they want to teach you about hanggliding and they will explain the physics behind how to obtain flight."

- 13 minutes - Video: http://www.opb.org/programs/ofg/segments/view/1808

- 3 minutes to wrap up

○ Slide 5

- Question posed to class: On the other map in the video where all the zip codes were one color, how many houses did they test in order color it red? (at least 30)

- Question posed to class: How many houses do you think live in each of those zip codes? (100's or 1000)

- Question posed to class: Is 30 out of 1000 , or $3 \%$, a good amount of data? (No)

- Question posed to class: What did Brett Sherry say about the data? (Need more data to make better maps because you can't just look at the map and say whether your house is radon free or not)

- Question posed to class: So what zip code are we in? (97080)

- "It says that we have low potential of having high radon levels but... (Every house should be tested)"

- Slide 6

- Go through each bullet point and go over Radon detector instructions if needed.

Related Concepts: Geologic history of Oregon, permeability, rock types, radioactive decay, periodic table of the elements, human health, lung cancer, mapping data, community outreach. 
Materials: 3-day radon test kits and brochures (English and Spanish) for each student.

Handouts and worksheets: 3 -day radon test kits and brochures (English and Spanish) for each student.

\section{Created Curriculum - Introduction to Soil Texture}

Fellow: Kat Barnard (Geology)

Teacher: Brie Bui (Dexter McCarty School)

Advisor: Dr. Scott Burns (Geology)

Learning goals: Practice field techniques that are commonly used by soil scientists and by determining soil textures they will make a physical connection between texture, porosity and permeability. Once textures are learned, it is easy to relate soil texture to vegetation needs.

Target Grade: $8^{\text {th }}$ grade Integrated Science. Earth and Physical emphasis.

State Standards: 6.1P.1 Describe physical and chemical properties of matter and how they can be measured. 7.2E.4 Explain how landforms change over time at various rates in terms of constructive and destructive forces. 8.2E.2 Describe the processes of Earth's geosphere and the resulting major geological events.

Activity Summary: One-day inquiry activity on soil textures. About 40-50minute activity on using the scientific method of "magic fingers," which is used by soil scientists in order to determine the texture of various soil types in the field. The method is clearly explained using the attached flow chart.

Activity Plan: Groups of 4 works well, but this could be done in pairs.

Set up:

1) Paint buckets of water should be placed around the room with towels for washing hands rather than letting the dirt go down the drains (if you have sinks).

2) Obtain approximately one quart-sized bag of soil for each of at least 4-6 soils with different textures from the region. 
3) Place each soil texture type in a bowl for each group.

4) Each group will practice on at least two different soil textures.

5) Place one of the soil textures as an "unknown" in the center of the room as the mystery soil.

Introduction (5-10 minutes):

1) A flow chart for performing "magic fingers" is attached. Use approximately one fist full of soil and, wetting slowly with a spray bottle or dropper until a ball can be formed and then follow the flow chart. It is important to not let them add too much water to the samples.

2) Using your own sample and the overhead projector, wet a handful of soil and follow the flow chart provided in order to demonstrate how to make a ball with the soil, how to add more soil if the sample gets too wet, and how to SLOWLY add the water to wet it.

\section{Work time (30 minutes):}

1) The students should then practice "magic fingers" on the soils of known textures at their desks, following the flow chart, and when they think they know it, they can guess and you can tell them if they are correct or not.

2) When they are correct they can switch samples with another group and practice again.

3) When they have successfully identified two textures they then can attempt to determine the texture of a mystery soil.

4) Have the students wash their hands in the provided buckets between samples.

Related Concepts: Permeability and porosity should be addressed earlier in the soil curriculum. They will add to their concept of permeability and porosity when wetting sandy samples and the water flows through the sample vs. when they wet a clay sample and it holds onto the water. 
Materials: Buckets for hand rinsing, paper towels, newspaper for the desks, water bottles/squirt bottles, bowls for soil, soil of various textures, soil texture flow chart.

Extensions: Grain size analysis, soil chemistry, agriculture. Students will start to see the relationship between soils and the types of vegetation that grow will in them. Agricultural needs differ with each crop, some doing well in sandy soils and others preferring more clay rich soils that hold water for longer periods of time. The concept of drought stress could also be introduced here.

Handouts and worksheets and Assessment Questions: On worksheet below. 


\section{DIRTY MUDDY STICKY GROSS!}

Inquiry: What are soil textures and how do scientists determine them in the field?

Materials: $\quad 6$ soil samples with different textures at stations

6 bowls (one for each sample)

Buckets for hand washing

Procedure:

Squirt bottle of water

1) You and your table partner practice on known soils.

2) Use the flow chart on the next page to determine the soil texture of each soil.

3) Record your texture in the table below for each of the 2 soils.

4) Ask your teacher if your known soil textures are correct before moving on.

\begin{tabular}{|l|l|l|l|}
\hline Soil & Soil \# & Soil \# & Mystery Soil \\
\hline Your texture & & & \\
\hline Actual texture & & & \\
& & & \\
\hline
\end{tabular}

5) Redo soils until your texture is correct.

6) When you feel confident about the soil textures, go to the mystery soil and figure out its texture using the same flow chart you used before.

\section{Questions:}

1) What was easier to determine: loam, clay, or sand? Why?

2) For you, what soil texture was the hardest to figure out? Why?

3) Did you need the same amount of water to make a ball for all the different soil textures that you practiced on?

4) If not, explain why you think that is. 


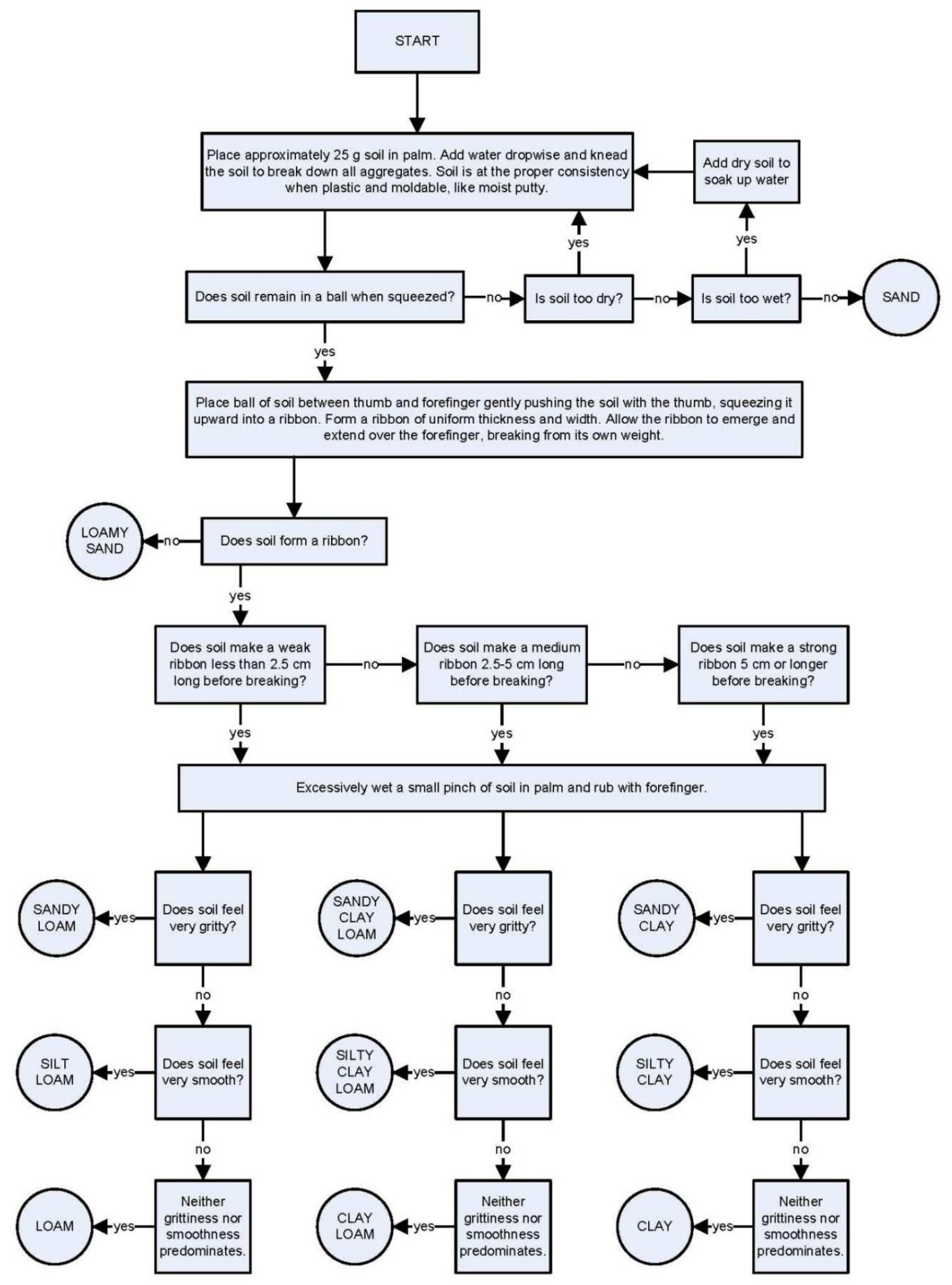




\section{Appendix I Farming Practices and Certification}

\section{Sustainable}

Low Input Viticulture and Enology (LIVE), Inc. is a non-profit organization that uses international standards for certifying sustainable agricultural practices in the US (Live, Inc., 2009). These standards are based on the International Organization for Biological and Integrated Control of Noxious Animals and Plants (IOBC-WPRS). The objectives of sustainability are not to remove synthetic fertilizers and pesticides from the vineyard but to use minimum amounts of both and only use them when absolutely necessary. Many vineyards in Oregon are certified under the LIVE program. There 118 wineries who have LIVE certified vineyards totaling 4031.7 acres of vine with 33 of these wineries located in the Willamette Valley AVA (Oregon Wine Board, 2009). Some wineries, like Rex Hill, have some acreage under Biodynamic ${ }^{\circledR}$ certification and some are LIVE Certified Sustainable (Rex Hill, 2009). Other wineries visited for this research that are LIVE certified include Lange Estate, Stoller, Amity, and Willakenzie (Lange Estate Winery and Vineyards, 2009; Stoller Family Estate, 2009; Amity Vineyards, 2009; Willakenzie Estate, 2009).

The main themes of sustainability are to promote grape production and the business while respecting the environment. It is important that the farmers' health is protected so education about the chemicals and timing of application are emphasized. At 
some wineries, profit is the most desired aspect and the risk associated with going

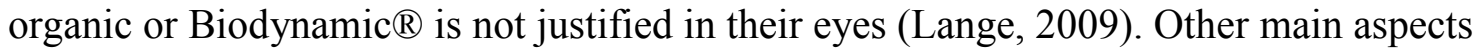
of sustainability involve promoting biological diversity in the vineyard by planting cover crops of clover and flowers (Brown, 2009; Malavolta, 2009). Natural mechanisms and cycles within the vineyard are also a priority and compost is made from the material taken out of the vineyards and put back each year. This promotes soil fertility without the use of synthetic fertilizers. The last objective is to minimize pollution so many vineyards will hand pick and sort and use biodiesel in the trucks and tractors (Lange, 2009). As with the other certification processes, there are fees, paperwork, and check-ups at certified vineyards in order to ensure that sustainable practices continue to occur (Malavolta, 2009).

At Sokol Blosser their motto includes the 3 P's, which are Planet, People, and Profit (Brown, 2009). This motto goes directly along with sustainability although they are not LIVE certified but are Oregon Tilth Organic certified (Sokol Blosser, 2009). Amity Vineyards is LIVE Certified Sustainable and they work very hard on experiments in the vineyard. One such experiment is to establish cover crops that reduce the competition for water and nutrients with the vines and prevent erosion while eliminating the need for herbicides to remove the bad weeds. Doing these experiments is a life-long passion of Myron Redford from Amity Vineyards and his desire is to reduce his dependence on synthetic herbicides as much as possible (Redford, 2009). Tilling is not a viable choice in 
Redford's opinion because the machinery will compact the soil so he continues to test different cover crops that will not compete with his vines or need to be mowed (Redford, 2009).

\section{Organic}

There are around 20 wineries and vineyards in Oregon, four in the northern Willamette Valley, that are certified organic through the Oregon Tilth program with a total of 1010.9 acres. The certified organic vineyards in the Willamette Valley as of 2009 include Cooper Mountain Vineyards (110 acres), Sokol Blosser Vineyards (82.8 acres), Willamette Valley Vineyards (24.4 acres) and Evasham Wood Vineyard and Winery, Inc. (12.6 acres) (Oregon Wine Board, 2009). Oregon Tilth Certification is granted through a nonprofit organization utilizing the USDA National Organic Program guidelines (Oregon Tilth, 2009). Certification requires payment of fees, tremendous amounts of paperwork, and annual check-ups. Different certification requirements are needed for the words used and type of label on the wine. If all grapes are organic than "100\% Organic" may be put on the label (Oregon Tilth, 2009). You may also put the phrase "Organically Grown Grapes" if all the grapes are grown organically. If "Organic Wine" is wanted on the label then the grapes must be grown organically and no sulfites are allowed to be added to the wine during the winemaking process (De Domingo, 2009). Other labeling includes "Organic," which means 95\% of the ingredients are organic, and "Made with Organic Grapes," meaning only $70 \%$ of the ingredients are organic. 
The requirements for being organic include that the vineyard have three years with no application of synthetic herbicides, pesticides, or fertilizers. No Genetically Modified Organics (GMOs) or synthetic products of any kind can be used in the growing process. Some non-synthetic or nonagricultural substances are also prohibited, as well as nonorganic agricultural substances, ionizing radiation, or sewage sludge (USDA, 2009). The land also must have defined boundaries and a buffer zone between areas where prohibited substances may be in use and the site of the organic cropland. For example, at Cooper Mountains Vineyards a housing development next to the vineyards must utilize organic landscaping and yard management so as not to hurt the vineyards (Cooper Mountain Vineyards, 2009) (Figure 121).

In order to promote healthy soil and prevent erosion and nutrient deficiencies, organic practices are implemented instead of using fertilizers and pesticides. These include tilling and cover cropping to promote vegetation in the vineyard rows that will not compete with the vines for nutrients and will reduce soil erosion during large rain events. Tilling the cover crop into the soil puts $\mathrm{C}$ and $\mathrm{N}$ back into the soil as well. Rotating the cover crop will also create a diverse environment for micro and macro organisms. To keep weeds from growing up around the vines, organic mulch or plastic (as long as it is removed later) can be laid. Hand or mechanized weeding is also allowed as well as using livestock grazing, mowing, and flaming (USDA, 2009). 


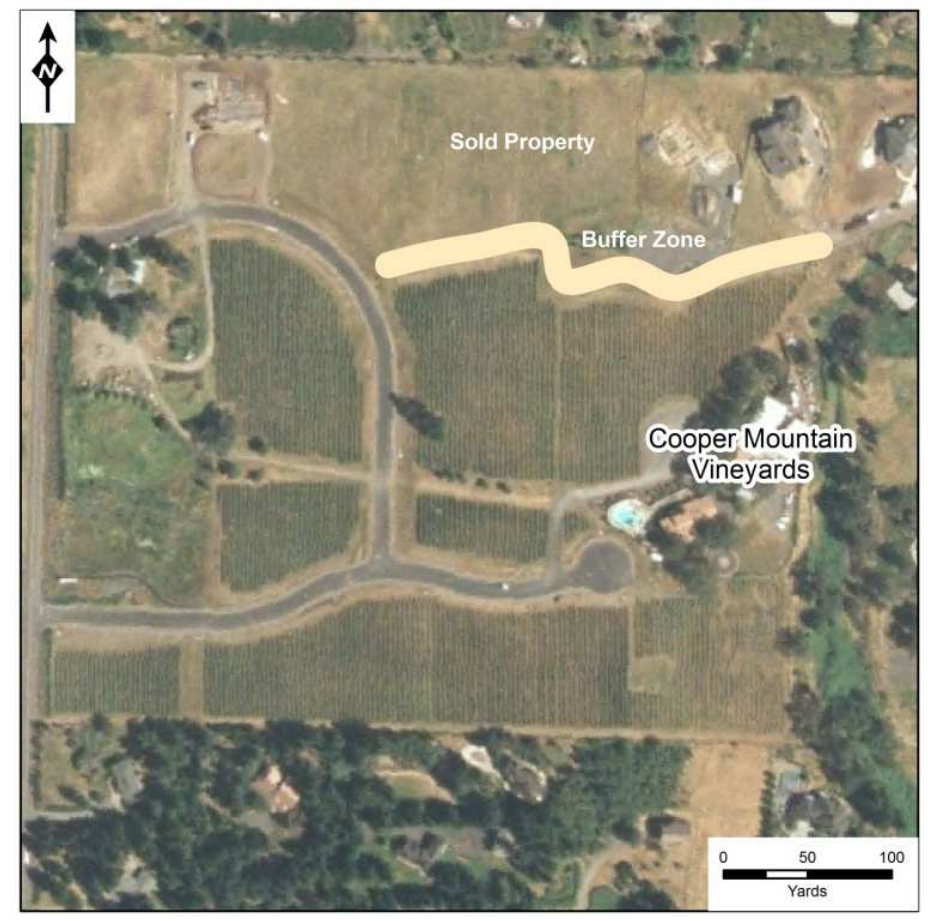

Figure 121. Cooper Mountain Vineyards and the sold property to the north of the vineyards. This sold property has requirements for owners to also be organic and not use chemicals in their yards that could harm the vineyards (Ludlow, 2009).

One of the most important aspects of mono cropping is pest and disease management. In order to prevent the spread of diseases, sanitation of mechanical devices and work clothes is necessary. Since Amity Vineyards are not grafted onto resistant rootstock, extreme sanitation is required in their vineyards to prevent the spread of the phylloxera louse (Amity Vineyards, 2009). Enhancing crop health in general is another effective method for disease management. This includes selecting vine species that are more suitable for the site and resistant to prevalent pests and diseases (USDA, 2009). Pest problems can also be controlled through the augmentation or introduction of predators of 
these pests, or using lures, traps, or repellents. Disease spread can be mitigated by using non-synthetic biological, botanical, or mineral inputs (USDA, 2009).

In the winery, all products used must be on the Organic Product List and all cleaning agents for the winery equipment must be organic. Ionization or $\mathrm{Cl}$ products are strictly forbidden. When making wine, the yeast used for fermentation must also contain only organic N. No additions of synthetic products are allowed in the wine and total sulfites must be kept less than $100 \mathrm{ppm}$, which is $50 \%$ less than other commercial wines (De Domingo, 2009). Sulfites are needed to reduce oxidation in the wine and act as an antimicrobial agent. Sulfites act as a preservative which protects against off colors and flavors and prevents spoilage (Goode, 2014). Minimum amounts of sulfites needed to resist off flavors depends on the type of wine. These amounts range from $10 \mathrm{ppm}$ for a Semillon to $400 \mathrm{ppm}$ for a botrytis wines. Sulfites are the culprit when dealing with wine headaches in most cases (Goode, 2014). Being organic involves changing many standard farming practices like using compost instead of fertilizers to provide nutrients and using pheromone lures for bugs instead of pesticides. It takes courage to make the switch but many wineries and vineyards in Oregon have become organic in the last twenty years and many more are following (Hellman, 2003). 


\section{Biodynamic}

Demeter Biodynamic ${ }^{\circledR}$ agricultural techniques are equated to organic certification with the addition of homeopathy and astrology. Biodynamic food will be 'true to its essence and provides deeply penetrating nutrition that is medicinal as well as delicious' (demeter-usa.com). These practices were based on Rudolf Steiner's “Agricultural Course" and the spiritual context of Anthroposophy (Steiner et al., 2004). Steiner influenced a feeling of a 'broader and richer' world, wanted to start another religion like Christianity or Islam that fed the world's hunger for 'spiritual values'. Some bitter hostility came from the thought that only a trickster could preach a fundamentally irrational doctrine and acquire a large following. He toured Europe presenting his lectures in the early 1900's, establishing a following, and his ambition was to build a temple by 1914 called the Goetheanum in Dornach, Switzerland that was made of wood and other natural products (Wilson, 1985). Rudolf Steiner lectured on ways to practice agriculture by focusing on the soil. The belief is that healthy soil is healthy for people and that people could be healed through the soil (De Domingo, 2009). The tangible and intangible forces that exist in the world can affect the soil quality through climate, wildlife, the sun, and the distant cosmos. (Demeter Association, Inc., 2009).

According to the Rex Hill website, Biodynamic ${ }^{\circledR}$ farming is more stringent than organic farming and takes into account the energy and spiritual aspect of farming as well as the physical aspect (Rex Hill, 2009). This was also conveyed at Cooper Mountain 
where a balance in the vineyards is established by the energy transferred from the cosmos to the vines through certain practices. At Cooper Mountain Vineyards the homeopathic aspect includes making preparations and using water from an Energy Vortex Fountain (Ludlow, 2009). The preparations include things like yarrow, chamomile, nettle, oak bark, dandelion, valerian, horsetail, silica, and manure. They use the herbs and flowers to make compost and teas that are mixed with the energized water. This small amount of tea is then added to large vats of water, in which the energy from the tea can be propagated throughout the liquid by the force of the atomic particles. The teas are sprayed onto the vines at certain times, not as a preventative action, but as an enhancement and a giving of energies. This enhancement involves creating harmony between the energy in the cosmos and the energy needed to support good bacteria and microorganisms in the vineyard soil (De Domingo, 2009). At Montinore Estate, the same types of preparations are used in order to enhance the fruit on the vine (Montinore Estate, 2009).

The compost used at Biodynamic ${ }^{\circledR}$ farms includes the skins, seeds, stems, and clippings from each vineyard. In the spring the specific compost for each vineyard, made from the refuse and blended with buffalo or cow manure, is spread to enhance nutrients and release the energy that was taken out of vineyard back into it (De Domingo, 2009). Biodynamic ${ }^{\circledR}$ practices are based on using the natural energy cycles within the farm and keeping outside inputs to a minimum. Another major concept in Biodynamic ${ }^{\circledR}$ agriculture is that the vines needed to be stressed and taught how to survive with slightly 
deficient amounts of nutrients. This will make the vines stronger so when a disease or drought attacks them they are more resistant to harm (De Domingo, 2009). All the nutrients needed are provided by using cover crops of grass and wildflowers, rotating them every year for the first couple years and mowing them down so they feel like their livelihood is threatened. This will cause them to over seed and establish strong roots. After a few years the result is a diverse environment for a variety of organisms (De Domingo, 2009).

The basis of using an astrological calendar is to harness the energies of the cosmos at certain times of the year and give them to the vineyard. This is accomplished by using cow horns, filling them with compost from the year before and strategically placing them throughout the vineyards. When burying them at sunrise the day of the spring solstice, you will harness energy in the universe and given it to the vines. At Cooper Mountain Vineyards, it is said that shortly after the horns are buried bud-break occurs. In the same manner, the horns are removed in the fall at sunset on the winter solstice to take the energy from the vines and release it back into the universe. This release signals the vines to go dormant for the winter (Ludlow, 2009).

In the winery, no additives are allowed to be added to the wine. All the yeast and bacteria in the wine are native for fermentation and a maximum of $100 \mathrm{ppm} \mathrm{S}\left(\mathrm{SO}_{2}\right)$ can be residual in the bottle. No acidification, chaptalization (addition of sugar to increase 
alcohol content), or corrective additions are allowed either (De Domingo, 2009). The astrological calendar is also used to determine fruit and flower days, which are days that you should spend in the vineyard or the winery, respectively. When you should open your bottle of wine is also determined by these fruit and flower days (Ludlow, 2009). The wine is allowed to express the climate, soil, and geology of the location in which the grapes were grown because even the preparations are so dilute they are like not adding anything at all. The grapes are harvested, brought to the winery, fermented and put in barrels by block in order to preserve the flavor of each unique area in the vineyard (De Domingo, 2009).

The certification process is the same as getting certified by other organizations. You fill out tons of paperwork, pay fees, and get annual check-ups. There are eight Demeter Biodynamic ${ }^{\circledR}$ wineries in Oregon totaling 650 acres and five of them are located in the northern Willamette Valley. The wineries with the most Biodynamic ${ }^{\circledR}$ acreage are Cooper Mountain (110 acres), Momtazi Vineyard (230 acres), and Montinore Estate (220 acres). Brick House Vineyard, Bergstrom, Resonance Vineyard, and Rex Hill also practice Biodynamic ${ }^{\circledR}$ agriculture and have $27.5,23.5,20$, and 12 acres, respectively, of Demeter Biodynamic ${ }^{\circledR}$ certified vines (Oregon Wine Board, 2009).

Skeptics and supporters of Biodynamic ${ }^{\circledR}$ practices have looked into its effects on flavor and soil biology but published studies are scarce. In one study on soil biology in 
organic and Biodynamic vineyards, the end result was that the Biodynamic preparations did not significantly affect the soil biotic parameters tested compared to just using compost. The parameters included microbial biomass, respiration, dehydrogenase activity, soil carbon, earthworm population and biomass (Carpenter-Boggs, 2000). Testing Merlot made from Biodynamic and organically grown winegrapes was performed using perceptible sensory differences. The results of these tests concluded that Biodynamic and organic 2003 and 2004 wines tasted differently. The2003 Biodynamic wines were said to have higher musty/earth aroma and bitterness than the organic wine and that the 2004 organic wines was higher in musty/earthy aroma and astringency and bitterness than the Biodynamic wine of the same vintage (Ross, 2009).

\section{Salmon-Safe}

The Salmon - Safe program is partnered with the LIVE Certified Sustainable and Oregon Tilth Certified Organic programs. This is an optional additional certification that has its own fees and paperwork associated with it. Certification is valid for three years with annual check-ups. To be considered Salmon - Safe a scoring system is used and a field assessor visits the vineyards in question. The intent of Salmon - Safe certification is to commend farm operations that address the impacts they have on salmonid stream ecosystem health (Salmon - Safe, 2005). 
The four ways that a farmer may impact salmon are 1) the introduction of surface or sub-surface runoff including sediment, energy (temperature), or chemicals into the stream, 2) elimination or reduction of riparian corridor vegetation, 3) direct alteration of the stream banks, streamside, or in-stream habitat, 4) alteration of flow regimes through groundwater pumping or water diversions (Salmon - Safe, 2005). To assess these impacts, the scoring system will subtract points when the farmer is ignorant to these best management practices and add points with the farmer is in full compliance with these practices for each element, or grouping of farm management ideas. These elements include riparian and wetland management, irrigation and water use, erosion and sediment control, fertility and pest management systems, animal management, and biological diversity. To meet the certification, all elements of best management practices must be positive; therefore, there can be negative scores within each group but the overall score must be positive. Annual visits will determine whether or not there is improvement or not and if certification is still valid in case major changes have occurred in the vineyard (Salmon - Safe, 2005).

Examples of things the assessors are looking for include buffer zones between the vineyard and the streams, allowing for riparian zones (Cooper Mountain Vineyards, 2009). If there are excessive stream crossings or poorly designed crossings, you will get a negative score. If the farmer uses cover crops and little irrigation in order to reduce erosion, a positive score is given. When the farmer uses natural methods to control weeds 
and pests, without using "high risk" pesticides and herbicides, a positive score is given. The farmer's knowledge of soil chemistry and nutrient needs, as well as having the soil tested regularly to determine what nutrients are needed, deserves a positive score as well. If the farmer uses heavy machinery in excess that compacts the soil and increases runoff a negative score is given (Salmon - Safe, 2005).

One of the elements of Salmon - Safe certification is optional and relates to biological diversity. To increase biodiversity there are many options for farmed areas and non-farmed areas. Some of the ways to increase biodiversity within the vineyard are to rotate the cover crops and alternate the rows that are mowed to ensure that not all the habitat for insects is removed at once. Minimizing tillage under the vines will allow for plant residues to accumulate and increase the diversity of the soil organisms. Compost, cover crops, and tilled-in plant residues are great ways to increase soil fertility and biodiversity. Outside of the vineyard, planting hedgerows of multiple species and improving riparian vegetation, as well as building water reservoirs, will attract and support beneficial organisms and wildlife. Allowing for neighboring fields to be fallow and woodlands to be left as natural as possible also will insure the biodiversity that is so important (Salmon - Safe, 2005). 


\section{Oregon Certified Sustainable}

Practicing sustainable grape growing and winemaking ensures the land, animals, rivers, and aquatic life will still be here for generations to come. Oregon Certified Sustainable Wine (OCSW) focuses on shared principles of Low Input Viticulture and Enology (LIVE), Food Alliance, USDA National Organic Program and its certifying agencies (Oregon Tilth, Stellar Certification Services and others) and Demeter Biodynamic ${ }^{\circledR}$. To be OCSW certified there are certain agricultural and winemaking requirements. Of the fruit used by the winemaker, $97 \%$ must be certified by LIVE, USDA Organic, Demeter Biodynamic ${ }^{\circledR}$, Food Alliance, and Salmon - Safe. The winemaking requirements also include that the processor or facility must be certified by either LIVE, USDA Organic, Demeter Biodynamic ${ }^{\circledR}$, or the Food Alliance. Once these certifications are in place, you can also be certified as an Oregon Certified Sustainable Wine (Live, Inc., 2009).

There are many wines already certified by the OCSW, which started in 2007 . The first wineries to achieve this label were Sokol Blosser Winery and Willamette Valley Vineyards, both in the northern Willamette Valley. Many more wines were allowed to use this label in 2008 including wines from Adelsheim Vineyard, Amity Vineyards, Anne Amie, Argyle, Bethel Heights Vineyard, Chehalem, Cristom, Montinore, Panther Creek Cellars, Ponzi, Rex Hill, Sokol Blosser, Stoller, Willakenzie, Willamette Valley Vineyards, and Wooldridge Creek (Live, Inc., 2009; Montinore Estate, 2009; Sokol 
Blosser, 2009). The OCSW is a great marketing strategy to allow for one label to represent all the others and many more wineries will probably be utilizing it in the future (Oregon Wine Board, 2009).

\section{Conclusions}

An abundance of information is available online about the organic, Biodynamic ${ }^{\circledR}$, or sustainability practices carried out by various wineries in the northern Willamette Valley. Winery owners and employees are more than willing to discuss their own methodology or experimentation that they carry out in their vineyards to become more sustainable. Many are working towards sustainability or are organic in many ways but do not have the certification. Reasons for not being certified include, but are not limited to, the cost of the certification process, the paperwork that is necessary to track all input to the winery and vineyards, or the thoughts that it is unnecessary marketing and not needed if you make great wine.

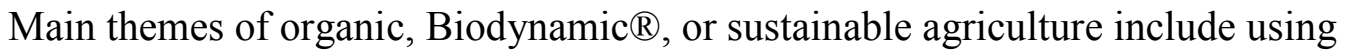
compost created by the vineyard and placed back into it, using cover crops to reduce erosion and provide a diverse habitat for good insects and organisms, and reducing need of synthetic additives in the wine because the fruit is taken care of. If the vineyard is healthy, the fruit will be delicious, and very little will need to be done in the winery to make good wine. The most important difference between these certifications and logos is 
that some still allow for the input of synthetic pesticides and herbicides but the application is regulated and kept to an absolute minimum, while others do not allow any such application at all. Oregon Tilth Certified Organic and Demeter Biodynamic ${ }^{\circledR}$ wines are made from vineyards that have had no synthetic input for over 3 years. LIVE Certified Sustainable, Salmon - Safe, and Oregon Certified Sustainable Wine may still have used some amount of chemicals in the vineyard and winemaking.

Although much interest in being sustainable and/or organic scientific research is limited in determining if such practices actually improve the quality of the wine. Many highly rated wines in France, California, and Oregon are certified organic or biodynamic but the actual mechanism that makes the wines better is still not understood. Some research concludes that there are sensory differences between the organic and biodynamic wines (Ross, 2009). Whether or not this is based on differences in the vineyard is not supported, however, from the theory that biodynamic vineyards have more soil organisms that promote better vine health. A study found that there was no significant difference between vineyards given compost and compost with biodynamic preparations (Carpenter-Boggs, 2000). Further research is needed to understand the effects of organic, Biodynamic ${ }^{\circledR}$, and sustainable practices on the wine produced in Oregon. 


\section{References for Appendix I}

Amity Vineyards, 2009, www.amityvineyards.com (accessed December 2009).

Brown, M.K., 2009, GSA Vineyard tour: Direct Sales Manager, Sokol Blosser Winery, October 17, 2009.

Carpenter-Boggs, L., Kennedy, A.C., and Reganold, J.P., 2000, Organic and Biodynamic Management: Effects of Soil Biology: Soils Science Society of America Journal, Vol. 64, p. 1651-1659.

Cooper Mountain Vineyards, 2009, www.coopermountainwine.com (accessed December 2009).

De Domingo, Gilles, 2009, Personal communication: Winemaker, Cooper Mountain Vineyards, November 24, 2009.

Demeter Association, Inc., 2009, www.demeter-usa.org (accessed December 2009).

Goode, J., 2014, the Science of Wine from Vine to Glass: Berkeley, California, University of California Press, 216 p.

Hellman, E., ed., 2003, Oregon Viticulture: Corvallis, Oregon State University Press, 264 p.

Malavolta, C., and Boller, E.F., eds., 2009, Guidelines for Integrated Production of Grapes - IOBC Technical Guideline III, $3^{\text {rd }}$ Edition: IOBC/WPRS Bulletin, Vol. 46.

Montinore Estate, 2009, www.montinore.com (accessed December 2009).

Lange Estate Winery and Vineyards, 2009, www.langewinery.com (accessed December 2009).

Lange, J., 2009, Personal communication: Owner, Lange Estate Winery and Vineyard, November 28, 2009.

LEED, 2009, New Construction and Major Renovations Rating System: U.S. Green Building Council, Inc., 108 p.

Live, Inc., 2009, www.livecertified.org (accessed December 2009). 
Ludlow, Jason, 2009. Personal communication: Sales and Education, Cooper Mountain Vineyards, November 27, 2009.

Oregon Tilth, 2009, www.tilth.org (accessed December 2009).

Oregon Wine Board, 2009, www.oregonwine.org (accessed December 2009).

Redford, M., 2009, Personal communication: Senior Winemaker/Owner/President, Amity Vineyards, November 28, 2009.

Rex Hill, 2009, www.rexhill.com (accessed December 2009).

Roberts, S., 2009, Wine Trails of Oregon - A guide for uncorking your memorable wine tour: Mercer Island, WA, South Slope Publishing, 537 p.

Ross, C.F., Weller, K.M., Blue, R.B., and Reganold, J.P., 2009, Difference Testing of Merlot Produced from Biodynamically and Organically Grown Winegrapes: Journal of Wine Research, Vol. 20, No. 2, p. 85-94.

Salmon - Safe, 2005, Salmon - Safe $®$ Farm Management Certification Program - Field Assessor's Guidelines 4.2: Salmon - Safe ${ }^{\circledR}$, Inc., 21 p.

Sokol Blosser, 2009, www.sokolblosser.com (accessed December 2009).

Steiner, R., Adams, G., and Pfeiffer, E., 2004, Agriculture Course: The Birth of the Biodynamic Method: Forest Row, Rudolf Steiner Press, 176 p.

Stoller Family Estate, 2009, www.stollervineyards.com (accessed December 2009).

USDA, 2009, National Organic Program Regulatory Text: U.S. Department of Agriculture, Agricultural Marketing Service, $58 \mathrm{p}$.

Willakenzie Estate, 2009, www.willakenzie.com (accessed December 2009).

Wilson, C., 1985, Rudolf Steiner, the Man and His Vision - An Introduction to the Life and Ideas of the Founder of Anthroposophy: Wellingborough, Northamptonshire, Aquarian Press, 176 p. 